UNIVERSIDAD NACIONAL DE LA PLATA

FACULTAD DE CIENCIAS NATURALES Y MUSEO

"Taxonomía y filogenia de Trichocereus (Berg.) Riccob. (Trichocereeae-

Cactaceae)"

Tesis presentada para optar al grado de Doctor en Ciencias Naturales de la Universidad Nacional de La Plata

Bióloga M. Sc. Adriana Sofía Albesiano Hoyos

Director: Dr. Roberto Kiesling

Co-Directora: Dra. Susana Freire

La Plata, Argentina

Agosto 3 de 2015 


\section{COMISIÓN ASESORA}

Dr. Roberto Kiesling, Instituto Argentino de Investigaciones de las Zonas Áridas-IADIZA, CONICET.

Dra. Susana Freire, Instituto de Botánica Darwinion-San Isidro. Prof. Titular, Cátedra de Botánica Sistemática II, Facultad Ciencias Naturales y Museo, Universidad Nacional de La Plata.

\section{DEFENSA ORAL Y PÚBLICA}

Lugar y Fecha:

Calificación:

TRIBUNAL

Firma: Aclaración

Firma: Aclaración

Firma: Aclaración 


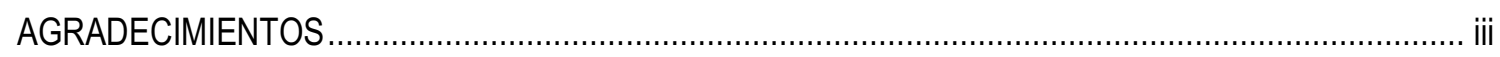

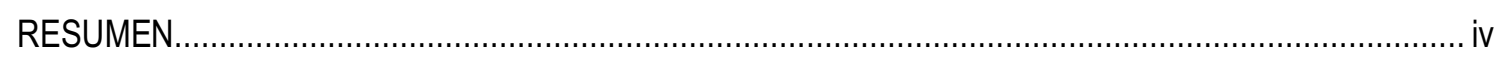

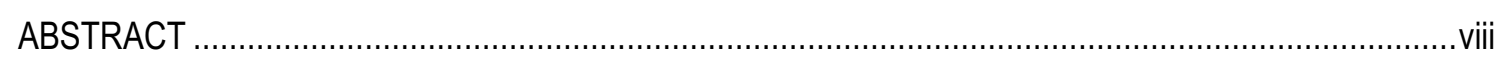

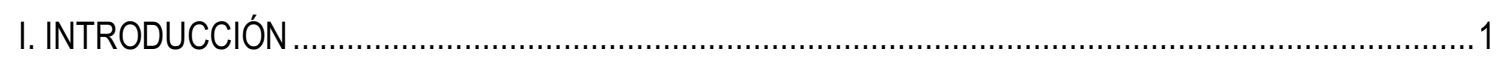

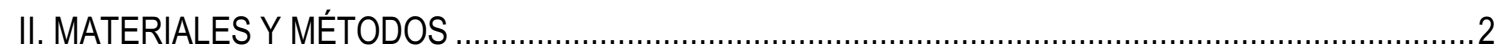

III. HISTORIA DEL GÉNERO / ANTECEDENTES HISTÓRICOS …..................................................... 2

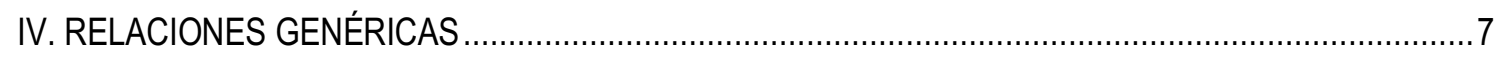

V. MORFOLOGÍA DEL GÉNERO Y GRUPOS RELACIONADOS ..................................................

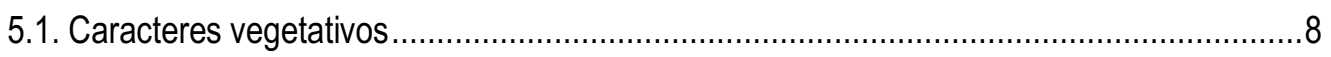

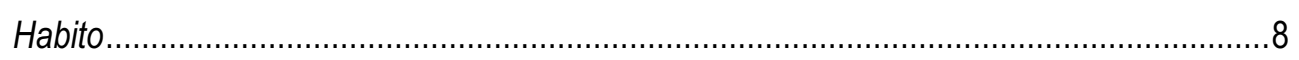

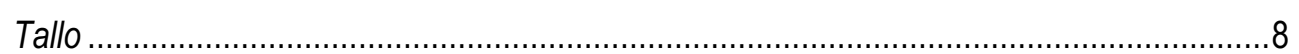

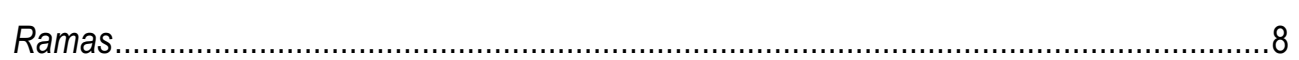

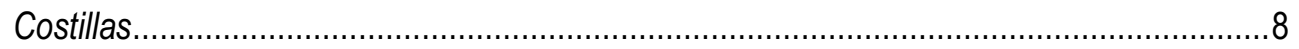

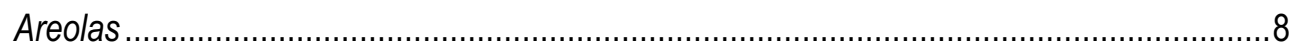

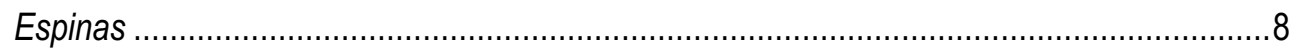

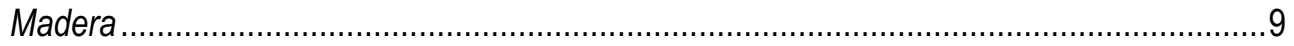

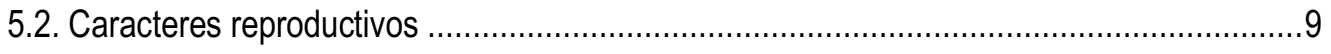

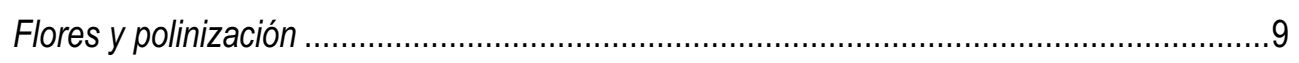

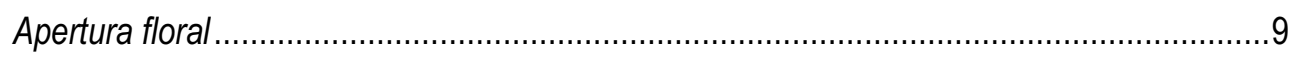

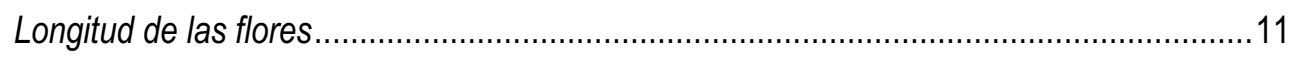

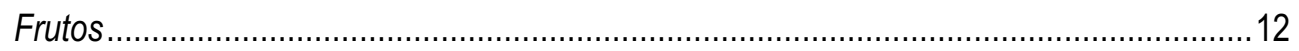

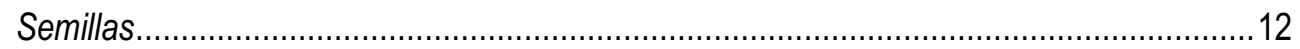

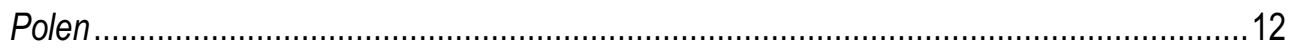

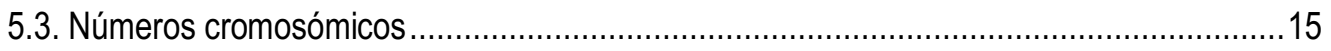

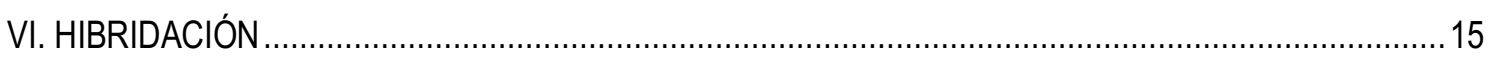

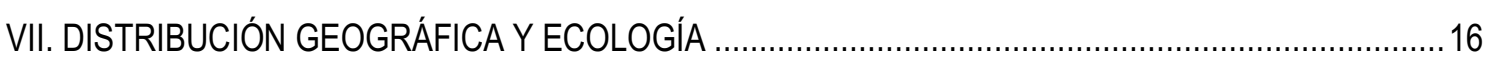

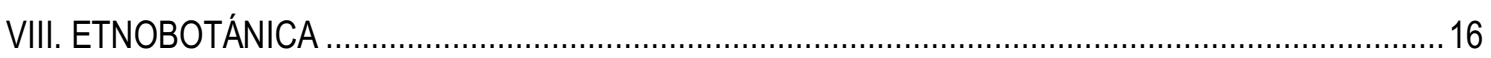

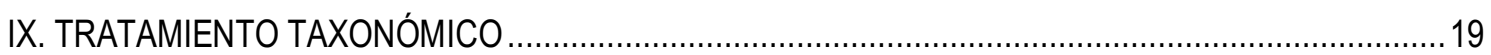

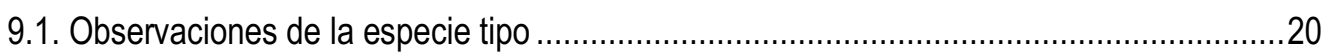

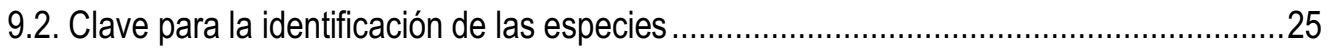

9.3. Clave para la identificación de las especies de Argentina: ..............................................29

9.4. Clave para la identificación de las especies de Bolivia, Ecuador y Perú ...........................30

9.5. Clave para la identificación de las especies de Chile .....................................................31

9.6. Descripción de las especies y taxones infraespecíficos .................................................32

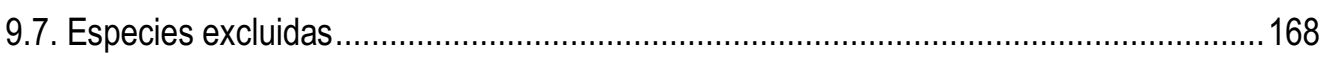




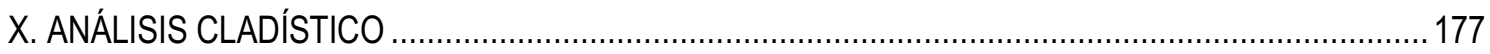

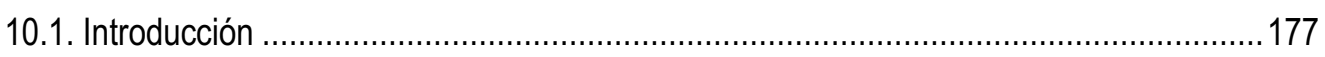

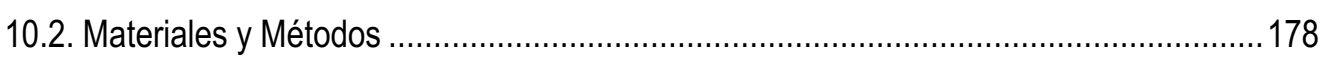

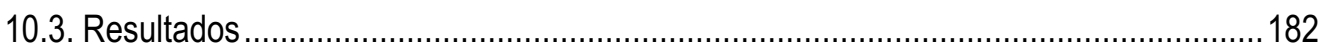

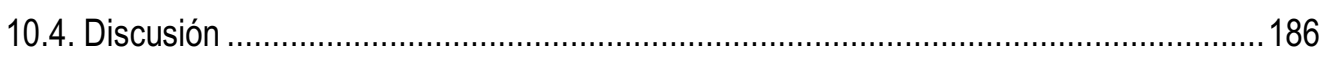

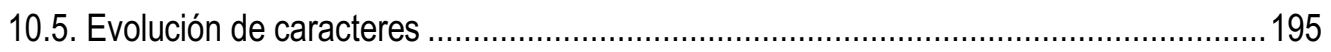

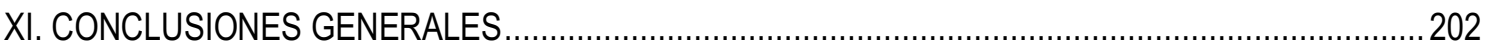

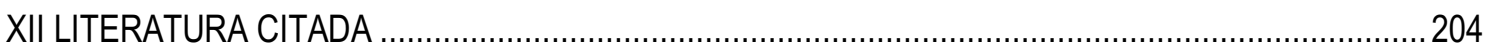

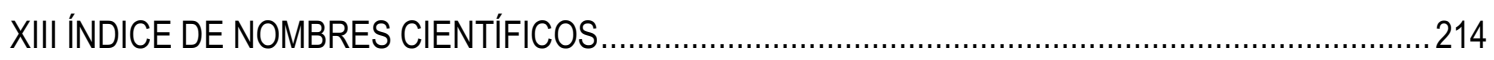

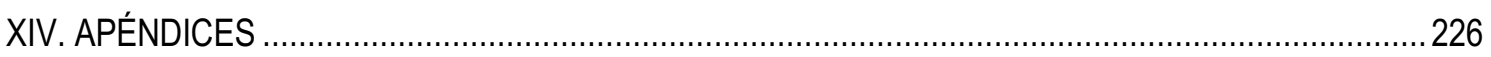

14.1. Formulario para la toma de datos morfológicos en campo ........................................226

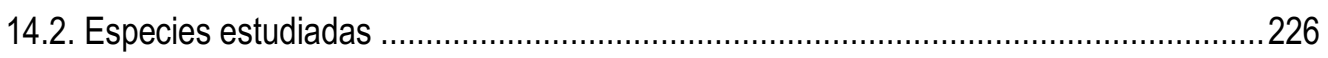

14.3. Lista de caracteres morfológicos y sus estados .......................................................228

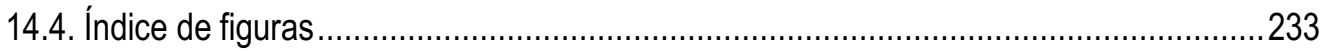

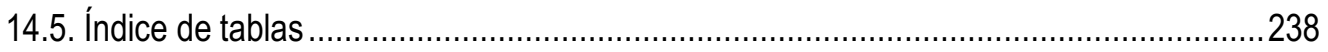




\section{AGRADECIMIENTOS}

Esta tesis surgió de una serie de ideas compartidas con el Dr. Roberto Kiesling, que conformaron el proyecto "Taxonomía y Filogenia del género Trichocereus". El apoyo constante y decidido de Roberto, como consejero y profesor a lo largo de la investigación fueron decisivos para la realización de este trabajo. A la Dra. Susana Freire por dirigir este proyecto con tanto interés, entusiasmo, y por contribuir a mi crecimiento profesional.

Agradezco a Salvador Arias-M., Leopoldo Arrieta, Ayra Faúndez, Luis Faúndez, Omar Ferrari, Rodrigo Flores, Iris Peralta, Patricio Saldivia, Teresa Terrazas, Matin Terry y Monserrat Vázquez, por la ayuda que me brindaron tanto en las labores de campo y en el laboratorio.

A los directores y curadores de los herbarios consultados (Stephan Beck, Manuel Belgrano, Norma Deginani, Laura Iharlegui, Eduardo Méndez, Inés Meza, Mélica Muñoz, Nora Muruaga, James Solomon y Luc Willemse), por la gentileza en la resolución de dudas, envió de imágenes y préstamo del material solicitado.

A Detlev Metzing por el envío de algunas publicaciones históricas, a Daniel Schweich por el préstamo de dos de sus fotos de campo. A Cecilia Scoones, por la elaboración de las ilustraciones.

A la Sociedad Alemana de Cactus y a la Sociedad Inglesa de Cactus, por los subsidios que posibilitaron el desarrollo de este trabajo. A la Organización de Estados Americanos-OEA por el otorgamiento de la beca Doctoral.

A la Universidad Nacional de La Plata, especialmente a la Facultad de Ciencias Naturales y Museo por mi formación Doctoral.

Agradezco a la Facultad de Ciencias Agrarias de la Universidad Nacional de Cuyo, especialmente al Laboratorio de Biología Molecular (Adrian Ruiz Leal), donde realicé el procesamiento de las muestras vegetales para la obtención de las secuencias de ADN de cloroplasto.

Finalmente agradezco a mi familia, mi madre y mis hermanos por su apoyo y confianza, siempre constante y necesaria. 


\section{RESUMEN}

El género Trichocereus se encuentra representado por 58 taxones (38 especies, 10 subespecies, 8 variedades y 2 formas), muchos de los cuales constituyen un elemento dominante del paisaje y definen provincias fitogeográficas áridas y semiáridas en la Argentina, Bolivia, Chile, Ecuador y Perú.

El estudio del género se realizó sobre la base de caracteres morfológicos (altura de los individuos, porte, ramificación y diámetro, morfología de las costillas, areolas, espinas, flores, frutos y semillas) y moleculares (secuencias de ADN del cloroplasto, trnL-F y rp/16). Se realizaron cuatro exploraciones botánicas (enero-febrero de 2007, noviembre de 2008, diciembre de 2009 y octubre de 2010), a las regiones áridas y semiáridas de la Argentina, Bolivia y Chile. Además, los estudios exomorfológicos se complementaron con la observación de materiales depositados en los siguientes herbarios: BAB, CORD, CTES, LIL, LP, LPB, MERL, MEXU, NY, SGO, SI, U.

Como resultado del estudio taxonómico se proponen:

A- Doce combinaciones: Eulychnia coquimbana (Molina) Albesiano, Trichocereus candicans subsp. pseudocandicans (R. Kiesling) Albesiano, Trichocereus chiloensis subsp. australis (F. Ritter) Albesiano, Trichocereus chiloensis subsp. eburneus (Phil. ex K. Schum.) Albesiano, Trichocereus chiloensis subsp. panhoplites (K. Schum.) Albesiano, Trichocereus schickendantzii subsp. shaferi (Britton \& Rose) Albesiano, Trichocereus schickendantzii subsp. smrzianus (Backeb.) Albesiano, Trichocereus strigosus var. vatteri (R. Kiesling) Albesiano, Trichocereus tarijensis var. poco (Backeb.) F. Ritter ex Albesiano, Trichocereus tarijensis var. poco (Backeb.) F. Ritter ex Albesiano f. poco, Trichocereus tarijensis var. poco (Backeb.) F. Ritter ex Albesiano f. albiflorus (Cárdenas) Albesiano, Trichocereus wilkeae (Backeb.) Albesiano.

B- Once nuevos sinónimos: Trichocereus callianthus F. Ritter como sinónimo de Trichocereus strigosus var. vatteri (R. Kiesling) Albesiano, Trichocereus chiloensis var. conjungens F. Ritter de Trichocereus bolligerianus (Mächler \& Helmut Walter) Albesiano, Trichocereus fabrisii R. Kiesling de Trichocereus schickendantzii (F.A.C. Weber) Britton \& Rose, Trichocereus glaucus F. Ritter de Trichocereus uyupampensis Backeb., Trichocereus glaucus f. pendens F. Ritter de Trichocereus uyupampensis Backeb., Trichocereus manguinii Backeb., de T. schickendantzii (F.A.C. Weber) Britton \& Rose, Trichocereus quadratiumbonatus F. Ritter de Trichocereus spachianus (Lem.) Riccob., Trichocereus rowleyi (H. Friedrich) R. Kiesling de Lobivia grandiflora Britton \& Rose, Trichocereus serenanus F. Ritter de T. deserticola (Werderm.) Looser, Trichocereus serpentinus (M. Lowry \& M. Mend.) Guiggi de Trichocereus vasquezii Rausch, Trichocereus thelegonoides (Speg.) Britton \& Rose de Trichocereus spachianus (Lem.) Riccob. 
C- Tres nombres nuevos: Trichocereus faundezii Albesiano, Trichocereus pectiniferus Albesiano para Trichocereus coquimbanus sensu Britton \& Rose, non Cactus coquimbanus Molina, non Cereus coquimbanus sensu K.Schum., non Echinopsis coquimbana sensu Friedrich \& G.D. Rowley y Trichocereus undulosus Albesiano.

D- Nueve lectotipificaciones: Helianthocereus pecheretianus Backeb., Lobivia grandiflora Britton \& Rose, Lobivia hyalacantha Speg., Lobivia oreopepon Speg., Trichocereus bertramianus Backeb., Trichocereus manguinii Backeb., Trichocereus pachanoi Britton \& Rose, Trichocereus santaensis Rauh \& Backeb. y Cereus thelegonus F.A.C. Weber.

E- Cincuenta y dos neotipificaciones: Cactus coquimbanus Molina, Cereus andalgalensis F.A.C. Weber, Cereus bridgesii Salm-Dyck var. brevispina K. Schum., Cereus bridgesii Salm-Dyck var. longispinus C.A. Maass, Cereus bridgesii Salm-Dyck, non Echinopsis bridgesii Salm-Dyck., Cereus candicans Gillies ex Salm-Dyck var. robustior Salm-Dyck, Cereus candicans Gillies ex Salm-Dyck var. tenuispinus Pfeiff., Cereus chiloensis var. eburnea Phil. ex K. Schum., Cereus chiloensis var. panhoplites K. Schum., Cereus gladiatus Lem., Cereus huascha F.A.C. Weber, Cereus huascha F.A.C. Weber var. flaviflora F.A.C. Weber, Cereus huascha F.A.C. Weber var. rubriflorus F.A.C. Weber, Cereus intricatus Salm-Dyck, Cereus lagenaeformis C.F. Först., Cereus lamprochlorus Lem., Cereus macrogonus (SalmDyck) Riccob., Cereus nitens Salm-Dyck ex Otto \& Dietr., Cereus nitens Salm-Dyck ex Otto \& Dietr., Cereus quisco Remy, Cereus rosei Werd., Cereus santiaguensis Speg., Cereus spachianus Lem., Cereus spinibarbis Otto ex Pfeiff., Cereus tacaquirensis Vaupel, Cereus terscheckii Parm. ex Pfeiff., Cereus thelegonoides Speg., Echinocereus strigosus (Salm-Dyck) Lemaire var. rufispinus Rümpler, Echinocereus strigosus (Salm-Dyck) Lemaire var. spinosior Salm-Dyck ex Rümpler's, Echinopsis schickendantzii F.A.C. Weber, Echinopsis smrziana Backeb., Eulychnia spinibarbis (Otto ex Pfeiff.) Britton \& Rose, Pilocereus pasacanus F.A.C. Weber, Soehrensia formosa (Pfeiff.) Backeb. var. maxima Backeb., Soehrensia huascha (F.A.C. Weber) Y. Itô var. rosiflora Y. Itô, Trichocereus auricolor Backeb., Trichocereus chiloensis var. australis F. Ritter, Trichocereus herzogianus Cárdenas, Trichocereus herzogianus Cárdenas var. totorensis Cárdenas, Trichocereus narvaecensis Cárdenas, Trichocereus poco Backeb., Trichocereus puquiensis Rauh \& Backeb., Trichocereus purpureopilosus Weing., Trichocereus skottsbergii Backeb., Trichocereus skottsbergii var. breviatus Backeb., Trichocereus taquimbalensis var. wilkeae Backeb., Trichocereus terscheckii (Parm. ex Pfeiff.) Britton \& Rose var. montanus Backeb., Trichocereus uyupampensis Backeb., Trichocereus vasquezii Rausch, Trichocereus vollianus Backeb., Trichocereus vollianus var. rubrispinus Backeb., Trichocereus werdermannianus Backeb.

F- En muchos casos se debieron designar neotipos, debido a que los autores habían basado sus descripciones de especies sobre un ejemplar vivo que nunca fue documentado como especímen de 
herbario. Se seleccionaron ejemplares tipo representativos, que presentaran en conjunto un corte transversal y/o longitudinal del tallo y flor. Cuando se pudo se eligieron ejemplares cercanos a la localidad original.

Para cada taxón se elaboró una ficha que presenta la siguiente información: sinónimos, tipos, iconografías, fotos, descripción original, descripción ampliada, distribución y hábitat, comentarios taxonómicos y nomenclaturales, al igual que exsiccata. Trece claves son suministradas, una para los géneros Echinopsis, Lobivia y Trichocereus, una clave general, tres por países, tres de las subespecies de Trichocereus candicans, Trichocereus chiloensis, Trichocereus schickendantzii, cuatro de las variedades de Trichocereus huascha, Trichocereus macrogonus, Trichocereus strigosus, Trichocereus tarijensis y una de las formas de $T$. tarijensis. Se proporciona una lista de los taxones excluidos; por cuanto corresponden a otro género o cuya resolución no pudo lograrse por falta de información.

Como resultado del estudio filogenético se proponen:

G- Las relaciones filogenéticas de Trichocereus fueron examinadas sobre la base de 39 caracteres exomorfológicos y secuencias de ADN del cloroplasto, trnL-F y rp/16 de 17 especies de Trichocereus, incluyendo otros tres géneros de la tribu Trichocereeae (Echinopsis, Lobivia, Setiechinopsis), dos de Notocacteae (Eulychnia, Wigginsia) y uno de Hylocereeae (Harrisia). El análisis filogenético combinado con base en datos morfológicos y datos de secuencias de ADN, recuperó a Trichocereus como monofilético sí las dos especies de Harrisia son parte de él. Además, el clado Trichocereus fue apoyado por tres sinapomorfías: crecimiento basítono con ramas postradas (ramas producidas desde la base y sin un tallo principal), escamas imbricadas a lo largo del tubo floral y frutos subglobosos. Trichocereus presenta una afinidad cercana con Lobivia al compartir dos homoplasias: costillas agudas $\left(45-90^{\circ}\right)$ y escamas del receptáculo próximas entre sí.

H- De los resultados de este estudio se propone que Echinopsis y Trichocereus deben mantenerse separados, lo cual ya había sido sugerido por varios autores. Trichocereus es cercano al género Lobivia, específicamente a un grupo de especies que fueron transferidas al género Soehrensia ( $S$. bruchii, S. formosa), pero que en la actualidad son consideradas pertenecientes a Lobivia.

I- Helianthocereus es un género que agrupa especies de Trichocereus con flores coloreadas (amarillas, anaranjadas y rojas) y diurnas, por ejemplo $\mathrm{H}$. andalgalensis, $\mathrm{H}$. atacamensis (tiene flores blancas, las cuales permanecen abiertas dos 0 tres días) y $\mathrm{H}$. tarijensis, las cuales en el análisis filogenético simultáneo pertenecen a tres clados diferentes dentro de Trichocereus, por lo que se acepta que Helianthocereus sea considerado sinónimo de Trichocereus. 
J- Como resultado del análisis filogenético Trichocereus arboricola, Harrisia earlei y Harrisia hahniana forman un clado apoyado por cuatro sinapomorfías: presencia de raíces adventicias, tallos totalmente expuestos sobre la superficie del suelo y con costillas amplias, con un ángulo mayor de $180^{\circ}, \mathrm{y}$ semillas grandes, de 2 a 2,9 mm.

K- Los taxones infraespecíficos de la especie tipo, Trichocereus macrogonus var. macrogonus y T. macrogonus var. pachanoi son taxones hermanos, al compartir la sinapomorfía, ramas verde-glaucas.

Palabras clave: ADN de cloroplasto, Echinopsis, evolución de caracteres, filogenia, Lobivia, morfología, taxonomía, Trichocereus. 


\section{ABSTRACT}

Trichocereus genus is represented by 58 taxa (38 species, 10 subspecies, 8 varieties and 2 forms), many of which are a dominant feature of the landscape and define arid and semiarid phytogeographical provinces in Argentina, Bolivia, Chile, Ecuador and Peru.

The study of the genus was made on the basis of morphological characters (height of individuals, habit, branching and diameter, morphology of the ribs, areoles, spines, flowers, fruits and seeds) and molecular (chloroplast DNA sequences trnL-F and rp/16). Four botanical explorations (January-February 2007, November 2008, December 2009 and October 2010), to arid and semiarid regions of Argentina, Bolivia and Chile were performed. In addition, studies were complemented exomorphological observing materials deposited in the following herbaria: BAB, CORD, CTES, LIL, LP, LPB, MERL, MEXU, NY, SGO, SI, U.

As a result of taxonomic study is proposed:

A- Twelve combinations: Eulychnia coquimbana (Molina) Albesiano, Trichocereus candicans subsp. pseudocandicans (R. Kiesling) Albesiano, Trichocereus chiloensis subsp. australis ( $\mathrm{F}$. Ritter) Albesiano, Trichocereus chiloensis subsp. eburneus (Phil. ex K. Schum.) Albesiano, Trichocereus chiloensis subsp. panhoplites (K. Schum.) Albesiano, Trichocereus schickendantzii subsp. shaferi (Britton \& Rose) Albesiano, Trichocereus schickendantzii subsp. smrzianus (Backeb.) Albesiano, Trichocereus strigosus var. vatteri (R. Kiesling) Albesiano, Trichocereus tarijensis var. poco (Backeb.) F. Ritter ex Albesiano, Trichocereus tarijensis var. poco (Backeb.) F. Ritter ex Albesiano f. poco, Trichocereus tarijensis var. poco (Backeb.) F. Ritter ex Albesiano f. albiflorus (Cárdenas) Albesiano, Trichocereus wilkeae (Backeb.) Albesiano.

B- Eleven new synonyms: Trichocereus callianthus F. Ritter as a synonym for Trichocereus strigosus var. vatteri (R. Kiesling) Albesiano, Trichocereus chiloensis var. conjungens F. Ritter for Trichocereus bolligerianus (Mächler \& Helmut Walter) Albesiano, Trichocereus fabrisii R. Kiesling for Trichocereus schickendantzii (F.A.C. Weber) Britton \& Rose, Trichocereus glaucus F. Ritter for Trichocereus uyupampensis Backeb., Trichocereus glaucus f. pendens F. Ritter for Trichocereus uyupampensis Backeb., Trichocereus manguinii Backeb., for T. schickendantzii (F.A.C. Weber) Britton \& Rose, Trichocereus quadratiumbonatus F.Ritter for Trichocereus spachianus (Lem.) Riccob., Trichocereus rowleyi (H. Friedrich) R. Kiesling for Lobivia grandiflora Britton \& Rose, Trichocereus serenanus F. Ritter for T. deserticola (Werderm.) Looser, Trichocereus serpentinus (M. Lowry \& M. Mend.) Guiggi for Trichocereus vasquezii Rausch, Trichocereus thelegonoides (Speg.) Britton \& Rose for Trichocereus spachianus (Lem.) Riccob. 
C- Three new names: Trichocereus faundezii Albesiano, Trichocereus pectiniferus Albesiano for Trichocereus coquimbanus sensu Britton \& Rose, non Cactus coquimbanus Molina, non Cereus coquimbanus sensu K.Schum., non Echinopsis coquimbana sensu Friedrich \& G.D. Rowley and Trichocereus undulosus Albesiano.

D- Nine lectotypifications: Helianthocereus pecheretianus Backeb., Lobivia grandiflora Britton \& Rose, Lobivia hyalacantha Speg., Lobivia oreopepon Speg., Trichocereus bertramianus Backeb., Trichocereus manguinii Backeb., Trichocereus pachanoi Britton \& Rose, Trichocereus santaensis Rauh \& Backeb. and Cereus thelegonus F.A.C. Weber.

E- Fifty-two neotypifications: Cactus coquimbanus Molina, Cereus andalgalensis F.A.C. Weber, Cereus bridgesii Salm-Dyck var. brevispina K. Schum., Cereus bridgesii Salm-Dyck var. Iongispinus C.A. Maass, Cereus bridgesii Salm-Dyck, non Echinopsis bridgesii Salm-Dyck., Cereus candicans Gillies ex Salm-Dyck var. robustior Salm-Dyck, Cereus candicans Gillies ex Salm-Dyck var. tenuispinus Pfeiff., Cereus chiloensis var. eburnea Phil. ex K. Schum., Cereus chiloensis var. panhoplites K. Schum., Cereus gladiatus Lem., Cereus huascha F.A.C. Weber, Cereus huascha F.A.C. Weber var. flaviflora F.A.C. Weber, Cereus huascha F.A.C. Weber var. rubriflorus F.A.C. Weber, Cereus intricatus Salm-Dyck, Cereus lagenaeformis C.F. Först., Cereus lamprochlorus Lem., Cereus macrogonus (Salm-Dyck) Riccob., Cereus nitens Salm-Dyck ex Otto \& Dietr., Cereus nitens Salm-Dyck ex Otto \& Dietr., Cereus quisco Remy, Cereus rosei Werd., Cereus santiaguensis Speg., Cereus spachianus Lem., Cereus spinibarbis Otto ex Pfeiff., Cereus tacaquirensis Vaupel, Cereus terscheckii Parm. ex Pfeiff., Cereus thelegonoides Speg., Echinocereus strigosus (Salm-Dyck) Lemaire var. rufispinus Rümpler's, Echinocereus strigosus (SalmDyck) Lemaire var. spinosior Salm-Dyck ex Rümpler's, Echinopsis schickendantzii F.A.C. Weber, Echinopsis smrziana Backeb., Eulychnia spinibarbis (Otto ex Pfeiff.) Britton \& Rose, Pilocereus pasacanus F.A.C. Weber, Soehrensia formosa (Pfeiff.) Backeb. var. maxima Backeb., Soehrensia huascha (F.A.C. Weber) Y. Itô var. rosiflora Y. Itô, Trichocereus auricolor Backeb., Trichocereus chiloensis var. australis F. Ritter, Trichocereus herzogianus Cárdenas, Trichocereus herzogianus Cárdenas var. totorensis Cárdenas, Trichocereus narvaecensis Cárdenas, Trichocereus poco Backeb., Trichocereus puquiensis Rauh \& Backeb., Trichocereus purpureopilosus Weing., Trichocereus skottsbergii Backeb., Trichocereus skottsbergii var. breviatus Backeb., Trichocereus taquimbalensis var. wilkeae Backeb., Trichocereus terscheckii (Parm. ex Pfeiff.) Britton \& Rose var. montanus Backeb., Trichocereus uyupampensis Backeb., Trichocereus vasquezii Rausch, Trichocereus vollianus Backeb., Trichocereus vollianus var. rubrispinus Backeb., Trichocereus werdermannianus Backeb. 
F- In many cases the authors fail to designate neotypes because they had based their descriptions of species in a live specimen which was never documented as herbarium specimen. Representative type specimens were selected, together showing a transverse and/or longitudinal section of the stem and flower. When we could, we collected specimens close to the original location.

For each taxon a tab that displays the following information was produced: synonyms, types, iconographies, pictures, original descriptions, extended descriptions, distribution, habitat, taxonomic and nomenclatural comments and exsiccata: Thirteen taxonomic keys are supplied, three to genus Echinopsis, Lobivia y Trichocereus, a general key, three from each countries, three subspecies of Trichocereus candicans, Trichocereus chiloensis, Trichocereus schickendantzii, four varieties Trichocereus huascha, Trichocereus macrogonus, Trichocereus strigosus, Trichocereus tarijensis and one of the forms of $T$. tarijensis. A list of excluded taxa is provided; because they correspond to another genus or whose resolution could not be achieved due to lack of information.

As a result of phylogenetic study is proposed:

G- The phylogenetic relationships of Trichocereus were examined on the basis of 39 exomorphological characters and chloroplast DNA sequences, trnL-F and rp/16 for 17 species of Trichocereus, including three other genera of the tribe Trichocereeae (Echinopsis, Lobivia, Setiechinopsis), two of Notocacteae (Eulychnia, Wigginsia) and one of Hylocereeae (Harrisia). The combination of both phylogenies (morphological and DNA) confirmed the monophyly of Trichocereus, defined by the following three synapomorphies: basitonic growth with prostrate branches (branches produced from the base and without a main stem), imbricate scales along the floral tube and subglobose fruits. Trichocereus has a close affinity with Lobivia to share two homoplasies: acute ribs (45-90 $)$ and scales receptacle next to each other.

$\mathrm{H}$ - The results of this study suggested that Echinopsis and Trichocereus must be kept separate, which had already been suggested by several authors. Trichocereus is close to the genus Lobivia, specifically a group of species that were transferred to the genus Soehrensia (S. bruchii, S. formosa), but today are considered belonging to Lobivia.

I- Helianthocereus is a genus that groups Trichocereus species with colourful (yellow, orange and red) day-opening flowers, for example $H$. andalgalensis, $H$. atacamensis (it has white flowers which remain open two or three days) and $H$. tarijensis, in which simultaneous phylogenetic analysis belong to three different clades within Trichocereus. Therefore Helianthocereus is considered to be synonymous with Trichocereus. 
J- As a result of phylogenetic analysis Trichocereus arboricola, Harrisia earlei and $\mathrm{H}$. hahniana form a clade supported by four synapomorphies: presence of adventitious roots, stems totally exposed on the ground surface, with ribs broad, with an angle higher than $180^{\circ}$, and seeds large, from 2.0 to $2.9 \mathrm{~mm}$.

K- Infraspecific taxa of the type species, Trichocereus macrogonus var. macrogonus and $T$. macrogonus var. pachanoi are sister taxa, to share the synapomorphy, glaucous-green branches.

Keywords: chloroplast DNA, Echinopsis, character' evolution, phylogeny, Lobivia, morphology, taxonomy, Trichocereus. 


\section{INTRODUCCIÓN}

En la actualidad la taxonomía de Cactaceae se basa principalmente en los trabajos de Anderson (2001) y Hunt et al. (2006), los cuales son obras generales y modernas, dirigidas a amateurs y coleccionistas de cactus, que carecen de estudios de campo, claves para la identificación taxonómica de las especies, de la historia nomenclatural completa de géneros y especies, descripciones originales, comentarios taxonómicos, nomenclaturales, una descripción detallada de los caracteres morfológicos y sin comparaciones con taxones relacionados.

La taxonomía de Cactaceae cuenta con muy pocas monografías, solo unas 10 de los casi 100 géneros aceptados en la actualidad han sido objeto de una revisión sistemática moderna. Desde hace más de 50 años se han propuesto miles de nombres nuevos, sin una revisión crítica de su validez nomenclatural y estatus sistemático.

El género Trichocereus pertenece a la subtribu Trichocereinae Buxbaum, y esta a su vez a la tribu Trichocereeae Buxbaum, de la subfamilia Cactoideae y comprende 58 especies de los Andes de Ecuador, Perú, Bolivia, Argentina y Chile.

Trichocereus fue propuesto por Berger (1905) como un subgénero de Cereus, género que antiguamente agrupaba a todas las cactáceas columnares. En 1909, Riccobono lo transfirió a nivel de género. Sin embargo, Friedrich (1974) reúne varios géneros, entre ellos Trichocereus y Lobivia, con Echinopsis. El mismo criterio fue seguido por Rowley (1974), Friedrich \& Glaetzle (1983), Anderson (2001, 2005), Hunt et al. (2006) y Schlumpberger y Renner (2012). Mientras que Kiesling (1978), Ritter (1980a, 1980b, 1981), Gibson \& Nobel (1986) y Hunt (2013), entre otros, reconocen a Trichocereus como un género separado de Echinopsis.

Trichocereus se define morfológicamente por los tallos cilíndricos, con costillas poco profundas, flores grandes $(8-30 \mathrm{~cm})$, ovario ancho $(2,0-2,5 \mathrm{~cm})$ y tubo floral recubierto por escamas subuladas, de cuyas axilas emergen abundantes pelos negros, marrones, grises o blancos (Kiesling 1978, Kiesling \& Ferrari 2005). Riccobono (1909) reconoció Trichocereus como género con base en los tallos columnares y la pilosidad en las flores, características que refieren a la etimología del nombre.

La complejidad y diversidad de los géneros de la tribu Trichocereeae (Acanthocalycium, Chamaecereus, Echinopsis s. str., Hymenorebutia, Lobivia, Pseudolobivia, Soehrensia y Trichocereus), es posiblemente el problema de mayor interés a nivel genérico, por lo menos para las cactáceas sudamericanas. Existen más de 100 nombres de especies de Trichocereus, y no hay hasta el momento un tratamiento moderno de conjunto para el género, sólo existen dos tratamientos taxonómicos, uno para la Argentina (Kiesling 1978) y otro para Ecuador (Madsen 1989), y descripciones de especies en floras locales para la Argentina (Ritter 1980a; Trevisson \& Demaio 2006; Trevisson \& Perea 2009); Bolivia (Ritter 1980a; Navarro 1996; Navarro \& Maldonado 2002), Chile (Hoffmann \& Walter 2004; Ritter 1980b) y Perú (Ritter 1981; Brako \& Zarucchi 1993; Ostolaza 2011). Si bien fueron enumeradas para el Paraguay y 
Brasil, se trata de diversos tipos de errores o de especies actualmente atribuidas a otros géneros (Kiesling 1978).

La intención de este trabajo no es analizar la sistemática de la tribu Trichocereeae, sino aclarar si Echinopsis en el sentido amplio de Friedrich (1974) y Rowley (1974) es correcto, o si hay que volver al concepto tradicional, de considerarlos tres géneros -Echinopsis, Lobivia y Trichocereus-, los cuales se diferencian por la forma de los tallos, tamaño y pilosidad en las flores y por la distribución geográfica. Para ello se proponen los siguientes tres objetivos:

1) Confirmar la monofilia del género Trichocereus.

2) Delimitar las especies de Trichocereus, ampliar las descripciones y resolver los problemas nomenclaturales.

3) Establecer las relaciones entre las especies del género Trichocereus sobre la base de las características morfológicas y moleculares, con el fin de esclarecer la taxonomía de un grupo complejo dentro de una tribu poco conocida, y de importancia biológica y cultural.

\section{MATERIALES Y MÉTODOS}

Se realizaron cuatro exploraciones botánicas (enero-febrero de 2007, noviembre de 2008, diciembre de 2009 y octubre de 2010), a las regiones áridas y semiáridas de la Argentina, Bolivia y Chile, donde se tomaron datos del hábitat (localización y tipo de vegetación), y de los ejemplares, altura de los individuos y morfología de las costillas, areolas, espinas, flores, frutos y semillas según Buxbaum (1950, 1953, 1955), características que fueron consignadas en un formulario (Anexo 14.1). Se recolectaron fragmentos, los cuales fueron procesados y depositados en los Herbarios LIL, MERL y AGUCH (colección de Luis Faúndez, Santiago, Chile). Además, los estudios exomorfológicos se complementaron con la observación de materiales pertenecientes a los herbarios BAB, CORD, CTES, LIL, LP, LPB, MERL, MEXU, NY, SGO, SI, U. El material tipo estudiado se señala con el acrónimo del herbario, seguido por un signo de exclamación (!), que indica la observación personal por este autor.

\section{HISTORIA DEL GÉNERO / ANTECEDENTES HISTÓRICOS}

Trichocereus fue propuesto por Berger (1905) como subgénero de Cereus (para 14 especies), género que antiguamente agrupaba a todas las cactáceas columnares. En 1909, Riccobono lo transfirió a nivel de género; pero con sólo dos especies (T. macrogonus y $T$. spachianus). Otras especies continuaban en otros géneros como Cereus (C. atacamensis, C. eriocarpus), Echinopsis (E. candicans, $E$. lamprochlora), y Echinocereus (E. spinibarbis). Posteriormente, Britton \& Rose (1920) proponen por primera vez una clave para diferenciar las 19 especies de Trichocereus que ellos reconocieron (Tabla 1). 
Tabla 1. Clasificación taxonómica de Trichocereus (1920-2013), indicando especies, subespecies, variedades, y géneros relacionados.

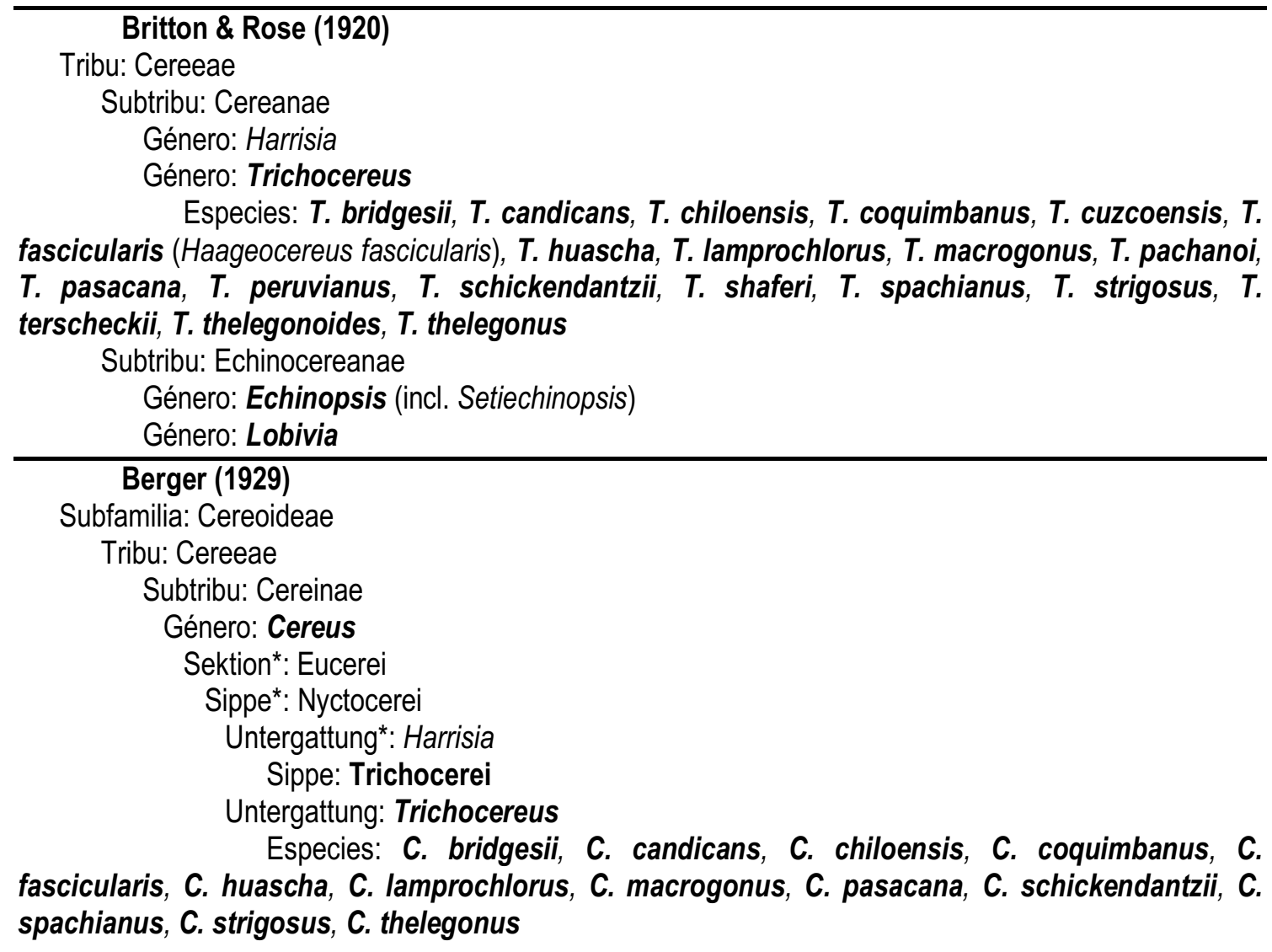

Backeberg (1958)

Subfamilia: Cereoideae

Tribu: Cereeae

Semitribu: Austrocereeae

Subtribu: Austrocereinae

Clan: Trichocerei

Subclan: Nyctotrichocerei

Género: Setiechinopsis

Género: Trichocereus

Subgénero: Trichocereus (T. bridgesii, T. candicans, T. pachanoi, T. peruvianus, $T$. schickendantzii, $T$. terscheckii, etc.)

Subgénero: Medioeulychnia ( $T$. chiloensis, $T$. coquimbanus, $T$. deserticola, T. skottsbergii, etc.)

Género: Echinopsis

Subclan: Heliotrichocerei

Género: Helianthocereus

Subgénero: Helianthocereus: $H$. pasacana (T. atacamensis), $H$. tarijensis, etc.

Subgénero: Neohelianthocereus: $H$. huascha, $H$. pecheretianus, $H$. grandiflorus, etc.

Subtribu: Austrocactinae

Clan: Lobiviae

Subclan: Eriolobiviae 


\section{Género: Lobivia}

Subgénero: Lobivia, Neolobivia

Semitribu: Boreocereeae

Subtribu: Boreocereinae

Clan: Nyctocerei

Género: Harrisia

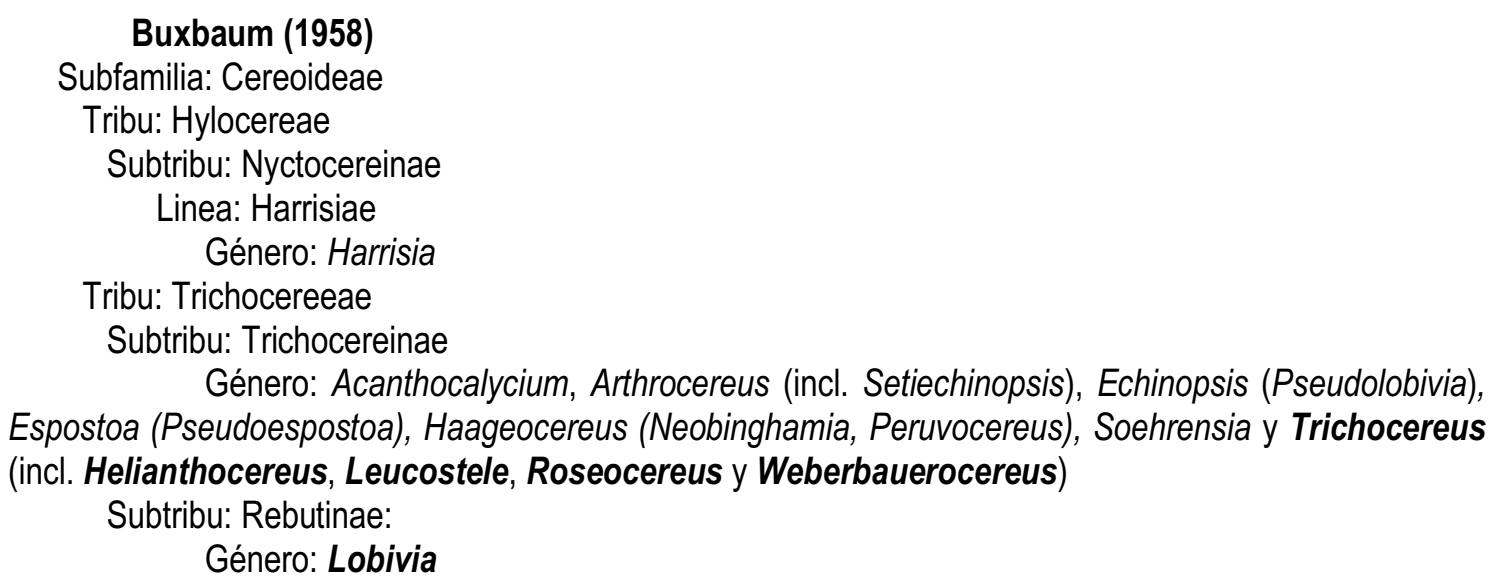

Friedrich (1974), Rowley (1974)

Tribu: Echinopsideae (nuevo nombre de remplazo para Trichocereeae)

Subtribu: Echinopsidinae

Género: Echinopsis

Subgénero: Acanthocalycium

Subgénero: Echinopsis

Sección: Echinopsis

Sección: Hymenorebutia

Sección: Pseudoechinopsis

Subgénero: Trichocereus

Sección: Soehrensia (non Lobivia s. str.)

Sección: Trichocereus (incl. Helianthocereus)

Especies: $\boldsymbol{E}$. antezanae, $\boldsymbol{E}$. atacamensis, $E$. bertramiana, $\boldsymbol{E}$. camarguensis, $E$. candicans, E. cephalomacrostibas, E. chalaensis, E. chiloensis, E. coquimbana, E. courantii, $E$. cuzcoensis, E. deserticola, E. escayachensis, $E$. friedrichii, $E$. fulvilana, E. glauca, E. herzogiana, $E$. huascha, E. lagenaeformis, E. litoralis, $E$. macrogona, E. manguinii, E. narvaecensis, E. nigripilis, E. orurensis, E. pachanoi, E. pasacana, E. peruviana, E. poco, E. puquiensis, E. purpureopilosus, E. rivierei, $E$. rubinghiana, E. santaensis, E. santiaguensis, E. skottsbergii, E. strigosa, $E$. tacaquirensis, E. taquimbalensis, E. toratensis, E. tarijensis, E. tarmaensis, E. terscheckii, E. thelegona, E. thelegonoides, E. trichosus, E. tulhuayacensis, E. tunariensis, E. uyupampensis, E. vollianus, E. werdermanniana

Género: Lobivia

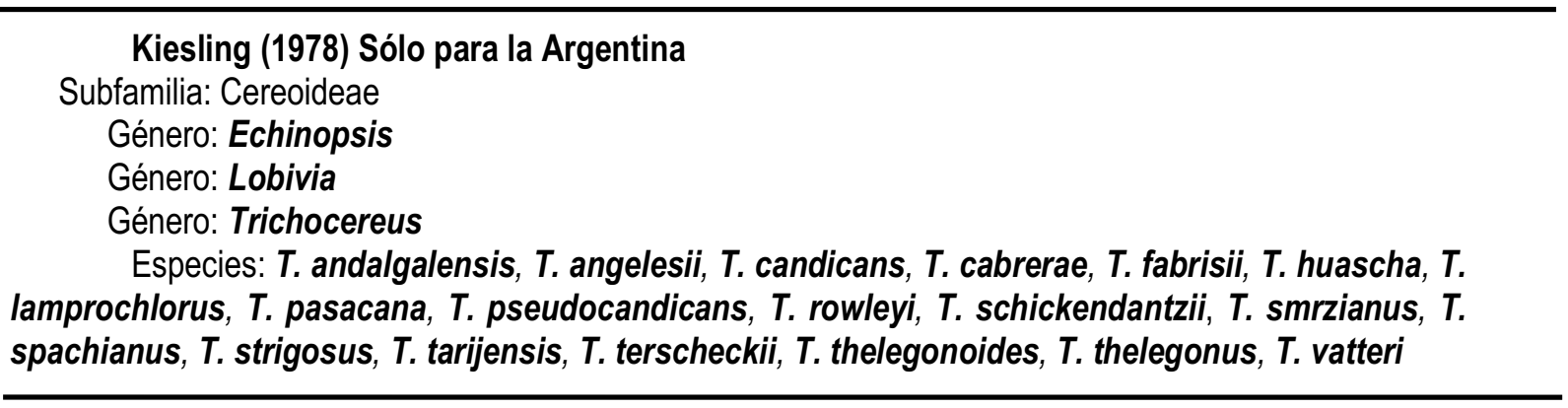


Ritter (1980a, 1980b, 1981)

Género: Echinopsis (incl. Setiechinopsis)

Género: Eriocereus (incl. Harrisia)

Género: Trichocereus

Especies: T. andalgalensis, T. angelesii, T. antezanae, T. bridgesii, T. callianthus, $T$. caulescens, $T$. chuquisacanus, $T$. eremophilus, $T$. fulvilanus, $T$. glaucus, $T$. quadratiumbonatus, $T$. riomizquensis, $T$. scopulicola, $T$. serenanus, $T$. tacnaensis, $T$. terscheckioides, $T$. tenuispinus, $T$. torataensis, etc.

Variedades: T. chiloensis var. australis, T. chiloensis var. borealis, $T$. chiloensis var. conjungens, etc.

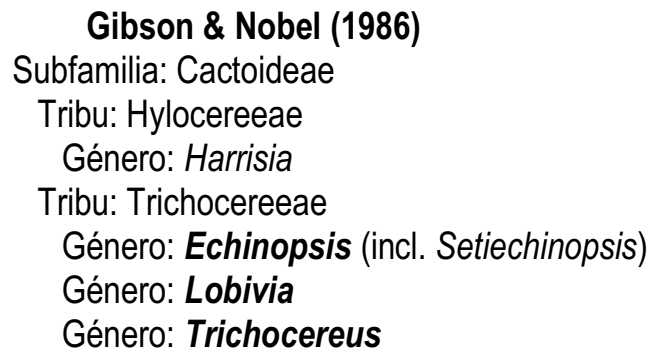

Hunt et al. (2006)

Subfamilia: Cactoideae

Género: Echinopsis (incl. Acanthocalycium, Acantholobivia, Chamaecereus, Helianthocereus, Lobivia, Pseudolobivia, Setiechinopsis, Soehrensia, Trichocereus)

Género: Harrisia

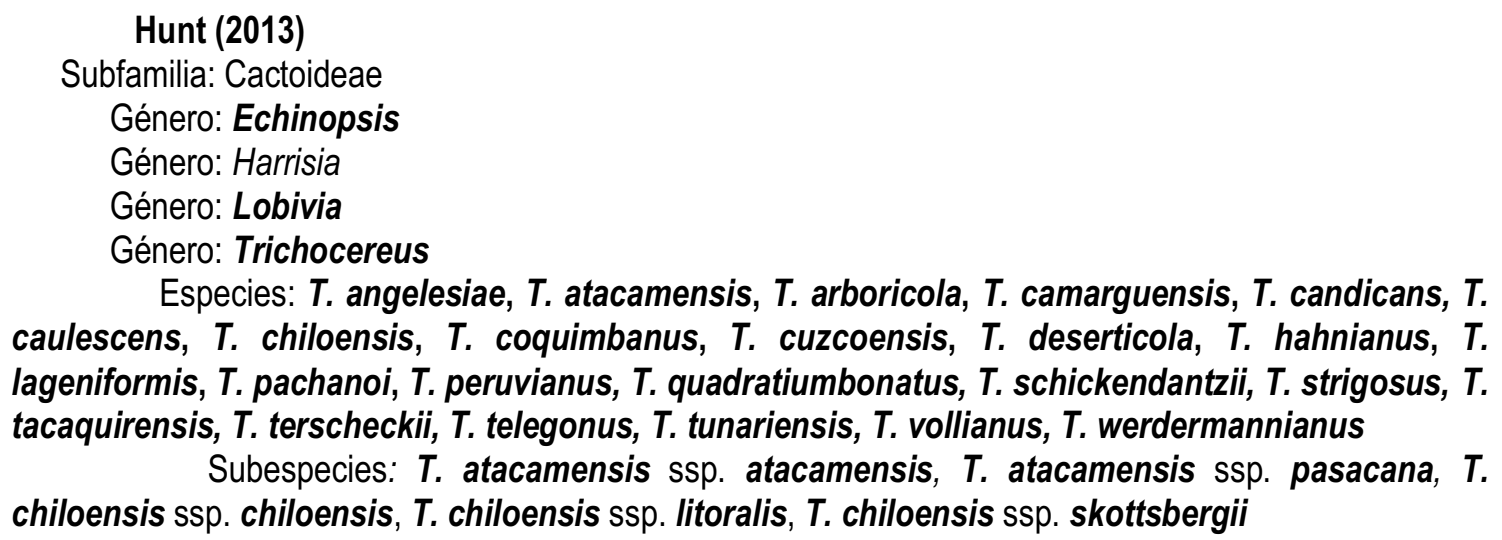

Especies: $T$. angelesiae, $T$. atacamensis, $T$. arboricola, $T$. camarguensis, $T$. candicans, $T$. caulescens, $T$. chiloensis, $T$. coquimbanus, $T$. cuzcoensis, $T$. deserticola, $T$. hahnianus, $T$. lageniformis, T. pachanoi, T. peruvianus, T. quadratiumbonatus, T. schickendantzii, $T$. strigosus, $T$. tacaquirensis, $T$. terscheckii, T. telegonus, $T$. tunariensis, $T$. vollianus, $T$. werdermannianus

Subespecies: $T$. atacamensis ssp. atacamensis, $T$. atacamensis ssp. pasacana, $T$. chiloensis ssp. chiloensis, T. chiloensis ssp. litoralis, T. chiloensis ssp. skottsbergii

* Los rangos de Berger (1929) "Sektion", "Sippe" y "Untergattung" no están de acuerdo con el artículo 4.1. del Código Internacional de Nomenclatura Botánica (McNeill et al. 2012).

Desde su creación en 1909 por Riccobono, este género no sufre modificaciones, salvo algunas especies nuevas que se le suman por Britton \& Rose (1920), hasta que Backeberg (1949) propone el género Helianthocereus, para las especies de Trichocereus con flores de colores vistosos (amarillas, 
anaranjadas y rojas) y con apertura diurna. Según, Backeberg, las especies con flores blancas y apertura floral nocturna permanecen en Trichocereus.

Buxbaum (1958) realizó una clasificación de la subfamilia Cereoideae, proponiendo la tribu Trichocereeae, y designando a Trichocereus como género tipo de la tribu. Además, dentro de Trichocereeae, la subtribu Trichocereinae, agrupando los siguientes géneros (los sinónimos entre paréntesis, sin explicación, dada la índole general del trabajo): Acanthocalycium, Arthrocereus (incl. Setiechinopsis), Echinopsis (incl. Pseudolobivia), Espostoa (incl. Pseudoespostoa), Haageocereus (incl. Neobinghamia, Peruvocereus), Soehrensia y Trichocereus (incl. Helianthocereus, Leucostele, Roseocereus y Weberbauerocereus) (Tabla 1). Según Buxbaum, la subtribu se caracteriza por "tallos grandes y columnares, pocas veces globulares; flores radiales, campanuladas a infundibuliformes; perigonio grande, sobre todo blanco o blanquecino, a veces de colores brillantes; la cámara nectarial presente 0 ausente; inserción de los estambres en la base del receptáculo o por encima de la cámara nectarial".

Friedrich (1974) define y reúne varios géneros, incluyendo a Soehrensia (non Lobivia s. str.) y Trichocereus, con Echinopsis (Tabla 1), basados únicamente en dos caracteres florales, pelos en las axilas de las escamas del hipanto, y disposición de los estambres en dos grupos- aun cuando estos caracteres están presentes en otros géneros de la tribu Trichocereeae (Buxbaum 1958) o son polimórficos en unas pocas especies, como en el caso de Lobivia grandiflora. Según Friedrich (I.c.), Echinopsis comprende tres subgéneros: Acanthocalycium; Echinopsis con tres secciones -Echinopsis, Hymenorebutia y Pseudoechinopsis; y Trichocereus con las secciones Trichocereus y Soehrensia. Por otra parte, la subtribu Echinopsidinae (nombre nuevo dado por Friedrich para remplazar Trichocereinae), es definida solo por la cámara nectarial sin dar detalles de sus características.

Rowley (1974) pasó todos los nombres de Trichocereus a Echinopsis, sin estudiar las especies, incluso comete errores nomenclaturales al combinar nombres inválidos.

Kiesling (1978), mejora el conocimiento de las especies de Trichocereus del territorio argentino, al ilustrarlas, describirlas y proporcionar una clave para diferenciarlas. Además, considera que al género propuesto por Backeberg -Helianthocereus-, le debe corresponder como máximo la categoría de subgénero.

Ritter (1980a, 1980b, 1981) hace comentarios de géneros y especies de la familia Cactaceae en Argentina, Bolivia, Chile y Perú, pero sin claves para la identificación de los géneros y especies, y la ausencia de algunos especímenes tipo en el mencionado herbario $(U)$ o incompleta indicación de los basónimos. Además, Ritter propone especies nuevas y combinaciones de Trichocereus ( $T$. eremophilus, T. glaucus, T. serenanus, T. atacamensis var. pasacana, T. tarijensis var. poco, entre otras, Tabla 1).

Friedrich \& Glaetzle (1983) estudiaron la ultraestructura de la testa de las semillas de Echinopsis sensu lato s.l., incluye todas las especies de Chamaecereus, Echinopsis s. str., Helianthocereus, Hymenorebutia, Pseudolobivia p.p, Soehrensia, Trichocereus, usando el Microscopio Electrónico de 
Barrido (SEM), proponiendo nueve grupos basados en estos datos. Los cuatro primeros (la, lb, lla y llb) corresponden a especies del subgénero Trichocereus, y en el grupo lla ellos también incluyen especies de Soehrensia. Recientemente, se han propuesto clasificaciones (Hunt \& Taylor 1986, Hunt 1999, Anderson 2005, Hunt et al. 2006) aceptando la hipótesis de Friedrich (1974), donde el género Echinopsis (s.I.) incluye Acanthocalycium, Chamaecereus, Echinopsis s. str., Helianthocereus, Hymenorebutia, Pseudolobivia, Setiechinopsis, Soehrensia y Trichocereus, así como Lobivia.

\section{RELACIONES GENÉRICAS}

El género Trichocereus pertenece a la tribu Trichocereeae Buxbaum, y a la subtribu Trichocereinae Buxbaum. La subtribu se separó de sus parientes más cercanos hace 7,5-6,5 millones de años (Arakaki et al. 2011), y morfológicamente se caracteriza por sus tallos columnares o en algunas ocasiones globulares y las flores zigomórficas (Schick 2011), campanuladas a infundibuliformes; con tépalos grandes, principalmente blancos o blancuzcos, algunas veces de colores brillantes (amarillas, anaranjadas y rojas); cámara nectarial presente 0 ausente y la inserción de los estambres que comienza en la base del receptáculo o sobre la cámara nectarial (Buxbaum 1958).

Echinopsis, Lobivia y Trichocereus están cercanamente relacionados, y la gran mayoría de las especies pueden ser asignadas claramente y sin dificultad a cualquiera de estos tres géneros, usando los caracteres morfológicos en la siguiente clave:

\section{Clave para el reconocimiento de Echinopsis, Lobivia y Trichocereus}

1. Plantas de 0,5 a $12 \mathrm{~m}$ de alto, erectas, ascendentes o raro rastreras. Ramas tan o casi tan altas como el tallo central. Tallos y ramas basales cilíndricas. Madera fibrosa, dura y sin traqueidas de banda ancha en plantas adultas. Mayormente de los Andes, desde Ecuador hasta la Argentina y Chile.

\section{Trichocereus}

1'. Plantas de 0,1 a 0,3 m de alto (1 m, a veces 1,5 en Echinopsis leucantha, Echinopsis ayopayana y Lobivia grandiflora), mayormente globosas o deprimidas. Ramificado o no. Tallo mayormente globular o deprimido (cilíndrico en Echinopsis leucantha, Echinopsis ayopayana y Lobivia formosa). Madera sin fibras, blanda y con traqueidas de banda ancha en plantas adultas.

2. Flores menores de $9 \mathrm{~cm}$ de largo, campanuladas, largo de la flor completa es aproximadamente igual al diámetro del perigonio, receptáculo cónico, con pelos densos en las areolas del receptáculo y escamas numerosas y muy próximas entre sí o sobrelapándose. Frutos secos. Distribuida en la región andina de la Argentina, Bolivia y Perú.

\section{Lobivia}

2'. Flores de 10 a $24 \mathrm{~cm}$ de longitud, largo de la flor completa es dos veces el diámetro del perigonio, infundibuliformes, receptáculo tubular, pelos pocos en las areolas del receptáculo y escamas muy pocas y espaciadas entre sí. Frutos semisecos. Mayormente en sudamérica oriental, extrandina, Brasil y Uruguay, con algunas especies en los Andes de Argentina y Bolivia.

Echinopsis 


\section{MORFOLOGÍA DEL GÉNERO}

\subsection{Caracteres vegetativos:}

Habito: Plantas erectas, péndulas, decumbentes y ascendentes (Fig. 1 y 2, llustración 1A-C), raro rastreras; tallo solitario, solo en lugares muy secos de Chile y partes de Salta, hasta $15 \mathrm{~m}$ de alto como en Trichocereus atacamensis, arborescente o formando densos arbustos de 2-3 $\mathrm{m}$ de alto o menos de un metro (ej: Trichocereus thelegonus).

Tallo: Especies como Trichocereus atacamensis presentan un tallo principal ramificado a 1,5 m de altura y de hasta $15 \mathrm{~m}$ de alto (Fig. $2 \mathrm{C}$ ), y no ramificado en $T$. tarijensis (Fig. 2F). En T. chiloensis subsp. litoralis y $T$. skottsbergii presentan un tallo principal de donde surgen las primeras ramas de 0,5-3 $\mathrm{m}$ de alto (Fig. 2C), y hasta $50 \mathrm{~cm}$ de diámetro. Muchos individuos de algunas especies carecen de un tallo principal (ej: Trichocereus candicans, Trichocereus deserticola, Trichocereus spinibarbis), formando matas ramificadas de la base (Fig. 1A).

Ramas: Cilíndricas, erectas o ascendentes, raro rastreras, naciendo de la base del tallo principal o más arriba. El diámetro (6,0-25 cm) y el color (verde-claro, verde-oscuro o grisáceo) varía dentro y entre las especies. En Trichocereus thelegonus los extremos apicales son ascendentes (Fig. 1B). El anillo vascular es grueso y muchas veces muy duro en tallos adultos. Los ápices son subesféricos mayormente.

Costillas: 9-25 (-40), anchas (hasta $5 \mathrm{~cm}$ ), bajas (hasta $2 \mathrm{~cm}$ ), borde generalmente obtuso. En las especies ascendentes, como Trichocereus nigripilis, Trichocereus spinibarbis, las características de las costillas se mantienen constantes a lo largo de las ramas, mientras que en especies arbóreas, como T. atacamensis, se presentan diferencias en el número y amplitud entre las costillas del ápice y la base. En Trichocereus faundezii, $T$. thelegonus, $T$. undulosus las costillas son abultadas en la zona de las areolas (tuberculadas).

Areolas: Pueden ser circulares, oblongas u ovadas, bajas (hasta $10 \mathrm{~mm}$ de alto), con pilosidad blanca, amarilla, gris, marrón o negra (Fig. 3E-G).

Espinas: Teretes, las radiales cortas (hasta $2 \mathrm{~cm}$ ), numerosas (11-21), en un ángulo de $75^{\circ}$ al eje de la rama (divaricadas) o adpresas a la superficie de la rama $\left(15^{\circ}\right)$; pueden o no entrecruzarse con las espinas de las areolas vecinas; las centrales largas $(10-20 \mathrm{~cm})$, pocas (1-6), y perpendiculares a la rama o divaricadas. Su estructura puede ser débil y flexible (cerdosa) o rígidas y tiesas (aciculares 0 subuladas) (Fig. 3E-G, Fig. 5K-L, llustración 1E-G). 
Madera: En el xilema primario de las plántulas de Trichocereus andalgalensis, T. atacamensis, T. candicans, $T$. schickendantzii, $T$. strigosus y $T$. terscheckii se presentan traqueidas de banda ancha, con engrosamientos anulares y helicoidales de la pared celular, cuya función consiste en proteger el lumen de la traqueida ante la pérdida de agua en los periódos de máxima sequía, se encogen en la medida que pierden agua y se expanden a medida que la absorben. En los individuos adultos, la madera se caracteriza por ser fibrosa, dura y las traqueidas carecen de banda ancha (Mauseth \& Plemons 1998; Mauseth 2004; Cenizo et al. 2013) (llustración 11).

\subsection{Caracteres reproductivos:}

Flores y polinización: Flores apicales y/o subapicales, en $T$. tarijensis y $T$. herzogianus las flores se disponen alrededor del ápice, formando una corona; campanuladas, largas (8-30 cm); ovario ancho (2-3 cm); tubo floral largo $(4-7 \mathrm{~cm})$, ancho (2-3 cm en la parte superior); recubierto por escamas subuladas, 0,6-3,0 cm de longitud (siendo más cortas las del ovario), totalmente verdes o verdes con ápice marrón; de cuyas axilas surgen numerosos (20-40) pelos grises, marrones o negros, cortos a largos (0,6 a $2 \mathrm{~cm})$; nectarios angostos (3-4 mm), tubulares, cortos (13-23 mm), blanco-verdosos; estambres con filamentos blancos y anteras amarillas, y dispuestos en dos series, la primera serie se distribuye a lo largo del tubo floral, y la segunda, conforma un anillo en la garganta del tubo floral; ovario rodeado por el receptáculo (tejido caulinar), difícilmente diferenciable; estilo verde-claro, largo $(5-11 \mathrm{~cm})$, angosto $(1-3$ $\mathrm{mm})$, estigma con numerosos lóbulos (13-16), papilosos, amarillo-claro, erectos, largos (0,7-2,0 cm); tépalos externos linear-acuminados, los internos espatulados, largos $(3-7 \mathrm{~cm})$, anchos $(1,3-2,0 \mathrm{~cm})$, amarillo-verdoso o blanco-amarillento con líneas longitudinales rosa o marrón, raro rosado-intenso, amarillos, fucsia y rojos; corola de 6-18 cm de diámetro (cuando abiertas) (Fig. 4H-I, llustración 1H).

Las flores que son polinizadas por los animales (mayormente insectos) tendrán una mayor producción de semillas por fruto, en comparación de la anemofilia, asegurando mayor cantidad de granos de polen en el estigma de una flor, después de visitar muchas flores de la misma especie, y a su vez los descendientes presentarán una mayor variabilidad genética, con posibilidades de adaptarse a nuevos ambientes, y de competir con otras especies. (Gibson \& Nobel 1986). También, la polinización cruzada es favorecida por la hercogamia (los diferentes grados de separación entre las anteras y estigma en la misma flor), la cual es muy frecuente en Cactáceas, por ejemplo en Ariocarpus fissuratus, Opuntia imbricata, Pilosocereus lanuginosus, P. moritzianus, Stenocereus queretaroensis, entre otros (Mandujano et al. 2010). Todas las especies del género Trichocereus presentan los estilos más largos que las anteras (T. bolligerianus, T. chiloensis subsp. chiloensis, T. macrogonus var. pachanoi, T. tarijensis).

Apertura floral: Las cactáceas columnares subtropicales como $T$. atacamensis y $T$. tarijensis son polinizadas por insectos y aves mientras que las neotropicales como Stenocereus griseus, son polinizadas principalmente por murciélagos. El sistema de cruzamiento en $T$. atacamensis y $T$. terscheckii 


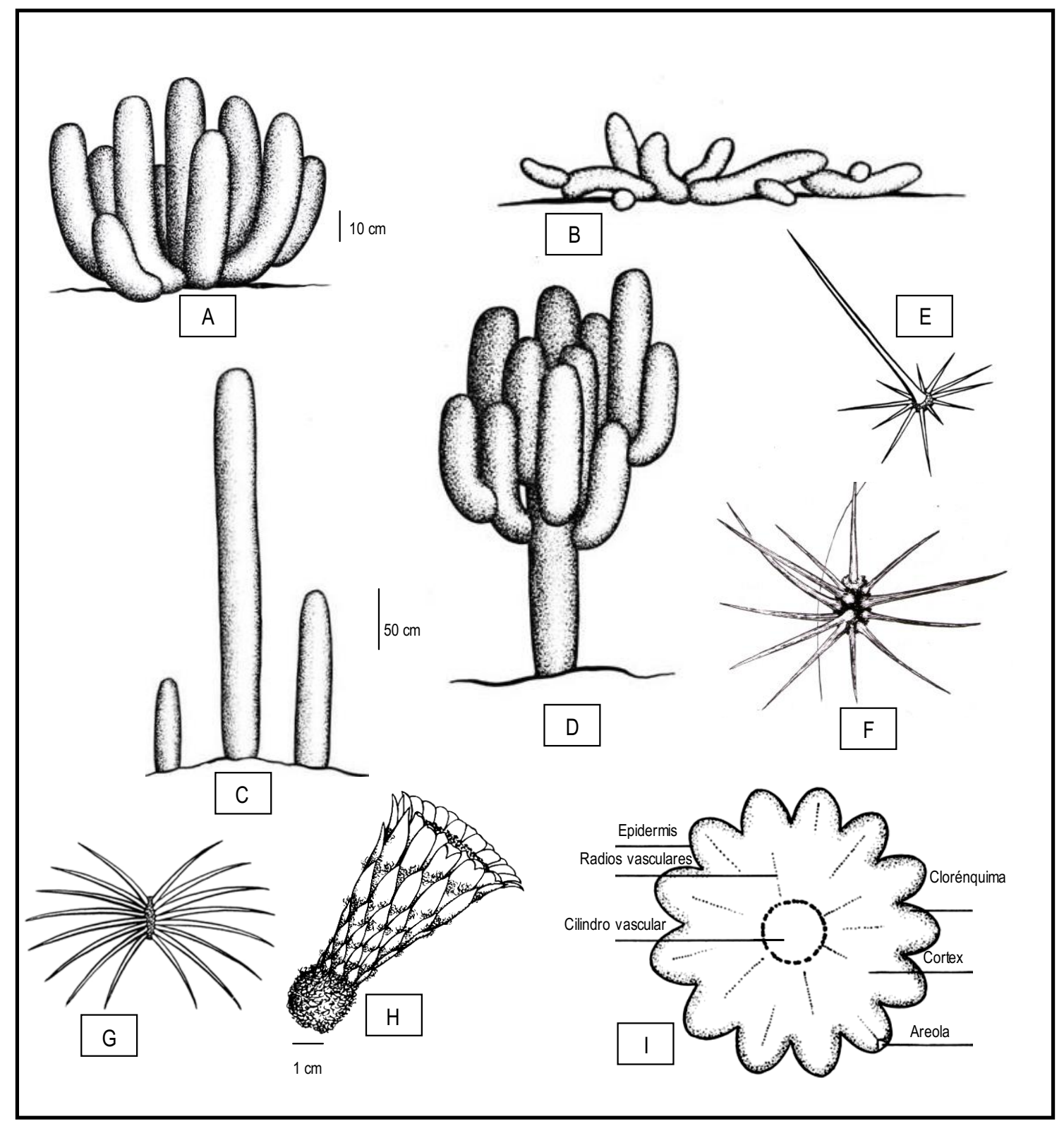

Ilustración 1. A. En T. huascha var. pecheretianus los tallos son ascendentes, crecen inicialmente próximos a la horizontal y luego se levantan hasta alcanzar la vertical. B. En T. thelegonus los tallos crecen decumbentes, tumbados pero con sus ápices ascendentes. C. En algunos individuos de $T$. atacamensis el tallo principal no es ramificado. D. En $T$. terscheckii las plantas son arbóreas, con ramificaciones a un metro de alto. Ramas de segundo y tercer orden más cortas (24-27 cm de diámetro). E. Espinas radiales cortas (hasta $2 \mathrm{~cm}$ ), numerosas (11-21) y divaricadas; espinas centrales largas (10-20 $\mathrm{cm}$ ), pocas (1-6) y perpendiculares a la rama. F. En $T$. atacamensis las espinas del tronco, hasta más 0 menos $1,5 \mathrm{~m}$ son fuertes, rígidas, más arriba hay una transición y se hacen débiles, cerdosas por varios metros hasta llegar al ápice. G. En T. pectiniferus la disposición de las espinas radiales en las areolas adultas son adpresas a la superficie del tallo y pectinadas (organizadas horizontalmente en forma de peine). H. Flor campanulada, 8-30 cm de largo, ovario ancho $(2-3 \mathrm{~cm})$, con escamas imbricadas de cuyas axilas surgen pelos numerosos (20-40). I. Corte transversal del tallo. 
es xenogámico (los óvulos solo pueden ser fecundados por polen proveniente de otras plantas), por lo que dependen de agentes externos como abejas (Apis mellifera), avispas (Polybia ruficeps), polillas (Achaea ablunaris y Manduca diffissa) y colibrís (Patagona gigas) para su fecundación (Badano \& Schlumpberger 2001, Schlumpberger \& Badano 2005, Ortega et al. 2010). Estos investigadores también registraron la presencia de escarabajos que consumen las partes florales, y permanecen en la flor por largos periodos de tiempo, aun después de que la flor se ha marchitado, y las hormigas, las cuales se alimentan del néctar, realizando una perforación en la zona nectarial. En ambos casos, no juegan un papel importante en la polinización. En el caso de $T$. terscheckii cuya apertura floral es nocturna, las polillas pertenecientes a las familias Sphingidae y Noctuidae juegan un papel importante en la polinización, y por tanto en la producción de frutos y semillas (Ortega et al. 2010).

Roig y Schlumpberger (2008), encontraron una relación mutualista entre especies de Opuntioideae y Cactoideae y las del género Brachyglossula (Hymenoptera: Colletidae), y cuyo rango de distribución de estas abejas se sobrelapan con el de las especies polinizadas. T. tarijensis es visitada por B. martinezi, distribuida desde el norte de la Argentina, en la provincia de Jujuy (Tilcara, Humahuaca), hasta el sur de Bolivia, en el departamento de Potosí (Villazón), lo cual concuerda con la localización de T. tarijensis, en la provincia fitogeográfica puneña. En una región geográfica diferente, Trichocereus candicans es polinizada por Brachyglossula communis, la cual ha sido registrada para la Argentina en las provincias de Salta, Tucumán, Catamarca, La Rioja, San Juan y Mendoza.

Lematire et al. (2014) estudiaron la polinización en Trichocereus chiloensis subsp. chiloensis, la cual se caracteriza por: presentar polinización cruzada, las flores puden estar abiertas de 20 a 22 horas, emitir aromas, $(E)$-nerolidol y presentan características externas asociadas a polinizadores nocturnos, como las polillas (Manduca sexta-Sphingidae-Lepidoptera) y diurnos, Dolichophaonia sp. (DipteraMuscidae) y del orden Heminoptera Apis mellifera (Apidae), Leioproctus semicyaneus (Colletidae), entre otros.

También, se ha reportado una relación mutualista en otras especies de la tribu Trichocereeae, por ejemplo las flores de Echinopsis ancistrophora son visitadas por B. communis y Lobivia grandiflora por Brachyglossula ancasti, endémica de la Sierra de Ancasti, en la Provincia de Catamarca (Argentina). Existen polinizadores como Manduca sexta, que selecciona ciertas flores para polinizar, por la presencia de un determinado compuesto en el perfume floral (Schlumpberger \& Raguso 2008). En el caso de Setiechinopsis mirabilis sus flores emiten fragancias cuyo componente principal es el benzoato de metilo, el cual atrae a determinados polinizadores nocturnos, como las polillas, en búsqueda del néctar.

Longitud de las flores: La longitud de las flores en T. terscheckii $(15-21 \mathrm{~cm})$ pueden limitar el acceso de las polillas con lengua corta al néctar, pero aquellas de la familia Noctuidae pueden desplazarse hasta la cámara nectarial, por el diámetro interno de la corola $(3-5 \mathrm{~cm}$ ) (Ortega et al. 2010). 
Frutos: Cercanos al ápice o laterales, umbilicados, dehiscentes por una rajadura longitudinal, con su parte externa rodeada por el receptáculo, por lo que estrictamente deberían llamarse pseudobayas, 3-4 cm de largo, 3-5 cm de diámetro; recubierto por numerosas escamas subuladas (más de 11), de cuyas axilas emergen abundantes pelos marrones, grises o blancos, 4-6 mm de largo; verdeoscuro, pericarpio blanco (Fig. 5J-L).

Semillas: Según la forma, las semillas pueden ser: ampliamente ovales (proporción largo/ancho: 1,1-1,4); perfil ovalado (1,5-2,0); circulares-orbiculares (menores de 1,09) o estrechamente ovaladas (23). Por el tamaño son: muy pequeñas (0,3-0,8 mm) en $T$. andalgalensis; medianas (1,2-1,9 mm) en $T$. schickendantzii; largas (2,0-2,9 mm) en $T$. arboricola. Según el brillo son opacas o brillantes. Forma en $S$ de las paredes anticlinales de las células de la testa. Algunas semillas (T. macrogonus var. pachanoi) muestran un borde que sobresale en el dorso de la semilla (quilla), el cual corresponde al plegamiento de las capas superiores de la testa (Fig. 72Q).

Polen: El diámetro polar y ecuatorial del polen $(45-109 \mu \mathrm{m})$ varía entre las especies del género Trichocereus, mientras que se mantienen constantes los siguientes caracteres: forma (esferoidal), número de colpos (tricolpado con un pequeño porcentaje de granos de polen hexacolpados), presencia en la exina de perforaciones (0,4-0,6 $\mu \mathrm{m}$ de diámetro) que atraviesan completamente el tectum y espínulas

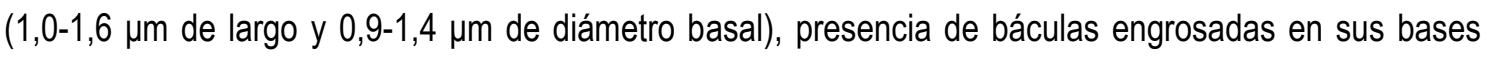
(Kiesling 1978). En T. terscheckii se ha estimado en 2238 el promedio de granos de polen por estambre (Ortega et al. 2010).

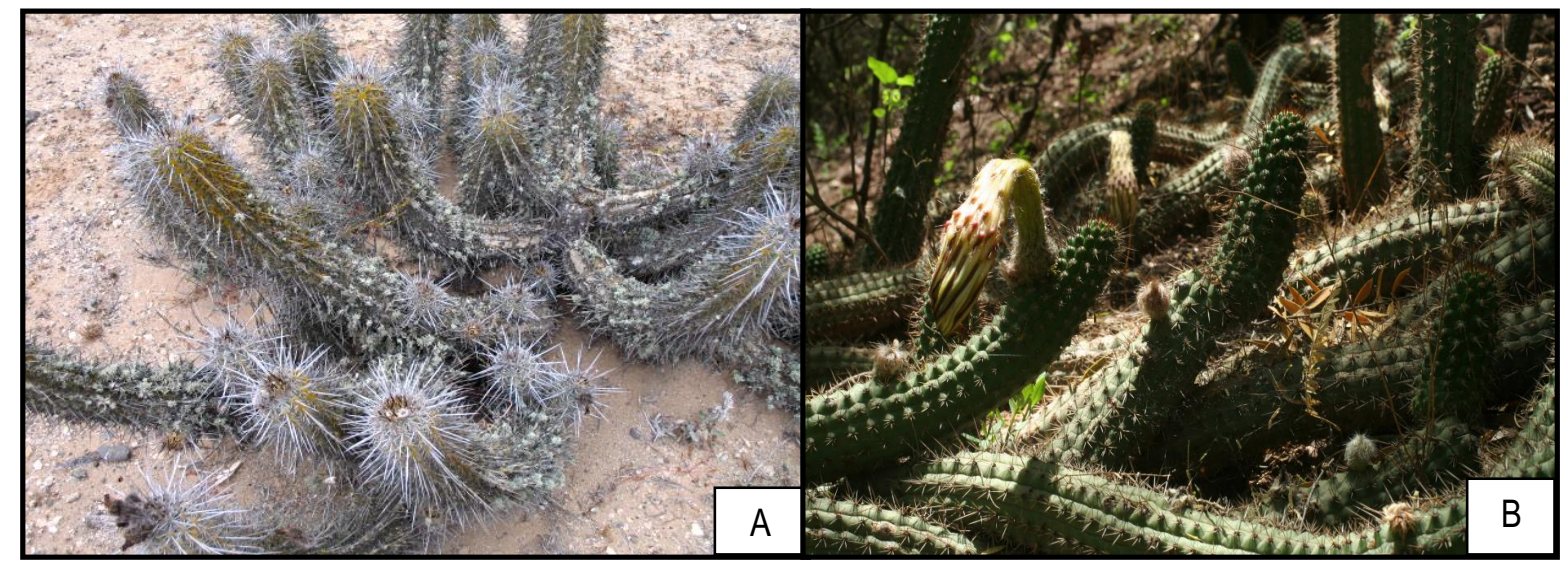

Figura 1. A) Plantas ascendentes de $80 \mathrm{~cm}$ de alto en Trichocereus spinibarbis. Tallos ramificados a nivel del suelo y cubiertos por líquenes. B) Trichocereus thelegonus con ramas reclinadas sobre el suelo, con los extremos apicales ascendentes, y presencia de mamelones subhexagonales en las costillas. 


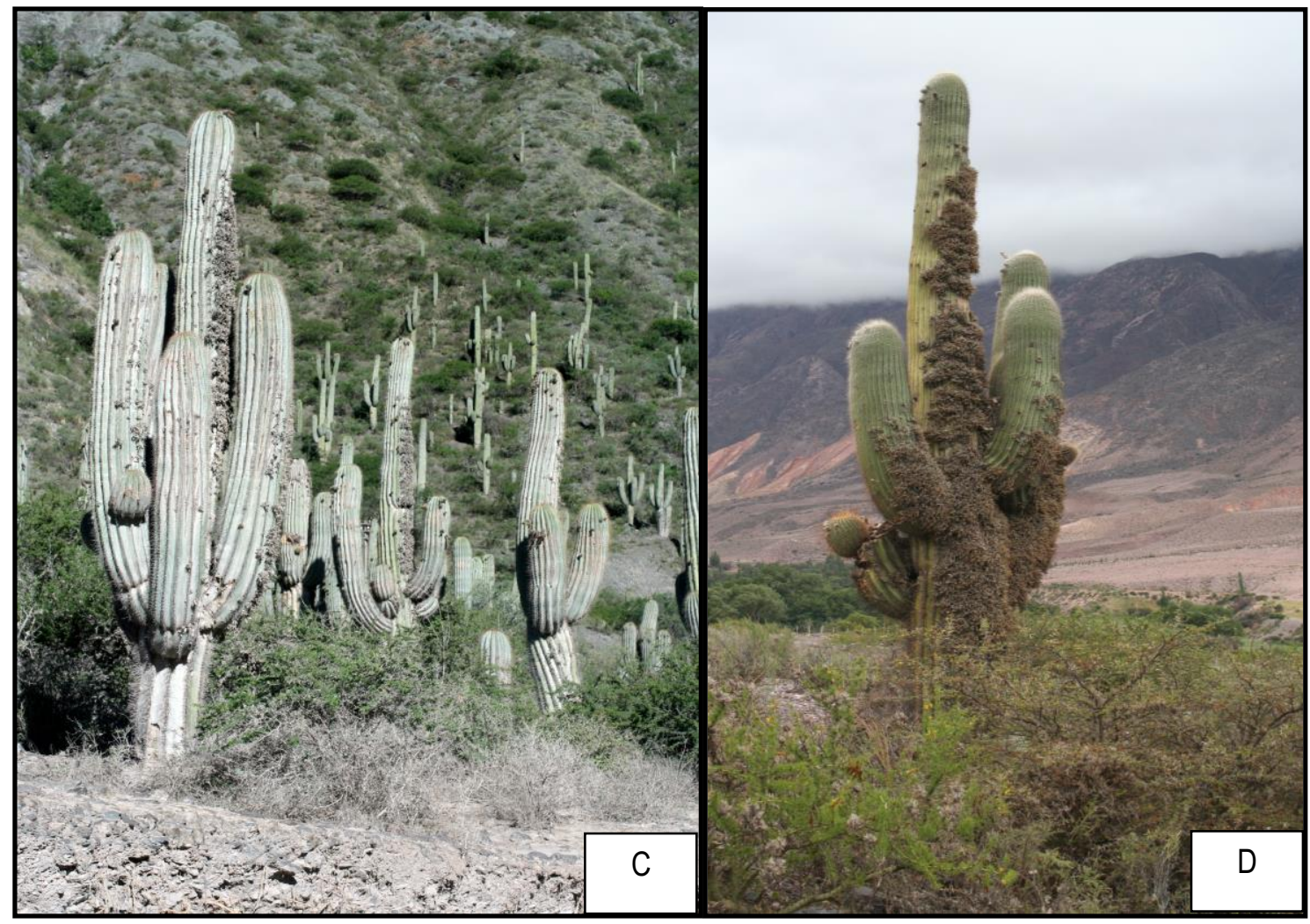

Figura 2. Trichocereus atacamensis con individuos erectos de hasta $15 \mathrm{~m}$ de alto, con tallo de $50 \mathrm{~cm}$ de diámetro. C) Provincia de Salta, Quebrada del Toro. D) Provincia de Jujuy, Quebrada Humahuaca, Maimará.

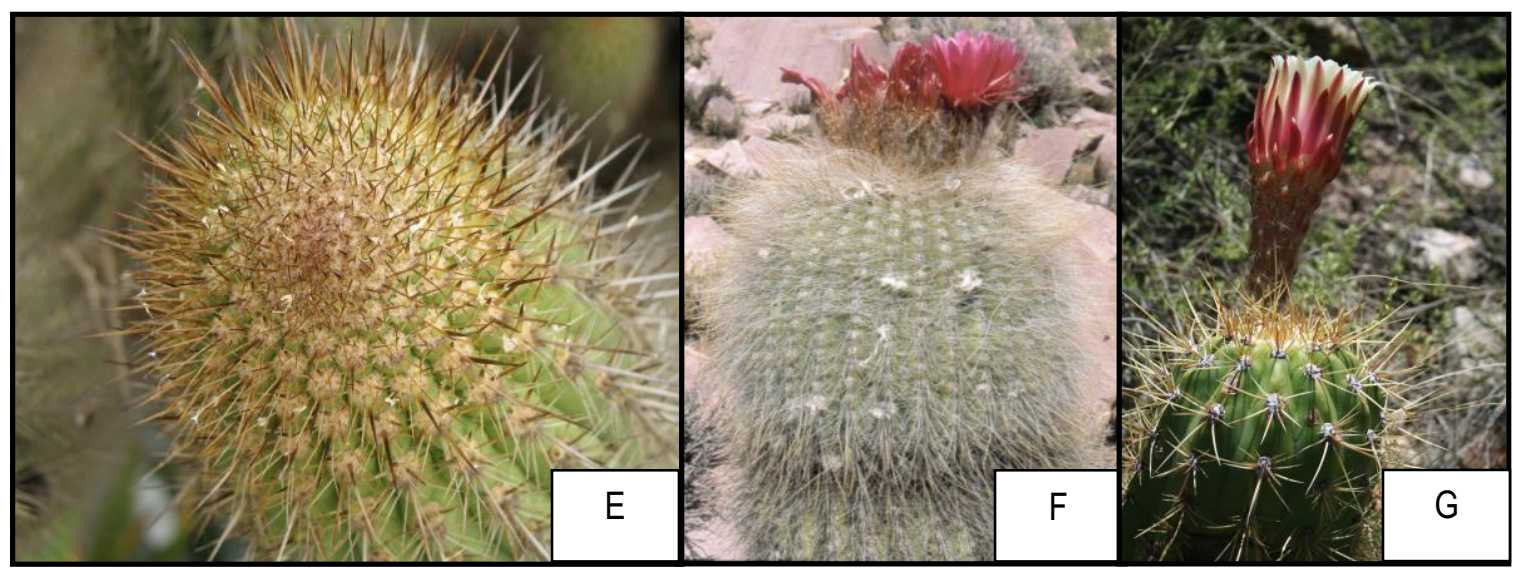

Figura 3. E) Rama de Trichocereus bolligerianus en cuyo ápice se observan las areolas con pilosidad amarilla, una espina central (base verde y ápice marrón) y espinas radiales 12-16 (algunas son verdes en la base y ápice marrón, otras son gris-claro). F) Ápice del tallo de Trichocereus tarijensis con areolas de tomento blanco-crema; espinas centrales 1-8, aciculares, amarillo-crema con punta marrónrojizo; espinas radiales 4-19, aciculares, algo onduladas, blanco-crema 0 amarillas. G) Trichocereus candicans con pilosidad amarilla y gris en el ápice, cuatro espinas centrales y ocho espinas radiales. 


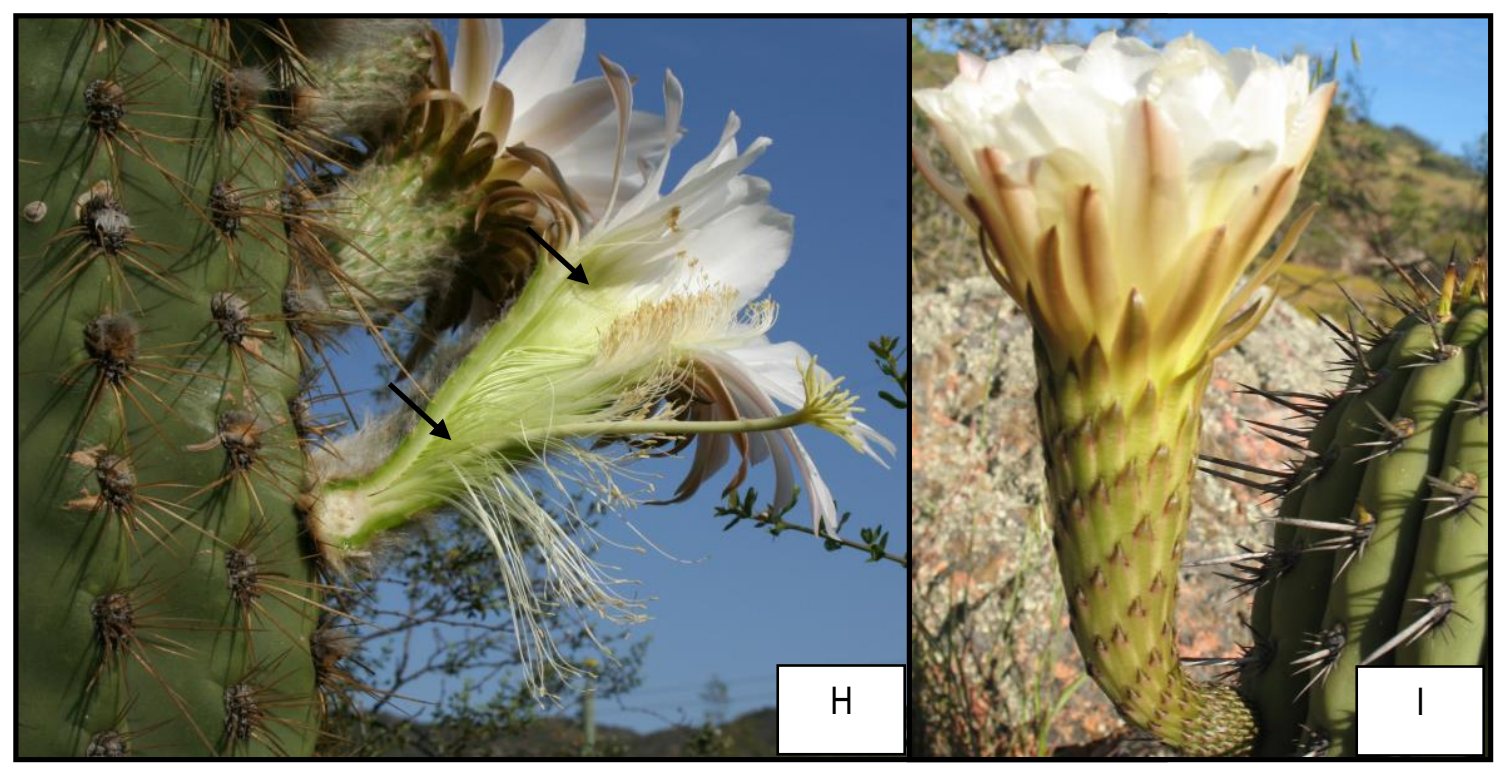

Figura 4. H) Flores subapicales de Trichocereus terscheckii rodeadas por tejido caulinar (hipanto), estambres blancos y dispuestos en dos series, la inferior y la superior (indicadas por las flechas), cámara nectarial debajo de la serie inferior de los estambres, estigma con 16 lóbulos. I) Flor campanulada de Trichocereus chiloensis subsp. australis, de $21 \mathrm{~cm}$ de largo y tubo floral recubierto de escamas, de cuyas axilas surgen pelos marrones, tépalos internos blancos.

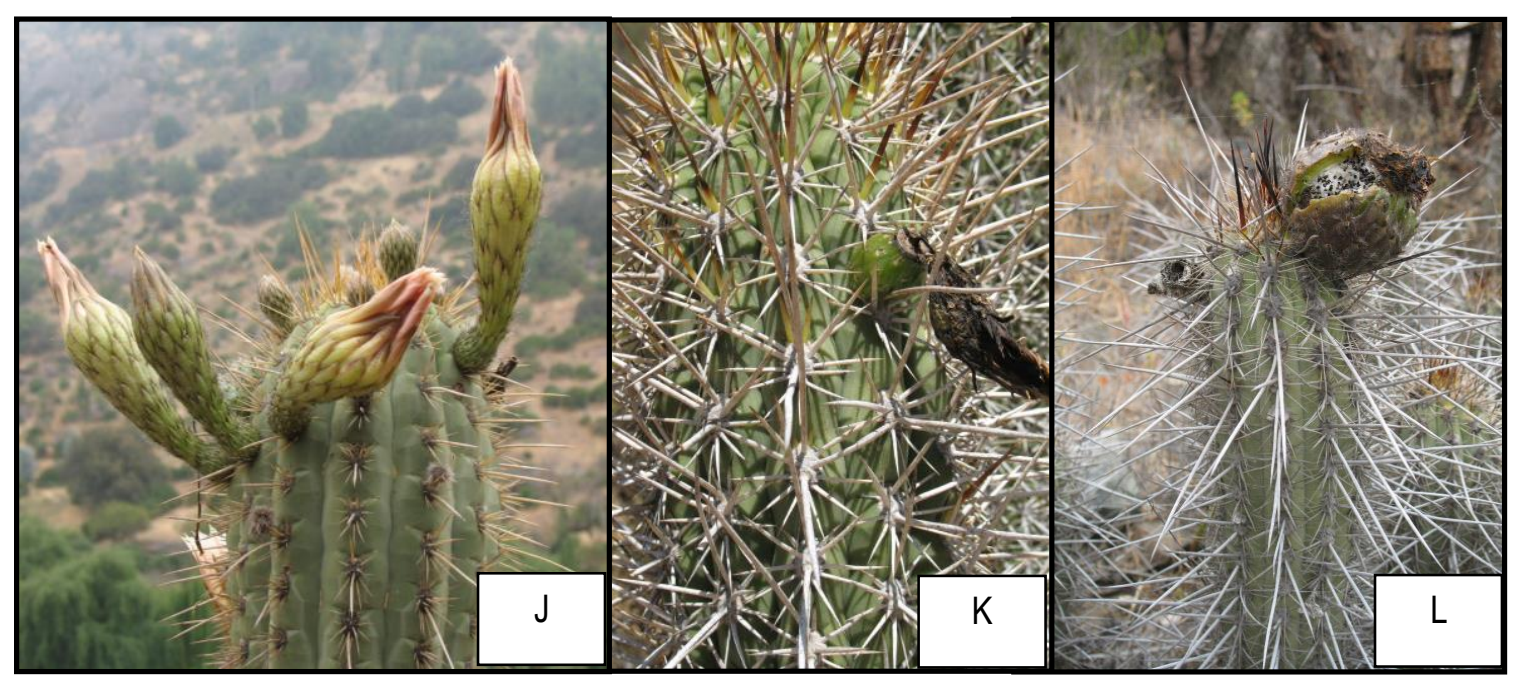

Figura 5. J) Primera etapa de formación de los frutos en Trichocereus chiloensis. K) Restos de hipanto y perigonio en el fruto de Trichocereus chiloensis subsp. panhoplites. L) Fruto con dehiscencia longitudinal en Trichocereus pectiniferus. 


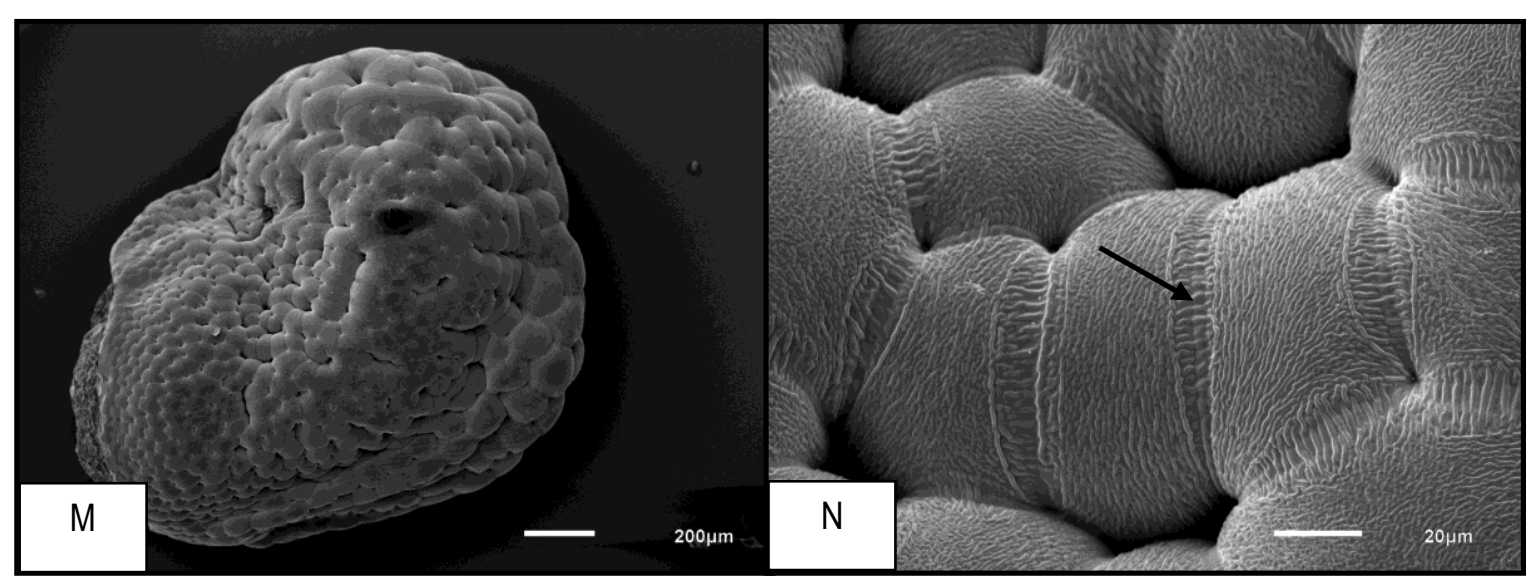

Figura 6. M) Semillas medianas (1,4 mm de largo) de Trichocereus skottsbergii, con células de la testa en forma de S. N) Presencia de estrías intercelulares (indicadas por la flecha) y poros que permiten la hidratación.

\subsection{Números cromosómicos:}

Los cromosomas en la familia Cactaceae son pequeños $(2,3 \mu \mathrm{m})$, y su número básico es $X=11$ (Las Peñas et al. 2009). En el género Trichocereus se reportan especies diploides ( $2 n=22)$, por ejemplo en Trichocereus chiloensis (Katagiri 1952, Diers 2008), Trichocereus deserticola, Trichocereus huascha, Trichocereus terscheckii (Diers 2008) y Trichocereus macrogonus var. macrogonus (Kiesling 1978). Especies tetraploides $(2 n=44)$ como en el caso de $T$. candicans (Las Peñas et al. 2009) y $T$. spachianus (Katagiri 1952).

\section{HIBRIDACIÓN}

Se han registrado híbridos naturales entre especies de Trichocereus, como sucede con Trichocereus candicans y Trichocereus strigosus que forman Trichocereus xmendocinus Méndez, cuyas semillas en condiciones de laboratorio tienen un porcentaje de viabilidad del $52 \%$ y los granos de polen de $54,2 \%$. Trichocereus xmendocinus ha sido encontrado en los cerros de la Puntilla en Mendoza, el cual se reproduce por semillas y agamicamente. (Méndez 2000).

Según Kiesling (com. pers.), T. cabrerae con bastante seguridad puede considerarse de origen híbrido entre $T$. terscheckii y $T$. strigosus, apareciendo esporádicamente en lugares donde conviven las especies supuestamente parentales. Sin embargo, sus poblaciones son uniformes y con características propias y se pueden reproducir por sí mismas (parte de sus semillas son fértiles). También, se han observado híbridos intergenéricos, entre Trichocereus atacamensis x Denmoza rhodacantha, xTrichomoza roseiflora (Font \& Picca 2001; Rowley 2004) y Trichocereus tarijensis x Oreocereus celsianus (Ritter 1981; Rowley 2004). 


\section{DISTRIBUCIÓN GEOGRÁFICA Y ECOLOGÍA}

Trichocereus presenta una distribución continua a lo largo de la cordillera de los Andes desde Ecuador, a través de Perú, Bolivia, centro y norte de Chile hasta el noreste patagónico (Fig. 7); en la Argentina, el 95\% sus especies presenta una distribución continua desde las provincias de Jujuy, Salta, Tucumán, Catamarca, Santiago del Estero, Córdoba, La Rioja, San Juan, Mendoza, norte de Neuquén, en las sierras de Lihuel Calel (La Pampa) y T. candicans presenta una distribución amplia desde La Rioja, San Juan, Mendoza, San Luis, Córdoba, La Pampa y en el sudoeste de Buenos Aires, o sea, en el área austral de la provincia fitogeográfica del Monte. Se han mencionado especies para Paraguay y Brasil, pero se trata de especies actualmente atribuidas a otros géneros. Trichocereus se localiza desde el nivel del mar (T. bolligerianus, $T$. candicans) hasta los $4500 \mathrm{~m}$ de altitud (T. atacamensis, $T$. tarijensis), en planicies con suelos aluviales o lomeríos con baja o moderada pendiente y suelos someros, entre vegetación graminosa o en roquedales entre arbustos, donde predomina el estrato arbustivo subxerofítico espinoso.

En la Provincia Fitogeográfica del Monte se localiza el mayor número de taxones, $T$. angelesiae, T. cabrerae, T. candicans subsp. pseudocandicans y Trichocereus strigosus var. vatteri, y $T$. atacamensis define la provincia fitogeográfica de la Prepuna.

Las especies ascendentes, menores de $1 \mathrm{~m}$ de alto como $T$. andalgalensis, $T$. candicans, $T$. strigosus, crecen a la sombra de especies arbóreas espinosas y sobre suelos casi desnudos, mientras que las especies arbóreas, mayores de 1,5 m de alto como $T$. atacamensis, $T$. bridgesii, $T$. chiloensis, $T$. terscheckii, entre otras, se localizan sobre laderas rocosas, planicies, valles secos entre jarillales, dominando el paisaje, por el porte elevado de las plantas. T. bolligerianus y T. macrogonus var. macrogonus crecen en la cordillera de la costa de Chile y Perú respectivamente, colgando de los acantilados costeros.

\section{ETNOBOTÁNICA}

Los indígenas y campesinos de Bolivia y del noroeste de la Argentina han utilizado durante mucho tiempo los tallos, las espinas y los frutos de Trichocereus atacamensis (= $T$. pasacana), $T$. tarijensis y $T$. terscheckii. Los tallos constituyen reservorios de agua y forraje para los animales, cuando hay escasez de pastos. Las características de la madera son apreciadas en carpintería y ebanistería; así como el tamaño (hasta ca. $13 \mathrm{~cm}$ ) y dureza de las espinas, que fueron empleadas en la costura y elaboración de peines en la Argentina. También se extraen las pectinas del mucílago de los tallos, que han dado muy buenos resultados en la purificación del agua para beber y en la construcción, para lograr una mejor adherencia de la cal (Kiesling 1978).

Bajo el nombre común local español de "San Pedro", y también en indígena "achuma 0 huachuma", o los nombres botánicos $T$. macrogonus var. macrogonus (= T. peruvianus) y $T$. macrogonus 


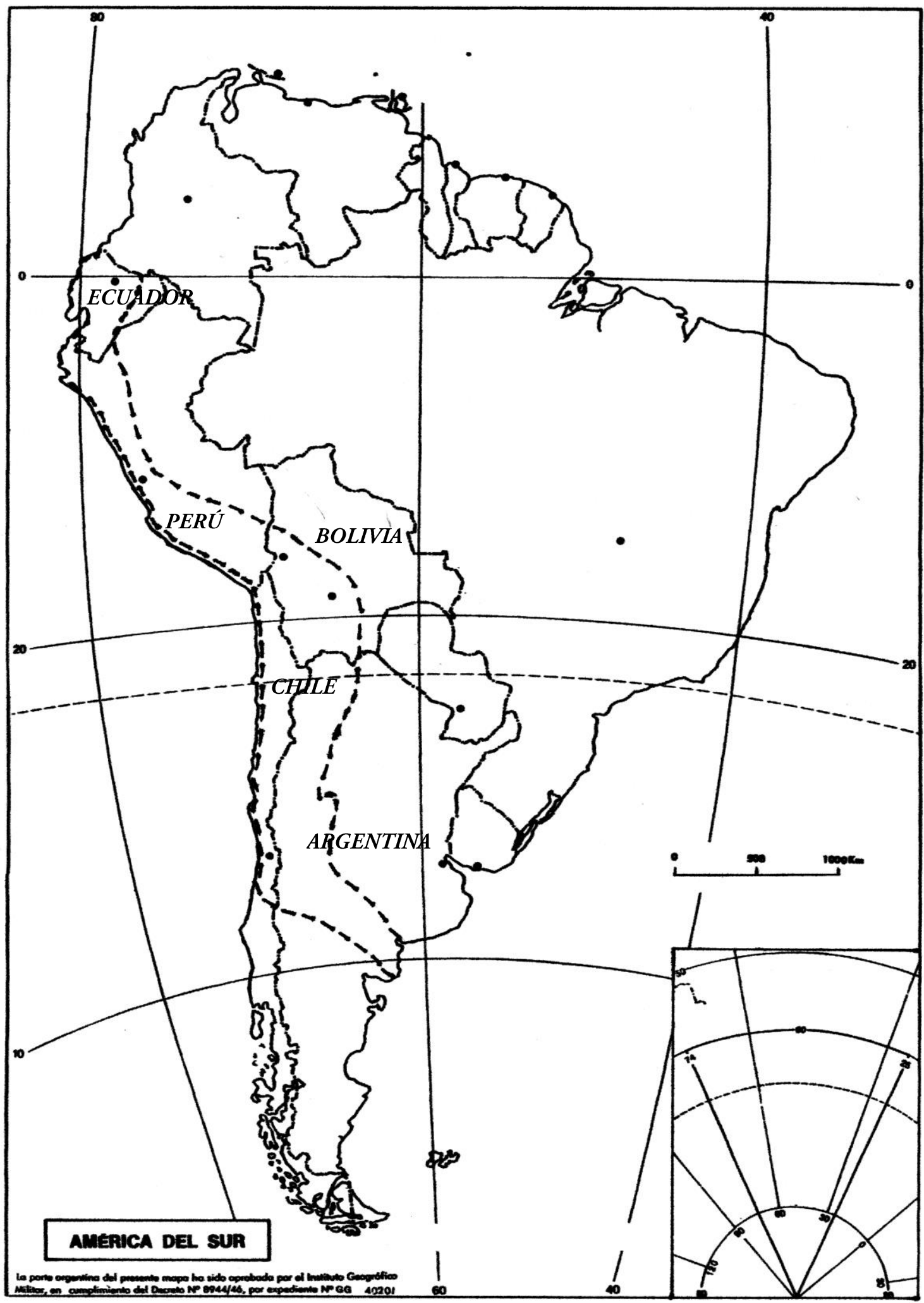

Figura 7. Distribución del género Trichocereus a lo largo de los Andes de Ecuador, Perú, Bolivia, Chile y la Argentina, donde alcanza la costa Atlántica. Distribución demarcada por una línea punteada negra. 
var. pachanoi ( $\equiv T$. pachanoi), estas plantas son ampliamente conocidas por sus propiedades alucinógenas (Schultes \& Hofmann 1979:154-155; Anderson 2001: 247).

Antes del arribo de los españoles, habían sido utilizadas en Perú como un narcótico con propósito terapeútico, como ha sido probado por referencias arqueológicas muy recientes (aprox. 1300 años A.C., Anderson 2001: 46), y en rituales, como se encuentra representado en las cerámicas precolombinas del Perú y otros objetos arqueológicos (Ostolaza 1995: 76-82).

Para Bolivia, Cárdenas (1969: 367-370) menciona a T. pachanoi solamente como cultivada. Actualmente, este cactus es parte de las ceremonias sincréticas chamánicas del Perú, para curaciones y magia, aunque su importancia ha disminuido con el tiempo. Schultes \& Hoffmann (1979: 154-155), describen la planta como cultivada en Ecuador, Perú y Bolivia lo cual explica las referencias de esos países a través de la literatura botánica. Anderson (2001) también se refirió a Echinopsis peruviana (三Trichocereus peruvianus) como el "San Pedro macho", quizás debido a sus espinas más desarrolladas, como una fuente equivalente de alcaloides, y alusión a una "rara" forma de cuatro costillas de "San Pedro" que se creía poseer unas "especiales propiedades curativas".

Anderson, citando a Davis (1983), además complementó que la planta fue domesticada a lo largo de la costa, pero que se originó en zonas más altas. Anderson posiblemente consultó las publicaciones de Ostalaza y por comunicación personal, pero esa información también puede haberse originado en la creencia popular o en entrevistas a chamanes.

Algunas de las referencias en la literatura de cactus que han sido mencionadas, y que están relacionadas con niveles de alcaloides entre las especies de Trichocereus, posiblemente se han apoyado en análisis bioquímicos de algunos individuos, pero muchos de esos reportes parecen estar basados en el comportamiento popular o en las comunicaciones chamánicas. Aunque varias publicaciones científicas han reportado el contenido de alcaloides (particularmente mescalina, el alcaloide psicoactivo predominante) del "San Pedro", sólo hay un trabajo que ha sido publicado (Ogunbodede et al. 2010), con análisis realizados en varias muestras de orígenes conocidos, en un modo comparativo (muestreos similares, la misma técnica e instrumentación, etc.), los resultados reportados en ese trabajo sugieren que el contenido de mescalina es más alto en plantas usadas por chamanes que en otras cultivadas o en plantas naturales.

También la concentración más alta de mescalina en el estudio fue encontrada en plantas de $E$. pachanoi a diferencia de E. peruviana, aunque los niveles de mescalina mostraron gran variación entre las muestras de plantas analizadas, incluyendo plantas del mismo complejo de especies bajo discusión en este trabajo. Hubo sugerencia de correlación entre la concentración de alcaloides y el número de costillas $u$ otros caracteres morfológicos, pero tales correlaciones no fueron probadas. Parece razonable concluir que las plantas usadas por los chamanes son selectivamente cultivadas por ellos. 


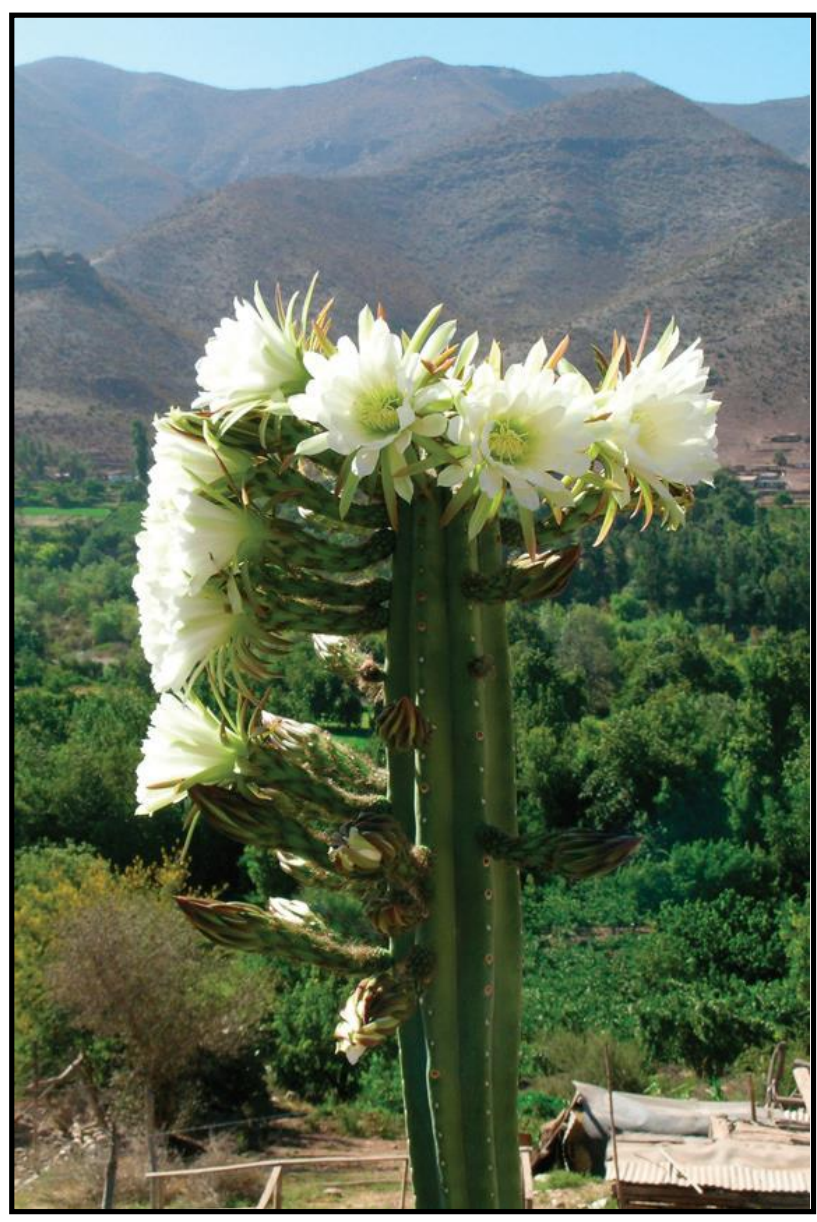

Actualmente es difícil determinar en un modo preciso el verdadero origen geográfico de $T$. macrogonus, cultivada ampliamente. En base a la literatura y en los especímenes de herbario, la especie esta naturalmente distribuida en valles altos de Perú y quizás en el noroccidente de Bolivia, pero es cultivada en un área amplia, incluyendo Ecuador y norte de Chile (Fig. 8). Algunos pobladores la reportan para el noroccidente de Argentina (com. pers. R. Kiesling).

Plantas naturales son fenotípicamente diferentes de las cultivadas, y les han colocado diferentes nombres -por los botánicos, e igualmente por los lugareños.

Figura 8. Trichocereus macrogonus cultivado en una casa rural al norte de Chile (entre Vallenar y Ovalle). Foto de Daniel Schweich.

\section{TRATAMIENTO TAXONÓMICO}

Trichocereus (Berger) Riccob., Boll. Reale Orto Bot. Palermo 8 (4): 236. 1909. ESPECIE TIPO: Cereus macrogonus Salm-Dyck [Trichocereus macrogonus (Salm-Dyck) Riccob.]

Cereus Mill. subgénero Trichocereus Berger, Rep. (Annual) Missouri Bot. Gard. 16: 73.1905.

Helianthocereus Backeb., Cact. Succ. J. Gr. Brit. 11: 53. 1949.

Leucostele Backeb., Kakteen And. Sukk.: 36. 1953.

Echinopsis Zucc., p.p. sensu Friedrich \& Rowley, IOS Bulletin 3 (3): 79-99. 1974.

Plantas terrestres o raro epífitas, erectas (columnares), con tallos cilíndricos, solitarios y rectos (hasta $15 \mathrm{~m}$ de alto y $50 \mathrm{~cm}$ de diámetro) o formando densas matas (ascendentes, decumbentes 0 arbustivas), con ramas ligeramente arqueadas, simples, solo ramificadas en la base (0,5-3,0 $\mathrm{m}$ de alto), verde-oscuro a verde-glauco, con pocas costillas (9) a numerosas (40), anchas (hasta $5 \mathrm{~cm}$ ) y bajas (hasta $2 \mathrm{~cm}$ ). Areolas en el borde las costillas, con abundante lanosidad cuando jóvenes y espinas 
diferenciables o no en radiales y centrales, pocas (4) a numerosas (21), desde flexibles hasta rígidas, de pocos milímetros hasta más de $15 \mathrm{~cm}$ de largo, aciculares o subuladas. Flores campanuladas, zigomorfas (a causa de los estambres declinados y de la curvatura del receptáculo), largas (hasta $30 \mathrm{~cm}$ ), receptáculo a la altura del ovario ancho $(2-3 \mathrm{~cm})$, y junto con el tubo floral cubiertos por abundantes escamas subuladas y gruesas, de cuyas axilas surgen pelos negros, grises o marrones; tépalos exteriores carnosos, lineares, agudos, recurvados, sepaloides, verdozo o rojizo; tépalos interiores petaloides, blanco, amarillo, anaranjado hasta rojo, delgados, espatulados, con el borde superior entero 0 finamente aserrado y terminado en un mucrón apical. Estambres dispuestos en dos series, la superior formando un anillo en el borde del receptáculo, erguidos, la inferior espiralada, declinada con numerosos estambres que nacen desde la parte inferior del tubo, anteras amarillas; ovario globoso o ligeramente alargado, truncado, con numerosos rudimentos seminales anátropos, con funículos largos y blancos, placentación parietal, unilocular; estilo verde-claro y largo $(5-11 \mathrm{~cm})$, estigma con numerosos lóbulos (1316), papilosos, amarillo-claro. Pseudobayas globosas, subglobosas u ovadas, con el estilo o el perigonio seco persistente, con dehisciencia longitudinal, verdes, amarillos, anaranjados o rojizos. Semillas negras o marrones, en forma de coma o urna, con testa lisa o verrucosa.

Comprende 58 taxones (38 especies, 10 subespecies, 8 variedades y 2 formas), de los Andes de Ecuador, Perú, Bolivia, Argentina y Chile.

\subsection{Observaciones de la especie tipo:}

Cereus macrogonus fue descrito por Salm-Dyck (1850: 203), quién ofrece una descripción extensa de sus caracteres vegetativos. Su protólogo carece de información de las flores y el sitio de origen, pero suministra varios caracteres vegetativos, los cuales tomados en conjunto pueden ser aplicados a una sola especie de la familia Cactaceae.

A inicios del siglo XX, las especies de Trichocereus fueron tratadas colectivamente como parte del género Cereus. Berger (1905) hizo una importante contribución al segregar los componentes del antiguo género colectivo Cereus, creando varios subgéneros (muchos de ellos elevados por otros autores a nivel genérico). El reconoció 14 especies dentro de su nuevo subgénero Trichocereus, uno de los cuales es: "C. (Trichocereus) macrogonus Salm-Dyck. I.c. 115.-¿Andes?"

Unos pocos años después, Riccobono (1909: 236) elevó Trichocereus, entre otros subgéneros de Berger a nivel genérico, incluyendo en este sólo dos especies: T. macrogonus (Salm-Dyck) Riccob. y T. spachianus (Lem.) Riccob. Britton \& Rose (1920) adoptaron el género Trichocereus, ampliando este para incluir un total de 19 especies, y designando a Cereus macrogonus como la especie tipo. Esta designación ha sido seguida hasta hoy por los siguientes autores: Castellanos \& Lelong 1938: 399, 1943 : 87; Kiesling 1978: 281; Hunt 1967: 453; Madsen 1989: 27; Anderson 2005: 215; Hunt et al. 2006: 90. La tipificación de la especie tipo se realizó recientemente (Albesiano \& Kiesling, 2012). 
Los nombres Cereus macrogonus y Trichocereus macrogonus han sido utilizados frecuentemente en libros de Botánica y horticultura, como también en catálogos comerciales, desde la época de las publicaciones de Salm-Dyck (1850) hasta comienzos del siglo XX. Más adelante, el uso del epíteto específico macrogonus pudo haber disminuido, debido a las descripciones de Trichocereus pachanoi y T. peruvianus que realizaron Britton \& Rose (1920), en su gran monografía, abarcando un gran subconjunto de grupos de plantas que habían sido conocidas previamente como T. macrogonus, pero a pesar de esto, muchos autores y horticultores aun continuan empleando el nombre T. macrogonus para una especie muy bien conocida, usada como pie de injerto.

Las monografías más recientes, Anderson $(2001,2005)$, reconocen a Trichocereus macrogonus (bajo Echinopsis), y distinguen como especies distintas a Echinopsis pachonoi y E. peruviana.

De la descripción original de C. macrogonus (Fig. 9), los caracteres que se consideran importantes son: el número de costillas (6-7), su espesor y su forma muy obtusa, redondeada en la sección transversal, como también su epidermis de color glauco; y un surco transversal epidérmico, justo encima de cada areola. Las areolas están separadas aproximadamente $2,5 \mathrm{~cm}$, situadas en la superficie superior de cada costilla, surcos basales y transversales en el borde de la costilla (la forma y la profundidad de los surcos y su distancia arriba de la areola varía entre las poblaciones, y aun entre individuos dentro de una población).

Las areolas jóvenes tienen 7 a 9 espinas radiales y una espina central; pero en las areolas adultas (basales) hay entre 18 a 20 espinas, algunas de ellas (3-4) son más anchas que otras, aproximadamente $1 \mathrm{~cm}$ de longitud y marrones. El número de espinas de las areolas basales mencionadas por Salm-Dyck es mayor (cerca del doble), comparadas con plantas ahora cultivadas bajo este nombre, pero la variación en el número y tamaño de las espinas está muy afectado por la intensidad de la luz y otras condiciones ambientales. Las plantas cultivadas pueden tener de 0 a 10 espinas en diferentes areolas de la misma rama. Las plantas silvestres tienen muchas más: T. santaensis Rauh \& Backeb. y T. chalaensis Rauh \& Backeb. (ver abajo) parecen plantas silvestres de la misma especie, pero muestran una espinación más densa.

Después de Salm-Dyck, la única referencia a C. macrogonus en el siglo XIX (excepto la de Schumann, ver abajo), fueron escritas por Labouret (1853: 352), Rümpler (1885: 706), quienes sólo repitieron la información de Salm-Dyck, y Weber (1899), quien dio una descripción corta de una planta que había florecido, evidentemente un Trichocereus, dado el tamaño y la pilosidad de sus flores.

Basado en las flores producidas por plantas maduras después de la descripción original, casi todos los botánicos posteriores han usado el epíteto específico macrogonus para referirse a una especie de Trichocereus (bajo Cereus: Weber 1899; Berger 1904, 1905; como Trichocereus: Riccobono 1909; Schelle 1926; Borg 1937, 1951; y como Echinopsis: Hunt 1989, 1992, 1999; Anderson 2001, 2005), así como autores de libros de horticultura (ver abajo una lista más completa). 
Solo un autor, K. Schumann, en 1890 y 1897-1898, usó el nombre C. macrogonus para una especie del Brasil, la cual es a menudo nombrada bajo el género Pilosocereus (Fig. 10), como Schumann trabajó en el Jardín Botánico de Berlin, de donde Salm-Dyck supuestamente recibió este espécimen, allí puede haber alguna posibilidad de que él tuviera una planta original y pueda haber sido correcta.

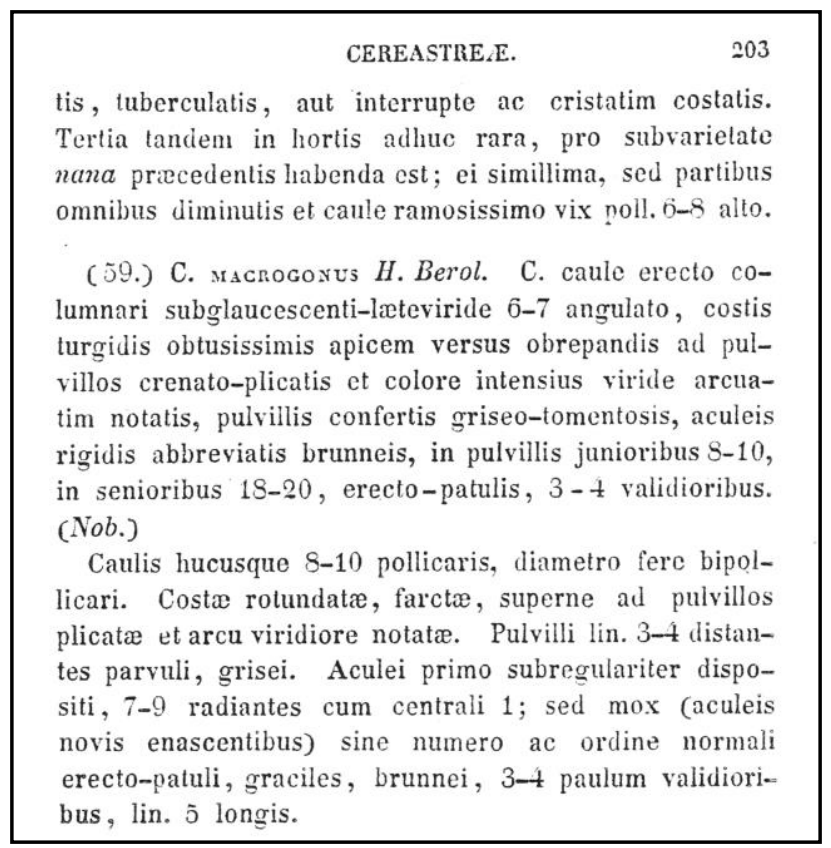

Figura 9. Parte de la publicación de Salm-Dyck (1850) con la descripción original de Cereus macrogonus.

Schumann primero usó ese nombre en la Flora Brasilensis de Martius (1890). La planta que el describió e ilustró no tenía todos los atributos mencionados en la descripción de Salm-Dyck, tales como los surcos encima de las areolas, y quizás el error de identificación se debió a que él fue influenciado por el color de la epidermis y el número de costillas -ver abajo acerca de Krainz (1975).

La asignación de Schumann del epíteto específico macrogonus para una especie que actualmente es considerada perteneciente al género Pilosocereus fue rechazada por Berger (1904), quien también dio una descripción completa de la planta, la cual corresponde a una especie de Trichocereus, además completó las características mencionadas en el protologo. El hecho de que Berger dedicara una nota especial para refutar el uso del nombre por una gran autoridad como Schumann es muy significativo. Berger basó su argumento en la descripción temprana de Weber (1899), y en plantas cultivadas en el Jardín Botánico cerca del mar mediterráneo. Berger afirma que las plantas ampliamente cultivadas corresponden a un Trichocereus. En su libro de 1929, Berger de nuevo mencionó brevemente el error de Schumann. Cuando Schumann (1897-1898) publicó en fascículos la monografía de la familia, Cereus macrogonus (1898: 121-122) se mantuvo en el concepto de su publicación anterior, en la Flora Brasiliensis. Sin embargo, en un comentario seguido de la descripción de Cereus bridgesii (1898: 107108), menciona "este es muy similar, sino el mismo C. macrogonus". En mi opinión, T. brigdesii es muy afín a T. macrogonus. 


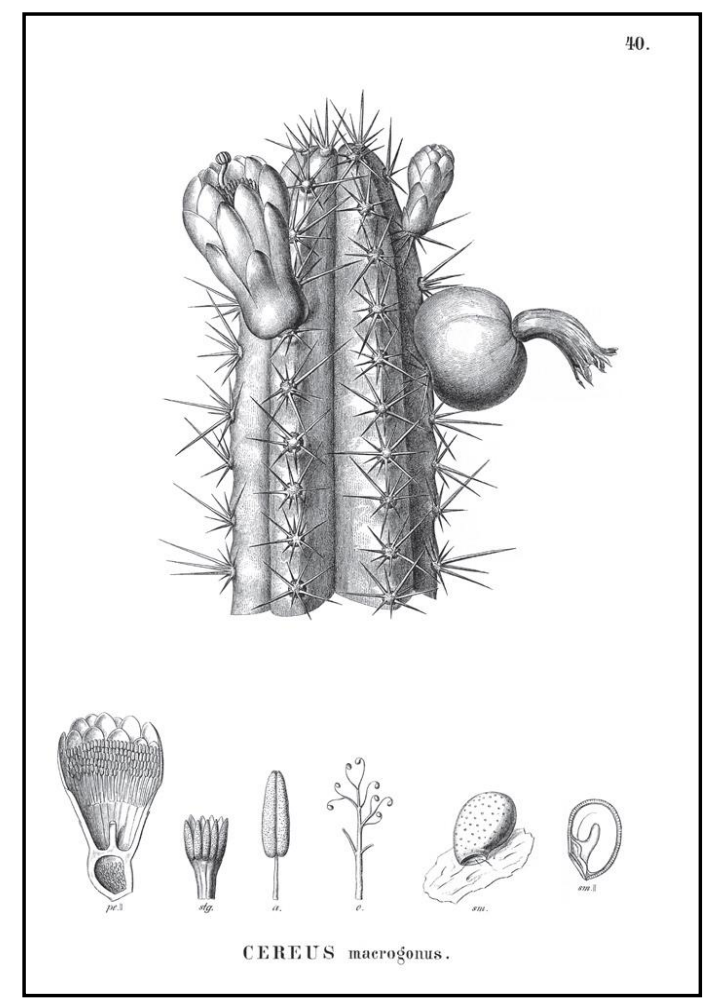

Figura 10. llustración de Cereus macrogonus en Schumann, Flora brasiliensis (1890), sin duda una especie de Pilosocereus, según el concepto actual.

Cereus bridgesii es una especie de origen conocido (cerca a la Paz, Bolivia), y siempre ha sido considerada como parte de Trichocereus desde la creación de este subgénero y posteriormente del género. Adicionalmente, Schumann no incorporó a $C$. macrogonus en el subgénero Pilocereus (actualmente el género Pilosocereus), seguramente porque su clasificación se basaba en caracteres vegetativos, y porque la especie que el consideró no presentaba pelos largos y conspicuos en las areolas del tallo.

Britton \& Rose (1920) designaron a C. macrogonus como la especie tipo del género Trichocereus, además, la incluyeron en la clave y escribieron una descripción de ésta. Simultáneamente, ellos describieron a $T$. peruvianus y $T$. pachanoi. Por otra parte, se consideran esos tres nombres coespecíficos (ver inmediatamente abajo). Britton \& Rose (1920) también consideraron que la especie mencionada por Schumann $(1890,1898)$ como C. macrogonus fue un error, y que en realidad correspondía a Cephalocereus arrabidae (Lem.) Britton \& Rose, ahora Pilosocereus arrabidae (Lem.) Byles \& Rowley. Posteriormente, Werdermann (1942: 98 y 108) confirmó el error de Schumann.

Se considera que los tres nombres (Trichocereus macrognus, $T$. pachanoi y $T$. peruvianus) corresponden a sólo una especie, por la epidermis glauca de los tallos, el número bajo de costillas (6-9, pero raramente por debajo de 4), las cuales son obtusas, cerca de $2 \mathrm{~cm}$ de alto y $2,5 \mathrm{~cm}$ de ancho, con un surco inmediatamente distal a las areolas y semillas opacas, las cuales presentan una cresta dorsal. Aunque estas características son variables dentro y entre las poblaciones, se considera que el grado de 
variabilidad es meritorio para el reconocimiento intraespecífico. Estos estados de caracteres pueden estar presentes en otros taxones de la subfamilia Cactoideae, pero no todos combinados, diferencias notables en algunos caracteres morfológicos (ver adelante la clave taxonómica), y en la distribución geográfica garantiza la diferenciación a nivel de variedad de $T$. macrogonus var. macrogonus (= $T$. peruvianus) y $T$. macrogonus var. pachanoi ( $\equiv T$. pachanoi).

Schelle (1926, Fig. 19) no solo describió sino que también ilustró, Cereus macrogonus. Aunque claramente la reproducción es pobre, representa un cactus columnar cultivado, con pocas costillas (ca. 5) ampliamente obtusas y flores apicales, y pueden ser fácilmente identificadas como una especie del grupo de Trichocereus que se está considerando.

Borg (1937: 134, 1951: 180) suministró una descripción amplia de T. macrogonus, pero también mencionó a Argentina y Bolivia como los países de origen. El destacó su uso como pie de injerto.

Rauh (1958) no hizo referencia a T. macrogonus en su libro de los Cactus de Perú, pero si describió algunas especies muy estrechamente relacionadas.

Las publicaciones de Backeberg \& Knuth (1936) y Backeberg (1966) mencionan a $T$. macrogonus, pero no adicionan más información de la ya conocida. La segunda referencia es extraña, porque Backeberg había publicado en una nota anterior (1941) que había encontrado plantas silvestres de T. macrogonus en Perú, y luego más de una página de texto y una foto clara, donde se menciona la sinonimia de T. macrogonus (S.-D.) Ricc. = T. peruvianus Br. et Rose. No podemos saber si posteriormente había cambiado de opinión o simplemente olvidó su propia nota. En su trabajo más amplio, Backeberg (1959a) presentó como una forma silvestre de T. macrogonus la ilustración de una planta encontrada por Werner Rauh en el centro de Perú. Esta planta muestra espinas más robustas en comparación con plantas cultivadas. En el mismo libro otras especies muy similares son incluidas, entre ellas $T$. santaensis Rauh \& Backeb. del norte de Perú (con una ilustración muy similar), T. chalaensis Rauh \& Backeb. del sur de Perú, y también $T$. peruvianus y $T$. pachanoi -todas muy estrechamente parecidas a $T$. macrogonus de acuerdo a mi concepto. Sin embargo, no se encontró en este trabajo ninguna referencia a su nota de 1941 ni a su viaje a Perú, ni a su hallazgo de individuos silvestres de $T$. macrogonus.

La referencia de Krainz (1975) es confusa. Bajo el encabezado Trichocereus macrogonus, el describe una especie de Trichocereus que está de acuerdo con la descripción original, y suminstra una foto de un espécimen, cultivado en su propia institución en Suiza, que muestra una flor grande que seguramente corresponde a Trichocereus, pero también incluyó otras dos fotos de plantas cultivadas en Jardines en España que muestran tallos con frutos, los cuales parecen corresponder a una especie de Pilosocereus, a juzgar por la forma comprimida y la dehiscencia de sus frutos. Muy probablemente confundió diferentes plantas bajo el mismo nombre como Schumann parece haber hecho. Krainz también siguió la información de Schumann de 1890, donde menciona a Rio de Janeiro-Brasil como lugar de origen de la planta. 
Como ya se ha señalado, el nombre de $C$. macrogonus fue constantemente usado a finales del siglo XIX y comienzos del siglo XX. Aun más recientemente, los nombres Cereus macrogonus, Trichocereus macrogonus y Echinopsis macrogona han sido utilizados -y por lo tanto aun siguen siendo empleados- tanto por botánicos especialistas (Berger 1929: 136; Borg 1937: 135 y 1951: 180; Rowley 1974: 96, lo ubicó como sinónimo bajo Echinopsis; Krainz 1. I. 1975 sin paginación; Hunt 1992: 57, 138 y 1999: 190; Anderson 2001: 272 and 2005: 235) como en literatura hortícola (Rothers 1923: 44, 124; Schelle 1926: 19, 105; Petersen 1927: 32, 71; Kupper 1929: 66; Houghton 1931: 116; Backeberg \& Knuth 1936: 203; Backeberg 1941; Backeberg 1959a: 1119 y 1966: 438, entre otros; Říha and Šubík 1981: 180; Hunt 1989: 239; Innes 1990: 146; Mordhorst 2008: 218), así como en catálogos comerciales (e.g., Haage 1927: 10 y 1938: 4, entre otros; Kreuzinger 1935: 38; Wenzel 1937: 4; Holly Gate Nurseries 1977/78: 4; Abbey Garden 1981: 38; Veg Saatzucht Zierpflanzen Erfurt 1979: 5; Köhres 1986: sin paginación). Estas referencias demuestran que el epíteto macrogonus aun se usa.

Algunas publicaciones también muestran ilustraciones, por ejemplo, Schelle (1926, Fig. 19), Backeberg (1959a, Fig. 1075) y Anderson (2001: 273 y 2005: 235). Hunt (1989) realizó una referencia a una ilustración publicada por Haustein, en Der Kosmos-Kakteenführer 131 (1983); esta ilustración es consistente con la identificación de la especie, excepto que Brasil es dado como el país de origen, seguramente siguiendo la opinión de Schumann (1890). Muchas de las referencias mencionadas anteriormente, destacan la epidermis glauca y el uso de la especie como pie de injerto.

En su más reciente libro, Ostolaza (2011) reconoce tanto a Echinopsis pachanoi y E. peruviana, diferenciadas solamente por la espinación más robusta y por la concentración de alcaloides aparentemente más alta en E. peruviana, la cual ha sido encontrada por él en la región de Lima (claramente como una planta silvestre).

\subsection{Clave para la identificación de las especies:}

1. Plantas con un tallo definido, solitario o ramificado desde 80 a $100 \mathrm{~cm}$ de altura

2. Espinas del ápice débiles, flexibles (cerdosas)

3. Plantas columnares, muy poco ramificadas, generalmente sin ramificaciones. Costillas numerosas

T. atacamensis

3'. Plantas arbustivas 0 arborescentes, ramificadas. Costillas 12 a 17

T. skottsbergii

2'. Espinas del ápice rígidas, tiesas

4. Costillas tuberculadas, $2 \mathrm{~cm}$ de ancho

T. undulosus

4'. Costillas no tuberculadas, $3-5 \mathrm{~cm}$ de ancho

5. Ramas con epidermis amarillo-verdoso. Tallo de 40-60 cm de diámetro

T. werdermannianus

5'. Ramas con epidermis verde-clara, verde-grisáceo o verde-oscura. Tallo de 12-30 cm de ancho 
6. Espinas de las areolas basales subaplanadas, no hay diferencia entre radiales y ni centrales; solo dos superiores y dos inferiores

6 '. Espinas de las areolas basales aciculares o subuladas, diferenciadas en radiales y centrales

7. Espinas de la base: centrales 1-6; radiales hasta 50, se entrecruzan con las espinas de las areolas vecinas. Flores de $14 \mathrm{~cm}$ de largo, apicales, dispuestas alrededor del ápice

\section{T. tarijensis}

7'. Espinas de la base: centrales 1; radiales 5, las cuales no se entrecruzan con las espinas radiales vecinas. Flores de $20 \mathrm{~cm}$ o más longitud, subapicales y a lo largo de las costillas

8. Ramas de $10-25 \mathrm{~cm}$ de diámetro. Costillas $1,5-4,0 \mathrm{~cm}$ de ancho y hasta $2 \mathrm{~cm}$ de alto

T. chiloensis

8'. Ramas de $27-45 \mathrm{~cm}$ de diámetro. Costillas de hasta $5,5 \mathrm{~cm}$ de ancho y $4 \mathrm{~cm}$ de alto

T. terscheckii

1.. Plantas ramificadas de la base

9. Plantas bajas, menores de $1,50 \mathrm{~m}$

10. Ramas reclinadas sobre el suelo con los extremos apicales ascendentes

11. Presencia de mamelones subhexagonales en las costillas

T. thelegonus

11'. Costillas sin mamelones subhexagonales

12. Costillas angostas $(8-10 \mathrm{~mm})$. Flores de $22 \mathrm{~cm}$ de longitud

T. vasquezii

12'. Costillas anchas $(2,5-2,8 \mathrm{~cm})$. Flores de $13-19 \mathrm{~cm}$ de longitu

T. uyupampensis

10'. Ramas que empiezan primero con una orientación horizontal, y que después cambia a la vertical

13. Ramas con menos de 10 costillas

14. Costillas altas $(1-1,8 \mathrm{~cm})$ y anchas $(2-3 \mathrm{~cm})$, areolas distanciadas $3-5 \mathrm{~cm}$, espinas subuladas

T. candicans

14'. Costillas bajas $(0,8-1,0 \mathrm{~cm})$ y angostas $(1 \mathrm{~cm})$, areolas distanciadas $1-2 \mathrm{~cm}$, espinas aciculares, cerdosas, flexibles y curvadas

T. spinibarbis

13'. Ramas con 10 a 20 costillas

15. Espinas colocadas ordenadamente (de a pares, una central definida y erecta), rectas

T. andalgalensis

15’ Espinas de disposición irregular, algo retorcidas

16. Costillas tuberculadas

T. faundezii

16'. Costillas no tuberculadas

17. Espinas exteriores adultas adpresas al tallo (ángulo de divergencia ca. 15 grados), dispuestas a manera de peine

T. pectiniferus

17'. Espinas exteriores adultas divergentes al tallo (ángulo de divergencia ca. 75 grados), dispuestas a manera de radios 
18. Tallos cilíndricos o muchas veces en forma de barril. Ápice de los tallos ligeramente hundidos. Espinas subuladas

18'. Tallos cilíndricos. Ápice de los tallos no hundidos. Espinas aciculares

19. Espinas centrales cortas $(0,1-2,3 \mathrm{~cm})$

20. Plantas epífitas. Ramas de 2,5-4,0 cm de diámetro

T. arboricola

20'. Plantas terrestres. Ramas de $5-15 \mathrm{~cm}$ de diámetro

21. Tallos claviformes, espinas subuladas

T. clavatus

21'. Tallos cilíndricos, espinas aciculares

22. Ramas de $60 \mathrm{~cm}$ de alto, $5 \mathrm{~cm}$ de diámetro, ausencia de surcos encima de las areolas del ápice. Espinas centrales (1) y radiales (9). Flores de $17 \mathrm{~cm}$ de largo

T. camarguensis

22'. Ramas de $100 \mathrm{~cm}$ de alto, $9 \mathrm{~cm}$ de diámetro, con dos pequeños surcos en forma de "v" encima de las areolas del ápice. Espinas centrales (4-5) y radiales (15-19). Flores de $23 \mathrm{~cm}$ de largo

T. lamprochlorus

19'. Espinas centrales largas (hasta $10 \mathrm{~cm}$ )

23. Costillas amplias, $1,3 \mathrm{~cm}$, epidermis verde-brillante. Espinas radiales no se entrecruzan con las espinas de las areolas vecinas

T. vollianus

23'. Costillas angostas, $1 \mathrm{~cm}$, epidermis verde-opaco. Espinas radiales se entrecruzan con las espinas de las areolas vecinas

24. Flores cortas (hasta $10 \mathrm{~cm}$ ), tépalos amarillos, raramente blancos o anaranjados

T. huascha

24'. Flores largas (hasta 13-22 cm), tépalos blancos, raramente amarillos

25. Espinas subapicales totalmente negras

T. nigripilis

25'. Espinas subapicales grises o grises con puntas marrón

26. Plantas hasta $60 \mathrm{~cm}$ de alto. Costillas $15-18$, de $2 \mathrm{~mm}$ de alto y $4 \mathrm{~mm}$ de ancho.

Espinas menores de $1 \mathrm{~mm}$ de ancho, apicales rojo-vinoso

T. strigosus

26'. Plantas hasta $1,20 \mathrm{~m}$. Costillas $10-15$, de $10 \mathrm{~mm}$ de alto y $10 \mathrm{~mm}$ de ancho. Espinas de 1,5 a $2 \mathrm{~mm}$ de diámetro, apicales negras con base amarilla o grisoscuro con manchas negras

T. deserticola

9'. Plantas altas, de 2 a $6 \mathrm{~m}$

27. Ramas con 6 a 8 costillas

28. Espinas de la base subaplanadas, no hay diferencia entre radiales y ni centrales; solo dos superiores y dos inferiores

T. bridgesii

28'. Espinas de la base aciculares o subuladas, radiales y centrales

29. Presencia de un surco dérmico encima de cada areola

T. macrogonus 
29'. Ausencia de un surco dérmico sobre las areolas

30. Ramas de 7-10 cm de grosor, costillas bajas (menos de $2 \mathrm{~cm}$ )

T. cuzcoensis

30'. Ramas de 11-15 cm de diámetro, costillas altas (1,5-2,2 cm)

31. Costillas de la base angostas $(2,6 \mathrm{~cm})$, con espinas centrales ausentes o pocas $(0-1)$, cortas $(4-6 \mathrm{~cm})$, veteado entre gris y marrón

T. taquimbalensis

31'. Costillas de la base amplias $(4 \mathrm{~cm})$, con 4 espinas centrales largas $(6-8 \mathrm{~cm})$, negras

T. wilkeae

27'. Ramas con 11 a 28 costillas

32. Ramas de 5-8 cm de diámetro

33. Ramas sin surco interareolar horizontal, menor número de costillas (12), costillas altas $(1 \mathrm{~cm})$, una espina central en areolas basales

T. angelesiae

33'. Ramas con surco interareolar horizontal, que divide las costillas en mamelones subcuadrados, mayor número de costillas (16), costillas bajas $(0,5 \mathrm{~cm})$, espinas centrales en areolas basales de 1 a 4

T. spachianus

32'. Ramas de $9-35 \mathrm{~cm}$ de ancho

34. Tallos de hasta $35 \mathrm{~cm}$ de diámetro. Espinas muy delgadas y numerosas, radiales de la base hasta 50. Flores de $14 \mathrm{~cm}$ de largo, apicales, dispuestas alrededor del ápice

T. tarijensis

34'. Tallos de hasta $25 \mathrm{~cm}$ de diámetro. Espinas no como las anteriores, radiales de la base hasta 24. Flores de $20 \mathrm{~cm}$ o más de longitud, subapicales, a lo largo de las costillas

35. Espinas del ápice cerdosas, no punzantes, ligeramente torcidas

T. tacaquirensis

35'. Espinas del ápice aciculares o subuladas, rectas y punzantes

36. Costillas altas $(1,5-2,5 \mathrm{~cm})$

37. Ápice de las ramas agudo

T. chiloensis

37'. Ápice de las ramas clavado a obtuso

38. Ramas de $22 \mathrm{~cm}$ de ancho, espinas diferenciadas en centrales y radiales. Flores de 10$13 \mathrm{~cm}$ de largo, tépalos internos fucsia

T. herzogianus

38'. Ramas de $12 \mathrm{~cm}$ de diámetro, espinas no diferenciadas en radiales ni centrales. Flores de $15-17 \mathrm{~cm}$ de longitud, tépalos internos blancos

T. tunariensis

36'. Costillas bajas $(0,5-1,3 \mathrm{~cm})$

39. Espinas 10, sin diferenciarse en radiales ni centrales, amarillo-opaco

T. cabrerae

39'. Espinas centrales 4-6, radiales 13-13, verde-oliva, marrón-oscuro o gris claro 
40. Tallos erectos y/o decumbentes, flores de $14 \mathrm{~cm}$ de longitud, dispuestas a lo largo de las costillas, estilo de $8 \mathrm{~cm}$ de largo

T. bolligerianus

40'. Tallos erectos, flores de $20 \mathrm{~cm}$ de longitud, dispuestas alrededor del ápice, estilo de 13 $\mathrm{cm}$ de largo

T. narvaecensis

\subsection{Clave para la identificación de las especies de Argentina:}

1. Plantas epífitas

T. arboricola

1'. Plantas terrestres

2. Plantas columnares, mayores de $2 \mathrm{~m}$ de alto

3. Flores de ca. $14 \mathrm{~cm}$ de largo, generalmente distribuidas en el ápice, formando una corona alrededor del mismo, tépalos rojizos

T. tarijensis

3'. Flores de $15-30 \mathrm{~cm}$ de longitud, localizadas a lo largo de las costillas, tépalos internos desde blanco niveo-amarillento

4. Plantas ramificadas de la base. Ramas de $5-8 \mathrm{~cm}$ de diámetro, mayormente con surco interareolar horizontal y recto, que divide las costillas en mamelones subcuadrados

T. spachianus

4'. Plantas con tronco definido. Ramas de $24-27 \mathrm{~cm}$ de diámetro. Costillas sin surco interareolar ni mamelones subcuadrados

5. Costillas de las ramas 8 a 18. Espinas apicales rígidas. Flores de unos $19-25 \mathrm{~cm}$. Habita lugares bajos $(800-1400 \mathrm{~m})$

T. terscheckii

5'. Costillas de las ramas 20-30. Espinas apicales flexibles, parecidas a cerdas. Flores de unos 15 cm de largo. Habita de (1000) 2000 a 3000 m, según la latitud

T. atacamensis

2 '. Plantas ascendentes y decumbentes, menores de $2 \mathrm{~m}$ de altura

6. Presencia de mamelones subhexagonales en las costillas. Tallos mayormente rastreros

T. thelegonus

6'. Costillas sin mamelones subhexagonales. Tallos ascendentes o erectos

7. Plantas de 1,5 a $2,0 \mathrm{~m}$ de alto

8. Diámetro de los tallos ca. $6,5 \mathrm{~cm}$, con 12 costillas

T. angelesiae

8'. Tallos de 9-11 (-20) cm de diámetro, con 15-18 (-22) costillas

T. cabrerae

$7^{\prime}$. Plantas menores de $1 \mathrm{~m}$ de alto

9. Espinas colocadas ordenadamente (de a pares, una central definida y erecta), rectas

T. andalgalensis

9'. Disposición irregular, algo retorcidas 
10. Costillas anchas $(2-3 \mathrm{~cm})$ y altas $(1-3 \mathrm{~cm})$

11. Tallos cilíndricos o muchas veces en forma de barril. Ápice de los tallos ligeramente hundidos, costillas 10-20, areolas separadas $1 \mathrm{~cm}$, espinas cortas $(0,5-1,2 \mathrm{~cm})$, delgadas

T. schickendantzii

11'. Tallos cilíndricos. Ápice de los tallos no hundidos, costillas 8-9, areolas distanciadas $3-5 \mathrm{~cm}$, espinas largas $(1,7-4,0 \mathrm{~cm})$, subuladas

T. candicans

10'. Costillas angostas (menores de $1 \mathrm{~cm}$ ) y bajas (menores de $1 \mathrm{~cm}$ )

12. Espinas cortas $(0,3-1,0 \mathrm{~cm})$

T. lamprochlorus

12'. Espinas largas $(1-7 \mathrm{~cm})$

13. Flores cortas $(10 \mathrm{~cm})$, tépalos amarillos, raramente blancos 0 anaranjados

T. huascha

13'. Flores largas $(18-22 \mathrm{~cm})$, tépalos blancos, raramente amarillos

T. strigosus

9.4. Clave para la identificación de las especies de Bolivia, Ecuador y Perú:

1. Plantas epífitas

1'. Plantas terrestres

2. Plantas ascendentes

3. Diámetro de las ramas menor de $8 \mathrm{~cm}$

4. Costillas angostas $(8-10 \mathrm{~mm})$. Flores de $22 \mathrm{~cm}$ de longitud

T. vasquezii

4'. Costillas anchas $(2,5-2,8 \mathrm{~cm})$. Flores de $13-19 \mathrm{~cm}$ de longitud

5. Espinas centrales de $1 \mathrm{~cm}$ de longitud

T. camarguensis

5'. Espinas centrales de 2-8 cm de largo

T. uyupampensis

3'. Diámetro de las ramas entre $8-15 \mathrm{~cm}$

T. clavatus

2'. Plantas erectas

6. Menos de 10 costillas

7. Espinas subaplanadas

T. bridgesii

7'. Espinas redondas

8. Espina central acicular

T. macrogonus

8'. Espina central subulada

9. Ramas angostas $(7-10 \mathrm{~cm})$

T. cuzcoensis

9. Ramas gruesas $(11-20 \mathrm{~cm})$ 
10. Costillas de la base de angostas $(2,6 \mathrm{~cm})$, con espinas centrales ausentes o pocas $(0-1)$, cortas $(4-6 \mathrm{~cm})$, veteado entre gris y marrón

T. taquimbalensis

10'. Costillas de la base amplias $(4 \mathrm{~cm})$, con 4 espinas centrales largas $(6-8 \mathrm{~cm})$, negras

T. wilkeae

6'. Más de 10 costillas

11. Espinas del ápice cerdosas, no punzantes, ligeramente torcidas

12. Plantas muy poco ramificadas, generalmente sin ramificaciones. Costillas numerosas (24-40)

12'. Plantas ramificadas desde la base. Costillas 12

T. atacamensis

11'. Espinas del ápice aciculares o subuladas, rectas y punzantes

13. Flores de $10-13 \mathrm{~cm}$ de largo

14. Espinas radiales no se entrecruzan con las espinas de las areolas vecinas

T. herzogianus

14'. Espinas radiales se entrecruzan con las espinas de las areolas vecinas

T. tacaquirensis

13'. Flores de $14 \mathrm{~cm}$ o más de longitud

15. Plantas bajas (hasta $1,5 \mathrm{~m}$ de alto)

T. tarijensis

15. Plantas altas (hasta $12 \mathrm{~m}$ de alto)

16. Epidermis amarillo verdoso

T. werdermannianus

16'. Epidermis verde claro a oscuro

17. Costillas de la base con un surco interareolar horizontal que divide a las costillas en mamelones subcuadrados

T. spachianus

$17^{\prime}$ Costillas de la base sin un surco interareolar horizontal y sin mamelones subcuadrados

18. Plantas ramificadas a nivel del suelo con ramas de 15 a $22 \mathrm{~cm}$ de diámetro

T. narvaecensis

18'. Plantas con un tronco de hasta $1,5 \mathrm{~m}$ de alto (raro sin ramificaciones), del cual surgen ramas de $1^{\circ}, 2^{\circ}$ y $3 r$. órden. Ramas de $24-27 \mathrm{~cm}$ de diámetro

T. terscheckii

9.5. Clave para la identificación de las especies de Chile:

\begin{tabular}{|c|c|}
\hline \multicolumn{2}{|l|}{ 1. Espinas del ápice débiles y flexibles (cerdosas) } \\
\hline 2. Plantas columnares, muy poco ramificadas. Costillas numerosas (24-40) & T. atacamensis \\
\hline 2'. Plantas arbustivas 0 arborescentes, ramificadas. Costillas 12 a 17 & T. skottsbergii \\
\hline \multicolumn{2}{|l|}{ 1'. Espinas del ápice fuertes y rígidas } \\
\hline \multicolumn{2}{|c|}{ 3. Plantas erectas. Costillas pocas $(7-8)$ y altas $(2,5 \mathrm{~cm})$. Mayor distancia entre las areolas $(2,5 \mathrm{~cm})$} \\
\hline & T. macrogonus \\
\hline \multirow{2}{*}{\multicolumn{2}{|c|}{$\begin{array}{l}\text { 3'. Plantas erectas, ascendentes y pendientes. Costillas numerosas (10-21) y bajas (menos de } 2 \mathrm{~cm} \text { ). } \\
\text { Menor distancia entre las areolas ( } 2 \mathrm{~cm} \text { o menos) }\end{array}$}} \\
\hline & \\
\hline 4. Ramas de $5-10 \mathrm{~cm}$ de diámetro & \\
\hline
\end{tabular}


5. Espinas exteriores adultas adpresas al tallo (ángulo de divergencia ca. 15 grados), pectinadas

T. pectiniferus

5'. Espinas exteriores adultas divergentes al tallo (ángulo de divergencia ca. 75 grados), dispuestas a manera de radios

6. Espinas radiales 7-10, grises. De la XV Región

T. uyupampensis

6'. Espinas radiales 14-20, marrón a marrón verdoso. De la II, III y IV Región

7. Espinas subapicales totalmente negras

T. nigripilis

7'. Espinas subapicales grises o grises con puntas marrón

8. Espinas cerdosas abundantes (más de 10), flexibles y curvadas en el ápice, subápice y parte media de los tallos

T. spinibarbis

8'. Espinas cerdosas ausentes o pocas (menos de 10)

T. deserticola

4'. Ramas $10-25 \mathrm{~cm}$ de diámetro

9. Costillas notablemente abultadas en la zona de las areolas (tuberculadas)

10. Plantas bajas ( $80 \mathrm{~cm}$ de altura), ascendentes y ramificadas a nivel del suelo

T. faundezii

10'. Plantas altas (2,5 cm de altura), arbustivas y ramificadas a partir de un tronco

T. undulosus

9'. Costillas no engrosadas en la zona de las areolas

11. Costillas bajas $(0,6-1,0 \mathrm{~cm})$, en la parte media de los tallos

T. bolligerianus

11'. Costillas altas $(1,1-1,5 \mathrm{~cm})$, en la parte media de los tallos

T. chiloensis

\subsection{Descripción de las especies y taxones infraespecíficos:}

1. Trichocereus andalgalensis (F.A.C. Weber) Hosseus, Arch. Esc. Farm. Cienc. Med. Córdoba 9: 69. 1939

Cereus andalgalensis F.A.C. Weber en K. Schum., Gesamtbeschr. Kakt.: 168. 1897. Tipo no designado. Lobivia andalgalensis (F.A.C. Weber) Britton \& Rose, The Cactaceae 3: 56, fig. 72. 1922 (excepto descripción y figura: Echinopsis aurea var. dobeana). Helianthocereus andalgalensis (F.A.C. Weber) Backeb., Cact. Succ. J. (Los Angeles) 23: 48. 1951. Salpingolobivia andalgalensis (F.A.C. Weber) Y. Itô, Explan. Diagr. Austroechinocactinae: 141. 1957. Lobivia huascha (F.A.C. Weber) W.T. Marshall var. andalgalensis (F.A.C. Weber) Rausch, Lobivia 3: 172. 1977. TIPO: Argentina, Prov. Catamarca, Dpto. Andalgalá, Nov. 1975, R. Kiesling 1068 (Neotipo, SI 162149, aquí designado).

Cereus huascha F.A.C. Weber var. rubriflorus F.A.C. Weber, Monatsschr. Kakteenk. 3: 151. 1893. Tipo no designado. Trichocereus huascha (F.A.C. Weber) Britton \& Rose var. rubriflorus (F.A.C. Weber) Backeb. \& F.M. Knuth, Kaktus-ABC: 206. (1935) 1936. Helianthocereus huascha (F.A.C. Weber) Backeb. var. rubriflorus (F.A.C. Weber) Backeb., Cactus (Paris) 10(45): 210. 1955. Echinopsis huascha (F.A.C. Weber) H. Friedrich \& G.D. Rowley var. rubriflora (F.A.C. Weber) H. Friedrich \& G.D. Rowley, 
I.O.S. Bull. 3(3): 96. 1974. Lobivia huascha (F.A.C. Weber) W.T. Marshall var. rubriflora (F.A.C. Weber) G.D. Rowley, Cact. Succ. J. Gr. Brit. 44(4): 81. 1982. Lobivia huascha (F.A.C. Weber) W.T. Marshall var. rubriflora (F.A.C. Weber) Rausch, Lobivia 85: 72.1987 [1985-86 publ. 1987], (nom. illeg., por superfluo, Art. 52.1). TIPO: Argentina, Prov. Catamarca, 4 km SE Andalgalá, 1080 m, 23 Ene. 1973, P. Cantino 593 (Neotipo, SI 162148; Isoneotipo, CORD, aquí designados).

Trichocereus auricolor Backeb., en Backeberg \& Kunth, Kaktus-ABC: 412 (200). (1935) 1936. Trichocereus andalgalensis (F.A.C. Weber) Hosseus var. auricolor (Backeb.) F. Ritter, Kakteen Südamerika 2: 438. 1980, nom. inval., falta la página del basónimo (Art. 41.5).

Iconografías: Ritter (1980a), fotos 295-296: 725. Anderson (2005): 231. Hunt et al. (2006), fig. 4: 250. Kiesling \& Ferrari (2005), foto 42: 58. Trevisson \& Perea (2009), fotos 81: 120; A38-A41: 139.

Descripción original de Cereus andalgalensis F.A.C. Weber en K. Schum., Gesamtbeschr. Kakt.: 168. 1897:

Herr Dr. Weber schreibt mir, daß er C. Huascha Web. var. rubriflora Web. jetzt für eine eigene Art ansieht; er nennt sie C. Andalgalensis Web. Sie unterscheidet sich von jener durch kleinere und schlankere Gestalt des Stammes, der mehr verästelt und gelber ist. Die Stacheln sind schwächer, weniger zahlreich; die Blüten kleiner, blutrot.

Descripción ampliada: Plantas ascendentes, ramificadas desde la base. Tallos cilíndricos, ascendentes, $80 \mathrm{~cm}$ de alto, $5 \mathrm{~cm}$ de diámetro, epidermis verde-claro. Costillas 14, obtusas, 0,6 cm de alto y $1 \mathrm{~cm}$ de ancho. Areolas ovales, 0,3 cm de ancho, separadas entre sí por $1 \mathrm{~cm}$. Espinas dispuestas regularmente, amarillas, a veces con ápice rojizo, ligeramente flexibles, aciculares, menos de $1 \mathrm{~mm}$ de diámetro; una central, 4,5 cm de largo máximo, cerca de 10 radiales, dispuestas de a pares, $1,0-1,5 \mathrm{~cm}$ de largo. Flores subapicales, $7-9 \mathrm{~cm}$ de largo, raro $5-6 \mathrm{~cm}, 10 \mathrm{~cm}$ de diámetro (cuando abiertas), ovario de 1,7-2,0 cm de ancho, tubo floral de 2,2-3,5 cm de diámetro; escamas de $2 \mathrm{~mm}$ de ancho y 3-4 mm de largo, de cuyas axilas emergen pocas cerdas y abundante lanosidad amarilla, de $1 \mathrm{~cm}$ de largo, la cual cubre abundantemente el ovario; tépalos rojos o amarillos, exteriores triangulares, 0,7 cm de ancho y 1,7 $\mathrm{cm}$ de largo; tépalos intermedios $2 \mathrm{~cm}$ de largo, amarillos con ápice marrón, tépalos interiores oblanceolados, rojo-oscuro brillante o amarillos con ápice marrón, $2 \mathrm{~cm}$ de ancho, 4,5-5,0 cm de largo; estambres con filamentos del mismo color que el perigonio, anteras amarillas, la serie superior de filamentos de 0,5 mm de diámetro y 1,2 cm de largo, los filamentos de la serie inferior de 3,5 cm de largo; estilo verde, rosado en la parte superior, 7,2-7,6 cm de largo; estigmas con 14 lóbulos papilosos, subteretes, $6 \mathrm{~mm}$ de ancho y 0,8-1,3 cm de largo. Pseudobaya globosa, $3,5 \mathrm{~cm}$ de diámetro, parte externa amarillo-anaranjado y cavidad ovárica con funículos blancos. Semillas negras, con una cresta longitudinal, con células subhexagonales, separadas por un pequeño surco y con perforaciones angostas en los ángulos (Fig. 11). 


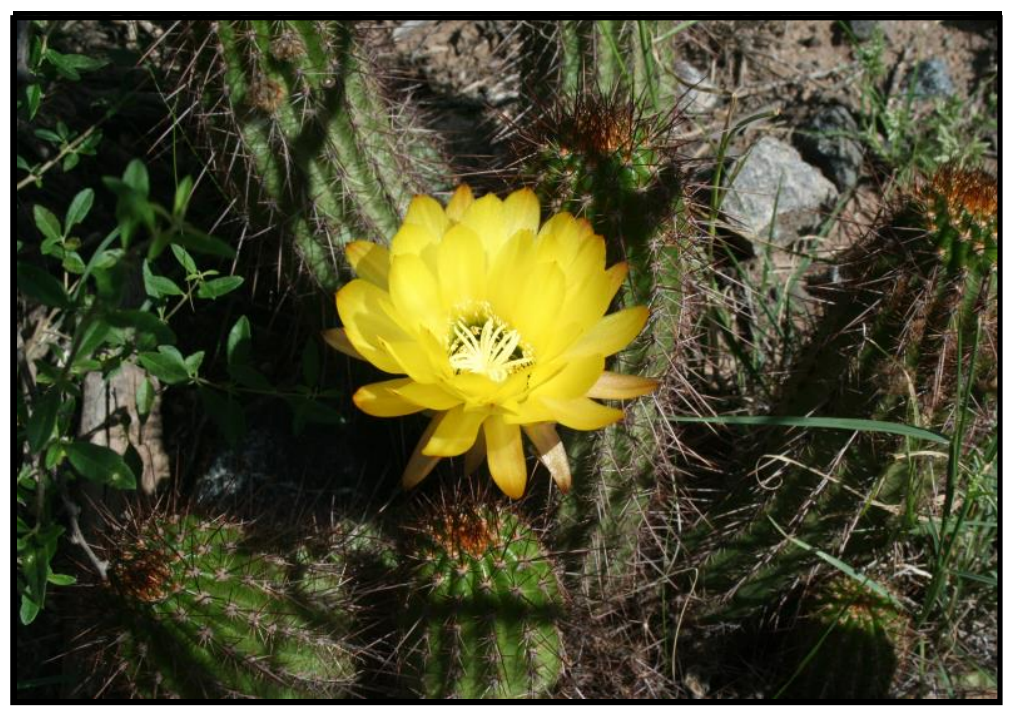

Figura 11. Trichocereus andalgalensis. Provincia de San Juan, Valle Fértil.

Distribución y hábitat: Especie endémica de la Argentina, de las provincias de Catamarca, en algunas sierras del norte de la provincia de La Rioja y en San Juan, Valle Fértil (Fig. 73). En Catamarca se distribuye en las sierras de Ambato, Ancasti, Graciana y Manchado, entre 500 a 2000 m de altitud. Crece a la sombra de especies arbóreas espinosas, sobre suelos casi desnudos. Fitogeográficamente ocupa el distrito chaqueño serrano y en claros rocosos del extremo austral de la provincia de las yungas (Kiesling 1978, Trevisson \& Perea 2009).

Comentarios morfológicos y sus consecuencias en la taxonomía y nomenclatura: Se seleccionó el ejemplar R. Kiesling 1068 (SI) como Neotipo de Cereus andalgalensis porque reúne las características mencionadas en la descripción original. Este ejemplar presenta dos cortes longitudinales del tallo, pudiéndose observar el número de costillas, espinas radiales y centrales, su forma y tamaño y cuatro cortes longitudinales de la flor, donde se puede ver su forma, longitud, ancho del ovario, densidad de las escamas, cantidad de pilosidad y estambres.

Se eligió el ejemplar P. Cantino 593 (SI) como Neotipo de Cereus huascha var. rubriflorus por ser de la localidad de donde se describió la variedad, presenta un corte transversal y dos cortes longitudinales del tallo, apreciandosé el número de costillas, forma, tamaño, cantidad de espinas radiales y centrales, cuatro cortes longitudinales de la flor pudiendo verse su longitud, ancho, densidad de las escamas, pilosidad, estambres y un corte longitudinal del fruto con semillas.

Generalmente los tépalos de $T$. andalgalensis son rojos o amarillos, y se consideran una excepción los individuos con tépalos albinos. Trevisson \& Perea (2009) muestran flores de otros colores, lo que también parecen ser excepciones.

El porte y el diámetro de los tallos se ven influenciados por la altitud, el grado de exposición a la radiación solar y al viento. En las partes altas de la Sierra de Ancasti (hacia el norte), se observan 
poblaciones de menor tamaño y tallos más anchos (Kiesling 1978), diferenciándolas del resto de las poblaciones.

No se han observado híbridos entre $T$. andalgalensis y $T$. huascha a pesar que en algunas localidades crecen simpátricamente (Kiesling 1978), lo cual confirma sus límites específicos. Hacia el norte de la Sierra de Ancasti se han observado posibles híbridos entre $T$. andalgalensis y Lobivia grandiflora (com. pers. R. Kiesling).

Autores como Anderson (2005) consideran que $T$. huascha y $T$. andalgalensis son especies tan parecidas que las han sinonimizado, pero se han encontrado caracteres que permite diferenciarlas (Tabla 2). En realidad, la confusión entre estas dos especies proviene de las descripciones originales, donde se las compara o se menciona una como variedad de la otra.

Tabla 2. Diferencias entre $T$. andalgalensis y $T$. huascha.

\begin{tabular}{|l|l|l|}
\hline \multicolumn{1}{|c|}{ CARACTERES } & \multicolumn{1}{c|}{ T. andalgalensis } & \multicolumn{1}{c|}{. huascha } \\
\hline Altura máxima de los tallos & $80 \mathrm{~cm} \quad 100 \mathrm{~cm}$ \\
\hline Disposición de las espinas y forma & $\begin{array}{l}\text { Regular (de a pares, una central definida } \\
\text { y erecta), rectas }\end{array}$ & Irregular, algo retorcidas \\
\hline Color y forma de las espinas & Amarillo-brillante, casi con tonos de rojo & Amarillo-crema, opacas \\
\hline Longitud de las espinas centrales & Cortas, hasta 4,5 cm & Largas, hasta $7 \mathrm{~cm}$ \\
\hline Forma de las flores & Campanuladas & Cónicas \\
\hline Longitud de las flores & Cortas, $7 \mathrm{~cm}($ raro $5-6 \mathrm{~cm}$ ) & Largas, $10 \mathrm{~cm}$ \\
\hline Color de los filamentos estaminales & $\begin{array}{l}\text { Rojos en la de tépalos rojos, amarillos en } \\
\text { los de tépalos amarillos }\end{array}$ & Amarillos \\
\hline Hábitat & Mayormente en zonas húmedas & Mayormente en zonas secas \\
\hline
\end{tabular}

Por la disposición regular de las espinas, la foto 231 de Anderson (2005), parece corresponder a T. andalgalensis y no a T. huascha.

Material de Herbario estudiado: Argentina, Prov. Catamarca, Dpto. El Alto, De Anjillón a El Alto, 26 Nov. 1979, P. Legname 9506 (LIL); Sierra de Ancasti, entre Sucuma y las Cuestecillas, en el camino que va de El Alto a Alijián, E. DiFulvio \& A.T. Hunziker 19620 (CORD); Sierra de Ancasti, entre Las Cañas y El Alto, Jun. 1964, A.E. Cocucci \& A.T. Hunziker 17521 (CORD); entre La Cumbre y El Alto, Sierra de Ancasti, 1923 m, 16 Nov. 2006, B. O. Schlumpberger 470 (CORD); Sierra de Ancasti, 1418 m, 18 Nov. 2006, B. O. Schlumpberger 475 (CORD); Dpto. Andalgalá, Qda. Rio de la Cañada, 23 Oct. 1933, Peirano, 9906 (LIL); Cuesta de la Chilca, 1500 m, Nov. 1937, Schreiter 10389 (LIL); 10 Dic. 1965, R. Subilis et al. 18522 (CORD); El Suncho, 1500 m, 18 Feb. 1950, H. Sleumer 1951 (LIL); El Alamito, ca. 1500 m, 20 Feb. 1951, H. Sleumer 1671 (LIL); 4 km SE Andalgalá, 1080 m, 23 Ene. 1973, P. Cantino 593 (CORD, SI); ibidem, P. Joergensen, 1532 (SI); 6 km N (above) Choya on Ruta Provincial 47 towards Mina Capillitas, lower part of the Cuesta Mina Capillitas, 1750 m, 10 Dic. 1998, B.E. Leuenberger et al. 4655 (CORD); Dpto. Pomán, Cuesta de la Sebila, 2 Dic. 1951, F. Vervoorst 3404 (LIL); Sierra de Ambato (falda O) El Rincón, 1500 m, 21 Feb. 1970, L. Ariza \& A.T. Hunziker 20561 (CORD). Prov. La Rioja, J.F. 
Quiroga, S. "La Malanza", 4-8-1977, F. Biurrun 1026 (SI); Dpto. Arauco, Sierra de Velasco, paraje llamado Ashá, 17 Km al oeste de Aimogasta, 25 Feb. 1991, F. Biurrun \& E.J. Cáceres 3552 (SI); 24 Dic. 1918, C. Spegazzini s.n. (LP ex LPS 23117).

2. Trichocereus angelesiae R. Kiesling, Darwiniana 21 (2-4): 314.1978 (como "angelesii").

Echinopsis angelesiae (R. Kiesling) G.D. Rowley, Repert. PI. Succ. 29: 5. 1980. TIPO: Argentina, Prov. Salta, Dpto. Guachipas, entre Alemania y Cafayate, El Sapo, 27 Dic. 1976, R. Kiesling 1302 (Holotipo, SI 28585 a y b!).

Iconografía: Hunt et al. (2006), fig. 1: 231.

Descripción original de Trichocereus angelesiae R. Kiesling, Darwiniana 21 (2-4): 314. 1978 :

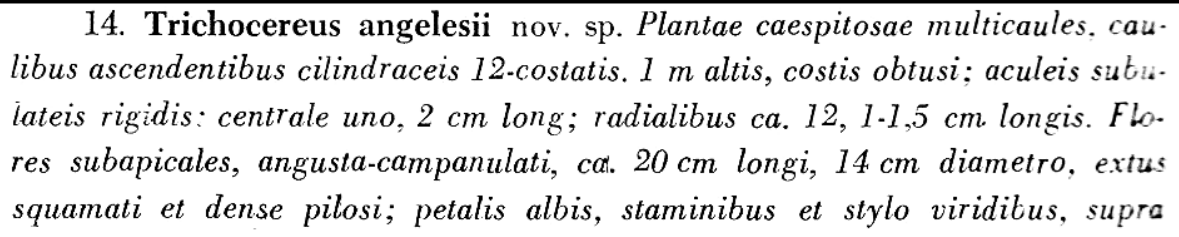
libus ascendentibus cilindraceis 12 -costatis. $1 \mathrm{~m}$ altis, costis obtusi; aculeis sutulateis rigidis: centrale uno, $2 \mathrm{~cm}$ long; radialibus ca. 12, 1-1,5 cm. longis. Flo. res subapicales, angusta-campanulati, ca. $20 \mathrm{~cm}$ longi, $14 \mathrm{~cm}$ diametro, extus squamati et dense pilosi; petalis albis, staminibus et stylo viridibus, supra cremeis.

Descripción ampliada: Plantas de 1,5 m o poco más de alto, con numerosos tallos, formando matas. Tallos con la parte inferior reptante, cilíndricos, ascendentes, ramificados en la porción rastrera, verde-claro, opaco, 6,5 cm de diámetro. Costillas 12 , de $1 \mathrm{~cm}$ de alto y 1,3 cm de ancho, obtusas, algo sobresalientes bajo las areolas. Areolas ovales, $4 \mathrm{~mm}$ de diámetro y $6 \mathrm{~mm}$ de alto, con pilosidad escasa y corta. Espinas rígidas, aciculares, de base ancha, una central, erecta, $2 \mathrm{~cm}$ de largo, radiales 12, una inferior de hasta $1,5 \mathrm{~cm}$ de largo, y las otras de menor tamaño, dispuestas de a pares laterales. Flores naciendo cerca del ápice de los tallos, $20 \mathrm{~cm}$ de largo y $14 \mathrm{~cm}$ de diámetro (cuando están abiertas); receptáculo y ovario cubiertos por escamas agudas, 5-10 mm de largo, amarillentas, con pelos lanosos bastante rígidos en las axilas, $2 \mathrm{~cm}$ de largo, amarillos en el ovario y castaños en el receptáculo. Tépalos exteriores sepaloides, ensiformes, $6 \mathrm{~mm}$ de ancho, $5 \mathrm{~cm}$ de largo, agudos, castaño-rojizos, tépalos interiores espatulados y mucronados a apiculados, $2 \mathrm{~cm}$ de ancho y $6 \mathrm{~cm}$ de largo, blancos; ovario subgloboso, a veces truncado, $2 \mathrm{~cm}$ de diámetro; estilo verde-claro en la parte inferior y crema en la parte superior, declinado, sobrepasando los estambres y llegando al borde del perigonio en antesis; estigma con 12 a 16 radios, papilosos, amarillos, 1,0-1,5 cm de largo; cámara nectarial de $1 \mathrm{~cm}$ de largo, verdeclara, ubicada en el fondo del tubo; estambres en dos series, la inferior espiralada, localizada desde la cámara nectarial hasta $5 \mathrm{~cm}$ en el tubo, filamentos de $8-11 \mathrm{~cm}$ de largo, declinados, verde-claro en su base y amarillo-claro en el ápice; serie superior erguida, de una sola hilera de estambres, filamentos de $2,7 \mathrm{~cm}$ de largo (Fig. 12). 


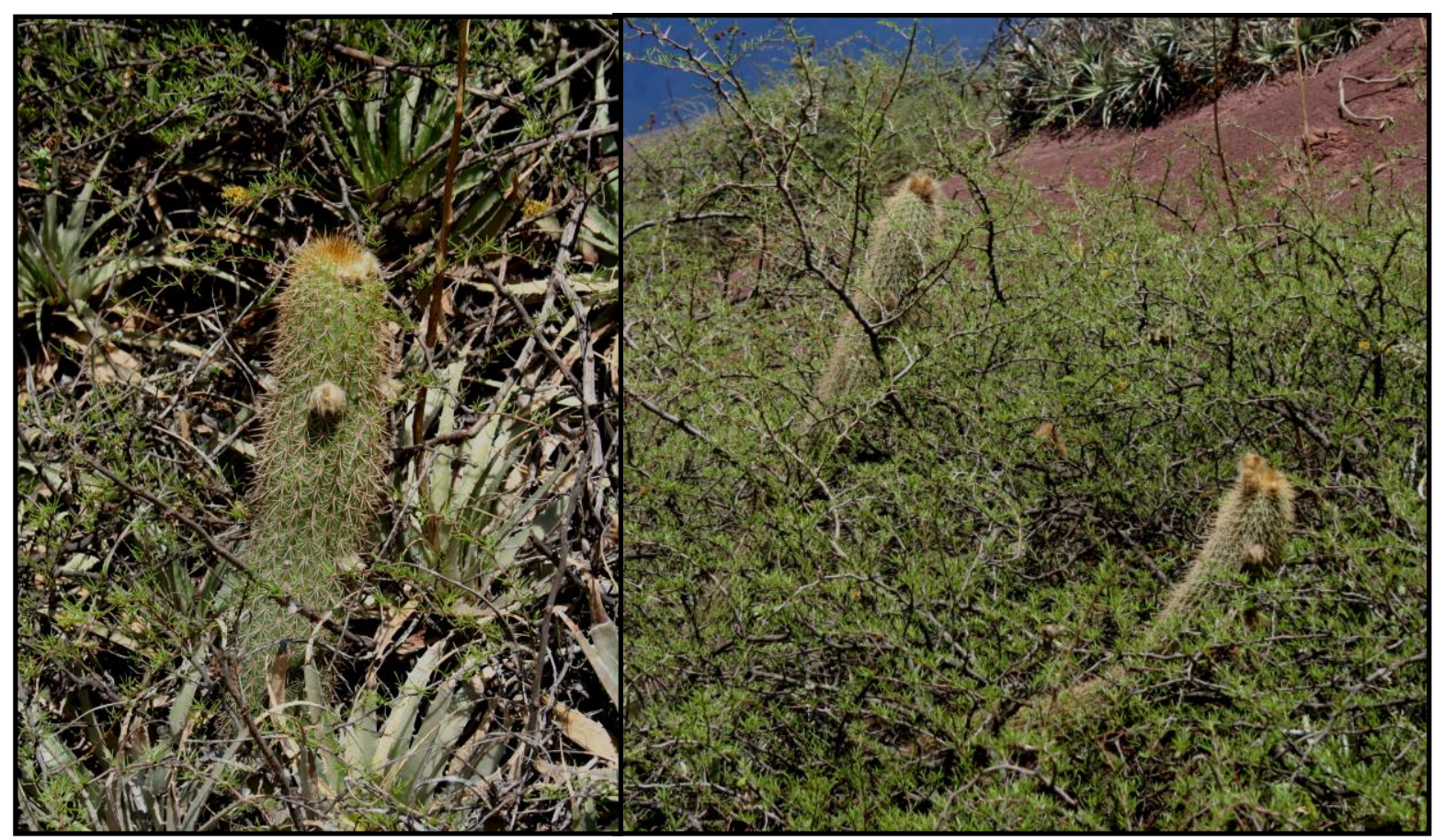

Figura 12. Trichocereus angelesiae. Provincia de Salta, en el trayecto de Cafayate a la Viña, El Obelisco a Tres Cruces.

Distribución y Hábitat: Especie endémica de la Argentina, en la provincia de Salta, en los departamentos de Cafayate y Guachipas, abundante en quebradas laterales al este de la quebrada del río Las Conchas, desde Tres Cruces a El Sapo y un poco más al sur (Fig. 73). Se localiza en lugares áridos, con vegetación escasa, conviviendo con Deuterocohnia sp., Gymnocalycium spegazzinii, Prosopis sp., Trichocereus terscheckii y Tephrocactus weberi, entre 500-1700 m de altitud (Kiesling 1978).

Comentarios morfológicos y sus consecuencias en la taxonomía y nomenclatura: Según Kiesling (1978), T. angelesiae tiene cierto parecido a T. lamprochlorus y en especial con T. strigosus por su hábito de crecimiento y longitud de las flores, pero presenta características que las diferencia resumidas en las tablas 3 y 4 .

Tabla 3. Diferencias entre $T$. angelesiae y $T$. lamprochlorus.

\begin{tabular}{|l|l|l|}
\hline \multicolumn{1}{|c|}{ CARACTERES } & \multicolumn{1}{c|}{ T. angelesiae } & \multicolumn{1}{c|}{ T. lamprochlorus } \\
\hline Color de la epidermis & Más grisácea & $\begin{array}{l}\text { Verde-brillante cuando jóvenes, } \\
\text { tornándose oscuro con la edad. }\end{array}$ \\
\hline No. de espinas centrales & 1 & $4-5$ \\
\hline No. de espinas radiales & 12 & $15-19$ \\
\hline Longitud y consistencia de las espinas & Largas (hasta $2 \mathrm{~cm}$ ) y flexibles & $\begin{array}{l}\text { Cortas (menos de } 1 \mathrm{~cm} \text { ) y no } \\
\text { flexibles }\end{array}$ \\
\hline
\end{tabular}


Tabla 4. Diferencias entre $T$. angelesiae y $T$. strigosus.

\begin{tabular}{|l|l|l|}
\hline \multicolumn{1}{|c|}{ CARACTERES } & \multicolumn{1}{c|}{$\boldsymbol{T}$. angelesiae } & \multicolumn{1}{c|}{ T. strigosus } \\
\hline Tamaño de las plantas & $1,5 \mathrm{~m}$ & hasta $0,60 \mathrm{~m}$ \\
\hline Exposición de la epidermis & Puede observarse & $\begin{array}{l}\text { Cubierta por espinas, lo cual dificulta su } \\
\text { observación }\end{array}$ \\
\hline No. de espinas centrales & 1 & $3-4$ \\
\hline No. de espinas radiales & Hasta 12 & Hasta 16 \\
\hline
\end{tabular}

Material de Herbario estudiado: Argentina, Prov. Salta, Dpto. Cafayate, 1700 m, 19 Oct. 2005, M. Saravia \& F. Moschione 35 (SI); Dpto. Guachipas, entre Alemania y Cafayate, El Sapo, 27 Dic. 1976, R. Kiesling 1302 (SI 28585).

3. Trichocereus arboricola Kimnach, Cact. Succ. J. (Los Angeles) 62(1): 4, ill. 1990.

Echinopsis arboricola (Kimnach) Mottram, Cact. Consensus Initiat. 2: 8. 1997. TIPO: Bolivia, Dept. Tarija, Prov. Arce, valley of Río Chillaguatas below Rancho Nogalar on trail between Sidaras and Tariquia, 1100 m, J. Solomon 11311 (Holotipo, HNT; Isotipos, MO 04989464! US)

Iconografías: Kimnach (1990), figs. 1-4: 3-5. Anderson (2005): 217. Hunt et al. (2006), figs. 3-4: 231.

Descripción original de Trichocereus arboricola Kimnach, Cact. Succ. J. (Los Angeles) 62(1): 4. 1990:

Caules tandem pendens, ad $1.2 \mathrm{~m}$ longi, 2.5-4 cm crassi, costis 9-11 et ca. $5 \mathrm{~mm}$ altis; areolae 3-4 $\mathrm{mm}$ distans, spinis 9-15 acicularibus, ad $23 \mathrm{~mm}$ longis, flavido-brunneolis. Flores nocturne, infundibuliformes, $12-13 \mathrm{~cm}$ longi, orificio 9-10 cm lato; receptaculum 8-8.5 cm longum, pilis ad 15 $\mathrm{cm}$ longis, 3-5 cm crissum ad apicem, pericarpio 10-12 $\mathrm{mm}$ longis et 16-20 mm longae et 2-5 mm latae base; tepala exteriors linearo-acuminata, $1-7 \mathrm{~cm}$ longa et 5-10 $\mathrm{mm}$ lata, purpureo-brunnea; tepala interiores oblanceolata obtuse mucronata, 5-6 cm longa et ca. $2.5 \mathrm{~cm}$ lata, cremea; nectaria $\mathrm{ca} .1 \mathrm{~cm}$ longa; stamina 3-9 cm longa; stylus 9-9.5 cm longus, ca. 2 mm crassus, lobis 11-13.

Stems at first suberect to erect, finally pendent, to $1.2 \mathrm{~m}$ long or more, $2.5-4 \mathrm{~cm}$ thick, emitting aerial roots along side even on erect stems, dark green; ribs 9-11, ca. $5 \mathrm{~mm}$ high; podaria nearly square or subconical, compressed laterally, 2-3 mm high, 3-5 mm wide; areoles 3-4 mm apart on each rib, at apex of podarium, the wool mass 1-2 mm wide and high, cream; spines 9-15, evenly radiate, acicular, sharp, 1-23 mm long, usually 1 longer than the rest, yellowish to brownish.

Flowers from near steam apex, nocturnal, $12-13 \mathrm{~cm}$ long, the outer tepals opening $13-15 \mathrm{~cm}$ wide, the inner tepals opening 9-10 $\mathrm{cm}$ wide, receptacle 8-8.5 $\mathrm{cm}$ long, upcurving; pericarpel 10-12 $\mathrm{mm}$ long, 16-20 mm thick, the podaria ca. 2-3 $\mathrm{mm}$ apart, obtuse or flattened, 3-4 $\mathrm{mm}$ long and wide, smooth, shiny, green, bracteoles appressed, deltoid or acuminate, acute, $1.5-2 \mathrm{~mm}$ long, amber-green, hairs mostly parallel to receptacle, 20-40 in each areole, sinuous, 7-10 mm long, mostly back, some grey; remainder of receptacle ca. $7.5 \mathrm{~cm}$ long, $12-15 \mathrm{~mm}$ thick just above 
pericarpel, 14-18 $\mathrm{mm}$ thick at mid-point, $3-3.5 \mathrm{~cm}$ thick at apex, yellowish green, podaria obtuse to obtuse-flattened, $0.5-2.5 \mathrm{~cm}$ long, the longest ones near center, $4-7 \mathrm{~mm}$ wide, $1-2 \mathrm{~mm}$ high, bracteoles appressed, deltoid-acuminate, acute, 3-12 $\mathrm{mm}$ long, 2-5 $\mathrm{mm}$ wide near base, dark green, often reddish near apex, hairs as on pericarpel, to $15 \mathrm{~mm}$ long; lowermost of outer tepals strongly recurving at full expansion of flower, the upper ones less so and expanding to $13-15 \mathrm{~cm}$ wide; all outer tepals purplish brown or streaked with yellow, acute, acuminate to linear-acuminate, $1-7 \mathrm{~cm}$ long, 5-10 mm wide; inner tepals forming a campanulate corolla with an opening 9-10 cm wide, oblanceolate, obtuse but with an acute cusp, 5-6 cm long, ca. $1 \mathrm{~cm}$ wide at base and $2.5 \mathrm{~cm}$ wide at middle, cream, the lower ones streaked reddish on exterior face; ovule chamber oblate-globose, 6-8 $\mathrm{mm}$ long, 8-12 $\mathrm{mm}$ wide; nectaries and here $5-9 \mathrm{~cm}$ long, the remainder in a throat-circle at apex and 3-4 cm long; all filaments ca. $0.75 \mathrm{~mm}$ thick, greenish cream, the anthers ca. $3 \mathrm{~mm}$ long and 1 mm wide, yellow; style 9-9.5 cm long, ca. 2 mm thick, greenish.

Descripción ampliada: Plantas epífitas, ramas erectas o péndulas, de hasta $1 \mathrm{~m}$ de largo. Ramas originadas desde la base, 2,5-4,0 cm de diámetro, verde-oscuro, con raíces caulinares tanto en las ramas péndulas como en las erectas. Costillas 9-11, amplias (ca. 1350), de $5 \mathrm{~mm}$ de alto. Areolas 3-4 mm de separación, de 1-2 mm de ancho y alto, con pilosidad blanca. Espinas 9-15, radiales, aciculares, punzantes, 1-23 mm de largo, amarillo a marrón. Flores subapicales, $13 \mathrm{~cm}$ de largo, $15 \mathrm{~cm}$ de diámetro cuando abiertas; receptáculo de $9 \mathrm{~cm}$ de largo; ovario de 1,0-1,2 cm de largo, $2 \mathrm{~cm}$ de ancho, escamas deltoides, acuminadas 0 agudas, 1,5-2,0 cm de largo, de cuyas axilas surgen pelos (20-40), de $7 \mathrm{~mm}$ de largo, negros y algunos grises; tubo floral de 1,4-1,8 mm de diámetro (en el centro); tépalos externos linear-acuminados, 1-7 cm de largo, 5-10 mm de ancho, marrón-púrpura; los internos espatulados, 5-6 cm de largo, 2,5 cm de ancho, blancos; filamentos de 0,75 mm de diámetro, amarillo-claro; anteras de $3 \mathrm{~mm}$ de largo y $1 \mathrm{~mm}$ de ancho, amarillas; estilo de $9,5 \mathrm{~cm}$ de largo y $2 \mathrm{~mm}$ de ancho, verde-claro, estigma con 11-13 lóbulos de 1,5 a 2 cm de largo. Semillas largas (2,0 a 2,9 mm) (Fig. 13).

Distribución y Hábitat: Se localiza en el norte de Argentina, en la Provincia de Salta, en el bosque subtropical submontano, en el Parque Nacional Baritú (Hilgert \& Kiesling 2002) (Fig. 73), y en el sur de Bolivia, en el departamento de Tarija, en el bosque húmedo subtropical, entre 500-1100 m (Kimnach 1990, Albesiano 2014) (Fig. 74).

\section{Comentarios morfológicos y sus consecuencias en la taxonomía y nomenclatura: Esta} especie fue descrita por Kimnach (1990) para el género Trichocereus y posteriormente Mottram (1997) lo transfiere al género Echinopsis. El análisis filogenético con base en caracteres morfológicos y moleculares (Albesiano \& Terrazas 2012), confirma que este taxón pertenece al género Trichocereus, y es cercano a Harrisia hahniana y $\mathrm{H}$. earlei ya que forman un clado al compartir cuatro sinapomorfías: presencia de raíces caulinares, tallos reptantes, costillas amplias (ángulo mayor de $135^{\circ}$ ), y semillas de 2,0 a 2,9 mm de largo (Albesiano \& Terrazas 2012). 
Trichocereus arboricola y $T$. vasquezii son similares morfológicamente por presentar los tallos de menor diámetro dentro del género Trichocereus, pero existen diferencias (Tabla 5), que permiten considerarlos como dos taxones separados (Kimnach 1990).

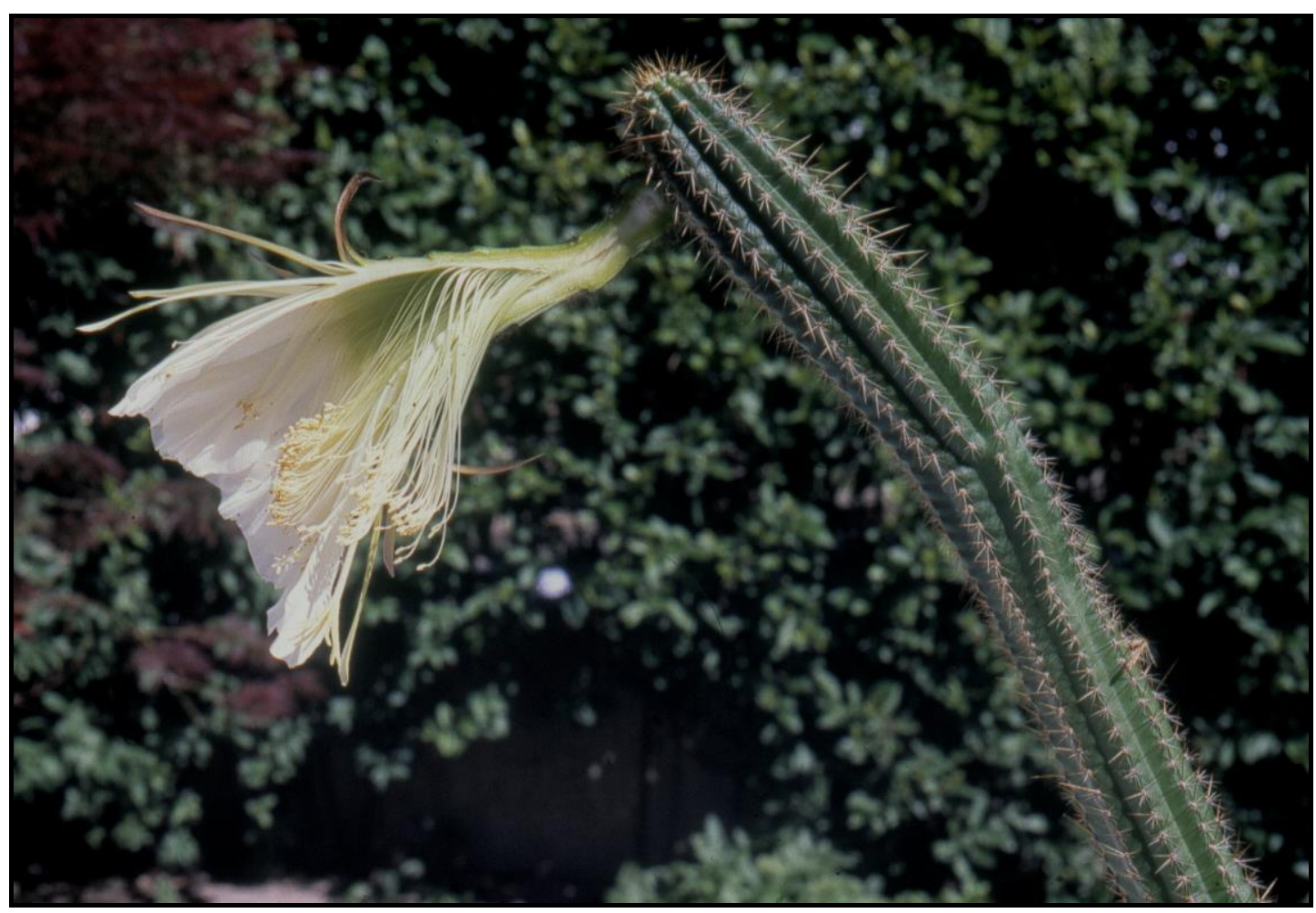

Figura 13. Trichocereus arboricola. Planta de cultivo, colección de N. Hilgert, recolección del Parque Nacional Baritú.

Tabla 5. Caracteres que diferencian a $T$. arboricola de $T$. vasquezii

\begin{tabular}{|l|l|l|}
\hline CARACTERES & \multicolumn{1}{|c|}{ T. arboricola } & \multicolumn{1}{c|}{ T. vasquezii } \\
\hline Hábito & Epifito & Terrestre \\
\hline Diámetro de los tallos & $2,5-4,0 \mathrm{~cm}$ & $4,0-5,0 \mathrm{~cm}$ \\
\hline Longitud de las flores & $13 \mathrm{~cm}$ & $22 \mathrm{~cm}$ \\
\hline Hábitat & Bosque húmedo subtropical & Matorrales subxerofíticos \\
\hline
\end{tabular}

Material de Herbario estudiado: Argentina, Prov. Salta, Dpto. Santa Victoria, PN Baritú, 4 Oct. 1996, N. Hilgert \& P. Arenas 1510 (SI). Bolivia, Dept. Tarija, Prov. Arce, valley of Río Chillaguatas below Rancho Nogalar on trail between Sidaras and Tariquia, 1100 m, J. Solomon 11311 (MO). 
4. Trichocereus atacamensis (Phil.) W.T. Marshall \& T.M. Bock, Cactaceae: 94. 1941.

Cereus atacamensis Phil. Fl. Atacam.: 23. 1860. Helianthocereus atacamensis (Phil.) Backeb., Die Cactaceae 2: 1315. 1959. Echinopsis atacamensis (Phil.) H. Friedrich \& G.D. Rowley, I.O.S. Bull. 3(3): 94. 1974. Trichocereus atacamensis (Phil.) W.T. Marshall \& T.M. Bock subsp. atacamensis, Lazaroa 17: 54. 1996. Leucostele atacamensis (Phil.) Schlumpb., Cactaceae Syst. Init. 28: 29. 2012. TIPO: Chile, II Región de Antofagasta, Prov. El Loa, San Pedro de Atacama, Mina de San Bartolo, 22¹4' lat. m., 2438 m, R.A. Philippi 31 (Lectotipo, SGO 052685! designado por Muñoz: 91. 1960).

Pilocereus pasacanus F.A.C. Weber, en Förster, Handb. Cacteenk. 2: 678. 1885. Tipo no designado. Cereus pasacana (F.A.C. Weber) F.A.C. Weber, Monatsschr. Kakteenk. 3: 165. 1893. Cephalocereus pasacanus (F.A.C. Weber) F.A.C. Weber, Index Kewensis 1: 89. 1906. Trichocereus pasacana (F.A.C. Weber) Britton \& Rose, The Cactaceae 2: 133. 1920. Helianthocereus pasacana (F.A.C. Weber) Backeb, Cactac. Handb. Kakteenk. 2: 1314. 1959. Echinopsis pasacana (F.A.C. Weber) H. Friedrich \& G.D. Rowley, I.O.S. Bull. 3(3): 96. 1974. Trichocereus atacamensis (Phil.) W.T. Marshall \& T.M. Bock var. pasacana (F.A.C. Weber) F. Ritter, Kakteen Südamerika 2: 447. 1980. Echinopsis atacamensis (Phil.) H. Friedrich \& G.D. Rowley subsp. pasacana (F.A.C. Weber) G. Navarro, Lazaroa 17: 54. 1996. Trichocereus atacamensis subsp. pasacanus (F.A.C. Weber ex Rümpler) Guiggi, Cactology 3: 8. 2012. TIPO: Argentina, Prov. Jujuy, Tilcara, 27 Oct. 1964, A.L. Cabrera 16340B (Neotipo, LP!, designado por Albesiano 18: 118. 2012).

Cereus eriocarpus Phil., Anal. Mus. Nac. Chile 2: 27. 1891. TIPO: Chile, I Región de Tarapacá, Calcalhuay, 3700 m, R.A. Philippi s.n. (Lectotipo, SGO 052688! designado por Muñoz: 91. 1960).

Trichocereus cephalopasacana Frič. Möller's Deutsche Gärtn.-Zeitung (15) 44. 169. 1929, nom. nud.

Trichocereus eremophilus F. Ritter, Kakteen Südamerika 2: 559. 1980. TIPO: Bolivia, Dpto. Potosí, Prov. Nor Lípez, Mpio. Colcha K, 3600-3900 m, F. Ritter 49a (Holotipo, U, no visto; Isotipo, SGO 121151!).

Leucostele rivierei Backeb., Kakteen And. Sukk.: 40. 1953.

Iconografías: Spegazzini (1925): 118. Marshall \& Bock (1941), foto 42: 93. Backeberg (1959a), fotos 1261-1263: 1308-1310. Ritter (1980b), foto 1080: 1226. Mauseth et al. (2002): 270-271. Hoffmann \& Walter (2004), lámina 14: 87. Kiesling \& Ferrari (2005), foto 40: 56. Albesiano (2012), foto 1: 119. 
Descripción original de Cereus atacamensis Phil. Fl. Atacam.: 23. 1860:

148. Cereus alacamensis $P h$. C. simplex, columna-
ris, crassissimus; costis numerosissimis; pulvillis 6 din.
crassis, lana fulva, demum nigrescente tectis; spinis tereti-
bus, tenuibus, filiformibus, numerosissimis, irregulariter in-
aequalibus, usque ad $30-40,4$ pollices longis.
Sic Cereum ingentem, simplicem, columnarem voco,
quem ad minas de S. B artolo dictas prope Atacama op-
pidum $22^{\circ} 14^{\prime}$ lat. m. et 8000 p. s. m. e distantia vidi, ubi
incolis K'hávul audit, et cujus lignum durum, etsi poris
et foraminibus magnis pertusum in oppido dicto ad portas
aliaque ejusmodi conficienda adhibetur. Tabulas 2 pedes
latus ex hoc Cacto confectas vidi! Vir egregius, minis
illis praepositus, plantam me trahere jussit, quam sedulo
usque ad Santiago conduxi, sed in itinere plus vicies a
mulis in solum dejecta et concussa, quando cistulam, qua
inclusa ibat, aperui putrefacta apparuit.

Descripción ampliada: Tallos erectos, hasta $15 \mathrm{~m}$ de alto. Tallo de aproximadamente $47 \mathrm{~cm}$ de diámetro. Las ramas salen de $1 \mathrm{a} 3 \mathrm{~m}$ del suelo, son de $25 \mathrm{~cm}$ de diámetro y muy pocas veces se ramifican. También, se presentan plantas sin ramificaciones. Costillas del ápice 25, obtusas, $1 \mathrm{~cm}$ de ancho, con areolas redondas, $3 \mathrm{~mm}$ de alto y $2 \mathrm{~cm}$ de ancho, con pilosidad blanca con algo grisáceo; espinas centrales 4, dispuestas en cruz, $5 \mathrm{~cm}$ de largo, aciculares, flexibles y débiles (cerdosas), de $1 \mathrm{~mm}$ de diámetro, blancuzcas o amarillas; espinas radiales 18, de $2 \mathrm{~cm}$ de largo, entremezcladas con las espinas radiales de las areolas vecinas, aciculares, $1 \mathrm{~mm}$ de diámetro, débiles y flexibles, amarillas. Costillas de la base 24-40, obtusas, de $5 \mathrm{~cm}$ de ancho y $2 \mathrm{~cm}$ de alto, con areolas circulares, de $3 \mathrm{~mm}$ de alto y $2 \mathrm{~cm}$ de ancho, con tomento gris; con siete espinas centrales, de hasta $9 \mathrm{~cm}$ de largo y $3 \mathrm{~mm}$ de diámetro, aciculares, amarillas; espinas radiales más de 15, de $3 \mathrm{~cm}$ de largo, aciculares y amarillas. Flores generalmente subapicales, raro apicales, ca. $15 \mathrm{~cm}$ de largo, con abundante pilosidad marrónclaro, de 1 a $2 \mathrm{~cm}$ de largo en el ovario y tubo floral; perigonio de $18 \mathrm{~cm}$ de diámetro (cuando abiertas); ovario de 2 a $3 \mathrm{~cm}$ de ancho; con escamas florales de $1 \mathrm{~cm}$ de largo, verdes con ápice marrón, escamas florales del tubo de 1 a $2 \mathrm{~cm}$ de largo, verde o verde-amarillento con ápice marrón; tépalos externos 4-6 $\mathrm{cm}$ de longitud, generalmente blancos, raro amarillo-verdoso o blanco-amarillento con líneas longitudinales marrón, raro rosado-intenso; tépalos internos son blancos o cremosos; estilo verde, de 8 $\mathrm{cm}$ de largo; estigma con lóbulos amarillos, de $1 \mathrm{~cm}$ de longitud. Pseudobaya lateral mayormente, 2-3 cm de largo y $3-4 \mathrm{~cm}$ de diámetro, recubierto por escamas subuladas, de cuyas axilas emergen abundantes pelos blancuzcos. Semillas de 1,4 mm de largo y 0,8 mm de ancho, rugosas (Fig. 14). 


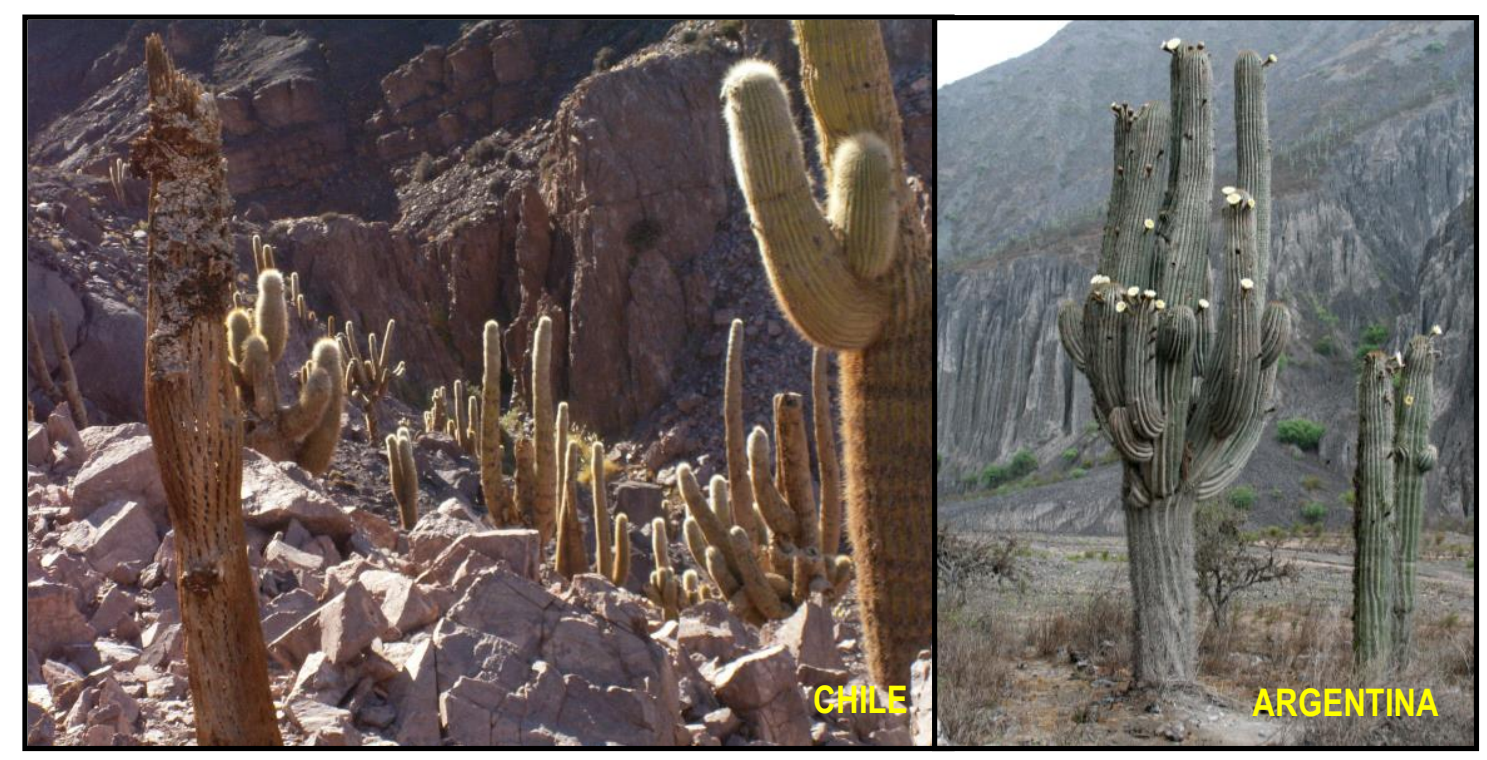

Figura 14. Trichocereus atacamensis. Argentina, Provincia de Salta, Qda. del Toro. Chile, Provincia El Loa, Comuna Calama, Pampa Puno. Foto Luis Faúndez.

Distribución y hábitat: Se distribuye en las zonas áridas y semiáridas NW Argentino (Fig. 73), S de Bolivia (Fig. 74) y del NE Chileno (Fig. 75A). En Chile se localiza en la I Región de Tarapacá y en la II Región de Antofagasta, en el desierto altoandino de Atacama y en las comunidades de la prepuna, provincia a la que define, entre 2400-3700 m. En la Argentina crece en las provincias de Jujuy, Salta, Tucumán y Catamarca, en la prepuna, entre los 2000-3500 m de altitud, en laderas rocosas, semiplanicies y planicies, siendo un elemento conspicuo del paisaje, por el porte elevado de sus plantas. En Bolivia se localiza en los departamentos Oruro y Tarija, entre 3500-4000 m de altitud (Albesiano 2014).

Comentarios morfológicos y sus consecuencias en la taxonomía y nomenclatura: Se escogió el ejemplar de A. Cabrera 16340 (LP) como Neotipo de Pilocereus pasacanus porque agrupa los caracteres morfológicos descritos en la descripción original, también presenta dos cortes transversales de tallo, identificandosé el número de costillas, espinas y la forma que estas últimas presentan, también por la presencia de dos flores, donde se aprecia la longitud, ancho, ancho del ovario, densidad de las escamas y pilosidad.

En una comunicación que envió Luc Willemse, curador del herbario $U$ (Holanda), informa que el ejemplar tipo: Ritter 49a (holotipo de Trichocereus eremophilus), no existe en esta institución, como aparece citado en Ritter (:iii.1979, 1980a) y en Eggli et al. (1996).

Comparando las descripciones originales y el material herborizado de Cereus atacamensis, Cereus eriocarpus y Pilocereus pasacanus, se observa una alta similitud en el porte (erectas, de 3 hasta $15 \mathrm{~m}$ de alto), grosor de los tallos (ca. 40-47 cm), número de costillas (24-40) y fisonomía de las espinas apicales (delgadas y flexibles), por lo que se propone reunirlos bajo $T$. atacamensis. La variación en la ramificación (número de ramas), se debe al hábitat húmedo o seco en que crece esta especie (com. pers. 
R. Kiesling). Britton \& Rose (1920) observaron la semejanza entre T. pasacana y Cereus atacamensis, proponiendo reunirlos, lo cual fue efectuado por Marshal \& Bock (1941) y aceptado por Kiesling \& Ferrari 2005, Kiesling et al. 2008, entre otros autores.

Material de Herbario estudiado: Argentina, Prov. Catamarca, Dpto. Andalgalá, $12 \mathrm{Km} \mathrm{N}$ (above) Choya on Ruta Provincial 47 towards Mina Capillitas, 1960 m, 10 Dic. 1998, B.E. Leuenberger et al. 4651 (CORD); Dpto. de Belén, Hualfín, 2000 m, 20 Feb. 1947, D. Droghetii s.n. (LIL); Loma Redonda (60 Km de Santa María), 5 Dic. 1960, A. Ruiz-L. 21648 (MERL); ibidem, Yacutula, 26 Oct. 1974, R. Kiesling 802 (SI); $45 \mathrm{Km}$ on ruta 53 (given as 43 on some maps) from turnoff towards Antofagasta de la Sierra, $3 \mathrm{Km}$ below turnoff of access road to Los Nacimientos de San Antonio, 2800 m, 20 Feb. 1994, B.E. Leuenberger et al. 4290 (CORD); Dpto. Santa María, Cerrillos-Sierra Aconquija, 3100 m, 17 Dic. 1933, Peirano 9797 (LIL); San José, 18 Feb. 1999, E. Martinez 2097 (MERL 53795); Sierra Los Nacimientos, 29 Nov. 2006, B.O. Schlumpberger 518 (CORD). Prov. Jujuy, Tilcara, 27 Oct. 1964, A.L. Cabrera 16340 (LP); Tilcara a Maimará, 29 Oct. 1981, M.M. Costa 2547 (SI). Prov. Salta, Tintin, 3004 m, 3 Dic. 1960, A. RuizL. 21616 (MERL); ibidem, 2804 m, 30 Dic. 1960, A. Ruiz-L. 21647 a-e (MERL); Dpto. Cachi, Palermo, 20 Oct. 1948, A. Burkart 17616 a,b (SI); Dpto. Guachipas, al E de Sta. Bárbara, 1600 m, 2 Oct. 2005, M. Saravia 26 (MCNS); Dpto. Rosario de Lerma, Qda. del Toro, entre Chorrillos e Ing. Maury, 2100-2600 m, 6 Nov. 1985, L. Novara \& Zardini 2946 (MCNS); ibídem, Ruta 51 Km 45, 27 Ene. 2003, L. Novara 11904 (MCNS). Prov. Tucumán, Los Cardones a Santa Rosa (Qda. Amaicha), 2500-3000 m, Dic. 1931, Schreiter 7204 (LIL); Herbario 66736 (LIL); Dpto. Tafi, entre el Infiernito y Amaicha, Los Cardones, 5 Nov. 2002, A.A. Cocucci 1998 (CORD); sureste de Amaicha del Valle, 15 Dic. 2006, B.O. Schlumpberger 593 (CORD). Bolivia, Dpto. Tarija, Prov. Eustaquio Méndez, Iscayachi, $19 \mathrm{Km}$ hacia Curqui, $3500 \mathrm{~m}, 10$ Nov. 1993, St. G. Beck et al. 22082 (LPB); Dpto. Oruro, Prov. L. Cabrera, Mpio. Salinas de García Mendoza, 3738 m, Jul. 2006, M. Arakaki \& N. Quispe 1723 (LPB). Chile, II Región de Antofagasta, Prov. Antofagasta, Dpto. Cementerio, camino cañería Antofagasta al N cementerio de Toconce, 23 Nov. 1969, H.C. Martin 516 (SI); ibidem, H.C Martin 517 (SI).

Otro material estudiado: Chile, I Región de Tarapacá, Prov. Iquique, ciudad de Iquique, Playa Brava, sobre el nivel del mar, 12 Nov. 2008, (observado en cultivo).

5. Trichocereus bolligerianus (Mächler \& Helmut Walter) Albesiano, Haseltonia 17: 18. 2012.

Echinopsis bolligeriana Mächler \& Helmut Walter. Kakteen And. Sukk. 54 (10): 269, ill. 2003. Leucostele bolligeriana (Mächler \& Helmut Walter) Schlumpb., Cactaceae Syst. Init. 28: 29. 2012. TIPO: Chile, VI Región del Libertador General Bernardo O’Higgins, Prov. Cardenal Caro, Punta de Lobos, Ene. 2003. Walter 213 a, b (Holotipo, SGO!). 
Trichocereus chiloensis (Colla) Britton \& Rose var. conjungens F. Ritter, Kakteen Südamerika 3: 1109, ill. 1980. TIPO: Chile, V Región de Valparaíso, Küstengebiet. Häufigauch bei Limache, Olmué und Granizo, östlich von Valparaiso FR 228c. (Holotipo, U 160273!) (El nombre del holotipo está escrito en un labelo de herbario como "T. chilensis var. conjungens").

Iconografías: Ritter (1980b), foto 1062: 1221. Hoffmann \& Walter (2004), lámina 15: 89. Hunt et al. (2006), Fig. 4: 232. Albesiano (2012), foto 2: 120.

Descripción original de Echinopsis bolligeriana Mächler \& Helmut Walter. Kakteen Sukk. 54 (10): 269. 2003:

\begin{abstract}
Echinopsis bolligeriana W. Mächler \&
H. Walter, spec. nov.

Lat. diagn.: Caules $8.12 \mathrm{~cm}$ crassi. $1.2 \mathrm{~m}$ longi, basi proliferans, pendens vel decumbens, radices adventices formans; costae 20 , perobtusae, 3-5 $\mathrm{mm}$ altae, 12 usque ad 14 $\mathrm{mm}$ latae, vix crenatae, tuberculosae et undulatae; areolae $5 \mathrm{~mm}$ diam., orbiculares, non obliquae, brunneotomentosae; spinae aciculares, luridobrunneae, centrales $3-4,5 \mathrm{~cm}$ longae; ovarium ca. $25 \mathrm{~mm}$ diam., squamis rubris et lana longa brunnea densa obtectum, apice applanato; tubus floralis lana brunnea et squamis longis angustis praeditus; camara nectarifera angusta, $4.5 \mathrm{~mm}$ lata, ca. $30 \mathrm{~mm}$ alta; fructus ruber, $3.4 \mathrm{~cm}$ diam., globosus,
\end{abstract}

apice non elongato, obtectus ut ovarium; semina ca. $1,8 \mathrm{~mm}$ longa, $1 \mathrm{~mm}$ lata, nigra, nitida, ventraliter paulum excelsa et vix crenata, hilo valde obliquo.

Typusfundort: Punta de Lobos, Prov. Cardenal Caro, Chile. Verbreitung bis ca. $3 \mathrm{~km}$ nach Süden und $7 \mathrm{~km}$ nach Norden.

Holotypus: Chile, Prov. Cardenal Caro, Punta de Lobos, Januar 2003, Helmut Walter, $H W 213$ (SGO).

Etymologie: Die neue Art ist benannt nach Dr. Thomas Bolliger, Leiter der Sukkulenten-Sammlung Zürich, dem wir den Hinweis verdanken, der $\mathrm{zu}$ ihrer Beschreibung führte.

Descripción ampliada: Plantas erectas o colgantes, 2-6 m de largo, ramificadas a nivel del suelo. Ramas de $18 \mathrm{~cm}$ de diámetro. Costillas del ápice 17, obtusas, 0,6-2,0 cm de ancho, $3 \mathrm{~mm}$ de alto; areolas ovadas, $2 \mathrm{~mm}$ de alto, 6-8 mm de ancho, con pilosidad amarilla en el ápice, base gris o negra; espinas centrales 1-4, de 0,3 a $2 \mathrm{~cm}$ de largo, aciculares, base verde-claro, marrón en la parte media y ápice; espinas radiales 16, de 0,5 a $2 \mathrm{~cm}$ de largo, aciculares, base gris-claro o verde, en el medio verde y ápice marrón. Costillas de la base hasta 20 , obtusas, $2 \mathrm{~cm}$ de ancho, $10 \mathrm{~mm}$ de alto; areolas ovadas, 2 $\mathrm{mm}$ de alto, $6 \mathrm{~mm}$ de ancho, con pilosidad gris o marrón; espinas centrales 4-6, de 0,2-6 cm de largo, menos de $0,7 \mathrm{~mm}$ de diámetro, aciculares, verde-oliva o marrón-oscuro; espinas radiales 15 , de 1-2 cm de largo, aciculares, flexibles, diámetro menor de $0,7 \mathrm{~mm}$, verde-oliva o gris-claro. Flores subapicales, 10 3 , de $14 \mathrm{~cm}$ de largo, con abundante pilosidad marrón en el ovario y tubo floral, perigonio de $7 \mathrm{~cm}$ de diámetro (cuando abiertas), ovario 2-3 cm de ancho; escamas florales del pericarpelo de $2 \mathrm{~cm}$ de largo, verde con ápice marrón, escamas florales del tubo $3 \mathrm{~cm}$ de largo, verde o verde-amarillento con ápice marrón, tépalos 4-6 cm de longitud, amarillo-verdoso o blanco-amarillento con líneas longitudinales marrón, estilo verde, $8 \mathrm{~cm}$ de largo, estigmas amarillos, 1,5 cm de longitud. Pseudobaya subapical, 2-3 
$\mathrm{cm}$ de largo y $3-4 \mathrm{~cm}$ de diámetro, recubierta por escamas triangulares, de cuyas axilas emergen abundantes pelos marrones y grises. Semillas de 1,8 mm de largo y $1 \mathrm{~mm}$ de ancho (Fig. 15).

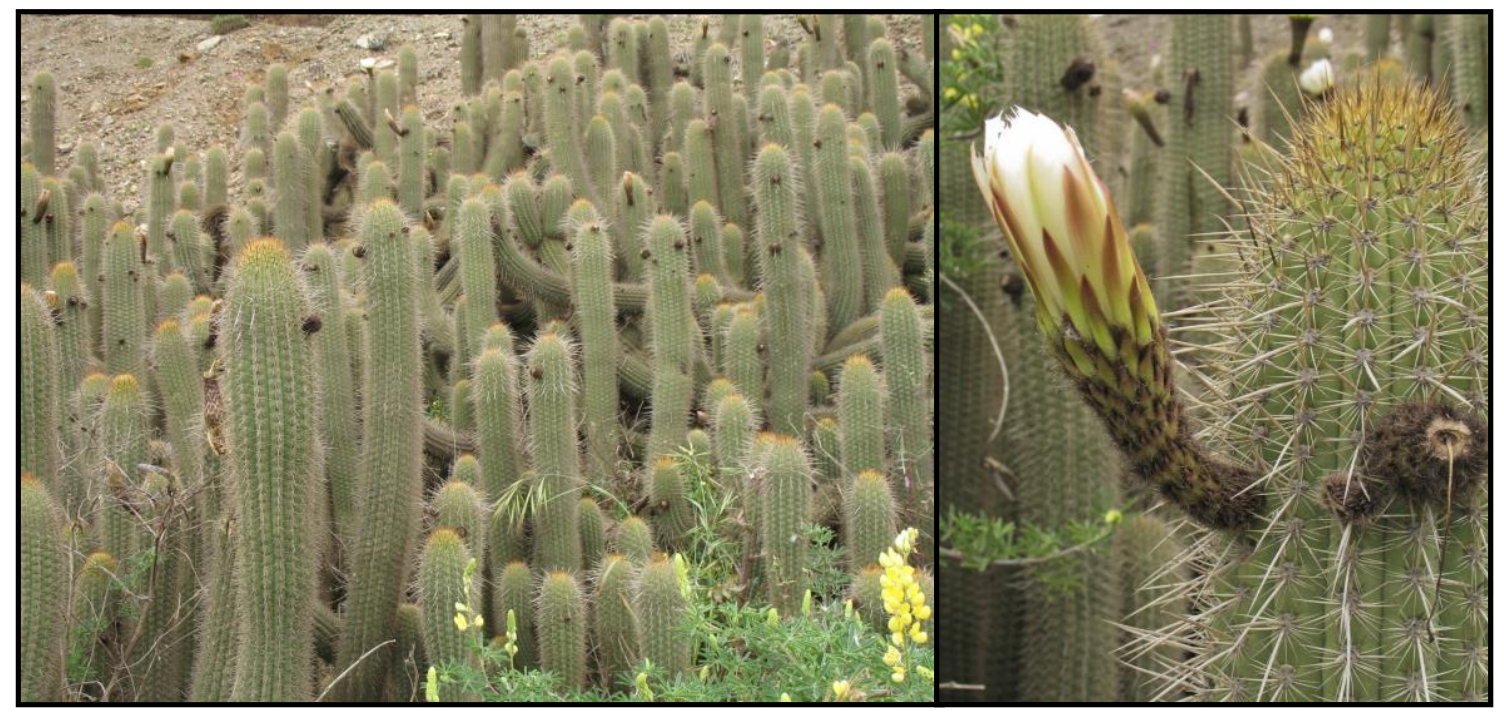

Figura 15. Trichocereus bolligerianus. Chile, VI Región del Libertador General Bernardo O'Higgins, Costa de Pichilemú.

Distribución y hábitat: Trichocereus bolligerianus crece en la V y VI Región, en los cerros de la cordillera de la Costa; próximos al mar, y en laderas inclinadas $\left(15-20^{\circ}\right)$, donde parte de la vegetación ha sido transformada por la actividad turística (Fig. 75A).

\section{Comentarios morfológicos y sus consecuencias en la taxonomía y nomenclatura:} Analizando las descripciones originales de $T$. chiloensis var. conjungens y Echinopsis bolligeriana, se observa una alta similitud en el número de costillas, y en la cantidad y morfología de las espinas, por lo que se propone reunir estos dos taxones.

Trichocereus chiloensis var. conjungens ha sido considerado sinónimo de Echinopsis chiloensis (Anderson 2005), y últimamente de T. chiloensis subsp. chiloensis (Kiesling et al. 2008), pero al analizar la filogenia del género Trichocereus (Albesiano \& Terrazas 2012, Fig. 3), existe suficiente evidencia morfológica (costillas bajas y agudas) y molecular, que permite considerarla como una especie separada de $T$. chiloensis subsp. chiloensis.

Los individuos en las poblaciones de Trichocereus bolligerianus observados en la VI Región son de menor tamaño (2 $\mathrm{m}$ de alto), debido a las condiciones drásticas del ambiente (mayor influencia de la corriente fría de Humboldt), en comparación con la región de Valparaíso, donde las poblaciones se desarrollan bajo condiciones benignas y lugares más protegidos. 
Material de Herbario estudiado: Chile, VI Región del Libertador General Bernardo O'Higgins,

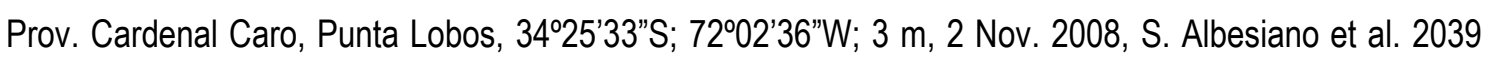

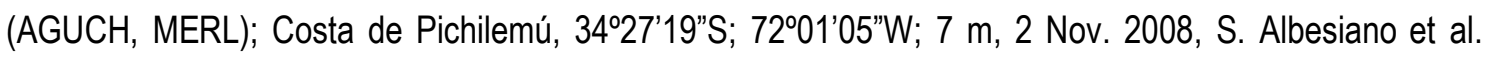
2040 (AGUCH, MERL).

6. Trichocereus bridgesii (Salm-Dyck) Britton \& Rose, The Cactaceae 2: 134. 1920.

Cereus bridgesii Salm-Dyck, Cact. Hort. Dyck. 1849: 208. 1850, non Echinopsis bridgesii SalmDyck. Tipo no designado. TIPO: Bolivia, Dpto. La Paz, Prov. Murillo, 3000 m, 7 Sep. 1986, J.C. Solomon 15576 (Neotipo, LPB, aquí designado).

Cereus lagenaeformis C.F. Först., Hamb. Gartenz. 17: 164. 1861. Tipo no designado. Cereus bridgesii Salm-Dyck var. lageniformis (C.F. Först.) K. Schum., Gesamtbeschr. Kakt.: 108. 1897. Cereus bridgesii Salm-Dyck f. lageniformis (C.F. Först.) Schelle, Handb. Kakteenkult.: 75. 1907. Trichocereus bridgesii (Salm-Dyck) Britton \& Rose var. lageniformis (C.F. Först.) Borg, Cacti.: 138. 1937. Echinopsis lagenaeformis (C.F. Först.) H. Friedrich \& G.D. Rowley, I.O.S. Bull. 3(3): 96. 1974. TIPO: Bolivia, La Paz, Prov. Murillo, 3000 m, 30 Ene. 1983, J.C. Solomon 9458 (Neotipo, LPB, aquí designado).

Cereus bridgesii Salm-Dyck var. brevispina K. Schum., Gesamtbeschr. Kakt.: 108. 1897. Tipo no designado. Cereus bridgesii Salm-Dyck f. brevispinus (K. Schum.) Schelle, Handb. Kakteenkult:: 75. 1907. Trichocereus bridgesii (Salm-Dyck) Britton \& Rose var. brevispinus (K. Schum.) Borg, Cacti: 138. 1937. TIPO: Bolivia, Dpto. La Paz, Prov. Larecaja, Mpio. Sorata, 2700 m, 3 Nov. 2002, R. Kiesling, J.M. Chalet, E. Foik, V. Foik, L. Hoeren 10031a (Neotipo, LPB; Isoneotipo, SI, aquí designados).

Cereus bridgesii Salm-Dyck var. longispinus C.A. Maass, Monatsschr. Kakteenk. 15: 119. 1905. Tipo no designado. Trichocereus bridgesii (Salm-Dyck) Britton \& Rose var. Iongispinus (C.A. Maass) Borg. Cacti: 138. 1937. TIPO: Bolivia, Dpto. La Paz, Prov. Loayza, del desvío de Urmiri, bajando $6 \mathrm{~km}$ hacia Sapahaqui, 3 Ene. 1991, St. G. Beck 17906 (Neotipo, LPB; Isoneotipo, SI, aquí designados).

Iconografía: Backeberg (1959a), foto 1077: 1121. 
(72.) C. Bridgesir Nob. C. caule erecto robusto subglaucescenti-læteviride 6-7 angulato, costis latis rotundatis lævissime sinuato - repandis, pulvillis remotis tomento parco instructis, aculeis 5 subapplanatis, gilvis, tribus superioribus adscendentibus intermedio longissimo, duobus infcrioribus aqualibus deflexis. (Nob.)

Caulis hucusque pedalis diametro poll. 2 cum dimidio subglaucescens et lætissime virens. Costæ turgidæ, obtusissimæ. Pulvilli pollicem distantes, parvuli, grisei. Aculei subflexiles, pungentes, fulvido-gilvi, basi applanati, superiores 3 sursum tendentes, lateralibus brevioribus lin. 9, et intermedio sesquipollicem longis, inferiores 2 deflexi lin. 15 longi.

Advexit arno 1846 Dom. Bridges hanc præclaram speciem e Bolivia. Locus ei in ordinaiione Cereorum tribuendus est prope C. geometrizantem et C. Beneckei.

Descripción ampliada: Plantas erectas de $4 \mathrm{~m}$ de alto y ramificadas desde la base 0 a $1 \mathrm{~m}$ de altura. Ramas de 8-12 cm de diámetro. Costillas del ápice 6, obtusas, $2 \mathrm{~cm}$ de ancho, 1,5 mm de alto; areolas circulares, $4 \mathrm{~mm}$ de alto, $6 \mathrm{~mm}$ de ancho, con pilosidad gris y marrón-oscuro, con un surco en la parte superior; una espina central; espinas radiales 2-7, de 2 a $7 \mathrm{~cm}$ de largo, subaplanadas, $1 \mathrm{~mm}$ de ancho, ápice negro y base marrón. Costillas de la base 6-7, obtusas, $3 \mathrm{~cm}$ de ancho, $2,5 \mathrm{~cm}$ de alto; areolas de $2 \mathrm{~cm}$ de distancia entre ellas, circulares u ovadas, $2 \mathrm{~mm}$ de alto, 4-6 $\mathrm{mm}$ de ancho, con tomento gris y con un surco en la parte superior; espinas $2-4$, no hay diferencia entre radiales y ni centrales; solo dos superiores y dos inferiores, de 3-10 cm de largo, subaplanadas, 1,5 mm de diámetro, base negra y ápice marrón, otras totalmente color de vino tinto sin espinas la parte basal. Flores 3-8, apicales y subapicales, de $20 \mathrm{~cm}$ de largo, con abundante pilosidad marrón en el ovario y tubo floral; corola de $8 \mathrm{~cm}$ de diámetro (cuando abiertas); ovario $3 \mathrm{~cm}$ de ancho; tubo floral de $2 \mathrm{~cm}$ de ancho, escamas florales del pericarpelo de $3 \mathrm{~cm}$ de largo, verde con ápice marrón; escamas florales del tubo de 5-7 cm de largo, verde o verde-amarillento con ápice marrón; tépalos de 6-9 cm de longitud, amarilloverdoso o blanco-amarillento con ápice y líneas longitudinales marrón; estilo verde, $13 \mathrm{~cm}$ de largo; estigma con lóbulos amarillos, de 2,2 cm de longitud. Pseudobaya verde-oscuro, apical y subapical, 2-4 $\mathrm{cm}$ de alto, 3-5 cm de diámetro, recubierta por abundantes pelos marrones y grises, y cavidad ovárica con funículos blancos. Semillas negras, $1 \mathrm{~mm}$ de alto y 1,2 mm de ancho (Fig. 16). 


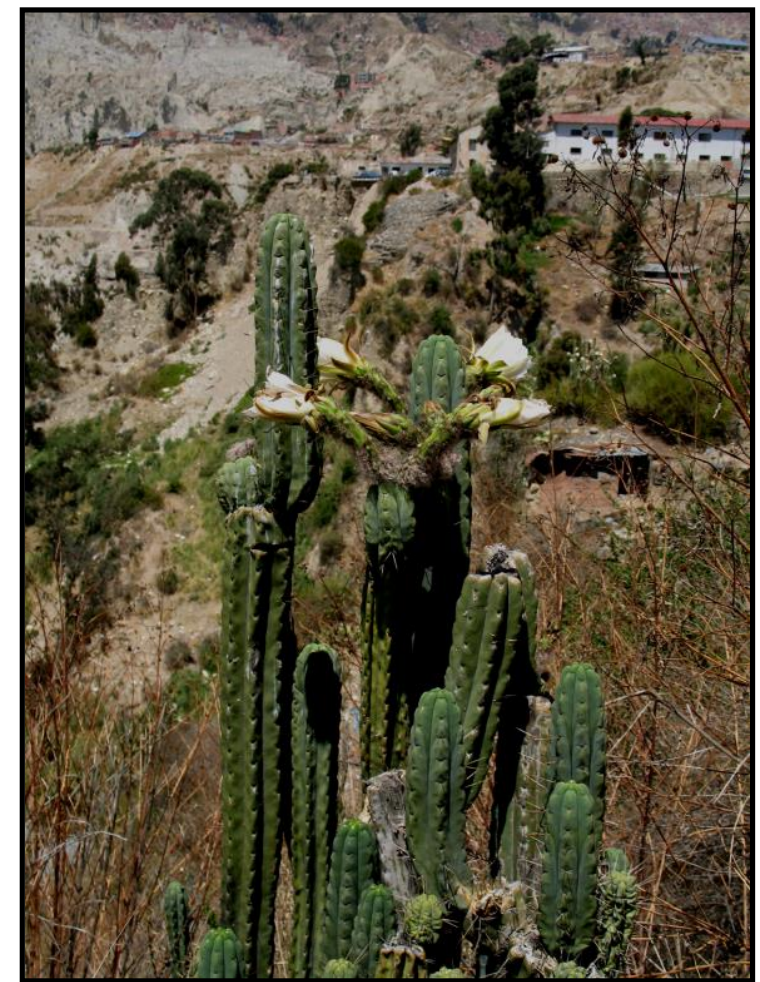

Figura 16. Trichocereus bridgesii. Bolivia, Municipio La Paz.

Distribución y hábitat: Endémica de Bolivia, donde se emplea como cerca viva (Borg 1937). Se localiza en los alrededores de la ciudad de La Paz (Fig. 74), y en bosques abiertos de Prosopis sp., Ephedra americana, Schinus molle y Oreocereus fossulatus, entre 2700-4500 m (Navarro 1996, Albesiano 2014).

Comentarios morfológicos y sus consecuencias en la taxonomía y nomenclatura: Se seleccionó el ejemplar J.C. Solomon 15576 (LPB) como Neotipo de Cereus bridgesii porque reúne las características mencionadas en la descripción original, el cual muestra un corte longitudinal y uno transversal del tallo, observandosé el número, ancho y alto de las costillas así como la cantidad, forma y longitud de las espinas, además se aprecia el largo, el ancho de la flor, la densidad de las escamas, pilosidad y el número de estigmas en tres flores.

Se eligió como Neotipo de Cereus lagenaeformis el ejemplar J.C. Solomon 9458 (LPB), porque agrupa los caracteres morfológicos nombrados de la descripción original, además presenta dos cortes del tallo, uno longitudinal y otro transversal, mostrando el número y el alto de las costillas, así como la cantidad, forma y longitud de las espinas, también se observa la forma y el largo de la flor, ancho del ovario, densidad de las escamas, pilosidad y número de estambres.

Se escogió el ejemplar R. Kiesling et al. 10031a (LPB) como Neotipo de Cereus bridgesii var. brevispina, debido a que reúne los caracteres morfológicos mencionados en la descripción original, y muestra dos cortes longitudinales y uno transversal del tallo, observando el número, ancho y alto de las 
costillas, cantidad, longitud y número de espinas, también se presentan dos cortes longitudinales de la flor; apreciando su forma, su longitud, ancho del ovario y tubo floral, densidad de las escamas y pilosidad.

Se seleccionó como Neotipo de Cereus bridgesii var. longispinus el ejemplar St. G. Beck 17906 (LPB), porque agrupa los caracteres morfológicos mencionados en la descripción original, además muestra dos cortes de tallo, uno longitudinal y otro transversal, y dos cortes longitudinales de flor, identificando los caracteres vegetativos y reproductivos de la variedad.

Trichocereus bridgesii se asemeja a Trichocereus macrogonus por el número de costillas (7) y la separación de las areolas $(2,5 \mathrm{~cm})$, pero se distingue a nivel molecular (trnL-F y rpl16) y morfológico por la disposición de las espinas (dos superiores y dos inferiores, no hay diferencia entre radiales y centrales), la cantidad (cuatro) y la forma (subaplanada) (Albesiano \& Terrazas 2012).

Material de Herbario estudiado: Bolivia, Dpto. La Paz, Prov. Murillo, Hacienda Huajchilla, ca. 13 Km SE de Calacoto, a lo largo del río La Paz, 3000 m, 30 Ene. 1983, J.C. Solomon 9458 (LPB); Mpio. La Paz, 4500 m, 18 Nov. 2008, S. Albesiano \& N. Quispe 2094 (LPB); Prov. Loayza, del desvío de Urmiri bajando 6 km hacia Sapahaqui, 3 Ene. 1991, St. G. Beck 17906 (LPB); Prov. Larecaja, Mpio. Sorata, 2700 m, 3 Nov. 2002, R. Kiesling et al. 10031a (LPB).

7. Trichocereus cabrerae R. Kiesling, Hickenia 1(6): 30. 1976.

Echinopsis cabrerae (R. Kiesling) G.D. Rowley, Repert. Pl. Succ. 27: 5. 1979. TIPO: Argentina, Prov. La Rioja, Dpto. Chilecito, de río Capayán a Chilecito, 26 Mar. 1976, R. Kiesling 1208 (Holotipo, SI 28584!)

Iconografías: Kiesling (1978), fig. 14: 310. Trevisson \& Perea (2009), foto 83: 122.

Descripción original de Trichocereus cabrerae R. Kiesling, Hickenia 1(6): 30. 1976:

Trichocereus cabrerae " nov. sp. Frutex ad $2 m$ altus, caulibus ascendentibus, ad basem solum ramosis, pallide viridibus; costis 15-18, obtusis; areolis eburneis valde lanosis, $0,6 \mathrm{~cm}$ altis $0,5 \mathrm{~cm}$ latis; aculeis radiantibus, \pm 10 , castaneis, irregulariter dispositis, $0.5-6 \mathrm{~cm}$ longis, majoribus retrorsis centralibus. Flores anguste campanulati $15-17 \mathrm{~cm}$ longi, $10 \mathrm{~cm}$ crassi, externe prasini, squamati, albido-lanosi; petalis candidis, mucronatis, spathulatis, $6,5 \mathrm{~cm}$ longis, $2,5 \mathrm{~cm}$ latis; staminibus biseriatis, prasinis, superioribus $3 \mathrm{~cm}$ longis, inferioribus $6-8 \mathrm{~cm}$ longis; stylo cilindrico, $16 \mathrm{~cm}$ longo, $3,5 \mathrm{~cm}$ crasso, flavovirente, 21 lobulato; lobulis subteretibus, papillosis, $2,5 \mathrm{~cm}$ longis, $0,1 \mathrm{~cm}$ crassis.

Fructus viridis, $\pm 4 \mathrm{~cm}$ crassus, globosus, meleo-lanosus; perianto sicco persistente.

Matas de hasta $2 \mathrm{~m}$ de alto y $3(-4)^{\prime} \mathrm{m}$ de diámetro. Raices superficiales, delgadas, muy ramificadas. Tallos solo ramificados en la base, ascendentes, con la zona rastrera breve $(10-40 \mathrm{~cm})$ y la erecta vertical de hasta $1,5-2 \mathrm{~m}$ de alto y $9-11 \mathrm{~cm}$ de diámetro, de color verde claro \pm vivo, luego opacandose. Costillas 17 (15-18) de $\pm 1 \mathrm{~cm}$ de alto y $1,3-2,3 \mathrm{~cm}$ de ancho, con borde redondeado y surco intercostal agudo. Areolas con abundante lanosidad color blanco amarillento, de $0,6 \mathrm{~cm}$ de altas y $0,5 \mathrm{~cm}$ de ancho, ovales, separadas $\pm 1,2 \mathrm{~cm}$. Espinas \pm 10 blandas, color castaño cuando jóvenes, luego decolorándose, de color amarillo opaco, de disposición irregular, rectas, dificilmente diferenciables en radiales y centrales; las periféricas pequeñas y delgadas: $0,5 \mathrm{~cm}$ de largo y $0,3 \mathrm{~mm}$ de diámetro; las más largas son reflexas de hasta $6 \mathrm{~cm}$ de largo y $0,5 \mathrm{~mm}$ de diámetro.

Flores laterales, naciendo del tercio superior de los tallos, estrechamente acampanadas, de $15-17 \mathrm{~cm}$ de largo $\mathrm{y} \pm 10 \mathrm{~cm}$ de diámetro cuando abiertas (18-20 cm de largo $\mathrm{y} \pm 6 \mathrm{~cm}$ de diámetro cuando cerradas). Pericarpelo y tubo 


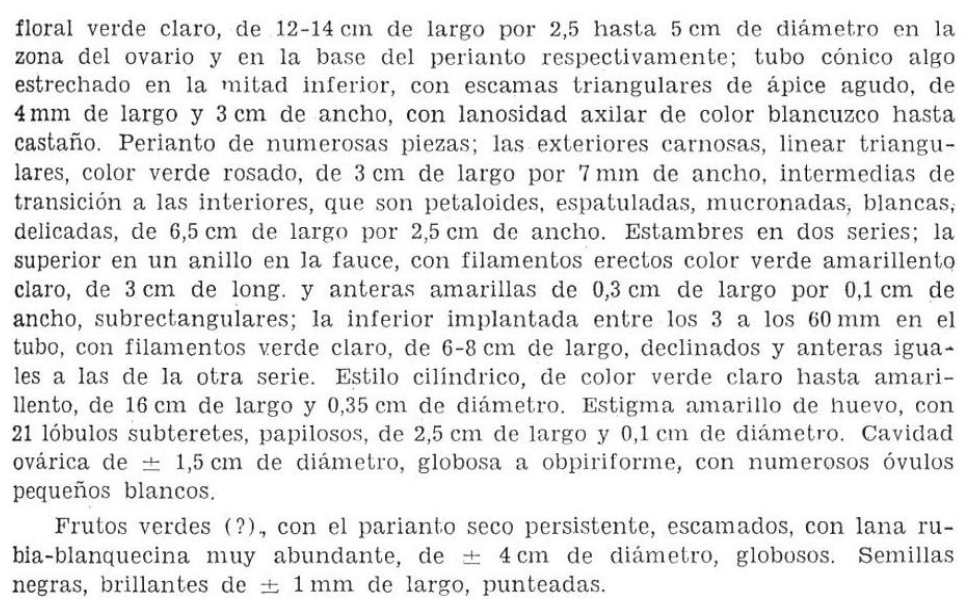

Descripción ampliada: Plantas ascendentes de $2 \mathrm{~m}$ de alto y 3-4 m de diámetro, con raíces superficiales y delgadas. Tallos ramificados desde la base, inicialmente rastreros $(10-40 \mathrm{~cm})$ y luego ascendentes (hasta 1,5-2,0 m de alto), 9-11 (-20) cm de diámetro, epidermis verde-claro tornándose opaca con la edad. Costillas 14-18 (-22), de $1 \mathrm{~cm}$ de alto, 1,3-2,3 cm de ancho, con bordes redondeados y surco intercostal agudo. Areolas de $6 \mathrm{~mm}$ de alto y $5 \mathrm{~mm}$ de ancho, ovales, separadas por 0,5-1,2 cm y con abundante pilosidad blanco-amarillenta. Espinas 10, aciculares, cuando jóvenes son castañas y cuando adultas amarillo-opaco, de disposición irregular y poco diferenciable entre radiales y centrales, las externas son pequeñas ( $5 \mathrm{~mm}$ de largo) y delgadas ( $0,3 \mathrm{~mm}$ de diámetro), las más largas son de $6 \mathrm{~cm}$ de largo y $0,5 \mathrm{~mm}$ de diámetro. Flores subapicales, cuando abiertas de $15-17 \mathrm{~cm}$ de largo y $10 \mathrm{~cm}$ de diámetro, cuando cerradas de $18-20 \mathrm{~cm}$ de largo y $6 \mathrm{~cm}$ de ancho; ovario y tubo floral de $12-14 \mathrm{~cm}$ de largo, 2,5 hasta $5 \mathrm{~cm}$ de diámetro en el ovario y en la base del perianto respectivamente, con escamas triangulares de $4 \mathrm{~mm}$ de ancho y $3 \mathrm{~cm}$ de largo, de cuyas axilas emergen abundantes pelos blancos hasta castaños; tépalos exteriores carnosos, linear triangulares, verde-rosado, $3 \mathrm{~cm}$ de largo y $7 \mathrm{~mm}$ de ancho; tépalos intermedios e internos petaloides, espatulados, mucronados, blancos, 6,5 $\mathrm{cm}$ de largo y 2,5 cm de ancho; estambres de la serie superior erectos, con filamentos verde-amarillento, $3 \mathrm{~cm}$ de largo, anteras subrectangulares, $3 \mathrm{~mm}$ de ancho, los de la serie inferior declinados, con filamentos verde-claro, 6-8 cm de largo; estilo verde-claro a amarillo, $16 \mathrm{~cm}$ de largo y 3,5 mm de diámetro; estigma amarillo con 21 lóbulos subteretes, papilosos, 2,5 cm de largo y $1 \mathrm{~mm}$ de diámetro. Pseudobayas externamente verdes, globosas, $4 \mathrm{~cm}$ de diámetro, con abundante pilosidad rubia-blanquecina. Semillas negras, brillantes, $1 \mathrm{~mm}$ de largo y punteadas (Fig. 17).

Florece desde finales de noviembre hasta enero, y los frutos están maduros desde finales de este último mes. 


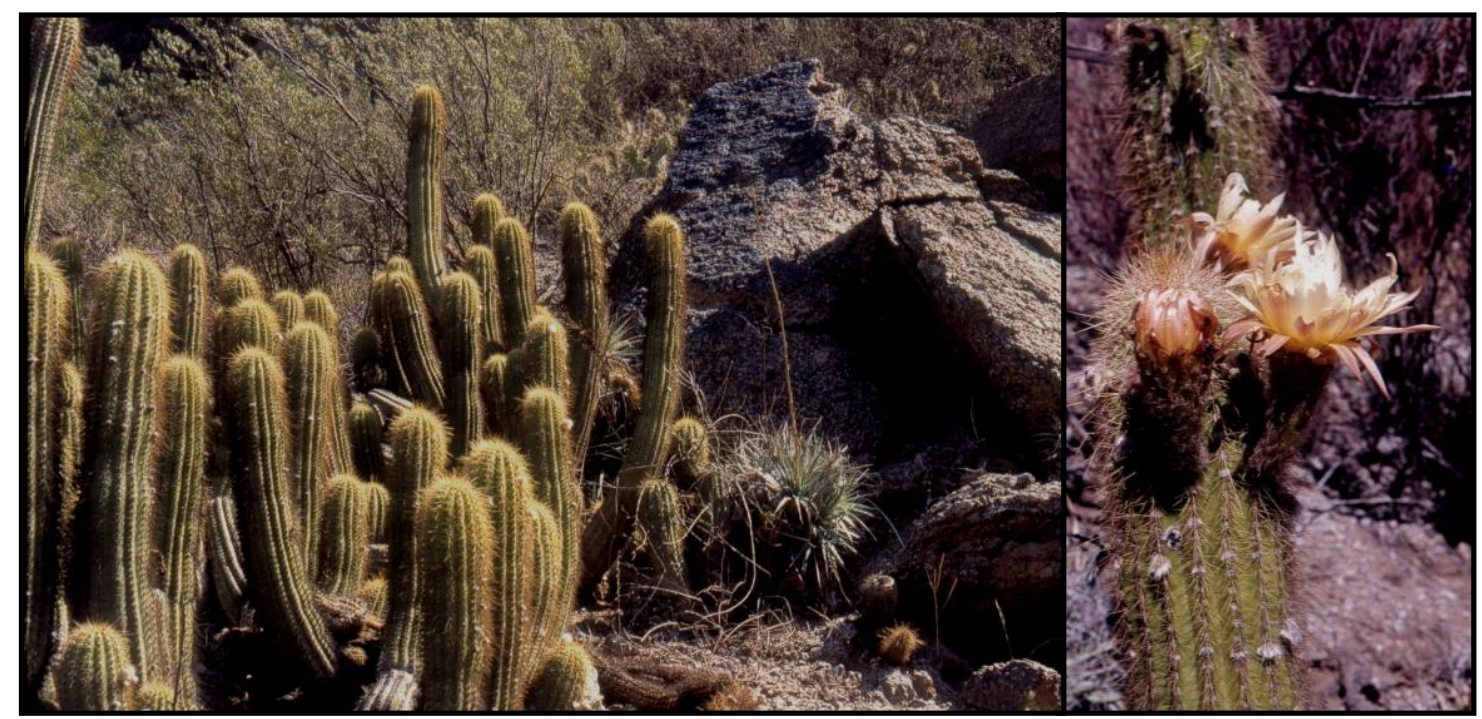

Figura 17. Trichocereus cabrerae. Argentina, Provincia La Rioja, entre Chilecito y Famatina.

Distribución y Hábitat: Endémica del oeste Argentino (Fig. 73), en las provincias de Catamarca, La Rioja y San Juan, entre 500 a 3500 m. En La Rioja se localiza entre Famatina, Chilecito y Mazán, siendo muy abundante al norte de Chilecito, hasta el límite con Catamarca, y al sur de esta última provincia. En San Juan se conoce de Valle Fértil, Ischigualasto (Kiesling 1978). Se encuentra en terrenos planos o inclinados, sobre suelos pedregosos, en ambientes muy secos y calurosos de bosques del Chaco Serrano y Monte (Trevisson \& Perea 2009).

Comentarios morfológicos y sus consecuencias en la taxonomía y nomenclatura: Según Kiesling (com. pers.), T. cabrerae con bastante seguridad puede considerarse de origen híbrido entre $T$. terscheckii y $T$. strigosus, apareciendo esporádicamente en lugares donde conviven las especies supuestamente parentales. Sin embargo, sus poblaciones son uniformes y con características propias (Tabla 6), por otro lado se pueden reproducir por sí mismas (parte de sus semillas son fértiles). También, se ha observado variaciones entre las poblaciones, por ejemplo, tépalos blancos 0 amarillos, tallos de diferente diámetro y coloración.

Tabla 6. Diferencias entre $T$. strigosus, $T$. cabrerae y $T$. terscheckii

\begin{tabular}{|l|l|l|l|}
\hline CARACTERES & T. strigosus & T. cabrerae & T. terscheckii \\
\hline Altura de las plantas & $60 \mathrm{~cm}$ & $2 \mathrm{~m}$ & $15 \mathrm{~m}$ \\
\hline Diámetro de las ramas & $5-7 \mathrm{~cm}$ & $9-11 \mathrm{~cm}$ & $24-27 \mathrm{~cm}$ \\
\hline Ancho de las costillas & $0,4-0,8 \mathrm{~cm}$ & $1,3-2,3 \mathrm{~cm}$ & $3,0-5,5 \mathrm{~cm}$ \\
\hline Distancia entre las areolas & $0,4-0,8 \mathrm{~cm}$ & $1,2 \mathrm{~cm}$ & $1,5-3,0 \mathrm{~cm}$ \\
\hline $\begin{array}{l}\text { Longitud de los estambres de la serie } \\
\text { superior }\end{array}$ & $3,7 \mathrm{~cm}$ & $3 \mathrm{~cm}$ & $2 \mathrm{~cm}$ \\
\hline
\end{tabular}


Material de Herbario estudiado: Argentina, Prov. Catamarca, Dpto. Andalgalá, $9 \mathrm{Km} \mathrm{SE}$ of Andalgalá, via the road to Cuesta de la Chilca, 1010 m, 7 Nov. 1972, P. Cantino 416 (CORD); entre Poman y Mazan, 13 Nov. 1975, R. Kiesling 1087 (SI); Dpto. Andalgalá, río Chañarcito, Nov. 1975, R. Kiesling 1111 (MERL 56238, SI). Prov. La Rioja, Los Sarmientos, cerca Chilecito, Mar. 1879, G. Hieronymus \& G. Niederlein 848 (CORD); cruce entre Famatina y Chilecito, 21 Ene. 2007, S. Albesiano et al. 2032 a y b (MERL 58794, 58802).

8. Trichocereus camarguensis Cárdenas, Revista Agric. (Cochabamba) 8: 17, ill. 1953.

Echinopsis camarguensis (Cárdenas) H. Friedrich \& G.D. Rowley, I.O.S. Bull. 3(3): 94.1974. TIPO: Bolivia, Dpto. Chuquisaca, Prov. Nor Cinti, Mpio. Camargo, 2500 m, M. Cárdenas 5041 (Holotipo, LIL 531596!).

Trichocereus caulescens F. Ritter, Cactus (Paris) No. 87: 11. 1966. Echinopsis caulescens (F. Ritter) M. Lowry, Cactaceae Syst. Init. 14: 13. 2002. Soehrensia caulescens (F. Ritter) Schlumpb., Cactaceae Syst. Init. 28: 30. 2012. Trichocereus camarguensis Cárdenas subsp. caulescens (F. Ritter) Guiggi, Cactology 3: 5. 2012. TIPO: Bolivia, Prov. Tarija, Tarija No. 9, [1931] F. Ritter 73 (Holotipo, U "no visto"; Isotipo, SGO 121160!)

Trichocereus cajasensis F. Ritter, Kakt. Südamer. 2: 566. 1980, nom. inval., falta la diagnosis en latín (Art. 39.1).

Iconografías: Ritter (1980a), foto 454: 766. Hunt et al. (2006), Fig. 3: 232.

Descripción original de Trichocereus camarguensis Cárdenas, Revista Agric. (Cochabamba) 8: 17. 1953:

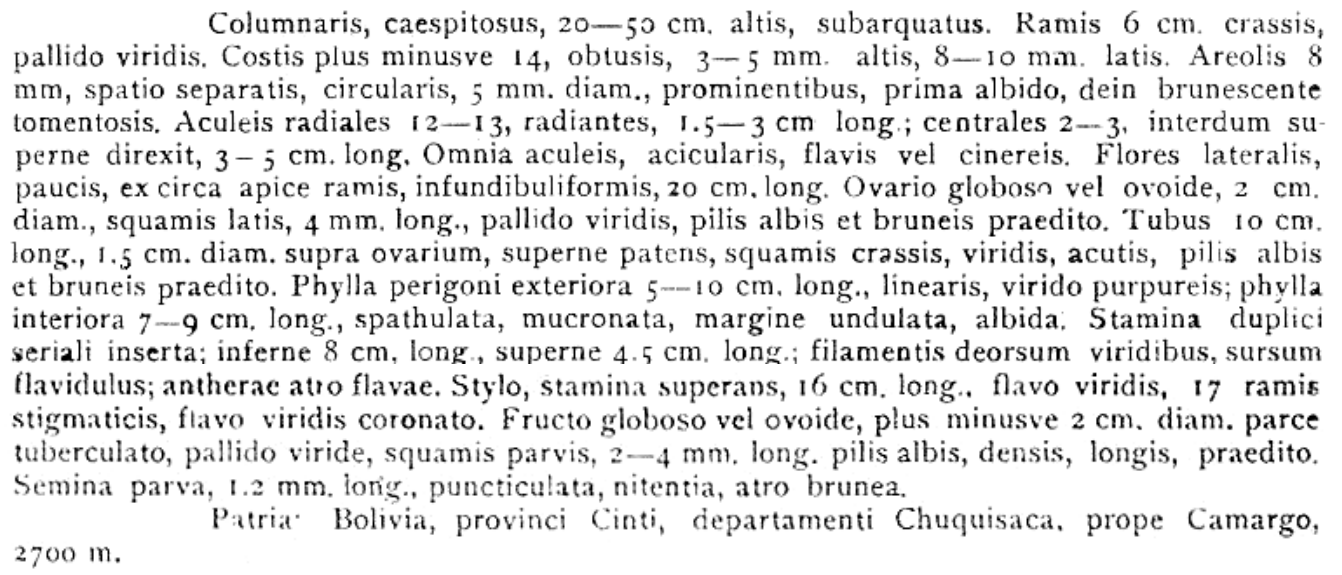


Descripción ampliada: Plantas de $60 \mathrm{~cm}$ de alto. Tallos ascendentes, cilíndricos, $5 \mathrm{~cm}$ de diámetro. Costillas del ápice obtusas, 12, de $7 \mathrm{~mm}$ de ancho, $3 \mathrm{~mm}$ de alto; areolas circulares, $1 \mathrm{~mm}$ de alto, $3 \mathrm{~mm}$ de ancho, pilosidad amarilla; una espina central, acicular, 1,1 cm de largo, blanca con ápice negro, perpendicular al tallo; espinas radiales 9 , aciculares, $1 \mathrm{~cm}$ de largo, blancas y dirigidas hacia el tallo. Costillas de la base 13, obtusas, $2,8 \mathrm{~cm}$ de ancho, $5 \mathrm{~mm}$ de alto, areolas circulares, $1 \mathrm{~mm}$ de alto, 3 $\mathrm{mm}$ de ancho, pilosidad amarilla; una espina central, acicular, 1,1 cm de largo, blanca con ápice negro, perpendicular al tallo; espinas radiales 9 , aciculares, $1 \mathrm{~cm}$ de largo, blancas y dirigidas hacia el tallo. Flores subapicales 2, con pilosidad crema o marrón en el ovario y tubo floral, $17 \mathrm{~cm}$ de largo; corola $8 \mathrm{~cm}$ de diámetro (cuando abiertas); ovario y tubo floral de $2 \mathrm{~cm}$ y $2,5 \mathrm{~cm}$ de ancho respectivamente; escamas florales del pericarpelo verde-oscuro, escamas florales de tubo verdes, tépalos amarillo-crema, los externos de 5,5 cm de largo, intermedios de 7,5 cm de longitud e internos de $6 \mathrm{~cm}$ de largo; estilo $13,5 \mathrm{~cm}$ de largo; estigma con lóbulos de $2 \mathrm{~cm}$ de longitud (Fig. 18).

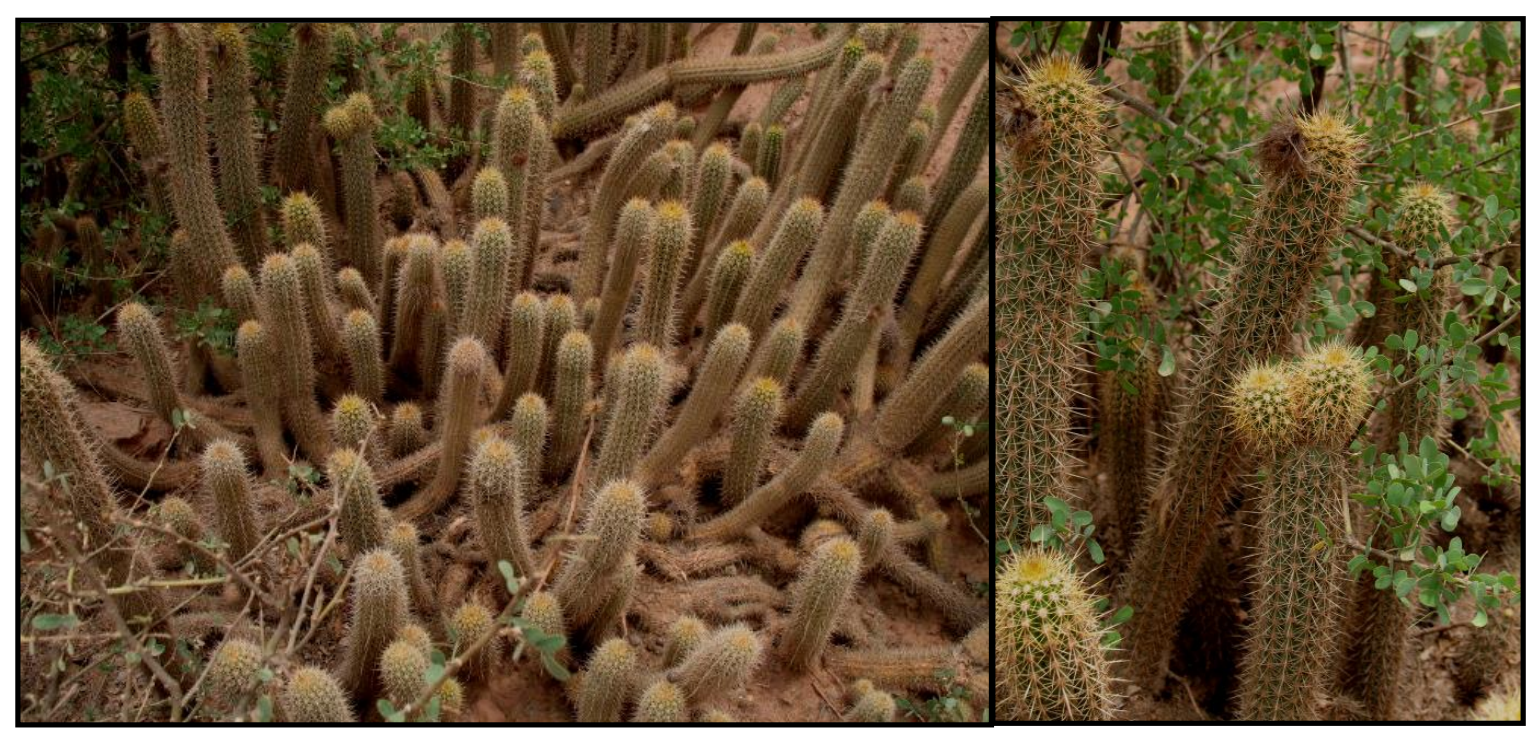

Figura 18. Trichocereus camarguensis. Bolivia, Dpto. de Tarija, a la entrada del municipio de Camargo.

Distribución y hábitat: Se localiza al sur de Bolivia, en el departamento de Tarija, en la provincia fitogeográfica prepuneña (Fig. 74), caracterizada por un clima mesotropical semiárido a seco, en áreas perturbadas de matorrales xerofíticos, en suelos arcillosos rojos (Cárdenas 1953a, Cabrera \& Willink 1980, Navarro 1996, Albesiano 2014). 
Comentarios taxonómicos y nomenclaturales: Según Eggli et al. (1996), Ritter publicó provisionalmente el nombre $T$. cajasensis, por tal razón no menciona una diagnosis en latín.

Material de Herbario estudiado: Bolivia, Dpto de Chuquisaca, a la entrada del municipio de Camargo, 17 Dic. 2009, S. Albesiano et al. 2079 (MERL).

9. Trichocereus candicans (Gillies ex Salm-Dyck) Britton \& Rose, The Cactaceae 2: 142, ill. 1920.

Cereus candicans Gillies ex Salm-Dyck, Hort. Dyck: 335. 1834. Echinocactus candicans (Gillies ex Salm-Dyck) hort. ex Pfeiffer, Enum. Diagn. Cact: 91. 1837. Echinocereus candicans (Gillies ex SalmDyck) Lem. ex Rümpler, Handb. Cacteenk., ed. 2: 832. 1885. Echinopsis candicans (Gillies ex Salm-Dyck) F.A.C. Weber (pro syn.) ex D.R. Hunt, Bradleya 5: 92. 1987. Soehrensia candicans (Gillies ex Salm-Dyck) Schlumpb., Cactaceae Syst. Init:: 28: 30. 2012.

Cereus candicans Gillies ex Salm-Dyck var. tenuispinus Pfeiff., Enum. Diagn. Cact: 91. 1837. Tipo no designado. Cereus candicans Gillies ex Salm-Dyck var. tenuispinus Gay, Fl. Chil. (Gay) 3: 21. 1848 (nom. illeg., por superfluo, Art. 52.1) Trichocereus candicans (Gillies ex Salm-Dyck ) Britton \& Rose var. tenuispinus (Pfeiff.) Backeb., Cactus (Paris) 41: 107. 1954. "Echinopsis candicans (Salm-Dyck) F.A.C. Weber" (sic) var. tenuispina (Pfeiff.) H. Friedrich \& G.D. Rowley, I.O.S. Bull. 3(3): 94. 1974. TIPO: Argentina, Prov. San Juan, Dpto. Ullúm, 10 Feb. 2000, R. Kiesling, A.F. Wulff \& T.S. Tombesi 9450 (Neotipo, SI, aquí designado).

Cereus candicans Gillies ex Salm-Dyck var. robustior Salm-Dyck, Cact. Hort. Dyck 1849: 43. 1850. Tipo no designado. Cereus candicans Gillies ex Salm-Dyck f. robustior (Salm-Dyck) K. Schum., Gesamtbeschr. Kakt.: 70. 1897. Cereus candicans Gillies ex Salm-Dyck f. robustior (Salm-Dyck) Schelle, Handb. Kakteenkult. 66. 1907 (nom. illeg., por superfluo, Art. 52.1). Trichocereus candicans (Gillies ex Salm-Dyck) Britton \& Rose var. robustior (Salm-Dyck) Borg, Cacti: Gard. Hand. Ident. Cult.: 140. 1937. TIPO: Argentina, Prov. San Juan, Dpto. Iglesia, de la Ciénaga a Iglesia, Nov. 1975, R. Kiesling 1074 (Neotipo, Sl, aquí designado).

Cereus gladiatus Lem., Cact. Aliq. Nov.: 28. 1838. Tipo no designado. Cereus candicans Gillies ex Salm-Dyck var. gladiatus (Lem.) K. Schum., Gesamtbeschr. Kakt.: 70. 1897. Cereus candicans Gillies ex Salm-Dyck f. gladiatus (Lem.) Schelle, Handb. Kakteenkult. 66. 1907. Trichocereus gladiatus (Lem.) Frič, Mollers Deutsch. Gartner-Zeit. XLVII: 421. 1932. Trichocereus gladiatus (Lem.) Backeb., Backeb. \& F.M. Knuth, Kaktus-ABC: 202. (1935) 1936 (nom. illeg., por superfluo, Art. 52.1). Trichocereus candicans (Gillies ex Salm-Dyck ) Britton \& Rose var. gladiatus (Lem.) A. Berger ex Castellanos, Rev. Fac. Ciencias Agrarias (Mendoza) 6 (2): 263. 1957. "Echinopsis candicans (Gillies ex Salm-Dyck) F.A.C. Weber" (sic) var. gladiata (Lem.) H. Friedrich \& G.D. Rowley, I.O.S. Bull. 3(3): 94. 1974. Trichocereus candicans 
(Gillies ex Salm-Dyck) Britton \& Rose var. gladiatus (Lem.) Y. Itô, Cactaceae (Itô): 161.1981 (nom. illeg., por superfluo, Art. 52.1). TIPO: Argentina, Prov. La Pampa, Lihuel Calel, 18 Feb. 1948, A. Burkart 15966 (Neotipo, $\mathrm{Sl}$, aquí designado).

Cereus nitens Salm-Dyck ex Otto \& Dietr., Allg. Gartenzeit. 13: 354. 1845. Tipo no designado. Trichocereus candicans (Gillies ex Salm-Dyck ) Britton \& Rose var. nitens (Salm-Dyck ex Otto \& Dietr.) F. Ritter, Kakteen Südamerika 2: 443. 1980 (error en la página del basónimo). TIPO: Argentina, Prov. Córdoba, San Carlos, 25 Oct. 1974, R. Kiesling 808 (Neotipo, LP, aquí designado).

Cereus candicans Gillies ex Salm-Dyck var. dumesnilianus Zeiss, Monatsschr. Kakteenk. 3: 140. 1893, nom. nud.

Cereus candicans Gillies ex Salm-Dyck var. courantii K. Schum., Gesamtbeschr. Kakt. 70. 1897. Cereus candicans Gillies ex Salm-Dyck f. courantii (K. Schum.) Schelle, Handb. Kakteenkult. 66. 1907. Trichocereus candicans (Gillies ex Salm-Dyck) Britton \& Rose var. courantii (K. Schum.) Borg, Cacti: Gard. Hand. Ident. Cult:: 140. 1937. Trichocereus candicans (Gillies ex Salm-Dyck) Britton \& Rose var. courantii (K. Schum.) A. Castellanos, Rev. Fac. Cs. Agrarias (Mendoza) 6(2): 263. 1957 (nom. illeg., por superfluo, Art. 52.1). Trichocereus courantii (K. Schum.) Backeb., Cactus (Paris) 41: 107. 1954. Echinopsis courantii (K. Schum.) H. Friedrich \& G.D. Rowley, I.O.S. Bull. 3(3): 95. 1974.

Cereus lamprochlorus Lem. var. salinicola Speg., Anales Mus. Nac. Buenos Aires 7: 286. 1902. TIPO: Argentina, Prov. Buenos Aires, Dpto. Bahía Blanca, no propiamente Bahía Blanca, 17 Feb. 1902, C. Spegazzini s.n. [LP ex LPS 23021 [Lectotipo, LP, designado por Kiesling, Darwiniana 21 (2-4): 323. 1978, ver Katinas et al. 2004].

Iconografías: Hunt et al. (2006), fig. 1: 233. Kiesling \& Ferrari (2005), foto 47: 63. Trevisson \& Demaio (2006): 65. Trevisson \& Perea (2009), foto 84: 123.

Descripción original de Cereus candicans Gillies ex Salm-Dyck, Hort. Dyck: 335. 1834:

(Cereus candicans Gillies.) C. erectus, pallide-virens 9 angularis, costis latis obtusis; aculeis ex. areola lata albidotomentosa stramineis, exterioribus 9-10 radiantibus, centralibus 4 validioribus, infimo validissimo.

Caulis crassus nitidus, apice omnino glaber. Hucusque vir semipedalis.

Distribución y hábitat: Endémica de la Argentina (Fig. 73) y abundante en la provincia del Monte en San Juan y Mendoza, existiendo también en las provincias de La Rioja, Córdoba, San Luis, La Pampa y sur de Buenos Aires, en Espinal, Chaqueña y del Monte, entre 500 a 2500 m de altitud (Kiesling 1978). 


\section{Comentarios morfológicos y sus consecuencias en la taxonomía y nomenclatura: Se eligió}

como Neotipo de Cereus candicans var. tenuispinus el ejemplar R. Kiesling et al. 9450 (SI), debido a que reúne los caracteres morfológicos mencionados en la descripción original, y presenta dos cortes longitudinales del tallo, observandosé el número, forma y tamaño de las espinas radiales y centrales, también un corte longitud de una flor, en la que se aprecia su tamaño, densidad de las escamas, cantidad de pilosidad y número de estigmas.

Se escogió el ejemplar R. Kiesling 1074 (SI) como Neotipo de Cereus candicans var. robustior por ser el más cercano a la descripción original, además muestra tres cortes transversales del tallo, uno de ellos corresponde al ápice, identificando el número, longitud y forma de las espinas, así como la cantidad de costillas, también, tres cortes longitudinales de la flor, donde se aprecia la forma, tamaño, diámetro del ovario, densidad de las escamas, pilosidad así como el androceo y pistilo.

Se seleccionó como Neotipo el ejemplar A. Burkart 15966 (SI) de Cereus gladiatus debido a que reúne los caracteres morfológicos mencionados en la descripción original, y presenta dos cortes, transversal y longitudinal del tallo, apreciandosé la cantidad de costillas y espinas, al igual que la forma y longitud de estas últimas.

Se escogió el ejemplar R. Kiesling 808 (LP) como Neotipo de Cereus nitens porque agrupa los caracteres morfológicos nombrados en la descripción original, además se muestra un corte longitudinal y uno transversal del tallo al igual que de la flor, identificando los caracteres vegetativos y reproductivos de la especie.

Cereus candicans ha sido transferida a los géneros Echinocactus, Echinocereus, Echinopsis, Soehrensia y Trichocereus. Del análisis cladístico del género Trichocereus con base en caracteres morfológicos y moleculares (Albesiano \& Terrazas 2012), resultó que esta especie corresponde al género Trichocereus, y se encuentra relacionada con $T$. pectiniferus, $T$. spinibarbis y $T$. deserticola al compartir las siguientes tres homoplasias: ramas cuya longitud no es superior de un metro, receptáculo a la altura del ovario de $2,5 \mathrm{~cm}$ de ancho y paredes anticlinales de las células de la testa en forma de $\mathrm{S}$.

Según Schlumpberger y Renner (2012), basados en tres secuencias de marcadores de cloroplasto (trnS-G, trnL y rp/16), T. candicans y $T$. lamprochlorus son especies hermanas. Morfológicamente son similares por sus areolas grandes, con abundante pilosidad blanca y tépalos blancos, pero estas dos especies se diferencian por varios caracteres vegetativos (Tabla 7). 
Tabla 7. Diferencias entre $T$. candicans y $T$. lamprochlorus

\begin{tabular}{|l|l|l|}
\hline CARACTERES & T. candicans & T. lamprochlorus \\
\hline Diámetro de los tallos & $12 \mathrm{~cm}$ & Menores de $10 \mathrm{~cm}$ \\
\hline Color de los tallos & Verde-opaco & Verde-brillante \\
\hline No. costillas & $8-9(-11)$ & $11-15$ \\
\hline Areolas sobresalientes & No & Sí \\
\hline Longitud de las espinas & $4 \mathrm{~cm}$ & $0,3-1 \mathrm{~cm}$ \\
\hline
\end{tabular}

Trichocereus candicans y Trichocereus strigosus forman híbridos, Trichocereus xmendocinus Méndez, cuyas semillas en condiciones de laboratorio tienen un porcentaje de viabilidad del $52 \%$ y los granos de polen de $54,2 \%$. Trichocereus xmendocinus solo ha sido encontrado en los cerros de la Puntilla en Mendoza, el cual se reproduce por semillas y agámicamente. (Méndez 2000). (Observado en: Cerros de la Puntilla, 500 m, 9 Oct. 2008, S. Albesiano 2037 [MERL]).

Trichocereus pseudocandicans es parecido a Trichocereus candicans por la altura de las plantas $(1 \mathrm{~m})$, forma cilíndrica de los tallos, areolas con abundante tomento blanco, y separadas entre sí por $2 \mathrm{~cm}$, etc., por lo que se propone a T. pseudocandicans como subespecie de esta última.

\section{Clave para la identificación de las subespecies de Trichocereus candicans}

1. Espinas subuladas, costillas 9 , tépalos internos blanco-níveo subsp. candicans

1'. Espinas aciculares, costillas 11-13, tépalos internos de colores varios, raro blanco o crema, pero nunca blanco niveo subsp. pseudocandicans

10. Trichocereus candicans (Gillies ex Salm-Dyck ) Britton \& Rose subsp. candicans

TIPO: Argentina, Mendoza? Oct. 1823, Gillies s.n. (Neotipo, "Cactus candidus", K, designado por Hunt \& Taylor, Cactaceae Syst. Init.: 23: 7. 2006).

Iconografías: Kiesling \& Meglioli (2003), fig. 190: 193; foto: 256. Anderson (2005): 222. Lambert (2010), fig. 252: 306.

Descripción ampliada: Plantas ascendentes, de 1 a $3 \mathrm{~m}$ de diámetro. Tallos de 25-60 cm de alto, $12-16 \mathrm{~cm}$ de diámetro, cilíndricos, ascendentes, verde-pálido. Costillas del ápice 9 , obtusas, 2-3 cm de ancho, $1 \mathrm{~cm}$ de alto; con areolas redondas, $5 \mathrm{~mm}$ de alto y $1 \mathrm{~cm}$ de ancho, con tomento blanco, grisclaro y oscuro; espinas centrales 4, dispuestas en cruz, 2,5-6,0 cm de largo, 1-2 mm de diámetro, 
subuladas, rectas o ligeramente arqueadas, amarillas con base marrón y luego gris; espinas radiales 13, de 0,7-4,5 cm de largo, $1 \mathrm{~mm}$ de diámetro, amarillas con base marrón. Costillas de la base 8-9, obtusas, $2,8 \mathrm{~cm}$ de ancho y $1,8 \mathrm{~cm}$ de alto, con areolas circulares, $2 \mathrm{~mm}$ de alto y $1 \mathrm{~cm}$ de ancho, con tomento gris-oscuro, 3-5 cm de distancia entre ellas; con 4 espinas centrales, $4 \mathrm{~cm}$ de largo y $1 \mathrm{~mm}$ de diámetro, subuladas, marrones; espinas radiales 11 , de 1,7-3 cm de largo, subuladas, $1 \mathrm{~mm}$ de diámetro, amarillas. Flores generalmente subapicales, $18-23 \mathrm{~cm}$ de largo, 8-19 cm de diámetro, apenas aromáticas, con abundante pilosidad marrón-claro, 1 a $2 \mathrm{~cm}$ de longitud en el ovario y tubo floral; ovario y tubo floral de 2,5-2,6 cm de ancho; escamas florales de 0,7 a $2 \mathrm{~cm}$ de largo, 4-8 $\mathrm{mm}$ de ancho, verde 0 verdeamarillento con ápice marrón; tépalos externos linear-lanceolados, 5-8 cm de longitud, $1 \mathrm{~cm}$ de ancho en la base, verdes con la base rojiza, tépalos intermedios rosados, internos blancos, espatulados, $7 \mathrm{~cm}$ de largo, $3 \mathrm{~cm}$ de ancho, mucronados; estambres superiores con filamentos de $3 \mathrm{~cm}$ de longitud y $1 \mathrm{~mm}$ de diámetro, blancos; anteras de 2,5 mm de largo, 1,5 mm de ancho, amarillas; estambres inferiores con filamentos blanco-verdosos, $8 \mathrm{~cm}$ de longitud, $1 \mathrm{~mm}$ de diámetro; cámara nectarial de $1 \mathrm{~mm}$ de largo, blanco-verdosa; estilo de $17 \mathrm{~cm}$ de longitud, 0,6 cm de diámetro, blanco-amarillento; estigma con 17-20 lóbulos, de 1,2-1,7 cm de largo y 1,5-2,0 mm de diámetro, amarillos. Pseudobaya mayormente lateral, de dehiscencia longitudinal, $7 \mathrm{~cm}$ de largo, 5-7 cm de diámetro; parte externa amarilla tornándose rosada, 6 $\mathrm{mm}$ de espesor, cavidad ovárica rellena de funículos carnosos, blancos, de $2 \mathrm{~cm}$ de diámetro. Semillas de $1,5 \mathrm{~mm}$ de largo, $1 \mathrm{~mm}$ de alto y $0,7 \mathrm{~mm}$ de ancho; testa con células hexagonales, verrugosas, con estrías transversales en la zona de contacto.

Florece entre octubre y febrero y sus frutos maduran entre diciembre y marzo (Fig. 19). La floracion y fructificación de esta especie evidentemente depende de la disponibilidad de agua, ya que luego de épocas secas se demora la floración o incluso no florecen (obs. personal, en Mendoza).

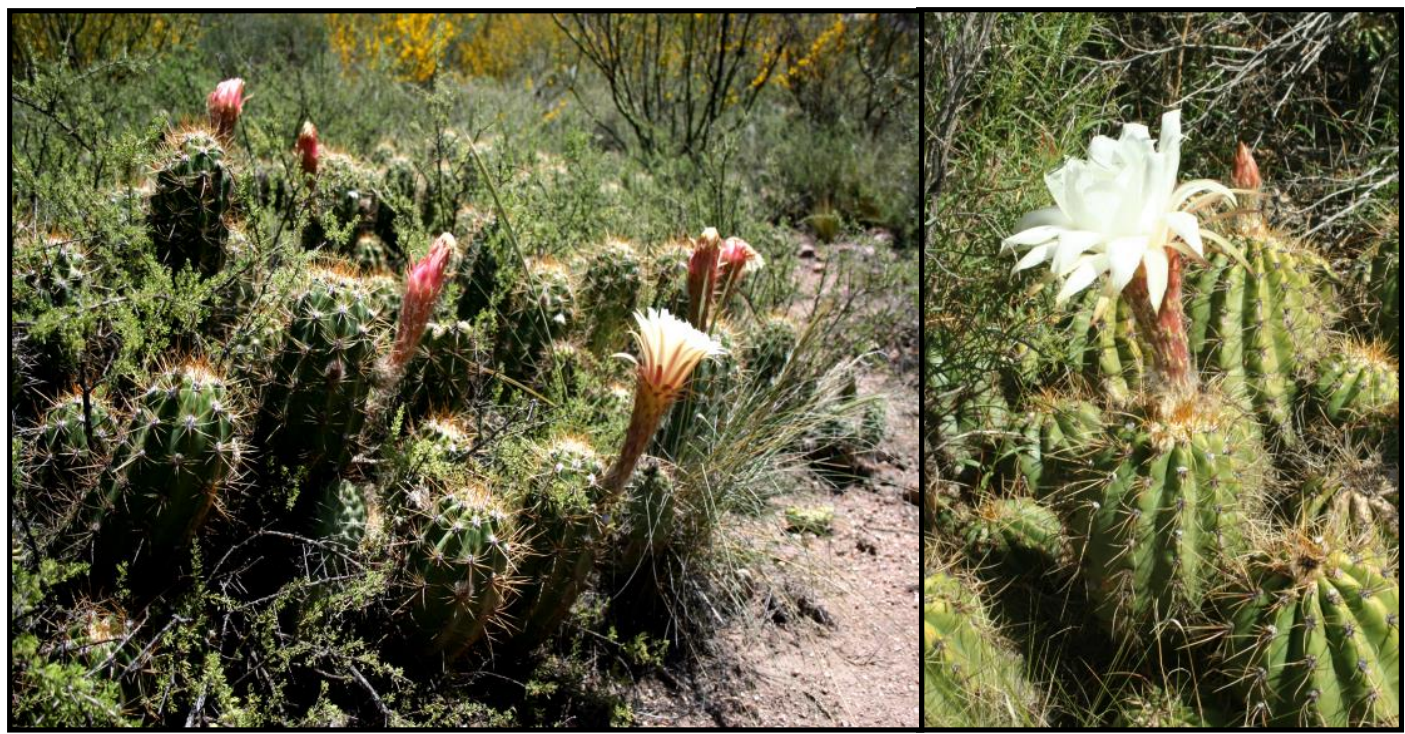

Figura 19. Trichocereus candicans subsp. candicans. Argentina, Provincia de Mendoza, cerca de la ciudad de Mendoza. 
Comentarios nomenclaturales: El ejemplar tipo de T. candicans designado por Hunt \& Taylor (Cactaceae Syst. Init.: 23: 7. 2006), no corresponde a un lectotipo sino a un neotipo, porque dicho ejemplar no se menciona en la descripción original ni tiene la anotación del autor. Por otro lado, se duda que Salm-Dyck haya visto el ejemplar de Gilles, porque él tenía plantas de $T$. candicans en su jardín de Alemania, las cuales sirvieron para describir esta especie (com. pers. R. Kiesling).

Material de Herbario estudiado: Argentina, Prov. Córdoba, Dpto. Capital, 25 Abr. 1899, Stuckert 23007 (LP); ibídem, Qda. Las Rosas, 1 Abr. 1965, R. Subils et al. s.n. (CORD 1116); Dpto. Santa María, cerros vecinos al Dique José de la Quintana, 19 Nov. 1966, R. Subils \& A. Maspero s.n. (CORD 691); San Carlos, 25 Oct. 1974, R. Kiesling 808 (LP). Prov. Mendoza, Dpto. Capital, near anfiteatro at foot of Cerro de la Gloria just outside city of Mendoza, 900 m, 8 Ene. 1995, B.E. Leuenberger et al. 4446 (CORD); Dpto. Las Heras, cerca al Cerro de la Gloria, Dic. 1931, A. Ruiz-L. 2583 (MERL); ibidem, 24 Dic. 1937, A. Ruiz-L. 4720 (MERL); ibidem, 22 Nov. 1948, A. Ruiz-L. 12020, 12027 (MERL); ibidem, 9 Nov. 1960, A. Ruiz-L. 21608 (MERL); Dpto. Luján, Chacras de Coria, Mar. 1959, A. Ruiz-L. 21609 (MERL); Potrerillos, Vallecitos, 21 Nov. 1991, I. Peralta (MERL 52608); oeste de Potrerillos, 1650 m, 4 Feb. 2007, S. Albesiano \& R. Kiesling 2036 (MERL 58796). Prov. La Pampa, Dpto. Lihuel Calel, Cerros, 18 Feb. 1948, A. Burkart 15966 (SI). Prov. La Rioja, 2 Mar. 1967, R. Kiesling 9 (LP); cruce entre Famatina y Chilecito, 21 Ene. 2007, S. Albesiano et al. 2029 (MERL 58799); Dpto. Chilecito, oeste de Chilecito, 275 m, 26 Oct. 2006, B. O. Schlumpberger 406 (CORD). Prov. San Juan, Dpto. Iglesia, de la Ciénaga a Iglesia, Nov. 1975, R. Kiesling 1074 (SI); Ischigualasto, 10 May. 1986, E. Ezcurra \& C. Montaña s.n. (MERL 47181).

11. Trichocereus candicans (Gillies ex Salm-Dyck) Britton \& Rose subsp. pseudocandicans (R. Kiesling) Albesiano, comb. et stat. nov.

Trichocereus pseudocandicans R. Kiesling, Hickenia 1(6): 32. 1976. Helianthocereus pseudocandicans Backeb., Kakteenlexikon 187. 1966; nom. inval., por no designar tipo (Art. 40.1). Echinopsis pseudocandicans (Backeb. ex R. Kiesling) Friedrich \& Glaetzle, Bradleya 1: 96. 1983. Trichocereus candicans subsp. pseudocandicans (Backeb.) J. Lodé, Cact.-Avent. Int. No. 97: 2. 2013; nom. inval., por basarse en un nombre invalido. TIPO: Argentina, Prov. La Rioja, Dpto. Famatina, 16 Km al norte de Chilecito, 26 Oct. 1974, R. Kiesling 807 (Neotipo, LP! designado por Kiesling: 33. 1976).

Trichocereus candicans (Gillies ex Salm-Dyck) Britton \& Rose var. roseoflorus Backeb., Descr. Cact. Nov. 3: 15. 1963, nom. inval., por no designar tipo (Art. 40.1). Helianthocereus pseudocandicans Backeb. var. roseoflorus (Backeb.) Backeb., Kakteenlexikon 187, ill. 1966, comb. inval.

Helianthocereus pseudocandicans Backeb. var. flaviflorus Backeb., Kakteenlexikon 187. 1966, nom. inval., por no designar tipo (Art. 40.1). 
Trichocereus candicans (Gillies ex Salm-Dyck) Britton \& Rose f. rubriflorus F. Ritter, Kakteen Südamerika 2: 440, ill. 1980. TIPO: Argentina, Prov. La Rioja, Famatina, F. Ritter 8a (Holotipo U; Isotipo, SGO 121207!)

Iconografías: Ritter (1980a), foto 298: 726. Kiesling (1978), fig. 17: 319. Trevisson \& Perea (2009), foto 86: 125.

Descripción original de Trichocereus pseudocandicans R. Kiesling, Hickenia 1(6): 32. 1976:

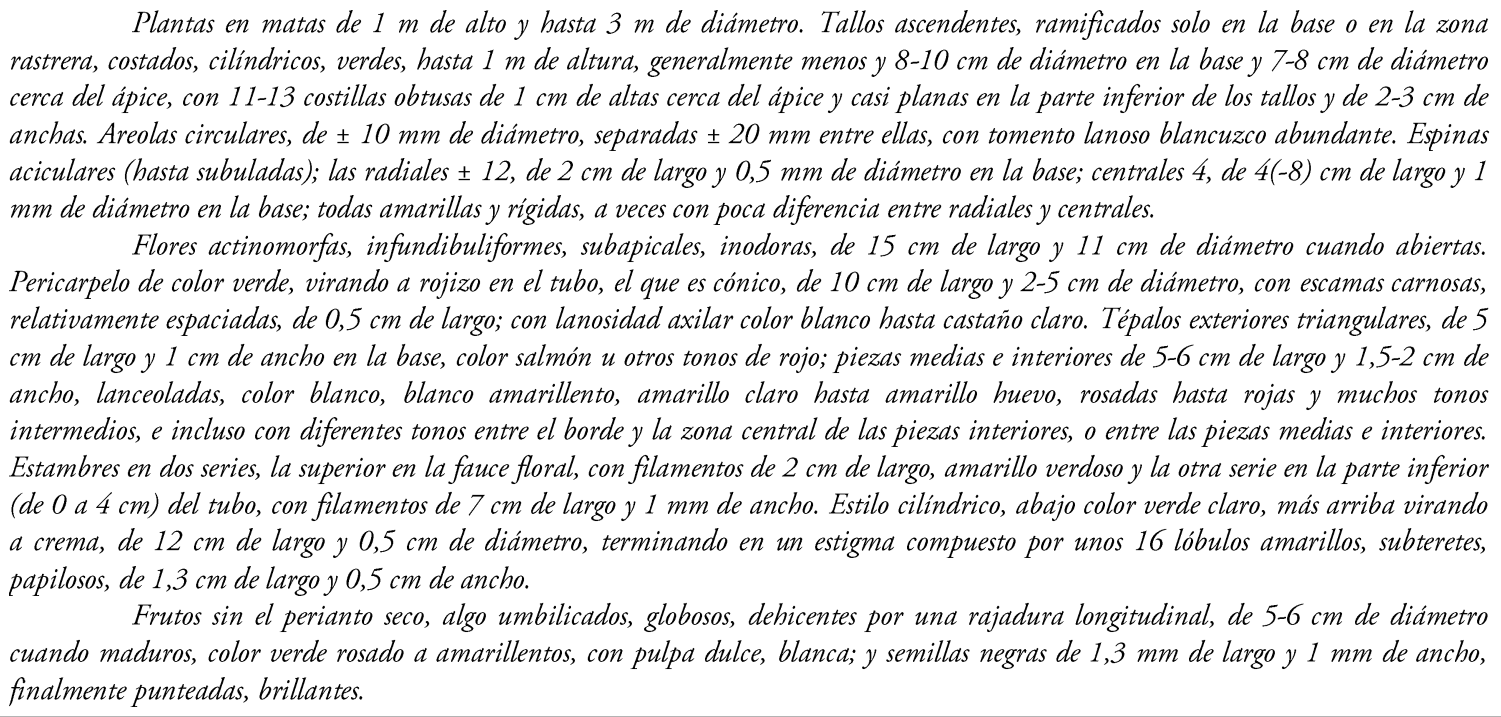

Descripción ampliada: Plantas ascendentes, hasta $3 \mathrm{~m}$ de diámetro. Tallos de 60-100 cm de alto, 8-10 cm de diámetro, cilíndricos, ascendentes, verde-oscuro, ramificados en la base. Costillas del ápice obtusas, de un centímetro de alto; con areolas de $8 \mathrm{~mm}$ de alto; una espina central, acicular, $5,3 \mathrm{~cm}$ de largo, $1 \mathrm{~mm}$ de diámetro, amarilla, a veces amarillento-amarronada; espinas radiales 8 , aciculares, de $1 \mathrm{~mm}$ de diámetro, $4 \mathrm{~cm}$ de largo, de igual color que la espina central. Costillas de la base 11-13, obtusas, 2-3 cm de ancho; con areolas circulares, de $1 \mathrm{~cm}$ de ancho, con abundante pilosidad blanca y separadas entre sí por $2 \mathrm{~cm}$; espinas aciculares y subuladas, radiales 12, de $2 \mathrm{~cm}$ de largo y 0,5 $\mathrm{mm}$ de ancho, centrales 4, de 4-8 cm de longitud y $1 \mathrm{~mm}$ de diámetro, amarillas, rígidas y en algunos casos no se diferencian las radiales de las centrales. Flores de 15-18 cm de largo, inodoras, corola de 11-14 cm de diámetro, ovario de $2 \mathrm{~cm}$ de ancho, tubo floral de $3-5 \mathrm{~cm}$ de diámetro, con escamas carnosas de $5 \mathrm{~mm}$ de largo, de cuyas axilas emergen pelos blancos o castaños. Tépalos exteriores de $3-5 \mathrm{~cm}$ de longitud, mayormente rojizos, tépalos intermedios e interiores de 6-8 cm de largo, de color variable: desde blancoamarillentos, amarillo-claro hasta oscuro, rosados y hasta rojos; estambres superiores con filamentos de 2 $\mathrm{cm}$ de longitud, amarillo-verdosos; estambres inferiores de $7 \mathrm{~cm}$ de longitud, $1 \mathrm{~mm}$ de diámetro; estilo de 11-12 cm de longitud, 0,5 cm de diámetro, concolores con los tépalos; estigma con 15 lóbulos, de 1,3-1,8 $\mathrm{cm}$ de largo y $5 \mathrm{~mm}$ de diámetro, amarillos. Pseudobaya con dehiscencia lateral, 5-6 cm de diámetro; 
parte externa verde-rosada a amarilla y cavidad ovárica con funículos blancos. Semillas negras, 1,3 mm de largo y $1 \mathrm{~mm}$ de ancho, testa finamente punteada y brillante (Fig. 20).

Florece entre octubre y febrero. Los frutos maduran entre enero y marzo.

Distribución y Hábitat: Endémica de la Argentina de la Provincia de la Rioja (Fig. 73), desde el norte de Famatina hasta la Cuesta de Miranda, sobre cerros y valles, entre 1000-2000 m de altitud. Ocupa la provincia fitogeográfica del Monte, donde predomina el matorral xerófilo bajo (menos de $2 \mathrm{~m}$ ) de Leguminosas (Senna rigida y Zuccagnia punctata) y Zigofiláceas (Larrea sp. y Bulnesia sp.), con claros de suelo desnudo (Kiesling 1978).

\section{Comentarios morfológicos y sus consecuencias en la taxonomía y nomenclatura: Los} nombres propuestos por Backeberg, Helianthocereus pseudocandicans, Trichocereus candicans var. roseoflorus, Helianthocereus pseudocandicans var. flaviflorus son inválidos, por cuanto al momento de su publicación Backeberg no designó el material Tipo, según lo dispuesto en el artículo 40.1 del Código Internacional de Nomenclatura Botánica (McNeill et al. 2012).

Hunt et al. (2006) consideran que T. pseudocandicans es sinónimo de T. candicans, pero se encontraron suficientes caracteres morfológicos como para considerarla subespecie de $T$. candicans: forma de las espinas (principalmente aciculares vs. subuladas), cantidad de costillas (11-13 vs. 9), color de las piezas interiores del perigonio (varios colores vs. blanco níveo). Para Kiesling (1978), T. candicans subsp. pseudocandicans es un híbrido de reciente formación, aun no estabilizado genéticamente y derivado de $T$. candicans.

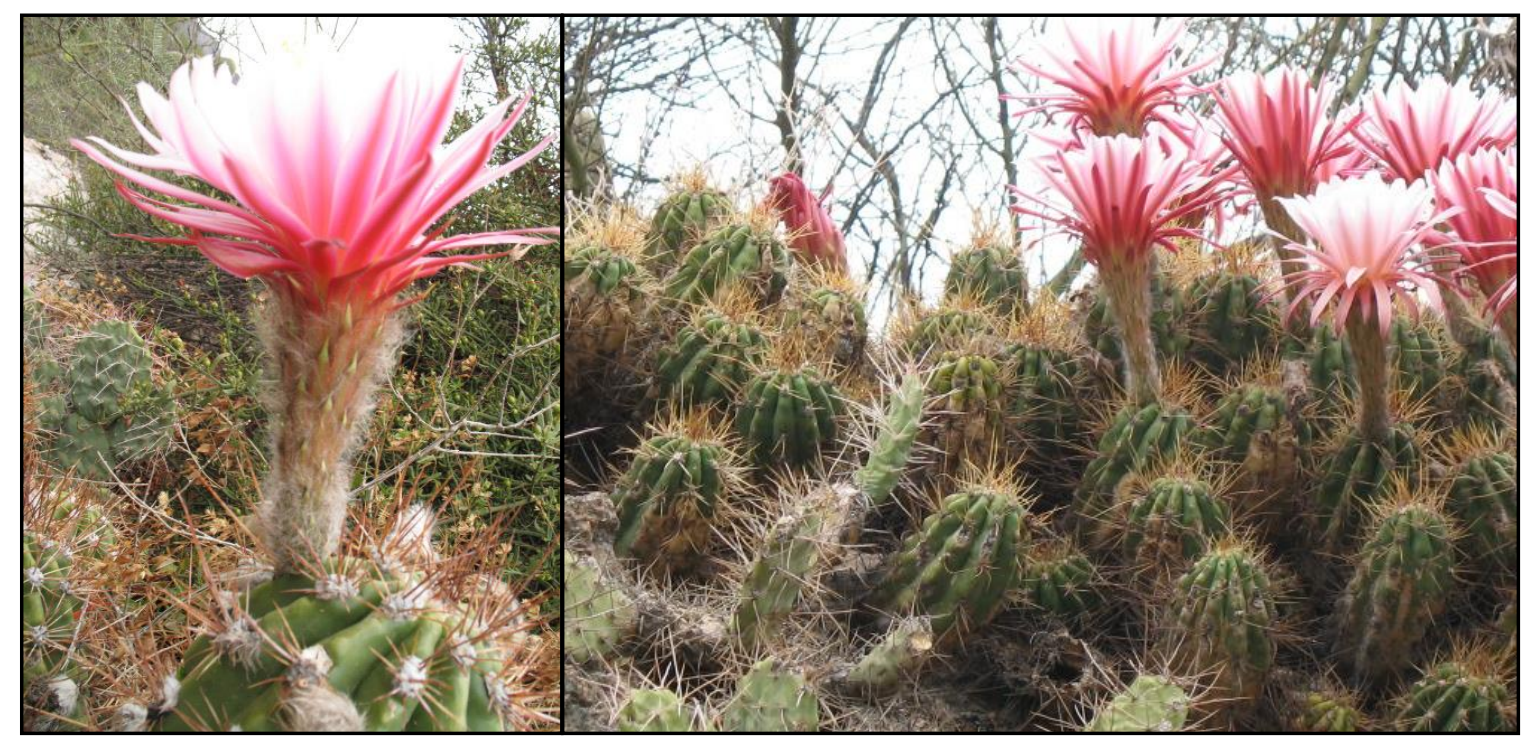

Figura 20. Trichocereus candicans subsp. pseudocandicans. Argentina, Provincia de La Rioja, entre Chilecito y Famatina. 
Material de Herbario estudiado: Argentina, Prov. La Rioja, Dpto. Famatina, R. Kiesling 1069 (SI); ibidem, Nov. 1975, R. Kiesling 1088 (SI); Sierra de Famatina, 1324 m, 28 Oct. 2006, B. 0. Schlumpberger 411 (CORD); Famatina, 1370 m, 14 Nov. 2006, B. O. Schlumpberger 462 (CORD); Famatina, 28 Oct. 2006, B. O. Schlumpberger 510 (CORD); cerca de Miranda, 23 Mar. 1976, R. Kiesling 1207 (SI); Cuesta de Miranda, 1977 m, 27 Oct. 2006, B. O. Schlumpberger 410 (CORD); Dpto. Chilecito, oeste de Chilecito, 275 m, 26 Oct. 2006, B. O. Schlumpberger 407, 408 (CORD); Alto Carrizal, 1930 m, 21 Ene. 2007, S. Albesiano et al. 2033 a, b (MERL 58803); entre Chilecito y Famatina, 16 Oct. 2010, S. Albesiano \& R. Kiesling 2092 (MERL).

12. Trichocereus chiloensis (Colla) Britton \& Rose, The Cactaceae 2: 137, ill. 1920.

Cactus chiloensis Colla, Hortus Ripul. App. 2: 342. 1826. Cereus chiloensis (Colla) DC., Prodr. 3 : 465. 1828. Echinocereus chiloensis (Colla) Console \& Lem., Rev. Hort. 35: 173. 1864, nom. nud. Echinocereus chiloensis (Colla) Console \& Lem., Illustr. Hortic. xi. Misc. 15. 1864. Echinopsis chiloensis (Colla) H. Friedrich \& G.D. Rowley, I.O.S. Bull. 3(3): 94. 1974. Leucostele chiloensis (Colla) Schlumpb., Cactaceae Syst. Init. 28: 29. 2012.

Descripción original de Cactus chiloensis Colla, Hortus Ripul. App. 2: 342. 1826:

2x. C. Chroosssis (Colla pl. rar. hort. ripul. app. 2. p. 342.) ovato-erectus roangularis, angulis obtusis, aculeis pallido-pellucidis, medio validiore, lanugine

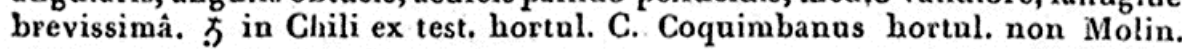

Descripción ampliada: Plantas erectas, 1-6 m de alto. Ramas de 10-25 cm de diámetro. Costillas del ápice 11-17, obtusas, 0,6-3 cm de ancho, 3-7 mm de alto; con areolas oblongas u obovadas, 1-4 mm de alto, 0,6-1,3 cm de ancho, ápice con pilosidad amarillenta, parte media y baja con pilosidad gris o negra o totalmente amarillenta; espinas centrales 1-6, aciculares, 0,3-15 cm de largo, punta marrón, base verde-claro, las subapicales son de ápice marrón y la base gris o blancas con algunos puntos negros o grises; espinas radiales 8-19, de 0,4 a 4,0 cm de largo, aciculares, rígidas, marrón-oscuro, verdes, amarillas, grises o blancas con punta marrón. Costillas de la base 11-21, obtusas, 1,5-4,0 cm de ancho, 0,2-2,0 cm de alto; con areolas circulares, oblongas o elípticas, 1-5 mm de alto, 0,5-1,3 cm de ancho, las más viejas hundidas, con pilosidad amarilla, marrón, gris-claro, gris-oscuro o negra; espinas centrales 1-7; generalmente 4, aciculares y rectas, 0,2-20 cm de largo, hasta $2 \mathrm{~mm}$ de diámetro, ápice marrón o rojizo y base gris o negra o totalmente verde-oliva o marrón-oscuro; espinas radiales 9-24, aciculares, flexibles o rígidas, 1,0-2,7 cm de largo, menor de 1,5 mm de ancho, amarillas, verde-oliva 0 gris-claro con ápice marrón, gris-oscuro o negro. Flores 1-8, subapicales, 11-21 cm de largo, con abundante pilosidad marrón en el ovario y tubo floral; corola 7-11 cm de diámetro (cuando abiertas); ovario 2-3 cm de ancho; con escamas florales de 1-3 cm de largo, verdes con ápice marrón; escamas 
florales del tubo de 1,0-4,5 cm de largo, ápice marrón, en la parte media verde y verde-amarillentas en la base; tépalos espatulados, $4-7 \mathrm{~cm}$ de longitud, ápice rosado y base blanco-amarillento, con líneas longitudinales marrones; estilo verde, $10 \mathrm{~cm}$ de largo; estigma amarillo, 1-2 cm de longitud. Pseudobaya subapical, 2-4 cm de largo, 3-5 cm de diámetro, recubierto por escamas subuladas, con abundantes pelos axilares marrones y grises. Semillas de $2 \mathrm{~mm}$ de largo y $1 \mathrm{~mm}$ de ancho.

Distribución y Hábitat: $T$. chiloensis es la especie del género Trichocereus con mayor área de distribución en Chile, ocupando las regiones: II, IV, V, VI, VII, VIII, RME, desde la costa Pacífica hacia el interior, en los valles de los ríos y en las laderas, desde el nivel del mar hasta los $1500 \mathrm{~m}$.

Comentarios taxonómicos y nomenclaturales: Ritter (1980b) corrigió en oposición al Art. 51.1 del Código Internacional de Nomenclatura para algas, hongos y plantas (McNeill et al. 2012), el nombre del epíteto específico chiloensis por chilensis, basado en que no corresponde a la isla Chiloe, sino a Chile.

Console y Lemaire proponen el nombre Echinocereus chiloensis (Rev. Hort. 35: 173. 1864), sin proveer una descripción de la especie. Posteriormente, Lemaire (Cact:: 61. 1868) menciona que el nombre se basa en Cereus chiloensis (Britton \& Rose 1920).

\section{Nombres dudosos de variedades:}

Los siguientes taxones fueron excluidos del tratamiento taxonómico, por cuanto la información suministrada en la descripción original sobre el color y número de espinas centrales y radiales no son suficientes para la identificación taxonómica, faltarían datos en conjunto sobre las características del tallo: hábito, altura y diámetro, además, del número de costillas. Igualmente, no se tuvieron en cuenta las variedades cuyo diámetro de los tallos se encuentra por debajo de lo observado en campo.

Cereus chiloensis var. brevispinula Salm-Dyck., Cact. Hort. Dyck. 1849: 199. 1850. (El nombre aparece como "C. chilensis var. brevispinula").

Cereus chiloensis var. flavescens Salm-Dyck., Cact. Hort. Dyck. 1849: 199. 1850. (El nombre aparece como "C. chilensis var. flavescens").

Cereus chiloensis var. heteromorpha K. Schum., Gesamtbeschr. Kakt. 63. 1897. (El nombre aparece como "C. chilensis var. heteromorpha").

Cereus chiloensis var. polygona Salm-Dyck., Cact. Hort. Dyck. 1849: 199. 1850. (El nombre aparece como "C. chilensis var. polygona").

Cereus chiloensis var. poselgeri K. Schum., Gesamtbeschr. Kakt. 63. 1897. (El nombre aparece como "C. chilensis var. poselgeri").

Cereus chiloensis var. pycnacantha (Salm-Dyck) K. Schum., Gesamtbeschr. Kakt. 63. 1897. (El nombre aparece como "C. chilensis var. pycnacantha"). 
Cereus chiloensis var. zizkaana K. Schum., Gesamtbeschr. Kakt. 63. 1897. (El nombre aparece como "C. chilensis var. zizkaana")

T. chiloensis presenta una alta variación intraespecífica con respecto al hábito de crecimiento, diámetro de los tallos, además del número y forma de las espinas, por lo que se proponen seis subespecies, siguiendo la propuesta de Schumann (1899) y Ritter (1980b).

\section{Clave para la identifiación de las subespecies de Trichocereus chiloensis}

1. Plantas bajas, 1-1,5 $\mathrm{m}$, formando densos arbustos ascendentes subsp. panhoplites

1'. Plantas altas, mayores de $2 \mathrm{~m}$, arbustivas o arbóreas

2. Espinas radiales adultas flexibles, muy delgadas y numerosas (14-24) subsp. litoralis

2 '. Espinas radiales adultas fuertes, rígidas y pocas (menos de 14)

3. Diámetro de los tallos entre $9-10 \mathrm{~cm}$ subsp. chiloensis

3'. Diámetro de los tallos entre $13-25 \mathrm{~cm}$

4. Presencia de espinas blancas en areolas subapicales, espinas radiales en areolas adultas 1113 subsp. eburneus

4.' Presencia de espinas grises con ápice marrón en areolas subapicales, espinas radiales en areolas adultas $7-10$ subsp. australis

\section{Trichocereus chiloensis (Colla) Britton \& Rose subsp. chiloensis}

TIPO: Chile, Región Metropolitana, Santiago, Río San Francisco, 1800m, 11 Dic. 1924, Werdermann 478 (Neotipo, K no visto, designado por Hunt \& Taylor: 7. 2006; Isoneotipos SI 079802! $\mathrm{MO})$.

Cereus quisco Remy, Fl. Chil. 3: 19. 1847. Tipo no designado. TIPO: Chile, Región IV (de Coquimbo), Prov. Elqui, Mpio. Vicuña, 29051.37’S; 70²2.33`W, 1280 m, 27 Oct. 1997, U. Eggli \& B.E. Leuenberger 3052. (Neotipo, aquí designado: SGO 144120. Isoneotipos: B, CONC, ZSS).

Trichocereus chiloensis [chilensis] (Colla) Britton \& Rose var. borealis F. Ritter, Kakteen Südamerika 3: 1109. 1980. TIPO: IV Región de Coquimbo, Prov. Elqui, valley of Elqui, Huanta, FR 228d. (Holotipo, U!).

Iconografía: Ahumada \& Faúndez (2007): 144.

Descripción ampliada: Plantas de hasta $6 \mathrm{~m}$ de alto. Ramas de $10 \mathrm{~cm}$ de diámetro. Costillas 11-18, obtusas, 10-15 mm de alto. Areolas del ápice 5-12 mm de ancho; una espina central; areolas de la base con 4 espinas centrales, $3-20 \mathrm{~cm}$ de largo, más largas y gruesas que las radiales. Espinas radiales 
hasta 13, de $2 \mathrm{~cm}$ de largo, cuando jóvenes marrón-oscuro, luego gris-claro con puntas marrón o grisoscuro en su totalidad. Flores de $13 \mathrm{~cm}$ de largo, tépalos blancos, lineares, ovalados, apiculados en la punta (Fig. 21).

Distribución y hábitat: Comprende la IV, V y la Región Metropolitana, desde la costa hacia el interior, en los alrededores de Limanche, Olmué, Santiago, entre otros (Fig. 75A). Constituye un elemento importante en el paisaje de la zona mediterránea de Chile.

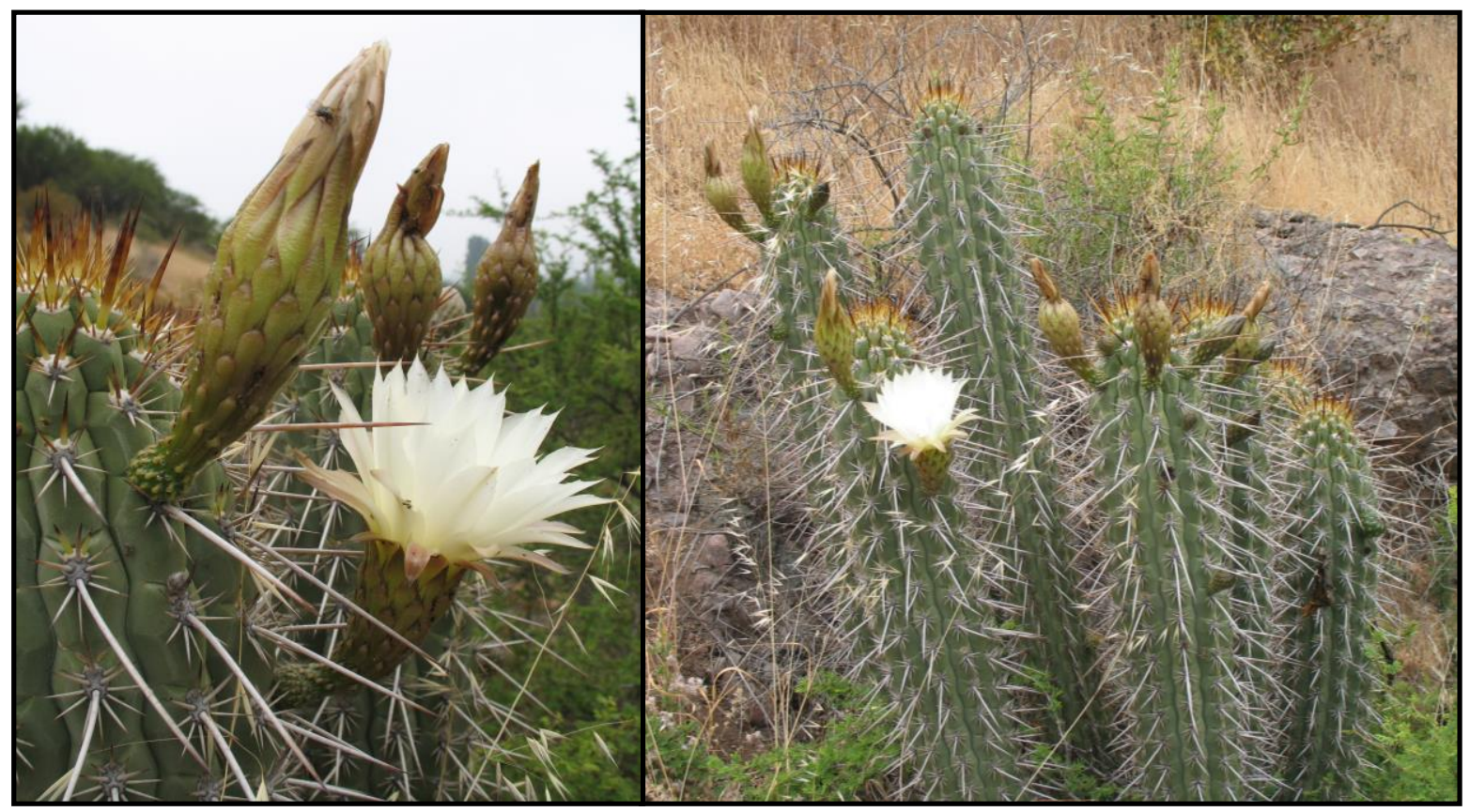

Figura 21. Trichocereus chiloensis subsp. chiloensis. Chile, IV Región de Coquimbo, Provincia Elqui.

Comentarios nomenclaturales: Se seleccionó como Neotipo de Trichocereus chiloensis subsp. chiloensis el ejemplar de U. Eggli \& B.E. Leuenberger 3052 (SGO), por ser el más cercano a la descripción original, y por presentar un corte transversal y dos longitudinales del tallo apreciandosé la forma, la longitud y el número de espinas por areola, una flor donde se observa su longitud y grosor, cantidad de escamas y la pilosidad en el ovario y tubo floral.

Material de Herbario estudiado: Chile, IV Región de Coquimbo, Prov. Limarí, Mpio. Ovalle, 36

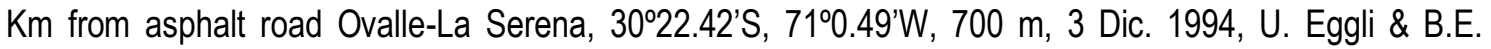
Leunberger 2570 (SGO); Prov. Elqui, $2 \mathrm{Km} \mathrm{S}$ of main road La Serena-Vicuña, $620 \mathrm{~m}, 30^{\circ} 2.79^{\prime} \mathrm{S}$, 7049.17'W, U. Eggli \& B.E. Leuenberger 3042 (SGO); Mpio. Vicuña, 2951.37'S, 70²2.33'W, 1280 m, U. Eggli \& B.E. Leuenberger 3052 (SGO). 
14. Trichocereus chiloensis (Colla) Britton \& Rose subsp. australis (F. Ritter) Albesiano, Haseltonia 18: 123. 2012).

Trichocereus chiloensis (Colla) Britton \& Rose var. australis F. Ritter, Kakteen Südamerika 3: 1108, ill. 1980. TIPO: Chile, VII Región del Maule, Prov. Talca, Dpto. Lontué, Villa Prat, Abril de 1954, F. Ritter 228a (Holotipo, U, extraviado). TIPO: Chile, V Región de Valparaíso, Cuesta Las Chilcas, 3251'05”S; 7052'39”W, 400-440 m, 5 Nov. 2008, S. Albesiano, L. Faúndez, R. Flores \& P. Saldivia 2042 (Neotipo, MERL!; Isoneotipo AGUCH!, designados por Albesiano 18: 123. 2012).

Iconografías: Ahumada \& Faúndez (2007): 141. Hoffmann \& Walter (2004), lámina 16: 91. Albesiano (2012), foto 3: 123.

Descripción original de Trichocereus chiloensis var. australis F. Ritter, Kakteen Südamerika 3: 1108. 1980:

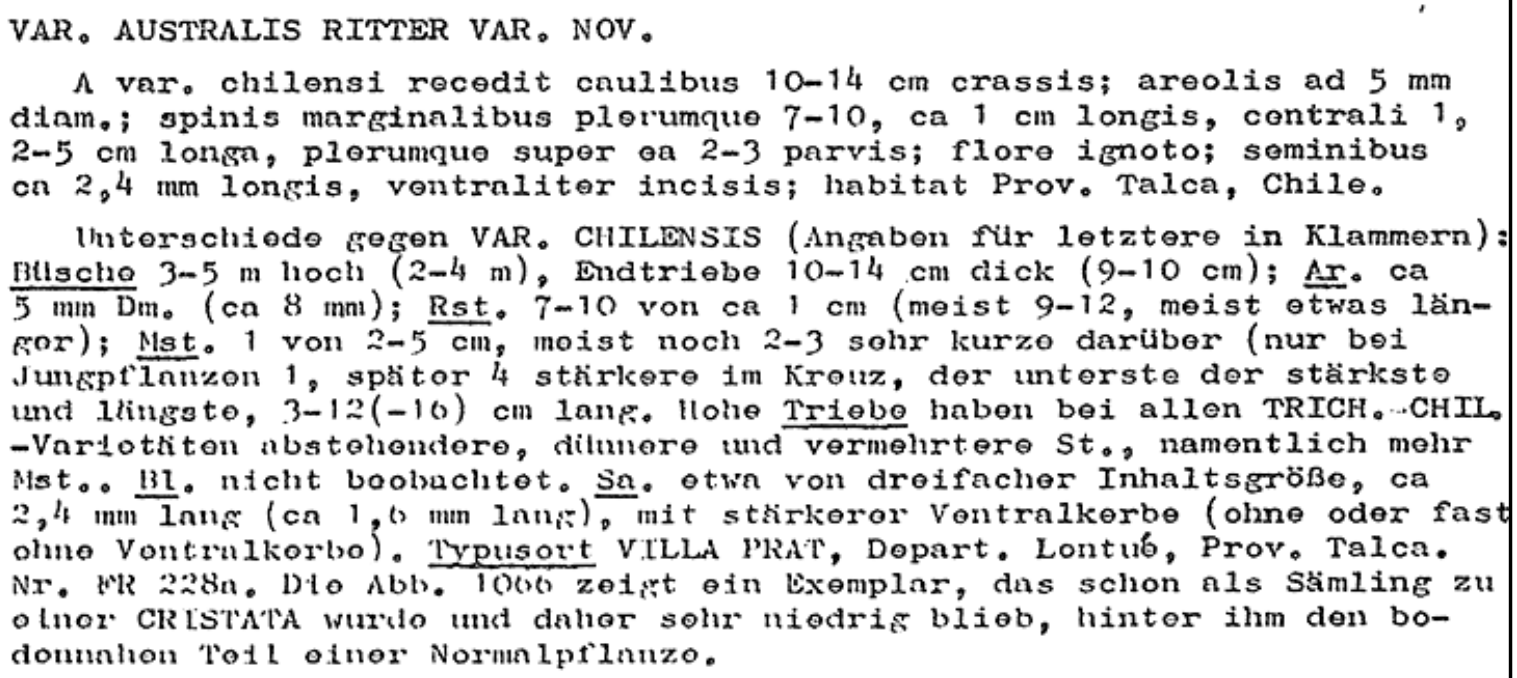

Descripción ampliada: Plantas de 2-4 m de alto. Tallos erectos y cilíndricos, $13-25 \mathrm{~cm}$ de diámetro. Costillas del ápice obtusas, 13-15, de 1-3 cm de ancho, 3-5 mm de alto; areolas obovadas, 1-2 $\mathrm{mm}$ de alto, 7-8 mm de ancho, con pilosidad amarilla en el ápice y en la base gris, o totalmente amarillas; espinas centrales 1-3, aciculares, 1-8 cm de largo, amarillo-oscuro a marrón en las puntas y en la base verde 0 amarillo, algunas espinas subapicales son de base gris y ápice marrón; espinas radiales 9 , aciculares, 0,4-4,0 cm de largo, amarillas y otras son verdes o grises con punta marrón. Costillas de la base 12-16, de 2 a $4 \mathrm{~cm}$ de ancho, 0,2-2,0 cm de alto, con areolas redondeadas, algunas hundidas, 1-2 $\mathrm{mm}$ de alto, 6-10 mm de ancho, con pilosidad gris-claro u oscuro o negra; espinas centrales 1-3, aciculares, 2-6 cm de largo, ápice marrón o rojizo, base gris o negra, la más larga dirigida perpendicularmente al tallo; espinas radiales 11 , aciculares, $2 \mathrm{~cm}$ de largo, amarillas, verdes con punta marrón o negras. Flores subapicales, con pilosidad crema o marrón en el ovario y tubo floral, $11-21 \mathrm{~cm}$ de 
largo; corola 7-11 cm de diámetro (cuando abiertas); ovario 2-3 cm de diámetro; con escamas florales de ca. $3 \mathrm{~cm}$ de largo, con el ápice marrón y centro verde-oscuro; escamas florales de tubo subuladas, $3-5 \mathrm{~cm}$ de largo, puntas marrón, en el medio verde y base amarilla; tépalos espatulados, 4-7 cm de longitud, ápice rosado y base amarillo-claro; estilo verde, $6-10 \mathrm{~cm}$ de largo; estigma amarillo-claro, hasta $2 \mathrm{~cm}$ de largo (Fig. 22).

Distribución y Hábitat: Se localiza en las Regiones V, VI y VII, sobre las laderas de la cordillera de la costa, donde predomina el estrato herbáceo y arbustivo, con algunos elementos arbustivos dispersos (Fig. 75A).

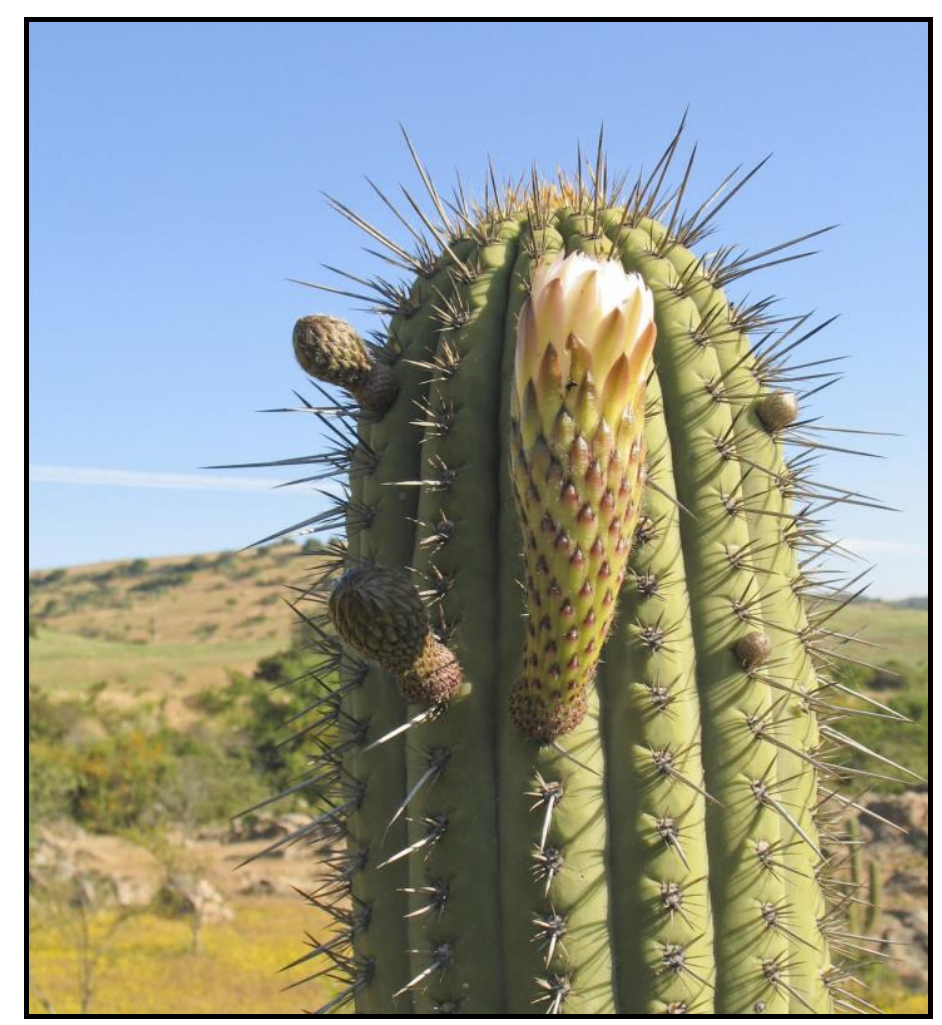

Figura 22. Trichocereus chiloensis subsp. australis. Chile, VI Región de O' Higgins, Prov. Cardenal Caro, Comuna de Litueche.

Comentarios nomenclaturales: El ejemplar tipo (FR 228a) esta mencionado (Ritter: iii. 1979, 1980b), para el Herbario Nacional de Holanda (U). Según Eggli et al. (1996), este material se encuentra perdido, y por lo tanto designamos un Neotipo, S. Albesiano et al. 2042 (MERL), en la publicación de Albesiano 18: 123. 2012, de la región de Valparaíso, que reúne las características morfológicas de la descripción original. Además, en la publicación de Eggli et al. (1996), se indican semillas bajo el número FR 228a, presentes en el Herbario de Zurich (ZSS), pero no se tiene seguridad de que correspondan a la misma recolección que el tipo de Trichocereus chiloensis var. australis F. Ritter 228a, ya que en la descripción original no se nombra que hayan sido depositados en este herbario.

El nombre aparece como " $T$. chilensis var. australis". 
Material de Herbario estudiado: Chile, Región Metropolitana, Prov. Cordillera, $8.5 \mathrm{Km}$ above puente El Yeso, in the valley of the río Volcán, 1420-1500 m, 1/2/1993, U. Eggli \& B. Leuenberger 2299 (SGO). VI Región de O' Higgins, Prov. Colchagua, comuna de San Fernando, Manantiales, 34³7'10"S; 7102'47”W; 338 m, 2 Nov. 2008, S. Albesiano et al. 2038 (MERL, AGUCH); Prov. Cardenal Caro,

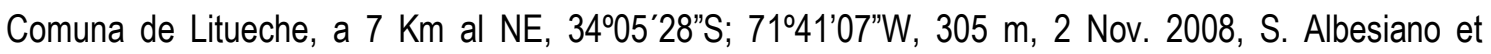
al.2041 (MERL, AGUCH). V Región de Valparaíso, Cuesta Las Chilcas, 3251'05"S; 7052'39”W, 400-440 m, 5 Nov. 2008, S. Albesiano et al. 2043 (MERL, AGUCH).

15. Trichocereus chiloensis (Colla) Britton \& Rose subsp. eburneus (Phil. ex K. Schum.) Albesiano, Haseltonia 18: 124. 2012.

Cereus chiloensis (Colla) DC. var. eburnea Phil. ex K. Schum., Gesamtbeschr. Kakt.: 63. 1899. (El nombre aparece como "Cereus chilensis var. eburnea") Eulychnia eburnea Phil, nom. nud. (según Schumann, I.c.). Cereus chiloensis (Colla) DC f. eburneus (Phil.) Schelle, Handb. Kakteenkult.: 63. 1907. (El nombre aparece como "Cereus chilensis f. eburneus"). Trichocereus chiloensis (Colla) Britton \& Rose var. eburneus (K. Schum.) F. Ritter, Kakteen Südamerika 3: 1109. 1980, nom. inval., falta información del basónimo: nombre, lugar y fecha de su publicación (Art. 41.5). (El nombre aparece como "Trichocereus chilensis var. eburneus") TIPO: Chile, IV Región de Coquimbo, 31028'00"S; 7109'52"W, 870 m, 6 Nov. 2008, S. Albesiano et al. 2049 (Neotipo, MERL!; Isoneotipo AGUCH!, designados por Albesiano 18: 124. 2012).

Iconografía: Albesiano (2012), foto 4: 124.

Descripción original de Cereus chiloensis var. eburnea Phil. ex K. Schum., Gesamtbeschr. Kakt.: 63. 1899:

Var. 0. eburnea K. Sch. (Eulychnia eburnea Philippi) ist im Gegensatz viel kräftiger; meist sind nur 1-2 Mittelstacheln vorhanden, die jung bräunlich sind, bald aber elfenbeinweiß werden.

Descripción ampliada: Plantas erectas, de $2 \mathrm{~m}$ de alto. Ramas laterales ramificadas a nivel del suelo, verde-claro, $13 \mathrm{~cm}$ de grosor, el ápice con abundantes espinas aciculares, marrones, de $1 \mathrm{~mm}$ de diámetro. Costillas del ápice 12, obtusas, $2 \mathrm{~cm}$ de ancho, $4 \mathrm{~mm}$ de alto; con areolas obovadas, de $1 \mathrm{~mm}$ de alto y $8 \mathrm{~mm}$ de ancho, con pilosidad en areolas jóvenes amarilla, luego gris-claro por decoloración; espinas centrales 4, aciculares, 4-15 cm de largo, 1,5 mm de diámetro, blancas con algunos puntos negros; espinas radiales 10, aciculares, $3 \mathrm{~cm}$ de largo, menos de $1 \mathrm{~mm}$ de diámetro, rígidas y blancas. Costillas de la base 12, obtusas, $3 \mathrm{~cm}$ de ancho, $1 \mathrm{~cm}$ de alto, con areolas obovadas, $1 \mathrm{~mm}$ de alto, 1,3 
$\mathrm{cm}$ de ancho, con abundante tomento gris-oscuro a negro; espinas centrales 4, aciculares, 6 a $12 \mathrm{~cm}$ de largo, 1,5 mm de diámetro, marrón-oscuro; espinas radiales 12, aciculares, 2,4 cm de largo, negras. Flores 5-8 por rama, subapicales, $13 \mathrm{~cm}$ de largo; corola de $8 \mathrm{~cm}$ de diámetro (cuando abiertas); ovario y tubo floral con escamas de 1,2 cm de largo, de ápice marrón y base verde, de cuyas axilas surgen abundantes pelos marrón, $2 \mathrm{~mm}$ de largo; tépalos 3-6 cm de largo, con ápice marrón y base amarillocrema (Fig. 23).

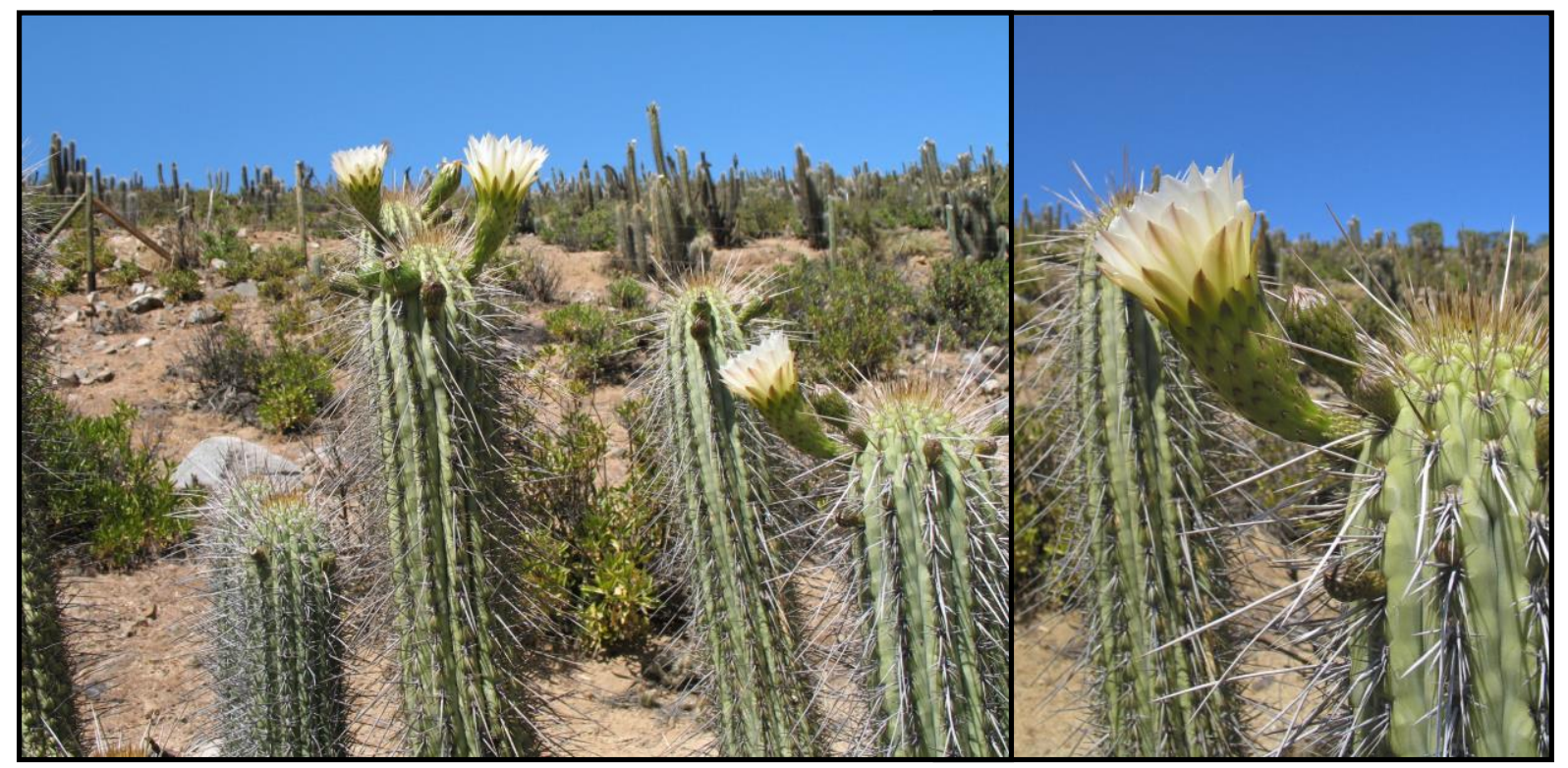

Figura 23. Trichocereus chiloensis subsp. eburneus. Chile, IV Región de Coquimbo, Provincia Choapa.

Distribución y Hábitat: Chile en la IV Región de Coquimbo, Prov. de Choapa, en laderas que no sobrepasan los $900 \mathrm{~m}$ de altitud, y donde el tipo fisonómico dominante corresponde al matorral xerofítico de menos de $2 \mathrm{~m}$ de alto, destacándose las cactáceas columnares de los géneros Eulychnia y Trichocereus (Fig. 75A).

Comentarios nomenclaturales: Se eligió como Neotipo el ejemplar S. Albesiano et al. 2049 (MERL), publicado en Albesiano 18: 124. 2012, porque presenta las características mencionadas en la descripción original, además por presentar un corte transversal y uno longitudinal del tallo con flores y frutos, correspondiendo a los caracteres vegetativos y reproductivos de la subespecie.

Material de Herbario estudiado: Chile, IV Región de Coquimbo, Prov. Elqui, Mpio. Vicuña, 32 Km S of Vicuña, 30¹1.53'S; 70³9.61'W, 1650 m, 28 Oct. 1997, U. Eggli \& B.E. Leuenberger 3058 (SGO); Prov. Limarí, Mpio. Río Hurtado, 30¹6.03'S; 70³9.64'W, 1300 m, 28 Oct. 1997, U. Eggli \& B.E.

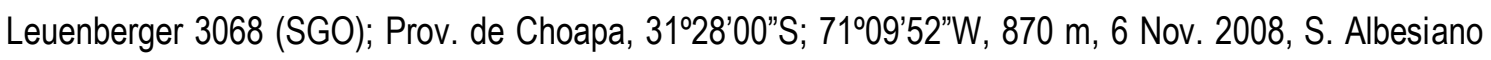
et al. 2049 (AGUCH, MERL). 
16. Trichocereus chiloensis (Colla) Britton \& Rose subsp. litoralis (Johow) Faúndez, Darwiniana 45(2): 237. 2007.

Cereus litoralis Johow, Revista Chilena Hist. Nat. 25: 157. 1921. Trichocereus litoralis (Johow) Looser, Revista Chilena Hist. Nat. 33. 598, ill. 1929. Echinopsis litoralis (Johow) Friedrich \& G.D. Rowley, I.O.S. Bull. 3 (3): 96. 1974. Echinopsis chiloensis subsp. litoralis (Johow) M. Lowry, Cactaceae Syst. Init. 16: 8. 2003. TIPO: Chile, V Región de Valparaiso, San Antonio, 5 Nov. 1997, U. Eggli, B. Leuenberger \& S. Arroyo 3110 (Neotipo, SGO 146136! designado por Faúndez \& Kiesling: 237. 2007; Isoneotipos, B, CONC, ZSS).

Iconografías: Looser (1929), Fig. 114: 599. Hoffmann (1989), lámina 10: 89. Hunt et al. (2006), Fig. 4: 233. Albesiano (2012), foto 5: 125.

Descripción original de Cereus litoralis Johow, Revista Chilena Hist. Nat. 25: 157. 1921:

Simplex columnaris, serius reclinatus, deinde prope
apicem geotropice resurrectus et a basi procumbente ramo-
sus, $1-2 \mathrm{~m}$. altus, $10-12 \mathrm{~cm}$. crassus, cinereo-viridis, apice
convexo aculeis viridibus dein melleis obtecto; costis 21
rotundatis, $5 \mathrm{~mm}$. altis, depressionibus lateri superiori areo-
larum contiguis in tubercula vix prominentia solutis; valle-
culis acutis, undulatis; areolis orbiculari-elliptieis, obliquis,
tomento brevi isabellino dein griseo vestitis, 1 cm. inter
se distantibus; aculeis radialibus ca 20 subulatis, centra-
libus 5-8 majoribus inaequalibus, omnibus denique griseis;
floribus lateralibus semper in caulis lateri septentrionali
i. e. solem versus spectante ortis, $12-14$ cm. longis, 10 cm.
latis; ovario globoso, squamoso, atque tubo perianthii lana
obscura vestito; tepalis exterioribus acutis, viridi-albescen-
tibus, apice rubeolis, interioribus acuminatis, apicem versus
interdum denticulatis, albis; staminibus exterioribus fau-
cem perianthii sulperantibus, filamentis pallide viridibus,
antheris sulphureis; stylo longitudine stamina exteriora
aequante, pallide viridi; stigmatibus $18-22$ luteo-albis; bacea
depressa, 3 -4 cm. crassa.

Descripción ampliada: Plantas de $3 \mathrm{~m}$ de alto, tallo principal de $50 \mathrm{~cm}$ de alto. Ramas $12-18 \mathrm{~cm}$ de diámetro; en algunos individuos las ramas inicialmente son procumbentes y luego se vuelven erectas; en otras plantas todas las ramas son erguidas. Costillas del ápice 17, obtusas, $1 \mathrm{~cm}$ de ancho, $3 \mathrm{~mm}$ de alto; areolas obovadas, $1 \mathrm{~mm}$ de alto, $6 \mathrm{~mm}$ de ancho, con pilosidad en areolas jóvenes amarilla, luego gris-claro por decoloración; espinas centrales 2-6, aciculares, 1-6 cm de largo, las más cortas con puntas marrón y base verde, y las más largas son grises o amarillo-oscuro; espinas radiales 15-19, aciculares, 2 cm de largo, algunas son verdes con ápice marrón, otras son totalmente grises o marrón-claro. Costillas de la base 17-21, obtusas, 2-4 cm de ancho, 0,3-1,0 cm de alto; areolas circulares, 2-5 mm de alto, $1 \mathrm{~cm}$ de ancho, grises o negras. Inmediato al límite superior de cada areola hay en la costilla un hundimiento transversal, que da oblicuidad a la areola. Espinas centrales 4-7, aciculares, 2-4 cm de largo, 1,5 mm de diámetro, verde-oliva o marrón-claro a oscuro; espinas radiales 15-24, aciculares, 1-2 cm de largo, 0,7 $\mathrm{mm}$ de diámetro, verdes con puntas marrón. Flores 1 o 2, subapicales, 12-16 cm de largo, $11 \mathrm{~cm}$ de diámetro cuando abiertas (4 cm en flores cerradas); ovario 1,5-2,2 cm de ancho, escamas florales del 
medio 1-2 cm de largo; escamas florales superiores de 2-3 cm; tépalos $5 \mathrm{~cm}$ de largo, blancos; estilo $8 \mathrm{~cm}$ de largo; estigma $1 \mathrm{~cm}$ de longitud. Pseudobaya de $5 \mathrm{~cm}$ de diámetro, $4 \mathrm{~cm}$ de alto, recubierta por abundantes pelos marrones y grises (Fig. 24).

Distribución y hábitat: Trichocereus chiloensis subsp. litoralis se localiza en Chile, en la IV y V Región, extendiéndose a lo largo de la costa del Aconcagua, desde Papudo hacia el sur, posiblemente en Valparaíso y Santiago, asimismo, en Zapallar y Cachagua, sobre planicies y laderas cercanas a la costa, entre 33 y $100 \mathrm{~m}$ de altitud, y donde sobresale por su altura de los estratos herbáceo y arbustivo, de Fuchsia lycioides con algunos arbolitos esparcidos (Fig. 75A).

Comentarios morfológicos y sus consecuencias en la taxonomía y nomenclatura: Por el parecido en el porte (plantas altas, mayores de $2 \mathrm{~m}$ y arbustivas), diámetro de los tallos (mayores de 10 $\mathrm{cm}$ ), número de costillas (ca. 21) y forma de las costillas (obtusas, separadas por surcos agudos y ondulados), T. litoralis se considera subespecie de T. chiloensis.

A su vez, la subespecie litoralis se diferencia de la subespecie tipo, por el número y morfología de las espinas radiales: flexibles, delgadas y numerosas (14-30) vs. fuertes, rígidas y pocas (menos de 14).

Los tallos de algunos individuos de $T$. chiloensis subsp. litoralis crecen de manera ascendente, similar a T. spinibarbis, pero se distingue de este último por el mayor diámetro de los tallos (12-18 cm vs. 4-10 cm), número de costillas (17-21 vs. 8-15), además del menor tamaño de las espinas centrales en areolas adultas $(4 \mathrm{~cm}$ vs. $10 \mathrm{~cm})$.

Looser (1929) encontró que los caracteres diferenciales (número de lóbulos del estigma y orientación de las flores), entre $T$. litoralis y $T$. chiloensis indicados en la descripción original de $C$. litoralis (Johow 1921), son de escaso valor diferencial, ya que algunos individuos de esta especie registran la misma cantidad de lóbulos del estigma (18) y sus flores se orientan hacia el norte.

En varias especies las primeras flores de cada año son hacia el norte, que es donde la rediacion solar estimula la floracion; más adelane muchas florecen en otras orientaciones.

Material de Herbario estudiado: Chile, IV Región de Coquimbo, Prov. Choapa, 14,5 Km on Panamericana $\mathrm{N}$ of turnoff from Panamericana to Los Vilos, in a steep valley between to road and the sea, 100 m, 10 Nov. 1991, U. Eggli \& B. Leuenberger 1664, 1668 (SGO); Mpio. Mincha, Caleta Oscuro, 3 Km W of Puerto Oscuro, 31025.27'S; 71035.68'W, 20-100 m, U. Eggli et al. 3087 (SGO) p.p.; Prov. Elqui, Mpio. Coquimbo, 22 Km W Tongoy towards Puerto Aldea, 30¹8.51'S; 71035.52'W, 31 Oct. 1997, U. Eggli et al. 3086 (SGO); V Región de Valparaíso, Prov. Petorca, La Ligua, Los Molles, 32013'59"S; 71³0'46"W; 21 m, 5 Nov. 2008, S. Albesiano et al. 2044 (MERL, AGUCH); Quilimarí, Petorca, La Ligua, Los Molles, 3207'17"S; 71027'47"W; 33 m, 5 Nov. 2008, S. Albesiano et al. 2047 (MERL, AGUCH). 


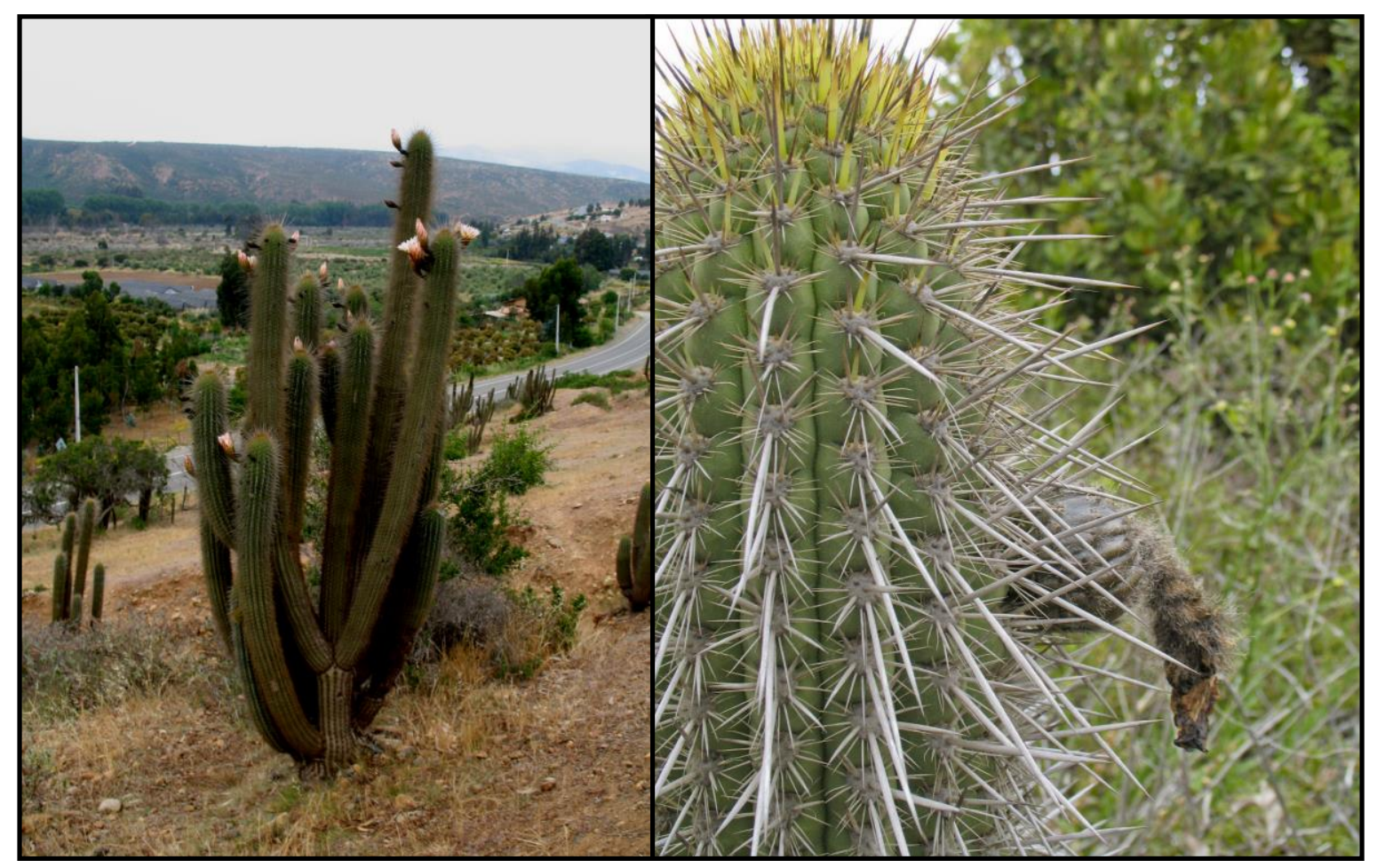

Figura 24. Trichocereus chiloensis subsp. litoralis. Chile, V Región de Valparaíso, Prov. Petorca, La Ligua, Los Molles.

17. Trichocereus chiloensis (Colla) Britton \& Rose subsp. panhoplites (K. Schum.) S. Albesiano, Haseltonia 18: 126. 2012.

Cereus chiloensis (Colla) DC. var. panhoplites K. Schum., Gesamtbeschr. Kakt. 63: 1899. (EI nombre aparece como "Cereus chilensis var. panhoplites"). Trichocereus chiloensis (Colla) Britton \& Rose var. panhoplites (K. Schum.) F. Ritter, Kakteen Südamerika 3: 1109, ill. 1980, nom. inval., falta mencionar el basónimo, el lugar y fecha de publicación (Art. 41.5). (El nombre aparece como "Trichocereus chilensis var. panhoplites"). TIPO: Chile, IV Región de Coquimbo, Provincia Limarí, Ovalle, Higueritas Unidas, 30²2'16”S; 71014'00"W, 477 m, 6 Nov. 2008, S. Albesiano, L. Faúndez, R. Flores \& P. Saldivia 2052 (Neotipo, MERL; Isoneotipo, AGUCH, designados por Albesiano 18: 126. 2012).

Iconografías: Ritter (1980b), foto 1059: 1221. Albesiano (2012), foto 6: 126.

Descripción original de Cereus chiloensis var. panhoplites K. Schum., Gesamtbeschr. Kakt. 63: 1899:

Var. o. panhoplites*) K. Sch. Oberster Mittelstachel sehr lang, bis $8 \mathrm{~cm}$ messend, steif, gerade vorgestreckt, Randstacheln 11, Mittelstacheln 4, jung fast schwarz. 
Descripción ampliada: Plantas bajas (1,0-1,5 m), ascendentes. Ramas originadas a nivel del suelo, $16 \mathrm{~cm}$ de diámetro. Costillas del ápice 11, obtusas, $3 \mathrm{~cm}$ de ancho, $7 \mathrm{~mm}$ de alto; con areolas obovadas, de $4 \mathrm{~mm}$ de alto, $1,3 \mathrm{~cm}$ de ancho, con pilosidad en areolas jóvenes amarilla, luego gris-claro por decoloración. Espinas centrales 1-3, subuladas, $8 \mathrm{~cm}$ de largo, $2 \mathrm{~mm}$ de diámetro, rectas y totalmente grises; radiales 6-10, de 2,0-2,4 cm de largo, aciculares, tres de ellas son de base verde y punta marrón, las restantes son grises. Costillas de la base 12, obtusas, $3 \mathrm{~cm}$ de ancho, $7 \mathrm{~mm}$ de alto; con areolas elípticas, $2 \mathrm{~mm}$ de alto, 1,3 cm de ancho, 10-15 mm de separación, totalmente con pilosidad gris, excepto en el área donde surgen nuevas espinas donde la pilosidad es amarilla. Espinas centrales 3-4, rectas, 6 a $9 \mathrm{~cm}$ de largo, aciculares, $2 \mathrm{~mm}$ de diámetro, gris con ápice negro; radiales 9-11, subuladas, $3 \mathrm{~cm}$ de largo, 1,5 mm de diámetro, gris con punta negra. Pseudobaya de 3,5 cm de largo, $4 \mathrm{~cm}$ de diámetro, recubierto de pelos color marrón (Fig. 25).

Distribución y hábitat: Chile, en las cercanías de Ovalle, en las planicies litorales, cercanas a la cordillera de la costa, a $500 \mathrm{~m}$ de altitud, y donde predominan el estrato herbáceo y arbustivo bajo (Fig. $75 A)$.

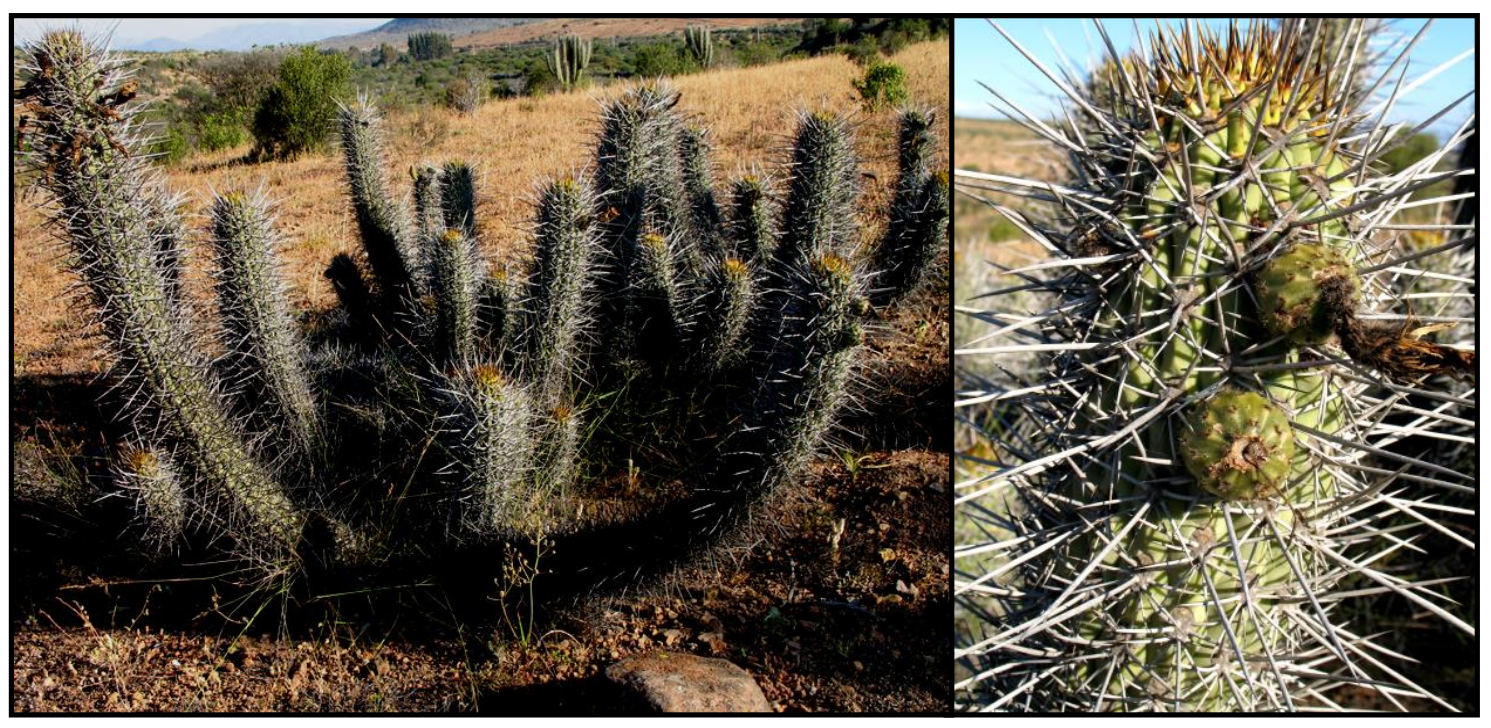

Figura 25. Trichocereus chiloensis subsp. panhoplites. Chile, IV Región de Coquimbo, Provincia Limarí, Ovalle, Higueritas Unidas.

Comentarios morfológicos y sus consecuencias en la taxonomía y nomenclatura: Se escogió el ejemplar S. Albesiano et al. 2052 como Neotipo de Cereus chiloensis var. panhoplites, en la publicación de Albesiano 18: 126. 2012, por ser el más cercano a la descripción original, y por presentar un corte longitudinal y uno transversal de tallo, donde se observa el número de costillas, forma, tamaño y cantidad de espinas, al igual que varios cortes longitudinales de las flores y frutos, apreciandosé su longitud, ancho, pilosidad y forma de las semillas. 
Britton y Rose (1920) y Anderson (2005) consideran que este taxón es sinónimo de T. chiloensis. Sobre la base de la descripción original y el material recolectado, encontramos evidencia como para considerarlo subespecie de T. chiloensis, por ejemplo, el porte ascendente de los tallos, ramificados a nivel del suelo, mientras que las demás subespecies pueden sobrepasar los $2 \mathrm{~m}$ y conformar arbustos y arbolitos, ramificados a pocos metros del suelo.

Material de Herbario estudiado: Chile, III Región de Atacama, Prov. Huasco, Mpio. Vallenar, 31 $\mathrm{Km}$ SW of the Panamericana on the gravel road to Mina Algarrobo, 28046.74'S, 70058.02'W, 1100-1250 m, 7 Dic. 1994, U. Eggli \& B.E. Leuenberger 2591 (SGO); IV Región de Coquimbo, Talinay, cerca de Ovalle, 24 Sep. 1957, C. Muñoz P. 4306 (SGO).

18. Trichocereus clavatus F. Ritter, Kakteen Südamerika 2: 564. 1980.

Echinopsis clavatus (F. Ritter) Hunt, Cactaceae Consensus Init. 4: 5. 1997. TIPO: Bolivia, Dpto. La Paz, Prov. Larecaja, mina Cascabel, 2800 m, F. Ritter 327 (Holotipo, U, no visto). Tipo citado para U, I.c. 1: iii, 1979.

Descripción original de Trichocereus clavatus F. Ritter, Kakteen Südamerika 2: 564. 1980:

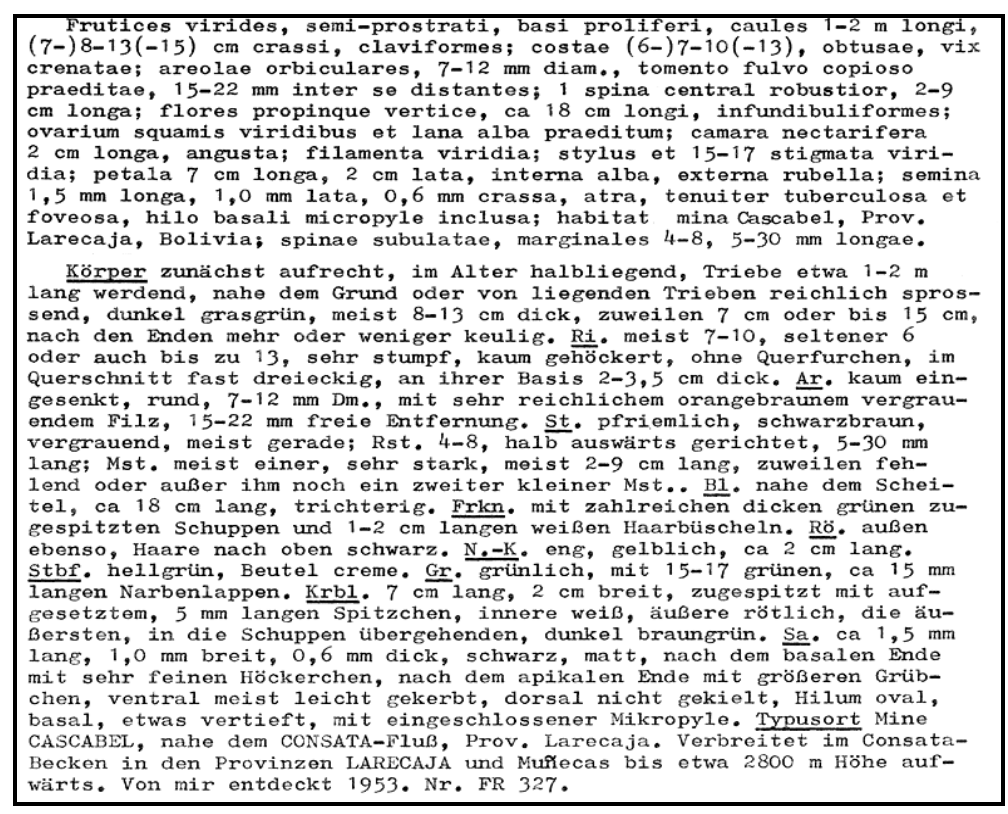

Descripción ampliada: Tallos inicialmente verticales para luego reclinarse, 1 a $2 \mathrm{~m}$ de largo, ramificados desde la base, $7-15 \mathrm{~cm}$ de diámetro, claviformes (con el extremo superior redondeado). Costillas 6-13, obtusas y ligeramente crenadas. Areolas circulares, 7-12 mm de diámetro, con abundante pilosidad amarillo-marrón, 15-22 mm de separación entre las areolas. Una espina central, subulada, 2 a 9 cm de largo, 2,5 mm de diámetro, marrón-oscuro en la base con el ápice más oscuro, radiales 4-8, 
subuladas, $2 \mathrm{~mm}$ de diámetro, 0,5-3,5 cm de largo y vinotino. Flores cerca del ápice, $18-20 \mathrm{~cm}$ de largo; ovario y receptáculo provisto de escamas de cuyas axilas nacen pelos blancos; cámara nectarial de $2 \mathrm{~cm}$ de largo y angosta; tépalos de $7 \mathrm{~cm}$ de largo, $2 \mathrm{~cm}$ de ancho, los internos blancos y los externos rosados. Semillas de 1,5 mm de largo, $1 \mathrm{~mm}$ de diámetro y 0,6 mm de grosor, negras, finamente tuberculada y con agujeros.

Distribución y hábitat: Bolivia en la provincia fitogeográfica puneña, valles secos interandinos aislados en la alta cuenca del río Beni, 2500-3000 m (Cabrera \& Willink 1980; Navarro 1996, Albesiano 2014). También, se localiza en el departamento de Chuquisaca, a $3000 \mathrm{~m}$, sobre laderas pedregosas, casi desnudas (Fig. 74).

Comentarios morfológicos y sus consecuencias en la taxonomía y nomenclatura: $T$. clavatus y $T$. camarguensis se diferencian por la forma de los tallos (claviformes vs. cilíndricos) y por la forma de las espinas (subuladas vs. aciculares).

Material de Herbario estudiado: Bolivia, Dpto. Chuquisaca, Prov. Nor Cinti, cerca de $40 \mathrm{Km}$ al norte de Camargo, Tucu Mayo, 3000 m, 17 Nov. 1993, R. Kiesling \& D. Metzing 8388 (LPB).

19. Trichocereus cuzcoensis Britton \& Rose, The Cactaceae 2: 136.1920

Cereus cuzcoensis (Britton \& Rose) Werderm. Neue Kakteen 101. 1931. Echinopsis cuzcoensis (Britton \& Rose) H. Friedrich \& G.D. Rowley, I.O.S. Bull. 3(3): 95. 1974. TIPO: Perú, Cuzco, 1 Sep. 1914, J. N. Rose 19022 (Holotipo, US perdido, Isotipo NY 386188!).

Trichocereus schoenii Rauh \& Backeb. Sitzungsber. Heidelberger Akad. Wiss., Math.-Naturwiss. KI. 1: 362, ill. 1958. Echinopsis schoenii (Rauh \& Backeb.) H.Friedrich \& G.D.Rowley. I.O.S. Bull. 3(3): 97. 1974, nom. inval., por no designar tipo (Art. 40.1).

Iconografías: Backeberg (1959a), foto 1079: 1122. Ritter (1981), foto 1190: 1552. Hunt et al. (2006), fig. 4: 234. 
Descripción original de Trichocereus cuzcoensis Britton \& Rose, The Cactaceae 2: 136. 1920:

Plants tall, 5 to 6 meters high, much branched, the branches somewhat spreading, light green when young; ribs 7 or 8 , low and rounded; areoles rather close together, 1 to $1.5 \mathrm{~cm}$. apart; spines numerous, often 12 , very stout, rigid, sometimes $7 \mathrm{~cm}$. long, swollen at base; flowers 12 to $14 \mathrm{~cm}$. long, doubtless nocturnal but, sometimes at least, remaining open during the morning, fragrant; flower-tube green, 5 to $6 \mathrm{~cm}$. long; inner perianthsegments oblong, white, 4 to $5 \mathrm{~cm}$. long; filaments weak, declining on the lower side of the throat; scales on the ovary and flower-tube small, bearing a few long hairs in their axils; fruit not known.

Collecied by J. N. Rose below Cuzco, Peru, September 1, 1914 (No. 19022).

Descripción ampliada: Plantas muy ramificadas, altas, de $6 \mathrm{~m}$ alt. Ramas erectas, rectas y cilíndricas, 7-10 cm de grosor, verde-brillante cuando jóvenes. Costillas 8 , bajas y redondeadas. Areolas ovaladas, 7-12 mm de largo, muy próximas entre sí, 1,0-1,5 cm de separación y con abundante pilosidad marrón. Espinas centrales 2-4, rígidas, 4-8 cm de largo; espinas radiales 8-16, de 1,0-1,5 cm de largo, las superiores subuladas y de 1,5-3,0 cm de longitud. Flores de $12-20 \mathrm{~cm}$ de largo, apicales y subapicales, 5 , tubo floral de $6 \mathrm{~cm}$ de longitud, cámara nectarial de $13 \mathrm{~mm}$ de largo, tépalos oblongos, blancos, 4-9 cm de longitud (Fig. 26).

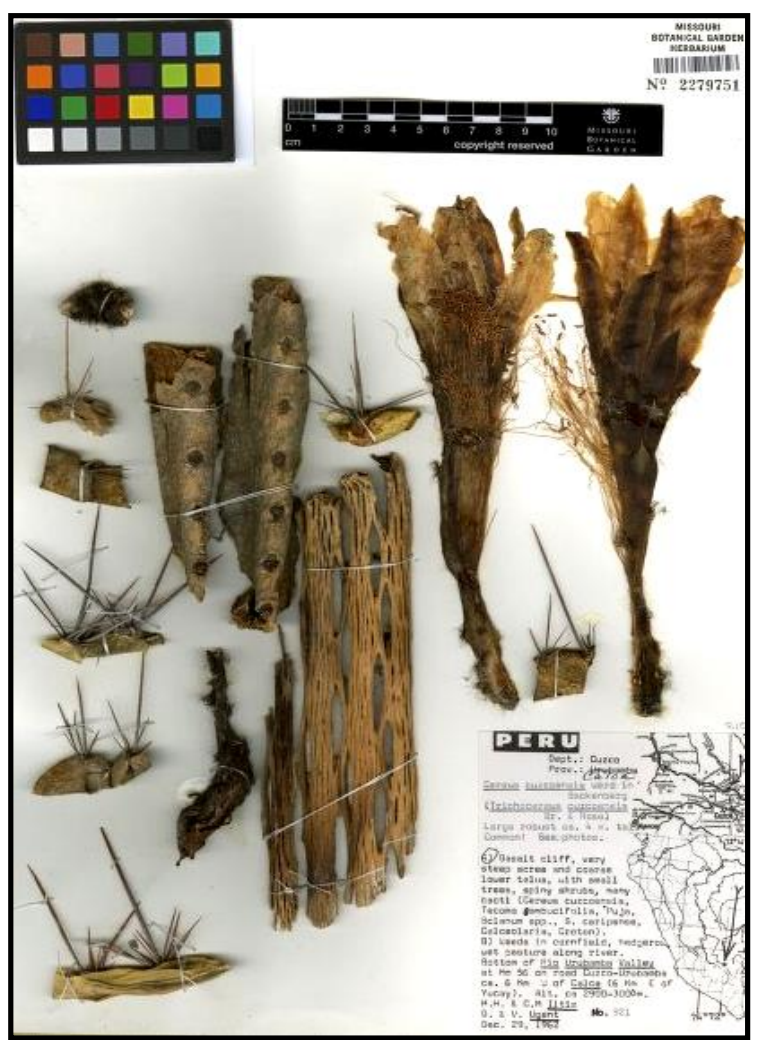

Figura 26. Trichocereus cuzcoensis. Bottom of Rio Urubamba Valley at Km 56 on road CuzcoUrubamba, ca. $6 \mathrm{Km}$ W of Calca (6 Km E of Yucay). 
Distribución y hábitat: En Perú meridional, en los departamentos de Ayacucho y Cuzco, entre 3000-3400 m de altitud (Fig. 76).

\section{Comentarios morfológicos y sus consecuencias en la taxonomía y nomenclatura: $T$.} cuzcoensis es semejante a T. macrogonus var. macrogonus por el número de costillas (menos de 9), y el diámetro de las ramas (inferior de $10 \mathrm{~cm}$ ), pero se diferencia de esta variedad por el color de los tallos (verde-brillante vs. verde-azulado o claro) y la menor distancia entre las areolas (1,0-1,5 cm vs. 2,0-2,5 cm). Además, Ritter (1981) diferenciaba estos dos taxones por la forma de las areolas (ovaladas vs. circulares).

En una comunicación enviada por Rusty Russell y John Boggan, curadores del herbario US (Smithsonian Institution), informan que el ejemplar tipo: J.N. Rose 19022 no existe en esta institución, como aparece citada en Hunt et al. (2006).

En la descripción original de Trichocereus schoenii se indica el número de recolección en campo, K185, pero hace falta la designación del ejemplar tipo, lo cual invalida el nombre.

Material de Herbario estudiado: Perú, Dpto. Cuzco, near Anta, chiefly valleys, lower mountain slopes, open inter Andine brush formation, 3600 m, Oct. 1936, J. West 8046 (MO); Province Quispicanchis, on road to Puno, Km 35 north of Cuzco, 3100 m, 11 Nov. 1957, P. C. Hutchison 1812 (MO); 3000 m, 29 Dec. 1962, H. Iltis, et al. 921 (MO). Entre los departamentos de Ayacucho y Apurimac, río Pampas, F. Ritter 677a (121250 SGO); ibidem, 7/1957, F. Ritter 677a (121251 SGO); cerca a Cuzco, 3400 m, F. Ritter 677a (121277 SGO).

20. Trichocereus deserticola (Werderm.) Looser, Chil. Hist. Nat. 33: 614. 1929.

Cereus deserticolus Werderm., en Notizbl. Bot. Gart. Berlin-Dahlem 10: 764. 1929. Trichocereus deserticolus (Werderm.) Backeb., Kaktus-ABC 202. (1935) 1936, nom. illeg., por superfluo, Art. 52.1. Echinopsis deserticola (Werderm.) H. Friedrich \& G.D. Rowley, I.O.S. Bull. 3(3): 95. 1974. TIPO: Chile, Prov. Antofagasta, Dpto. Taltal, Taltal, 500 m, Oct. 1925, Werdermann 869, p.p. (Lectotipo, B, 4594!, designado por Leuenberger \& Eggli: 690. 1996; Isolectotipos U!, F, G, K, LIL, MO!, S, U, US).

Trichocereus fulvilanus F. Ritter, Kakt. And. Sukkulent. 13: 165-167, ill. 1962. TIPO: Chile, Taltal, Jun. 1954, F. Ritter 263 (Holotipo, U 117827!).

Trichocereus serenanus F. Ritter, Kakt. And. Sukkulent. 16 (11): 212. 1965. TIPO: Chile, 15 Km al Oriente de la Serena, F. Ritter 533 (Holotipo, U 116996!).

Iconografías: Backeberg (1959a), fotos 1109-1111: 1143-1144. Hoffmann (1989), lámina 9a: 87. Albesiano (2012), foto 7: 127. 


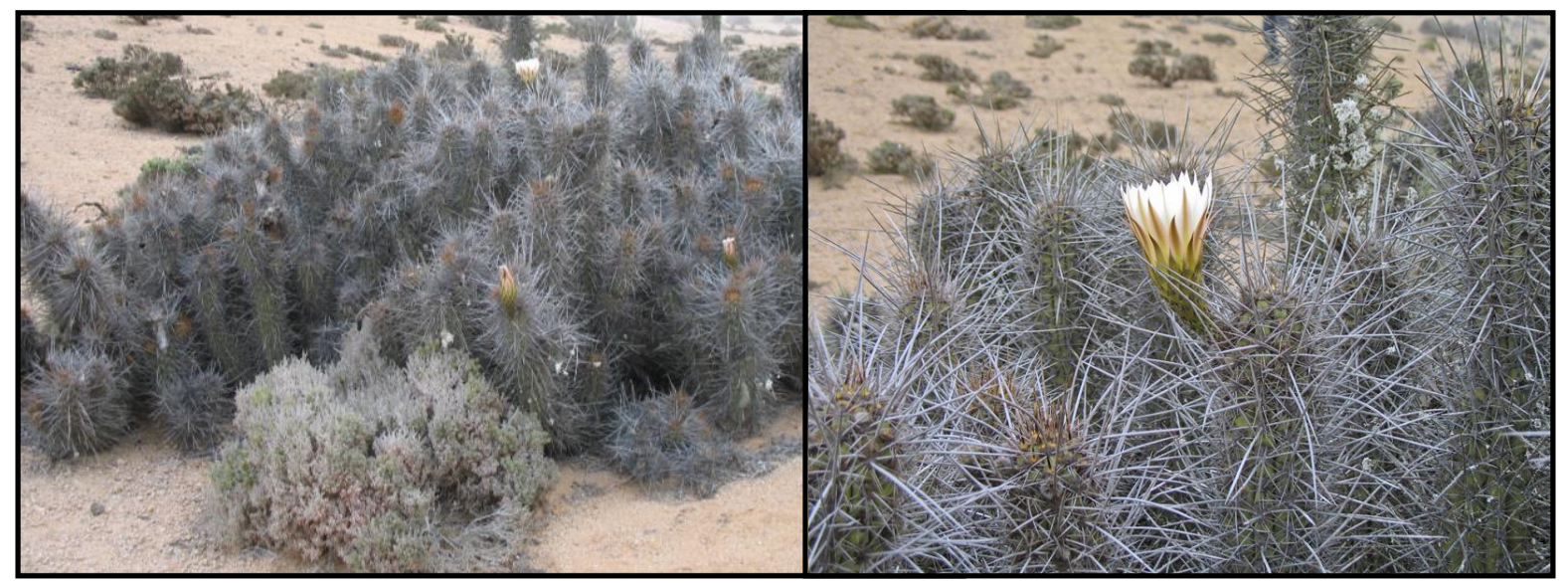

Figura 27. Trichocereus deserticola. Chile, II Región de Antofagasta, Parque Nacional Pan de Azúcar, Comuna Taltal, Las Lomitas.

Descripción original de Cereus deserticolus Werderm., en Notizbl. Bot. Gart. Berlin-Dahlem 10: 764. 1929:

Cereus deserticolus Werd. nov. spec. - Caulis erectus, simplex vel prope basim parce ramosus, altitudine 11,5 m, 7-10 cm diam., apicem versus angustatus; costae 8-10, ad 1,5-2,5 cm altae, supra areolas valde incisae; sinus acuti; areolae ad 1,2-1,5 cm approxi-matae, orbiculares vel ellipticae, $\mathrm{ca} .1 \mathrm{~cm}$ diam., tomento densuspullo dein griseo obtectae; aculei numerosi, 15-25, juventutedide pulli dein grisei, inaequales, peripherici aciculares vel subulata, 1-1,5 cm longi, centrales ca. 1-3, ad $12 \mathrm{~cm}$ longi, rectiarcuati; flores ex areolis junioribus erumpentes, infundibuliformes, $7-8 \mathrm{~cm}$ longi; tubus atque ovarium squamis lanceolatis, acuminatis, sursum gradatim ad 1 cm accrescentibus lanaque pulla ex squamorum axillis oriunda onsite; perigonii phylla exterior lanceolata, ad 3,5 $\mathrm{cm}$ longa, interior oblongo-lanceolata, $c a .4 \mathrm{~cm}$ longa, $c a .1,2-1,3 \mathrm{~cm}$ lata, basi attenuata, albida; stamina numerosa in-sequalia in tubi pariete ascendentia, quam petala multa breviora; stylus staminibus longioribus subaequilongus, ca. $4 \mathrm{~cm}$ longus; stigmata ca. 16 ad $1 \mathrm{~cm}$ longa; fructus ignotus.

Chile: Prov. Antofagasta, Dept. Taltal, bei Taltal, in ca. $500 \mathrm{~m}$

Höhe (blühend im Oktober 1925 - Werdermann n. 869).

Die Pflanzen wuchsen in einer vom Küstennebel reichlichbefeuchteten Schlucht oberhalb der Hafenstadt Taltal auf felsigemBoden oder zwischen grobem Gesteinsschutt. Am Grunde nieder? egend und häufiger verzweigt waren die Säulen gegen die Spitzem ca. $1 \mathrm{~m}$ bis $1,5 \mathrm{~m}$ lang aufgerichtet und 7-10 cm dick.

DiePlanzen standen einzeln oder zu kleinen, aber dichten Heckenmsammengeschlossen. Nur wenige Exemplare hatten schon ihretrichterförmigen, reinweißen und relative kurzen Blüten entwickelt.

Die neue Art ist zweifellos nahe verwandt mit Cereus nigripilis Phil., welchen Britton et Rose, Cactaceae II, p. 139, wieder als Synonym zu Cereus (Trichocereus) coquimbanus (Mol.) K. Sch. stellen. Sieweicht jedoch von diesem durch die geringere Zahl der durch scharfeFurchen voneinander getrennten Rippen, die bis auf die langen und Stark entwickelten 1-3 Mittelstacheln viel schwächere Bestachelungund die relativ kurzen Blüten ab.

Descripción ampliada: Plantas de hasta 1,5 $\mathrm{m}$ de alto, formando densos arbustos bajos. Tallos ligeramente arqueados y cilíndricos, 4 a $10 \mathrm{~cm}$ de diámetro, las inferiores procumbentes. Epidermis opaca y finamente aterciopelada. Costillas obtusas, surcos agudos, en el ápice 8-12, de $1 \mathrm{~cm}$ de ancho, $1 \mathrm{~cm}$ de alto; areolas obovadas, 4-6 mm de separación, las jóvenes $4 \mathrm{~mm}$ de alto, 1,0-1,4 cm de ancho, con pilosidad marrón-claro en la mitad superior y marrón-oscuro en la inferior o naranja-rojizo. Espinas rectas y algunas ligeramente onduladas, centrales 4 , aciculares, dispuestas en cruz, algunas crecen hacia 
arriba, 1,5 mm de diámetro, las más largas alcanzan los $8 \mathrm{~cm}$, negras con base amarilla o gris-oscuro con manchas negras, algunas cubiertas por líquenes (las que habitan zonas más húmedas); radiales 9-16, aciculares, 0,6-3,0 cm de largo, cinco espinas son amarillo-marrón y las restantes grises con ápice negro. Costillas de la base 10-15, $1 \mathrm{~cm}$ de ancho, 0,7-1,0 cm de alto; con areolas de 2-5 mm de alto, 0,5-1,4 cm de ancho, pilosidad marrón, gris o negro; con espinas centrales 4-6, blancas o verde-oliva con manchas marrones, aciculares, $2 \mathrm{~mm}$ de diámetro, $2-10 \mathrm{~cm}$ de largo (dos son las más largas), crecen horizontalmente; radiales 14-20, aciculares, marrón a marrón-verdoso, 1,1 cm de largo. Flores apicales, 1 0 2, con abundante pilosidad marrón en el ovario y tubo floral, 8-13 cm de largo; corola $6 \mathrm{~cm}$ de diámetro (cuando abiertas); ovario 2,0-2,5 cm de diámetro; escamas florales intermedias de $2 \mathrm{~cm}$ de longitud, con borde marrón y centro verde; escamas superiores $4,5 \mathrm{~cm}$ de largo, ápice rojo a rosa con bordes amarillos y centro verde; tépalos 4,3-5,3 cm de longitud, 1,3-2,0 cm de ancho, blancos a amarillos con líneas longitudinales rosa; estilo verde, $5 \mathrm{~cm}$ de largo, $3 \mathrm{~mm}$ de diámetro; estigma amarillo-claro, hasta $2 \mathrm{~cm}$ de largo y con más de 10 lóbulos. Pseudobayas principalmente apicales, 4-6 cm de largo, cubiertas con escamas subuladas de cuyas axilas emergen pelos de 4-6 mm de largo. Semillas de $1 \mathrm{~mm}$ de longitud (Fig. 27).

Distribución y Hábitat: Trichocereus deserticola crece en Chile (Fig. 75A), en las regiones II, III y IV (Faúndez en Kiesling et al. 2008), en los cerros de la cordillera de la costa, sobre cuerpos rocosos 0 entre grandes escombros de piedra, con pendientes que superan los 20 grados de inclinación, entre 250 y $600 \mathrm{~m}$ de altitud. Como especies acompañantes se encuentran: Heliotropium stenophyllum (Boraginaceae), Encelia canescens (Asteraceae), Adesmia argentea (Fabaceae), entre otras (Hoffmann 1989; Gajardo 1995).

\section{Comentarios morfológicos y sus consecuencias en la taxonomía y nomenclatura: Después} de comparar las descripciones originales junto al material herborizado de Cereus deserticolus, Trichocereus fulvilanus y Trichocereus serenanus, se propone reunirlos como sinónimos de $T$. deserticola, ya que se observa una similitud alta en el porte (arbustos pequeños de 1,5 m de alto), grosor de los tallos (menor de $10 \mathrm{~cm}$ ), número de costillas (inferior a 13), número de espinas centrales (ca. 4) y fisonomía de las espinas (aciculares, rectas y algunas ligeramente onduladas).

El holotipo de Cereus deserticolus (Werdermann 869) fue depositado en el herbario de Berlín y posteriormente destruido en 1943, durante la segunda guerra mundial, pero los isotipos se conservaron, gracias a que fueron guardados aparte del herbario general. Lamentablemente, algunos de ellos fueron severamente deteriorados por el agua, según lo comentado por Werdermann (1944), en una lista de sus duplicados, haciendo referencia a la serie No. 837 a 875 , los cuales fueron remplazados por otro conjunto de duplicados, entre los que se encontraba C. deserticolus, Werdermann 869, los cuales fueron distribuidos a otros herbarios. Los duplicados del ejemplar: Werdermann 869 fueron revisados por 
Leunberger y Eggli (1996), quienes aseguran que todos son mezcla, por cuanto las flores son de Trichocereus, y los fragmentos del tallo muestran caracteres anatómicos de Eulychnia.

Leuenberger \& Eggli (1996) consideran que en la descripción original de C. deserticolus (Werdermann 1929), el color de las espinas (gris-oscuro a gris-negrusco) y tomento de las areolas (negrusco a gris), corresponden a Eulychnia iquiquensis, pero no a $C$. deserticolus, con lo cual estoy en desacuerdo, debido a que en la comuna de Taltal, se encontraron individuos de $C$. deserticolus cuyas espinas centrales del ápice son negras o marrón-oscuro con base verde-claro, y las de la parte media del tallo principa son grises, también, el tomento de las areolas es gris, lo cual corresponde a lo descrito en la descripción original de esta especie.

Material de Herbario estudiado: Chile, $\Perp$ Región de Antofagasta, Prov. Antofagasta, Mpio. Taltal, $6 \mathrm{Km}$ E (above) of Paposo on road connecting to the Panamericana, 250.97'S; 70²6.21'W, 550600 m, 15 Dic. 1994, U. Eggli \& B. Leuenberger 2653 (SGO); 21 km N of Taltal towards Paposo, c. 1Km inland into Qda. Hueso Parado, somewhat to the N of Punta Agua Dulce, 25014.1'S; 70²5.4'W, 220 m, 17 Dic. 1994, U. Eggli \& B. Leuenberger 2664 (SGO); Cerro Perales, immediately E of Taltal, 25०25.5'S; 70²5.24'W, 600-800 m, 10 Oct. 1997, U. Eggli 2915 (SGO); Qda. Huanillos, comuna Taltal, 25057'35"S; 70³8'39"W, 256 m, 7 Nov. 2008, S. Albesiano, L. Faúndez, R. Flores \& P. Saldivia, 2055 (MERL, AGUCH); Parque Nacional Pan de Azúcar, Comuna Taltal, Las Lomitas, 25059'0,5"S; 70³6 '43"W, 693 m, 8 Nov. 2008, S. Albesiano, L. Faúndez, R. Flores \& P. Saldivia 2058 (MERL, AGUCH). II Región de Atacama, Prov. Chañaral, Falda Verde, $26^{0} 17.41^{\prime} \mathrm{S} ; 70^{\circ} 38.27^{\prime} \mathrm{W}, 400-450 \mathrm{~m}, 5$ Oct. 1997, U. Eggli 2888 (SGO); Qda. León, 26056’01”S, 7044'30”W, 329 m, 9 Nov. 2008, S. Albesiano, L. Faúndez, R. Flores \& P. Saldivia. 2060 (MERL, AGUCH); Prov. Copiapó, Comuna Copiapó, Qda. Matamoros, 27053'48"S; 71005'10"W, 193 m, 10 Nov. 2008, S. Albesiano, L. Faúndez, R. Flores \& P. Saldivia. 2061 (MERL, AGUCH); Prov. Huasco, Mun. Huasco, 11 Km N of Huasco Bajo, 28²3.38'S; 71011.18'W, 20-70 m, 20 Oct. 1997, U. Eggli \& B.E. Leuenberger, 2999 (SGO); Comuna Vallenar, 28ㅇ'1'”S; 6872'11”W, 88 m, 11 Oct. 2010, S. Albesiano, R. Kiesling, L. Faúndez \& P. Saldivia, 2089 (MERL).

21. Trichocereus faundezii Albesiano, Haseltonia 18: 128, ill. 2012.

TIPO: Chile, IV Región de Coquimbo, Prov. Choapa, 31²40'25"S; 71¹7'11"W, 197 m, 5 Nov. 2008, S. Albesiano, L. Faúndez, R. Flores \& P. Saldivia 2048. (Holotipo: MERL! Isotipo: AGUCH 64088!).

Iconografías: Albesiano (2012), fotos 8-9: 128. 
Descripción original de Trichocereus faundezii Albesiano.

Plantae caespitosae $80 \mathrm{~cm}$ altae. Rami decumbentes, aliqui arcuti, $14 \mathrm{~cm}$ diametri, viridulae. Costae 14-18, tuberculatae, obtusae, $2 \mathrm{~cm}$ latae et $3 \mathrm{~mm}$ altae. Areoles oblongae, $1 \mathrm{~mm}$ altae, $8 \mathrm{~mm}$ latae, cinereae. Spinae rigidae, aciculae et cinereae, centrales $1-3$, diametri $1 \mathrm{~mm}, 3.5 \mathrm{~cm}$ longae; radiales 9-12, longae $2 \mathrm{~cm}$, diametri $0.5 \mathrm{~mm}$, divaricatae. Flores 2-6, subapicales, $11 \mathrm{~cm}$ longae, $9 \mathrm{~cm}$ diametri, ovarius $2 \mathrm{~cm}$ diametri, squamae florales cum copiosis pilis brunneis, tepali albi cum apice roseo.

Descripción ampliada: Plantas ascendentes de $80 \mathrm{~cm}$ de alto. Ramas decumbentes, algunas arqueadas, $14 \mathrm{~cm}$ diámetro, verde-grisáceo. Costillas del ápice 18, tuberculadas, obtusas, $2 \mathrm{~cm}$ de ancho, $3 \mathrm{~mm}$ de alto; con areolas obovadas, de $1 \mathrm{~mm}$ de alto y $8 \mathrm{~mm}$ de ancho, grises, espinas aciculares, grises, las centrales 1-3, de $1 \mathrm{~mm}$ de diámetro, $2,5 \mathrm{~cm}$ de largo; radiales 9 , de $2 \mathrm{~cm}$ de largo y 0,5 $\mathrm{mm}$ de diámetro. Costillas de la base 14, tuberculadas, obtusas, $2,5 \mathrm{~cm}$ de ancho y $3 \mathrm{~mm}$ de alto; areolas obovadas, $1 \mathrm{~mm}$ de alto, $7 \mathrm{~mm}$ de ancho, grises; espinas grises y aciculares, centrales 3 , de $3,5 \mathrm{~cm}$ de largo, radiales 12 y $1,5 \mathrm{~cm}$ de longitud. Flores 2-6, subapicales, $11 \mathrm{~cm}$ de largo, $9 \mathrm{~cm}$ de diámetro, ovario de $2 \mathrm{~cm}$ de diámetro; escamas florales de la base $6 \mathrm{~mm}$ de largo, las superiores $2 \mathrm{~cm}$ de longitud, base verde, ápice rosado-amarronado y de cuyas axilas emergen abundantes pelos marrón oscuro; tépalos 5 cm de largo; en botones florales son rosado intenso tornándole blancos con ápice rosado-amarronado cuando adultos (Fig. 28).

Etimología: Especie dedicada a Luis Faúndez, botánico chileno, entusiasta, quien gentilmente nos acompañó y orientó en las exploraciones de campo por las zonas áridas y semiáridas de Chile.

Comentarios morfológicos y sus consecuencias en la taxonomía y nomenclatura: Por el habito (plantas ascendentes y menores de 1,5 m), esta especie es parecida a $T$. spinibarbis, pero se distinguen en el siguiente conjunto de caracteres (Tabla 8):

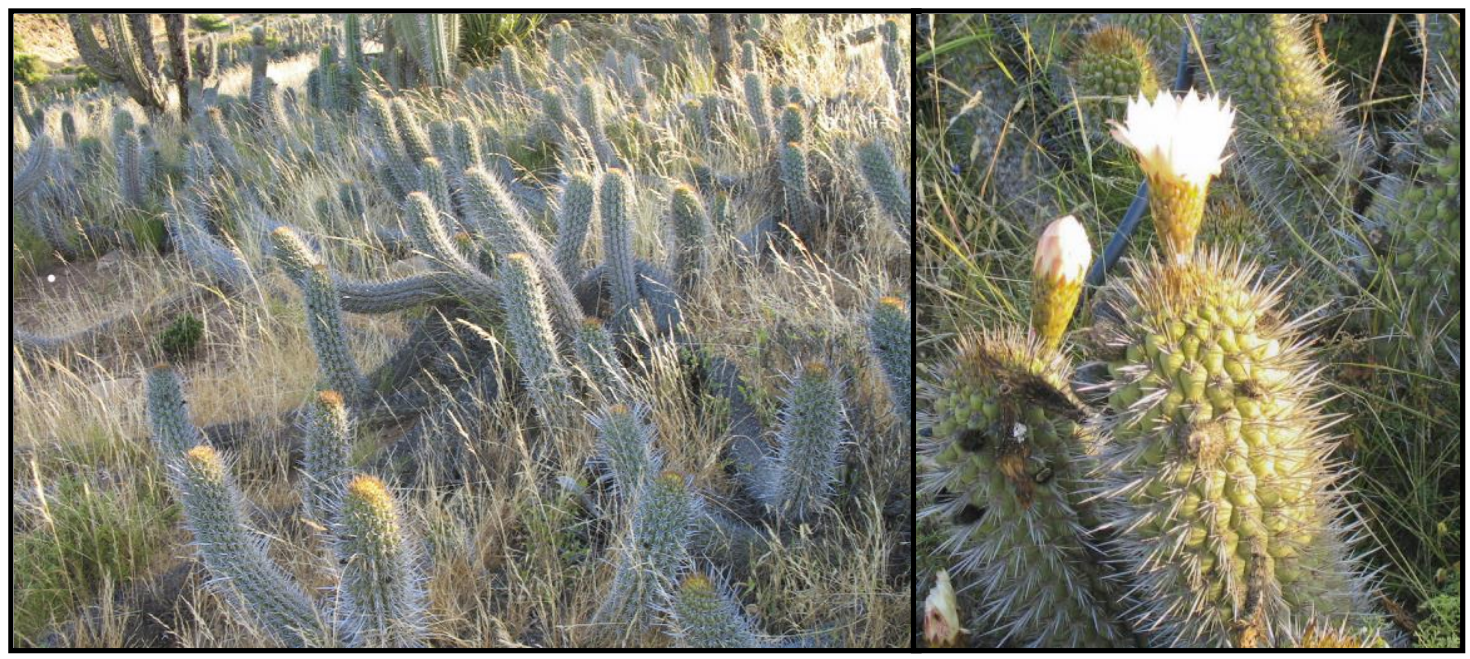

Figura 28. Trichocereus faundezii. Chile, IV Región de Coquimbo, Prov. Choapa. 
Tabla 8. Diferencias entre $T$. faundezii y $T$. spinibarbis

\begin{tabular}{|l|l|l|}
\hline CARACTERES & T. faundezii & T. spinibarbis \\
\hline Diámetro de las ramas & $14 \mathrm{~cm}$ & $10 \mathrm{~cm}$ \\
\hline No. de costillas en el ápice & 18 & 12 \\
\hline Costillas tuberculadas & Presente & Ausente \\
\hline Ancho de las costillas & $2 \mathrm{~cm}$ & $1 \mathrm{~cm}$ \\
\hline Longitud de las espinas centrales & $2,5 \mathrm{~cm}$ & $10 \mathrm{~cm}$ \\
\hline
\end{tabular}

22. Trichocereus herzogianus Cárdenas, Fuaux Herb. Bull. 1(5): 19, ill. 1953.

Helianthocereus herzogianus (Cárdenas) Backeb., Cactus (Paris) No. 45: 208. 1955. Tipo no designado. Echinopsis herzogiana (Cárdenas) H. Friedrich \& G.D. Rowley, I.O.S. Bull. 3(3): 95. 1974. Echinopsis tarijensis (Vaupel) H. Friedrich \& G.D. Rowley subsp. herzogianus (Cárdenas) G. Navarro, Lazaroa, 17: 56. 1996. TIPO: Bolivia, Prov. Loaiza, Dpto. La Paz, above Araca Valley, near Hacienda Tirco, 2800 m, M. Cárdenas 4826 (Holotipo, "Herb. Cárdenas no encontrado"). TIPO: Bolivia, Dpto. de Chuquisaca, Prov. Oropeza, Mpio Sucre, camino a la Virgen de Chataquita, 3555m, 13 Dic. 2009, S. Albesiano, N. Muruaga, A. Alaria \& R. Paz 2074 (Neotipo, MERL, aquí designado).

Trichocereus herzogianus Cárdenas var. totorensis Cárdenas, Fuaux Herb. Bull. 1(5): 19, ill. 1953. Tipo no designado. Helianthocereus herzogianus (Cárdenas) Backeb. var. totorensis (Cárdenas) Backeb., Cactus (Paris) No. 45: 208. 1955. Echinopsis herzogiana (Cárdenas) H. Friedrich \& G.D. Rowley var. totorensis (Cárdenas) H. Friedrich \& G.D. Rowley, I.O.S. Bull. 3(3): 95. 1974. Trichocereus totorensis (Cárdenas) F. Ritter, Kakteen Südamerika 2: 562. 1980. TIPO: Bolivia, Prov. Totora, Dpto. Cochabamba, about Km. 107 on the highway Cochabamba-Totora, 3400 m, M. Cárdenas 4826a (Holotipo, "Herb. Cárdenas no encontrado"). TIPO: Bolivia, Dpto. Potosí, camino de Vitichi a Potosí, 3223 m, 12 Dic. 2009, S. Albesiano, N. Muruaga, A. Alaria \& R. Paz 2071 (Neotipo, MERL, aquí designado).

Iconografías: Backeberg (1959a), fotos 1277, 1279: 1324. Ritter (1980a), fotos 434, 439: 760, 762. 
Descripción original de Trichocereus herzogianus Cárdenas, Fuaux Herb. Bull. 1(5): 19, ill. 1953:

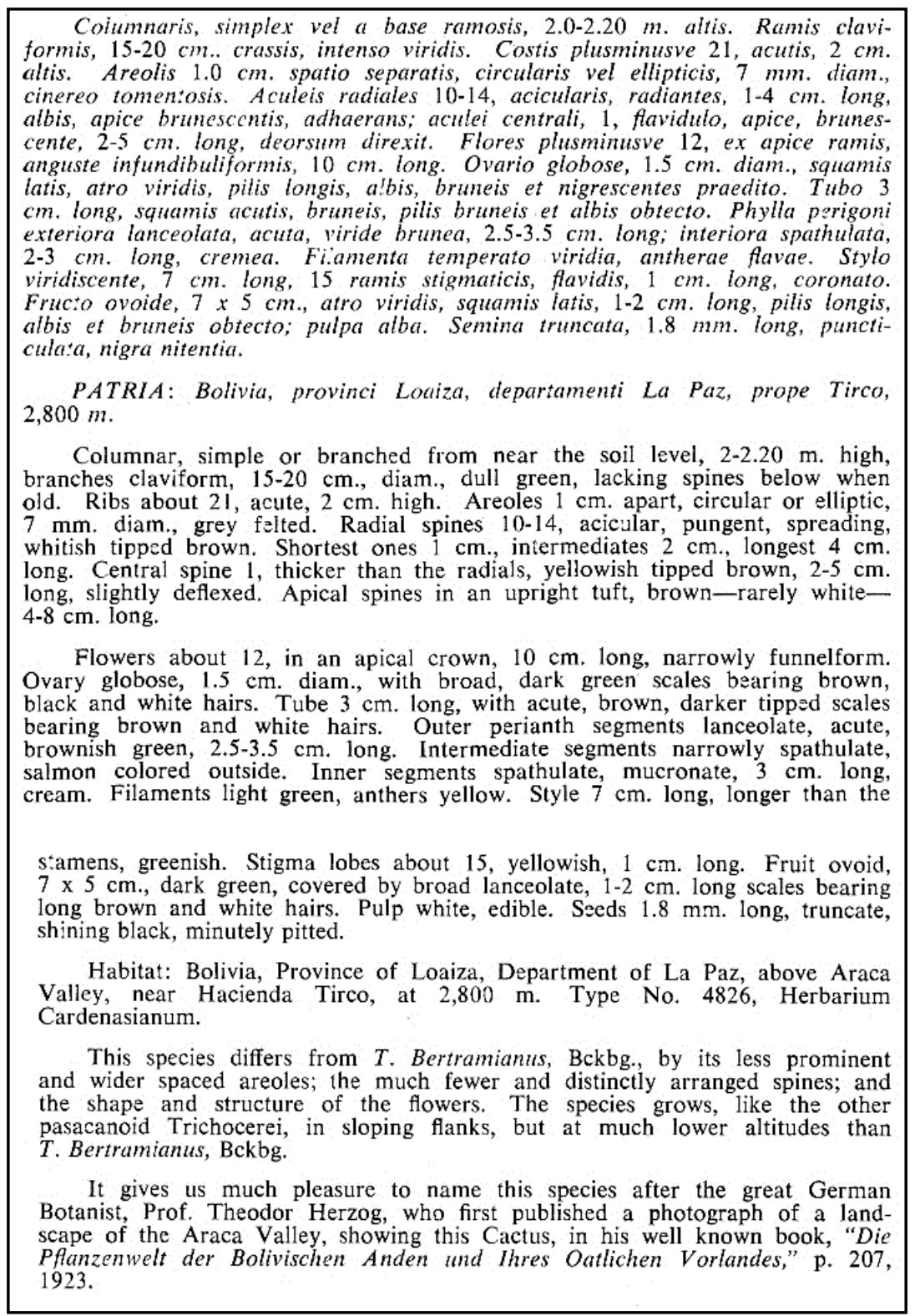

Descripción ampliada: Tallos erectos, simples o ramificados a nivel del suelo, hasta 2,20 m de alto. Ramas de $22 \mathrm{~cm}$ de diámetro, verde-opaco a verde-oscuro y claviformes. Costillas del ápice 15-19, agudas, $2 \mathrm{~cm}$ de ancho, 1,8 cm de alto, areolas ovadas, $4 \mathrm{~mm}$ de alto, 1,8 cm de ancho, amarillas en el ápice, grises en la parte media y baja o totalmente blanco-crema; espinas centrales 1-8, perpendiculares al tallo, 0,4-3,7 cm de largo, aciculares, $1 \mathrm{~mm}$ de diámetro, amarillo-crema, espinas radiales 4-13, de 0,8$3,0 \mathrm{~cm}$ de largo, blanco-crema, aciculares, perpendiculares al tallo, sin entremezclarse con las espinas radiales de las areolas vecinas. Costillas de la base $15-23$, de 0,8-2,5 cm de ancho y 0,6 a 2,5 cm de alto, obtusas; areolas ovadas, 0,2-1,0 cm de alto y 0,4-1,0 cm de ancho, gris-oscuro; 1-6 espinas centrales, 3 
cm de largo, aciculares, verde-oliva, perpendiculares al tallo; espinas radiales 3-15, de 0,7-1,4 cm de largo, aciculares, amarillo-marrón a verde-oliva, formando un ángulo de $20^{\circ}$ grados con el tallo. Flores 10 , generalmente apicales, dispuestas alrededor del ápice, algunas subapicales, 10-13 cm de largo, con abundante pilosidad negra, marrón y blanca en el ovario y tubo floral; corola de $13 \mathrm{~cm}$ de diámetro (cuando abiertas); ovario de 1,5-2,5 cm de ancho; tubo floral de $3 \mathrm{~cm}$ de diámetro; tépalos externos e intermedios lanceolados, agudos, 2,5-5,0 cm de longitud, salmón a fucsia con ápice negro, y los más internos espatulados, mucronados, fucsia, $6 \mathrm{~cm}$ de largo; estilo verde, de 7-9 cm de largo; estigmas con 15 lóbulos, amarillos, 1-2 cm de longitud, pueden superar o no la altura de los estambres. Pseudobaya verde-oscuro, 3,3-5,0 cm de largo y 3-7 cm de diámetro, cavidad ovárica con funículos blancos. Semillas negras, brillantes, 1,5-1,8 mm de largo y cubierta por pequeñas depresiones (Fig. 29).

Distribución y hábitat: Endémica de Bolivia. Se distribuye en las zonas semiáridas interandinas, en los departamentos de Chuquisaca, Cochabamba, Potosí, a una altitud de 2500-3500 m, sobre pendientes rocosas (Fig. 74) (Albesiano 2014).

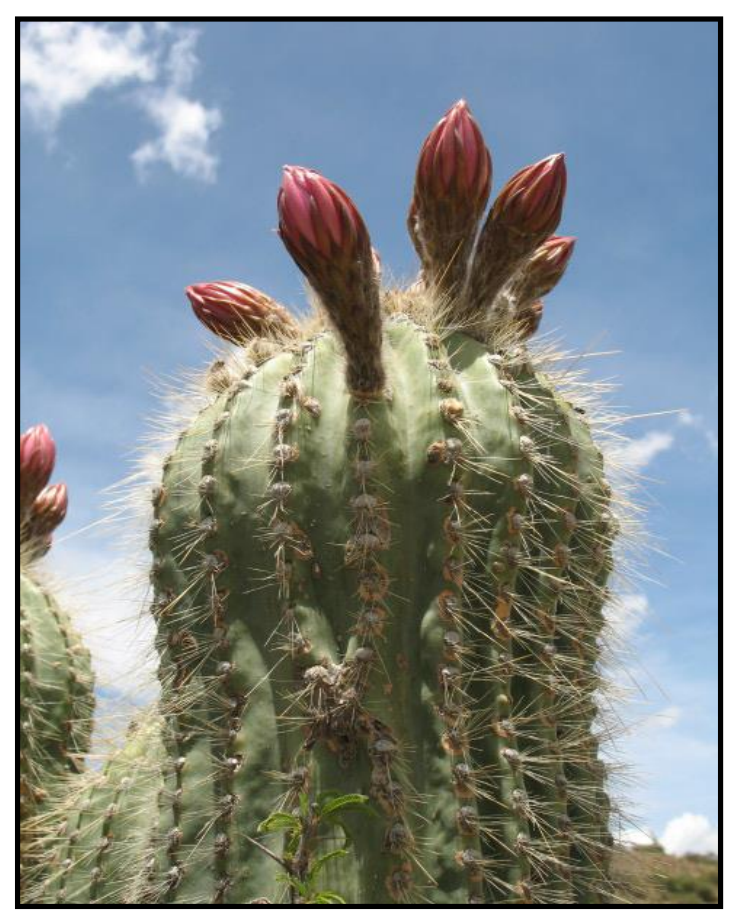

Figura 29. Trichocereus herzogianus. Bolivia, Dpto. Potosí, camino de Vitichi a Potosí.

\section{Comentarios morfológicos y sus consecuencias en la taxonomía y nomenclatura: Los} ejemplares tipo de Trichocereus herzogianus y y de Trichocereus herzogianus var. totorensis se encuentran perdidos, según Eggli \& Leuenberger (2005) y en comunicación personal con la curadora del herbario Lillo (Nora Muruaga), por consiguiente se designan Neotipos para ambos taxones [S. Albesiano et al. 2074 (MERL)] y [S. Albesiano et al. 2071 (MERL)] respectivamente, y los cuales reúnen las características morfológicas mencionadas en la descripción original. 
Navarro 1996, Anderson 2005 y Hunt et al. 2006 consideran a Trichocereus herzogianus subespecie de $T$. tarijensis, pero se han observado caracteres vegetativos que permite separarlos a nivel específico (Tabla 9).

Tabla 9. Diferencias entre $T$. herzogianus y $T$. tarijensis

\begin{tabular}{|l|l|l|}
\hline CARACTERES & T. herzogianus & T. tarijensis \\
\hline Ápice de los tallos & Claviformes & Hemisféricos \\
\hline Diámetro de las ramas & Menores de 22 cm & Entre 22 a $35 \mathrm{~cm}$ \\
\hline Número máximo de costillas & 23 & 35 \\
\hline Número de espinas & Menos de 20 & Entre 20-50 \\
\hline $\begin{array}{l}\text { Contacto de las espinas con las areolas } \\
\text { adyacentes }\end{array}$ & $\begin{array}{l}\text { La gran mayoría de las } \\
\text { espinas no se entrecruzan }\end{array}$ & $\begin{array}{l}\text { Gran proporción de las espinas } \\
\text { se entrecruzan }\end{array}$ \\
\hline
\end{tabular}

T. herzogianus var. totorensis se propone como sinónimo de $T$. herzogianus, ya que se encontraron individuos cuyas espinas presentan caracteres (número, longitud y color) que se encuentran dentro del rango de variación de la especie.

Material de Herbario estudiado: Bolivia, Dpto. Chuquisaca, Prov. Oropeza, Mpio Sucre, camino a la Virgen de Chataquita, 3555m, 13 Dic. 2009, S. Albesiano et al. 2074 (MERL). Dpto. Potosí, camino de Vitichi a Potosí, 3223 m, 12 Dic. 2009, S. Albesiano et al. 2071 (MERL).

23. Trichocereus huascha (F.A.C. Weber) Britton \& Rose, The Cactaceae 2: 142, ill. 1920.

Cereus huascha F.A.C. Weber, Monatsschr. Kakteenk. 3: 151. 1893. Tipo no designado. Lobivia huascha (F.A.C. Weber) W.T. Marshall, Cact. Suc. J. (Los Angeles) 9: 114. 1938. Helianthocereus huascha (F.A.C. Weber) Backeb., Cact. Suc. J. (Los Angeles) 23: 48. 1951. Salpingolobivia huascha (F.A.C. Weber) Y. Itô, Explan. Diagr. Austroechinocactinae 141. 1957. Echinopsis huascha (F.A.C. Weber) H. Friedrich \& G.D. Rowley, I.O.S. Bull. 3(3): 95. 1974. Soehrensia huascha (F.A.C. Weber) Y. Itô. ex Schlumpb., Cactaceae Syst. Init.: 28: 31. 2012, nom. inval., falta la página del basónimo (Art. 41.5), publicado válidamente en Cactaceae Syst. Init:: 29: 5. 2013. Trichocereus huascha (F.A.C. Web.) F. Ritter, Kakteen Südamerika 2: 438. 1980, nom. illeg., por superfluo (Art. 52.1).

Cereus huascha F.A.C. Weber var. flaviflora F.A.C. Weber, Monatsschr. Kakteenk. 3: 151. 1893. Tipo no designado. Trichocereus huascha (F.A.C. Weber) Britton \& Rose var. flaviflora (F.A.C.Weber) Hosseus, Revista Centro Estud. Farm. 2 (6): 20. 1926. TIPO: Argentina, Prov. Catamarca, Dpto. Ambato, Sierra de Ambato, 1096 m, 6 Nov. 2006, B. O. Schlumpberger 433 (Neotipo, CORD, aquí designado).

Lobivia hyalacantha Speg., Anales Soc. Ci. Argent. 99: 122. 1925. Acanthocalycium hyalacanthum (Speg.) Backeb., Kaktus-ABC: 225. 1936.

Echinopsis hyalacantha (Speg.) Werderm., Gartenflora: 302.1931; Backeb. Neue Kakteen: 85. 1931. Helianthocereus hyalacanthus (Speg.) Backeb. Cactaceae (Backeberg) 2: 1333. 1959. TIPO (Lectotipo, aquí designado: Spegazzini. Anales Soc. Ci. Argent. 99: 122-125. 1925, figura en pág. 123). 
Trichocereus auricolor Backeb., en Backeberg \& Kunth, Kaktus-ABC: 412 (200). (“1935”) 1936. Tipo no designado. Helianthocereus huascha (F.A.C. Weber) Backeb. var. auricolor (Backeb.) Backeb., Cactus (Paris) No. 45: 210. 1955. Echinopsis huascha (F.A.C. Weber) H. Friedrich \& G.D. Rowley var. auricolor (Backeb.) H. Friedrich \& G.D. Rowley, I.O.S. Bull. 3 (3): 95. 1974. TIPO: Argentina, Prov. La Rioja, Dpto. Famatina, Famatina, 1324 m, 11 Nov. 2006, B.O. Schlumpberger 455 (Neotipo, CORD, aquí designado).

Lobivia huascha (F.A.C. Weber) W.T. Marshall var. robusta Rausch, Lobivia 85: 141 (ante pag., 72). 1987. [1985-86 publ. 1987]. Echinopsis huascha (F.A.C. Weber) H. Friedrich \& G.D. Rowley subsp. robusta (Rausch) M. Lowry, Cactaceae Syst. Init.: 14: 14. 2002, nom. inval., falta la página del basónimo (Art. 41.5). Trichocereus huascha (F.A.C. Weber) Britton \& Rose subsp. robustus (Rausch) Guiggi, Cactology 3: 8. 2012. TIPO: Argentina, Catamarca apud Hualfin, Rausch 229 (Holotipo, ZSS).

Helianthocereus huascha var. macranthus Backeb., Kakteenlexikon: 186, ill. 1966, nom. inval., por no designar tipo (Art. 40.1).

Soehrensia huascha (F.A.C. Weber) Y. Itô var. rosiflora Y. Itô, Saboten 51, 52, 54. 1962, (sensu IPNI). Tipo no designado. TIPO: Argentina, Prov. La Rioja, Ruta Prov. No. 15, entre Chamical y La Rioja, a unos 60 Km de la primera. Campo La Chilca, 7 Nov. 1998, F. Biurrun \& L. Blanco 5415 (Neotipo, SI, aquí designado).

Iconografías: Anderson (2005): 231. Hunt et al. (2006), fig. 5: 250. Kiesling \& Ferrari (2005), foto 43: 59. Trevisson \& Perea (2009), foto 85: 124.

Descripción original de Cereus huascha F.A.C. Weber, Monatsschr. Kakteenk. 3: 151. 1893:

\begin{tabular}{|c|}
\hline 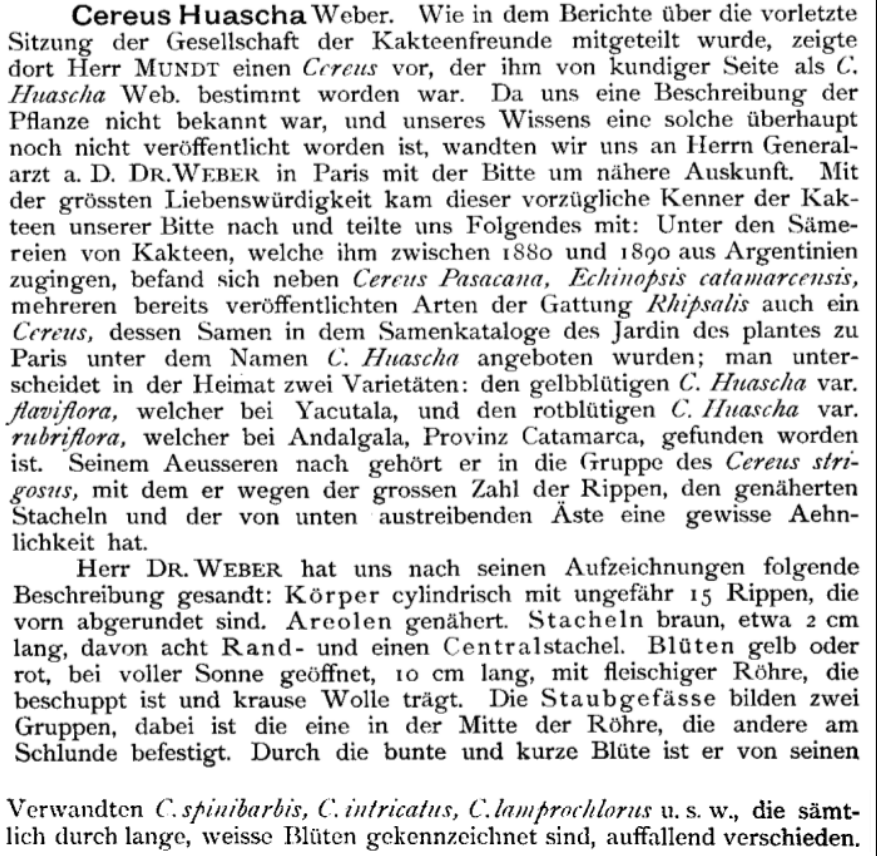 \\
\hline
\end{tabular}


Descripción ampliada: Plantas solitarias o ascendentes. Tallos hasta $1 \mathrm{~m}$ de alto, 4-10 cm de diámetro, cilíndricos, erectos, verde-claro cuando jóvenes a verde-grisáceo cuando adultos, ramificados en la base. Costillas 15-17, obtusas, $1 \mathrm{~cm}$ de ancho, 5-10 mm de alto; con areolas de 4-7 mm de largo, algo hundidas, $1,0-1,5 \mathrm{~cm}$ de distancia entre ellas y con pilosidad blanca. Espinas amarillas, rojizas, marrones a grises, algunas con la punta más oscura, radiales $9-11$, aciculares, 1,5 cm de largo, 0,25 mm de ancho; centrales 1-3, más gruesas que las radiales $(0,3 \mathrm{~mm}), 2-7 \mathrm{~cm}$ de largo. Flores generalmente subapicales, $10 \mathrm{~cm}$ de largo, 6-7 cm de diámetro; ovario de $2 \mathrm{~cm}$ de diámetro; escamas florales verdeoliva, las superiores rojizas, de cuyas axilas emergen pelos amarillentos o marrón-rojizo, de $1 \mathrm{~cm}$ de largo; tépalos externos de $4 \mathrm{~cm}$ de longitud, agudos, los interiores son obtusos, mucronados, amarillos, más raro blancos 0 anaranjados raro algo rojizos. Estambres con filamentos de 1,0-3,5 cm de largo, los de la serie superior blancos y los de la serie inferior verdes; estilo blanco, $5 \mathrm{~cm}$ de largo y $2 \mathrm{~mm}$ de ancho, con 17 lóbulos estigmáticos, amarillos y papilosos. Pseudobaya de $3 \mathrm{~cm}$ de diámetro, amarillo o rojizo. Semillas subreniformes, con una cresta longitudinal, $1,4 \mathrm{~mm}$ de largo, $1 \mathrm{~mm}$ de alto y 0,8 $\mathrm{mm}$ de ancho, negras y brillantes.

Distribución y hábitat: Endémica del noroeste argentino. En la provincia de Catamarca en los departamentos de Belén, Andalgalá y Tinogasta. En la Rioja desde el límite norte hasta los departamentos de Famatina y Capital. Ocupa la provincia fitogeográfica del Monte, entre 1000-2000 m de altitud, desprovistos de vegetación o debajo de arbustos xerófilos de Larrea divaricata, Larrea cuneifolia, Zuccagnia punctata, entre otras (Kiesling 1978, Kiesling et al. 2008).

Comentarios morfológicos y sus consecuencias en la taxonomía y nomenclatura: Se seleccionó como Neotipo de Cereus huascha var. flaviflora el ejemplar B. O. Schlumpberger 433 (CORD), porque reúne las características mencionadas en la descripción original, además presenta dos cortes longitudinales de la flor, identificando su forma, longitud, cantidad de escamas y pilosidad, además de presentar dos cortes longitudinales del tallo, uno de ellos corresponde al ápice, donde se observa el número de costillas, tamaño, cantidad y número de espinas.

Se escogió el ejemplar B.O. Schlumpberger 455 (CORD) como Neotipo de Trichocereus auricolor, por cuanto presenta las características vegetativas y reproductivas descritas en la descripción original.

Se seleccionó el ejemplar F. Biurrun \& L. Blanco 5415 (SI) como Neotipo de Soehrensia huascha var. rosiflora por ser el más cercano a la descripción original, además de presentar varios cortes transversales y longitudinales del tallo, observandosé el número de costillas, forma, tamaño y cantidad de espinas radiales y centrales, dos cortes longitudinales de flores y frutos, pudiéndose observar el tamaño, número de escamas, pilosidad y forma de las semillas. 
Trichocereus huascha fue descrita inicialmente en el género Cereus y transferida a Lobivia, Trichocereus y Echinopsis, entre otros. Consideramos que corresponde al género Trichocereus por la combinación de los siguientes caracteres morfológicos: tallos cilíndricos (4-10 cm de diámetro) y flores infundibuliformes de $2 \mathrm{~cm}$ de diámetro a la altura del ovario.

Autores como Anderson (2005) consideran que $T$. huascha y $T$. andalgalensis son especies tan parecidas que las han sinonimizado, pero existen caracteres que permite diferenciarlas como la altura de los tallos (hasta $100 \mathrm{~cm}$ vs. $40 \mathrm{~cm}$ ), disposición de las espinas (irregular vs. regular), y longitud de las flores (hasta $10 \mathrm{~cm}$ vs. $7 \mathrm{~cm}$ ).

Kiesling (1978) observó que los individuos distribuidos sobre las laderas de la cuesta de Zapata (al sur de Catamarca) y otras zonas altas, difieren en el porte de los tallos, longitud de las flores y color de los tépalos del resto de las poblaciones, por lo que este autor propuso la variedad pecheretianus.

\section{Clave para la identificación de las variedades de Trichocereus huascha}

1. Tallos de hasta $100 \mathrm{~cm}$ de alto, $6 \mathrm{~cm}$ de diámetro. Flores de $10-11 \mathrm{~cm}$ de largo

var. huascha

1'. Tallos de hasta $60 \mathrm{~cm}$ de alto, $11 \mathrm{~cm}$ de diámetro. Flores de 7-8 cm de largo var. pecheretianus

\section{Trichocereus huascha (F.A.C. Weber) Britton \& Rose var. huascha}

TIPO: Argentina, Prov. Catamarca, Dpto. Belén, Yacutula, verano de 1879-1880, F. Schickendantz 150 (Neotipo, CORD, aquí designado).

Iconografías: Britton \& Rose (1920), fig. 208-210: 141-142. Backeberg (1959a), fotos 12811283; 1286: 1327-1328. Rauch (1975): 169.

Descripción ampliada: Tallos de $1 \mathrm{~m}$ de alto y $6 \mathrm{~cm}$ de diámetro. Flores amarillas, algunas veces blancas, de 10 hasta $11 \mathrm{~cm}$ de largo (Fig. 30).

Distribución y hábitat: Endémica de la Argentina, se localiza en las provincias de Catamarca y La Rioja, entre 1000-2000 m de altitud (Fig. 73).

Comentarios nomenclaturales: Se eligió el ejemplar F. Schickendantz 150 (CORD) como Neotipo de Trichocereus huascha por ser de la localidad de donde se describió la especie, y por presentar dos cortes longitudinales de la flor, donde se observa el tamaño, ancho del ovario, densidad de las escamas, pilosidad, cantidad y disposición de los estambres, longitud del pistilo y número de estigmas. 


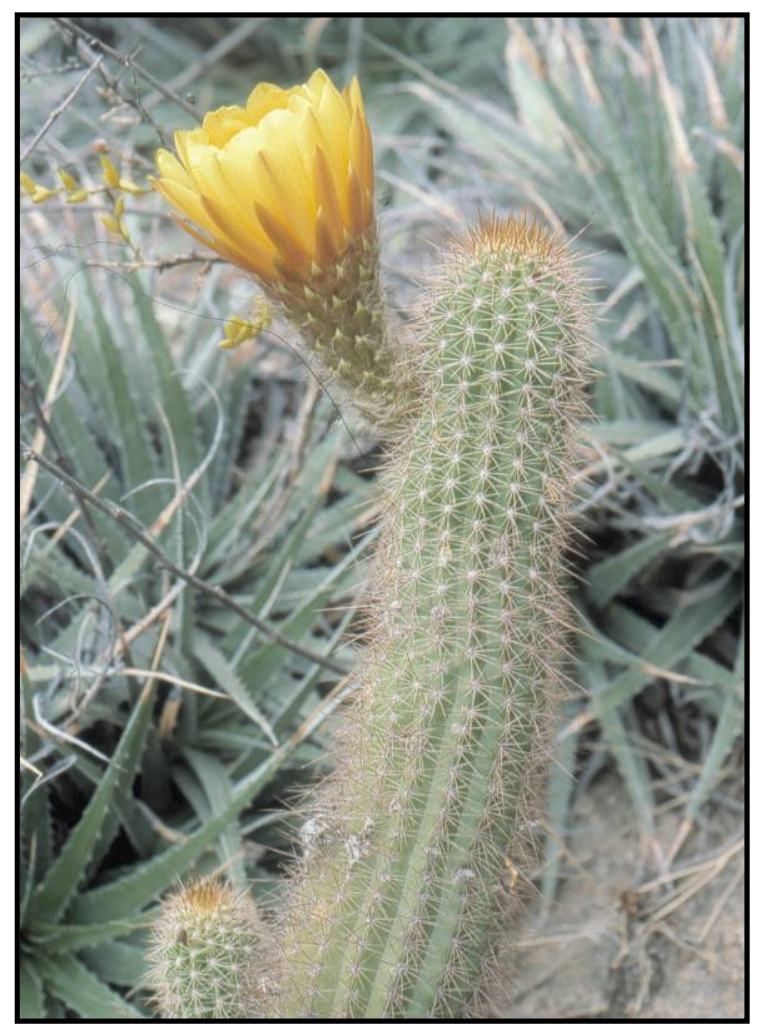

Figura 30. Trichocereus huascha var. huascha. Argentina, Provincia de Catamarca, norte de Belen.

Material de Herbario estudiado: Argentina, Prov. Catamarca, Dpto. Ambato, Sierra de Ambato, 906 m, 7 Nov. 2006, B. O. Schlumpberger 435, 440 (CORD); ibidem, 1087 m, 7 Nov. 2006, B. 0. Schlumpberger 437 (CORD); ibidem, 1087 m, 1 Nov. 2006, B. O. Schlumpberger 439 (CORD); ibidem, 1096 m, 6 Nov. 2006, B. O. Schlumpberger 433 (CORD); ibidem, Ruta No. 40, 1096 m, B.O. Schlumpberger 426 (CORD); ibidem, 1087 m, 8 Nov. 2006, B. O. Schlumpberger 443 (CORD); sur de Cuesta de Zapata, 22 Dic. 1972, R. Kiesling et al. 321 (LP); Dpto. Andalgalá, 1880, C. Spegazzini s.n. (LP, ex LPS 36289); Río Chañaritos, al pie de la cuesta de la Chilca, 10 Dic. 1965, A.T. Hunziker et al. s.n. (CORD 432); 9 Km SE of Andalgalá, via the road to cuesta de la Chilca, 1010 m, 7 Nov. 1972, P. Cantino 415 (CORD); Andalgalá a cuesta de las Chilcas, 30 Nov. 1951, F. Vervoorst 3402 (LIL); Andalgalá a río la Cañada, 980 m, 7 Mar. 1950, F. Vervoorst 693 (LIL); Dpto. Belén, Yacutula, verano de 1879-1880, F. Schickendantz 150 (CORD); ibidem, 26 Oct. 1974, R. Kiesling 803 (LP); Cuesta de Belén, 10 Dic. 1965, A.T. Hunziker et al. 18518, 18519 (CORD); Pozo de Piedra-Granadillas, 1900m, 25-31 Ene. 1952, Sleumer \& Vervoorst 2390 (LIL); Cerrito de la Cruz, 23 Feb. 1973, E.A. Ulibarri 423 (SI); Dpto. Tinogasta, La Mesada 73.5 Km N of Fiambalá on Ruta Provincial 43, 2150 m, 14 Dic. 1998, B.E. Leuenberger et al. 4692 (CORD); Los Nacimientos, 29 Nov. 2006, B.O. Schlumpberger 519 (CORD). Prov. La Rioja, Dpto. Capital, ruta 60, Km 1150-1151, 7 Dic. 1973, A.T. Hunziker \& Biurrun 2882, 2883 (CORD); ibidem, 18 Dic. 1973, A.T. Hunziker s.n. (CORD); vertiente occidental de la Sierra de Ambato, 
7 Feb. 1997, F. Biurrun \& E. Pagliari 4721 (SI); Ruta Prov. No. 15, entre Chamical y La Rioja, a unos 60 Km de la primera. Campo La Chilca, 7 Nov. 1998, F. Biurrun \& L. Blanco 5415 (SI); Dpto. Famatina, Campanas, 26 Oct. 1974, R. Kiesling 805 (LP); Sierra de Famatina, 1324 m, 28 Oct. 2006, B.O. Schlumpberger 412, 414 (CORD); Dpto. Famatina, Famatina, 1324 m, 11 Nov. 2006, B.O. Schlumpberger 455 (CORD); ladera oeste de la sierra de Paimán, 1700 m, Krapovickas \& J.H. Hunziker 5976 (BAB); Dpto. Castro Barros, Anjullón, 2 Mar. 1940, A. Castellanos, s.n. (BA); cuesta de la Cébila, el Alto, 18 Ene. 2007, S. Albesiano et al. 2028 (MERL); La Rioja a Catamarca, Oct. 1974, R. Kiesling s.n. (LP).

25. Trichocereus huascha (F.A.C.Weber) Britton \& Rose var. pecheretianus (Backeb.) R. Kiesling, Darwiniana 21 (2-4): 299. 1978. Helianthocereus pecheretianus Backeb., Cactus (Paris) No. 4647: 278. 1955 (ver también Cactus (Paris) 45: 210. 1955). Echinopsis pecheretiana (Backeb.) H. Friedrich \& G.D. Rowley, I.O.S. Bull. 3 (3): 96. 1974. TIPO: Argentina, fig. 11 (Lectotipo: en Backeb., I.C.: 277. 1955, aquí designado).

Helianthocereus pecheretianus var. viridior Backeb., Kakteenlexikon: 187, ill. 1966, nom. inval., por no designar tipo (Art. 40.1).

Iconografías: Backeberg (1955), fotos 10-12: 277. Backeberg (1979), fotos 162-163: 629-630.

Descripción ampliada: Tallos ascendentes de $60 \mathrm{~cm}$ de alto y $11 \mathrm{~cm}$ de diámetro. Flores amarillas, anaranjadas, rojizas o rosadas, 7 hasta $8 \mathrm{~cm}$ de largo (Fig. 31).

Distribución y hábitat: Endémica de la Argentina. Se localiza en las provincias de Catamarca y La Rioja, entre 1500-2000 m de altitud (Fig. 73).

Comentarios taxonómicos y nomenclaturales: Se rechaza la designación del tipo efectuada por Kiesling, I. c.: 299. 1978, por existir fotos en la publicación original de Backeberg, o sea "material original visto por el autor, y por permitirse en esa fecha una ilustracion como ejemplar tipo (Art. 40.4).

Material de Herbario estudiado: Argentina, Prov. Catamarca, Cuesta de Zapata, 26 Oct. 1974, R. Kiesling 804 (LP); Dpto. Ambato, Sierra de Ambato, 1087 m, 15 Nov. 2006, B.O. Schlumpberger 464 (CORD). 


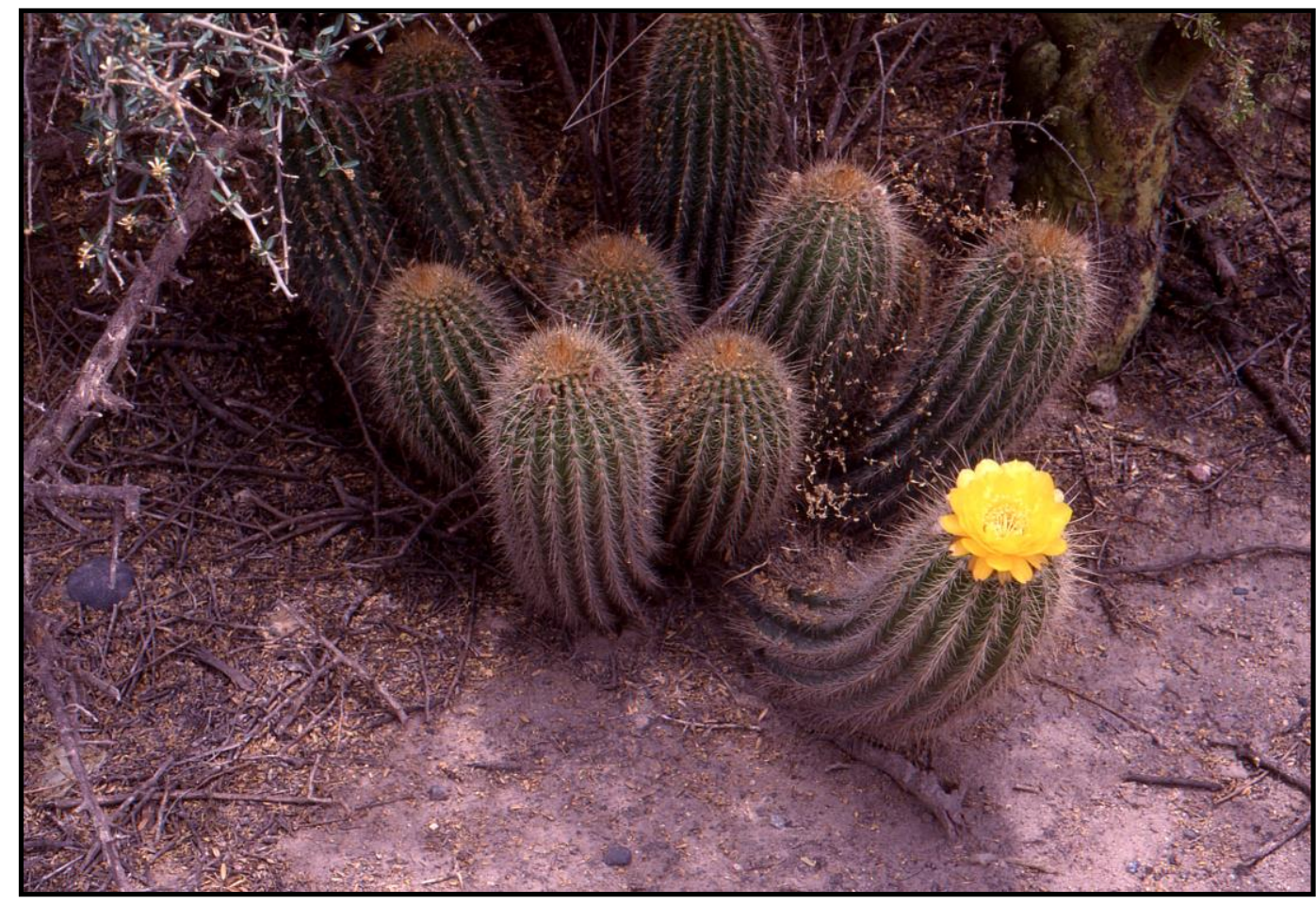

Figura 31. Trichocereus huascha var. pecheretianus. Argentina, sur de Catamarca, Cuesta de Zapata, límite con La Rioja.

26. Trichocereus lamprochlorus (Lem.) Britton \& Rose, The Cactaceae 2: 132, ill. 1920 (excepto descripción y figura).

Cereus lamprochlorus Lem., Cact. Aliq. Nov.: 30. 1838. Tipo no designado. Echinocereus lamprochlorus (Lem.) Engelm. ex J.N. Haage, Preis-Verz. Cact.: 22. 1859. Echinocereus lamprochlorus (Lem.) Rümpler's, Handb. Cacteenk. (ed. 2): 831.1885 (excepto descripción), nom. illeg., por superfluo, Art. 52.1. Echinopsis lamprochlora (Lem.) F.A.C. Weber, Dict. Hort. Bois. 1: 471. 1896. Trichocereus lamprochlorus (Lem.) Backeb., Kakteenlex.: 438. 1966, comb. sup. (Art. 52.1). Echinopsis lamprochlora (Lem.) F.A.C. Weber ex H. Friedrich \& Glaetzle, Bradleya 1: 96. 1983, comb. sup. (Art. 52.1). TIPO: Argentina, Prov. Córdoba, entre La Cumbre y Ascochinga, 24 Feb. 1957, A. Burkart 20438 (Neotipo, SI, aquí designado).

Trichocereus purpureopilosus Weing. Monat. Deutschen Kakteenges. 2: 96. 1930. Tipo no designado. Echinopsis purpureopilosa (Weing.) H. Friedrich \& G.D. Rowley. IOS Bull. 3(3): 97. 1974. TIPO: Argentina, Prov. Córdoba, San Roque, Sierra de Córdoba, 12 Ene. 1881, G. Hieronymus s.n. (Neotipo, CORD, aquí designado).

Trichocereus neolamprochlorus Backeb., Die Cactaceae 2: 1126. 1959, como un nombre nuevo para Echinocereus lamprochlorus (Lem.) Rümpler's. 
Iconografías: Backeberg (1959a), fotos 1083, 1092: 1126, 1133. Kiesling \& Ferrari (2005), foto 44: 60. Trevisson \& Demaio (2006): 66.

Descripción original: de Cereus lamprochlorus Lem., Cact. Aliq. Nov.: 30. 1838:

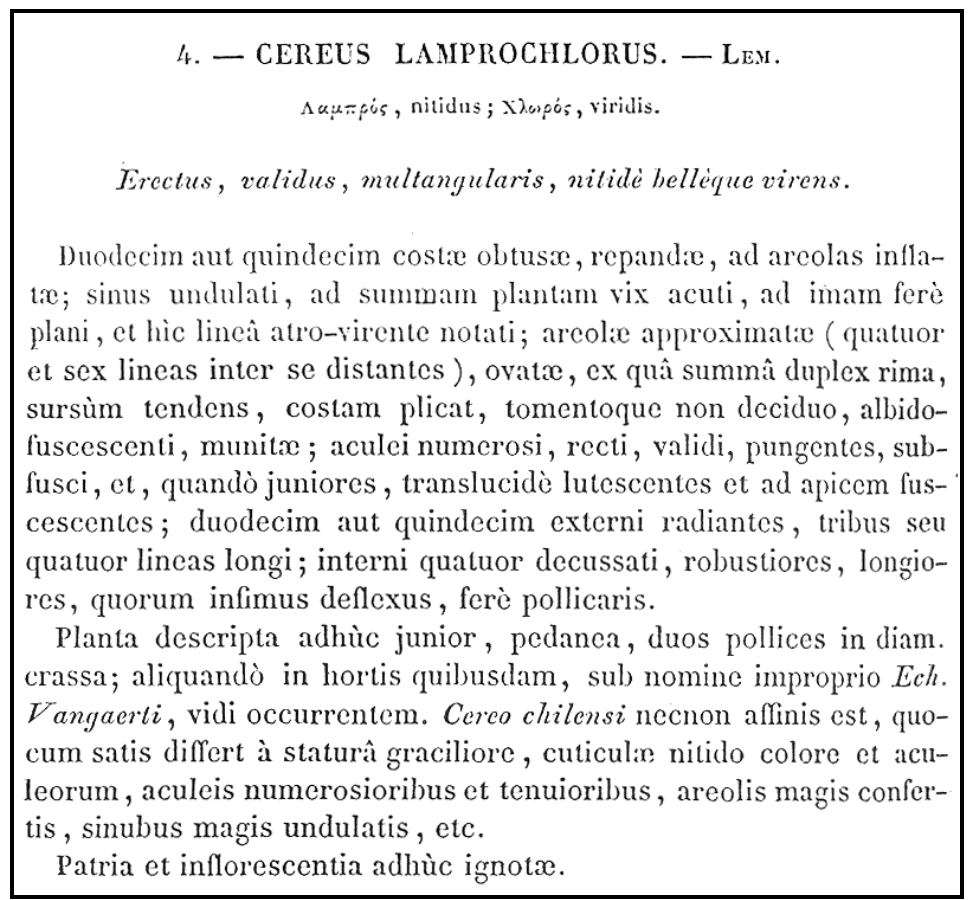

Descripción ampliada: Plantas de hasta un metro de alto, formando densos arbustos bajos, de crecimiento ascendente. Ramas ligeramente arqueadas y cilíndricas, $9 \mathrm{~cm}$ de diámetro, verde-brillante cuando jóvenes, opacas y oscuras cuando adultas. Costillas 12 (11-15), con dos pequeños surcos en forma de "v" encima de las areolas del ápice. Areolas circulares, 3,5 mm de diámetro, separadas $6 \mathrm{~mm}$, las del ápice con tomento blanco-amarillento, y las de la base parda-grisácea. Espinas del ápice amarillohialino, con base oscura, las de la base gris-oscuro a negro; centrales 4 (5), dispuestas en cruz, de 3-10 $\mathrm{mm}$ de largo; radiales 15-19, más delgadas que las centrales, $7 \mathrm{~mm}$ de longitud. Flores generalmente subapicales, infundibuliformes, $22 \mathrm{~cm}$ de largo, con abundante pilosidad purpura-oscuro hasta rojogrisáceo, de $8 \mathrm{~mm}$ de largo en el ovario y tubo floral; corola de $14 \mathrm{~cm}$ de diámetro (cuando abiertas); ovario de 2,2 cm de diámetro; escamas florales de $1 \mathrm{~cm}$ de largo, verdes con ápice marrón, escamas florales del tubo de $2 \mathrm{~cm}$ de largo, verdes; tépalos $5 \mathrm{~cm}$ de longitud, los exteriores rojo-carmín y los interiores blancos; estilo blanco-verdoso en la base, en el ápice verde-claro; lóbulos del estigma amarillos, $1,5 \mathrm{~cm}$ de longitud. Pseudobayas subglobosas, amarillo-anaranjadas, $4 \mathrm{~cm}$ de diámetro y con abundante pilosidad rojiza o rojo-grisáceo (Fig. 32). 


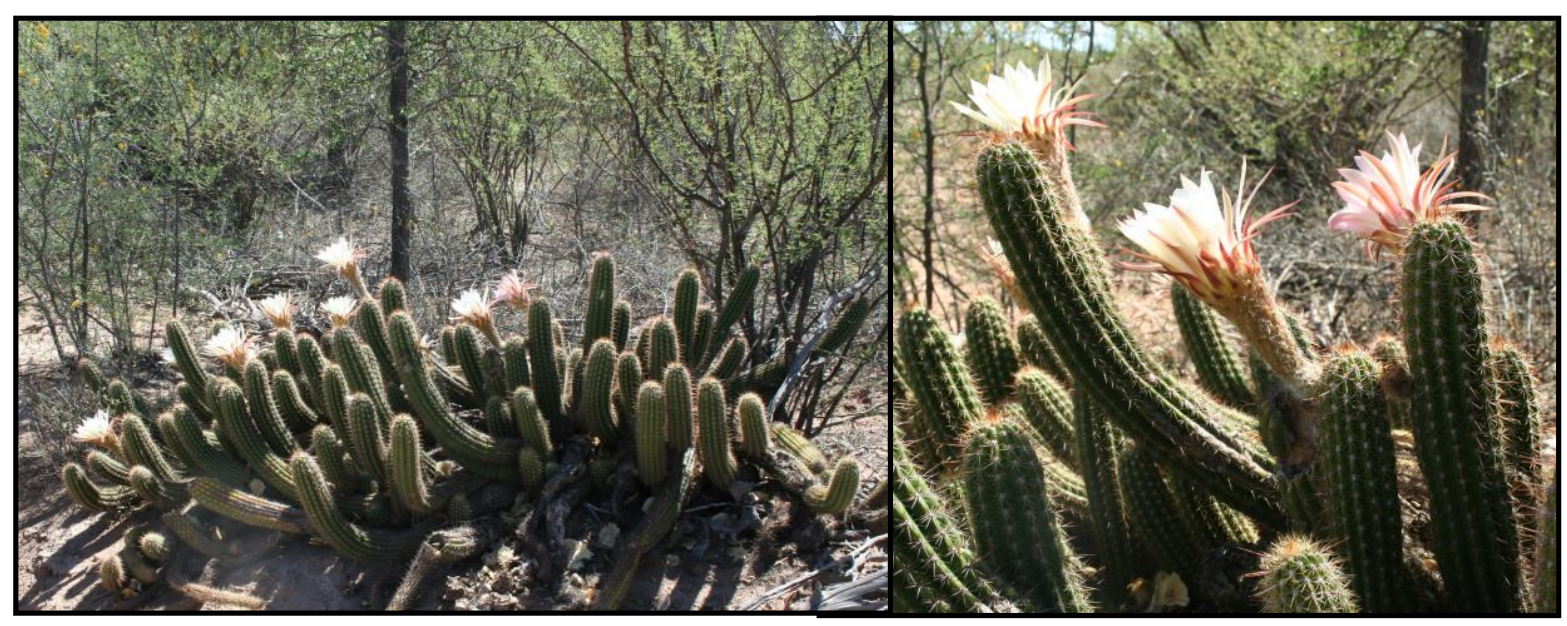

Figura 32. Trichocereus lamprochlorus. Argentina, Provincia de La Rioja, El Milagro.

Distribución y Hábitat: Endemismo de la Argentina, entre 500-1500 m, en las provincias de Córdoba, La Rioja y sur de Santiago del Estero (Fig. 73). En Córdoba se localiza al NW, en los roquedales de las Sierras Grandes y Chicas, y también en las planicies, entre vegetación graminosa rodeada por bosquecillos xerófilos caducifolios del Distrito Chaqueño Serrano. En la Rioja se distribuye al SE, en las Serranías de Malanzan y de Los Llanos, al igual que en las planicies, donde el tipo de vegetación dominante es el bosque xerófilo de Aspidosperma quebracho-blanco, Cereus forbesii, Harrisia pomanensis, Opuntia quimilo, Bromelia serra, entre otras (Kiesling 1978). Las plantas ubicadas en las planicies son de mayor porte $(1 \mathrm{~m})$ y diámetro de sus tallos $(9-12 \mathrm{~cm})$, ocasionada por la mayor disponibilidad de agua y nutrientes.

Comentarios morfológicos y sus consecuencias en la taxonomía y nomenclatura: Se escogió el ejemplar A. Burkart 20438 (SI) como Neotipo de Cereus lamprochlorus porque reúne las características mencionadas en la descripción original, y por presentar tres cortes transversales y tres longitudinales del tallo, observándose la cantidad de costillas, la forma, longitud y cantidad de espinas, dos cortes longitudinales de la flor, donde se aprecia la forma, longitud, diámetro a la altura del ovario, densidad de las escamas y pilosidad.

Se eligió como Neotipo de Trichocereus purpureopilosus el ejemplar G. Hieronymus s.n. (CORD), porque corresponde a la localidad de donde se describió la especie, además presenta dos cortes longitudinales de la flor, donde se observa su tamaño y la pilosidad que se origina de las axilas de las escamas.

Trichocereus lamprochlorus es fácilmente confundible con $T$. spachianus por el diámetro y altura de sus tallos, número de costillas y longitud de sus flores. Se diferencia por las flores laterales y no apicales, por no presentar surco interareolar y por tener areolas blancas y conspicuas. Por lo anterior, Kuntze, Schumann, Spegazzini, Britton y Rose confundieron Cereus lamprochlorus con Trichocereus spachianus, pero también con Trichocereus candicans y con Trichocereus huascha. Inicialmente, Cereus 
lamprochlorus fue descrito por Lemaire en 1838, brindando una descripción de los caracteres vegetativos, sin mencionar los reproductivos ni lugar de origen. En 1859, Engelmann transfiere esta especie al género Echinocereus, y posteriormente Rümpler (:831. 1885), también bajo Echinocereus, menciona el número de costillas (9-11) y como lugar de origen "Bolivia".

En 1892, Kuntze recolecta ejemplares que determina como Cereus lamprochlorus, en la provincia de Jujuy-Argentina, los cuales fueron estudiados por Schumann (:60. 1899), describiendo tallos y flores. Estos especímenes corresponden a T. spachianus (Kiesling, 1978).

Spegazzini (Anales Mus. Nac. Buenos Aires 7: 286. 1902) describe Cereus lamprochlorus var. salinicola, para Bahía Blanca-Prov. Buenos Aires, además de mencionar la presencia de $C$. lamprochlorus en las provincias de Córdoba y Mendoza (1905), pero la distribución de esta especie se restringe a Córdoba, sud-oeste de Sgo. del Estero y la Rioja; sin duda Spegazzini confundió estos taxones con $T$. candicans.

Britton y Rose (2: 132. 1920), transfieren C. lamprochlorus al género Trichocereus, pero en la descripción tuvieron en cuenta el concepto de Schumann (muy seguramente T. spachianus). Asimismo, J.S. Schafer (Schafer 13, NY), en 1917 recolectó para estos autores, cerca de Andalgalá-Prov. de Catamarca, T. huascha, que Britton y Rose incluyeron en Trichocereus lamprochlorus, pero sin utilizarlo para la descripción (Kiesling, 1978).

Material de Herbario estudiado: Argentina, Prov. Córdoba, Sierra de Córdoba, San Roque, 12 Ene. 1881, G. Hieronymus s.n. (CORD); Sierras entre La Cumbre y Ascochinga, 24 Feb. 1957, Burkart A. 20438 (SI); Minas, entre Piedras Blancas y Chacho, 24 Nov. 1976, F. Biurrun et al. 494 (SI); Dpto. Punilla, Palmar a la izquierda de la ruta, llegando a Capilla del Monte, 25 Abr. 1965, E. DiFulvio s.n. (CORD 688). Prov. La Rioja, Chamical, Ruta Nacional 79, entre Chamical y Casa de Piedra, 474 m, 16 May. 1989, Leguiza et al. 8 (SI); Dpto. R.V. Peñaloza, dejando algo al sur de Chepes, la Ruta Prov. No. 31, rumbo al sureste, hacia la Jarilla, 26 Nov. 1997, F. Biurrun et al. 4935 (SI); Dpto. Cnel. Felipe Varela, Ruta Nac. No 40, 1400 m, 30 Nov. 2002, F. Biurrun et al. 7712 (SI); 26 Abr. 1899; C. Spegazzini s.n. (LP, ex LPS 23040). Prov. Santiago del Estero, Ojo de Agua, Sierra de Sumampa, 1 Dic. 1943, A. Castellanos s.n. (BA 47533).

27. Trichocereus macrogonus (Salm-Dyck) Riccob., Boll. Reale Orto Bot. Palermo 8: 236. 1909.

Cereus macrogonus Salm-Dyck, Cact. Hort. Dyck. 1849: 203. 1850. Echinopsis macrogona (Salm-Dyck) H. Friedrich \& G.D. Rowley, I.O.S. Bull. 3(3): 96. 1974.

Trichocereus trichosus Cárdenas, Cactus (Paris) No.57: 249. 1957. Tipo no designado. Echinopsis trichosa (Cárdenas) H. Friedrich \& G.D. Rowley I.O.S. Bull. 3(3): 98. 1974. TIPO: Bolivia, 
Province de Cordillera, Département de Santa Cruz, route de Lagunillas à Santa Cruz, Mars 1949, A. Corro 5489 (Holotipo, "Herb. Cárdenas no encontrado"). (Neotipo, aquí designado: Cárdenas. Cactus (Paris) No.57: 249. 1957, figura en pág. 249).

Iconografías: Backeberg (1959a), foto: 1075. 1120. Ritter (1980a), fotos 448-449: 764. Hunt et al. (2006), fig. 3: 235. Albesiano (2012), fig. 10-11: 131.

Descripción original de Cereus macrogonus Salm-Dyck, Cact. Hort. Dyck. 1849: 203. 1850:

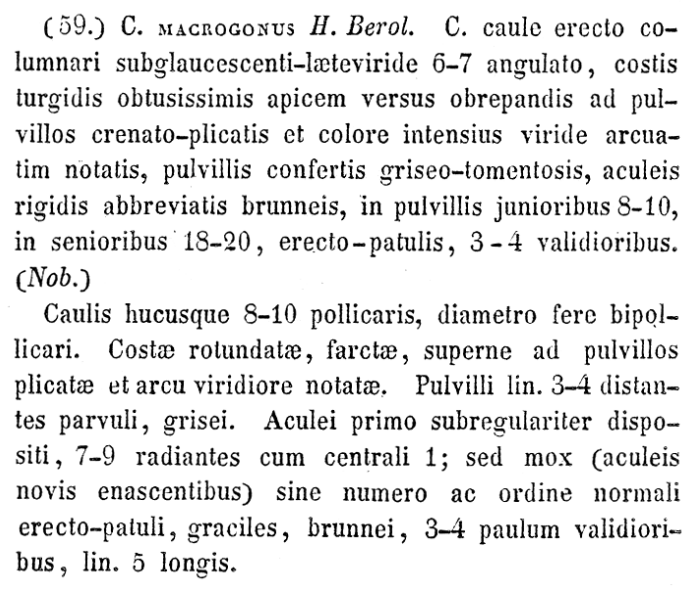

Descripción ampliada: Plantas erectas, 2,5-5,0 m de alto. Ramas 6-15 (-20) cm de diámetro. Costillas en la base 7-8, obtusas, 2,5 cm de ancho, $2 \mathrm{~cm}$ de alto. Areolas circulares, $6 \mathrm{~mm}$ de diámetro, todas con pilosidad gris o marrón-oscuro, con un surco en la epidermis encima de cada areola. Espinas aciculares; centrales 1-3, ca. 3,3 cm de largo, marrónes con puntos negros; espinas radiales ca. 8, de 2-8 $\mathrm{cm}$ de largo. Flores principalmente cerca del ápice, pocas veces en el ápice, $21 \mathrm{~cm}$ de largo, $2 \mathrm{~cm}$ de diámetro a nivel del ovario y cubierto de pelos marrón-claro; escamas del ovario de $1 \mathrm{~cm}$ de largo, verdes con ápice marrón, escamas sobre el tubo de $2,5 \mathrm{~cm}$ de largo, verdes o verde-amarillento con ápice marrón; tépalos de $9 \mathrm{~cm}$ de largo, principalmente verde-amarillento o amarillo-claro con líneas longitudinales marrones, pocas veces rosado-oscuro; estilo verde, $8 \mathrm{~cm}$ de largo; estigma amarillo, $1 \mathrm{~cm}$ de largo. Semillas ampliamente ovoides (proporción largo y ancho = 1,3 a 1,0), pequeñas $(0,9-1,1 \mathrm{~mm}$ de largo), opacas, sin quilla, testa con paredes anticlinales rectas.

Distribución y hábitat: Frecuentemente cultivada en Bolivia, Colombia, Chile, Ecuador y Perú como planta ornamental, cerca viva y por sus propiedades medicinales y mágicas. Probablemente es originaria de la parte media del Perú, en los valles secos interandinos, entre 2000-3000 m (Fernández \& Estupiñan 2005; Albesiano \& Kiesling 2012, Albesiano 2014).

\section{Comentarios morfológicos y sus consecuencias en la taxonomía y nomenclatura: El} ejemplar tipo de Trichocereus trichosus se encuentra perdido (comunicación personal de Nora Muruaga, 
curadora del herbario LIL), por consiguiente se designa un Neotipo, Cárdenas. Cactus (Paris) No.57: 249. 1957, figura en pág. 249, el cual reúne las características mencionadas en la descripción original.

Britton \& Rose (1920) describieron dos especies nuevas: T. peruvianus, la cual en nuestra opinión es la misma especie de C. macrogonus (y aun la misma variedad), y T. pachanoi. Nuestro concepto interpreta esta última como una variación infraespecífica de la misma especie, basados en los números diferentes y tamaños de las espinas. Los autores incluyeron una buena descripción, ilustración, indicación del sitio de origen, y citaron un espécimen tipo para ambos. Así, los últimos autores frecuentemente usan el nombre $T$. peruvianus pero no así $T$. macrogonus. Esta estrecha relación entre $T$. macrogonus y $T$. perurvianus -y aun sus sinónimos- ha sido mencionado por varios autores, incluyendo Backeberg \& Knuth (1936: 203), aunque en algunas publicaciones Backeberg no defiende esta opinión. Luego Madsen (1989) también considera a ambas como una sola especie. Ritter (1981: 1324) propuso a T. peruvianus como una forma de T. pachanoi, basado en observaciones de campo, donde él observó poblaciones morfológicamente intermedias entre los dos taxones. Ritter no menciona a Cereus (o Trichocereus) macrogonus en su trabajo.

Madsen (1989) describe e ilustra "Echinopsis pachanoi" en detalle (Fig. 33), dando T. peruvianus como un sinónimo; no obstante la única referencia a Cereus macrogonus en su trabajo, es al mencionarla como la especie tipo de Trichocereus. La ilustración de E. pachanoi (su Fig. 7) es muy clara, y su detallada descripción muestra gran concordancia con la descripción original de Salm-Dyck de Cereus macrogonus, aunque con un amplio rango de variación. Tanto Ritter y Madsen estudiaron las plantas y su variación en el campo. Nosotros aceptamos su argumento sobre la afinidad de $T$. peruvianus y $T$. pachanoi por ser claramente evidente y una señal de confirmación de nuestra opinión.

Anderson (2001: 272 y 2005: 235) describió e ilustró $T$. macrogonus, pero también dio $T$. pachanoi y $T$. peruvianus (bajo Echinopsis) como especies separadas. Su foto de T. macrogonus está en concordancia con nuestro concepto de especie, pero el origen dado es Bolivia. La mención de Bolivia como el país de origen para esta planta puede quizás estar basado en alguna literatura antropológica (por ejemplo Schultes \& Hoffmann 1979). Anderson ni comparó ni dio ninguna clave para diferenciar las especies.

En el último estudio abarcativo publicado sobre Cactaceae (Hunt et al. 2006), tanto Echinopsis peruviana como E. pachanoi son mencionadas como especies reconocidas. El nombre de "Echinopsis macrogona", sin embargo, es nombrado en el Apéndice III (p. 322): "Unreferred names," en la categoría de "Names whose original application is indeterminate or debatable." Hunt et al. establecen (p. 97) - sin explicación-que "Modern descriptions [of E. macrogona] deviate from the original, and the name may be misapplied..."

Una referencia previa de Hunt para E. macrogona (1989), incluyo el nombre como dudoso, pero igualmente omitió dar detalles en los que basó su duda. Una posible explicación podría ser que esta conclusión derivó de observaciones hechas en plantas de vivero o de invernaderos de aficionados. 
libro de Hunt et al. (2006) está escrito para una audiencia amplia, y no contiene ni claves ni discusión acerca de la relación de estas especies, y en este caso descuidó mencionar el nombre verdadero (o nombres) de la planta (s) la cual es "said to be a good grafting stock". No hace ninguna claridad Hunt del verdadero sentido de Cereus macrogonus de Salm-Dyck.

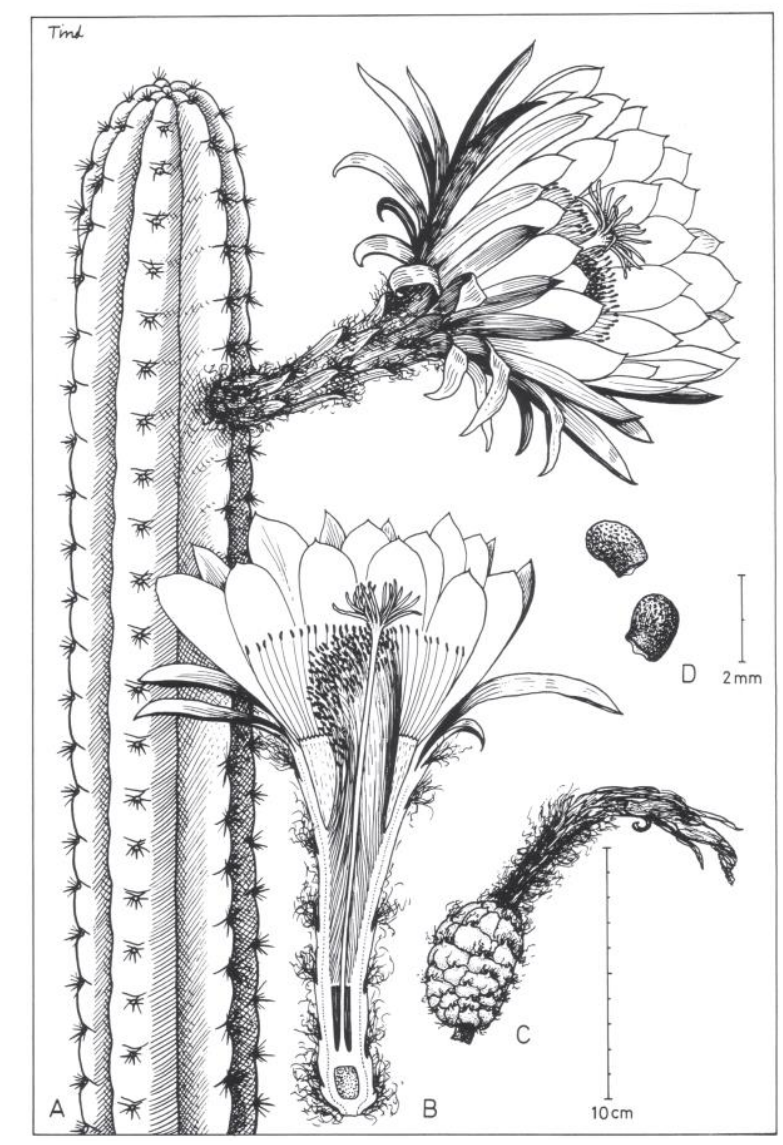

Figura 33. llustración de Madsen (1989) de T. macrogonus var. pachanoi (como Echinopsis pachanoi). A. Tallos con flores. B. Sección longitudinal de la flor. C. Fruto. D. Semillas.

La presencia o ausencia de espinas y su tamaño han sido tomados por diferentes autores como los principales caracteres para diferenciar $T$. peruvianus de $T$. pachanoi, pero estos son caracteres inconsistentes. La descripción original de $T$. pachanoi menciona la variablidad de las espinas, desde ausencia de espinas hasta 3 a 7 espinas, de hasta $1-2 \mathrm{~cm}$ de largo, como puede ser visto en el espécimen tipo en NY y US. Schultes \& Hoffmann (1979: 154) notaron que T. pachanoi no tiene espinas cuando es cultivado, pero las desarrolla bajo condiciones naturales. Se encontró la misma experiencia después de mover una planta cultivada de $T$. macrogonus de un área relativamente sombreada a una más expuesta (Albesiano \& Kiesling observación personal). Un hallazgo más consistente es que las espinas de las plantas en poblaciones de $T$. peruvianus son más grandes y más fuertes que las de $T$. pachonoi, como es evidente en las referencias bibliográficas de todos los autores que han estudiado estas plantas en la naturaleza, y en los especímenes de herbario. La clave de especies, descripciones y fotos de Britton \& Rose resaltan que $T$. peruvianus es de menor altura (2-4 m, pero hasta $5 \mathrm{~m}$ en la 
naturaleza) que $T$. pachanoi (3-6 $\mathrm{m}$, pero hasta $7 \mathrm{~m}$ en la naturaleza) y sus ramas no son tan cerradas y paralelas pero si más arqueadas.

Como resultado de la comparación de la descripción original con las especies de Trichocereus conocidas actualmente, se concluye que C. macrogonus Salm-Dyck es la misma especie conocida como T. peruvianus, y éste es coespecífico con T. pachanoi pero diferenciable a nivel inferior (intraespecífico). Análsis cladístico de evidencia combinada, caracteres morfológicos y moleculares ( $r p / 16$ y $\operatorname{trnL}-F$ ), confirman la relación estrecha entre ejemplares identificados como $T$. peruvianus y $T$. pachanoi (Albesiano \& Terrazas 2012).

Por otro lado, cabe señalar que Ritter (1981: 1324) y Madsen (1989: 27-28), los dos autores que observaron ampliamente las plantas en el campo, respectivamente consideraron a $T$. pachanoi y $T$. peruvianus como coespecíficos, distinguibles a nivel de forma (Ritter 1981), e indistinguibles y por consiguiente sinónimos (Madsen 1989). El trabajo de Ogunbodede et al. (2010) también se basa en muestras de campo documentadas, más algunas cultivadas; las diferencias fitoquímicas cuantitativas entre las muestras de $E$. peruviana y $E$. pachanoi pueden ser atribuidas a un rango amplio de plasticidad fenotípica dentro de una sola especie, la cual es más compatible con el reconocimiento taxonómico de dos variedades, que a dos especies separadas.

\section{Clave para la identificación de las variedades de T. macrogonus}

1. Espinas en las areolas adultas 18-20, de las cuales 3-4 son prominentes, largas, fuertes y más robustas (ca. $5 \mathrm{~cm}$ de largo, $1 \mathrm{~mm}$ de diámetro). Plantas hasta $5 \mathrm{~m}$ de alto, ramas erectas 0 ascendentes; tallos robustos, $16-20 \mathrm{~cm}$ de diámetro

var. macrogonus

1'. Espinas en las areolas adultas 3-7, ca. 0,5-2 cm de largo y menos de $1 \mathrm{~mm}$ de diámetro. Plantas de hasta 2-4 $\mathrm{m}$ de alto; tallos erectos, dispuestas paralelamente, tallos más delgados $6-11(-15) \mathrm{cm}$ de diámetro

var. pachanoi

\section{Trichocereus macrogonus (Salm-Dyck) Riccob. var. macrogonus.}

TIPO: Peru, Dpto. Junin, Prov. Tarma, between Acobamba and Palca, 2890 m, 1 Oct. 1982, D. Smith 2456 (Neotipo, SI! Isoneotipo, MO! designados por Albesiano \& R. Kiesling, 17: 32. 2012).

Trichocereus peruvianus Britton \& Rose, The Cactaceae 2: 136. 1920. Echinopsis peruviana (Britton \& Rose) H. Friedrich \& G.D. Rowley, IOS Bull. 3 (3): 97. 1974. Trichocereus pachanoi f. peruvianus (Britton \& Rose) F. Ritter, Kakteen Südamerika 4: 1324. 1981. Trichocereus macrogonus Riccob. var. peruvianus (Britton \& Rose) Lodé, Cact.-Avent. Int. 97: 3. 2012. TIPO: Peru, Dept. Matucana, vicinity of Matucana, 9 Jul. 1914, J.N. Rose \& Mrs. J.M. Rose 18658 (Holotipo, US761324! Isotipo, NY 386193!). 
Cereus rosei Werd., en Backeberg, Neue Kakteen 73: 101. 1931. Como un nombre nuevo para T. peruvianus Britton \& Rose. TIPO: Bolivia, Dpto. La Paz, Prov. Larecaja, Collabamba, 5 Nov. 2002, R. Kiesling, J.M. Chalet, E. Foik, V. Foik \& L. Hoeven 10041 (Neotipo, LPB! designado por Albesiano, 18 : 130. 2012).

Trichocereus puquiensis Rauh \& Backeb., en Backeb. Descr. Cact. Nov. 20. 1956. Echinopsis puquiensis (Rauh \& Backeb.) H. Friedrich \& G.D. Rowley, I.O.S. Bull. 3(3): 97. 1974. Echinopsis peruviana (Britton \& Rose) H. Friedrich \& G.D. Rowley subsp. puquiensis (Rauh \& Backeb.) Ostolaza, Cactaceae Consensus Init. 6: 8. 1998. TIPO: Bolivia, Prov. B. Saavedra, Puente Camota, carretera a Charazani, 15013'39"S; 6845'36"W, 1433 m, 12 Sep. 2004, L. Cayola, A. Antezana, F. Miranda, C. Cuevas \& D. Cuevas 1533, (Neotipo, LPB! designado por Albesiano, 18: 130. 2012).

Trichocereus tacnaensis F. Ritter, Kakteen Südamerika 4: 1326. 1981. TIPO: Perú, nordöstlich von Tacna, 3000-3500 m, 1959, F. Ritter 994 (Holotipo, U!)

Iconografías: Backeberg (1959a), foto 1075: 1120. Anderson (2005): 235, 240. Hunt et al. (2006), foto 1: 236.

Descripción ampliada: Plantas erectas (algunas veces decumbentes), $5 \mathrm{~m}$ de alto. Tallos verde-azulado o verde-claro. Ramas $16-20 \mathrm{~cm}$ de diámetro, fuertes. Costillas del ápice 7, obtusas, 2,5 cm de ancho, $3 \mathrm{~cm}$ de alto; con areolas circulares, $2 \mathrm{~cm}$ de distancia entre ellas, 1-3 mm de alto, $6 \mathrm{~mm}$ de ancho, con pilosidad gris o marrón-oscuro; espinas centrales 1-3, aciculares, 3-10 cm de largo, marrones con ápice negro; espinas radiales 7-10, aciculares, 1-2 cm de largo, rígidas, marrones con punta negra. Costillas de la base 8-10, obtusas, 1,2 cm de ancho, 1,3 cm de alto; areolas circulares, 1-3 mm de alto, 6$12 \mathrm{~mm}$ de ancho, con pilosidad gris con negro o marrón-oscuro, 2-3 cm de separación entre ellas; espinas centrales 3-4; aciculares, rectas, $5 \mathrm{~cm}$ de largo, $1 \mathrm{~mm}$ de diámetro, ápice negro, parte media marrón y base gris; espinas radiales 7-20, aciculares, 1-3 cm de largo, rígidas, marrones con ápice negro. Flores apicales y subapicales, $21 \mathrm{~cm}$ de largo, con pilosidad marrón en el ovario y tubo floral; corola de $7 \mathrm{~cm}$ de diámetro (cuando abiertas); ovario de $2 \mathrm{~cm}$ de ancho; escamas florales del ovario 1-3 cm de largo, verde con ápice marrón; escamas florales del tubo de $2,5 \mathrm{~cm}$ de largo, verde o verde-amarillento con ápice marrón; tépalos externos 6-9 cm de longitud, amarillo-verdoso o blanco-amarillento con ápice y líneas longitudinales marrón; estilo verde, $10 \mathrm{~cm}$ de largo; estigma amarillo, 1-2 cm de longitud. Pseudobaya verde-oscuro, subapical, 2-4 cm de largo, 3-5 cm de diámetro, recubierto por escamas subuladas, de cuyas axilas surgen abundantes pelos marrones y grises. Semillas negras, $2 \mathrm{~mm}$ de largo y $1 \mathrm{~mm}$ de ancho.

Distribución y hábitat: Nativa del Perú (Borg 1937), en los valles del departamento de Lima, a $2500 \mathrm{~m}$, en el valle de Puquio, a $3300 \mathrm{~m}$, al sureste de Ica y Tacna entre 3000-3500 m y al noreste de 
Estique (Ritter 1981). También se distribuye en Bolivia (1500 m), en laderas pedregosas casi desnudas (Figs. 74, 75B y 76).

Comentarios taxonómicos y nomenclaturales: El ejemplar D. Smith 2456 (SI) se eligió en la publicación de Albesiano \& Kiesling 17: 32. 2012 como Neotipo de Cereus macrogonus, porque reúne las características vegetativas más similares a las descritas en la descripción original, además de presentar tres cortes longitudinales de la flor, donde se observa la longitud del pistilo y la cantidad de escamas y pelos presentes en el ovario y a lo largo del tubo floral.

Se escogió el ejemplar R. Kiesling et al. 10041 (LPB) como Neotipo de Cereus rosei en la publicación Albesiano 18: 130. 2012, porque reúne las características vegetativas y reproductivas más similares a las descritas en la descripción original, además de presentar un corte transversal y dos longitudinales del tallo, observando los caracteres vegetativos de las costillas, areolas y espinas, además de un corte longitudinal de la flor, donde se identifica la longitud del ovario, tubo floral, tépalos y estambres.

Se selecciónó el ejemplar L. Cayola et al. 1533 (LPB) como Neotipo de Trichocereus puquiensis en la publicación Albesiano 18: 130. 2012, por ser el más cercano morfológicamente a la descripción original.

Britton y Rose en 1920 describen Trichocereus peruvianus, especie que se asemeja a $T$. macrogonus por el número (7-10) y características de las costillas (2 cm de alto y $2,5 \mathrm{~cm}$ de ancho), por el color de los tallos (verde-azulado o verde-claro), presencia de un surco encima de cada areola, y por la separación entre las areolas $(2,5 \mathrm{~cm})$, por lo que se considera sinónimo de la variedad tipo.

En la descripción original de Trichocereus puquiensis, se observa que los caracteres morfológicos son coincidentes con aquellos de la variedad tipo (ramas verde-claro, de $15 \mathrm{~cm}$ de diámetro, costillas 8-10, la presencia de un surco dérmico, justo por encima de cada aréola, y la diferencia entre espinas centrales y radiales). Trichocereus puquiensis es por lo tanto sinónimo de $T$. macrogonus var. macrogonus.

Trichocereus tacnaensis también es considerado sinónimo de esta variedad, aunque sus ramas de $12-15 \mathrm{~cm}$ de diámetro, puede deberse a los niveles altos de humedad en su medio.

Material de Herbario estudiado: Bolivia, Dpto. La Paz, Prov. Larecaja, Collabamba, 5 Nov. 2002, R. Kiesling et al. 10041 (LPB); Prov. B. Saavedra, Puente Camota, carretera a Charazani, 15013'39"S; 6845'36”W, 1433 m, L. Cayola et al. 1533, 1534 (LPB). Perú, Dpto. Tacna, oberhalb Tacna, 74 Km Weg Charaña-Tacna, ca. 3500 m, F. Ritter 994 (SGO). 
29. Trichocereus macrogonus (Salm-Dyck) Riccob. var. pachanoi (Britton \& Rose) Albesiano \& R. Kiesling, Haseltonia 17: 32, ill. 2012.

Trichocereus pachanoi Britton \& Rose, The Cactaceae 2: 134, ill. 1920. Cereus pachanoi (Britton \& Rose) Werderm., en Backeb, Neue Kakteen: 73. 1931. Echinopsis pachanoi (Britton \& Rose) H. Friedrich \& G.D. Rowley, IOS Bull. 3 (3): 96. 1974. TIPO: Ecuador, Cuenca, 17 al 24 Sep. 1918, J.N. Rose, A. Pachano \& G. Rose 22806 (Holotipo, US, perdido); (Lectotipo, NY!, designado por Albesiano \& Kiesling, 17: 32. 2012).

Trichocereus santaensis Rauh \& Backb., en Backeb. Descr. Cact. Nov. 20.1957 (1956). Echinopsis santaensis (Rauh \& Backb.) H. Friedrich \& G.D. Rowley, I.O.S. Bull. 3(3): 97. 1974. (Lectotipo, Backeberg, Die Cactaceae 2: 1113. 1959, designado por Albesiano \& R. Kiesling, 18: 131. 2012).

Trichocereus torataensis F. Ritter, Kakteen Südamerika 4: 1325, ill. 1981. TIPO: Perú, Torata, 3000 m, 1953, F. Ritter 1467 (Holotipo, U!)

Trichocereus huanucoensis Johnson, nom. nud.

Iconografías: Backeberg (1959a), fotos 1072-1074: 1119-1120. Madsen (1989), fig. 7: 29. Ritter (1981), foto 1186, 1193: 1550. Reyna \& Flores (2001), fotos 1-2: 28-29. Anderson (2005): 238. Hunt et al. (2006), fig. 4: 235. Albesiano (2012), fotos 10-11: 131.

Descripción original de Trichocereus pachanoi Britton \& Rose, The Cactaceae 2: 134. 1920:

Plants tall, 3 to 6 meters high, with numerous strict branches, slightly glaucous when young, dark green in age; ribs 6 to 8 , broad at base, obtuse, with a deep horizontal depression above the areole; spines often wantıng, when present few, 3 to 7 , unequal. the longest 1 to $2 \mathrm{~cm}$. long dark vellow to hrown. flower-huds pointed; flowers very large, 19 to $23 \mathrm{~cm}$. long, borne near the top of branches, night-blooming, very fragrant; outer perianth-segments brownish red; inner perianth-segments oblong, white; filaments long, weak, greenish; style greenish below, white above; stigma-lobes linear, yellowish; ovary covered with black curled hairs; axils of scales on flower-tube and fruit bearing long black hairs.

Descripción ampliada: Plantas de 2-4 m de alto, ramificadas desde la base. Tallos erectos, rectos, dispuestos paralelamente, cilíndricos, verde-oscuro y cuando jóvenes glaucos, 6-11 (-15) cm de diámetro. Costillas obtusas, generalmente 6-8 (-13), de 2,5 cm de alto, con areolas obovadas, redondas, 3-6 mm de ancho, separadas 1,5-2,7 cm, pilosidad amarilla en el ápice y en la base gris-claro. Una espina central, radiales hasta 6 , aciculares, marrones, dirigidas en varias direcciones, hasta $2 \mathrm{~cm}$ de largo, $\mathrm{y}$ menos de $1 \mathrm{~mm}$ de ancho. Flores 1-4, apicales y subapicales, $24 \mathrm{~cm}$ de largo, con pilosidad rizada, negra, $2 \mathrm{~cm}$ de largo en el ovario y tubo floral, perianto de $20 \mathrm{~cm}$ de diámetro (cuando abiertas); escamas florales del ovario subuladas, ca. 2-5 mm de largo, verde-oscuro, escamas florales de tubo subuladas, 20 $\mathrm{mm}$ de largo, puntas marrón, en el medio verde y base amarilla; ovario $3 \mathrm{~cm}$ de diámetro; tépalos espatulados, $11 \mathrm{~cm}$ de longitud, blancos; estilo blanco con base verde, 14-19 cm de largo; estigma amarillo-claro, hasta $3,5 \mathrm{~cm}$ de largo. Pseudobaya verde, $3 \mathrm{~cm}$ de diámetro, $6 \mathrm{~cm}$ de largo, recubiertas 
por escamas subuladas de cuyas axilas emergen abundantes pelos negros. Semillas negras, $2 \mathrm{~mm}$ de alto y $1,3 \mathrm{~mm}$ de ancho (Fig. 34).

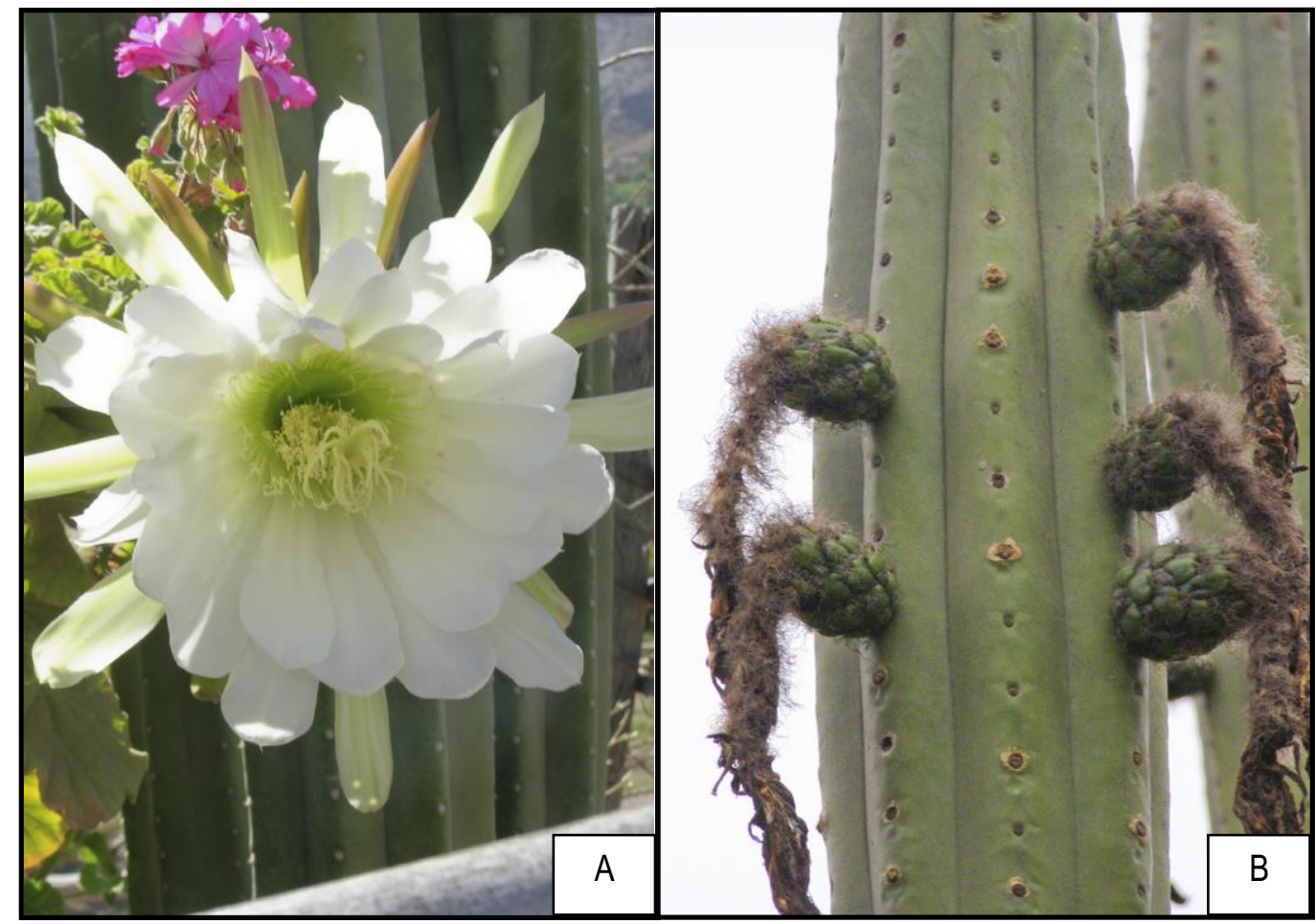

Figura 34. A) Trichocereus macrogonus var. pachanoi. Chile, entre Vallenar y Ovalle, Foto Daniel Schweich. B) Quito, Ecuador, Foto H. Smidlock.

Distribución y hábitat: Es la variedad de Trichocereus con distribución más septentrional. Se localiza en Bolivia, Chile, Ecuador, Perú (en los departamentos de Ancash, Cajamarca, La Libertad, Lambayeque, Lima, Loreto, Moquegua, Piura, Tumbes), en los acantilados a lo largo de los ríos, a alturas de hasta $3000 \mathrm{~m}$, también se cultiva como planta ornamental en jardines, parques y como cerca viva (Madsen 1989, Ogunbodede et al. 2010). Originaria del sur de Ecuador y norte de Perú, donde es conocida bajo el nombre de San Pedro (Figs. 75B y 76).

\section{Comentarios morfológicos y sus consecuencias en la taxonomía y nomenclatura: $\mathrm{El}$} especimen del herbario de US no se encuentra (no figura en la lista de los tipos de Herbario, y una consulta al curador, Rusty Russell- septiembre de 2008-, confirma que la muestra no se ha encontrado desde 1941), por lo tanto el especimen de NY, se designó como lectotipo.

Se considera conveniente designar a la variedad $T$. macrogonus var. pachanoi por su tendencia a tener espinas diminutas (menos de $1 \mathrm{~cm}$ de longitud, a menudo una pequeña fracción de esa longitud), aunque este carácter exibe plasticidad fenotípica, lo que demuestra la influencia de las diferentes condiciones del medio ambiente.

Trichocereus torataensis fue considerada sinónimo de la variedad pachanoi (Albesiano \& Kiesling 2012), por el diámetro de los tallos, (generalmente $7 \mathrm{~cm}$ ), distancia entre las areolas (hasta 2,5 
$\mathrm{cm}$ ), y por presentar pocas espinas radiales (menos de 7) y una espina central. Anderson (2005) y Hunt et al. (2006) consideran a T. torataensis sinónimo de E. peruviana, pero registros de esta última especie muestran un incremento en el número de espinas (20), de las cuales 3-4 son más largas y robustas $(5 \mathrm{~cm}$ de largo y $1 \mathrm{~mm}$ de diámetro).

En los herbarios del Missouri Botanical Garden y New York Botanical Garden existen isotipos de "Trichocereus huanucoensis Johnson" (2287797, 2287798MO! 00386189NY!), pero esta especie no presenta descripción ni diagnosis, por lo que corresponde a un nomen nudum. Se considera que corresponde a T. macrogonus var. pachanoi por la semejanza en el número de costillas (6), distancia entre las areolas $(2-2,5 \mathrm{~cm})$, número bajo de espinas (5), las cuales se diferencian entre una central y cuatro radiales.

Material de Herbario estudiado: Ecuador, Cuenca, 17 al 24 Sep. 1918, J. N. Rose et al. 22806 (NY). Perú, Dpto. Moquegua, Cuajones, ca. 3000 m, F. Ritter 1467 (121146 SGO). Peru, 31 May. 1963, H. Johnson s.n. (2287797, 2287798MO; 00386189 NY).

30. Trichocereus narvaecensis Cárdenas, Fuaux Herb. Bull. 1(5): 25. 1953.

Helianthocereus narvaecensis (Cárdenas) Backeb., Cactus (Paris) No. 45: 208. 1955. Tipo no designado. Echinopsis narvaecensis (Cárdenas) H. Friedrich \& G.D. Rowley, I.O.S. Bull. 3(3): 96. 1974. TIPO: Bolivia, Dpto. Tarija, Prov. O'Connor, near Narvaez, on the way from Tarija to Entre Ríos, at 2700 m, M. Cárdenas 4828 (Holotipo, "Herb. Cárdenas no encontrado"). TIPO: Bolivia, camino a Narváez, 2567 m, 19 Dic. 2009, S. Albesiano, N. Muruaga, A. Alaria \& R. Paz 2082 (Neotipo, MERL, aquí designado).

Descripción original Trichocereus narvaecensis Cardenas, Fuaux Herb. Bull. 1(5): 25. 1953:

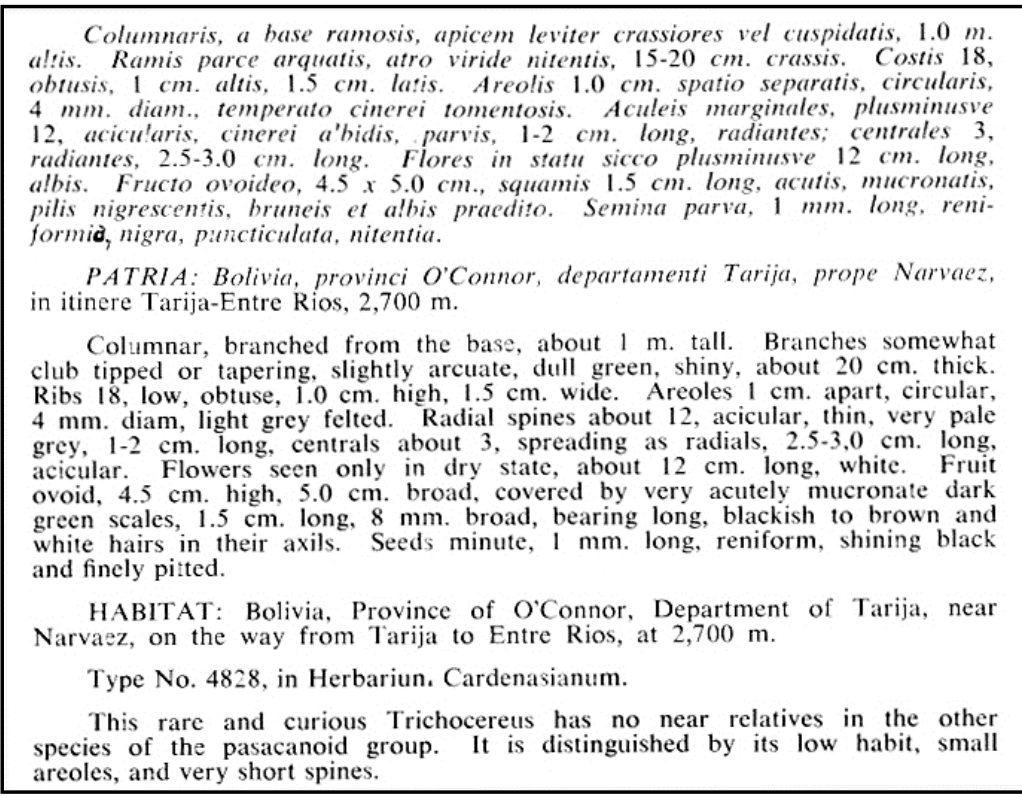


Descripción ampliada: Tallos erectos, ramificados a nivel del suelo, hasta $2 \mathrm{~m}$ de alto. Ramas ligeramente arqueadas, 15-20 cm de diámetro, verde-opaco. Costillas del ápice 17, obtusas, $1 \mathrm{~cm}$ de ancho, 0,5 cm de alto, con areolas ovadas, $2 \mathrm{~mm}$ de alto, 0,6 cm de ancho, con pilosidad amarilla; una espina central, perpendicular al tallo, $2 \mathrm{~cm}$ de largo, acicular, base verde en etapa de crecimiento, parte media y ápice de la espina marrón-claro a oscuro, espinas radiales 10, aciculares, 1,6 cm de largo, base verde, el resto marrón-claro a oscuro, perpendiculares al tallo, la gran mayoría sin entremezclarse con las espinas radiales de las areolas vecinas. Costillas de la base 15-18, obtusas, 2,5 cm de ancho, 1,3 cm de alto; areolas ovadas o circulares, $0,4 \mathrm{~cm}$ de alto, 0,6 cm de ancho, ovadas, con pilosidad amarillo-claro 0 gris, $1 \mathrm{~cm}$ de separación entre las areolas; espinas centrales 4, aciculares, 5-8 cm de largo, marrones, algunas crecen perpendiculares al tallo, otras con un ángulo de divergencia con el tallo de $136^{\circ}$ (medido desde arriba); espinas radiales 13, aciculares, $1-2 \mathrm{~cm}$ de largo, marrones o gris-claro, e igualmente dispuestas que las espinas centrales. Flores 1 a 8, localizadas alrededor del ápice, $20 \mathrm{~cm}$ de largo, ovario y tubo floral con abundante pilosidad negra, $6 \mathrm{~mm}$ de largo; corola de $13 \mathrm{~cm}$ de diámetro (cuando abiertas); ovario $3 \mathrm{~cm}$ de ancho; tubo floral $4,5 \mathrm{~cm}$ de diámetro; tépalos externos e intermedios lanceolados, agudos, 6-9 cm de longitud respectivamente, marrones con tintes verde, y los internos espatulados, mucronados, blancos, $9 \mathrm{~cm}$ de largo; estilo verde, $13 \mathrm{~cm}$ de largo; estigma amarillo, con varios lóbulos de $2 \mathrm{~cm}$ de longitud. Pseudobaya con dehiscencia longitudinal, verde-oscuro, $5 \mathrm{~cm}$ de largo, $4 \mathrm{~cm}$ de diámetro y cavidad ovárica con funículos blancos. Semillas reniformes, negras, brillantes, 1 $\mathrm{mm}$ de largo y cubierta por pequeñas depresiones (Fig. 35).

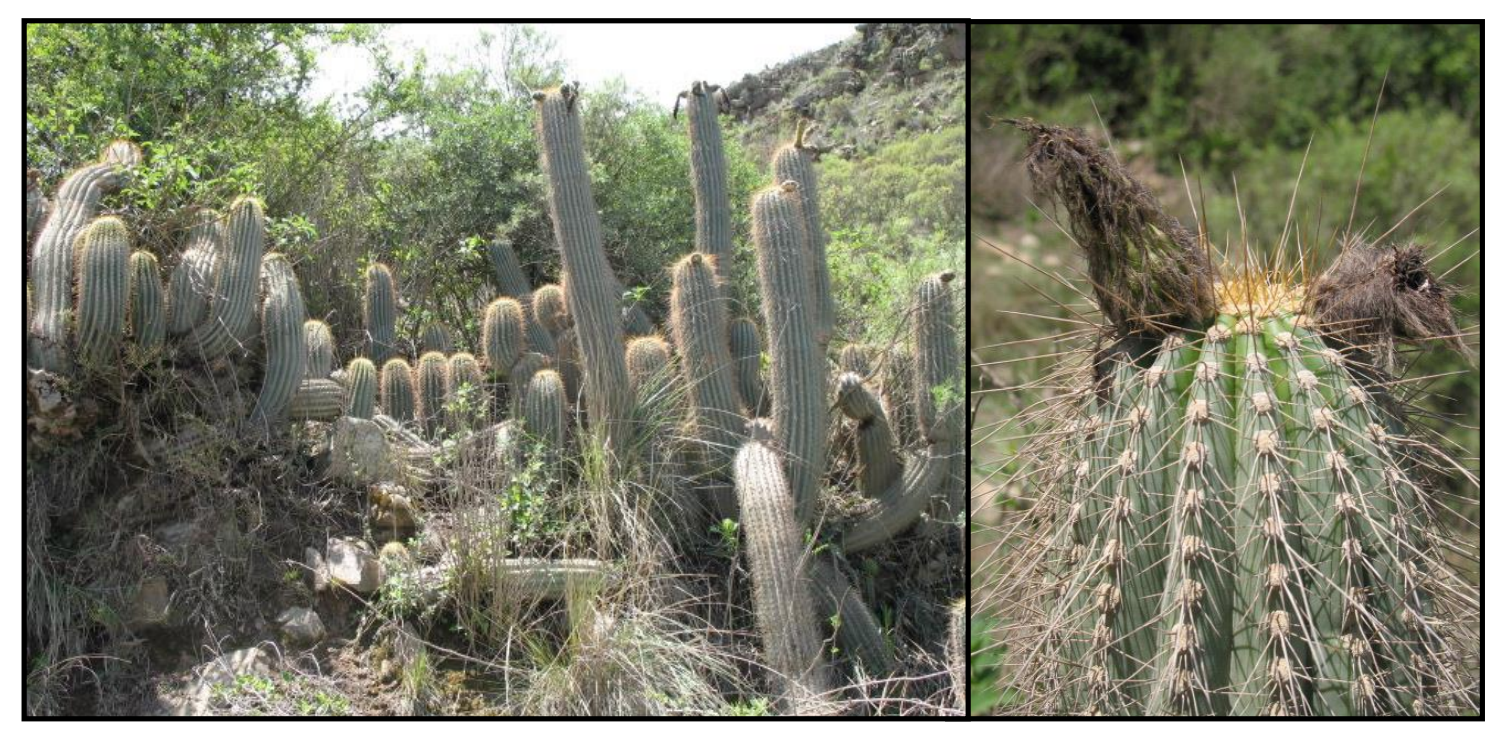

Figura 35. Trichocereus narvaecensis. Bolivia, Departamento de Tarija, camino a Narváez.

Distribución y hábitat: Especie endémica de Bolivia (Fig. 74), localizada en las zonas semiáridas altas del departamento de Tarija, entre 2500 a 2700 m (Albesiano 2014).

Comentarios morfológicos y sus consecuencias en la taxonomía y nomenclatura: El ejemplar tipo de Trichocereus narvaecensis se encuentra perdido (Eggli \& Leuenberger 2005 y 
comunicación personal de Nora Muruaga, curadora del herbario LIL), por consiguiente se designa un Neotipo, S. Albesiano et al. 2082 (MERL), que reúne las características mencionadas en la descripción original.

Anderson (2005) y Hunt et al. (2006) consideran a T. narvaecensis sinónimo de T. tarijensis subsp. tarijensis o de $T$. schickendantzii, respectivamente, a pesar de mostrar caracteres morfológicos que permiten considerarlos como taxones distintos (Tabla 10 y Tabla 11).

Tabla 10. Caracteres vegetativos y reproductivos que distinguen a $T$. narvaecensis de $T$. tarijensis subsp. tarijensis.

\begin{tabular}{|l|l|l|}
\hline CARACTERES & \multicolumn{1}{|c|}{ T. narvaecensis } & T. tarijensis subsp. tarijensis \\
\hline Hábito & $\begin{array}{l}\text { Ramificado de la base y } \\
\text { ascendente }\end{array}$ & Erecto y columnar \\
\hline Altura & Hasta $2 \mathrm{~m}$ & $2-6 \mathrm{~m}$ \\
\hline $\begin{array}{l}\text { Disposición de las espinas } \\
\text { entre las areolas vecinas }\end{array}$ & No se entrecruzan & Se entrecruzan \\
\hline Longitud de las flores & $20 \mathrm{~cm}$ & $13 \mathrm{~cm}$ \\
\hline Diámetro del ovario & $3 \mathrm{~cm}$ & $2,0-2,5 \mathrm{~cm}$ \\
\hline Diámetro del tubo floral & $4,5 \mathrm{~cm}$ & $2,5-3,0 \mathrm{~cm}$ \\
\hline Longitud del estilo & $13 \mathrm{~cm}$ & $9 \mathrm{~cm}$ \\
\hline Largo de los tépalos & $9 \mathrm{~cm}$ & $4,6 \mathrm{~cm}$ \\
\hline Color de los tépalos & Blancos & $\begin{array}{l}\text { Fucsia con ápice oscuro o } \\
\text { rosado-intenso y los más } \\
\text { internos blancos }\end{array}$ \\
\hline
\end{tabular}

Tabla 11. Diferencias entre $T$. narvaecensis y $T$. schickendantzii.

\begin{tabular}{|l|l|l|}
\hline CARACTERES & \multicolumn{1}{|c|}{ T. narvaecensis } & \multicolumn{1}{c|}{ T. schickendantzii } \\
\hline Hábito & Plantas altas (hasta 2 $\mathrm{m}$ de alto) & Plantas bajas (hasta $60 \mathrm{~cm}$ de altura) \\
\hline Diámetro de las ramas & $15-20 \mathrm{~cm}$ & Hasta $40 \mathrm{~cm}$ \\
\hline No. de costillas & $15-18$ & $11-14$ \\
\hline Forma de las espinas & Aciculares & Subuladas \\
\hline No. espinas centrales & 4 & 8 \\
\hline $\begin{array}{l}\text { Longitud de las espinas } \\
\text { centrales }\end{array}$ & $5-8 \mathrm{~cm}$ & $1,5 \mathrm{~cm}$ \\
\hline
\end{tabular}

Material de Herbario estudiado: Bolivia, Dpto. Tarija, Prov. Burnet O’ Connor, Tarija 46 Km hacia Palos Blancos, pasando Junacas, 2640 m, 14 Nov. 1993, St. G. Beck et al. 22200 (LPB); camino a Narváez, 2567 m, 19 Dic. 2009, S. Albesiano et al. 2082 (MERL).

31. Trichocereus nigripilis (Phil.) Backeb., Cactus Journ., Great Brit. 5: 49. 1937.

Cereus nigripilis Phil., Fl. Atacam. 23 (146): 197. 1860. Trichocereus chiloensis (Colla) Britton \& Rose var. nigripilis (Phil.) Espinosa, Revista Chilena Hist. Nat. 41: 292. 1937. Trichocereus coquimbanus sensu Britton \& Rose var. nigripilis (Phil.) Borg, Cacti: 181. 1951. Echinopsis nigripilis (Phil.) H. Friedrich \& 
G.D. Rowley, I.O.S. Bull. 3 (3): 96. 1974. TIPO: Chile, Coquimbo, Nov. 1853, R.A. Philippi 35 (Lectotipo, SGO 52682! designado por Muñoz: 92. 1960).

Iconografías: Backeberg (1959a), foto 1111: 1144. Albesiano (2012), foto 12: 132.

Descripción original de Cereus nigripilis Phil., Fl. Atacam. 23 (146): 197. 1860:

146. Cereus nigripilis $P h$. C. 3 -4-pedalis; ramis diamotri tripollicaris, costis $12-13$; verrucis prominentibus, confertis, lana brevissima, primum fulva, demum nigra vestitis; aculeis usque ad 20 imo 24 , cinereis, valde inaequalibus; minoribus setaeformibus, ad summum $10 \mathrm{lin}$. longis, divaricatis; majoribus centralibus robustioribus, fuscis usque ad 28 lin. longis, plerumque $16,15,12 \mathrm{lin}$. longis; flore albo, 5 pollices longo, tubuloso, basi pilis nigris dense obtecto, qui superius modo in apice squamarum calycinarum remanent; stylo dimidiam corollam aequante, stigmatibus erectis, 6 lin. longis.

A Coquimbo usque ad Paposo et forte magis ad boream crescit. In fructu, qui mihi siccus et insipidus, valde distinctus ab illo C. Quisco provinciarum centralium Chilensium videbatur, squamae calycinae subulatae, remotae, $1 / 2-1$ lin. longae, ciliis $2-3$ lin. longis, basi nigris, apice albis valde conspicuae. Semina nigra fere $1 / 2$ lin. longae.

Descripción ampliada: Plantas ascendentes, hasta 1,20 m de alto, formando arbustos densos y bajos. Tallos ligeramente arqueados, cilíndricos, 5-7 cm de diámetro. Costillas en el ápice 11, obtusas, 1 $\mathrm{cm}$ de ancho, $1 \mathrm{~cm}$ de alto; los surcos son ondulados; areolas redondas, $3 \mathrm{~mm}$ de alto, $7 \mathrm{~mm}$ de ancho, con pilosidad marrón en el ápice y gris en la parte inferior de la areola. Espinas rectas, centrales 4, aciculares, $2 \mathrm{~mm}$ de diámetro, $5 \mathrm{~cm}$ de largo, negras al igual que las espinas subapicales; radiales 13 , aciculares, 0,5 mm de diámetro, 0,7-2,0 cm de largo, negras, asimismo con las espinas subapicales. Costillas de la base 10, obtusas, $1 \mathrm{~cm}$ de ancho, $0,8 \mathrm{~mm}$ de alto; areolas $5 \mathrm{~mm}$ de alto, $8 \mathrm{~mm}$ de ancho, redondas, pilosidad gris-oscura; espinas centrales 4 , aciculares, $1,5 \mathrm{~mm}$ de diámetro, $6 \mathrm{~cm}$ de largo, grisclaro con punta negra; radiales 12, aciculares, $5 \mathrm{~mm}$ de diámetro, $1 \mathrm{~cm}$ de largo, gris-claro. Flores $13 \mathrm{~cm}$ de largo, ovario y tubo floral recubierto de pilosidad negra, lóbulos del estigma erectos, $1-2 \mathrm{~cm}$ de largo. Pseudobayas apicales, 3,5 cm de largo. Semillas 1,5 mm de largo, $1 \mathrm{~mm}$ de ancho, región hilo-micrópilo amarillo-oscuro (Fig. 36).

Distribución y Hábitat: Especie distribuida en Chile, en la III Región de Atacama y en la IV Región de Coquimbo, desde el nivel del mar hasta 700 m de altitud (Fig. 75B). 


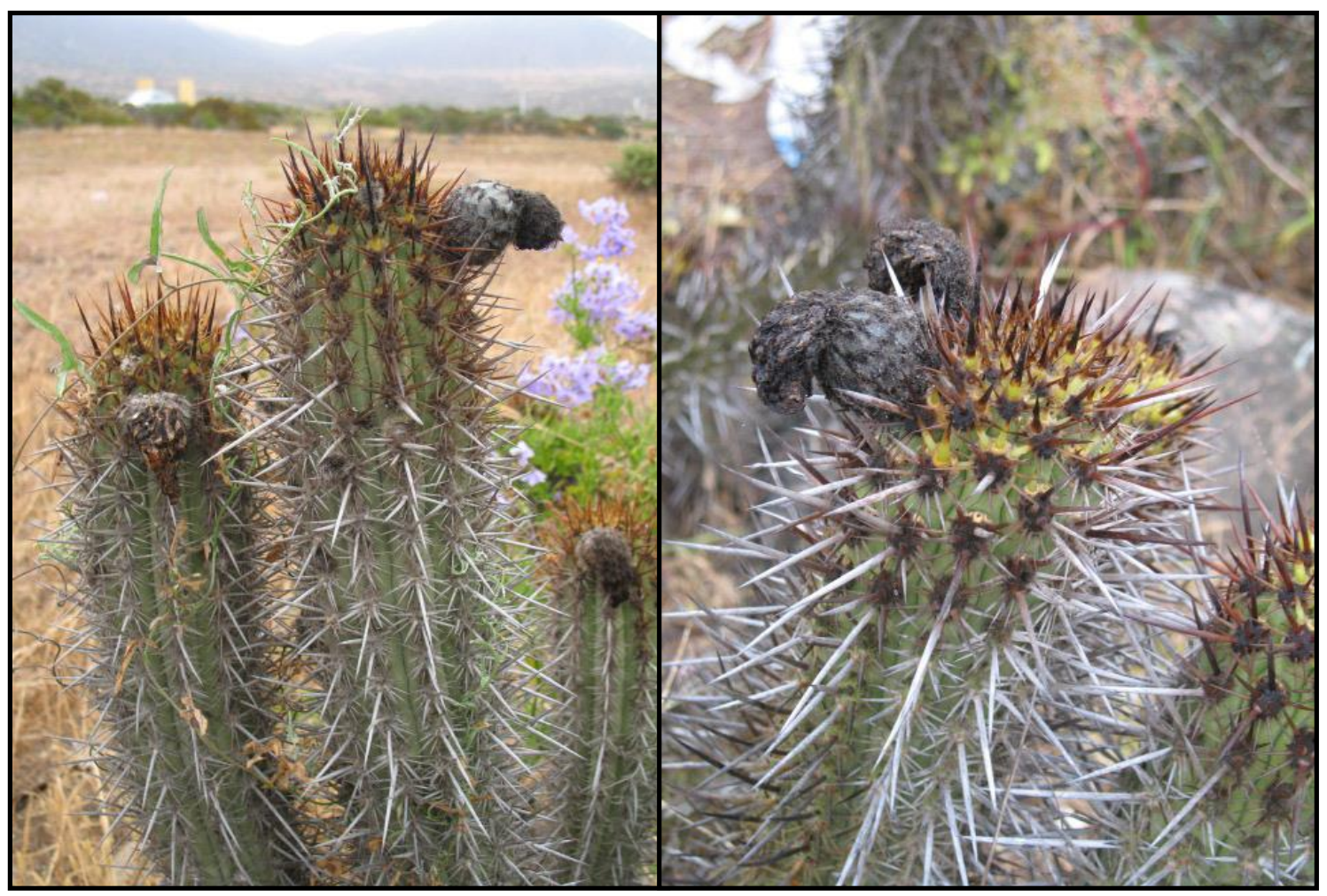

Figura 36. Trichocereus nigripilis. Chile, IV Región de Coquimbo, al N de la Serena.

Comentarios morfológicos y sus consecuencias en la taxonomía y nomenclatura: En la cartulina del ejemplar tipo de T. nigripilis aparece la siguiente anotación de U. Eggli y B. Leunberger 2/93: "flower is of Trichocereus, vegetative parts of Eulychnia", pero al revisar los caracteres vegetativos de las areolas (marrón-oscuro) y espinas: forma (cerdosas, aciculares y rígidas), cantidad (17), longitud (2 a 5 cm de largo) y color (grises), éstos coinciden con lo propuesto en la descripción original de $T$. nigripilis, por consiguiente en mi opinión las partes vegetativas no corresponden a Eulychnia sino a T. nigripilis.

Material de Herbario estudiado: Chile, III Región de Atacama, Prov. Huasco, Comuna Vallenar, $10 \mathrm{Km}$ al sur de Vallenar, 28³9'48”S, 70^45'49”W, 614 m, 6 Nov. 2008, S. Albesiano et al. 2054 (MERL, AGUCH); Qda. León, 26056'01"S; 7044'30”W, 330 m, 9 Nov. 2008, S. Albesiano et al. 2059 (MERL, AGUCH). IV Región de Coquimbo, al N de la Serena, 27,5 Km al N de la Ruta 5, al N de Juan Soldado, 2949'S; 71016'W, 11 Oct. 2010, S. Albesiano et al. 2083 (MERL).

32. Trichocereus pectiniferus Albesiano, Haseltonia 18: 133, ill. 2012.

TIPO: Chile, IV Región de Coquimbo, Juan Soldado, 2943'26"S; 71018'45”W, 166 m, 6 Nov. 2008, S. Albesiano, L. Faúndez, R. Flores \& P. Saldivia 2053 (Holotipo, MERL!; Isotipo, AGUCH 64080!). 
Trichocereus coquimbanus sensu Britton \& Rose, The Cactaceae 2: 139. 1920, non Cactus coquimbanus Molina, Sag. Stor. Nat. Chili: 170. 1782, non Cereus coquimbanus sensu K. Schum., Monatsschr. Kakteenk. 6: 166. 1896, non Echinopsis coquimbana sensu Friedrich \& G.D. Rowley, I.O.S. Bull. 3 (3): 94.1974.

Iconografías: Hoffmann (1989), lámina 9b: 87. Albesiano (2012), foto 13: 133.

Descripción original de Trichocereus pectiniferus Albesiano.

Plantae caespitosae altae $80 \mathrm{~cm}$. Rami decumbentes, aliqui arcuti, $5 \mathrm{~cm}$ diametri. Costae 11, obtusae, 2 $\mathrm{cm}$ latae. Areoles ovobadae rotundaeque, $3 \mathrm{~mm}$ altae, $1.2 \mathrm{~cm}$ latae, cinereae. Spinae centricae 4, in cruce, aciculae subulataeque, $2 \mathrm{~mm}$ latae, $1.5-6 \mathrm{~cm}$ longae, cinereae cum adultae sunt. Spinae radialis 15, aciculae, 1.3-2.2 cm longae, cinereae, adultae crescunt adpresas et in pectinis forma. Fructus apices et subapices, virides, $3 \mathrm{~cm}$ longi et 4.5 cm lati et cum squamis pilosis, quarum axillarum emergunt copiosos pilos brunneos cinereosque, pulpam albam, semina nigra.

Descripción ampliada: Plantas ascendentes, $80 \mathrm{~cm}$ de alto. Ramas hasta 15, decumbentes, algunas arqueadas, $5 \mathrm{~cm}$ diámetro. Costillas del ápice 11, obtusas, $2 \mathrm{~cm}$ de ancho; areolas obovadas, 2 $\mathrm{mm}$ de alto, 1,2 cm de ancho, pilosidad del ápice de cada areola amarilla y base gris. Espinas centrales 4, aciculares, 2 mm de diámetro, 1,5-6,0 cm de largo, algunas con el ápice marrón-oscuro, otras son verdes en la base (cuando estan creciendo) y marrones en el ápice, y otras gris-claro con ápice marrón, algunas crecen arqueadas; radiales 15, la mayoría son aciculares, muy pocas setosas (una por areola), $2 \mathrm{~cm}$ de largo, marrón-claro. Costillas de la base 10, obtusas, $2 \mathrm{~cm}$ de ancho y $7 \mathrm{~mm}$ de alto; con areolas redondas, $3 \mathrm{~mm}$ de alto, $7 \mathrm{~mm}$ de ancho, con pilosidad gris. Espinas centrales 4, aciculares, $5 \mathrm{~cm}$ de longitud, gris-claro, dispuestas en cruz y divaricadas (ca. $75^{\circ}$ ) al tallo, entrecruzándose con las espinas centrales de las areolas vecinas; radiales en areolas adultas 12, aciculares, 1,3 cm de largo, grises, pectinadas, adpresas al tallo (ca. $15^{\circ}$ ). Flores, solo se observaron pequeños restos florales, con abundante pilosidad negra. Pseudobaya apical o subapical, $3 \mathrm{~cm}$ de largo, $4,5 \mathrm{~cm}$ de diámetro, recubierta por escamas subuladas, $3 \mathrm{~mm}$ de largo y de cuyas axilas emergen abundantes pelos marrón y grises. Semillas con testa negra (Fig. 37).

Etimología: Especie caracterizada por la disposición de las espinas radiales en las areolas adultas, adpresas a la superficie del tallo y pectinadas (organizadas horizontalmente en forma de peine).

Distribución y Hábitat: T. pectiniferus crece en Chile, en la IV Región de Coquimbo (Fig. 75B), en altitudes que van desde el nivel del mar hasta los 500 m, asociado con Eulychnia sp., Copiapoa sp. y Opuntia sp. 


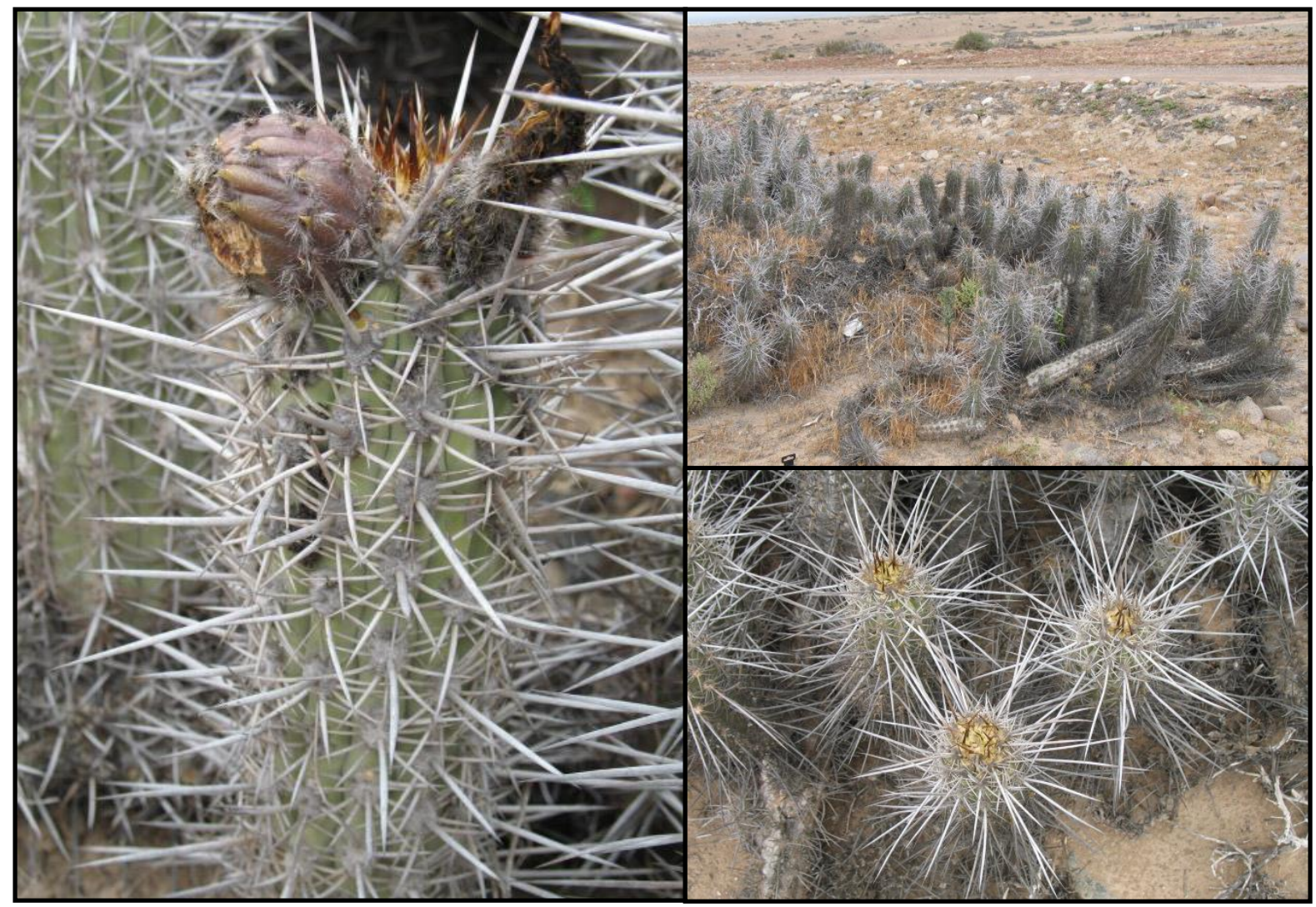

Figura 37. Trichocereus pectiniferus. Chile, IV Región de Coquimbo, camino a los Choros.

Comentarios morfológicos y sus consecuencias en la taxonomía y nomenclatura: Britton y

Rose realizan la combinación T. coquimbanus (Molina) Britton \& Rose, sin advertir que la descripción original de Cactus coquimbanus Molina (:170. 1782), corresponde a una especie del género Eulychnia. Molina destaca entre los caracteres vegetativos: el hábito de crecimiento (erecto y alto) y el gran tamaño de las espinas: $20 \mathrm{~cm}$ ("que en aquella época eran usadas para coser calcetines"), mientras que la planta descrita por Britton y Rose, presenta hábito ascendente y las espinas no superan los $8 \mathrm{~cm}$ de longitud. Es por ello que se ha propuesto como nueva la especie de Trichocereus distribuida en la Provincia de Coquimbo.

Esta se diferencia de $T$. glaucus y $T$. spinibarbis por la disposición de las espinas externas en las areolas adultas. En T. pectiniferus las espinas son adpresas al tallo (ángulo de divergencia ca. 15 grados), y a manera de peine, mientras que en $T$. glaucus y $T$. spinibarbis, se presentan divaricadas (ángulo de divergencia ca. 75 grados), y en forma radial.

Material de Herbario estudiado: Chile, IV Región de Coquimbo, Prov. Elqui, Mpio. La Serena, 1 Km E of El Peñón, 30².68'S, 71012.93'W, 160-250 m, 4 Dic. 1994. U. Eggli \& B. E. Leuenberger 2574 (SGO); Ruta 5, Km 514, Comuna Higuera, cuesta de Buenos Aires, 29³1'S; 71¹2'W, 270 m, 10 Oct. 2010, S. Albesiano et al. 2084 (MERL); camino a los Choros, 29¹3'S;71³2’W, 270 m, S. Albesiano et al. 
2085 (MERL); entrada a los Choros, $29^{\circ} 13^{\prime} \mathrm{S} ; 7^{\circ} 32^{\prime} \mathrm{W}, 90 \mathrm{~m}, 10$ Oct. 2010, S. Albesiano et al. 2086 (MERL).

33. Trichocereus schickendantzii (F.A.C. Weber) Britton \& Rose, The Cactaceae 2: 144.1920.

Echinopsis schickendantzii F.A.C. Weber, en Bois Dict. Hort. 1: 473. 1896. Cereus schickendantzii F.A.C. Weber, en Bois Dict. Hort. 1: 473. 1896, pro syn.

Trichocereus fabrisii R. Kiesling, Hickenia 1 (6): 29. 1976. Echinopsis fabrisii (R. Kiesling) G.D. Rowley, Repert. PI. Succ. 27: 5. 1979. Soehrensia fabrisii (R. Kiesling) Schlumpb., Cactaceae Syst. Init.: 28: 30. 2012. TIPO: Prov. Jujuy, Dpto. Tumbaya, Abra del Cerro Morado, 3300 m, 7 Ene. 1966, H.A. Fabris 6203 (Holotipo, LP!).

Iconografías: Hunt et al. (2006), Figs. 3: 236, 1: 237.

Descripción original de Echinopsis schickendantzii F.A.C. Weber, en Bois, Dict. Hort. 1: 473. 1896:

E. Schickendantzii Web. [Cereus Schickendantzii Web.] - Rép. Argentine, Tucuman. - Tige oblongue on cylindrique, haute de 15 à $25 \mathrm{~cm}$., sur $6 \mathrm{~cm}$. diam, vert clair, drageonnant à la base et formant des touffes à plusieurs tétes; 14 à 18 côtes verticales, subaiguës, peu profondes; aréoles rapprochées, nues. Aiguillons jaunâtres, grèles, faibles, pointus, longs de 5 à $10 \mathrm{~mm}$.; d'abord 9 extérieurs et 4 centraux, plus tard beaucoup plus nombreux. La fleur n'est pas encore connue; boutonapicillaire, couvert de laine noire. Fruit comestible et agréable.

Descripción ampliada: Plantas de hasta $60-100 \mathrm{~cm}$ de alto, simples 0 ascendentes. Ramas cilíndricas cuando adultas, 6-12 (40) cm de diámetro, verde-oscuro, opaco o brillante, hasta verde-claro, con el ápice levemente hundido. Costillas 10-20, de 1,5-3,0 cm de alto y 2-4 cm de ancho, obtusas, a veces algo crenadas. Areolas subcirculares, $0,8 \mathrm{~cm}$ de alto, $0,6 \mathrm{~cm}$ de ancho, con abundante pilosidad blanco-grisaceo, distanciadas $1 \mathrm{~cm}$. Espinas subuladas, rígidas, amarillo-oscuro hasta rojizas, las centrales 1-5 en areolas jóvenes, 8 en areolas adultas, de 1,5-3,0 cm de largo; radiales 11, de hasta 0,5$2,5 \mathrm{~cm}$ de largo. Flores naciendo muy cerca del ápice de los tallos, $13-18 \mathrm{~cm}$ de longitud, $18 \mathrm{~cm}$ cuando abiertas; pericarpelo y parte del receptáculo cubierto por escamas triangulares, alargadas, $1,0-1,5 \mathrm{~cm}$ largo, de cuyas axilas emerge abundante pilosidad marrón; tépalos externos carnosos, lineares, 3,0-4,5 cm de largo, los tépalos internos espatulados, blancos, 7,0-7,5 cm de largo y 1,0-2,5 cm de ancho; filamentos de los estambres con base verde y ápice amarillo; estilo amarillo, de $3 \mathrm{~mm}$ de diámetro y con ca. 23 estigmas. Pseudobayas globosas, de 2,5-5,0 cm de diámetro, parte externa verde-oscuro y cavidad ovárica con funículos blancos. Semillas negras, brillantes, de $1,5 \mathrm{~mm}$ de largo y 0,7-0,8 $\mathrm{mm}$ de ancho. 
Distribución y Hábitat: Argentina, en las provincias de Catamarca, Salta y Tucumán, entre 1500 a 2500 m en montañas con abundante vegetación, en el nivel superior de las Yungas.

\section{Comentarios morfológicos y sus consecuencias en la taxonomía y nomenclatura:}

T. schickendantzii presenta una alta variación intraespecífica con respecto al ancho de las costillas, color, número y tamaño de las espinas centrales y por su distribución, por lo que se proponen tres subespecies.

\section{Clave para la identificación de las subespecies de Trichocereus schickendantzii}

1. Espinas centrales $3-8$, de $1,5 \mathrm{~cm}$ de longitud, amarillo-oscuro hasta rojizas. De Salta, Catamarca, Tucumán y Jujuy

2. Ramas de $30-50 \mathrm{~cm}$ de alto, $13 \mathrm{~cm}$ de diámetro. Salta, Catamarca y Jujuy subsp. shaferi

2'. Ramas de 60-100 cm de alto, 30-40 cm de diámetro. Salta, Catamarca, Jujuy y Tucumán subsp. schickendantzii

1'. Una espina central, de $3 \mathrm{~cm}$ de largo, amarillo-oscuro. Endémica de Salta subsp. smrzianus

\section{Trichocereus schickendantzii (F.A.C. Weber) Britton \& Rose subsp. schickendantzii}

Tipo no designado. TIPO: Argentina, Prov. Salta, Dpto. Guachipas, al W de Las Juntas, 2380 m, 30 Nov. 2001, R. Kiesling \& T. Tombesi 10007 (Neotipo, SI, aquí designado).

Iconografía: Marshall \& Bock (1941), foto 43: 93.

Descripción ampliada: Plantas de hasta $60-100 \mathrm{~cm}$ de alto, simples 0 ascendentes. Ramas oblongas a cilíndricas, 6-17 (30-40) cm de diámetro, verde-oscuro, opaco, hasta verde-claro, con el ápice levemente hundido. Costillas 11-18, de 2,2 cm de alto, obtusas, a veces algo crenadas, separadas entre sí por una línea oscura. Areolas separadas entre sí por $1 \mathrm{~cm}$, subcirculares, $6 \mathrm{~mm}$ de ancho y con abundante pilosidad blanco-grisaceo. Espinas subuladas, amarillo-oscuro hasta rojizas, las centrales 3 en areolas jóvenes, 8 en areolas adultas, 1,5 cm de largo; radiales 10, de hasta 1,2 cm de largo. Flores apicales, infundibuliformes, $15-18 \mathrm{~cm}$ de longitud; pericarpelo y parte del receptáculo cubierto por escamas triangulares, alargadas, $1 \mathrm{~cm}$ largo, de cuyas axilas emerge abundante pilosidad marrón, $1 \mathrm{~cm}$ de longitud. Segmentos exteriores del perianto carnosos, lineares, $3 \mathrm{~cm}$ de largo, los segmentos internos son espatulados, blancos, $7 \mathrm{~cm}$ de largo y $1 \mathrm{~cm}$ de ancho. Pseudobayas globosas, $6 \mathrm{~cm}$ de largo y $5 \mathrm{~cm}$ de diámetro, verde-oscuro, cavidad ovárica con funículos blancos. Semillas negras, brillantes, 1,5 mm de largo y $0,7 \mathrm{~mm}$ de ancho (Fig. 38). 


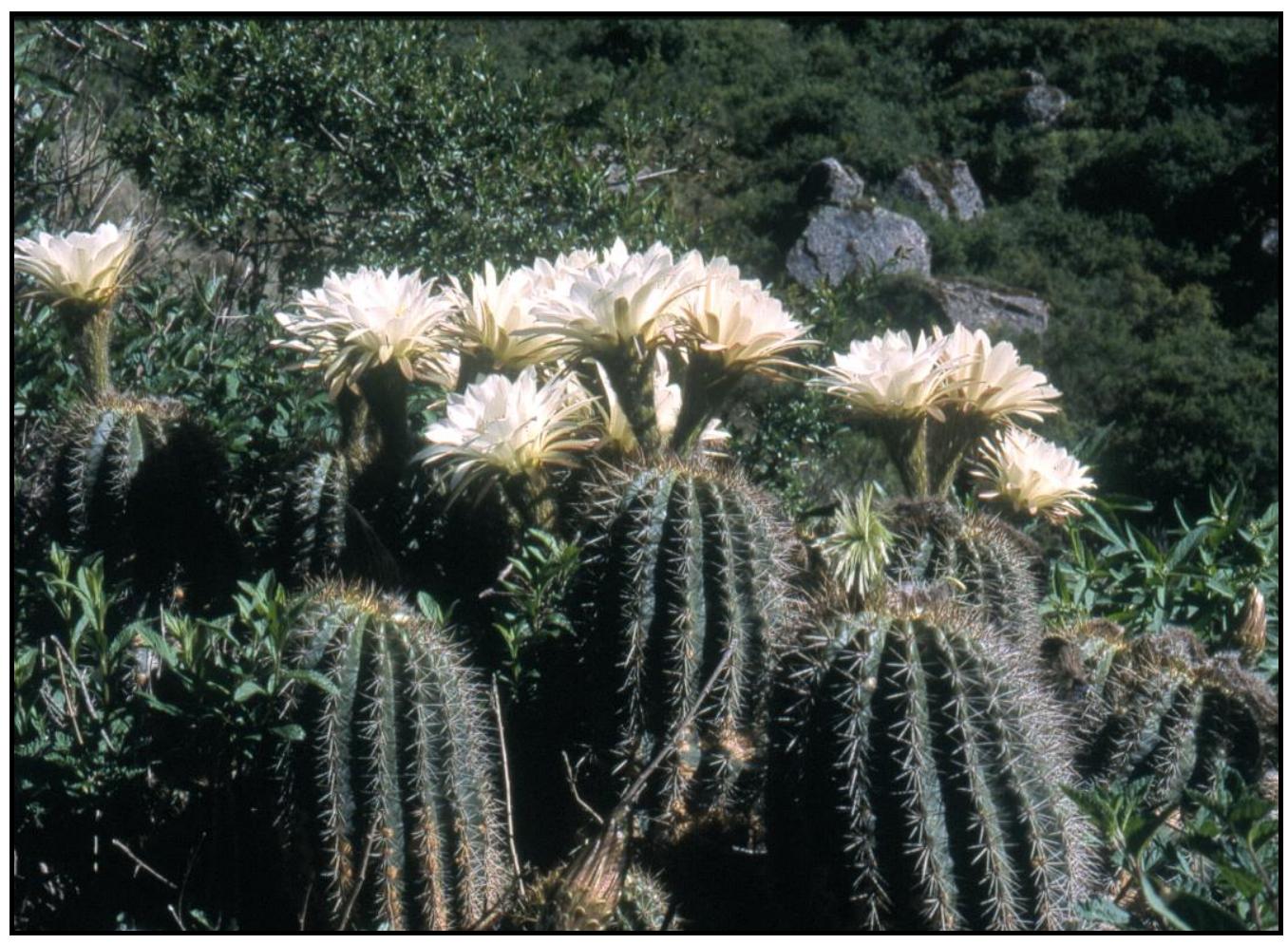

Figura 38. Trichocereus schickendantzii subsp. schickendantzii.

Distribución y Hábitat: Argentina (Fig. 73), en las provincias de Catamarca, Salta, Tucumán y Jujuy, en las Sierras de Aconquija y Cumbres Calchaquíes y laderas orientales de los Andes, localizada en los pastizales de altura (límite superior de la selva) o en las barrancas rocosas, a una altitud de $1500 \mathrm{a}$ 2500 m, ocupando las laderas húmedas, con vegetación herbácea y arbustiva baja (Kiesling 1977).

Comentarios nomenclaturales: Se escogió el ejemplar R. Kiesling \& T. Tombesi 10007 como Neotipo de Trichocereus schickendantzii subsp. schickendantzii porque presenta las características mencionadas en la descripción original, además por presentar varios cortes transversales y longitudinales del tallo y la flor, identificando los caracteres vegetativos y reproductivos de la subespecie.

Material de Herbario estudiado: Argentina, Prov. Catamarca, Dpto. Andalgalá, El Suncho, 1600 m, 3 Nov. 1930, Schreiter 6450 (LIL); ibidem, Narvaez, Nov. 1975, R. Kiesling 1112 A, B (MERL 56239, SI). Prov. Jujuy, Dpto. Capital, Lagunas de Yala, 6 Dic. 1969, R. Kiesling 27 (LP); termas de Reyes, 5 Dic. 2006, B.O. Schlumpberger 538 (CORD). Prov. Tucumán, Dpto. Trancas, 26¹5'S; 65³0'W, 1500 m, Nov. 1933, J. Schreiter 9742 (LIL); ibidem, 1500 m, 15 Nov. 1929, S. Venturi 10258 (MO). Prov. Salta, Dpto. Guachipas, al W de Las Juntas, 2380 m, 30 Nov. 2001, R. Kiesling \& T. Tombesi 10007 (SI); Fca. Carahuasi, Ruta 9, 4-5 km al E de Casa de Arcos, 2000 m, 10 Feb. 2010, L. Novara \& R. Kiesling 13269 (MCNS); Dpto. Rosario de Lerma, Qda. del Toro, ruta 51, Km 45, 27 Ene. 2003, L. Novara 11904 (MCNS). 
35. Trichocereus schickendantzii (F.A.C. Weber) Britton \& Rose subsp. shaferi (Britton \& Rose) Albesiano, comb. et stat. nov.

Trichocereus shaferi Britton \& Rose, The Cactaceae 2: 144. 1920. Echinopsis friedrichii G.D. Rowley, I.O.S. Bull. 3(3): 95. 1974, nom. nov. (non Echinopsis shaferi Britton \& Rose, The Cactaceae 3: 69. 1922). TIPO: Argentina, Prov. Salta, 1800 m, 11 Ene. 1917, J.A. Shafer 44 (Holotipo, 386194 NY!).

Trichocereus manguinii Backeb., Cactus (Paris) No. 35: 147, ill. 1953, sensu descripción, excepto figura. Echinopsis manguinii (Backeb.) H. Friedrich \& G.D. Rowley, I.O.S. Bull. 3(3): 96. 1974. TIPO: Argentina, Prov. Salta, 1800 m, 11 Ene. 1917, J.A. Shafer 44 (Lectotipo, 386195 NY, aquí designado).

Iconografía: Backeberg (1959a), foto 1080: 1123.

Descripción original de Trichocereus shaferi Britton \& Rose, The Cactaceae 2: 144. 1920:

Cespitose, cylindric, 3 to $5 \mathrm{dm}$. high, 10 to $12.5 \mathrm{~cm}$. in diameter, light green; ribs about 14, 10 to 15 $\mathrm{mm}$. high; areoles approximate, 5 to $7 \mathrm{~mm}$. apart, white-felted when young; spines about 10, acicular, $12 \mathrm{~mm}$. long or less, light yellow; flowers from the top of plant, 15 to $18 \mathrm{~cm}$. long; tube slender; outer perianth segments linear; inner segments probably white; scals of the ovary and flower-tube bearing long brown hairs.

Descripción ampliada: Planta ascendente, con tallos cilíndricos, de 30 a $50 \mathrm{~cm}$ de alto y $13 \mathrm{~cm}$ de diámetro, epidermis verde-brillante. Costillas 14, de 10 a $15 \mathrm{~mm}$ de alto. Areolas separadas por 5-7 $\mathrm{mm}$, con pilosidad blanca en las areolas jóvenes. Espinas 10, aciculares, $12 \mathrm{~mm}$ de largo y amarillas. Flores apicales, 15 a $18 \mathrm{~cm}$ de largo, ovario y tubo floral recubierto por escamas de cuyas axilas emergen abundantes pelos marrón. Tepalos blancos.

Distribución y Hábitat: Se localiza en las Provincias de Catamarca, Salta, cerca al municipio San Lorenzo, en barrancas abruptas en la Quebrada del Toro, por encima del nivel de la selva, a $1800 \mathrm{~m}$ de altitud y en Jujuy en Yala y Volcán (Fig. 73).

Comentarios morfológicos y sus consecuencias en la taxonomía y nomenclatura: Al transferir Trichocereus shaferi Britton \& Rose, The Cactaceae 2: 144.1920 a Echinopsis, no podía llamarse Echinopsis shaferi, porque ya existía Echinopsis shaferi Britton \& Rose, The Cactaceae 3: 69. 1922, para otra especie, previa y válidamente publicado, por lo tanto fue reemplazado por el nombre Echinopsis friedrichii G.D. Rowley, I.O.S. Bull. 3(3): 95. 1974.

El lectotipo de T. shaferi Britton \& Rose, J.A. Shafer 44 (NY), está montado en dos cartulinas, con números diferentes de herbario 386194 y 386195, sin una especificación en las etiquetas que correspondan a un solo ejemplar, por lo que el primer número ha sido seleccionado como lectotipo y el segundo como un duplicado.

La foto de Trichocereus manguinii en la descripción original (Backeberg 1953) no corresponde con la descripción de la planta, ya que muestra plantas de varios metros de alto y mayor diámetro que lo 
registrado en la descripción, cuyos caracteres corresponden a una planta pequeña $(95 \mathrm{~cm}$ de alto y $11 \mathrm{~cm}$ de diámetro). La foto le fue enviada por Orestes Marsoner desde "la Argentina", mientras que la descripción se basa en una planta cultivada de otro origen ("cultivada, de la misma época, mencionada como de la Argentina").

Material de Herbario estudiado: Prov. Salta, 1800 m, 11 Ene. 1917, J.A. Shafer 44 (NY).

36. Trichocereus schickendantzii (F.A.C. Weber) Britton \& Rose subsp. smrzianus (Backeb.) Albesiano, comb. et stat. nov.

Echinopsis smriana Backeb., Backeb. \& F.M. Knuth, Kaktus-ABC: 412 (219). (“1935”) 1936. Tipo no designado. Soehrensia smrziana (Backeb.) Backeb., Cactaceae 3: 1677. 1959. Trichocereus smrzianus (Backeb.) Backeb., Kakteenlex. 440, ill. 1966. Trichocereus smrzianus (Backeb.) F.Ritter, Kakteen Südamerika 2: 451. 1980, nom. illeg., por superfluo, Art. 52.1. TIPO: Argentina, Prov. Salta, Dpto. Rosario de Lerma, Quebrada de Escoipe, 19 Nov. 1975, R. Kiesling 1110 (Neotipo, SI, aquí designado).

Iconografía: Kiesling (1978), fig. 10: 300.

Descripción original de Echinopsis smrziana Backeb., Backeb. \& F.M. Knuth, Kaktus-ABC: 412 (219). (“1935”) 1936:

Echinopsis Smrziána Bckbg. 1935 -Bolivia: i Slugter nar Cachipampa, $2800 \mathrm{~m} \mathrm{H}$.

Echinopsis Smrziana Bckbg. sp. n. (ante p. 219). Colonias formans, variabilis, statu juvenili globosa, vivide viridis, deinde cylindrica, ad $16 \mathrm{~cm}$ alta, vetusta crassior, columnari-globosa, curvata, ad $40 \mathrm{~cm}$ longa $20 \mathrm{~cm}$ crassa, griseoviridis, proliferans, costis 10-15, rotundatis, $3 \mathrm{~cm}$ latis $10 \mathrm{~cm}$ altis; aculeis ca. 14 albis ad saturate aureobrunneis, aliis maculatis aliis basi obscuris, irregulariter positis, postea radialibus, acicularibus, tenuissimis, pungentibus, minimis $2 \mathrm{~mm}$ longis maximis centralibus ad $2 \mathrm{~cm}$ longis. - Argentina: Salta, barranca prope Cachipampa, alt. ca. $2800 \mathrm{~m}$.

Descripción ampliada: Plantas en cojín, hasta 1,5 m diámetro y 40-60 cm de alto. Tallos oblongos cuando jóvenes a cilíndricos cuando adultos, de ca. $14 \mathrm{~cm}$ de diámetro. Costillas 10-15, verdeoscuro, 1,5-3,0 cm de alto y $2 \mathrm{~cm}$ de ancho (cerca del ápice). Areolas en el borde de las costillas, con pilosidad blanca. Espinas subuladas, $1 \mathrm{~mm}$ de ancho en la base, rígidas, amarillo oscuro-opaco, una espina central de $3 \mathrm{~cm}$ de largo, 11 radiales de 1,0-2,5 cm de largo. Flores naciendo muy cerca del ápice de los tallos, 13-17 cm de largo cuando abiertas (15-19 cm cuando cerradas), ovario de 2,5 cm de diámetro, tubo floral de $4 \mathrm{~cm}$ de ancho, con escamas triangulares de 1,5 cm de largo, 0,5 cm de ancho, suculentas, verdes, con el ápice torcido y de cuyas axilas emerge abundante lanosidad castaña, gris 0 negruzca. Tépalos exteriores carnosos, triangulares, rosado-claro, $0,8 \mathrm{~cm}$ de ancho y $4,5 \mathrm{~cm}$ de largo; intermedios lineares rosados e interiores lanceolados, blancos, $2,5 \mathrm{~cm}$ de ancho y $7,5 \mathrm{~cm}$ de largo. 
Filamentos de los estambres superiores de $5 \mathrm{~cm}$ de largo, amarillo-crema, anteras subrectangulares, algo adelgazadas hacia el ápice; estambres de la serie espiralada declinados, con filamentos verdes de $7 \mathrm{~cm}$ de largo; estilo de $3 \mathrm{~cm}$ de largo, $2 \mathrm{~mm}$ de diámetro, verde en la base, aclarandose más arriba, estigma amarillo con 16 lóbulos, subteretes, $1,5 \mathrm{~cm}$ de largo, $15 \mathrm{~mm}$ de diámetro. Pseudobaya globosa, 2,5-4,0 $\mathrm{cm}$ de diámetro, parte externa verde-amarillenta, con el perianto marchito persistente. Semillas marrónoscuro a negras, $1,5 \mathrm{~mm}$ de largo, $1 \mathrm{~mm}$ de alto y $0,8 \mathrm{~mm}$ de ancho, con la región hilo micrópilar oblicua y muy alargada, testa brillante, con 1-3 poros en pequeñas depresiones, cresta longitudinal superior marcada, con giba cerca del extremo inferior del hilo (Fig. 39).

Distribución y Hábitat: De la Argentina, endémica de la provincia de Salta. Crece en laderas o en piedemontes, entre 1500-2500 m, en donde predominan herbáceas con sufrútices aislados (Fig. 73).

\section{Comentarios morfológicos y sus consecuencias en la taxonomía y nomenclatura:} Inicialmente fue descrita por Backeberg ([1935] 1936) en el género Echinopsis, pero sin mencionar los caracteres de la flor, fruto y semilla. Posteriormente, fue transferida a Soehrensia (Backeberg 1959a), y por último a Trichocereus (Backeberg 1966), cuando se conocieron las flores, cuya morfología corresponde a la de este último género.

La descripción original menciona en el comienzo "Bolivia", que contradice la localidad, "barranca de Cachipampa", de Salta, pero al final del protologo menciona correctamente Argentina.

Se designó el ejemplar R. Kiesling 1110 como Neotipo de Echinopsis smrziana, por ser el más cercano a los caracteres de la descripción original. El ejemplar muestra dos cortes transversales del tallo, en el que se observa el número de costillas, cantidad y forma de las espinas, y ocho cortes longitudinales de la flor, identificándose la forma, tamaño, pilosidad y número de estambres.

Material de Herbario estudiado: Argentina, Prov. Salta, Dpto. Cachi, Cuesta del Obispo, 26 Nov. 2006, B.O. Schlumpberger 500 (CORD); Dpto. Chicoana, Peña el Caracol, 2925 m, 21 Nov. 1999, F. Font \& P. Picca 6, 7 (SI); Cuesta del Obispo, Qda. El Sunchal, Km 54, 2870 m, 21 Nov. 1999, F. Font \& P. Picca 5 (SI); ibidem, 2885 m, 21 Nov. 1999, F. Font \& P. Picca 8 (SI); ibidem, 2970 m, 24 Nov. 1999, F. Font \& P. Picca 1 (SI); ibidem, 2000 m, 19 Dic. 2005, M. Saravia 50 (SI 54949); Quebrada de Escoipe, 19 Nov. 1975, R. Kiesling 1110 (SI); ibidem, San Martín, 19 Nov. 1995, R. Kiesling et al. 8722 (SI); Ruta 33, entre la Iglesia y la Escuela "Ernesto Rodriguez Pérez", 2515 m, 8 Dic. 2009, L.J. Novara 13245 (MERL 60399); Dpto. Rosario de Lerma, Cuesta del Obispo, 3000 m, 26 Dic. 1972, R. Kiesling et al. 327 (LP); ibidem, Ruta 33, Posta de la Virgen del Valle, 2878 m, 8 Dic. 2009, L.J. Novara et al. 13248 (MERL 60401). 


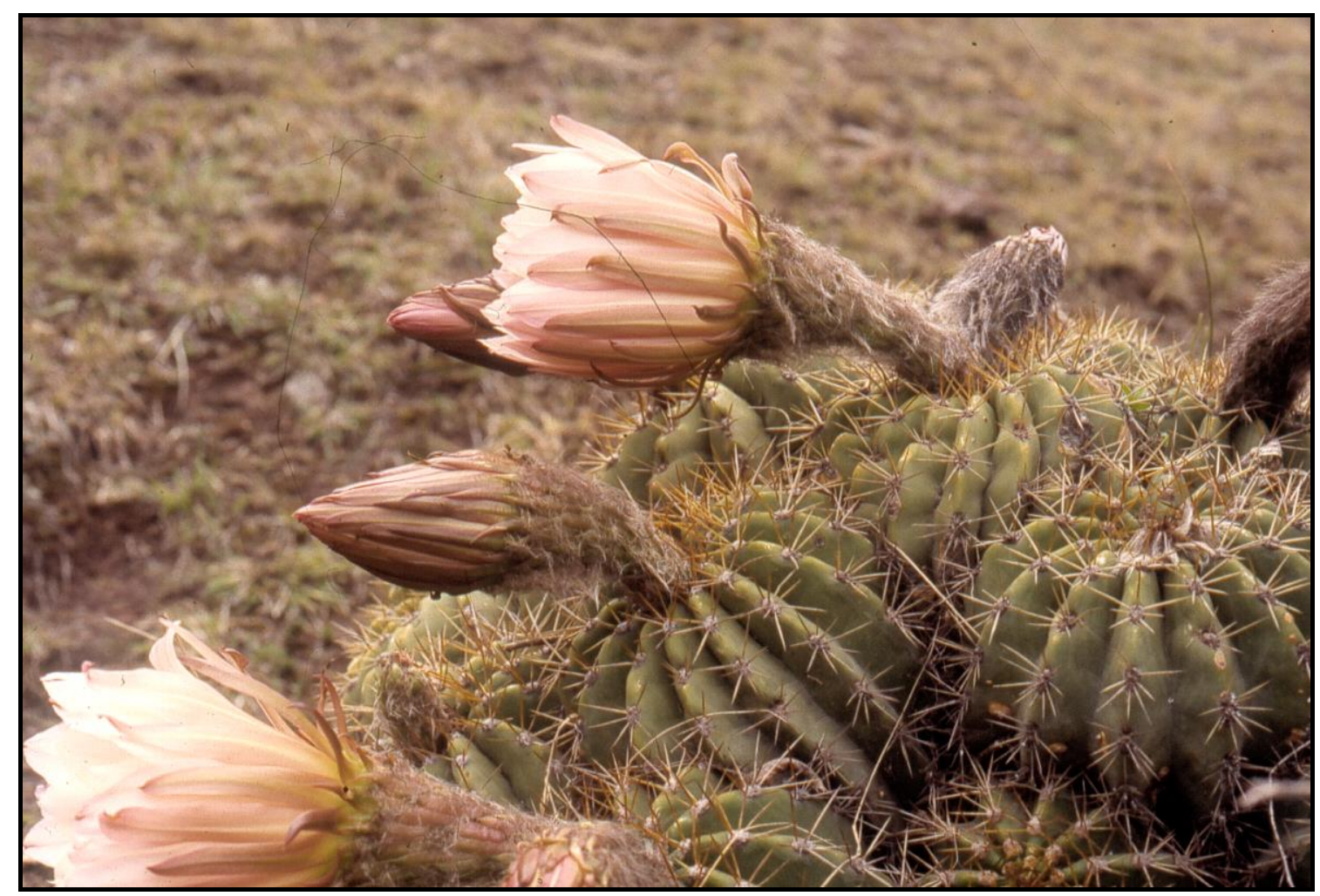

Figura 39. Trichocereus schickendantzii subsp. smrzianus. Argentina, Provincia de Salta, San Martín, en Quebrada de Escoipe.

37. Trichocereus skottsbergii Backeb., en Skottsb., Acta Horti Gothob. 18: 146, ill. 1950.

Echinopsis skottsbergii (Backeb.) H. Friedrich \& G.D. Rowley, I.O.S. Bull. 3 (3): 97. 1974. Tipo no designado. Echinopsis chiloensis (Colla) H. Friedrich \& G.D. Rowley subsp. skottsbergii (Backeb. ex Skottsb.) G.J. Charles. Cactaceae Syst. Init. 19: 13. 2005. Tipo: Skottsberg 834 (Lectotipo, GB, perdido, designado por Charles: 13. 2005) TIPO: Chile, Puerto Oscuro, al borde de la playa, $31^{\circ} 25^{\prime} 21^{\prime \prime S}$; 71035'24"W, 46 m, 6 Nov. 2008, S. Albesiano, L. Faúndez, R. Flores \& P. Saldivia 2050 (Neotipo, MERL; Isoneotipo, $\mathrm{AGUCH}$, aquí designados).

Trichocereus skottsbergii Backeb. ex Skottsb. var. breviatus Backeb., Descr. Cact. Nov.: 20. 1956. Echinopsis skottsbergii (Backeb.) H. Friedrich \& G.D. Rowley var. breviata (Backeb.) H. Friedrich \& G.D. Rowley. I.O.S. Bull. 3 (3): 98. 1974. TIPO: Chile, IV Región de Coquimbo, Dpto. Ovalle, Fray Jorge, 200 m, Nov. 1925, E. Werdermann 885 (Neotipo, SI! designado por Albesiano 18: 134. 2012).

Iconografías: Backeberg (1959a), fotos 1105-1108: 1141-1142. Ritter (1980b), foto 1070: 1223. Albesiano (2012), foto 14: 134.

Descripción original de Trichocereus skottsbergii Backeb., en Skottsb., Acta Horti Gothob. 18: 146. 1950: 
Erectus, supra basin nec non a latere ramosus, cinereo-viridis, saltem ad $1.2 \mathrm{~m}$ altus; ramis circ. ro- $12 \mathrm{~cm}$ crassis. Costae ad I2I3, areolis circ. I6 mm longis et $5 \mathrm{~mm}$ latis, copiose tomento nigricante instructis; aculei radiales circ. 22-26, horizontaliter divaricati, valde impares, $0.7-6.2 \mathrm{~cm}$ longi, flexibiles, tenui usque setacei, centrales 3 , 5-ro cm longi, flexibiles, partim setacei, paulum pungentes, omnes griseo-cornicolores. Flores $8-\mathrm{I} 2 \mathrm{~cm}$ longi, tubo lana umbrina \pm densa instructo, squamis crebis angustis, ovario dense squamato; phylla perigonii interiora lanceolata, alba, stylo staminibusque flavidis, stigmatibus circ. $13 \mathrm{~mm}$ longis. Fructus ignotus.

Hab. Estancia Frai Jorge, fl. I6/8 (n. 834).

Muy afín de $T$. deserticolus (Werd.) Bckbg, especie de Antofagasta, Taltal, caracterizada por sus espinas marginales cortas $(\mathrm{I}-\mathrm{I} .5 \mathrm{~cm}$ ) y sus costillas menos numerosas y también por ser ramificado desde la base. N. 834 es idéntico con Werdermann n. 885 ( $C$. chiloensis, Herb. Stockholm).

Descripción ampliada: Plantas erectas, mayores de $2 \mathrm{~m}$ de alto, pudiendo superar los $3 \mathrm{~m}$ (com. pers. Luis Faúndez). Ramas laterales originadas encima de la base, verde-grisáceas, $10-15 \mathrm{~cm}$ de diámetro, el ápice con abundantes espinas aciculares, menores de $0,5 \mathrm{~mm}$ de diámetro, amarillo-claro. Costillas del ápice 16, obtusas, 1,8 cm de ancho, $5 \mathrm{~mm}$ de alto; con areolas obovadas, $1 \mathrm{~mm}$ de alto y 1 $\mathrm{cm}$ de ancho, con pilosidad amarilla en el ápice y en la base gris; espinas centrales 3 , aciculares, 0,5 mm de ancho, 2-12 cm de largo, flexibles, algunas parecidas a cerdas y recurvadas, no tan puntiagudas, las más pequeñas presentan la base verde y el ápice marrón, las más grandes son grises con algunos puntos negros y punta marrón; espinas radiales 13-26 (tanto en el ápice y en la base del tallo), 2-6 cm de largo, aciculares, menos de $1 \mathrm{~mm}$ de diámetro, flexibles (parecidas a cerdas), apenas puntiagudas, base gris y ápice marrón. Costillas de la base 12-17, obtusas, de $2 \mathrm{~cm}$ de ancho, $1 \mathrm{~cm}$ de alto, con areolas obovadas, $1 \mathrm{~mm}$ de alto, 0,5-1,0 cm de ancho, con abundante tomento gris-oscuro a negro; con 4 espinas centrales, $7 \mathrm{~cm}$ de largo, aciculares, $3 \mathrm{~mm}$ de diámetro, verde con ápice marrón; espinas radiales 13 , hasta 2,5 cm de largo, aciculares, verde-oscuro con puntas marrón o totalmente blancas. Flores 1-3, subapicales, 8-12 cm de largo; ovario de 2,5 cm de diámetro, recubierto por escamas subuladas, de hasta $3 \mathrm{~mm}$ de largo, con abundantes pelos color marrón y negro; tubo floral de $5 \mathrm{~cm}$ de diámetro, cubierto por escamas, de cuyas axilas surgen cuantiosos pelos de igual color, de $6 \mathrm{~mm}$ de largo; tépalos externos espatulados, $1,7 \mathrm{~cm}$ de largo, con la base verde, ápice rosado, con una línea central rosada; tépalos internos espatulados, $3 \mathrm{~cm}$ de longitud, blancos, con ápice rosado; estilo amarillo, $8 \mathrm{~cm}$ de largo, estigma amarillo, 7-13 mm de largo. Pseudobaya de $3 \mathrm{~cm}$ de largo y $2 \mathrm{~cm}$ de diámetro (Fig. 40). 


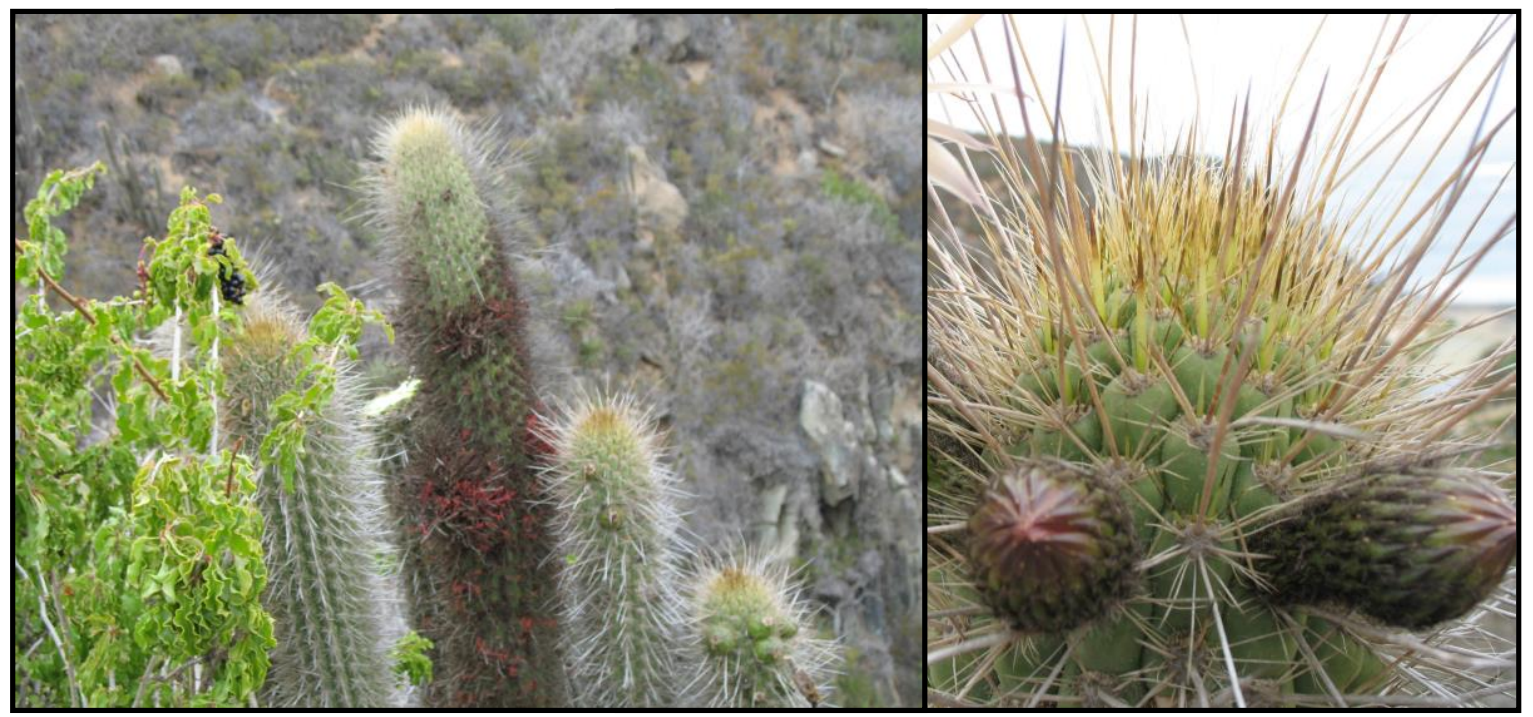

Figura 40. Trichocereus skottsbergii. Chile, IV Región de Coquimbo, Puerto Oscuro, al borde de la playa.

Distribución y Hábitat: T. skottsbergii se localiza en Chile (Fig. 75B), en Coquimbo, en el Parque Nacional Fray Jorge, situado a $30 \mathrm{Km}$ al occidente de Ovalle, y en Parque Nacional de Talinay; al sur occidente de Ovalle. Se localiza en las laderas de la cordillera de la costa, donde el tipo fisonómico dominante son los matorrales achaparrados y espinosos, desde el nivel del mar hasta los $200 \mathrm{~m}$.

Comentarios morfológicos y sus consecuencias en la taxonomía y nomenclatura: En una comunicación enviada por Claes Persson, curador del herbario GB (Suecia), informa (en litt.) que el ejemplar tipo, Skottsberg 834, no existe en esta institución, como aparece citada en Charles (2005), y por lo tanto designamos un Neotipo, S. Albesiano et al. 2050 (MERL), de la región de Puerto Oscuro, que reúne las características morfológicas de la descripción original.

Se escogió como Neotipo de Trichocereus skottsbergii var. breviatus el ejemplar E. Werdermann 885 (SI), por presentar las características mencionadas en la descripción original.

Backeberg (1950) considera que T. skottsbergii y $T$. deserticola son semejantes, pero se encontraron caracteres que permite diferenciarlos (Tabla 12).

Tabla 12. Diferencias entre $T$. deserticola y $T$. skottsbergii de acuerdo a los caracteres morfológicos.

\begin{tabular}{|l|l|l|}
\hline CARACTERES & T. deserticola & T. skottsbergii \\
\hline Origen de las ramas & A nivel del suelo & Hasta $80 \mathrm{~cm}$ del suelo \\
\hline No. costillas en el ápice & $8-12$ & 16 \\
\hline Diámetro de las ramas & Hasta $10 \mathrm{~cm}$ & Hasta $15 \mathrm{~cm}$ \\
\hline Longitud de las espinas radiales del ápice & Hasta $3 \mathrm{~cm}$ & Hasta $6 \mathrm{~cm}$ \\
\hline
\end{tabular}


Se ha observado que dentro de una misma población, existen individuos que se diferencian por el menor tamaño de sus flores y espinas centrales, habiendo sido nombrados como la variedad breviatus, pero estas características se encuentran en el rango morfológico de variación de la especie, razón por la cual, la variedad debe pasar a la sinonimia de la especie, tal como fue propuesto por Ritter (1980b).

Charles (2005) propuso T. skottsbergii como subespecie de T. chiloensis, pero dentro del estudio de la morfología de las espinas radiales del ápice, se observaron algunas diferencias: En T. skottsbergii las espinas son flexibles, no tan punzantes, y las más largas son de $6 \mathrm{~cm}$, mientras que en $T$. chiloensis son rígidas, punzantes y hasta $4 \mathrm{~cm}$ de longitud. Por lo anterior, se propone mantener $T$. skottsbergii separada a nivel específico de T. chiloensis, además, Charles no advirtió que esta especie había sido descrita por Backeberg y no por Skottsberg.

Material de Herbario estudiado: Chile, IV Región de Coquimbo, Dpto. Ovalle, Fray Jorge, 200 m, Nov. 1925, E. Werdermann 885 (SI); Prov. Elqui, Mpio. La Serena, Punta Teatinos, 29²9.29'S, 71017.36'W, 10-100 m, 5 Dic. 1994, U. Eggli \& B.E. Leuenberger 2579 (SGO); Puerto Oscuro, al borde de la playa, 31025'21"S; 71035'24"W, 46 m, 6 Nov. 2008, S. Albesiano et al. 2050 (AGUCH, MERL).

38. Trichocereus spachianus (Lem.) Riccob., Boll. Reale Orto Bot. Palermo 8: 237. 1909.

Cereus spachianus Lem., Hort. Universel 1: 225. 1839. Tipo no designado. Echinocereus spachianus Rümpler's, Förster Handb. Cacteenk. Ed. 2.2 (fascículos 13/14): 827. 1885. Echinopsis spachiana (Lem.) H. Friedrich y G.D. Rowley, IOS Bull. 3 (3): 98. 1974. Soehrensia spachiana (Lem.) Schlumpb., Cactaceae Syst. Init.: 28: 31. 2012. TIPO: Argentina, Prov. Jujuy, Dpto. Valle Grande, Nov. 1973, R. Kiesling 337 (Neotipo, SI; Isoneotipo, LP, aquí designados).

Cereus santiaguensis Speg., Anales Mus. Nac. Buenos Aires ser. 3, 4: 478. 1905. Tipo no designado. Trichocereus santiaguensis (Speg.) Backeb., en Backeberg \& Kunth, Kaktus-ABC: 204. (1935) 1936. Trichocereus santiaguensis (Speg.) Backeb., Cactaceae 2: 1107, ill. 1959. Echinopsis santiaguensis (Speg.) H. Friedrich y G.D. Rowley, IOS Bull. 3 (3): 97. 1974. TIPO: Argentina, Prov. Jujuy, Dpto. Capital, Lozano, 24 Abr. 1975, R. Kiesling et al. 1216 (Neotipo, SI, aquí designado).

Cereus thelegonoides Speg., Anales Mus. Nac. Buenos Aires ser. 3, 4: 480. 1905. Tipo no designado. Trichocereus thelegonoides (Speg.) Britton \& Rose, The Cactaceae 2: 131. 1920. Echinopsis thelegonoides (Speg.) H. Friedrich \& G.D. Rowley, IOS Bull. 3 (3): 98. 1974. Soehrensia thelegonoides (Speg.) Schlumpb., Cactaceae Syst. Init:: 28: 31. 2012. TIPO: Argentina, Dpto. Ledesma, camino a Valle Grande, antes de Abra de Cañas, 30 Oct. 1974, R. Kiesling et al. 795 (Neotipo, SI; Isoneotipo, LP, aquí designados). 
Trichocereus rubinghianus Backeb., Descr. Cact. Novarum 3: 15. 1963, nom. inval., por no designar tipo (Art. 40.1). Echinopsis rubinghiana (Backeb.) H. Friedrich y G.D. Rowley, Bull IOS. 3 (3): 97. 1974, comb. inval., por basarse en un nombre inválido.

Trichocereus quadratiumbonatus F.Ritter, Kakteen Südamerika 2: 566, ill. 1980. Echinopsis quadratiumbonatus (F. Ritter) D.R. Hunt, Cact. Consensus Initiat. 4: 5. 1997. TIPO: Bolivia, Santa Cruz, Prov. Cordillera, 1000 m, "12 Km westl. Boyuibe", 1963, F. Ritter 1156 (Holotipo, U).

Iconografías: Berger (1900): 93. Berger (1905), lámina 8, f. 2, 3. Britton \& Rose (1920), fig. 190: 132. Backeberg (1959a), foto 1058: 1109.

Descripción original de Cereus spachianus Lem., Hort. Universel 1: 225. 1839:

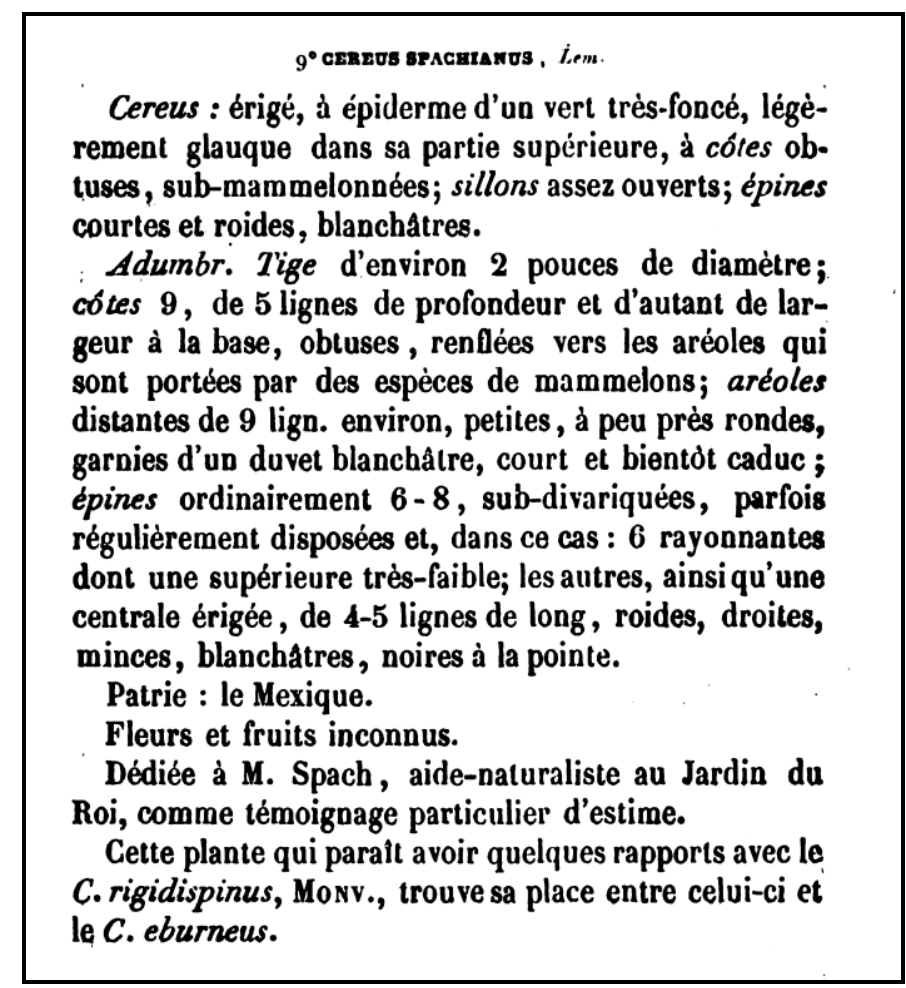

Descripción ampliada: Plantas erectas (1-2 $\mathrm{m}$ de alto), luego en general se quiebran por no soportar su propio peso. Tallos de 5-8 cm de diámetro, cilíndricos, verde-pálido a oscuro. Costillas del ápice 11 , obtusas, mamelonadas, $0,8 \mathrm{~cm}$ de ancho, $0,5 \mathrm{~cm}$ de alto, con areolas ovales, $2 \mathrm{~mm}$ de alto y 5 $\mathrm{mm}$ de diámetro, con tomento blanco; 1 espina central, 2,5 cm de largo, acicular, 0,5 mm de ancho, recta, perpendicular al tallo, negra; espinas radiales 7 , de $1 \mathrm{~cm}$ de largo, aciculares, $0,5 \mathrm{~mm}$ de ancho, negras y patentes al tallo (forman un ángulo de 75 a 1050). Costillas de la base 11-16, obtusas, con un surco interareolar horizontal que divide a las costillas en mamelones subcuadrados, $1,5 \mathrm{~cm}$ de ancho y $0,5 \mathrm{~cm}$ de alto, areolas ovales, 0,2 $\mathrm{mm}$ de alto y 0,5-0,8 cm de ancho, gris-oscura, $2 \mathrm{~cm}$ de distancia entre ellas; 1-4 espinas centrales, $1-3 \mathrm{~cm}$ de largo, aciculares, $0,5 \mathrm{~mm}$ de ancho, grises, perpendiculares al tallo 0 ligeramente dobladas hacia atrás; espinas radiales $7-11$, de $1 \mathrm{~cm}$ de largo, aciculares, 0,5 mm de ancho, 
grises y divaricadas. Flores generalmente apicales, raro subapicales, $22 \mathrm{~cm}$ de largo, aromáticas, con abundante pilosidad gris a negra; ovario de $3 \mathrm{~cm}$ de diámetro; escamas florales de $1 \mathrm{~cm}$ de largo, $4 \mathrm{~mm}$ de ancho; tépalos externos de $6 \mathrm{~cm}$ de longitud, tépalos internos blancos, oval-lanceolados, 8-11 cm de largo, $3 \mathrm{~cm}$ de ancho; estambres superiores con filamentos de 3,5 cm de longitud; estambres inferiores con filamentos de $9,5 \mathrm{~cm}$ de longitud, anteras de $2 \mathrm{~mm}$ de diámetro y $3 \mathrm{~mm}$ de largo, subrectangulares; cámara nectarial de 1,7 cm de largo; estilo de $18 \mathrm{~cm}$ de longitud, $0,4 \mathrm{~cm}$ de diámetro, verdoso en la base, en la parte superior blanco-amarillento; estigmas 22, lineares, 2,2 cm de largo y $1 \mathrm{~mm}$ de diámetro, amarillos. Pseudobaya globosa a elipsoide, 4-6 cm de diámetro. Semillas negras, brillantes, punteadas, en forma de coma alargada, muy verrucosas, con el surco apenas marcado y gruesas perforaciones, 1,2 $\mathrm{mm}$ de largo, $1 \mathrm{~mm}$ de alto y 0,6 $\mathrm{mm}$ de ancho (Fig. 41).

Distribución y Hábitat: Se distribuye en la Argentina en las provincias de Jujuy y Salta (Fig. 73), en León (Dpto. Capital) se encuentra en el borde superior de la selva, a $1600 \mathrm{~m}$ de altitud, bajo el dosel de varios árboles. En Abra de Cañas (Dpto. Ledesma) se localiza en lugares más húmedos y sombríos, y en otras localidades más secas y soleadas, a $1000 \mathrm{~m}$ de altitud. También se localiza en Bolivia, en los departamentos de Chuquisaca y Tarija, entre los 500 a 2000 m (Fig. 74) (Albesiano 2014).

\section{Comentarios morfológicos y sus consecuencias en la taxonomía y nomenclatura: El} ejemplar R. Kiesling 337 (SI) fue designado como Neotipo de Cereus spachianus, porque reúne las características mencionadas en la descripción original, además de presentar cortes del tallo y la flor, lo que permite observar los caracteres vegetativos y reproductivos de la especie.

Se designó el ejemplar R. Kiesling et al. 1216 (SI) como Neotipo de Cereus santiaguensis, por ser el más cercano a la descripción original. El ejemplar muestra cortes transversales del tallo, en el que se observa el número de costillas, cantidad y forma de las espinas, y cortes longitudinales de la flor, identificandosé la forma, tamaño y pilosidad.

Se eligió como Neotipo de Cereus thelegonoides el ejemplar R. Kiesling et al. 795 (SI), porque se recolectó en la Provincia de Jujuy, de donde fue descrita la especie, además de reunir las características mencionadas en la descripción original.

Las descripciones de $T$. quadratiumbonatus, $T$. spachianus y $T$. thelegonoides comparten varios caracteres vegetativos (tallos erectos, epidermis verde-clara, costillas obtusas y mamelonadas, espinas cortas y aciculares), y por consiguiente se consideran pertenecientes a una misma entidad específica, $T$. spachianus. $T$. santiaguensis posiblemente pertenezca a la misma especie aunque detalles de la descripción (4-7 m de alto), y su distribución no son coincidentes.

En la descripción original de Cereus spachianus, Lemaire (Hort. Universel 1: 225. 1839) da como lugar de origen México y no menciona los caracteres reproductivos. Posteriormente, Berger $(1900,1905)$ describe las flores y los frutos de individuos cultivados en el Jardín Botánico de La Mortola (Italia), 
citándola para la Argentina y transfiriéndola al subgénero Trichocereus. Asimismo, Britton y Rose (1920) la mencionan para la Argentina, pero sin una localidad definida, y sinonimizan Cereus santiaguensis bajo C. spachianus, lo que es aceptado por Spegazzini (1923), confirmando su distribución en la Argentina. Spegazzini recibió el ejemplar de C. santiaguensis de otro colector, por cuanto no aparece la Provincia de Santiago del Estero en la lista de expediciones botánicas de Spegazzini (Katinas et al. 2000). Kiesling (1978) lo considera nombre dudoso, adoptando para esta especie el nombre T. thelegonoides, pero al ser aqui tipificado, se resuelve la identidad de este nombre.

Con la tipificación de Cereus santiaguensis se fija este nombre como sinónimo de $T$. spachianus, mientras que hasta el momento era un nombre dudoso, porque nunca se encontró una planta con estas características en Santiago del Estero.

El epíteto spachianus fue aplicado por varios autores antiguos (Berger 1900, Britton \& Rose, 1920) o modernos (Rowley 1974; Anderson 2005 o Hunt 2006) a una especie de Trichocereus, cuyos caracteres coinciden con la descripción original, por lo que se acepta este criterio, y con la tipificación efectuada se fija este nombre.

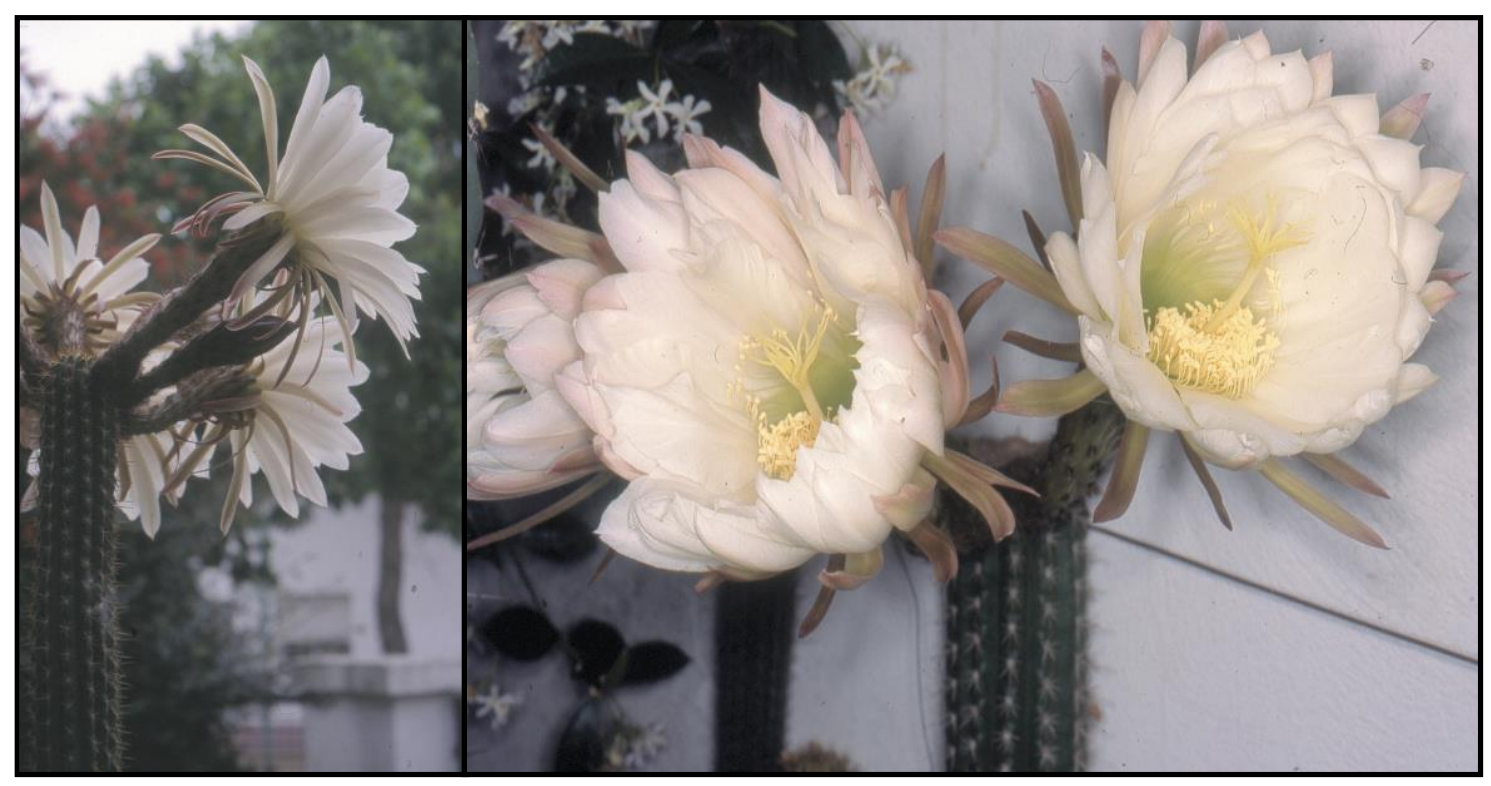

Figura 41. Trichocereus spachianus. Provincia de Jujuy, tomado de cultivo.

Material de Herbario estudiado: Argentina, Prov. Jujuy, Tilcara, Yala de Monte Carmelo, 2900, 19-21 Ene. 1966, H.A. Fabris et al. 6426 (LP); Dpto. Valle Grande, Nov. 1973, R. Kiesling 337 (LP, SI); Dpto. Valle Grande, Huacanqui, 31 Oct. 1974, R. Kiesling 793 (LP, SI); Dpto. Ledesma, camino a Valle Grande, antes de Abra de Cañas, 30 Oct. 1974, R. Kiesling et al. 795 (LP, SI). Dpto. Capital, Lozano, 24 Abr. 1975, R. Kiesling et al. 1216 (SI). Prov. Salta, Dpto. La Caldera: Cno. de cornisa a Jujuy, Ruta 9, Km 1641,9, 1486 m, 26 Nov. 2005. L. Novara \& Gerónimo 11083 (MCNS). Bolivia, Dpto. Chuquisaca, Prov. Oropeza, Barrancas, camino a los Alamos, 21 Nov. 1993, R. Kiesling \& D. Metzing 8435 (SI). Dpto. Tarija, entre Concepción y Tarija, 22 Oct. 1980, F. Zuloaga et al. 1250 (SI). 
39. Trichocereus spinibarbis (Otto ex Pfeiff.) F. Ritter, Kakt. And. Sukkulent. 16 (11): 212. 1965.

Cereus spinibarbis Otto ex Pfeiff., Enum. Diagn. Cact.: 86. 1837. Echinocereus spinibarbis (Otto ex Pfeiff.) K. Schum., Monatsschr. Kakteenk. 5: 124. 1895. Echinopsis spinibarbis (Otto ex Pfeiff.) Hoffm.Grob. Cactaceas. 1989. TIPO: Chile, III Región de Atacama, cerca de Vallenar, 28³5'S; 7046'W, 11 Oct. 2010, S. Albesiano, R. Kiesling, L. Faúndez \& P. Saldivia 2088 (Neotipo, MERL! designado por Albesiano 18: 135. 2012).

Iconografía: Albesiano (2012), foto 15: 135.

Descripción original de Cereus spinibarbis Otto ex Pfeiff., Enum. Diagn. Cact.: 86. 1837:

\begin{tabular}{|c|}
\hline 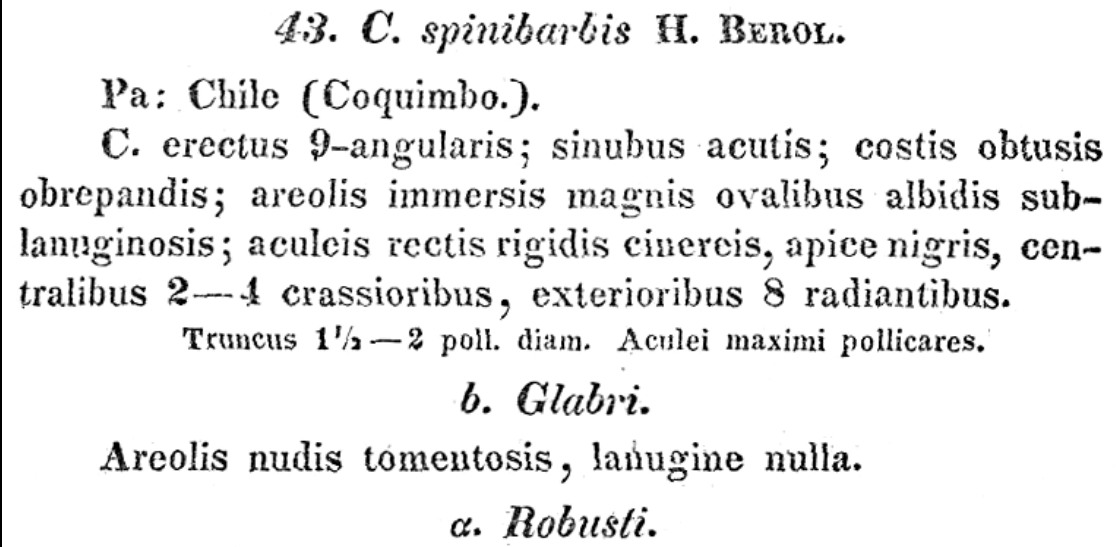 \\
\hline
\end{tabular}

Descripción ampliada: Plantas ascendentes, de hasta $80 \mathrm{~cm}$ de alto, formando densos arbustos bajos. Tallos ligeramente arqueados y cilíndricos, $6 \mathrm{~cm}$ de diámetro. Costillas del ápice 9 , obtusas, $1 \mathrm{~cm}$ de ancho, 0,8 $\mathrm{mm}$ de alto; los surcos son ondulados; con areolas redondas y obovadas, 5 $\mathrm{mm}$ de alto, $1 \mathrm{~cm}$ de ancho, con pilosidad amarilla en las areolas apicales y gris en las areolas subapicales. Espinas centrales 3-4, en las areolas subapicales dispuestas en cruz, 3-12 cm de largo, aciculares, 2 mm de diámetro, cerdosas, flexibles, curvadas, grises con puntas marrón; radiales 10-15, aciculares, 0,5 mm de diámetro, 1,5 cm de largo. Costillas de la base 9 , obtusas, $1 \mathrm{~cm}$ de ancho, $1 \mathrm{~cm}$ de alto; con areolas de $8 \mathrm{~mm}$ de alto, $1 \mathrm{~cm}$ de ancho, redondas, con pilosidad gris-oscura; espinas centrales 4, aciculares, 1,5 mm de diámetro, 2-9 cm de largo, gris-claro con puntas marrón; radiales 22, aciculares, $1 \mathrm{~cm}$ de largo, cerdosas, menores de $0,5 \mathrm{~mm}$ de diámetro, gris-claro con puntas marrón. Flores de $13 \mathrm{~cm}$ de largo, ovario y tubo floral recubierto de pilosidad negra, lóbulos del estigma erectos, $1-2 \mathrm{~cm}$ de largo. Pseudobayas apicales, $4 \mathrm{~cm}$ de largo. Semillas $1,5 \mathrm{~mm}$ de largo, $1 \mathrm{~mm}$ de ancho, región hilo-micrópilo amarillo-oscuro (Fig. 42). 


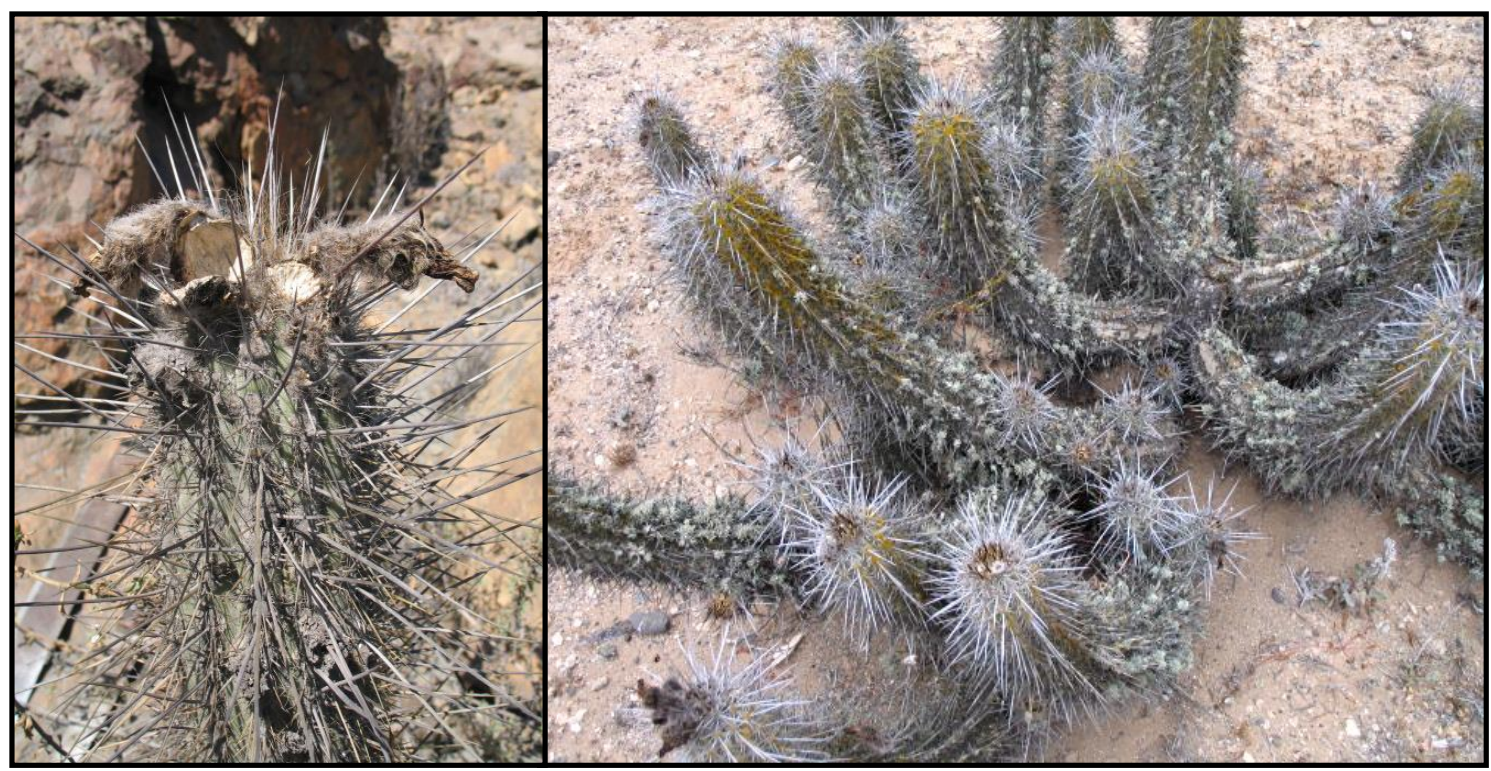

Figura 42. Trichocereus spinibarbis. Chile, Provincia Huasco, comuna Vallenar, cerca de Vallenar.

Distribución y Hábitat: T. spinibarbis se localiza en Chile, en la II Región de Antofagasta y en la III Región de Atacama, a 200 m de altitud (Fig. 75B).

\section{Comentarios morfológicos y sus consecuencias en la taxonomía y nomenclatura: Se eligió}

el ejemplar S. Albesiano et al. 2088 (MERL) como Neotipo de Cereus spinibarbis en Albesiano 18: 135. 2012, debido a que agrupa las características vegetativas mencionadas en la descripción original, además presenta varios cortes transversales y longitudinales del tallo, flores y frutos, donde se identifican los caracteres vegetativos y reproductivos de la especie.

Salm-Dyck (: 44, 199. 1850), establece una clasificación infragenérica para los taxones de Cereus, ubicando a C. spinibarbis en la subsección Velutini, con base en la epidermis opaca y finamente aterciopelada, y cercanía entre las areolas $(4-6 \mathrm{~mm})$. La observación realizada por Salm-Dyck es confiable, porque Pfeiffer era su discípulo, y sus plantas las conocía muy bien Salm-Dyck. Labouret (: 334. 1853) menciona el tamaño de las espinas, ca. $30 \mathrm{~cm}$ de largo. Esto no había sido referido en la descripción original.

Schumann (:62. 1899) transfiere C. spinibarbis a la sinonimia de Cereus chiloensis, sin aportar detalles, a pesar de que $C$. spinibarbis se diferencia de $C$. chiloensis en el aspecto de las plantas (densos arbustos bajos, generalmente menores de 1,5 $\mathrm{m}$ vs. plantas arbustivas 0 arborescentes mayores de 1,5 $\mathrm{m})$, diámetro de las ramas $(4-10 \mathrm{~cm}$ vs. $10-25 \mathrm{~cm})$ y epidermis finamente aterciopelada, característica ausente en C. chiloensis. 
Posteriormente, Britton y Rose (1920) transfieren Cereus spinibarbis al género Eulychnia [Eulychnia spinibarbis (Otto ex Pfeiff.) Britton \& Rose, The Cactaceae 2: 82-83, f. 122], sin proporcionar detalles de este cambio, y los caracteres morfológicos que se describen no corresponde con la descripción original sino con los de Eulychnia breviflora Phil.

Recientemente, Ritter (1980b) considera que Cereus spinibarbis corresponde al género Trichocereus, por cuanto la epidermis aterciopelada en los cactus chilenos se presenta únicamente en este género, y pasa E. spinibarbis Britton \& Rose (non Cereus spinibarbis Otto ex Pfeiff.) a la sinonimia de Eulychnia breviflora Phil.

En la descripción original de Cereus spinibarbis se mencionan dos taxones infraespecíficos, la variedad glabri, cuya única característica diferencial mencionada en el protologo, es la ausencia de lanosidad en las areolas, lo cual no ha sido observado en los ejemplares estudiados, y la variedad robusti carece de descripción y diagnosis, por lo que corresponde a un nomen nudum.

Material de Herbario estudiado: Chile, $\Perp$ Región de Antofagasta, Prov. Antofagasta, Comuna Taltal, 2526'S; 70³1'W, 11 Oct. 2010, S. Albesiano et al. 2091 (MERL). III Región de Atacama, 37 Km de Punta de Choro, 210 m, 11 Oct. 2010, S. Albesiano et al. 2087 (MERL); Prov. Huasco, comuna Vallenar, cerca de Vallenar, 283's; 7046'W, 11 Oct. 2010, S. Albesiano et al. 2088 (MERL).

40. Trichocereus strigosus (Salm-Dyck) Britton \& Rose, The Cactaceae 2: 143. 1920.

Cereus strigosus Salm-Dyck, Hort. Dyck.: 334. 1834. Echinocereus strigosus (Salm-Dyck) Lemaire, en Rümpler's Förster Handb. Cacteenk. Ed. 2. Vol. 2, (fascículos 13/14): 826. 1885. Echinopsis strigosa (Salm-Dyck) H.Friedrich \& G.D.Rowley I.O.S. Bull. 3(3): 98. 1974.

Echinocereus strigosus (Salm-Dyck) Lemaire var. spinosior Rümpler's, en Förster Handb. Cacteenk. Ed. 2. Vol. 2, (fascículos 13/14): 827. 1885 (como "Echinocereus strigosus var. spinosior Salm Dyck ex Rümpler's"). Cereus strigosus Salm-Dyck var. spinosior Salm-Dyck, Cact. Hort. Dyck. 1849: 43. 1850, nom. nud. Tipo no designado. TIPO: Argentina, Prov. San Juan, Dpto. Zonda, Quebrada del Zonda, 4 Nov. 1975, R. Kiesling 1061 (Neotipo, SI, aquí designado).

Echinocereus strigosus (Salm-Dyck) Lemaire var. rufispinus Rümpler's, en Förster Handb. Cacteenk. Ed. 2. Vol. 2, (fascículos 13/14): 827. 1885. Tipo no designado. TIPO: Argentina, Prov. Mendoza, Dpto. Capital, cerca del Parque General San Martín, Marzo 1939, A. Ruiz-L. 6138 (Neotipo, MERL, aquí designado).

Cereus intricatus Salm-Dyck, Cact. Hort. Dyck 1849: 194. 1850. Tipo no designado. Cereus strigosus Salm-Dyck var. intricatus (Salm-Dyck) F.A.C. Weber en K.Schum. Gesamtbeschr. Kakt. 68. 1897. Trichocereus strigosus (Salm-Dyck) Britton \& Rose var. intricatus (Salm-Dyck) Borg, Cacti: 139. 
1937. TIPO: Argentina, La Rioja, Dpto Chamical, Campo de exp. del INTA, 21 Ene. 1990, F. Biurrun \& E. Biurrun 3063 (Neotipo, SI, aquí designado).

Cereus strigosus Salm-Dyck var. longispinus C.A. Maass, Monatsschr. Kakteenk.: 15: 119. 1905. Tipo no designado. Trichocereus strigosus (Salm-Dyck) Britton \& Rose var. longispinus (C.A. Maass) Borg, Cacti: 139. 1937. TIPO: Argentina, Prov. San Juan, Dpto. Caucete, Marayes, 9 Nov. 1986, E. Haene 124 (Neotipo, SI, aquí designado).

Trichocereus strigosus (Salm-Dyck) Britton \& Rose var. variegatus Borg, Cacti: 139. 1937. Tipo no designado.

Trichocereus strigosus (Salm-Dyck) Britton \& Rose var. flaviflorus F. Ritter, Kakteen Südamerika 2: 440. 1980. TIPO: Argentina, Prov. La Rioja, Famatina, Feb. 1955, F. Ritter 999 (Holotipo, U).

Iconografías: Kiesling \& Meglioli (2003), fig. 189: 193; foto: 256. Anderson (2005): 244. Hunt et al. (2006), fig. 3: 237.

Descripción original de Cereus strigosus Salm-Dyck, Hort. Dyck.: 334. 1834:

\section{3-16 radiantibus setaceis flavidis, centralibus 4 longioribus fuscescentibus, infimo longissimo. \\ Sub nomine C. strigosi hanc speciem ex Anglia accepimus, a C. multangulari caule tenuiore, liucusque humiliore, costis minus numerosis, aculeisque paucioribus sed longioribus satis diversam. E semine copiose enata non variat. An C. myrio- phyllus Gillies? an C. ferox Haw. Phil. Mag? Patria non bene cognita, verisimiliter Chili.}

Distribución y hábitat: Endémica del oeste argentino, en las provincias de Mendoza, San Juan y La Rioja, en la provincia fitogeográfica del Monte. Habita laderas o terrenos planos, entre 500 y $800 \mathrm{~m}$ de altitud, donde la vegetación dominante corresponde al matorral xerófilo de Cassia aphylla, Larrea divaricata, Larrea cuneifolia, entre otros (Kiesling 1978).

Comentarios filogenéticos y sus consecuencias en la taxonomía y nomenclatura: Se escogió el ejemplar R. Kiesling 1061 (SI) como Neotipo de Echinocereus strigosus var. spinosior, por ser el más cercano morfológicamente a la descripción original, además de presentar dos cortes transversales y dos longitudinales del tallo, identificandosé la cantidad de costillas, forma, longitud y número de espinas, también dos cortes longitudinales de flor, en donde se observa la forma, tamaño y la cantidad de escamas, pilosidad y estambres.

Se seleccionó como Neotipo de Echinocereus strigosus var. rufispinus el ejemplar A. Ruiz-L. 6138 (MERL), porque agrupa las características morfológicas descritas en la descripción original. 
Se eligió el ejemplar F. Biurrun \& E. Biurrun 3063 (SI) como Neotipo de Cereus intricatus por reunir las características mencionadas en la descripción original. Este ejemplar consta de cuatro cortes transversales y tres longitudinales de tallo, pudiéndose observar el número de costillas, forma, longitud y número de espinas, además de presentar un corte longitud de la flor y fruto, en donde se observa la forma, tamaño, cantidad de escamas y pilosidad.

Se seleccionó el ejemplar E. Haene 124 (SI) como Neotipo de Cereus strigosus var. longispinus por ser el más cercano a las características de la descripción original. Consta de un corte transversal del tallo, donde se aprecia el número de costillas, forma, tamaño y cantidad de las espinas centrales y radiales, además de cuatro cortes longitudinales de flor, identificandosé su forma, longitud, diámetro del ovario, cantidad de escamas y pilosidad.

No se designó ejemplar Tipo de Trichocereus strigosus var. variegatus por no haber hallado un ejemplar con manchas amarillentas.

Especie inicialmente descrita por Salm-Dyck (1850) en el género Cereus, años después transferida por Lemaire (1885) al género Echinocereus, por Britton y Rose (1920) a Trichocereus y finalmente a Echinopsis por Rowley (1974). Del análisis cladístico de Trichocereus con base en caracteres morfológicos y moleculares (Albesiano \& Terrazas 2012), resulta que esta especie pertenece al género Trichocereus, relacionada con el clado de $T$. andalgalensis y $T$. schickendantzii, al compartir los siguientes caracteres: basítono con ramas arqueadas (las ramas laterales se arquean en la base, para luego erguirse), costillas obtusas, número máximo de costillas en la parte media de los tallos 20 , flores largas $(20-24 \mathrm{~cm}$ ), semillas circular-orbiculares, muy pequeñas (1 $\mathrm{mm}$ de largo y 0,5 mm de ancho).

Los taxones infraespecíficos con los epítetos intricatus, longispinus, rufispinus y spinosior describen el color de las espinas (blancas, amarillentas, rosadas hasta rojo-oscuro), tamaño (1,5 hasta 7 cm de largo) y cantidad (20), pero estas variaciones se encuentran dentro del rango de variación de la especie, y por tal razón se consideran sinónimos de $T$. strigosus. La variedad variegatus corresponde a un individuo cultivado, con déficit de clorofila.

Salm-Dyck (1850) propuso la variedad spinosior sin una diagnosis ni descripción, por lo que Rümpler's (1885) la describe, mencionando la altura de las plantas de 1,5 m. Se considera que la identificación de Rümpler es errónea, ya que $T$. strigosus es de más o menos medio metro 0 un poco más en condiciones favorables, según las observaciones realizadas en Mendoza, San Juan y La Rioja.

Cárdenas (1953a) menciona que T. camarguensis (de Bolivia) y $T$. strigosus se asemejan en el porte y en la naturaleza de las espinas, además de presentar caracteres (número de costillas, color de las espinas y tamaño), que permiten diferenciarlas como dos especies. Otros caracteres que las distinguen son (Tabla 13): 
Tabla 13. Otros caracteres que distinguen $T$. camarguensis y $T$. strigosus son:

\begin{tabular}{|l|l|l|}
\hline CARACTERES & T. camarguensis & \multicolumn{1}{|c|}{ T. strigosus } \\
\hline Color de la epidermis & Verde-claro & Verde-claro a oscuro \\
\hline Distancia entre las areolas & $8 \mathrm{~mm}$ & $5 \mathrm{~mm}$ \\
\hline No. Espinas radiales & Hasta 13 & Hasta 16 \\
\hline No. Espinas centrales en las areolas adultas & $1(3)$ & 4 \\
\hline Estambres de la serie superior & $5 \mathrm{~cm}$ largo & $4 \mathrm{~cm}$ largo \\
\hline
\end{tabular}

T. strigosus presenta una alta variación intraespecifica con respecto a su altura, ancho de las costillas, distancia entre las areolas, longitud de las flores y color de los tépalos, por lo que se proponen dos variedades.

\section{Clave para la identificación de las variedades de Trichocereus strigosus}

1 Tallos de hasta $100 \mathrm{~cm}$ de alto. Costillas angostas $(8 \mathrm{~mm})$, areolas separadas entre sí por 5-8 mm, flores largas $(18-22 \mathrm{~cm})$, tépalos blanco-niveo, raro blanco-crema var. strigosus

1' Tallos de $50 \mathrm{~cm}$ de altura. Costillas anchas $(1,0-1,5 \mathrm{~cm})$, areolas distanciadas por 10-15 mm, flores cortas $(10-14 \mathrm{~cm})$, tépalos rojos, anaranjados 0 amarillos, posiblemente también blanco var. vatteri

\section{Trichocereus strigosus (Salm-Dyck) Britton \& Rose var. strigosus}

TIPO: Argentina, Mendoza, Mar. 1824, Gillies s.n. (Neotipo, K, designado por Hunt \& Taylor, Cactaceae Syst. Init. 21: 8. 2006).

Iconografías: Kiesling \& Ferrari (2005), foto 46: 62. Trevisson \& Perea (2009), fotos 88: 127.

Descripción ampliada: Plantas ascendentes, hasta $1 \mathrm{~m}$ de diámetro. Tallos de 40-60 cm de alto, 5-7 cm de diámetro, cilíndricos, erectos, verde-claro a oscuro, ramificados en la base. Costillas del ápice 15-17, obtusas, $4 \mathrm{~mm}$ de ancho, $2 \mathrm{~mm}$ de alto; con areolas redondas, $2 \mathrm{~mm}$ de alto y $3 \mathrm{~mm}$ de ancho, con pilosidad blanca en la parte superior y gris en la inferior; espinas centrales 1, aciculares, menores de $1 \mathrm{~mm}$ de ancho, $1 \mathrm{~cm}$ de largo, rojo-vinoso; espinas radiales 3-11, de 0,7-2,7 cm de largo, menores de $1 \mathrm{~mm}$ de diámetro, aciculares, amarillo-claro, gris o rojo-vinoso, adpresas. Costillas de la base 17-18, obtusas, de $8 \mathrm{~mm}$ de ancho y $6 \mathrm{~mm}$ de alto; con areolas circulares, $1 \mathrm{~mm}$ de alto, $2 \mathrm{~mm}$ de diámetro, tomento gris, separadas $5 \mathrm{~mm}$ (4-8); con 3-4 espinas centrales, 1,3-7,0 cm de largo y menos de $1 \mathrm{~mm}$ de diámetro, aciculares, rosado-claro con ápice marrón o base amarillo, ápice rojo-vinoso, crecen dirigidas al cuerpo; espinas radiales 9-16, de 0,5-2,5 cm de largo, aciculares, menos de $1 \mathrm{~mm}$ de ancho, 
marrones. Flores generalmente subapicales, $18-22 \mathrm{~cm}$ de largo, $6 \mathrm{~cm}$ de diámetro (cuando están cerradas) y $15 \mathrm{~cm}$ (cuando están abiertas), con un leve aroma a jazmín; ovario de 2,5-3,0 cm de diámetro, tubo floral de $2 \mathrm{~cm}$ de ancho; escamas florales de 6-9 mm de largo, verde-claro con ápice marrón o verdeamarillento, de cuyas axilas emergen pelos rubios de $1 \mathrm{~cm}$ de largo y algunas cerdas negro-rojizas; tépalos externos de 3-6 cm de longitud, rosado-claro con ápice verde, tépalos intermedios lineares como lacinias, $6 \mathrm{~cm}$ de largo, rosados a blancos y los internos espatulados, amarillo-claro o blanco, $7 \mathrm{~cm}$ de largo. Estambres de la serie superior de 3,7 cm de longitud, blancos, la serie inferior de $8,5 \mathrm{~cm}$ de largo, verde-claro y dispuestos en espiral; estilo blanco, $13 \mathrm{~cm}$ de largo y $2,5 \mathrm{~mm}$ de ancho. Pseudobaya con dehiscencia longitudinal, 5,0-6,5 cm de largo, $4 \mathrm{~cm}$ de diámetro, parte externa amarilla 0 anaranjada cuando maduros; y cavidad ovárica de 1,2 cm. Semillas de 1,5 mm de largo, $1 \mathrm{~mm}$ de alto y 0,5 mm de ancho, negras y finamente punteadas (Fig. 43).

Distribución y Hábitat: Variedad endémica del oeste Argentino, distribuida en las provincias de Mendoza, San Juan, La Rioja y Catamarca, sobre planicies o laderas asociada con Bulnesia retama, Echinopsis leucantha, Larrea divaricata, Tephrocactus articulatus entre otras, de la provincia fitogeográfica del Monte (Fig. 73).

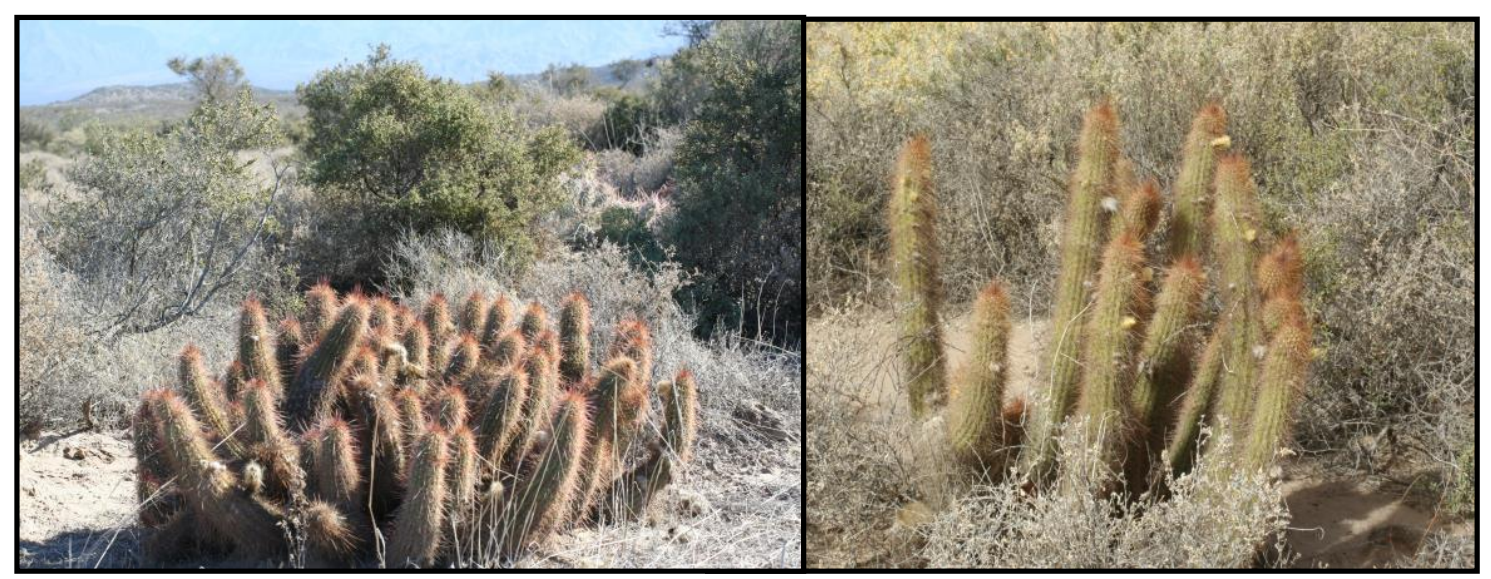

Figura 43. Trichocereus strigosus var. strigosus. Argentina, Provincia de Mendoza, Departamento Capital, cerca del Parque General San Martín.

Material de Herbario estudiado: Prov. Mendoza, Dpto. Capital, cerca del Parque General San Martín, Marzo 1939, A. Ruiz-L. 6138 (MERL); Cerro de la Gloria, 900-950 m, 23 Dic. 1949, H. Sleumer 34 (LIL); cerca del Cerro de La Gloria, 22 Dic. 1915, A. Ruiz-L. 2528 (MERL); ibidem, Dic. 1931, A. Ruiz-L. 2582 (MERL); ibidem, 24 Dic. 1937, A. Ruiz-L. 4722 (MERL); ibidem, 28 Nov. 1948, A. Ruiz-L. 12019 A-C, 12026 (MERL); ibidem, Mar. 1959, A. Ruiz-L. 21610 (MERL); La Puntilla, Nov. 1915, R. Sanzin 544 (SI); Cerro Pilar, R. Sanzin s.n. (SI); near anfiteatro at foot of Cerro de la Gloria just outside city of Mendoza, 900 m, 8 Ene. 1995, B.E. Leuenberger et al. 4447 (CORD). Prov. La Rioja, Dpto. Capital, Ruta provincial No 6, al S de S. Brata, 13 May. 1989, F. Biurrun 2825 (SI); de Chumbicha a Aimogasta, 1050 m, 17 Feb. 1993, W. Till 10280 (LIL); Dpto Chamical, Campo de exp. del INTA, 21 Ene. 1990, F. Biurrun 3063 (SI); 
Dpto. Chilecito, $1 \mathrm{Km} \mathrm{S}$ of Chilecito towards Patquía, 1050-1100 m, 13 Feb. 1994, B.E. Leuenberger et al. 4192 (CORD); Dpto.General Belgrano, entre Montenegro y Pozo Redondo, a 3 Km del primero, 24 Oct. 1996, L. Riedel \& M. Vieto 56 (SI); Dpto. General Felipe Varela (ex General Lavalle), 27 Km from culmination of Cuesta de Miranda towards Villa Unión (i.e. $15 \mathrm{Km}$ from Los Tambillos towards Villa Unión), 1450 m, 14 Feb. 1994, B.E. Leuenberger 4197 (CORD); Cuesta de Miranda, por la Ruta No. 40, yendo desde Chilecito a Villa Unión (1 Km antes de Siciliano desde Nonogasta), 2200 m, 15 Dic. 2005, M.L. Las Peñas \& F. Chiarini 214 (CORD); ibidem, (1 Km después de Piedra pintada), 15 Dic. 2005, M.L. Las Peñas \& F. Chiarini 222 (CORD); Dpto. General Lavalle, $60 \mathrm{Km} \mathrm{W}$ turnoff of Ruta 40 at Nonogasta towards Villa Unión ( $=27 \mathrm{Km}$ W of culmination of Cuesta La Miranda; $=33 \mathrm{Km}$ E of Villa Unión towards Nonogsta), just W of Puerto Alegre, 1440 m, 3 Ene. 1995, B.E. Leuenberger et al. 4414 (CORD); Dpto. Independencia, Guayapa-Patquia est. Sta. Rosa, 3 Dic. 1963, K.J. Hayward s.n. (LIL 487931); cruce entre Famatina y Chilecito, 21 Ene. 2007, S. Albesiano et al. 2030 A, B (MERL 58805); Los Tordecitas, 25 Nov. 1960, A. Ruiz-L. 21613 (MERL). Prov. San Juan, Dpto. Caucete, Marayes, 9 Nov. 1986, E. Haene 124 (SI); 6 Km de Marayes, 4 Ene. 1971, R. Kiesling 82 (LP); cerros de Pie de Palo, a \pm 3 Km al norte de pueblo homónimo, 22 Jul. 1974, L. Ariza-E. s.n. (CORD 635); 16 Km ESE of Pie de Palo towards Marayes on Ruta 141 (= $6 \mathrm{Km}$ from junction 20/141, $1 \mathrm{Km}$ W of Guayamas), $520 \mathrm{~m}, 12$ Ene. 1995, B.E. Leuenberger et al. 4465 (CORD); Dpto. Zonda, Quebrada del Zonda, 4 Nov. 1975, R. Kiesling 1061 (SI); 16 Km al N de Chilecito, 26 Oct. 1974, R. Kiesling 806, 806b (LP); Dpto. Valle Fertil, Ischigualasto, 10 May. 1986, E. Ezcurra \& C. Montaña s.n. (MERL 47178); Ruta Provincial No. 150, Ischigualasto (reserva provincial), $1 \mathrm{Km}$ del control de ingreso rumbo a la Hoyada, 29 Dic. 1997, F. Biurrun et al. 5055 (SI); Dpto. Ullum, 78.5 Km SE of Iglesia on Ruta 436 towards San Juan, on ascent of alluvial terraces $E$ of Cienaga de Gualilan (=47.5 Km SE of Alto del Colorado), 1730 m, 5 Ene. 1995, B.E. Leuenberger et al. 4439 (CORD).

42. Trichocereus strigosus (Salm-Dyck) Britton \& Rose var. vatteri (R. Kiesling) Albesiano, comb. et stat. nov.

Trichocereus vatteri R. Kiesling, Hickenia 1(6): 31. 1976. Echinopsis vatteri (R. Kiesling) G.D. Rowley, Repert. PI. Succ. 27: 5. 1979. TIPO: Argentina, Prov. La Rioja, Dpto. General Lavalle, Tambillos, 25 Ene. 1974, A.L. Cabrera, E.M. Zardini, N. Deginani, F.O. Zuloaga 24568 (A y B) (Holotipo, LP!).

Trichocereus callianthus F. Ritter, Kakteen Südamerika 2: 444. 1980, nom. inval., por no designar tipo (Art. 40.1). Lobivia huascha (F.A.C. Weber) W.T. Marshall var. calliantha (F. Ritter) Rausch, Lobivia 85: 69. 1986, comb. inval., se basa en un nombre inválido.

Iconografías: Ritter (1980a), foto 565: 797. Trevisson \& Perea (2009), foto 90: 129. 
Descripción original de Trichocereus vatteri R. Kiesling, Hickenia 1(6): 31. 1976:

Trichocereus vatterii ${ }^{3}$ nov. sp. Plantae caespitosae caulibus cilindraceis multiangulatis, $50 \mathrm{~cm}$ altis, ascendentibus, viridibus; costis 14-16 depressis; aculeis centralibus 1-4, 3,5 $-5 \mathrm{~cm}$ longis, radialibus circa 10, 1,5-2 cm longis. Flores subapicales, infundibuliformis, inodori, $10-14 \mathrm{~cm}$ longi, circa $10 \mathrm{~cm}$ diametro, externe squamato-pilosi; petalis luteis, aurantiacis vel rubris et intermediis (an albis?). Stamina et stylus cum periantho concolores vel pallide virides. Fructus globosi, 4-6 cm diametro, flavecentes ad carnei. Semen nigrum, punctatum, $1 \mathrm{~mm}$ longum et $0,5 \mathrm{~mm}$ latum, hilio obliquo.

Descripción ampliada: Plantas ascendentes, de hasta $50 \mathrm{~cm}$ de alto, aproximadamente 20 ramas. Tallos cilíndricos, ascendentes, verde-claro, $5,5-8,0 \mathrm{~cm}$ de diámetro. Costillas 14-16, obtusas, 5 $\mathrm{mm}$ de alto, 1,0-1,5 cm de ancho. Areolas distantes entre sí 1,0-1,5 cm, $4 \mathrm{~mm}$ de diámetro, circulares y con pilosidad blanca a castaña. Espinas amarillentas, a veces rojizas, aciculares, flexibles, $1 \mathrm{~mm}$ de ancho en la base, centrales 1-4, de 3,5-5,0 cm de largo, 10 radiales, 1,5-2,0 cm de largo. Flores inodoras, 10-14 cm de longitud, $10 \mathrm{~cm}$ de diámetro cuando abiertas, escamas del tubo floral y ovario triangulares, de 1,0-1,5 cm de largo, con pelos axilares rubios, los cuales son cerdosos en las escamas superiores. Tépalos externos linear-lanceolados, 2,5 cm de largo, $0,5 \mathrm{~cm}$ de ancho, tépalos interiores espatulados con un mucrón apical, rojos, anaranjados, amarillos o intermedios. Estambres con filamentos concolores con el perianto y anteras amarillas, $4 \mathrm{~mm}$ de largo y $1 \mathrm{~mm}$ de ancho, subrectangulares, algo adelgazadas hacia el ápice; filamentos de la serie inferior implantados desde la base del tubo hasta $4 \mathrm{~cm}$, con un largo de unos $4 \mathrm{~cm}$; los de la serie superior menores, forman un anillo en la fauce y con una longitud de $2 \mathrm{~cm}$. Parte interna del tubo del mismo color del perianto, pero cuando éste es amarillo el tubo es verde, lo mismo que la base de los filamentos y el estilo. Estilo de color algo más claro que el perianto, $7-9 \mathrm{~cm}$ de largo y $1,5 \mathrm{~mm}$ de diámetro, terminando en un estigma con 14 a 16 lóbulos amarillos, subteretes, $1,4 \mathrm{~cm}$ de largo. Ovario de $1 \mathrm{~cm}$ de diámetro. Pseudobayas globosas, 4-6 cm de diámetro, parte externa amarilla a veces rosada, cavidad ovárica con funículos blancos. Semillas negras, $1 \mathrm{~mm}$ de largo y 0,5 mm de ancho y alto, punteadas, carenadas con zona hilo-micropilar oblicua (Fig. 44).

Distribución y Hábitat: Variedad endémica del oeste argentino, localizada en las sierras de Sañogasta y sur-este de Famatina en la Provincia de La Rioja (Fig. 73). Crece bajo los arbustos pertenecientes a los siguientes géneros: Larrea, Lycium, Prosopis y Zuccagnia (Kiesling 1978).

Comentarios taxonómicos y nomenclaturales: La especie fue dedicada a Ernesto Vatter, quien enviaba plantas suculentas a Europa para su determinación taxonómica a mediados del siglo XX. Entonces conocida comercialmente y en el ambiente de amateurs como "Trichocereus vatter 15" (Kiesling 1976).

Trichocereus callianthus podría ser un híbrido entre $T$. candicans y $T$. vatteri descrita por Ritter para la localidad de Famatina en La Rioja, además, Ritter (1980) la consideró sinónimo de $T$. vatteri. 
Material de Herbario estudiado: Argentina, Prov. La Rioja, Dpto. Chilecito, Cuesta de Miranda, 1 Mar. 1967, R. Kiesling 2 (LP); ibidem, 25 Ene. 1974, A.L. Cabrera 24568 (SI); ibidem, 12 Ene. 1976, A. Cabrera et al. 27122, 27135 (SI); ibidem, 26 Mar. 1976, R. Kiesling 1206 (SI); ibidem, 25 Ene. 2007, S. Albesiano et al. 2035 (MERL 58801); ibidem, entre Miranda y Bordo Atravesado, ruta No 40, Km 548-549, 1950 m, 22 Ene. 1975, A.T. Hunziker 22677 (CORD); Dpto. Famatina, en la ladera W, en la Sierra de Paimán, 1700 m, Ene. 1949, A. Krapovickas \& A.T. Hunziker 5976 (CORD); 13 Km from Famatina towards Chilecito, on the left of the road, 1420-1450 m, 16 Feb. 1994, B. Leuenberger et al. 4224 (CORD); norte de Famatina, 183 m, 9 Nov. 2006, B.O. Schlumpberger 450 (CORD).

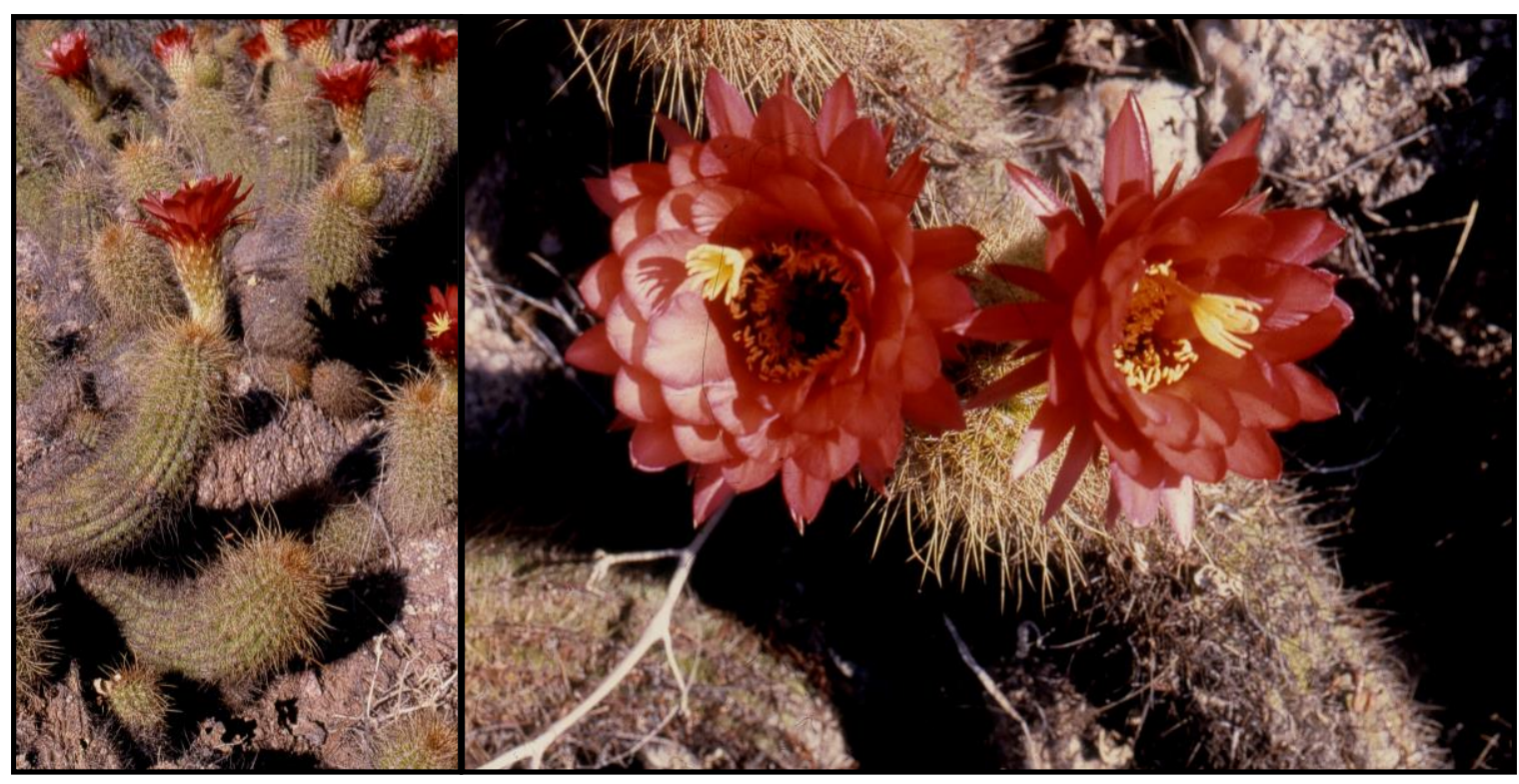

Figura 44. Trichocereus strigosus var. vatteri. Argentina, Provincia de La Rioja, Departamento Chilecito, Cuesta de Miranda.

43. Trichocereus tacaquirensis (Vaupel) Cárdenas ex Backeb., Cactac. Hand. Kakteenk. 2. ill. 1959.

Cereus tacaquirensis Vaupel, Monatsschr. Kakteenk. 26: 122. 1916. Echinopsis tacaquirensis (Vaupel) H. Friedrich \& G.D. Rowley, I.O.S. Bull. 3(3): 98. 1974. TIPO: Bolivia, N de Camargo, Tacaquira, 17 Feb. 1904, Fiebrig 2930 (Holotipo, B十). Neotipo: Bolivia, Dpto. Chuquisaca, Prov. Nor Cinti, Mpio. Camargo, cerca de Camargo, 2500 m, II/1949, M. Cárdenas 5013, pliegos A y B (LIL 530334, aquí designado).

Iconografías: Backeberg (1959a), fotos: 1056-1057: 1108; 1067c: 1115. Ritter (1980a), fotos 446-447: 764. 
- Columnaris; costis parum elevatis, (ut videtur) obtusis; areolis rotundatis vel ovalibus, pro rata magnis, juventute cirro molli mox deciduo, postea tomento denso obtectis; aculeis numerosis setiformibus, rectis vel flexuosis, non pungentibus, rubiginosis, inaequalibus, usque ad $8 \mathrm{~cm}$ longis; floribus magnis, infundibuliformibus; ovario atque tubo lana brunnea obtectis; sepalis lanceolatis, petalis oblongospathulatis; staminibus 2-serialibus, quam petala multo brevioribus; stylo crasso, stamina superante.

Pflanze säulenförmig, 2,5 m hoch. Rippen etwas über $1 \mathrm{~cm}$ hoch, nach dem gepressten Material zu urteilen stumpf; ihre 7ahl ist nicht angegeben. Areolen $1-1,5 \mathrm{~cm}$ von einander entfernt, rund, etwa $7 \mathrm{~mm}$ im Durchmesser, oder oval, und dann $12 \mathrm{~mm}$ lang, mit dichtem, graubraunem Wollfilz bekleidet; in der Jugend tragen sie ausserdem ein dichtes Büschel bis $1,5 \mathrm{~cm}$ langer, sehr feiner, grauweisser Haare. Stacheln selr zahlreich, bis 20 und mehr, borstenartig, zum Teil etwas gewunden, rötlichbram mit grauem Anflug, nicht stechend, ungleich lang, die längsten $8 \mathrm{~cm}$ lang; sie sind über die ganze Areole verteilt, doch so, dass die meisten in deren oberstem Teil stehen; Rand- und Mittelstacheln sind nicht deutlich zu unterscheiden.

Blüten gross, trichterförmig, etwas über $20 \mathrm{~cm}$ lang. Fruchtknotén und Röhre beschuppt und mit brauner Wolle bekleidet, die am Fruchtknoten besonders dicht stebt und etwa $2 \mathrm{~cm}$ lang ist; Schuppen im unteren Teil der Röhre spärlich, oben zahlreicher und mit der Basis einander berührend, lanzettlich, in eine Spitze ausgezogen; die untersten sind kaum $5 \mathrm{~mm}$ lang, die oberen nehmen bald an Grösse zu, um schliesslich in die äusseren. Blütenblätter überzugehen. Diese sind lanzettlich, zugespitzt, $6 \mathrm{~cm}$ lang; an der Basis

etwa $1 \mathrm{~cm}$ breit; die inneren sind mehr länglich-spatelförmig und weniger deutlich zugespitzt, bis $12 \mathrm{~cm}$ lang und bis $3 \mathrm{~cm}$ breit. Staubgofässe sehr zahlreich, in 2 Reihen; die obersten; an der Röhrenmündung vefestigten etwas über $2 \mathrm{~cm}$ lang und somit viel kürzer als die Blütenhülle; Staubbeutel $3 \mathrm{~mm}$ lang; Fäden in getnocknetem Zustande flach. schwarzbraun. Griffel kräftig, die Staubgefässe überragend; Narben nicht erhalten. Bl üten farbe weiss.

Die Art gehört wegen der grossen, trichterförmigen Blüten und der Behaarung von Fruchtknoten und Röhre in A. BERGERs Untergattung Trichocereus.

Die Heimat der Pflanze ist das südliche Bolivien, wo sie bei Tacaquira, nördlich von Camargo, an Hängen wächst. (FIEBRIG n. 2930, mit Blüten am 17. Februar 1904.)

Descripción ampliada: Plantas erectas, 2,5-4,0 m de alto, ramificadas desde la base, tallos verde-oscuro, $11 \mathrm{~cm}$ de diámetro. Costillas 12, obtusas, $1 \mathrm{~cm}$ de alto, 1,3 cm de ancho. Areolas separadas 1,0-1,5 cm, redondas u ovaladas, $7 \mathrm{~mm}$ de diámetro, $12 \mathrm{~mm}$ de ancho, con pilosidad grismarrón, mientras las areolas jóvenes llevan abundante pilosidad blanco-grisáceo de hasta $1,5 \mathrm{~cm}$ de largo. Espinas del ápice cerdosas, un poco retorcidas, no punzantes, de color marrón-rojizo con un poco de gris, más de 20 , sin diferenciarse entre radiales y centrales, la más larga de $8 \mathrm{~cm}$. Espinas de la base subuladas y grises; centrales 4, de 1,5 mm de diámetro, $7 \mathrm{~cm}$ de largo; radiales 12, de $3 \mathrm{~cm}$ de longitud, 1 $\mathrm{mm}$ de diámetro. Flores apicales, $20 \mathrm{~cm}$ de largo, segmentos externos del perigonio marrón-rojizo, segmentos internos oblongos y blancos; estilo verde en la parte inferior, blanco en la superior, lóbulos del 
estigma lineares, amarillos; anteras de $3 \mathrm{~mm}$ de largo, amarillos, axilas de las escamas del ovario y tubo recubiertas con pelos marrones, recurvados (Fig. 45).

Distribución y Hábitat: Nativa del sur de Bolivia, en los departamentos de Potosí (en los alrededores de Cucho Ingenio), y Chuquisaca (Tacaquira cerca de Camargo y en los alrededores de Villa Abecia), entre algarrobales al borde del camino o formando cardonales con $T$. werdermannianus y Parodia maassii (Cárdenas 1953 a, c; Albesiano 2014) (Fig. 74).

\section{Comentarios taxonómicos y nomenclaturales:}

El holotipo de C. tacaquirensis (Fiebrig 2930, 17 Feb. 1904), depositado en el herbario de Berlín no se encuentra (Anderson 2005, Hunt et al. 2006), por consiguiente se designa un Neotipo, el cual corresponde a un ejemplar recolectado por M. Cárdenas, montado en dos pliegos de herbario ( $\mathrm{A}$ y $B$ ), los cuales están labelados con la misma información sobre localidad, fecha, número de recolección y observaciones (información cruzada), y estaría de acuerdo con el Art. 8.3 del Código Internacional de Nomenclatura para algas, hongos y plantas (McNeill et al. 2012).

Material de Herbario estudiado: Bolivia, Dpto. Potosí, Prov. Nor Chichas, Ladera en Pucapampa, 2900 m, 19 Nov. 1987, M. Schulte 24 (LPB).

Figura 45. Trichocereus tacaquirensis. Bolivia.

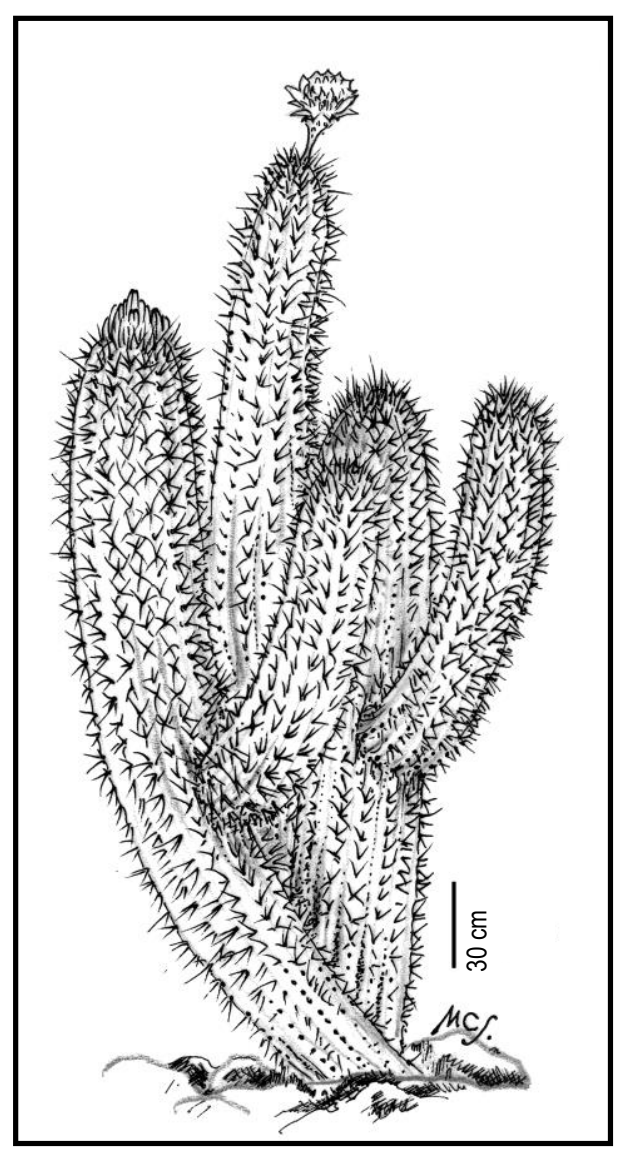

44. Trichocereus taquimbalensis Cárdenas, Revista Agric. (Cochabamba) 8: 16, ill. 1953.

Echinopsis taquimbalensis (Cárdenas) H. Friedrich \& G.D. Rowley, I.O.S. Bull. 3(3): 98.1974. Echinopsis tacaquirensis subsp. taquimbalensis (Cárdenas) G. Navarro, Lazaroa 17: 55. 1996. TIPO Bolivia, Dpto. Cochabamba, Prov. Tarata, 2800 m, M. Cárdenas 5029 (Holotipo, LIL 531530!)

Iconografía: Backeberg (1959a), foto: 1065. 1114. 
Descripción original de Trichocereus taquimbalensis Cárdenas, Revista Agric. (Cochabamba) 8: 16. 1953:

Columnaris, simplex vel ramosis, $1.202 .50 \mathrm{~m}$. altis. Ramis validis, apicem interdum leviter crassiores, atro viridis, $12-1 ; \mathrm{cm}$. crassis. Costis 9, obtusis, $1.5 \mathrm{~cm}$, altis, $2.5 \mathrm{~cm}$. latis. Areolis $1.5 \mathrm{~cm}$. interse distantibus, circularis vel elliptico triangularis, $1 \mathrm{~cm}$. diam., prominentis, albido vel cinereo tomentosis. Aculeis marginales $8-13$, subulatis, ra. diantes, $1-2 \mathrm{~cm}$. long,; aculei centrali i horizontaliter vel deorsum direxit, robusto, 3.5-6 $\mathrm{cm}$. long.; omnia aculea a basi incrassata, prima temperato brunescentia dein cinerea. Flores 4-8 ex apice ramis, infundibuliformes, $23 \mathrm{~cm}$. long. Ovario globoso, $2.2 \mathrm{~cm}$. diam., squamis $1 \mathrm{~cm}$. long, apice acuto, atro viridis, pilis albis et atro bruneis, $2 \mathrm{~cm}$. long. praedito, Phylla perigoni exteriora, oblonga, acuta, $9-10 \mathrm{~cm}$. long, brunescentia; interiora, spathulata, $8-$ IC $\mathrm{cm}$. long, mucronata, alba. Stamina duplo seriata; filamenta, temperato viridia, antherae fla. vae, Stylo $16 \mathrm{~cm}$. long., $14-16$ ramis stigmaticis flavis, $2 \mathrm{~cm}$. long. coronato. Fructo globoso, plus minusve $4 \mathrm{~cm}$. diam., squamis latis, atro viridis, pilis albis et atro bruneis praedito. Semina nigra, fere nitentia, reniformia, truncata, $1, ; \mathrm{mm}$. long., puncticulata.

in itinere Cliza-Anzaldo, $2,800 \mathrm{~m}$.

Patria: Bolivia, provinci Tarata, departamenti Cochabamba, prope Taquimbala

Descripción ampliada: Tallos erectos, hasta 2,5 m de alto, 11-15 cm de diámetro y ligeramente engrosados en los extremos, verde-oscuro. Costillas del ápice 8 , obtusas, $3,5 \mathrm{~cm}$ de ancho, $2 \mathrm{~cm}$ de alto; areolas obovadas, $1 \mathrm{~mm}$ de alto, $8 \mathrm{~mm}$ de ancho, blancas; espina central 1, perpendicular al tallo, $5,5 \mathrm{~cm}$ de largo, subulada, rígida, $2 \mathrm{~mm}$ de diámetro, marrón con punta negra; espinas radiales 7 , perpendiculares al tallo, $2,5 \mathrm{~cm}$ de largo, subuladas, $1 \mathrm{~mm}$ de diámetro, base marrón-oscuro, parte media gris y ápice negro. Costillas de la base 8 , obtusas, $2,6 \mathrm{~cm}$ de ancho, 1,5-2,2 cm de alto, areolas circulares u oblongas, $1 \mathrm{~cm}$ de ancho, $1,5 \mathrm{~cm}$ separadas entre sí, inmersas en el tallo, veteado entre negro y blanco; con 0-1 espina central, perpendicular al tallo, casi horizontal, 4-6 cm de largo, $2 \mathrm{~mm}$ de diámetro, subulada, veteado entre gris y marrón; espinas radiales 7-13, aciculares, 2,5 cm de largo, curvadas, radiantes, dirigidas hacia el cuerpo, algunas marrones otras blanco-crema con ápice marrón. Flores apicales, 4 a 8 por tallo, $23 \mathrm{~cm}$ de largo, diurnas; ovario de $3 \mathrm{~cm}$ de ancho, provisto de escamas verdeoscuro, $1 \mathrm{~cm}$ de largo y de cuyas axilas emerge abundante pilosidad marrón-claro y negro, $2 \mathrm{~cm}$ de largo y rizados; esta pilosidad también se manifiesta en las escamas del tubo floral; corola $15 \mathrm{~cm}$ de diámetro; tépalos externos pardo-rojizos, 7,5-10 cm de largo; tépalos intermedios con base pardo-rojizo y ápice blanco, $9 \mathrm{~cm}$ de largo; tépalos internos blancos, 8-10 cm de longitud; estilo verde, $16 \mathrm{~cm}$ de largo; lóbulos del estigma verdes y amarillos, $2,5 \mathrm{~cm}$ de longitud. Psedobaya verde-oscuro, $4 \mathrm{~cm}$ de diámetro, recubierta por abundantes pelos blanquecinos y negro-parduzco, ensortijados. Semillas $1,5 \mathrm{~mm}$ de largo, ligeramente brillantes, reniformes, truncadas y con finísimas depresiones punctiformes en su superficie, testa negra (Fig. 46).

Distribución y hábitat: Bolivia, especie descrita originalmente para el departamento de Cochabamba, en la provincia de Esteban Arze, en los municipios de Anzaldo (2800 m) y Tarata (Cárdenas 1953a). También, se localiza entre los departamentos de Potosí y Chuquisaca, en los alrededores de Millares, a $2299 \mathrm{~m}$, al igual que en el departamento de Tarija, camino a Incahuasi, a 
2323 m (Fig. 74). Se observa como cultivada y silvestre, en las faldas de las montañas secas y degradadas, con vegetación de Dodonaea viscosa, Kageneckia lanceolata y Carica quercifolia. Se localiza en la provincia fitogeográfica de la prepuna, cuyo clima es seco a semiárido [T: 17॰ C, P: $400 \mathrm{~mm}$ (Cabrera \& Willink 1980, Navarro 1996, Albesiano 2014)].

\section{Comentarios morfológicos y sus consecuencias en la taxonomía y nomenclatura:} Comparando las descripciones originales junto con el material herborizado de $T$. taquimbalensis y $T$. tacaquirensis, se observa una similitud en el porte (erectas, de hasta $3 \mathrm{~m}$ de alto) y en el número de costillas (9), pero también se presentan diferencias como en el color de las ramas (verde-oscuro vs. verde-claro), aspecto de las espinas del ápice (robustas vs. débiles y flexibles), número de espinas radiales en el ápice (menor de 10 vs. mayor de 15), y número de espinas centrales (1 vs. 3-5), por lo que se propone considerarlas dos especies distintas, y no como sinónimo (Hunt et al. 2006), o taxón infraespecífico (Navarro 1996, Anderson 2005).

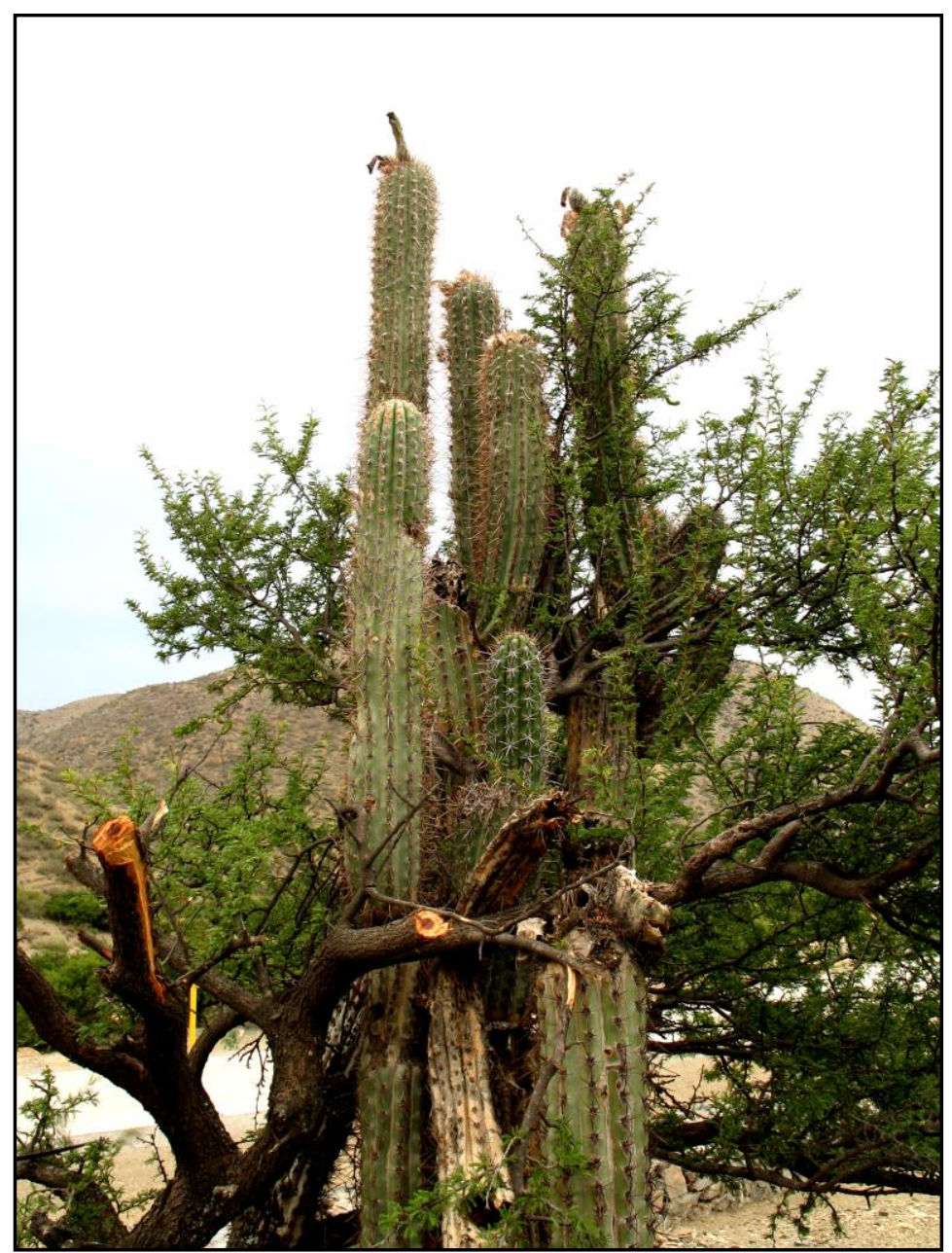

Figura 46. Trichocereus taquimbalensis. Bolivia, Departamento de Tarija, camino a Incahuasi, pasando el puente. 
Material de Herbario estudiado: Bolivia, entre los departamentos de Potosí y Chuquisaca, carretera que conduce de Potosí a Sucre, pasando Millares, 2299 m, 12 Dic. 2009, S. Albesiano et al. 2072 (MERL). Dpto. de Tarija, camino a Incahuasi, pasando el puente, 2323 m, 17 de Dic. 2009, S. Albesiano et al. 2080 (MERL).

45. Trichocereus tarijensis (Vaupel) Werderm., Kakteenkunde: 7. 1940.

Cereus tarijensis Vaupel, Monatsschr. Kakteenk. 26: 123. 1916. Helianthocereus tarijensis (Vaupel) Backeb., Cactus (Paris) No. 45: 208. 1955. Echinopsis tarijensis (Vaupel) H. Friedrich \& G.D. Rowley, I.O.S. Bull. 3(3): 98. 1974. Lobivia formosa (Pfeiff.) Dodds var. tarijensis (Vaupel) Rausch, Lobivia 85: 44.1985 [1987].

Trichocereus orurensis Cárdenas, Fuaux Herb. Bull. 1(5): 13, ill. 1953. Helianthocereus orurensis (Cárdenas) Backeb., Cactus (Paris) No. 45. 208. 1955. Echinopsis orurensis (Cárdenas) H. Friedrich \& G.D. Rowley, I.O.S. Bull. 3(3): 96. 1974. TIPO: Bolivia, La Joya cerca de Oruro, 3800 m, Nov. 1951, M. Cárdenas 4824 (Holotipo, LIL!)

Helianthocereus poco (Backeb.) Backeb. var. sanguiniflorus Backeb., Kakteenlexikon: 187, ill. 1966, nom. inval., por no designar tipo (Art. 40.1).

Descripción original de Cereus tarijensis Vaupel, Monatsschr. Kakteenk. 26: 123. 1916 :

Columnaris; costis non satis notis; areolis late-ellipticis vel ovalibus, pro rata magnis, approximatis, tomento flavido-brunneo, serius griseo, obteclis; aculeis in areolis inferioribus circiter $I_{0}-\mathrm{I}_{3}$, validis, pungentibus, inaequalibus, centrali $I$ ceteros longitudine atque crassitic superante, in areolis superioribus atque floriferis numerosioribus, tenuioribus, partim setiformibus; floribus pro rata brevibus, infundibuliformibus; ovario atque tubo lana brunnea dense obtectis; sepalis lanceolatis, petalis latioribus, potius spathulatis; slaminibus 2-serialibus; superioribus quam petala duplo fere brevioribus, inferioribus orificium tubi attingentibus; slylo crasso; stigmatibus numerosis, stamina vix superantibus.

Pflanze kurz-säulenförmig, $1,5 \mathrm{~m}$ hoch, $25 \mathrm{~cm}$ im Durchmesser. Zahl und Form der Rippen nicht näher bekannt. Areolen gross, breit-elliptisch bis oval, bis $1,5 \mathrm{~cm}$ lang, über $0,5 \mathrm{~cm}$ breit, mit dichtem gelblichbraunem, später grauem Wolltilz bekleidet, kaum $1 \mathrm{~cm}$ von einander entfernt. Stacheln 10-13, pfriemlich, starr, stechend, gelb- bis rotbraun, über die ganze Areole verteilt; ein besonders ausgeprägter Mittelstachel ist bis $7 \mathrm{~cm}$ lang, die Randstacheln sind kürzer und schwächer, aber unter sich ungleich. Im oberen, blühfähigen Teile der Pflanze sind die Areolen fast bis zur gegenseitigen Berührung genähert, der Filz ist länger, über. $0,5 \mathrm{~cm}$ lang, die Stacheln. sind zalılreicher, aber dünner, zum T'eil fast borstenförmig und biegsam.

Blüten verhältnismässig kurz, nur $10 \mathrm{~cm}$ lang, trichterförmig. Fruchtknoten und Röhre mit Schuppen, aus deren Achseln dicke Büschel brauner. Wolle hervortreten; Schuppen lanzettlich, spitz, unten sehr klein, nach oben zu grösser und allmählich in die äusseren, gleichgestalteten Hüllblätter übergehend. Die inneren Hüllblätter sind breiter, mehr spatelförmig, aber kurz gespitzt. Staubgefässe zahlreich, in zwei Reihen, die obersten etwa $2 \mathrm{~cm}$ lang und bis zur halben Höhe der inneren Hüllblätter reichend, die unteren etwa mit der Röhrenmündung abschliessend; Staubbeutel $3 \mathrm{~mm}$ lang; Fäden in getrocknetem Zustande schwarzbraun. Griffel ziemlich kräftig, in 
eine grössere Anzahl etwa $1 \mathrm{~cm}$ langer Narben geteilt, die über die Staubgefässe liaum hinausragen. Blütenfarbe hell-weinrot.

Die Art gehört wegen der trichterförmigen Gestalt der Blüte

und der Behaarung von Fruchtknoten und Röhre in A. BisRgers

Untergattung Trichocereus.

Ihre Heimat ist das südliche Bolivien, wo sie bei Escayache,

in der Nähe von Tarija, bei $3500 \mathrm{~m}$ Höhe auf steinigen Hügeln

wächst. (K. FIEBRIG n. 2770, mit Blüten am 1. Februar 1904.)

Descripción ampliada: Tallos erectos, 2-6 $\mathrm{m}$ de alto, solitarios o con pocas a varias ramas, cilíndricos, con ápices hemisféricos, $20 \mathrm{~cm}$ de largo. Tallo principal de $22 \mathrm{~cm}$ de diámetro o ramificado desde el suelo. Ramas de 20-35 cm de diámetro. Costillas del ápice 15-22, agudas hasta obtusas, 1,4-3,5 $\mathrm{cm}$ de ancho, 0,7-3,0 cm de alto, areolas redondas, 4-8 $\mathrm{mm}$ de alto, 0,6-1,8 cm de ancho, con tomento blanco-crema 0 amarillas en la parte superior de la areola, parte media y base gris; espinas centrales 1-8, aciculares, 0,4-5,0 cm de largo, $1 \mathrm{~mm}$ de diámetro, amarillo-crema con punta marrón-rojizo, perpendiculares al tallo; espinas radiales 4-19, aciculares, 0,5 mm de diámetro, 0,8-8,0 cm de largo, algo onduladas, blanco-crema o amarillas, desde perpendiculares hasta adpresas. Costillas de la base 12-28, agudas a obtusas, $0,8-3,0 \mathrm{~cm}$ de ancho y $0,6-2,8 \mathrm{~cm}$ de alto, areolas elípticas, oblongas 0 circulares, 0,2$1,2 \mathrm{~cm}$ de alto, $0,4-1,0 \mathrm{~cm}$ de ancho, con pilosidad totalmente gris-oscuro o gris-claro o base gris y el resto negro de la areola; espinas centrales 1-6, aciculares, 2,5-7,0 cm de largo, 0,5-1,0 mm de diámetro, algo curvadas, verde-oliva o amarillas o marrón-claro a gris-oscuro, perpendiculares al tallo; espinas radiales 3-50, aciculares, 0,7-4,0 cm de largo, verde-oliva o amarillo-oscuro o gris-oscuro, casi paralelas al tallo (ángulo menor de $20^{\circ}$ ). Flores 10-12, conformando una corona alrededor del ápice, raramente algunas laterales o subapicales, $14 \mathrm{~cm}$ de largo, con abundante pilosidad marrón-claro, 1 a $2 \mathrm{~cm}$ de largo en el ovario y tubo floral; corola de $13 \mathrm{~cm}$ de diámetro (cuando abiertas); ovario de 2,0-2,5 cm de ancho; tubo floral de 2,5-3,0 cm de ancho, escamas florales del ovario de $1 \mathrm{~cm}$ de largo, verdes con ápice morado, escamas florales del tubo 1-3 cm de largo, verde o verde-amarillento con ápice morado; tépalos 4-6 cm de longitud, todos fucsia con ápice oscuro o rosado-intenso y los más internos blancos; estilo verde, 7-9 cm de largo; lóbulos del estigma amarillos, 1,5-2,0 cm de longitud. Pseudobaya con parte externa verde-oscuro, 3,3-5,0 cm de largo, $3,5 \mathrm{~cm}$ de diámetro, recubierta por abundantes pelos blancuzcos. Semillas $1,5 \mathrm{~mm}$ de largo y con testa negra.

Distribución y hábitat: Se localiza en el suroeste de Bolivia y noroeste de Argentina, en la provincia fitogeográfica puneña, entre 3200 y 4200 m, sobre laderas (Albesiano 2014).

Comentarios morfológicos y sus consecuencias en la taxonomía y nomenclatura: Las plantas de la Argentina en su gran mayoría tienen flores totalmente rojo-oscuro, mientras que en Bolivia existen poblaciones con flores cada vez más claras a medida que decrece la latitud. 
En Bolivia se han observado poblaciones de T. tarijensis que se caracterizan por ser más altas, presentar un mayor diámetro de los tallos y espinas, y por lo tanto se proponen dos variedades y dos formas siguiendo la propuesta de Ritter (1980a).

\section{Clave para la identificación de las variedades de Trichocereus tarijensis}

1. Plantas menores de $2 \mathrm{~m}$ de alto, tallos de $20 \mathrm{~cm}$ de diámetro con 15 costillas, y menor número de espinas (21)

var. tarijensis

1'. Plantas mayores de $2 \mathrm{~m}$ de alto (hasta 4,5-6 m), tallos de 20 a $35 \mathrm{~cm}$ de diámetro con 20 a 35 costillas, y mayor número de espinas (24-56)

var. poco

\section{Trichocereus tarijensis (Vaupel) Werderm. var. tarijensis}

TIPO: Bolivia, Dpto. Tarija, Prov. Méndez, Mpio. Escayachi (= Iscayachi), cerca de Tarija, 3500m, sobre colinas rocosas, 1 Feb. 1904, K. Fiebrig 2770 (Holotipo B†; Lectotipo, K. Fiebrig 2770, SI 28593!, designado por R. Kiesling, Darwiniana 21 (2-4): 285. 1978. Isotipo, U 932! anotado en el pliego por P.C. Hutchison 3 May. 1960).

Iconografías: Kiesling (1978): 285. Kiesling \& Ferrari (2005), foto 41: 57.

Descripción ampliada: Tallos erectos, $2 \mathrm{~m}$ de alto, solitarios o con pocas a varias ramas, cilíndricos, con ápices hemisféricos, de $20 \mathrm{~cm}$ de largo. Tallo principal de ca. $20 \mathrm{~cm}$ de diámetro. Las ramas nacen a nivel del suelo, de $22 \mathrm{~cm}$ de diámetro. Costillas del ápice 15-19, agudas y obtusas, 1,4-2,0 $\mathrm{cm}$ de ancho, 0,7-1,8 cm de alto, con areolas ovadas, $4 \mathrm{~mm}$ de alto y 0,6-1,8 cm de ancho, blanco-crema 0 amarillas en el ápice, parte media y base gris; espinas centrales 1-8, de 0,4-4,0 cm de largo, aciculares, $1 \mathrm{~mm}$ de diámetro, amarillo-crema, perpendiculares al tallo; espinas radiales 4-13, de 0,8-3,0 cm de largo, aciculares, algo onduladas, blanco-crema o amarillas, perpendiculares al tallo. Costillas de la base 12-23, obtusas, 0,8-3,0 cm de ancho y 0,6-2,5 cm de alto, con areolas oblongas, 0,2-1,0 cm de alto y 0,4-1,0 cm de ancho, con pilosidad gris-oscuro; una a seis espinas centrales, 2,5-6,0 cm de largo, aciculares, algo curvadas, verde-oliva o amarillas, perpendiculares al tallo; espinas radiales 3-15, de 0,7-1,4 cm de largo, aciculares, verde-oliva o amarillo-oscuro, casi paralelas al tallo (ángulo menor de $20^{\circ}$ ). Flores 1-12 y conformando una corona alrededor del ápice, aunque se presentan algunas subapicales, $13 \mathrm{~cm}$ de largo, con abundante pilosidad marrón-claro, de 1 a $2 \mathrm{~cm}$ de largo en el ovario y tubo floral; corola de $13 \mathrm{~cm}$ de diámetro (cuando abiertas); ovario de 2,0-2,5 cm de ancho; tubo floral de 2,5-3,0 cm de ancho, escamas florales del pericarpelo de $1 \mathrm{~cm}$ de largo, verdes con ápice morado, escamas del tubo floral de 1-3 cm de largo, verde o verde-amarillento con ápice morado; tépalos 4-6 cm de longitud, fucsia con ápice negro, rosado-intenso y los más internos blancos; estilo verde, 7,5-9,0 cm de largo; lóbulos del estigma 
amarillos, $2 \mathrm{~cm}$ de longitud. Pseudobaya con parte externa verde-oscuro, 3,3 cm de largo y 3,5 cm de diámetro, recubierta por abundantes pelos blancuzcos y cavidad ovárica con funículos blancos. Semillas de $1,5 \mathrm{~mm}$ de largo y testa negra (Fig. 47).

Distribución y hábitat: Se localiza en el suroeste de Bolivia y noroeste de Argentina, en la provincia fitogeográfica puneña, entre 3200 y 4200 m, sobre laderas (Figs. 73 y 74).

Material de Herbario estudiado: Argentina, Prov. Jujuy, Dpto. Humahuaca, entre Humahuaca y Pucará, 3500 m, 20 Ene. 1998, R. Kieslig 8916 (SI). Bolivia, Dpto. Tarija, de Tarija a Iscayachi, 2000-3000 m, 20 Mar. 1982, R. Kiesling et al. 4014 A-B (SI).

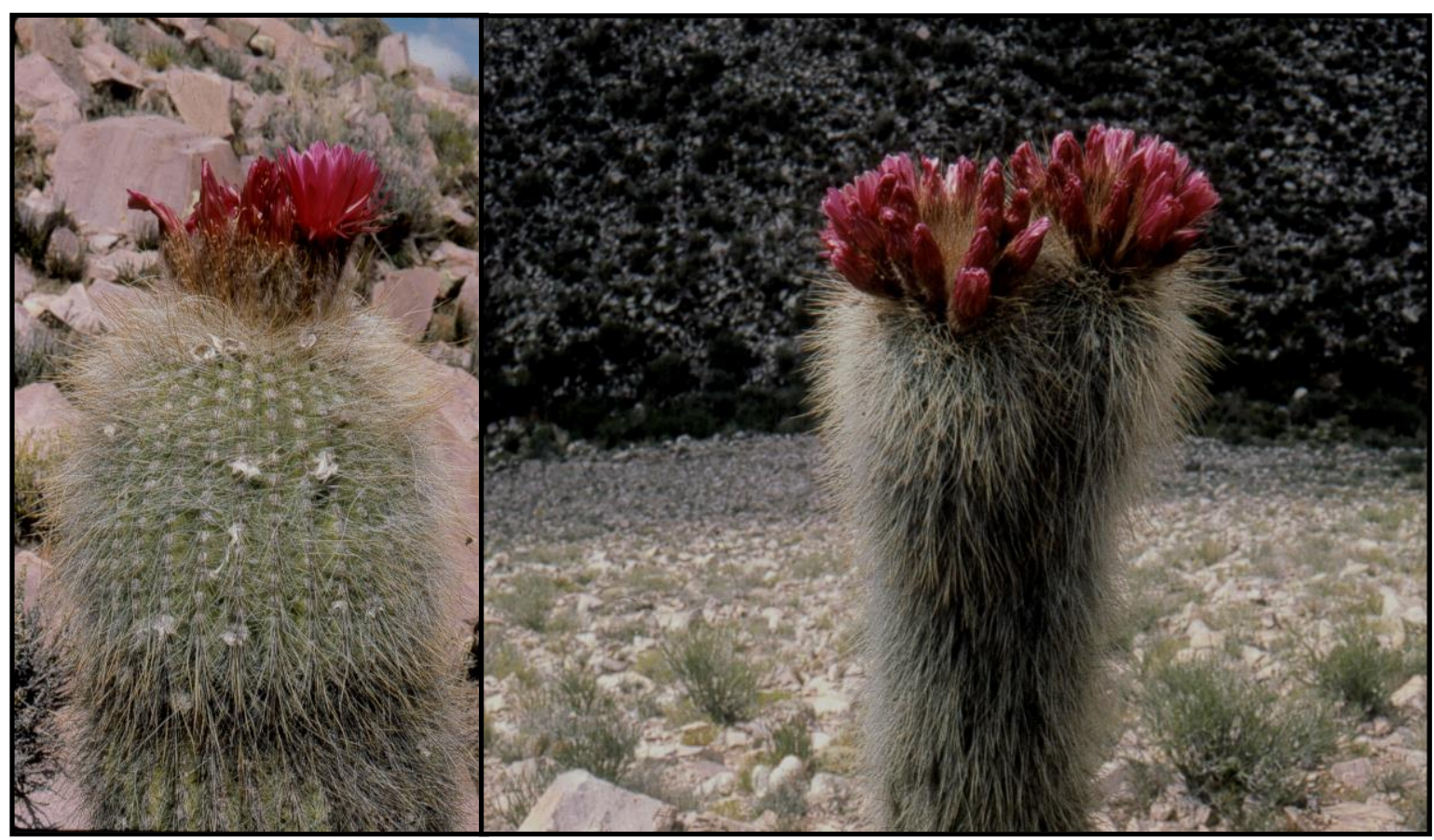

Figura 47. Trichocereus tarijensis var. tarijensis. Argentina, Provincia de Jujuy, al norte de Humahuaca, hacia Tres Cruces, al sur de Esquinas Blancas. A la derecha un ejemplar anormal por tener tallo dicótomo.

47. Trichocereus tarijensis (Vaupel) Werderm. var. poco (Backeb.) F. Ritter ex Albesiano, comb. et stat. nov.

Trichocereus poco Backeb., en Backeb. \& F.M. Knuth, Kaktus-ABC: 412. (“1935”) 1936. Tipo no designado. Helianthocereus poco (Backeb.) Backeb., Cact. Succ. J. (Los Angeles) 23: 48. 1951. Echinopsis poco (Backeb.) H. Friedrich \& G.D. Rowley, I.O.S. Bull. 3(3): 97. 1974. Trichocereus tarijensis (Vaupel) Werderm. var. poco (Backeb.) F. Ritter, Kakteen Südamerika 2: 560. 1980. comb. inval., (falta la página del basónimo, Art. 41.5). Lobivia formosa (Pfeiff.) Dodds var. poco (Backeb.) G.D. Rowley, Cact. Succ. J. Gr. Brit. 44 (4): 80. 1982. 
Trichocereus poco Backeb. var. fricianus Cárdenas, Fuaux Herb. Bull. 1(5): 11. 1953. Helianthocereus poco (Backeb.) Backeb. var. fricianus (Cárdenas) Backeb., Cactus (Paris) No. 45: 208. 1955. Echinopsis poco (Backeb.) H. Friedrich \& G.D. Rowley var. friciana (Cárdenas) H. Friedrich \& G.D. Rowley, I.O.S. Bull. 3(3): 97. 1974. TIPO: Bolivia, Dpto. Potosí, Prov. J.M. Linares, cerca de Kuchu Ingenio, 3600-3700m, Feb. 1950, M. Cárdenas 4987 (Holotipo, LIL 531579!).

Trichocereus tarijensis (Vaupel) Werderm. var. densispinus F. Ritter, Kakteen Südamerika 2: 449. 1980. TIPO: Argentina, Prov. Jujuy, Abra Pampa, F. Ritter 399 (Holotipo, U).

Iconografía: Backeberg (1959a), foto 1268: 1318.

Descripción original de Trichocereus poco Backeb., en Backeb. \& F.M. Knuth, Kaktus-ABC: 412. (“1935”) 1936:

"Trichocereus poco Bckbg. sp. n. (ante p. 204). T. pasacano Br. \& R. (v. ante p.203) similis sed multo humilior et minus crassus, aculeis flavis, serius longis, albis, setiformibus, flexibilibus, vix pungentibus, flore, ut dicitur, rubescente. - Boliviacent ralis ad Saltam Argentinae, alt. usque ad 4000 m."

Descripción ampliada: Tallos erectos, de hasta $6 \mathrm{~m}$ de alto, columnar no ramificado 0 raramente ramificado candelabriforme. Las ramas nacen a nivel del suelo, $35-40 \mathrm{~cm}$ de diámetro. Costillas del ápice 20-22, agudas, 1,5-3,5 cm de ancho, 1,5-3,0 cm de alto; con areolas redondas, 4-8 mm de alto y 6-8 mm de ancho, con pilosidad blanca y amarilla; espinas centrales 1-5, de $5 \mathrm{~cm}$ de largo, 0,51,0 mm de diámetro, blancas, con punta marrón-rojizo; radiales 8-19, de 3 a $8 \mathrm{~cm}$ de longitud, $0,5 \mathrm{~mm}$ de diámetro, marrón-claro, en otros individuos no hay diferencia entre radiales y centrales, aciculares, algunas ligeramente onduladas, la gran mayoría adpresas al tallo y algunas divaricadas (forman un ángulo abierto de $75^{\circ}$ con el tallo). Costillas de la base $25-28$, agudas, de 2,5-3,0 cm de ancho y 2,8 cm de alto, con areolas elípticas a circulares, $0,4-1,2 \mathrm{~cm}$ de alto y $1 \mathrm{~cm}$ de diámetro, con tomento amarillo, gris-claro o base gris y el resto negro; 3-6 espinas centrales, 2-7 cm de largo, aciculares, 0,5-1,0 mm de diámetro, marrón-claro a gris-oscuro; espinas radiales 13-50, de 1-4 cm de largo, aciculares, amarillas, marrón-claro o gris-oscuro. Flores mayormente muchas (ca. 5-15), conformando una corona alrededor del ápice, esporádicamente alguna solitaria en areolas adultas, 9-14 cm de largo, con abundante pilosidad marrón-claro, 1 a $2 \mathrm{~cm}$ de largo en el ovario y tubo floral; ovario $1,5 \mathrm{~cm}$ de largo y 2,5 cm de ancho, cubierto por escamas agudas, que portan abundantes pelos blancos y marrones; tubo floral de $3 \mathrm{~cm}$ de largo y $1,5 \mathrm{~cm}$ de ancho, con escamas agudas, verdes, las cuales llevan pelos blancos y marrón-rojizo; escamas florales del tubo de 1-3 cm de largo, verde o verde-amarillento con ápice morado, segmentos externos del perianto lanceolados, $3 \mathrm{~cm}$ de largo, marrón-verdoso; segmentos internos del perianto lanceolados, rojo-magenta brillante hasta blancos, $4 \mathrm{~cm}$ de largo; estambres en dos series, filamentos amarillo-claro, anteras amarillas; estilo verde, $7 \mathrm{~cm}$ de largo; estigma amarillo, 1,5 cm de longitud. 
Pseudobaya de 3,5-5,0 cm de largo y 2,3-3,5 cm de diámetro con parte externa verde-oscuro y recubierta por abundantes pelos blancuzcos. Semillas 1,3-1,5 mm de largo y con testa negra y brillante (Fig. 48).

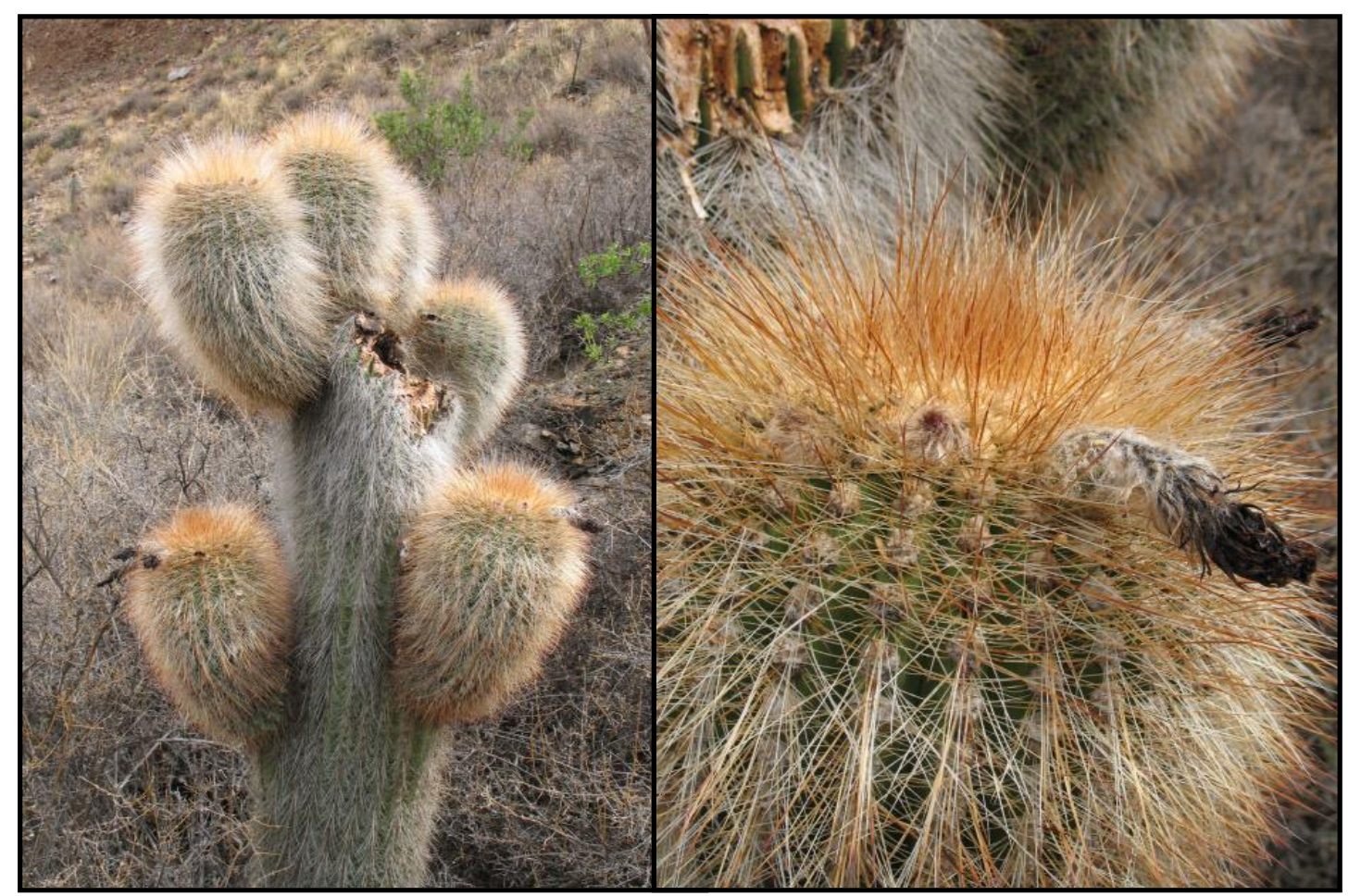
Humahuaca.

Figura 48. Trichocereus tarijensis var. poco. Argentina, Provincia de Jujuy, Quebrada de

Distribución y hábitat: Se localiza en las pendientes áridas y semiáridas de los Andes, al sur de Bolivia (Dpto. Potosí y Oruro), a $3800 \mathrm{~m}$ y al norte de la Argentina (Prov. Jujuy), ca. 3500 m.

Comentarios morfológicos y sus consecuencias en la taxonomía y nomenclatura: Varios autores consideran a T. poco como sinónimo de T. tarijensis (Kiesling 1978, Anderson 2005, Hunt et al. 2006), pero al estudiar las descripciones de Backeberg (1936) y Cárdenas (1953b), y observar ejemplares en las localidades tipo (Tupiza y Escayachi-Bolivia), se encontraron caracteres morfológicos que permiten diferenciarlos.

Las poblaciones de T. tarijensis var. poco presentan modificaciones ligeras con respecto al número de espinas y color de los tépalos, por lo que se proponen dos formas.

\section{Clave para la identificación de las formas de Trichocereus tarijensis var. poco}

1. Espinas hasta 50 por areola, tépalos rojo magenta

1'. Espinas 20 a 28 por areola, tépalos blancos 
48. Trichocereus tarijensis (Vaupel) Werderm. var. poco (Backeb.) F. Ritter ex Albesiano f. poco

Tipo no designado. TIPO: Argentina, Prov. Jujuy, Qda. Humahuaca, 10 Dic. 2009, S. Albesiano, N. Muruaga, A. Alaria \& R. Paz 2065 (Neotipo, MERL, aquí designado).

Iconografía: Hunt et al. (2006), fig. 2: 254.

Descripción ampliada: Tallos erectos, hasta $3 \mathrm{~m}$ de alto. Costillas del ápice 22, de 1,5 $\mathrm{cm}$ de ancho, $1,5 \mathrm{~cm}$ de alto, areolas de $8 \mathrm{~mm}$ de alto, blancas; no hay diferencia entre espinas radiales y centrales, 20 a 25 , de 1,5-9,0 $\mathrm{cm}$ de largo, 0,5 mm de diámetro, blancas y marrones, algunas ligeramente onduladas, la gran mayoría adpresas al tallo y algunas divaricadas. Costillas de la base 28 , agudas, $2,5 \mathrm{~cm}$ de ancho y $2,8 \mathrm{~cm}$ de alto, con areolas elípticas a redondas, $1,2 \mathrm{~cm}$ de alto y $1 \mathrm{~cm}$ de ancho, con tomento en la base gris y el resto negro; cuatro espinas centrales, de 2-6 cm de largo, gris-oscuro; espinas radiales 20-45, de 1,0-2,5 cm de largo, gris-oscuro. Flores de $9 \mathrm{~cm}$

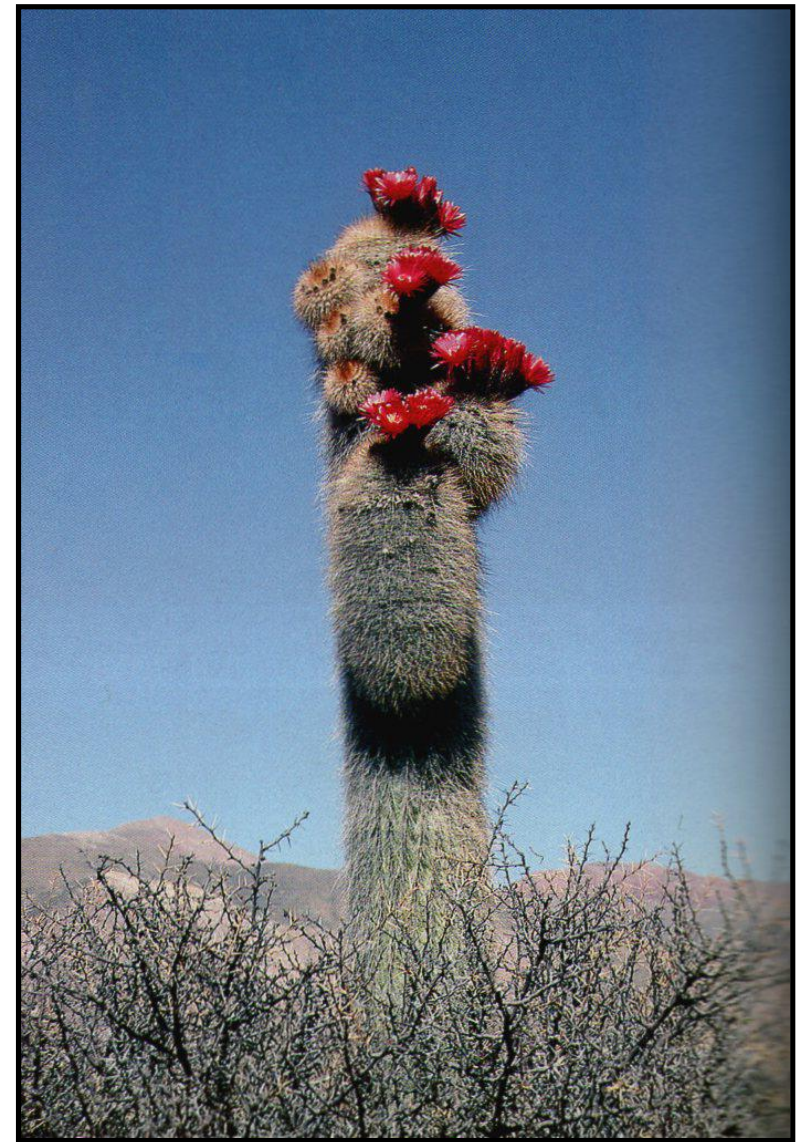
de largo, ovario de 2,5 cm de diámetro; tubo floral de 1,5 cm de ancho, segmentos internos del perianto rojo-magenta brillante (Fig. 49).

Figura 49. Trichocereus tarijensis var. poco f. poco. Foto: Hunt et al. (2006): 254.

Distribución y hábitat: Se distribuye al norte de la Argentina, en la Provincia de Jujuy, y al sur de Bolivia, en el Departamento de Potosí, a 3800 m, en laderas arbustivas junto con Puya sp. 0 Deuterocohnia sp. (Figs. 73 y 74).

Comentarios nomenclaturales: Se seleccionó como Neotipo el ejemplar S. Albesiano et al. 2065 (MERL), el cual se confeccionó en campo porque se acercaba a la descripción original. 
Material de Herbario estudiado: Argentina, Prov. Jujuy, Dpto. Humahuaca, Mina Aguilar, Espinazo del Diablo, 3800 m, 12 Feb. 1968, A.L. Cabrera et al. 18993 (SI); Qda. Humahuaca, 3450 m, 11 Dic. 2006, B.O. Schlumpberger 562 (CORD); El Aguilar, Río Dispensa, 6 Dic. 1970, D. Muhr 35 (LP); Dpto. Tilcara, arriba de San Gregorio, 3800 m, 29 Dic. 1952, H. Sleumer 3135 (SI); Qda. del Abra de la Cruz, 18 Feb. 1966, H.A. Fabris et al. 6388 (LP). Bolivia, Dpto. Potosí, Prov. Antonio Quijarro, 35 Km de Potosí hacia el S en Cucho Ingenio, 3800 m, 29 Nov. 1987, M. Schulte 38 (LPB, SI). Dic. 1931, M. Cárdenas $1(\mathrm{SI})$.

49. Trichocereus tarijensis (Vaupel) Werderm. var. poco (Backeb.) F. Ritter ex Albesiano f. albiflorus (Cárdenas) Albesiano, comb. et stat. nov.

Trichocereus poco Backeb. var. albiflorus Cárdenas, Fuaux Herb. Bull. 1(5): 12.1953. Helianthocereus poco (Backeb.) Backeb. var. albiflorus (Cárdenas) Backeb., Cactus (Paris) No. 45: 208. 1955. Echinopsis poco (Backeb.) H. Friedrich \& G.D. Rowley var. albiflora (Cárdenas) H. Friedrich \& G.D. Rowley, I.O.S. Bull. 3(3): 97. 1974. TIPO: Bolivia, Dpto. Potosí, Prov. J.M. Linares, cerca de Kuchu Ingenio, 3700m, Feb. 1950, M. Cárdenas 4986 (Holotipo, LIL 531594!).

Trichocereus bertramianus Backeb., Blätt. Kakteenf. (sin paginar), género 51: 2, ill. 1935(6). Helianthocereus bertramianus (Backeb.) Backeb., Cact. Succ. J. (Los Angeles) 23: 48. 1951. Echinopsis bertramiana (Backeb.) H. Friedrich \& G.D. Rowley, I.O.S. Bull. 3(3): 94. 1974. Lobivia formosa (Pfeiff.) Dodds var. bertramiana (Backeb.) Rausch, Lobivia 3: 164. 1975. Echinopsis tarijensis (Vaupel) H. Friedrich \& G.D. Rowley subsp. bertramiana (Backeb.) M. Lowry, Cactaceae Syst. Init.: 14: 14. 2002. TIPO: Foto s.n., en Backeb., I.c.: 2. 1935(6) (Lectotipo, aquí designado).

Trichocereus orurensis Cárdenas var. albiflorus Cárdenas, Fuaux Herb. Bull. 1(5): 16, ill. 1953. Helianthocereus orurensis (Cárdenas) Backeb. var. albiflorus (Cárdenas) Backeb., Cactus (Paris) No. 45 : 208. 1955. Echinopsis orurensis (Cárdenas) H. Friedrich \& G.D. Rowley var. albiflora (Cárdenas) H. Friedrich \& G.D.Rowley, I.O.S. Bull. 3(3): 96. 1974. TIPO: Bolivia, La Joya, cerca de Oruro, 3800 m, Nov. 1951, M. Cárdenas 4984 (Holotipo, LIL 531564!).

Iconografías: Backeberg (1959a), foto 1270: 1319. Anderson (2005): 245. Hunt et al. (2006), fig. 1: 254 . 
Descripción original de Trichocereus poco Backeb. var. albiflorus Cárdenas, Fuaux Herb. Bull. 1(5): 12. 1953:

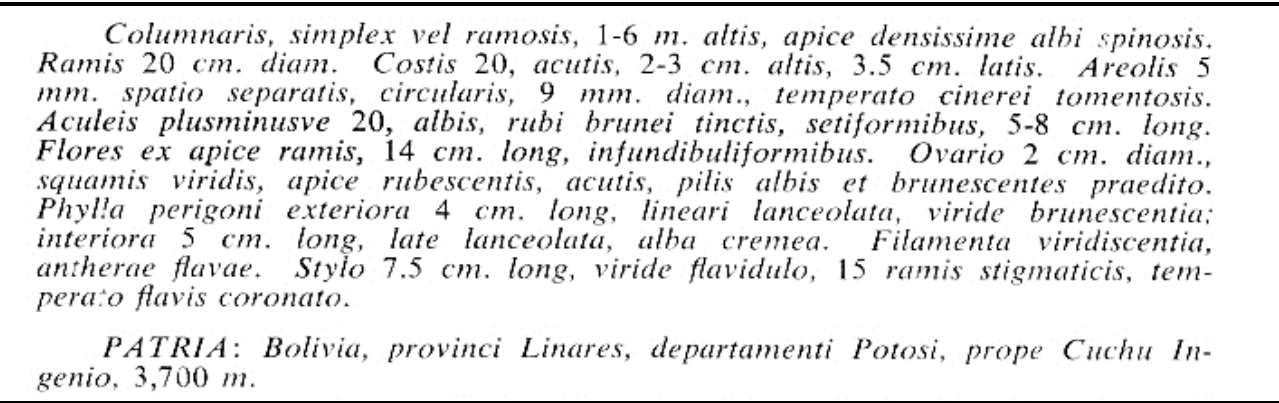

Descripción ampliada: Tallos erectos, solitarios o con pocas ramas, 1,5-6,0 m de alto, verdeclaro, anchos en la parte superior. Costillas ca. 20, de 1-3 cm de alto, $3,5 \mathrm{~cm}$ de ancho. Costillas del ápice

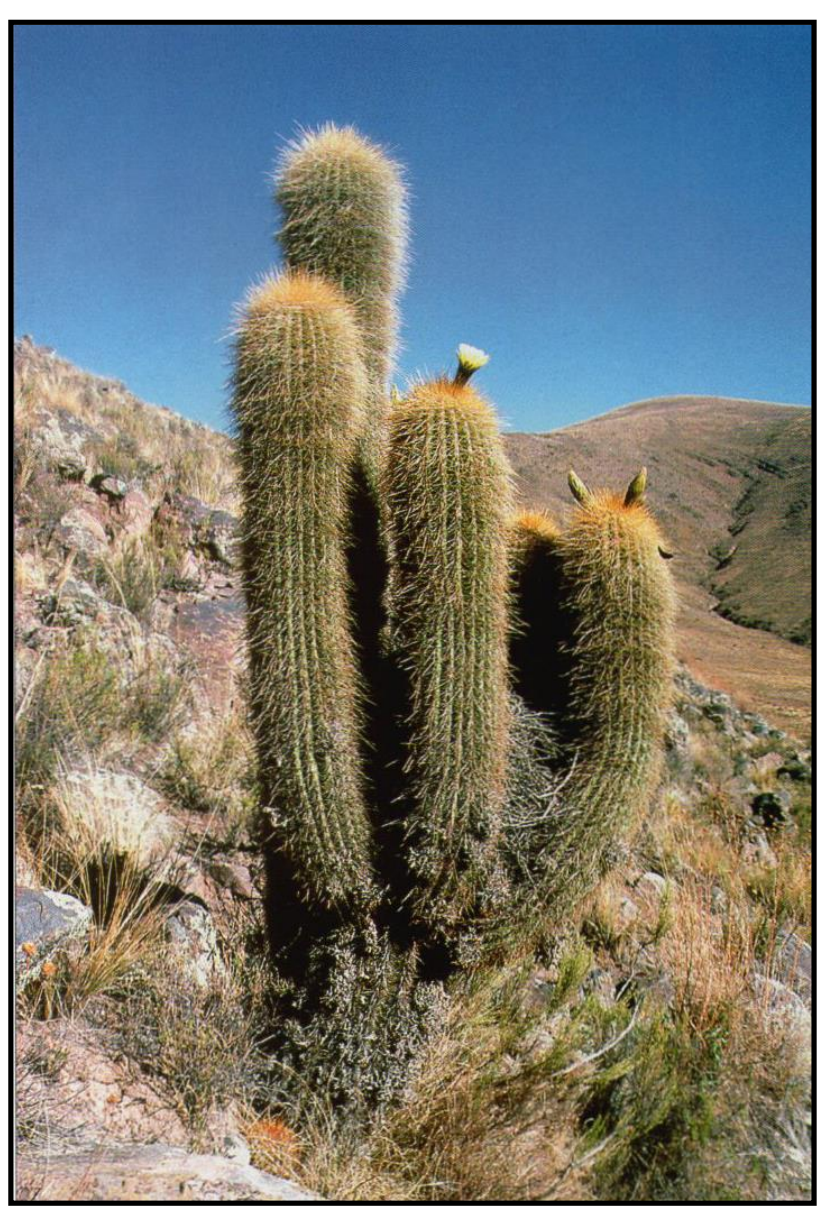
de los tallos con areolas de 4-7 $\mathrm{mm}$ de alto, 6-9 mm de diámetro, con pilosidad amarilla; espinas centrales $1-5$, una de ellas crece hacia abajo, $5-7 \mathrm{~cm}$ de largo, 0,5-1,0 $\mathrm{mm}$ de diámetro, marrón-claro o blanco-brillante con punta marrón-rojizo; radiales $8-19$, de 3 a 8 $\mathrm{cm}$ de longitud, 0,5 mm de diámetro, marrónclaro, algunas con la base rojiza. Costillas de la base de los tallos con areolas de 4-6 mm de alto, $9 \mathrm{~mm}$ de ancho, con tomento amarillo y gris-claro; espinas centrales 3-6, de 3,5-7,0 $\mathrm{cm}$ de largo, de 0,5-1,0 mm de diámetro, marrón-claro, radiales $12-22$, de 2,5-4,0 cm de largo, amarillas a marrón-claro, algunas con base rojiza. Flores de 10-14 cm de largo, segmentos internos del perianto blancocrema (Fig. 50).

Figura 50. Trichocereus tarijensis var. poco f. albiflorus. Foto : Hunt et al. (2006): 254.

Distribución y hábitat: Se distribuye en Bolivia en los departamentos de Cochabamba, La Paz, Oruro y Potosí, a 3500 m (Fig. 74), sobre suelos arcillosos, junto con Berberis boliviana. Su hábitat está siendo fuertemente intervenido por algunos cultivos, entre ellos el de papa. 
Material de Herbario estudiado: Bolivia, Dpto. Potosí, Prov. Tomas Frias, Km $28 \mathrm{~N}$ of Potosí on main road to Challapata (a few km W of Tarapaya), 19² $28^{\prime} \mathrm{S}, 65^{\circ} 49^{\prime} \mathrm{W}, 3400 \mathrm{~m}, 26$ Oct. 1983, J.C. Solomon 11334 (LPB); Prov. José M. Linares Lizarazu, Kucho Ingenio, 3500m, 17 Nov. 1993, R. Kiesling \& D. Metzing 8393 (LPB, SI). Dpto. Oruro, Pazña Oruro, Urmiri, entrando en la estación termal por la carretera del cañadón Bolivar, a 5 Km de la localidad, 27 Oct. 2000, G. Bourdy 2829 (LPB, SI).

50. Trichocereus terscheckii (Parm. ex Pfeiff.) Britton \& Rose, The Cactaceae 2: 140-141, ill. 1920.

Cereus terscheckii Parm. ex Pfeiff., en Otto \& Dietrich, Allg. Gartenzeitung 5: 370. 1837. Tipo no designado. Pilocereus terscheckii (Parm. ex Pfeiff.) Rümpler ex Pfeiff, Handb. Cacteenk.: 688. 1885. Echinopsis terscheckii (Parm. ex Pfeiff.) H. Friedrich \& G.D. Rowley, I.O.S. Bull. 3(3): 98. 1974. Leucostele terscheckii (Pfeiff.) Schlumpb., Cactaceae Syst. Init. 28: 29. 2012. TIPO: Argentina, Prov. La Rioja, cruce entre Famatina y Chilecito, $29^{\circ} 0^{\prime}$ 'S; $67^{\circ} 30^{\prime} \mathrm{W}, 21$ Ene. 2007, S. Albesiano, R. Kiesling, B. Ruthsatz \& M. Perea 2031 A y B (Neotipo, MERL 58798, aquí designado).

Trichocereus terscheckii (Parm. ex Pfeiff.) Britton \& Rose var. montanus Backeb., Cact. Succ. J. (Los Angeles) 23(2): 45. 1951. Tipo no designado. Echinopsis terscheckii (Parm. ex Pfeiff.) H. Friedrich \& G. D. Rowley var. montana (Backeb.) H. Friedrich \& G.D. Rowley, Repert. PI. Succ. 25: 10. 1976. TIPO: Argentina, Prov. Salta, Valle de Lerma, Osma, Ruta 68 Km 136, lomadas al norte del río Osma, 1200 m, 28 Nov. 2005, L. Novara 12296 (Neotipo, MCNS, aquí designado).

Trichocereus terscheckioides F. Ritter, Kakteen Südamerika 2: 446. 1980, nom. inval., por designar dos recolecciones tipo (Art. 40.2).

Iconografías: Backeberg (1959a), foto 1049: 1103. Ritter (1980a), foto 301: 727. Mauseth et al. (2002): 251-252. Kiesling \& Meglioli (2003), lámina 188: 191; foto: 253.

Descripción original de Cereus terscheckii Parm. ex Pfeiff., en Otto \& Dietrich, Allg. Gartenzeitung 5: 370. 1837:

\section{Cerens Terscheckii Ptım.}

C. erectus simplex 9-12 angularis hrumeo-rirens; sinubus acutis; costis ublusis rectis; areolis mannis albito-tomentosis el lanatis: aculeis exterioribus 12 radiantibus (supreno brevissimo, infumo longissino), centralibus 3 , onmibus gracilibus, rigidis, rectis, fulvis. 
Descripción ampliada: Plantas erectas, arbóreas, hasta $15 \mathrm{~m}$ de alto, simples o ramificadas. Ramificaciones naciendo a 60-100 cm de altura, de 27-45 cm de diámetro. Ramas de segundo y tercer orden más cortas, $24-27 \mathrm{~cm}$ de diámetro, epidermis verde-grisáceo hasta verde-oscuro. Costillas del ápice aproximadamente 13, obtusas, $3 \mathrm{~cm}$ de ancho, 1,4 cm de alto. Areolas obovadas, $2 \mathrm{~mm}$ de alto, 1 $\mathrm{cm}$ de ancho, con tomento gris-claro. Espinas (a veces ausentes en toda la planta), central una, acicular, $3 \mathrm{~cm}$ de largo, amarilla. Espinas radiales 5, aciculares, de 2,2 cm de largo, rigidas, punzantes y amarillas. Costillas de la base 13-19, obtusas, 5,5 cm de ancho, 2-4 cm de alto. Areolas de la base obovadas, hasta $6 \mathrm{~mm}$ de alto, 1-2 $\mathrm{cm}$ de ancho, con tomento negro. Espinas centrales 2-8, subuladas, $1 \mathrm{~mm}$ de diámetro, rectas, $3-9 \mathrm{~cm}$ de largo, amarillas y negras. Espinas radiales 7-15, ca. $4 \mathrm{~cm}$ de largo, aciculares, amarillas o pardas, 1,5 mm de diámetro. Areolas cáducas en tallos muy adultos. Flores laterales o subapicales, mayormente varias simultáneas, de $20 \mathrm{~cm}$ de largo o mayores, con abundante pilosidad marrón en el ovario y tubo floral, corola $7,5 \mathrm{~cm}$ de diámetro, ovario de $3 \mathrm{~cm}$ de ancho, escamas florales del pericarpelo de $2 \mathrm{~cm}$ de largo, verde con ápice marrón, escamas del tubo floral de $4 \mathrm{~cm}$ de largo, verdes 0 verdeamarillentas con ápice marrón, tépalos de 6,6 cm de longitud, blancos, raro rosados, estilo verde, $16 \mathrm{~cm}$ de largo, estigmas amarillos, $1 \mathrm{~cm}$ de longitud. Pseudobaya con parte externa verde-oscuro, $6,5 \mathrm{~cm}$ de largo, 4,5 cm de diámetro, recubierto por abundantes pelos blancos. Semillas en forma de urna, de 1,5 $\mathrm{mm}$ de largo y $1 \mathrm{~mm}$ de ancho, con testa marrón-oscuro a negro, con células subhexagonales y con hilo terminal grande (Fig. 51).

Localidad tipo: "Buenos Aires", seguramente queriendo decir Argentina o el puerto de procedencia.

Distribución y hábitat: Se localiza hacia el NW Argentino, desde Jujuy hasta San Juan, y en Bolivia hacia el SW (Figs. 73 y 74) (Albesiano 2014). Ocupa las laderas y valles secos, entre los 800 y $1400 \mathrm{~m}$, en el límite oeste de la provincia fitogeográfica chaqueña y en la de monte. Se encuentra en los jarillales, asomando sobre bosquecillos xerófilos espinosos o incluso en el ecotono entre estos y la selva (Kiesling 1978).

Comentarios morfológicos y sus consecuencias en la taxonomía y nomenclatura: Se eligió el ejemplar S. Albesiano et al. 2031 A y B (MERL) como Neotipo de Cereus terscheckii porque presenta las características nombradas en la descripción original. Es un ejemplar completo que cuenta con cortes transversales y longitudinales del tallo y la flor, lo que permite el reconocimiento de las características vegetativas y reproductivas de la especie.

Se escogió el ejemplar L. Novara 12296 (MCNS) como Neotipo de Trichocereus terscheckii var. montanus, debido a que reúne los caracteres mencionados en la descripción original. 
Ritter (1980a) propuso el nombre Trichocereus terscheckioides para individuos con un número mayor de costillas (19) y espinas centrales (8), por haber observado en campo poblaciones de $T$. terscheckii con individuos que registraban estas características, este taxón se considera sinónimo de esta última, debido a que estos caracteres se encuentran en el rango de variación de la especie.

Especie muy afín a $T$. atacamensis por el hábito arbóreo (mayores de $3 \mathrm{~m}$ de alto), y por la presencia de un tallo principal definido, pero presenta caracteres que la distinguen (Tabla 14). Aunque presentan similitud en sus semillas, las cuales son diferentes del resto de las especies de Trichocereus, en forma de urna y la región hilo-micrópilo está en un extremo, además de que las células de la testa son subhexagonales, dándole un aspecto de punteaduras a la testa y brillantes. En zonas como la Qda. del Toro y en Cafayate (Salta, Argentina), se presenta un flujo génico entre las poblaciones de estas dos especies, que origina híbridos a veces muy difíciles de diferenciar (Kiesling et al. 2009).

Tabla 14. Diferencias entre $T$. terscheckii y $T$. atacamensis

\begin{tabular}{|l|l|l|}
\hline CARACTERES & \multicolumn{1}{|c|}{ T. terscheckii } & \multicolumn{1}{c|}{ T. atacamensis } \\
\hline Ramificación & $\begin{array}{l}\text { Mayormente muy ramificado, } \\
\text { con ramas hasta de tercer orden }\end{array}$ & $\begin{array}{l}\text { Poco ramificado, con ramas de } \\
\text { primer orden }\end{array}$ \\
\hline No de costillas & Menos de 20 & Más de 24 \\
\hline Presencia de espinas & A veces ausentes & Siempre presentes \\
\hline Espinas & Todas rígidas & $\begin{array}{l}\text { Las de arolas superiores (por } \\
\text { encima de los 1,5 m) flexibles, } \\
\text { parecidas a cerdas }\end{array}$ \\
\hline Tamaño de las flores & Largas, $20 \mathrm{~cm}$ o más & Cortas, hasta $15 \mathrm{~cm}$ \\
\hline Distribución altitudinal & $800-1400 \mathrm{~m}$ & $(1600) 2000-3700 \mathrm{~m}$ \\
\hline
\end{tabular}

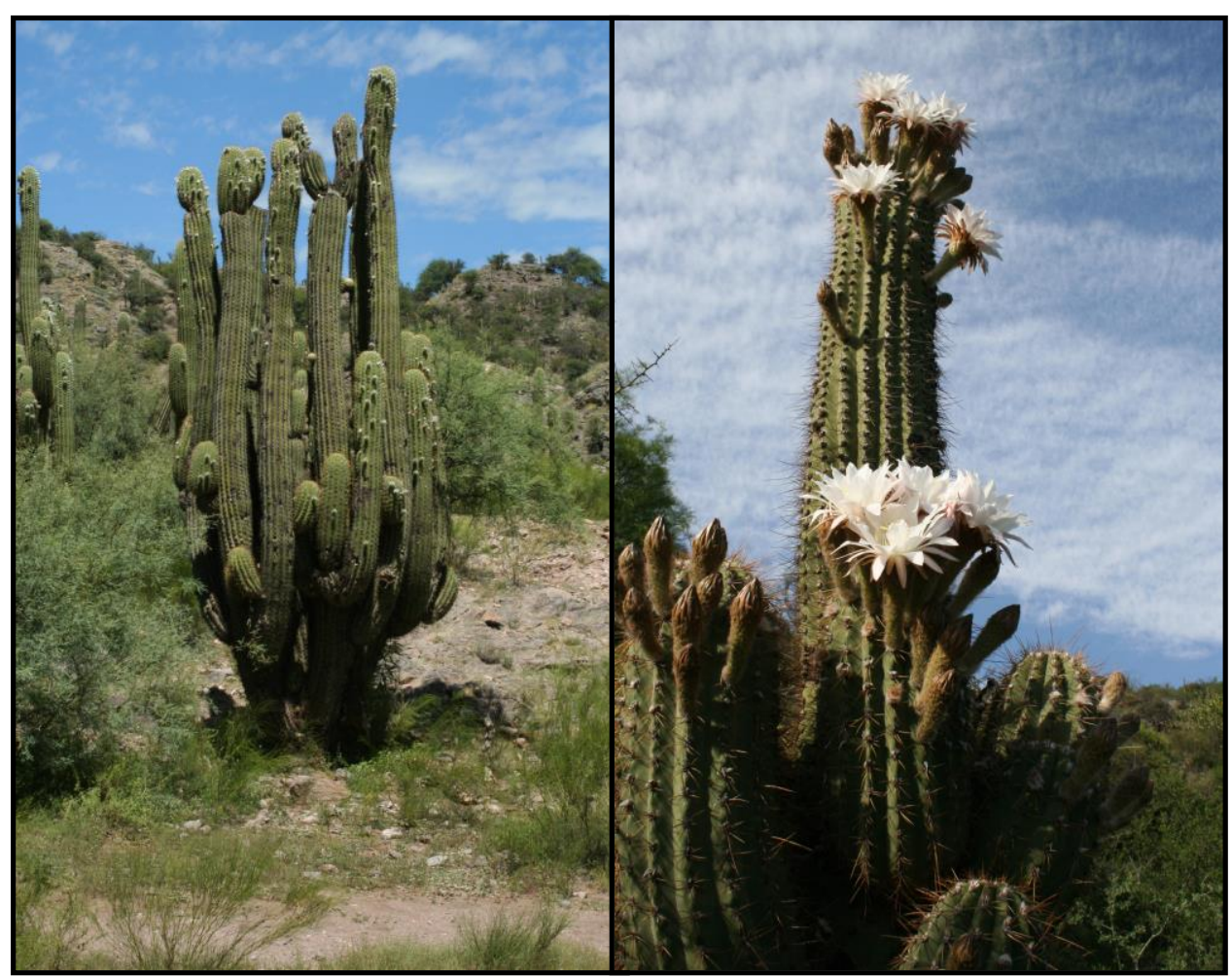

Figura 51. Trichocereus terscheckii. Argentina, Provincia de San Juan, Departamento Valle Fértil, sur de Balde del Rosario. 
Material de Herbario estudiado: Argentina, Prov. Catamarca, Dpto. Andalgalá, Ene. 1916, Joergensen 1528 (SI), base de la cuesta de la Chilca, 30 Nov. 1972, P. Cantino 460 (SI); Dpto. Belén, 5 Feb. 1973, E. Ulibarri 424 (SI); Sanagasta, 19 Feb. 1990, F. Biurrun 3157 (LP); ibidem, cerca de Amadores (Km 1335), hacia Chumbicha, 26 Nov. 1960, A. Ruiz-L. 21646 C, B (MERL); 11 Km from turnoff from Ruta 46 on the road over the Cuesta La Chilca towards Las Estancias, 1150 m, 10 Dic. 1998, B.E. Leuenberger et al. 4656 (CORD); Dpto. Ambato, Sierra de Ambato, 1096 m, 6 Nov. 2006, B.O. Schlumpberger 432 (CORD); Dpto. Paclín, $7 \mathrm{Km}$ from La Merced on ruta 38 towards San Fernando del Valle de Catamarca, 850 m, 25 Feb. 1994, B. Leuenberger et al. 4359 (CORD). Prov. Jujuy, Dpto. Santa Bárbara, El Fuerte, Sierra de Santa Bárbara, 1392 m, 27 Nov. 2000, A.A. Cocucci 1328 (CORD). Prov. La Rioja, Los Sarmientos cerca Chilecito, Mar. 1879, G. Hieronymus \& G. Niederlein 849 (CORD). Dpto. Capital, 1 Nov. 1977, F. Biurrun 1203 (SI); Las Pedercitas, 13 Jul. 1988, F. Biurrun et al. 2517 (SI); Dpto. Chamical, entre Chamical y Casa de Piedra, 21 Ene. 1990, F. Biurrun \& E. Biurrun 3060 (SI); Famatina, ladera de la sierra de Paimán, 1700 m, Ene. 1949, Krapovickas \& J.H. Hunziker 5979 (CORD); Sierra de Famatina, 1324 m, 28 Oct. 2006, B.O. Schlumpberger 415b (CORD); Dpto. Independencia, 19 Km from roadsign "Patquía" towards Chilecito (i. e. between Patquía and Los Colorados), flat roadside area, $520 \mathrm{~m}$, 13 Feb. 1994, B. Leuenberger et al. 4187 (CORD). Prov. Salta, Dpto. Guachipas, al E de Santa Bárbara, 1600 m, 6 Oct. 2005, M. Saravia 27 (SI); El Mollar, Qda. del Toro, 7 Dic. 2006, B.O. Schlumpberger 549 (CORD). Prov. San Juan, Ichigualasto, 10 May. 1987, E. Ezcurra \& C. Montaña s.n. (MERL 47177); Dpto. Caucete, Marayes, 9 Nov. 1986, E. Haene 121 (SI), Dpto. Valle Fértil, S de Balde del Rosario, 8 Mar. 1998, R. Kiesling 8958 (SI); Valle Fértil, La Majadita, 6 Ene. 2009, S. Albesiano et al. 2062 (MERL); Prov. Tucumán, Dpto. Trancas, Vipos, 800 m, 28 Oct. 1923, S. Venturi 2071 (LP); Prov. Salta, Qda. del Toro, 25 Feb. 1972, R. Kiesling 142 (SI).

51. Trichocereus thelegonus (F.A.C. Weber) Britton \& Rose, The Cactaceae 2: 130, ill. 1920.

Cereus thelegonus F.A.C. Weber, en K.Schum. Gesamtbeschr. Kakt. 78, ill. 1897. Echinopsis thelegona (F.A.C. Weber) H. Friedrich \& G.D. Rowley, I.O.S. Bull. 3(3): 98. 1974. Soehrensia thelegona (F.A.C. Weber) Schlumpb., Cactaceae Syst. Init.: 28: 31. 2012. TIPO: Argentina, Tucumán, "Vipos, [Dr. Jan] Authicus 6-VII-1892". (Lectotipo, P, aquí designado).

Iconografías: Anderson (2005): 246. Hunt et al. (2006), fig. 4: 238. Kiesling \& Ferrari (2005), foto 45: 61. 
Descripción original de Cereus thelegonus F.A.C. Weber, en K.Schum. Gesamtbeschr. Kakt.

78, 1897:

Columnaris parce ramosus, costis c. 13 humilibus transverse sulcatis et in mamillas basi subhexagonas solutis; aculeis radialibus $6-7$ acicularibus.

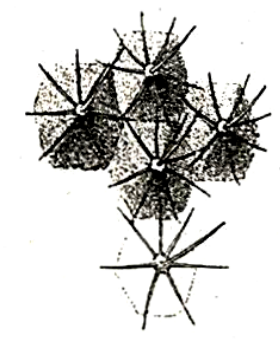

Fig. 14.

Stamm aufrecht, säulenförmig, wenig verzweigt. bis $2 \mathrm{~m}$ hoch und $7-\mathrm{S} \mathrm{cm}$ im Durchmesser, oben gerundet, am Scheitel mit gelblich weißem Wollfilz bedeckt und von braunen, parallel stehenden Stacheln beschlossen, im Neutrieb hellgrün, später dunkelgrün. Rippen etwa 13, später oder an großen Exemplaren wahrscheinlich mehr, durch scharfe Buchten gesondert, stumpf, niedrig, $5-6 \mathrm{~mm}$ hoch, später verlaufend und durch eine dunklere, zickzackförmige Furchen-Grundlinie geschieden, durch quere Furchen gegliedert und in etwa sechsseitige, niedrige, spitze Warzen zerlegt. Cereus thelegonus Web. Areolen 8-10 mm voneinander entfernt, kreisrund, Rippenstück, in Höcker $2 \mathrm{~mm}$ jm Durchmesser, mit gelblich weißem Wollfilz Original verlegt. bekleidet, bald verkahlend und dann etwas eingesenkt. Original von $\mathrm{Zambony.} \mathrm{Randstacheln} \mathrm{6-7,} \mathrm{spreizend,} \mathrm{der} \mathrm{untere,} \mathrm{der}$ lïngste, mißt bis $12 \mathrm{~mm}$, sie sind dünn, nadelförmig, wenig stechend; jung sind sie hellhoniggelb, oben braun, später vergrauen sie und werden bestoßen.

*) RüMPLER schreibt Chihuahua in Mexiko, statt Chuquisaca in Bolivien.

Descripción ampliada: Plantas decumbentes, que en algunas localidades cubren literalmente el suelo. Tallos rastreros, únicamente el ápice levantado o ascendentes al crecer en lugares húmedos y sombríos, $2 \mathrm{~m}$ de largo, cilíndricos, 6-8 $\mathrm{cm}$ de diámetro, verde-claro (cuando jóvenes) a oscuro (cuando adultos), raíces caulinares que nacen de las areolas en contacto con el suelo. Costillas 10-13, anchas, bajas, obtusas, formadas por mamelones subhexagonales, $6 \mathrm{~mm}$ de alto, $8 \mathrm{~mm}$ de ancho, $12 \mathrm{~mm}$ de largo, alineados longitudinalmente, separados por un surco transversal y siendo quebrada la línea que separa las costillas. Areolas en el ápice de los mamelones, distantes 1-2 cm, circulares, 4-8 mm de diámetro, con pilosidad blancuzca, gris y caduca. Una espina central, 2-4 cm de longitud, flexible, radiales rígidas, raro uncinadas, aciculares, $1 \mathrm{~mm}$ de diámetro, amarillas a negras, $1-2 \mathrm{~cm}$ de largo. Flores de 20 $\mathrm{cm}$ de largo, $15 \mathrm{~cm}$ de diámetro (cuando abiertas), escamas del ovario y tubo linear-triangulares, imbricadas, de cuyas axilas emergen cerdas rojizas y lanosidad ondulada; tépalos exteriores linearlanceolados, retrorsos, ligeramente carnosos, mucronados, verdes, $2,5 \mathrm{~cm}$ de largo y $6 \mathrm{~mm}$ de ancho; los internos blancos, mucronados, $8 \mathrm{~cm}$ de longitud, $1,5 \mathrm{~cm}$ de ancho; estambres de la serie superior con filamentos de $4 \mathrm{~cm}$ de largo y $1 \mathrm{~mm}$ de diámetro, blancuzcos, filamentos de la serie inferior de 9,5 $\mathrm{cm}$ de largo y $1 \mathrm{~mm}$ de diámetro, con base verdosa y ápice crema, anteras amarillas, 2,5 mm de longitud y $1 \mathrm{~mm}$ de diámetro; estilo de $13 \mathrm{~cm}$ de largo y $4 \mathrm{~mm}$ de ancho, base verde y ápice blancuzco; estigma con 12 lóbulos, subteretes, $1,5 \mathrm{~cm}$ de largo y $2 \mathrm{~mm}$ de diámetro, amarillos. Pseudobayas globosas 0 subglobosas, parte externa verde, $5 \mathrm{~cm}$ de largo, mamelonados, con abundante pilosidad marrón a rojiza. Semillas de 1,5 mm de diámetro, redondeadas 0 a veces angulosas, negras, brillantes, papilas finas alrededor del hilo, y el resto con diminutas perforaciones (Fig. 52). 
Distribución y hábitat: Especie endémica del oeste argentino, distribuyéndose en las provincias de Jujuy, Salta, Tucumán y noroeste de Catamarca (Fig. 73), entre 500-1000 m de altitud, en laderas rocosas desnudas o bajo árboles en lugares planos, en el bosque espinoso y seco de la provincia fitogeográfica del Chaco Serrano o en el bosque de transición entre esta provincia y las Yungas, donde se presenta más erecta (Kiesling 1978).

Comentarios morfológicos y sus consecuencias en la taxonomía y nomenclatura: Es la única especie del género Trichocereus que se caracteriza por ser rastrera, con costillas formadas por mamelones y con surcos intercostales en zig-zag.

Especie descrita originalmente en el género Cereus (Weber 1897), posteriormente transferida a Trichocereus (Britton \& Rose 1920), Echinopsis (Friedrich \& Rowley 1974) y recientemente a Soehrensia (Schlumpberger 2012). Se considera que debe corresponder al género Trichocereus por presentar las siguientes sinapomorfías: crecimiento basítono con ramas postradas, escamas imbricadas a lo largo del tubo floral y frutos subglobosos.

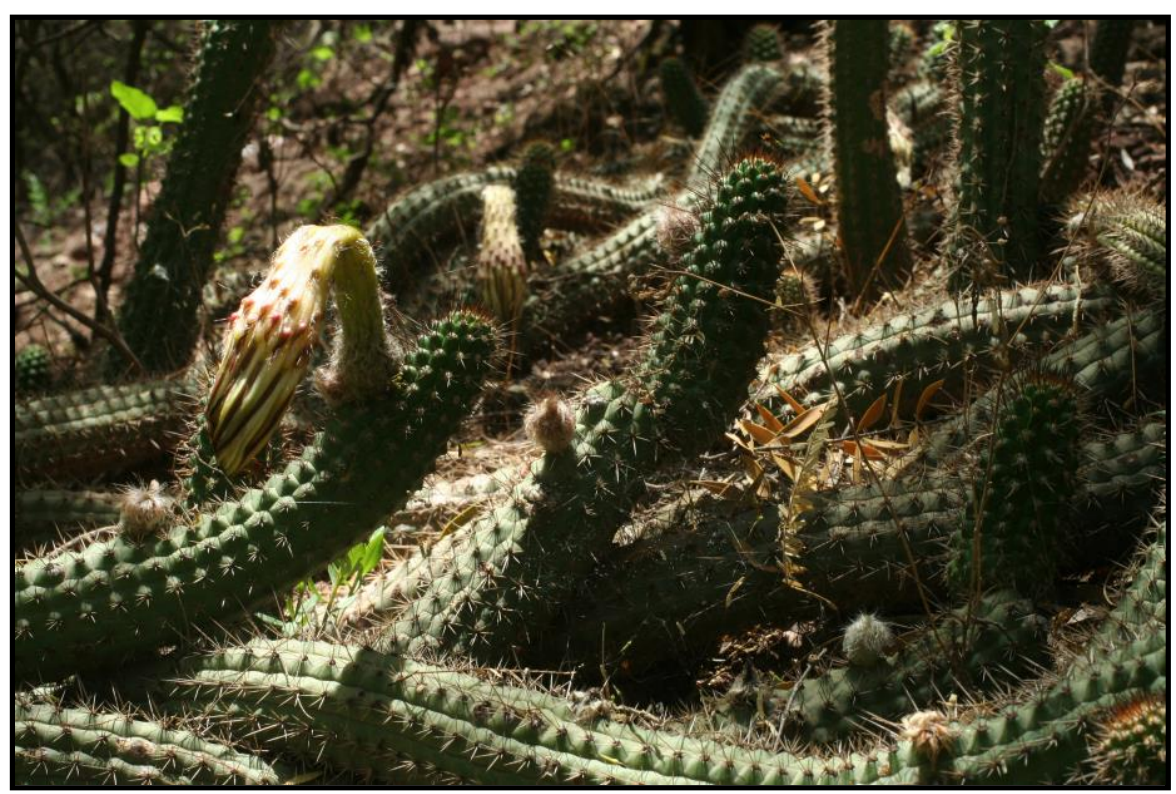

Figura 52. Trichocereus thelegonus. Argentina, Provincia de Salta, Departamento Guachipas, Alemania, entre la ciudad de Salta y Cafayate.

52. Trichocereus tunariensis Cárdenas, Cactus (Paris) 14 (64): 160, ill. 1959.

Echinopsis tunariensis (Cárdenas) H. Friedrich \& G.D. Rowley, I.O.S. Bull. 3(3): 98. 1974. Leucostele tunariensis (Cárdenas) Schlumpb., Cactaceae Syst. Init. 28: 29. 2012. TIPO: Bolivia, Dpto. Cochabamba, Prov. Cercado, Monte Tunari, in itineri Yurac Kkasa-San Miguel, 3800 m, Feb. 1958, M. Cárdenas 5499 (Holotipo, LIL 531539! Isotipo US, perdido).

Iconografías: Cárdenas (1959): 160. Hunt et al. (2006), Fig. 5: 238. 
Descripción original de Trichocereus tunariensis Cárdenas, Cactus (Paris) 14 (64): 160. 1959:

Columnaris a base ramosus, $2-3 \mathrm{~m}$ altis, Ramis $12 \mathrm{~cm}$ crassis, claviformis vel cylindricis, diluto vididis. Costis 16-21, acutis $1-1.5 \mathrm{~cm}$ altis, $1.5-1.7 \mathrm{~cm}$ latis. Areolis $1 \mathrm{~cm}$ inter se distantibus, ovalis, 4-6 mm diam. cinereo tomentosis. Aculeis plus minusve 17, radiantes, non distinguentis in radiales aut centrales, 5-60 mm long., longiores inferne direxit, omnes aculei gracilis, acicularis, flexuosis, flavidis. Flores ex apice ramis, numerosis, coronati, infundibuliformi, $15-17 \mathrm{~cm}$ long. Ovario globoso $2.5 \mathrm{~cm}$ diam., squamis $5 \mathrm{~mm}$ long., diluto viridis, apice roseo, pilis bruneis et nigris, densissime hirsutis praedito. Tubus $2 \mathrm{~cm}$ long. curvatus, bruneus, squamis acutis $6 \mathrm{~mm}$ long. roseus, pilis densis, bruneis et nigris instructus. Phylla perigoni exteriora $30 \mathrm{~mm}$ long. lanceolata, purpurea; interiora $65 \mathrm{~mm}$ long. late spathulata. superne rotunda, alba. Stamina duplo seriali inserta; inferiora ex $1 \mathrm{~cm}$ supra fundo tubus usque $1.5 \mathrm{~cm}$ infra basim petalia $6 \mathrm{~cm}$ long., filamenta diluto viridia; stamina superiora $3.5 \mathrm{~cm}$ long., filamenta inferne viridia, superne alba; antherae diluto flava brunescente. Stylus $10 \mathrm{~cm}$ long., $3 \mathrm{~mm}$ crassus, inferne

diluto viridis, superne albidis, 18 lobis stigmaticis flavidulis, $19 \mathrm{~mm}$ long. coronatus. Fructo globoso $4 \mathrm{~cm}$ alto, $5 \mathrm{~cm}$ crasso, atro viridis, squamis $1.5-2 \mathrm{~cm}$ long. abrupte acutis, pilis brevis, densis, atro bruneis, nigris et albis praedito. Pulpa alba, esculenta. Semina $1.5-2 \mathrm{~mm}$ long. puncticulata, nitentia.

Patria: Bolivia, provinci Cercado, departementi Cochabamba, Mons Tunari, in itinere Yurac Kkasa-San Miguel, 3,800 m.

Trichocereus tunariensis Cardenas nov. spec

\section{Description :}

Plantes colonnaires se ramifiant à la base, 2 à $3 \mathrm{~m}$ de haut. Rameaux, environ $12 \mathrm{~cm}$ de diamètre à la base. Aréoles distantes d'environ $1 \mathrm{~cm}$, ovales, $4-6 \mathrm{~mm}$, à feutrage gris. Aiguillons 17, étalés; les plus courts, $5 \mathrm{~mm}$ de long, les moyens, $12 \mathrm{~mm}$, les plus longs, $26 \mathrm{~cm}$ de long, dirigés vers le bas. Aiguillons des aréoles supérieures, $6 \mathrm{~cm}$ de long : tous très minces, aciculaires, flexibles, jaune paille.

Fleurs disposées en couronne au sommet des rameaux, nocturnes, infundibuliformes, $15-17 \mathrm{~cm}$ de long, $12-15 \mathrm{~cm}$ de diamètre au sommet. Ovaire globuleux, $2.5 \mathrm{~cm}$ de diamètre, muni d'écailles vert clair à sommet rosé, de $5 \mathrm{~mm}$ de long, couvertes d'un revêtement dense de poils laineux bruns et noirs, tube de $2 \mathrm{~cm}$ de long, légèrement incurvé brun clair, à écailles rosées de $6 \mathrm{~mm}$ de long, couvertes d'un épais revêtement de poils bruns et noirs; écailles de la partie supérieure du tube, $12 \mathrm{~mm}$ de long, très acuminées, vert pourpre. Segments extérieurs du périanthe, $30 \times 15 \mathrm{~mm}$, lancéolés, pourpre, vert foncé au centre ; segments médians, $55 \times 20 \mathrm{~mm}$; segments intérieurs larges. spathulés, $65 \times 45 \mathrm{~mm}$, arrondis à la partie supérieure, blancs. Etamines disposées sur 2 rangs, les plus inférieures prenant naissance à $1 \mathrm{~cm}$ au-dessus de la base du tube, et aboutissant à $1,5 \mathrm{~cm}$ au-dessous de la gorge, environ $6 \mathrm{~cm}$ de long; les supérieures, $3,5 \mathrm{~cm}$ de long, vertes inférieurement, blanches à la partie supérieure ; anthères jaunes à brunâtres. Style, $10 \mathrm{~cm}$ de long, $3 \mathrm{~mm}$ d'épaisseur, vert clair à la partie inférieure, blanc à la partie supérieure. Lobes du stigmate 18 , larges, jaunâtres, $18 \mathrm{~mm}$ de long.

Fruit globuleux, $4 \mathrm{~cm}$ de haut, $5 \mathrm{~cm}$ de diamètre, vert foncé, parfois teinté de pourpre foncé. Ecailles supérieures du fruit, 1,5-2 cm de long, acuminées; les inférieures larges, $8 \mathrm{~mm}$ de long. Toutes les écailles sont densément pourvues de poils courts brun foncé à noirâtres et de quelques poils blancs. Toute la base du fruit est couverte de poils. Pulpe blanche ou jaunâtre, comestible. Graines, 1,5-2 $\mathrm{mm}$ de long, finement ponctuées, brilrantes.

\section{Origine :}

Bolivie: Mont Tunari, département de Cochabamba, province de Cercado, entre Yurac Kkasa et San Miguel, $3.800 \mathrm{~m}$, février 1958. M. Cardesse, No 5499 (type) in Herbarium Cardenasianum. Cotype in the U.S. Nat. Herb. Smithsonian Institution, Washington.

\section{Observation :}

Ce Trichocereus du groupe des pasacanoïes rappelle Trichocereus herzogianus Card. var. totorensis Card., mais en diffère par ses côtes peu saillantes et moins nombreuses, ses aiguillons plus minces et son style plus court par rapport aux étamines supérieures. La Cactée colonnaire à aiguillons aciculaires rencontrée sur la route de Sacaba à Colomi a une altitude relativement basse se rapproche également de cette espèce.

Distribución y hábitat: Ha sido descrita para el departamento de Cochabamba, Provincia Cercado, entre Yurac Kkasa y San Miguel (Fig. 74), en el monte Tunari a 3800 m. Biogeográficamente se localiza en la prepuna (Cabrera \& Willink 1980, Albesiano 2014). 


\section{Comentarios morfológicos y sus consecuencias en la taxonomía y nomenclatura: No se}

encuentra el isotipo de $T$. tunariensis en el herbario del Instituto Smithsonian (http://collections.mnh.si.edu/search/botany/?v=s1), como ha sido mencionado en la publicación original.

Eggli y Leuenberger (2005) advierten lo siguiente:

i- En la etiqueta del holotipo aparece enero de 1956 como fecha de recolección, mientras que en el protólogo se indica febrero de 1958

ii- El holotipo presenta dos fotografías cuyas plantas tienen entre 14 a 16 costillas, y el material herborizado entre 22-24 costillas.

Según Cárdenas (1959), esta especie difiere de Trichocereus herzogianus por el menor diámetro de las ramas $(12 \mathrm{~cm}$ vs. $22 \mathrm{~cm})$, espinas no diferenciadas en radiales ni centrales, flores largas $(15-17 \mathrm{~cm}$ vs. $10-13 \mathrm{~cm})$ y por el color de los tépalos internos (blancos vs. fucsia) (Fig. 53).

Material de Herbario estudiado: Bolivia, Dpto. Cochabamba, Prov. Cercado, Monte Tunari, in itineri Yurac Kkasa-San Miguel, 3800 m, Feb. 1958, M. Cárdenas 5499

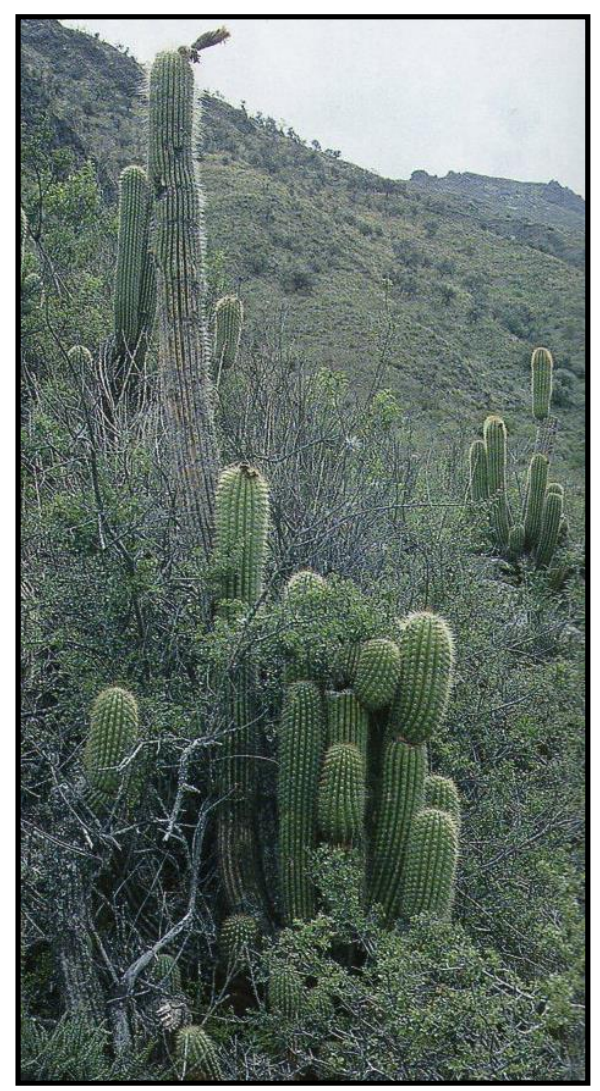
(LIL).

Figura 53. Trichocereus tunariensis. Foto Hunt et al. (2006): 238.

53. Trichocereus undulosus S. Albesiano, Haseltonia 18: 136, ill. 2012.

TIPO: Chile, IV Región de Coquimbo, Provincia Limarí, Peña Blanca, 3048'32"S; 71034'29”W, 359 m, 6 Nov. 2008, S. Albesiano, L. Faúndez, R. Flores \& P. Saldivia 2051 (Holotipo, MERL!; Isotipo, AGUCH!).

Iconografía: Albesiano (2012), foto 16: 136.

Descripción original de Trichocereus undulosus S. Albesiano.

Planta arborea, $2.5 \mathrm{~m}$ altae, ramificatae ex trunci $11 \mathrm{~cm}$ diametri. Ramae atrovirentes, erectae, $15 \mathrm{~cm}$ diametri. Costae 20, obtusae, $2 \mathrm{~cm}$ latae et $1 \mathrm{~cm}$ altae. Costae versantur separatae per sulcos acutos et ondulatos. Forma ondulata debetur quem costae sunt crassiores altitudinem areolae et qui areoles costarum vicinarum alternantur. Spinae rigidae, aciculae et atrovirentes; centrales 4, diametri $2 \mathrm{~mm}$ et $3.5 \mathrm{~cm}$ longae, radiales 12, diametri 0,5-1 $\mathrm{mm}, 1.5 \mathrm{~cm}$ longae. Flores subapicalis, infundibuliformes, $13 \mathrm{~cm}$ longae, ovarius $2.5 \mathrm{~cm}$ diametri et tubus floral cum copiosis pilis (pelos) cinereis, tepali albi cum apice brunneo. Fructus virides, $3 \mathrm{~cm}$ latae et 2.5 longae, cum copiosis pilis cinereis. Semina nigra. 
Descripción ampliada: Plantas de 2,5 m de alto, tallo principal de $11 \mathrm{~cm}$ de diámetro. Ramas verde-oscuro, $15 \mathrm{~cm}$ de diámetro. Costillas del ápice 20, obtusas y tuberculadas; areolas obovadas, $2 \mathrm{~mm}$ de alto, $8 \mathrm{~mm}$ de diámetro. Espinas centrales 3, de $4 \mathrm{~cm}$ de largo, $1 \mathrm{~mm}$ de diámetro en las areolas del ápice y $2 \mathrm{~mm}$ de diámetro en las areolas subapicales, blancas con manchas marrones. Espinas radiales aciculares, 12, de $1 \mathrm{~cm}$ de largo, 8-10 mm de ancho, blancas con manchas marrones. Costillas de la base 20, obtusas, tuberculadas, $2 \mathrm{~cm}$ de gruesas, $1 \mathrm{~cm}$ de alto; areolas obovadas, $2 \mathrm{~mm}$ de alto, $8 \mathrm{~mm}$ de diámetro, con pilosidad gris. Espinas centrales 4, aciculares, $2 \mathrm{~mm}$ de ancho, 2-4 cm de largo, verdeoscuro. Espinas radiales 12, aciculares, 1,5 cm de largo, 0,5-1,0 mm de diámetro, verde-oscuro. Flores 310, subapicales, $13 \mathrm{~cm}$ de largo, $6 \mathrm{~cm}$ de diámetro, ovario $2,5 \mathrm{~cm}$ de diametro, escamas florales intermedias de $2 \mathrm{~cm}$ de largo, verdes y con una línea marrón al medio y de cuyas axilas emergen abundantes pelos grises; tépalos $6 \mathrm{~cm}$ de longitud, blancos con una línea marrón en el centro; estilo $8 \mathrm{~cm}$ de extensión; lóbulos del estigma de $1 \mathrm{~cm}$ de largo. Pseudobayas con parte externa verde y cavidad ovárica con funículos blancos, $3 \mathrm{~cm}$ de diámetro, $2,5 \mathrm{~cm}$ de largo, recubierto por escamas subuladas, de cuyas axilas nacen pelos grises. Semillas negras (Fig. 54).

Etimología: El epíteto hace referencia a la forma de la costilla; notablemente ondulada, dando la apariencia de ser tuberculada.

Distribución y hábitat: Especie que crece en Chile, en la Región de Coquimbo, a $400 \mathrm{~m}$ de altitud (Fig. 75B), en matorrales bajos de Puya sp. y sobre roquedales.

Comentarios morfológicos y sus consecuencias en la taxonomía y nomenclatura: $T$. undulosus y $T$. skottsbergii se asemejan por la forma tuberculada de las costillas, pero a su vez presentan caracteres que permiten distinguirlas (Tabla 15):

Tabla 15. Diferencias entre $T$. undulosus y $T$. skottsbergii.

\begin{tabular}{|l|l|l|}
\hline CARACTERES & \multicolumn{1}{|c|}{ T. undulosus } & \multicolumn{1}{|c|}{ T. skottsbergii } \\
\hline Color de las ramas & Verde-oscuro & Verde-grisáceo \\
\hline No. de costillas & 20 & $12-17$ \\
\hline Espinas del ápice & Gruesas (1 mm) y rígidas & $\begin{array}{l}\text { Delgadas (menor de 0,5 mm) y } \\
\text { flexibles (cerdosas) }\end{array}$ \\
\hline Color de las espinas del ápice & $\begin{array}{l}\text { Blancas con manchas } \\
\text { marrones }\end{array}$ & $\begin{array}{l}\text { Grises con pocos puntos negros y } \\
\text { puntas marrón. }\end{array}$ \\
\hline $\begin{array}{l}\text { Grosor y largo espinas centrales } \\
\text { adultas }\end{array}$ & $2 \mathrm{~mm}$ y 3,5 cm de longitud & $1,5 \mathrm{~mm}$ y $7 \mathrm{~cm}$ de largo \\
\hline
\end{tabular}




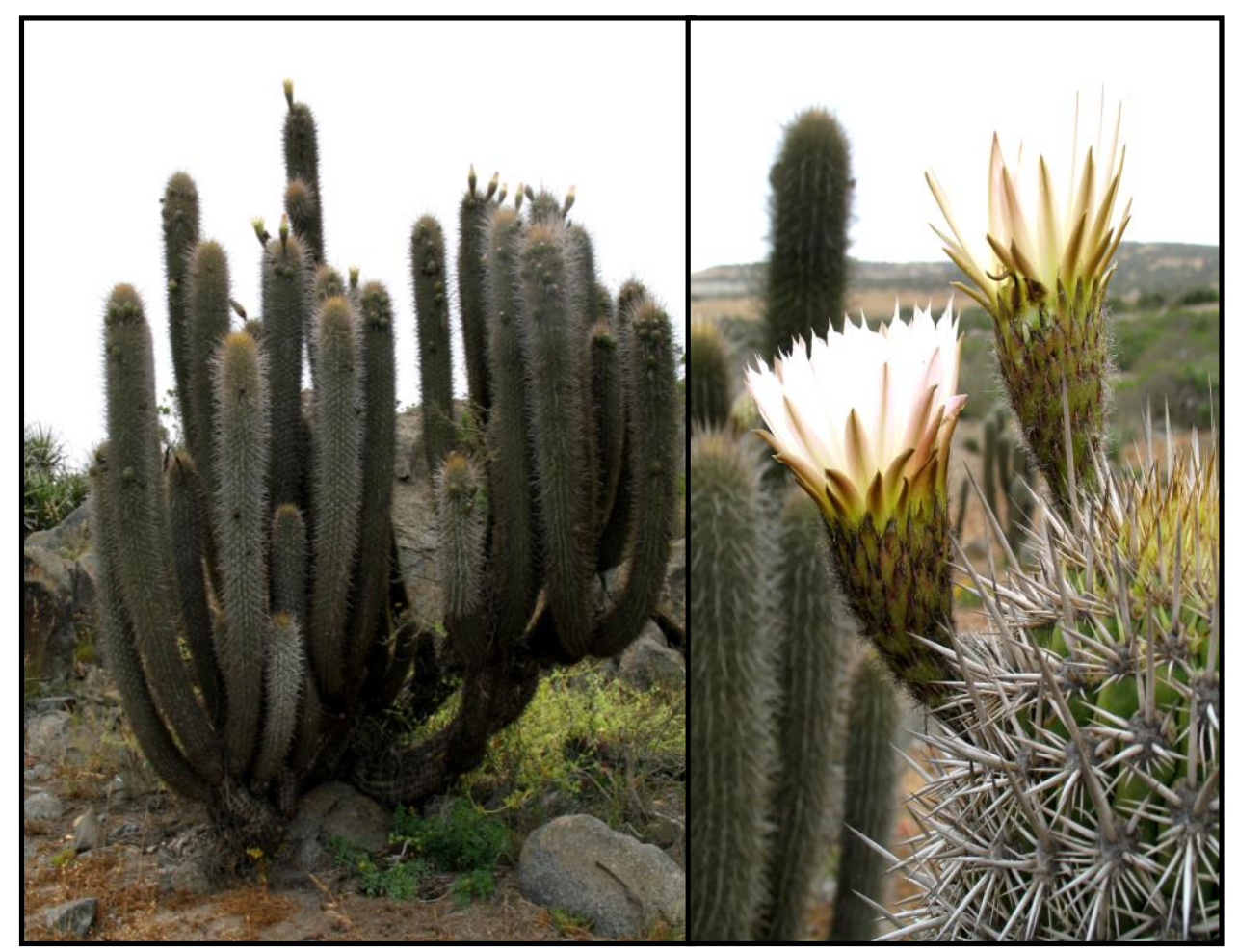
Blanca.

Figura 54. Trichocereus undulosus. Chile, IV Región de Coquimbo, Provincia Limarí, Peña

Material de Herbario estudiado: Chile, IV Región de Coquimbo, Provincia Limarí, Peña Blanca, 3048'32"S; 71³4'29"W, 359 m, 6 Nov. 2008, S. Albesiano, L. Faúndez, R. Flores \& P. Saldivia 2051 (MERL; AGUCH).

54. Trichocereus uyupampensis Backeb., en Backeb. \& F.M. Knuth, Kaktus-ABC: 412 (205). (“1935”) 1936.

Trichocereus uyupampensis Backeb., Blätt. Kakteenf.: 7. 1935, nom. nud, nom. inval., falta la diagnosis en latín (Art. 39.1). Tipo no designado. Echinopsis uyupampensis (Backeb.) H. Friedrich \& G.D. Rowley, I.O.S. Bull. 3(3): 99. 1974. Tipo no designado. TIPO: Foto: 1194 (Neotipo, aquí designado: Ritter. Kakteen Südamerika 4: 1553. 1981).

Trichocereus glaucus F. Ritter, Kakt. And. Sukkulent. 13: 180, ill. 1962. Echinopsis glauca (F. Ritter) H. Friedrich \& G.D. Rowley, I.O.S. Bull. 3 (3): 95. 1974. TIPO: Al sur de Perú, río Tambo, Julio 1954, F. Ritter 270 (Holotipo, U 117004!).

Trichocereus glaucus F. Ritter f. pendens F. Ritter, Kakt. And. Sukkulent. 13: 181. 1962, nom. inval., por no designar tipo (Art. 40.1). Trichocereus glaucus F. Ritter var. pendens (F. Ritter) Backeb., Kakteenlex. 437. 1966, comb. inval., se basa en un nombre inválido. Echinopsis glauca (F. Ritter) H. 
Friedrich \& G.D. Rowley f. pendens (F. Ritter) H. Friedrich \& G.D. Rowley, I.O.S. Bull. 3 (3): 95. 1974, comb. inval., se basa en un nombre inválido.

Iconografía: Ritter (1980b), foto 1078: 1225.

Descripción original de Trichocereus uyupampensis Backeb., en Backeb. \& F.M. Knuth, Kaktus-ABC: 412 (205). (“1935”) 1936.

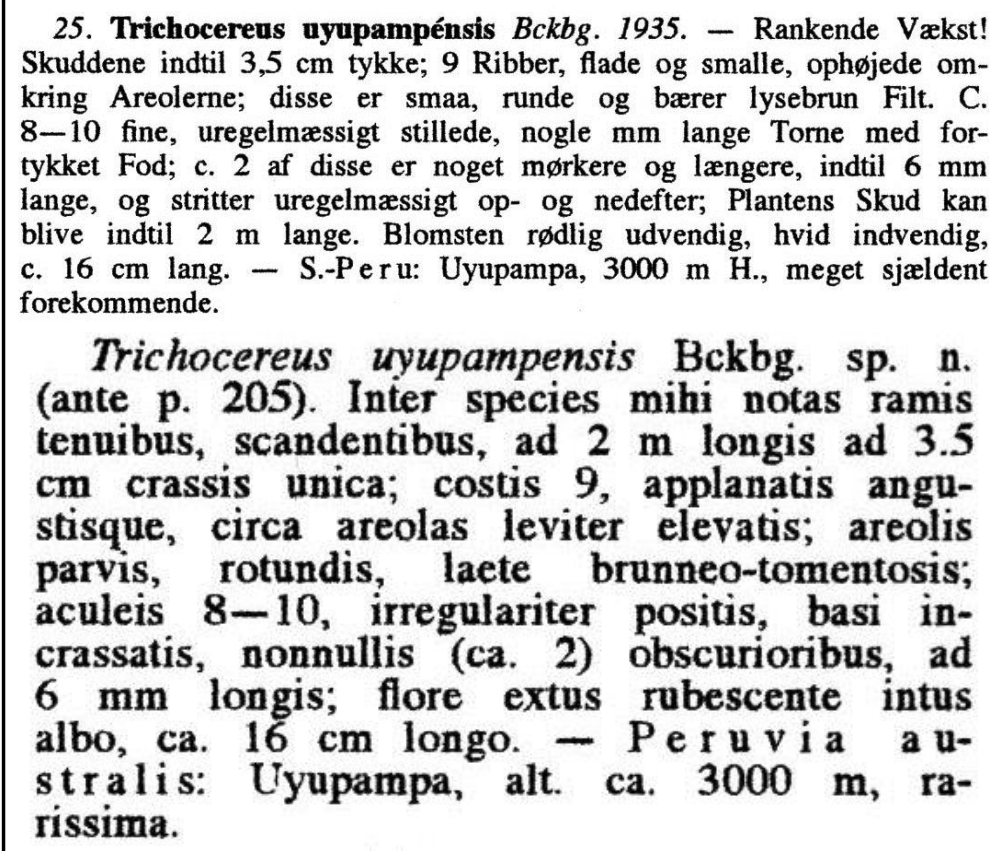

Descripción ampliada: Plantas rastreras, tallos ramificados desde la base, arbustivas. Ramas decumbentes o péndulas, 1-2 $\mathrm{m}$ de largo, 4-8 cm de diámetro, tallos jóvenes verde-opacos, tornándose gris-verdoso con la edad. Costillas 7-9, crenadas, $2,5 \mathrm{~cm}$ de ancho, 7,5-12,5 mm de alto. Areolas grises 0 marrón-claro, redondas, 5,0-7,5 mm de diámetro, 1-2 cm de separación entre ellas. Espinas del ápice negras a marrones, espinas de la parte media y baja de los tallos grises; espinas radiales 7-10, rígidas, fuertes, aciculares, 2-15 mm de largo, espinas centrales 3-6, sobresalientes, rectas, subuladas, 1,5 mm de diámetro, 2-8 cm de largo. Flores 13-19 cm de largo, abren en la tarde 0 en la noche, aromáticas; receptáculo con escamas de 2-5 mm de largo, subuladas, carnosas, verdes, provistas de pelos marrónoscuro; cámara nectarial 3-4 mm de diámetro, tubular, 13-23 mm de largo; tubo floral de 4,0-6,5 cm de largo, 2-3 cm de ancho en la parte superior, internamente blanco-verdoso, externamente verde-grisáceo, provisto de pelos (como en el receptáculo), escamas subuladas, de más de $1 \mathrm{~cm}$ de largo, verde-oscuro; estambres blancos, verdes en la parte inferior, insertos $2-3 \mathrm{~cm}$ de la base del tubo, extendiéndose hasta la parte superior donde finalizan, estilo 1-2 mm de ancho, verde-pálido, ápice blanco algunas veces marrón, 10-11 cm de largo, de los cuales 14-18 mm corresponden a los lóbulos del estigma, cuyo número 
varía de 13 a 16, amarillo-blancuzco; tépalos 5-8 cm de largo, 1-2 cm de ancho, ápice serrado o liso rematando en un mucrón, la base es $2 / 3$ a $3 / 4$ de estrecha, los tépalos exteriores son más cortos, con forma de espátula y el ápice remata en una punta; tépalos interiores blancos o algo rosados. Pseudobaya verde-oscuro, $4 \mathrm{~cm}$ de largo, $3 \mathrm{~cm}$ de diámetro, ápice romo, cavidad ovárica con funículos blancos. Semillas de 1,2 mm de largo, $1 \mathrm{~mm}$ de ancho, 0,6 mm de espesor, testa negra brillante, región hilomicropilar en la parte basal oval, negruzca (Fig. 55) (Ritter 1962, 1980b, Backeberg 1976).

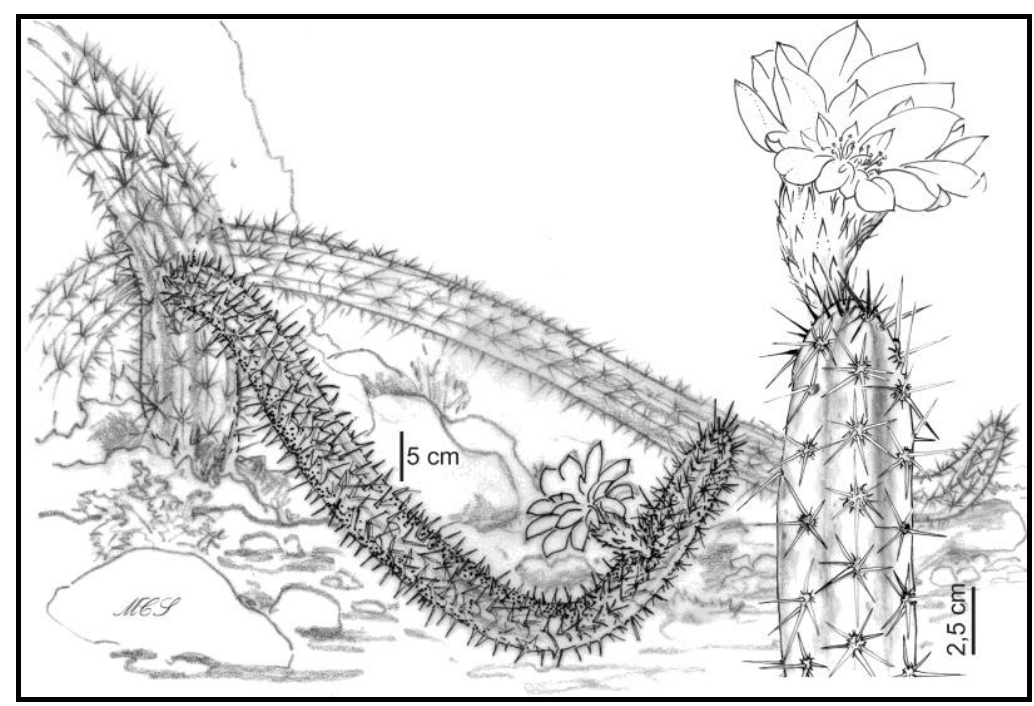

Figura 55. Trichocereus uyupampensis localizada al sur de Perú, Dpto. de Arequipa.

Distribución y Hábitat: Al sur de Perú, Dpto. de Arequipa (Fig. 76), en las montañas de la parte baja del río Tambo y en Dpto. de Monquegua, región de llo. En el norte de Chile, XV Región de Arica y Parinacota, Prov. Arica, al sur de Arica (Fig. 75B), en los acantilados cercanos a la costa, entre 400-600 m (Backeberg 1976, Anderson 2005, Kiesling et al. 2008).

\section{Comentarios morfológicos y sus consecuencias en la taxonomía y nomenclatura:} Backeberg (1935) mencionó a Trichocereus uyupampensis como un nomen nudum cuando describió la vegetación presente en la región árida del sur del Perú. Meses después Backeberg ([“1935”] 1936) publica la diagnosis y la descripción de esta especie, pero sin designar un holotipo, y por tanto se designa como Neotipo a la foto 1194, publicada por Ritter (1981).

Backeberg (1976) propone a T. glaucus como una variedad de T. uyupampensis, pero se encontraron bastantes caracteres morfológicos en común (forma de crecimiento, diámetro de los tallos, número de costillas, número y forma de las espinas radiales, entre otros), por lo que aquí se propone reunirlos.

Ritter (1962) propone la forma pendens, la cual se destaca solamente por los tallos péndulos, y se localiza al sur de la región de Arica en Chile. Se considera que la forma del crecimiento de los tallos, se debe al hábitat donde crece la especie, ya sea en los paredones rocosos cercanos a la costa (hábito 
péndulo) o hacia el interior, en las montañas que circundan los ríos (hábito erecto), y por tal razón, se propone ampliar el concepto morfológico de $T$. glaucus.

Por otra parte, Ritter no publicó validamente el nombre T. glaucus f. pendens, debido a que no designó un ejemplar tipo, según el Art. 40.1 del Código Internacional de Nomenclatura para algas, hongos y plantas (McNeill et al. 2012), y por consiguiente la combinación Echinopsis glauca f. pendens es inválida.

55. Trichocereus vasquezii Rausch, Kakt. And. Sukk., 25(9): 193, ill. 1974.

Echinopsis vasquezii (Rausch) G.D. Rowley, Repert. Pl. Succ. 24: 6. 1975. Tipo: Rausch 619 (Holotipo, W perdido). TIPO: Bolivia, Dpto. Santa Cruz, Prov. Caballero, 0,5 Km W of bridge over Rio Comarapa at Comarapa, along highway to Cochabamaba, 17055'S; 64033'W, 1825 m, 24 Nov. 1999, M. Nee 50596 (Neotipo, LPB, aquí designado).

Echinopsis serpentina M. Lowry \& M. Mend., Cactus World 29 (2): 95, ill. 2011. Trichocereus serpentinus (M. Lowry \& M. Mend.) Guiggi, Cactology 3 (Suppl. II): 5. 2012. TIPO: Bolivia, Dpto. La Paz, Prov. Muñecas, Camata, bellow the village along a bridle path on the road from Charazani to Apolo, 10 Nov. 2008, M. Mendoza 3369 (Holotipo, USZ; Isotipos K, LPB).

Iconografías: Rausch (1974): 193-194. Lowry \& Mendoza (2011), fotos 8-10: 96-97.

Descripción original de Trichocereus vasquezii Rausch, Kakt. And. Sukk., 25(9): 193. 1974:

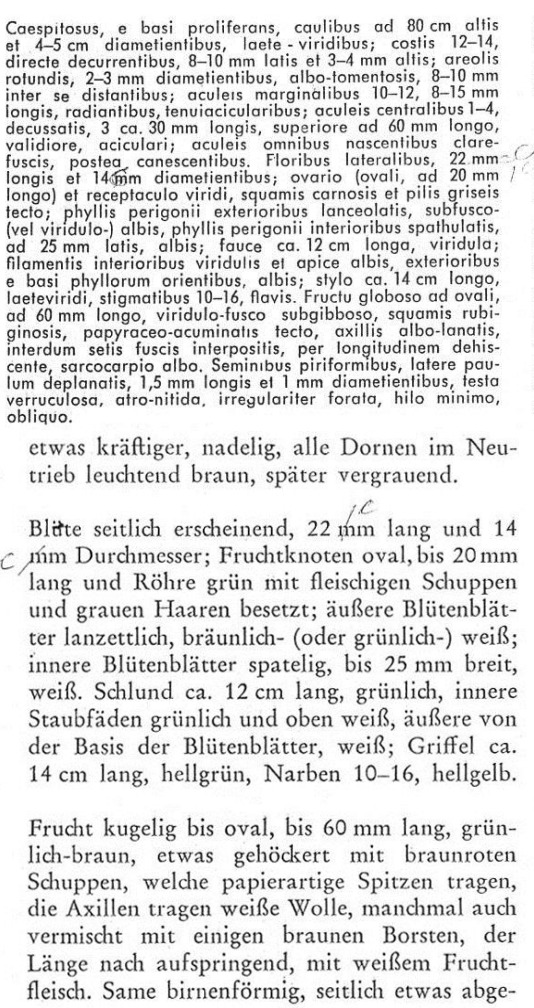

Patria: Bolivia, secundum viam Pojo-Comarapa (Catalinas),

Typus: Rausch 619 ir. Herbario Musei Historiae Naturalis -

Gruppenbildend, von der Basis aus sprossend; Triebe bis $80 \mathrm{~cm}$ hoch und $4-5 \mathrm{~cm}$ Durchmesser, frischgrün; Rippen 12-14, senkrecht herablaufend, $8-10 \mathrm{~mm}$ breit und $3-4 \mathrm{~mm}$ hoch; Areolen rund, 2-3 mm Durchmesser, weißfilzig, 8 bis $10 \mathrm{~mm}$ voneinander entfernt; Randdornen $10-12,8-15 \mathrm{~mm}$ lang, strahlend, dünn-nadelig; Mitteldornen 1-4, im Kreuz stehend, 3 davon ca. $30 \mathrm{~mm}$ lang und der obere bis $60 \mathrm{~mm}$ lang,

flacht, 1,5 mm lang und $1 \mathrm{~mm}$ Durchmesser, mit kleinwarziger, schwarzglänzender Testa, die unregelmäßig mit Löchern versehen ist, der $\mathrm{Na}$ bel ist sehr klein und schief.

Heimat: Bolivien, an der Straße Pojo-Comarapa (Catalinas) auf $2.400 \mathrm{~m}$.

Typus: Rausch 619 im Herbarium des Naturhistorischen Museums der Stadt Wien.

Jeder Kakteensammler würde diesen kleinen, buntbestachelten Trichocereus ohne Blüte und Frucht für einen Cleistocactus halten. Wie groß war die Überraschung, als Roberto Vasquez 1968 erstmalig Trichocereen-Früchte an den Pflanzen finden konnte und somit eine Klassifikation möglich machte. 
Descripción ampliada: Plantas bajas $(80-100 \mathrm{~cm})$, ascendentes, decumbentes o con los ápices reclinados. Ramas originadas a nivel del suelo, $4-5 \mathrm{~cm}$ de diámetro, verde-brillante. Costillas 9-14, de 8 a $10 \mathrm{~mm}$ de ancho, 3-6 mm de alto. Areolas del ápice circulares, 2,0-4,5 mm de diámetro, $2 \mathrm{~mm}$ de alto, 8$10 \mathrm{~mm}$ de separación entre las areolas, con pilosidad amarilla; espina central 1, amarilla, 1,4 cm de largo; espinas radiales 9 , vino-tinto claro con ápice marrón, $7 \mathrm{~mm}$ de largo. Areolas de la base $\underline{\underline{b m}} 1 \mathrm{~mm}$ de alto, $4 \mathrm{~mm}$ de diámetro, con tomento gris en la base y parte media de la areola, ápice amarillo; espinas centrales 2-3, amarillas en la base y parte intermedia, negro en el ápice, 1,7 cm de largo, 0,8 cm de diámetro; espinas radiales 5-12, amarillas con ápice negro, 0,8-1,5 cm de largo. Flores laterales, $22 \mathrm{~cm}$ de largo, ovario $2 \mathrm{~cm}$ de diámetro, tubo floral $4 \mathrm{~mm}$ de diam., con escamas verdes de cuyas axilas surgen pelos grisáceos, corola $6 \mathrm{~cm}$ de diámetro (cuando abiertas), estilo $13 \mathrm{~cm}$ de largo; tépalos externos lanceolados, morado-marrón, los intermedios rosado, los internos espatulados, blancos; estambres blanco-crema, lóbulos del estigma amarillo-verdoso. Pseudobaya recubierta de pelos marrones. Semillas piriformes, aplanadas de costado, 1,5 $\mathrm{mm}$ de largo, $1 \mathrm{~mm}$ de diámetro, con testa verrugosa, negra, brillante, con perforaciones irregulares e hilo pequeño y oblicuo (Fig. 56).

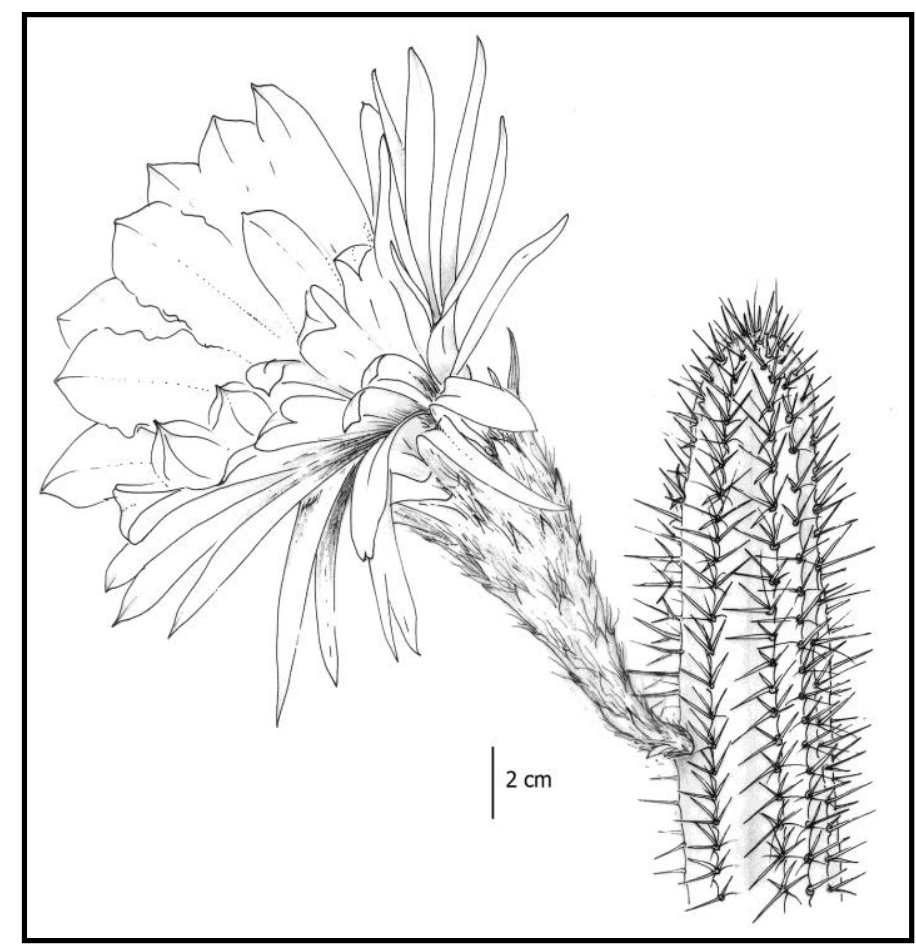

Figura 56. Trichocereus vasquezii. Bolivia, Dpto. Santa Cruz.

Distribución y hábitat: Trichocereus vasquezii se distribuye en las regiones semiáridas de los departamentos de Cochabamba y Santa Cruz en Bolivia, entre 1800 a 2500 m (Fig. 74) (Albesiano 2014).

Comentarios taxonómicos y nomenclaturales: En la descripción original (Rausch 1974), las medidas correspondientes a la longitud de las flores, diámetro y largo de los frutos son dudosas. 
En una comunicación enviada por Armin Löckher, investigador asociado al herbario W (ViennaAustria), informa que el ejemplar tipo: Rausch 619 no existe en esta institución, como aparece citada en Rausch (1974), por lo tanto se designa un Neotipo, M. Nee 50596 (LPB), el cual reúne las características mencionadas en la descripción original. Según Kiesling (com. pers.) W. Rausch en sus primeros años acostumbraba a describir taxones de cactáceas y posteriormente depositaba en ese museo una copia de la publicación y un ejemplar vivo. El personal del Museo trataba de cultivar ese ejemplar, para herborizarlo cuando floreciera, pero gran parte de ese material se perdió por falta de instalaciones adecuadas para su cultivo. Años despues, el mismo autor efectuaba el mismo procedimiento con el Jardín de Suculentas de Zurich, donde sí hay instalaciones adecuadas y mayormente preservaron material para herbario con parte del material vivo, cuando florecía.

Material de Herbario estudiado: Bolivia, Dpto. Santa Cruz, Prov. Caballero, 0,5 Km W of bridge over Rio Comarapa at Comarapa, along highway to Cochabamaba, 17055'S; 643'W, 1825 m, 24 Nov. 1999, M. Nee 50596 (LPB)

56. Trichocereus vollianus Backeb., en Backeb. \& F.M. Knuth, Kaktus-ABC: 412 (205). ("1935”) 1936.

Trichocereus vollianus Backeb., Blätt. Kakteenf.: 9. 1935, nom. nud., nom. inval., falta la diagnosis en latín (Art. 39.1). Tipo no designado. Echinopsis volliana (Backeb.) H. Friedrich \& G.D. Rowley, I.O.S. Bull. 3(3): 99. 1974. TIPO: Bolivia, Dpto. Tarija, Prov. Cercado, Santa Ana de la Nueva, 1929 m, 19 Dic. 2009, S. Albesiano, N. Muruaga, A. Alaria \& R. Paz 2081 (Neotipo, MERL, aquí designado).

Trichocereus vollianus Backeb. var. rubrispinus Backeb., en Backeb. \& F.M. Knuth, Kaktus-ABC: 412 (206). (1935) 1936. Tipo no designado. TIPO: Bolivia, Dpto. Chuquisaca, Prov. Oropeza, camino a Yotala, 2628 m, 14 Dic. 2009, S. Albesiano, N. Muruaga, A. Alaria \& R. Paz 2075 (Neotipo, MERL; Isoneotipo LIL, aquí designados).

Iconografías: Hunt et al. (2006), figs. 1-2: 239. 
Descripción original de Trichocereus vollianus Backeb., en Backeb. \& F.M. Knuth, Kaktus-ABC: 412 (205). (“1935”) 1936.

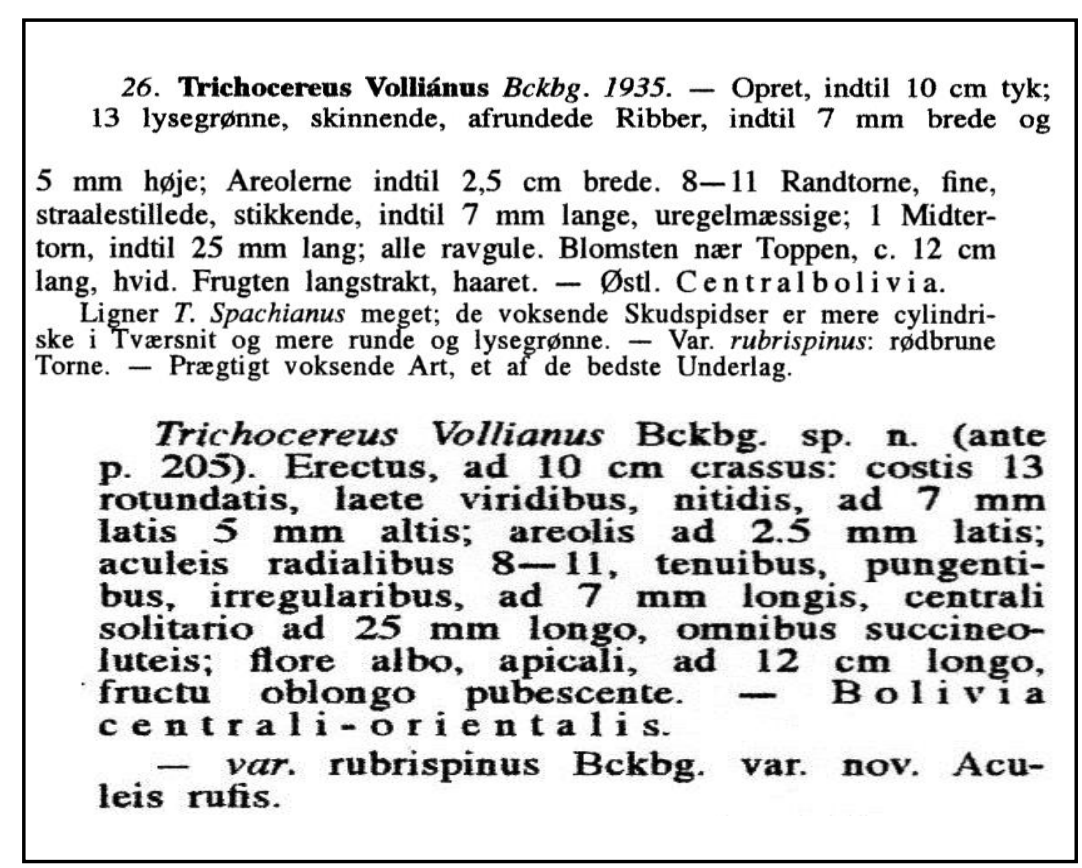

Descripción ampliada: Plantas erectas, ramificadas desde la base, de $80 \mathrm{~cm}$ a $1,40 \mathrm{~m}$ de alto. Ramas 8-11 cm de diámetro, epidermis verde-brillante. Costillas del ápice 13-17, obtusas, 7-8 mm de ancho, 4-5 mm de alto; areolas oblongas, $1 \mathrm{~mm}$ de alto, $5 \mathrm{~mm}$ de ancho, con pilosidad gris y/o amarilla; espinas centrales 1-3, aciculares, 1,5-4,0 cm de largo, punta marrón, base verde-claro o totalmente marrones, dispuestas perpendicularmente al tallo; espinas radiales 8-11, aciculares, 0,7-2,0 cm de largo, blanco-crema a gris o marrones. Costillas de la base 13-15, obtusas, 0,7-1,3 cm de ancho, 4-5 mm de alto; areolas circulares u oblongas, $1 \mathrm{~mm}$ de alto, $4 \mathrm{~mm}$ de ancho, grises o negras, 2,5 $\mathrm{cm}$ de separación entre las areolas; espinas centrales 0-3, aciculares, 2,5-3,0 cm de largo, amarillo-crema o gris, dispuestas perpendicularmente al tallo, algunas con el ápice ligeramente curvado; espinas radiales 7-14, aciculares, 0,7-1,3 cm de largo, gris-claro o grises con ápice marrón y dispuestas casi que paralelamente al tallo. Flores apicales y subapicales, $12-23 \mathrm{~cm}$ de largo, con abundante pilosidad blanco-crema con algunos pelos marrón en el ovario y tubo floral; corola de $12-24 \mathrm{~cm}$ de diámetro (cuando abiertas); ovario $2,5 \mathrm{~cm}$ de ancho; tubo floral de 3,0-3,5 cm de diámetro; escamas florales del ovario 1,0-4,5 cm de largo, verdeoscuro o marrón; escamas florales del tubo 4,5-8,0 cm de largo, verde-oscuro o verdes con líneas marrones; tépalos 8,5-14 cm de longitud, blancos; estilo verde-claro, $11,5-20 \mathrm{~cm}$ de largo; lóbulos del estigma amarillos, $2 \mathrm{~cm}$ de longitud. Pseudobaya umbilicada, pilosa (Fig. 57).

Distribución y hábitat: Se localiza en Bolivia, en las regiones semiáridas de los departamentos de Cochabamba, Chuquisaca, La Paz, Santa Cruz y Tarija (Fig. 74), entre 1900 a 3500 m, sobre laderas 
con vegetación de arbustos bajos, que no sobrepasan los $2 \mathrm{~m}$ de alto, además de presentarse sectores desprovistos de vegetación por la acción del hombre (Albesiano 2014).

Comentarios taxonómicos y nomenclaturales: Trichocereus vollianus fue mencionado por Backeberg (1935) cuando describía la vegetación presente en la regiones áridas de Chile, Bolivia y la Patagonia, sin proporcionar una diagnosis en latín para esta especie, por lo que este nombre es inválido según el artículo 39.1 del Código Internacional de Nomenclatura para algas, hongos y plantas (McNeill et al. 2012), meses después Backeberg ([“1935”] 1936) publica la diagnosis y la descripción ampliada de Trichocereus vollianus.

Se seleccionó el ejemplar S. Albesiano et al. 2081 (MERL) como Neotipo de Trichocereus vollianus, por ser el más cercano a las características mencionadas en la descripción original. El ejemplar consta de cortes longitudinales y transversales de tallo y flor, permitiendo reconocer las características vegetativas y reproductivas de las costillas, espinas y flores.

Se eligió como Neotipo de Trichocereus vollianus var. rubrispinus el ejemplar S. Albesiano et al. 2075 (MERL), porque reúne las características mencionadas en la descripción original.

Material de Herbario estudiado: Bolivia, Dpto. Chuquisaca, Prov. Oropeza, camino a Yotala, 2628 m, 14 Dic. 2009, S. Albesiano et al. 2075 (MERL; LIL). Dpto. Tarija, Prov. Cercado, Santa Ana de la Nueva, 1929 m, 19 Dic. 2009, S. Albesiano et al. 2081 (MERL).

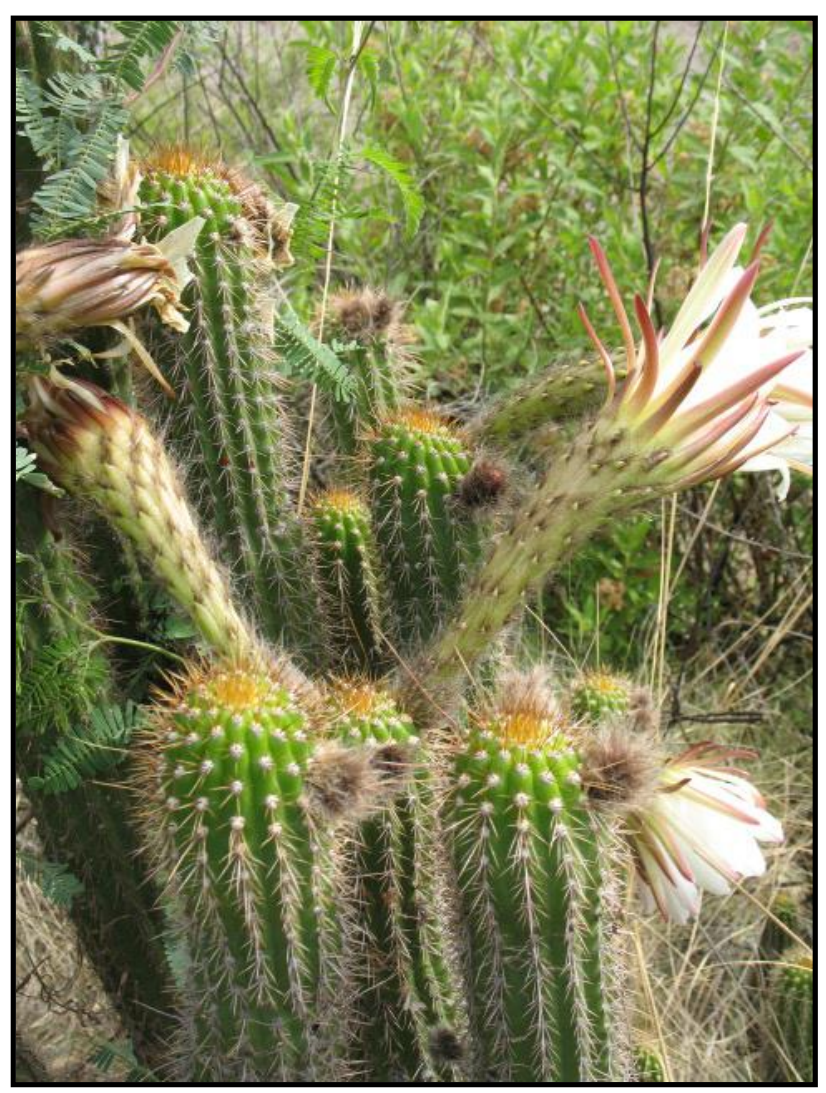

Figura 57. Trichocereus vollianus. Bolivia, Dpto. Chuquisaca, Prov. Oropeza, camino a Yotala. 
57. Trichocereus werdermannianus Backeb., en Backeb. \& F.M. Knuth, Kaktus-ABC: 412 (206). (“1935”) 1936.

Trichocereus werdermannianus Backeb., Blätt. Kakteenf.: 9. 1935, nom. nud., nom. inval., falta la diagnosis en latín (Art. 39.1). Tipo no designado. Echinopsis werdermanniana (Backeb.) H. Friedrich \& G.D. Rowley, I.O.S. Bull. 3(3): 99. 1974. Leucostele werdermanniana (Backeb.) Schlumpb., Cactaceae Syst. Init. 28: 30. 2012. TIPO: Bolivia, Dpto. de Potosí, Prov. Nor Chichas, San Antonio, Quechisla, 3000 m, Dic. 1946, M. Cárdenas 5014 (Neotipo, LIL, aquí designado).

Iconografías: Backeberg \& Knuth ([“1935”] 1936): 21. Hunt et al. (2006), fig. 3: 239.

Descripción original de Trichocereus werdermannianus Backeb., en Backeb. \& F.M. Knuth, Kaktus-ABC: 412 (206). (“1935”) 1936.

27. Trichocereus Werdermanniánus Bckbg. 1935. - Danner mægtige, træformede Eksemplarer. Stammen indtil $60 \mathrm{~cm}$ tyk, Kronen tæt; Skuddene indtil $16 \mathrm{~cm}$ tykke, først med 6 , senere flere Ribber, svarende til den forøgede Tykkelse. Areolerne med hvid Filt. 8 Randtorne; 1 Midtertorn, længere, kraftig, sylformet, dens Fod mørkere; Tornene straagule. Blomsten hvid. - S.-B olivia: i Dale i c. 3000 $\mathrm{m} \mathrm{H}$.

Af lignende Størrelse som T. pasacana, men med tykkere Skud og færre Torne. Billede S. 21.

b) Kortere, gule (og røde?) Blomster.

Trichocereus Werdermannianus Bckbg. sp. n. (ante p. 206). Arboreus, giganteus, trunco ad $60 \mathrm{~cm}$ crasso, apice ramis densis, erectis, ad $16 \mathrm{~cm}$ crassis coronato; costis ramorum primum 6 postea pluribus; areolis albo-tomentosis; aculeis marginalibus 8 , stramineis, centrali solitario longiore, robusto, subulato, basi obscuro; flore albo. - B olivia a us $t r a \mathrm{l}$ i s, in vallibus, alt. $3000 \mathrm{~m}$.

Descripción ampliada: Plantas erectas, $5 \mathrm{~m}$ de alto, con un tallo principal de un metro de largo y 40-60 cm de diámetro. Ramas numerosas, más de cinco, $16-26 \mathrm{~cm}$ de diámetro, epidermis amarilloverdoso. Costillas del ápice 10-16, obtusas, $3 \mathrm{~cm}$ de ancho, $2 \mathrm{~cm}$ de alto; areolas circulares, $1 \mathrm{~mm}$ de alto, $5 \mathrm{~mm}$ de ancho, pilosidad gris; espinas 14 , aciculares, 1,5-2,5 cm de largo, algunas rectas otras curvas, dispuestas perpendicularmente al tallo, totalmente amarillas, otras con el ápice marrón, no hay diferencia entre espinas centrales y radiales. Costillas de la base 13-14, obtusas, $3 \mathrm{~cm}$ de ancho, 2,5 cm de alto; areolas circulares, $1 \mathrm{~mm}$ de alto, $5 \mathrm{~mm}$ de ancho, gris-oscuro a negras, 2,5 cm de separación entre las areolas; espinas $6 \mathrm{~cm}$ de largo, algunas rectas otras curvas, espinas centrales 1, negra, $7 \mathrm{~cm}$ de 
largo; espinas radiales 6 , negras, 1,3-5,0 cm de largo, subuladas, robustas, en algunas areolas no hay diferencia entre radiales y centrales, y otras carecen de espinas. Flores principalmente apicales y algunas subapicales, $20 \mathrm{~cm}$ de largo, con abundante pilosidad gris y marrón en el ovario y tubo floral; tépalos blancos. Pseudobaya de 3,5 cm de diámetro, piloso. Semillas de 1,3 cm de largo, rugosas (Fig. 58).

Distribución y hábitat: Endémica de Bolivia, se localiza en las regiones semiáridas de los departamentos de Potosí y Tarija, entre 2900 a 3700 m (Fig. 74), sobre laderas con vegetación de arbustos bajos (Albesiano 2014).

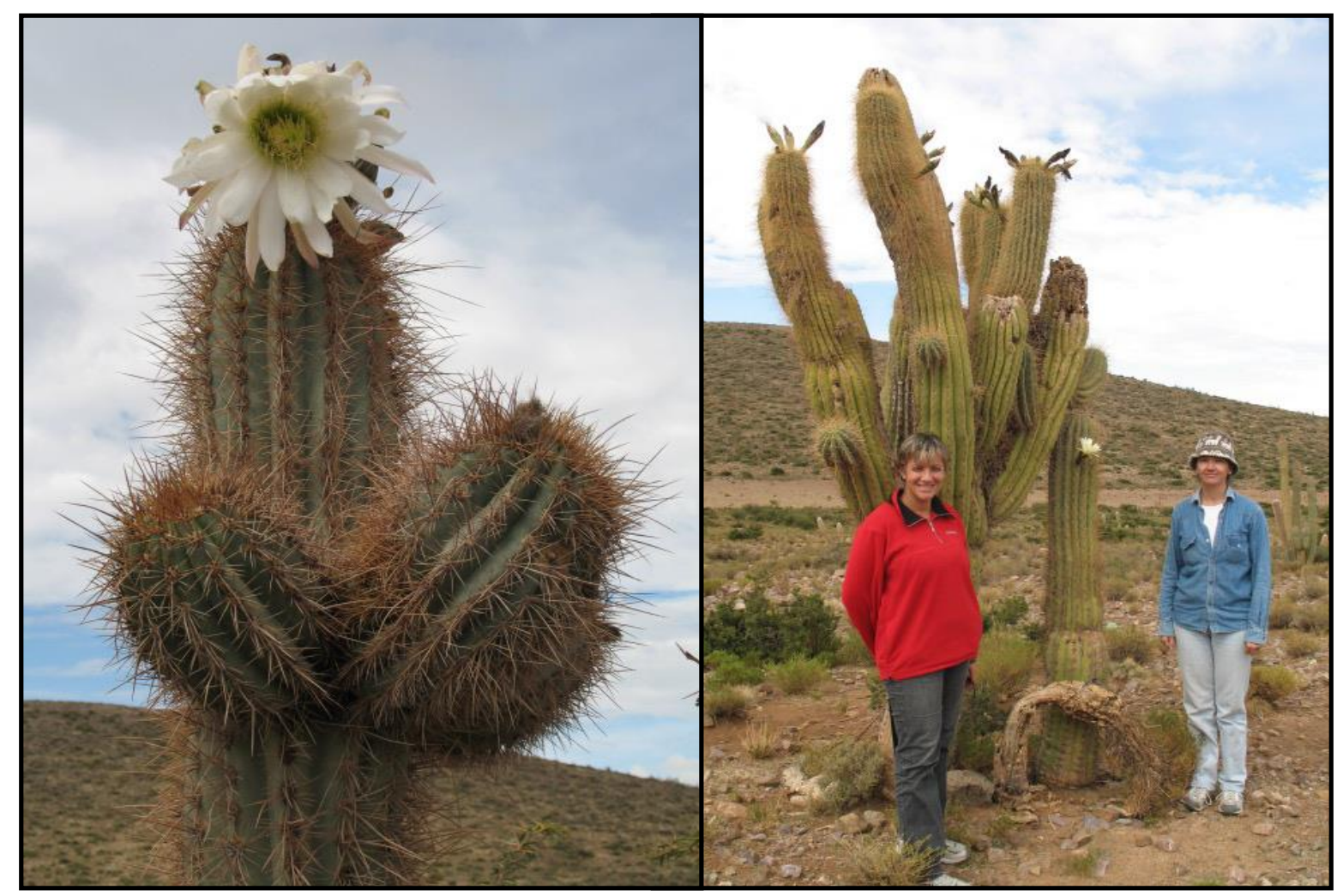

Figura 58. Trichocereus werdermannianus. Bolivia, Departamento Potosí, Provincia Nor Chichas, San Antonio, Quechisla.

\section{Comentarios morfológicos y sus consecuencias en la taxonomía y nomenclatura:}

Se seleccionó el ejemplar M. Cárdenas 5014 (LIL) como Neotipo de T. werdermannianus, por ser morfológicamente el más cercano a la descripción original. Consta de varios cortes transversales del tallo, apreciandosé el número de costillas, forma, tamaño y cantidad de las espinas centrales y radiales, además de dos cortes longitudinales de una flor y fruto, identificandosé su forma, longitud, diámetro del ovario, cantidad de escamas, pilosidad y semillas.

T. werdermannianus ha sido considerado sinónimo de T. terscheckii (Anderson 2005), pero se han observado caracteres morfológicos que permiten distinguirlos como dos especies (color de la epidermis, que en $T$. werdermannianus es amarillo-verdoso mientras que en $T$. terscheckii es verdeoscuro, asimismo la posición de las flores, mayormente apicales frente a subapicales). 
T. werdermannianus fue mencionado por Backeberg (1935) en las descripciones de los tipos de vegetación presentes en la regiones áridas de Chile, Bolivia y la Patagonia, sin proporcionar una diagnosis en latín, por lo que este nombre es inválido según el artículo 39.1 del Código Internacional de Nomenclatura para algas, hongos y plantas (McNeill et al. 2012). Meses después Backeberg ([1935] 1936) publica la diagnosis y la descripción de esta especie.

Los nombres Echinopsis werdermannii Frič ex Z. Fleisch. (1962) y Echinopsis werdermanniana (Backeb.) H. Friedrich \& G.D. Rowley (1974), deben ser considerados como homónimos, debido a que son tan similares que es probable confundirlos (Art. 53.3).

Material de Herbario estudiado: Bolivia, Dpto. Potosí, Prov. Nor Chichas, San Antonio, Quechisla, 3000 m, Dic. 1946, M. Cárdenas 5014 (LIL); camino de Villazón a Tupiza, Humaya, 2923 m, 11 Dic. 2009, S. Albesiano et al. 2068 (MERL).

58. Trichocereus wilkeae (Backeb.) Albesiano, stat. nov.

Trichocereus taquimbalensis Cárdenas var. wilkeae Backeb., Descr. Cact. Nov.: 20. 1956. Tipo no designado. Echinopsis taquimbalensis (Cárdenas) H. Friedrich \& G.D. Rowley var. wilkeae (Backeb.) H. Friedrich \& G.D. Rowley I.O.S. Bull. 3(3): 98. 1974. TIPO: Bolivia, departamento de Potosí, camino de Villazón a Tupiza, 2923 m, 11 Dic. 2009, S. Albesiano, N. Muruaga, A. Alaria \& R. Paz 2067 (Neotipo, MERL, aquí designado).

Iconografía: Backeberg (1959a), foto: 1066. 1115.

Descripción original de Trichocereus taquimbalensis Cárdenas var. wilkeae Backeb., Descr. Cact. Nov.: 20. 1956:

Differt a typo aculeis radialibus $t$ adpressis, curvatis, apice saepe obscuriore, ad $2,5 \mathrm{~cm}$ longis; aculeis centralibus e.d 4, parte inferiore \pm compressis, basi valde incrassata; floribus albis. - Bolivia australis (Prope Tupiza).

Descripción ampliada: Tallos erectos, hasta 2,5 $\mathrm{m}$ de alto, $11-15 \mathrm{~cm}$ de diámetro y ligeramente engrosados en los extremos, verde-claro. Costillas del ápice 8, obtusas, 4,5 cm de ancho, $1,5 \mathrm{~cm}$ de alto; areolas obovadas, $3 \mathrm{~mm}$ de alto, $1,5 \mathrm{~cm}$ de ancho, pilosidad blanca; espinas centrales 3-4, dirigidas hacia el ápice, 2,2-4,5 cm de largo, subuladas, rígidas, marrón-claro con bandas transversales marrón-oscuro; espinas radiales 6 , subuladas, $1 \mathrm{~mm}$ de diámetro, 2,5-5,5 $\mathrm{cm}$ de largo, dirigidas hacia el tallo, de igual color que las centrales. Costillas de la base 8 , obtusas, $4 \mathrm{~cm}$ de ancho, $1,5 \mathrm{~cm}$ de alto, areolas elípticas, 1 $\mathrm{cm}$ de ancho, $5 \mathrm{~mm}$ de alto, en algunas la pilosidad se ha perdido; 4 espinas centrales, curvadas y 
dirigidas al tallo, 6-8 cm de largo, subuladas, negras; espinas radiales 7, subuladas, $1-4 \mathrm{~cm}$ de largo, negras, curvadas y dirigidas hacia el cuerpo. Flores apicales, cuatro por tallo, $27 \mathrm{~cm}$ de largo; ovario $3 \mathrm{~cm}$ de ancho, provisto de escamas verde-oscuro, $1 \mathrm{~cm}$ de largo, de cuyas axilas emerge abundante pilosidad marrón-claro y negro, de $2 \mathrm{~cm}$ de largo y rizados, esta pilosidad también se manifiesta en las escamas del tubo floral; corola de $16 \mathrm{~cm}$ de diámetro (cuando abiertas); tépalos externos verdes con marrón, $7,3 \mathrm{~cm}$ de largo; tépalos intermedios con base pardo-rojizo y ápice blanco, $11 \mathrm{~cm}$ de largo; tépalos internos blancos, $11 \mathrm{~cm}$ de longitud; estilo verde, $19 \mathrm{~cm}$ de largo; lóbulos del estigma amarillos, 2,6 cm de longitud (Fig. 59).

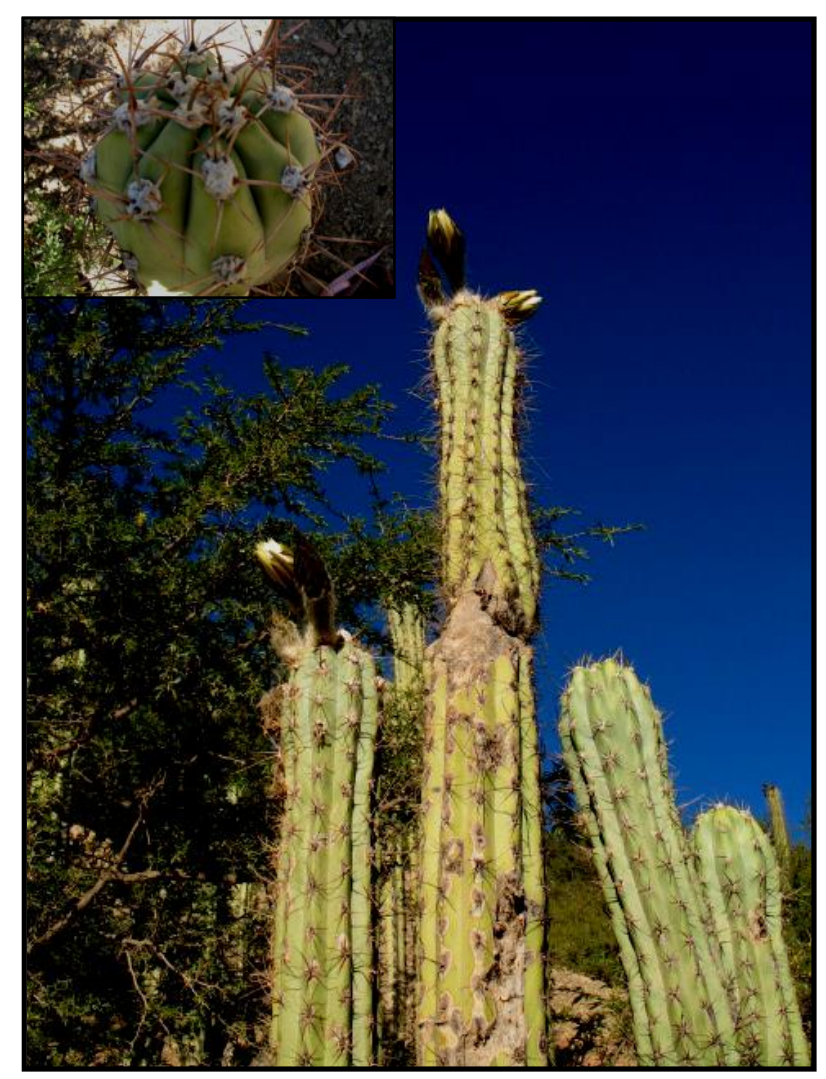

Figura 59. Trichocereus wilkeae. Bolivia, Departamento Potosí, camino de Villazón a Tupiza.

Distribución y hábitat: Trichocereus wilkeae fue descrita para el departamento de Potosí, en el municipio de Villazón (Backeberg 1959a). También se ha observado al borde del camino que comunica Villazón con Tupiza (Fig. 74). Fitogeográficamente se localiza en la prepuna (Cabrera \& Willink 1980).

Comentarios taxonómicos y nomenclaturales: Se escogió el ejemplar S. Albesiano et al. 2067 (MERL) como Neotipo de Trichocereus taquimbalensis var. wilkeae porque fue coleccionado expresamente en la localidad de donde se describió la especie, presenta dos cortes longitudinales de la flor, donde se observa su tamaño y la pilosidad que se origina de las axilas de las escamas, además de varios cortes transversales y longitudinales del tallo, apreciando la cantidad de costillas, espinas radiales y centrales, su forma y longitud. 
Con base en las observaciones de los individuos vistos en campo, se propone a $T$. wilkeae en el rango de especie por las costillas de la base amplias $(4 \mathrm{~cm})$, con espinas radiales adpresas al tallo, con ápices oscuros, cuatro espinas centrales, largas $(6-8 \mathrm{~cm})$ y negras.

Por lo anterior no se acepta la propuesta de Ritter (1980a), de ubicarlo como sinónimo de $T$. tacaquirensis, ni tampoco la de Anderson (2005), de considerarlo sinónimo de T. tacaquirensis subsp. taquimbalensis.

Material de Herbario estudiado: Bolivia, Dpto. Potosí, camino de Villazón a Tupiza, 2923 m, 11 Dic. 2009, S. Albesiano et al. 2067 (MERL).

\subsection{Especies excluidas:}

Trichocereus coquimbanus (Molina) Britton \& Rose, The Cactaceae 2: 139. 1920 (excepto descripción y figura).

Eulychnia coquimbana (Molina) S. Albesiano, Haseltonia 18: 138. 2012.

Cactus coquimbanus Molina, Sag. Stor. Nat. Chili: 170. 1782. Cereus coquimbanus (Molina) K. Schum., Monatsschr. Kakteenk. 6: 166. 1896. Echinopsis coquimbana (Molina) Friedrich \& G.D. Rowley, I.O.S. Bull. 3 (3): 94. 1974. TIPO: Lámina VI, en: C. Skottsberg. 1950. Acta Horti Gothob. 18 (Neotipo, designado por Albesiano 18: 138. 2012).

Eulychnia spinibarbis (Otto ex Pfeiff.) Britton \& Rose, The Cactaceae 2: 82-83, ill. 1920. TIPO: Lámina VIlb, en: C. Skottsberg. 1950. Acta Horti Gothob. 18 (Neotipo, designado por Albesiano 18: 138. 2012).

Se eligió la lámina VI de Skottsberg (1950) como Neotipo de Cactus coquimbanus en Albesiano: 18: 138. 2012, porque reúne las características mencionadas en la descripción original.

Se escogió como Neotipo de Eulychnia spinibarbis, la lámina VIlb de Skottsberg (1950) en Albesiano: 18: 138. 2012, porque presenta los caracteres morfológicos más semejantes a los mencionados en la descripción original.

Al realizar la nueva combinación, Trichocereus coquimbanus, Britton y Rose efectuaron una identificación equivocada; atribuyéndola a una especie de Trichocereus, que se considera que es $T$. pectiniferus. La especie descrita por Molina tiene según su autor tallos erectos, altos y espinas de $20 \mathrm{~cm}$ ("que en aquella época eran usadas para coser calcetines"), por lo que corresponde al género Eulychnia, mientras que la planta descrita por Britton y Rose, es ascendente, de un metro de alto y las espinas no superan los $8 \mathrm{~cm}$ de longitud.

Se incluye la combinación de Echinopsis coquimbana, debido a que Friedrich y Rowley realizaron la transferencia de todas las especies de Trichocereus publicadas por Britton y Rose (1920) al género Echinopsis, sin realizar un estudio nomenclatural y taxonómico de cada especie. 
Eggli \& Walter (2012) proponen rechazar el nombre Cactus coquimbanus Molina, porque los caracteres mencionados en la descripción original ("Cactus erectus, longus, 10-angularis: angulis obtusis, spinis longissimus rectis") no son suficientes para saber si corresponden a una especie del género Eulychnia o Trichocereus, ambos presentes en los alrededores de la ciudad de Coquimbo. Nuestras observaciones de los caracteres vegetativos nos permiten concluir que la descripción de $C$. coquimbanus corresponde a una especie del género Eulychnia, mientras que la descripción de Trichocereus coquimbanus, corresponde a plantas ascendentes las cuales no sobrepasan los $80 \mathrm{~cm}$ de alto y con espinas cortas $(6 \mathrm{~cm})$.

Trichocereus formosus (Pfeiff.) F. Ritter, Kakteen Südamerika 2: 450. 1980.

Echinocactus formosus Pfeiff., Enum. Diagn. Cact. 50. 1837. Echinopsis formosa (Pfeiff.) Jacobi ex Salm-Dyck, Cact. Hort. Dyck 1849: 39. 1850. Acanthocalycium formosum (Pfeiff.) Backeb., KaktusABC: 224. (1935) 1936. Lobivia formosa (Pfeiff.) Dodds, Cact. Succ. J. (Los Angeles) 8: 146, ill. 1937. Soehrensia formosa (Pfeiff.) Backeb., Cactaceae 3: 1678. 1959. TIPO: Argentina, Mendoza, Gillies s.n., "Cactus speciosus" no preservado (Lectotipo, K, no visto, designado por Hunt \& Taylor, Cactaceae Syst. Init.: 7. 2006).

Lobivia oreopepon Speg., Anales Soc. Ci. Argent. 99: 125, ill. 1925. Echinopsis oreopegon (Speg.) Werderm., Gartenflora 80: 302. 1931 (error para oreopepon). Acanthocalycium oreopegon (Speg.) Backeb., Kaktus-ABC: 225. (1935) 1936, (error por oreopepon). Soehrensia oreopepon (Speg.) Backeb., Cactaceae 3: 1674. 1959. TIPO: Foto s.n., en Anales Soc. Ci. Argent. 99: 126. 1925 (Lectotipo, aquí designado).

Trichocereus ingens (Backeb.) F. Ritter, Kakteen Südamerika 2: 451. 1980. Soehrensia ingens Backeb., Cact. Succ. J. (Los Angeles) 23: 86. 1951. Echinopsis ingens (Backeb.) H. Friedrich \& G.D. Rowley, I.O.S. Bull. 3(3): 96. 1974. TIPO: Argentina, between Andalgalá and Concepción, at 2400 m, 28 Dec. 1916, Shafer 23 (Holotipo, no visto, designado por Backeb., I.c.: 86. 1951).

Trichocereus uebelmannianus (Lembcke \& Backeb.) F. Ritter, Kakteen Südamerika 2: 451. 1980; 3: 1116. 1980, nom. inval. Soehrensia uebelmanniana Lembcke \& Backeb. Cactaceae 3: 1925. 1959, nom. inval., por no designar tipo (Art. 40.1). Lobivia formosa (Pfeiff.) Dodds var. uebelmanniana (Lembcke \& Backeb.) Rausch, Lobivia: 48. 1985, nom. inval. Echinopsis uebelmanniana (Lembcke \& Backeb.) A.E. Hoffm., nom. inval., falta la página del basónimo (Art. 41.5).

Soehrensia formosa (Pfeiff.) Backeb. var. maxima Backeb., Cactaceae 3: 1682. 1959. Tipo no designado. Soehrensia formosa (Pfeiff.) Backeb. var. polycephala Backeb., Cactaceae 3: 1682. 1959. TIPO: Argentina, Prov. San Juan, Dpto. Iglesia, 11 Oct. 1978, A.L. Cabrera, S.M. Botta, R. Kiesling \& A.G. López 29631 (Neotipo, SI, aquí designado). 
Iconografías: Doods (1937): 146, 148-149. Kiesling \& Meglioli (2003), fig. 182: 184. Kiesling \& Ferrari (2005), foto 59: 75. Trevisson \& Perea (2009), foto 40: 79.

Descripción original de Echinocactus formosus Pfeiff., Enum. Diagn. Cact. 50. 1837:

\section{E. formosus H. Angl.}

Meloc. Gilliesii Hort.

Pa: Mendoza.

E. subglobosus vel oblongus pallide virens; costis 16 verticalibus obtusis repandis; areolis subremotis ovalibus sublanatis griseis; aculeis acicularibus rigidis, centralibus 2-4 longis brunneis, exterioribus 8-10, superioribus fuscis, inferioribus albis.

Spec. 5 poll. diam., 41/2 poll. altum. Areolae 4-5 lin. distantes. Aculei centrales 1-11/2 poll. longi.

Descripción ampliada: Plantas globosas o cortamente columnares, simples o ramificadas en la base. Tallos muy gruesos $1(2,5) \mathrm{m}$ de alto y $20-90 \mathrm{~cm}$ de diámetro, raro más, verde-claro. Costillas 12-35 0 más, bajas, obtusas. Areolas circulares u ovadas, 0,8-1,2 cm de largo, con pilosidad amarillo-claro. Espinas 10-20, aciculares, flexibles, generalmente blancuzcas o también amarillentas hasta castañas, difícilmente diferenciables en radiales y centrales, 2,5-8,0 cm de largo. Flores acampanadas, dispuestas alrededor del ápice, 6-8 cm de largo y diámetro, receptáculo verde-claro, con escamas verde-rojizas provistas de abundantes pelos castaños. Tépalos amarillos o anaranjados, raro rojos. Pseudobayas de 4$8 \mathrm{~cm}$ de diámetro, 3,5-4,0 cm de alto, globosas, parte externa amarilla-verdosa en la base, del centro hacia el ápice rosado a rojo, con dehiscencia longitudinal. Semillas ovoides, pequeñas (4 mm de largo, 2,5 mm de ancho) y lisas (Figura 60).

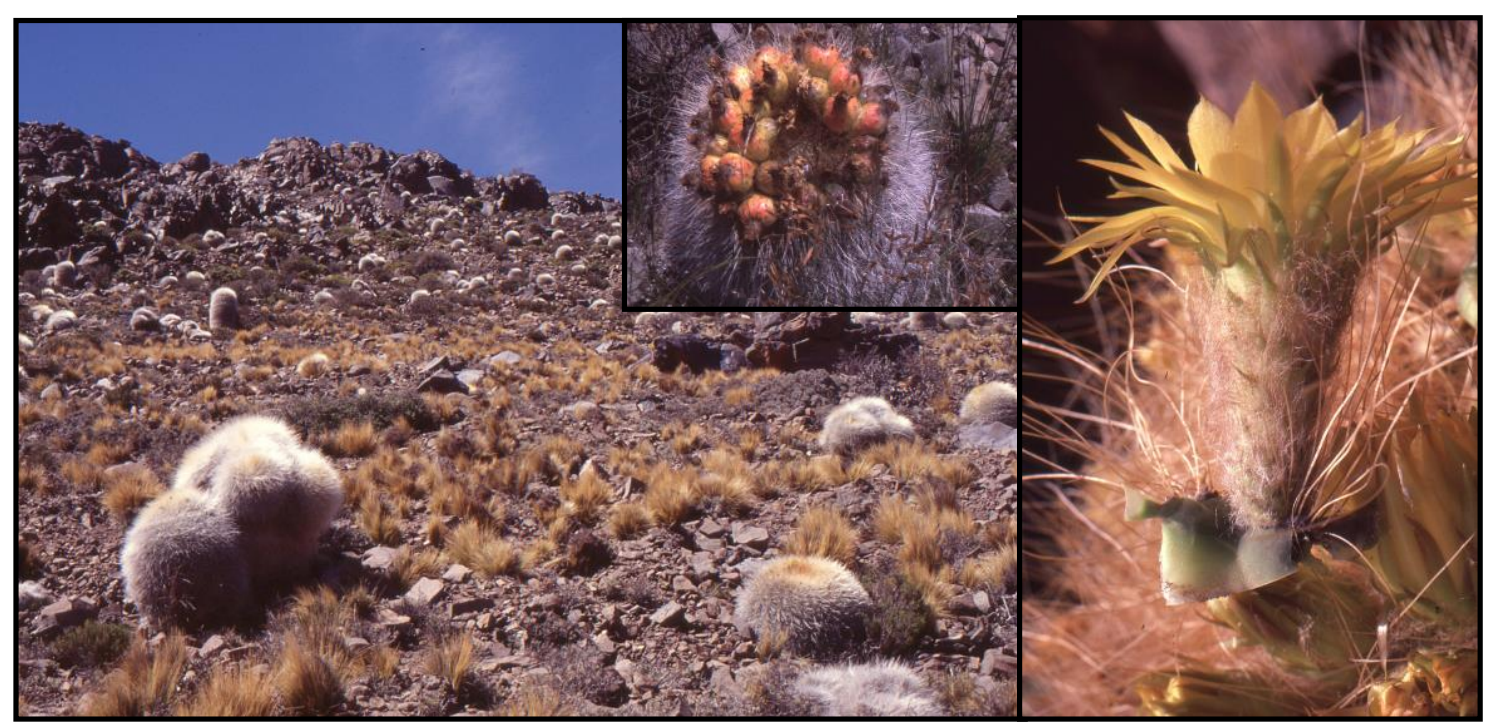

Figura 60. Lobivia formosa. Provincia de San Juan, Estancia Don Carmelo.

Distribución y hábitat: Se localiza en Chile, en la II Región de Antofagasta, en el paso hacia la Prov. de San Juan, y en la Argentina presenta una distribución continua desde las Provincias de 
Catamarca, La Rioja, San Juan y Mendoza, en la Precordillera y Cordillera, entre 2000 a $4000 \mathrm{~m}$ de altitud, prefiriendo laderas rocosas con orientación E o N (Kiesling \& Meglioli 2003).

Comentarios morfológicos y sus consecuencias en la taxonomía y nomenclatura: Se escogió el ejemplar A.L. Cabrera, et al. 29631 (SI) como Neotipo de Soehrensia formosa var. máxima, debido a que reúne las características más semejantes a las mencionadas en la descripción original, y es de la zona mencionada por Backeberg (camino a Chile por San Juan).

Especie inicialmente descrita por Pfeiffer (1837) en Echinocactus, género que antiguamente agrupaba a todas las cactáceas globosas, sin tener en cuenta otros caracteres vegetativos, florales 0 carpológicos. Posteriormente, fue transferida por Salm-Dyck (1850) al género Echinopsis, por Backeberg ([“1935”] 1936) a Acanthocalycium, por Dodds (1937) a Lobivia, nuevamente por Backeberg (1959b) a Soehrensia y finalmente por Ritter (1980a) a Trichocereus. Se acepta la propuesta de considerarla como especie perteneciente al género Lobivia, por la longitud de las flores, 6-8 cm; forma de las escamas del receptáculo, lanceoladas, estrechamente elípticas y angostas hacia los extremos; cercanas pero sin llegar a sobreponerse y con pilosidad intermedia entre Echinopsis y Trichocereus.

Material de Herbario estudiado: Argentina, Prov. Catamarca, Dpto. Antofagasta, Antofagasta de la Sierra, 3700 m, 26 Feb. 2004, S. Cuello 97 (LIL); ibidem, Feb. 2004, S. Cuello 98 (LIL). Prov. La Rioja, Vinchina, 15 Dic. 1996, F. Biurrun \& J. Molina 4582 (SI); ibidem, 12 Nov. 2006, B.O. Schlumpberger 458 (SI); Famatina, 2906/2927, 19 Dic. 2011, G.E. Barboza et al. 3249 (SI); Alto Carrizal, 1930 m, 21 Ene. 2007, S. Albesiano et al. 2034 (MERL); camino a Chile por Jague, Pastillos, 3800 m, 26 Ene. 2007, R. Kiesling et al. 10291 (MERL). Prov. Mendoza, Dpto. Las Heras, Estancia El Salto, 1820 m, 1/18 May. 1936, J. Semper 4038 (MERL); Qda. del Toro, 12 Nov. 1948, A. Ruiz-L. 12015 (MERL); ibidem, 2000 m, Nov. 1915, R. Sanzin 568. (SI); Uspallata, Qda. del Chacay, 2400 m, 21 Ene. 1985, F. Roig 16453 (MERL). Prov. San Juan, Dpto. Iglesia, Qda. Agua Negra, 6 Nov. 1975, R. Kiesling 1072 (SI); ibidem, Oct. 1977, R. Kiesling 4022 (SI); ibidem, 11 Oct. 1978, A.L. Cabrera, S.M. Botta, R. Kiesling \& A.G. López 29631 (SI); Reserva de San Guillermo, 5 Nov. 1980, R. Kiesling 2957 (SI); 17 Ene. 1997, 2980, R.H. Fortunato \& A. Adelqui 5528, 5534 (SI).

Trichocereus rowleyi (H. Friedrich) R. Kiesling, Darwiniana 21 (2-4): 295. 1978.

Echinopsis rowleyi H. Friedrich, I.O.S. Bull. 3(3): 97. 1974 (como Echinopsis rowley), nombre nuevo para Lobivia grandiflora Britton \& Rose.

Lobivia grandiflora Britton \& Rose, The Cactaceae 3: 57. 1922; enmend. Werderm., Bluh. Kakteen And. Sukk. Pflanzen: 117. 1936. (non Echinopsis grandiflora Linke, Berliner Allg. Gartenzeitung 25: 239. 1857). Chamaecereus grandiflorus (Britton \& Rose) Frič., Kaktusář 2: 63. 1931. Helianthocereus 
grandiflorus (Britton \& Rose) Backeb., Cactus (Paris) No. 45: 210. 1955. [non Trichocereus grandiflorus Backeb., Kakteenlexikon: 438. 1966, nom. inval., por no designar tipo (Art. 40.1)]. Lobivia huascha (F.A.C. Weber) W.T. Marshall var. grandiflora (Britton \& Rose) Rausch, Lobivia 3: 172. 1977. Soehrensia grandiflora (Britton \& Rose) Schlumpb., Cactaceae Syst. Init.: 28: 30. 2012. TIPO: Argentina, between Andalgala and Conception, on gravel, 1750 m, 28 Dic. 1916, J.A. Shafer 28 (Lectotipo, 385862 NY; Isolectotipo, $937075 \mathrm{MO}$ aquí designados).

Trichocereus lobivioides Graeser \& F. Ritter, Kakteen Südamerika 2: 444. 1980, nombre nuevo para Lobivia grandiflora Werd, Bluh. Kakteen And. Sukk. Pflanzen: 117. 1936.

Lobivia purpureominiata F. Ritter, Kakteen Südamerika 2: 460, ill. 1980. TIPO: Argentina, Prov. Catamarca, zwischen La Puerta und Andalgalá, 1959, F. Ritter 997 (Holotipo, U).

Iconografías: Werdermann ([1936] 1937), lámina 117: 117. Rauch (1975): 174. Kiesling (1978), fig. 8: 295. Hunt et al. (2006), fig. 6: 252. Trevisson \& Perea (2009), foto 87: 126.

Descripción original de Lobivia grandiflora Britton \& Rose, The Cactaceae 3: 57. 1922:

Globose to short-cylindric, 7.5 to $10 \mathrm{~cm}$. in diameter, 15 to $20 \mathrm{~cm}$. long; ribs about 14; areoles about 1 cm. apart; spines about 15, slender, subulate, about $1 \mathrm{~cm}$. long, yellowish; flowers funnel-form, $10 \mathrm{~cm}$. long; perianth-segments narrow, acuminate, 4 to $5 \mathrm{~cm}$. long, pink; scales on the ovary narrow, 10 to $12 \mathrm{~mm}$. long, a little hairy in their axils.

Collected by J. A. Shafer between Andalgala and Concepcion, Argentina, December 28, 1916, altitude 1,750 meters (No. 28).

The showy pink flowers of this plant are larger than those of any of the other species which we have included in this genus.

Descripción ampliada: Plantas globosas a cilíndricas, 8-10 cm de diámetro y $15-20 \mathrm{~cm}$ de alto, epidermis verde-claro a oscuro, ápice ligeramente umbilicado. Costillas aproximadamente 14, redondeadas, $6 \mathrm{~mm}$ de alto. Areolas separadas $1 \mathrm{~cm}$, con pilosidad amarillenta, luego gris y posteriormente caduca. Espinas radiales 6-12, aciculares, con la base un poco más ancha, amarillas a castaño-claro, a veces con la punta más oscura, 4-6 mm de largo; centrales 1-4, más oscuras que las radiales, $1 \mathrm{~cm}$ de largo. Flores actinomorfas, naciendo de las areolas apicales, $10 \mathrm{~cm}$ de largo y $8,5 \mathrm{~cm}$ de diámetro (cuando abiertas). Ovario y tubo floral de $7 \mathrm{~cm}$ de largo, recubiertos por escamas angostamente triangulares, de $7 \mathrm{~mm}$ de largo, verde-oliva hasta verde-rojizo, de cuyas axilas emergen pelos marrones y algunas cerdas. Tépalos exteriores rojo-claro, con una línea central verde, de 1,3 cm de largo y $5 \mathrm{~mm}$ de ancho; interiores rojo-brillante hasta rosado, con bordes más oscuros, $4,5 \mathrm{~cm}$ de longitud y $1,6 \mathrm{~cm}$ de ancho, espatulados con ápice redondeado del cual sobresale un mucrón central agudo; estambres con filamentos purpúreo opaco; estilo de $6 \mathrm{~cm}$ de largo, declinado, rojo; estigma 11-13 lobulado, de 1,5 cm de longitud, amarillos y superando a los estambres. Frutos subglobosos, parte externa amarillenta, $3 \mathrm{~cm}$ de diámetro, cavidad ovárica con funículos blancos. Semillas negras y brillantes, punteadas, casi rectas, 1,3 $\mathrm{mm}$ de largo, $1 \mathrm{~mm}$ de alto y 0,8 mm de ancho, hilo terminal apenas oblicuo (Fig. 61). 
Distribución y Hábitat: Especie endémica de la Provincia de Catamarca (Argentina), en las sierras de Graciana, del Manchado y de Guayamba (cuesta del Totoral). Crece en la provincia fitogeográfica del Monte, entre pastizales o arbustos de Larrea y Prosopis, entre 1000-2000 m, y sus flores permanecen abiertas de 24 a 48 hs (Kiesling 1978)

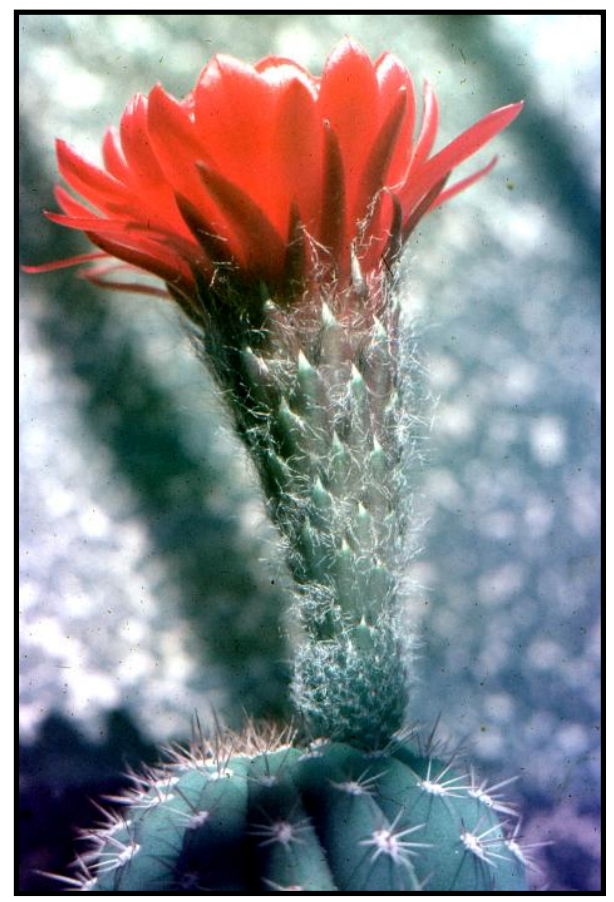

Figura 61. Lobivia grandiflora. Provincia de Catamarca, entre Andalgalá y Concepción.

Comentarios morfológicos y sus consecuencias en la taxonomía y nomenclatura: De acuerdo con las características morfológicas y los resultados del análisis cladístico del género Trichocereus (Albesiano \& Terrazas 2012), esta especie corresponde al género Lobivia, la cual comparte con Lobivia bruchii dos caracteres homoplásicos: plantas adultas con ramas de $3 \mathrm{~cm}$ de diámetro y con aproximadamente 15 costillas. Este clado junto con Lobivia kieslingii presenta la combinación única de cinco caracteres homoplásicos: flores pequeñas $(6-9 \mathrm{~cm}$ de largo), receptáculo floral con escamas lanceoladas, tépalos rojos, frutos semisecos y semillas brillantes.

Al transferir Lobivia grandiflora Britton \& Rose a Echinopsis, no puede llamarse Echinopsis grandilfora, porque ya existía Echinopsis grandiflora Linke, Berliner Allg. Gartenzeitung 25: 239. 1857, previa y válidamente publicado, por lo tanto fue propuesto el nombre Echinopsis rowleyi.

Graeser y Ritter (Kakteen Südamerika 2: 444. 1980) sugieren el nombre de Trichocereus lobiviodes para remplazar Lobivia grandiflora Werdemann ([1936] 1937), por ser ilegítimo (homónimo posterior), pero al revisar el trabajo de Werdermann, éste sólo amplía la descripción de L. grandiflora Britton \& Rose.

Friedrich (1974) considera que esta especie presenta características de Lobivia y Trichocereus, considerándola intermedia entre estos dos géneros. 
Anderson (2005) sugiere que L. grandiflora es sinónimo de $T$. huascha, pero se observan características que permiten considerarlas como dos taxones diferentes (Tabla 16):

Tabla 16. Caracteres que distinguen L. grandiflora de T. huascha.

\begin{tabular}{|l|l|l|}
\hline CARACTERES & \multicolumn{1}{|c|}{ Lobivia grandiflora } & \multicolumn{1}{c|}{ Trichocereus huascha } \\
\hline Altura de los tallos & $15-20 \mathrm{~cm}$ & $100 \mathrm{~cm}$ \\
\hline Longitud de las espinas radiales & Cortas $(4-6 \mathrm{~mm})$ & Largas $(1,5 \mathrm{~cm})$ \\
\hline Longitud de las espinas centrales & Cortas $(1 \mathrm{~cm})$ & Largas $(2-7 \mathrm{~cm})$ \\
\hline Disposición de las espinas & Definida & Desordenadas \\
\hline Color de los tépalos & Rojo claro & $\begin{array}{l}\text { Amarillos, raro blancos, anaranjados o } \\
\text { rojizos }\end{array}$ \\
\hline Color del estilo & Rojo & Blanco \\
\hline Número de lóbulos estigmáticos & $11-13$ & 17 \\
\hline
\end{tabular}

L. grandiflora es similar a T. andalgalensis, pero difiere por la longitud de los tallos $(15-20 \mathrm{~cm}$ vs. $80 \mathrm{~cm}$, y por el largo de las flores (10 cm vs. $7 \mathrm{~cm}$ ) (Kiesling 1978).

Hunt et al. (2006) afirman que el ejemplar tipo (Shafer 28) se encuentra depositado en US, pero al consultar el herbario virtual (http://collections.mnh.si.edu/search/botany/?v=s1), no aparece registrado en esta institución. Seguramente Hunt y colaboradores siguieron lo expresado en la obra original, que los tipos estan en US y los isotipos en NY.

Material de Herbario estudiado: Argentina, Prov. Catamarca, Dpto. Ambato, El Rodeo, A. T. Hunziker 1283 (CORD). Between Andalgala and Conception, on gravel, 1750 m, 28 Dic. 1916, J.A. Shafer 28 (NY; MO); entre la Cumbre y El Alto, Sierra de Ancasti, 1988 m, 16 Nov. 2006, B. O. Schlumpberger 471 (CORD); ibidem, Sierra de Ancasti, 1848 m, 17 Nov. 2006, B. O. Schlumpberger 476 (CORD).

Trichocereus walteri (R. Kiesling) J.G. Lamb., Cactus d'Argentine 2a ed.: 321. 1997.

Lobivia walterii R. Kiesling, Hickenia 1(7): 35. 1976. Echinopsis walteri (R. Kiesling) H. Friedrich \& Glaetzle, Bradleya 1: 96. 1983. Lobivia huascha (F.A.C. Weber) W.T. Marshall var. walteri (R. Kiesling) Rausch, Lobivia 85: 69. 1987. Trichocereus walteri (R. Kiesling) J.G. Lamb., Cactus d'Argentine: 295. 1993, nom. inval., falta la página del basónimo (Art. 41.5). Soehrensia walteri (R. Kiesling) Schlumpb., Cactaceae Syst. Init.: 28: 31. 2012. TIPO: Argentina, Prov. Salta, Dpto. Rosario de Lerma, Qda. Escoipe, 19 Nov. 1975, R. Kiesling \& O. Ferrari 1109 (Holotipo, SI 28587!).

Iconografías: Lambert (2010), fig. 266: 322. Kiesling et al. (2011), foto 52: 116. 
Descripción original de Lobivia walterii R. Kiesling, Hickenia 1(7): 35. 1976:

Lobivia walterii ${ }^{2}$ nov. sp. Plantae pulviniformes, prasinae; ramis globosis costis circa 11 plus minusve acutis; aculeis in areolis juvenibus 5, postea usque 15 et ultra, 1-2,5 cm longis, acicularibus, luteis, flexibilibus. Flores subapicales, campanulati, actinomorphi, 7-9,5 cm longi, leviter aromatici. Pericarpellum et receptaculum viridia, conica, cum lanositate grisea-fusca squamata. Sepala carnosa, linearia, plus minusque rubescente-carnea. Petala spathulata, vitellina, 4,8 cm longa et $1,8 \mathrm{~cm}$ lata. Stamina biseriata, erecta. Stylus cylindricus, infra viridis, supra flavescens, $4,4 \mathrm{~cm}$ longus, lobulis stigmatis $15,1 \mathrm{~cm}$ longis. Fructus globosus, subdepressus, $\pm 2-2,5 \mathrm{~cm}$ diamero, flavovirens. Semina nigra, punctata, $1,3 \mathrm{~mm}$ longa, hilo obliquo.

Descripción ampliada: Tallos globosos, verde-claro, $16 \mathrm{~cm}$ de alto y diámetro (cuando jóvenes), en estado adulto las plantas forman cojines, con muchas ramas laterales. Costillas 11, de 1,5-2,5 cm de alto y ancho, con poca lanosidad blanca. Espinas del ápice 5, espinas de la base 150 más, 1,0-2,5 cm de largo, aciculares, 0,5 mm de ancho, flexibles y amarillas. Flores apicales, actinomorfas, acampanadas, diurnas, ligeramente aromáticas, $9 \mathrm{~cm}$ de diámetro, 7,5-9,0 cm de largo (cuando abiertas), $4 \mathrm{~cm}$ de diámetro, 9,5 cm de largo (cuando cerradas); ovario y tubo floral verdes, cónicos, $4,5 \mathrm{~cm}$ de largo, $1,8 \mathrm{~cm}$ de ancho a la altura del ovario hasta $3,5 \mathrm{~cm}$ en la fauce floral; con escamas agudas, carnosas, $5 \mathrm{~mm}$ de ancho, $9 \mathrm{~mm}$ de largo, de cuyas axilas emergen pelos gris-oscuro. Piezas exteriores del perianto lineartriangulares, verdosas con bordes rosados, $2,8 \mathrm{~cm}$ de largo, 0,7 cm de ancho; intermedias lineares, amarillas con la punta rojiza, algo más grandes que las exteriores; interiores espatuladas, amarillointenso, 4,8 cm de largo, 1,8 cm de ancho; estambres en dos series, la superior en la base de las piezas interiores del perianto, filamentos de 1,4 cm de largo, 0,1 cm de diámetro, amarillo-claro, la serie inferior espiralada, filamentos de 2,2 cm de largo, verdosos, anteras subrectangulares de $2 \mathrm{~mm}$ de longitud, $1 \mathrm{~mm}$ de ancho, amarillas. Estilo verdoso en la base y en el ápice amarillo, 4,4 cm de largo, $3 \mathrm{~mm}$ de diámetro, estigma con 15 lóbulos, amarillo-cremoso, con lóbulos subteretes, $1 \mathrm{~cm}$ de largo y 1,5 mm de diámetro, papilosos; ovario globoso, 1,4 cm de diámetro. Frutos globosos, algo deprimidos, 2,0-2,5 cm de diámetro, 1,7-2,0 cm de alto, con el perianto seco persistente, parte externa verde-amarillento, con escamas pequeñas, $4 \mathrm{~mm}$ de largo y $2 \mathrm{~mm}$ de ancho, triangulares, carnosos, muy espaciadas, con lanosidad corta en sus axilas, gris-claro, cavidad ovárica con funículos blancos. Semillas negras, finamente punteadas, $1,3 \mathrm{~mm}$ de largo, $1 \mathrm{~mm}$ de alto y $0,8 \mathrm{~mm}$ de ancho, hilo oblicuo, cresta longitudinal poco marcada, costados hundidos (Fig. 62).

Distribución y hábitat: Especie endémica de la provincia de Salta, en la quebrada de Escoipe, entre 2000-2900 m, sobre laderas pedregosas y graminosas. Sus poblaciones se han visto reducidas debido a la destrucción de su hábitat, por el trazado de caminos (Kiesling 1976, Kiesling 2011). 


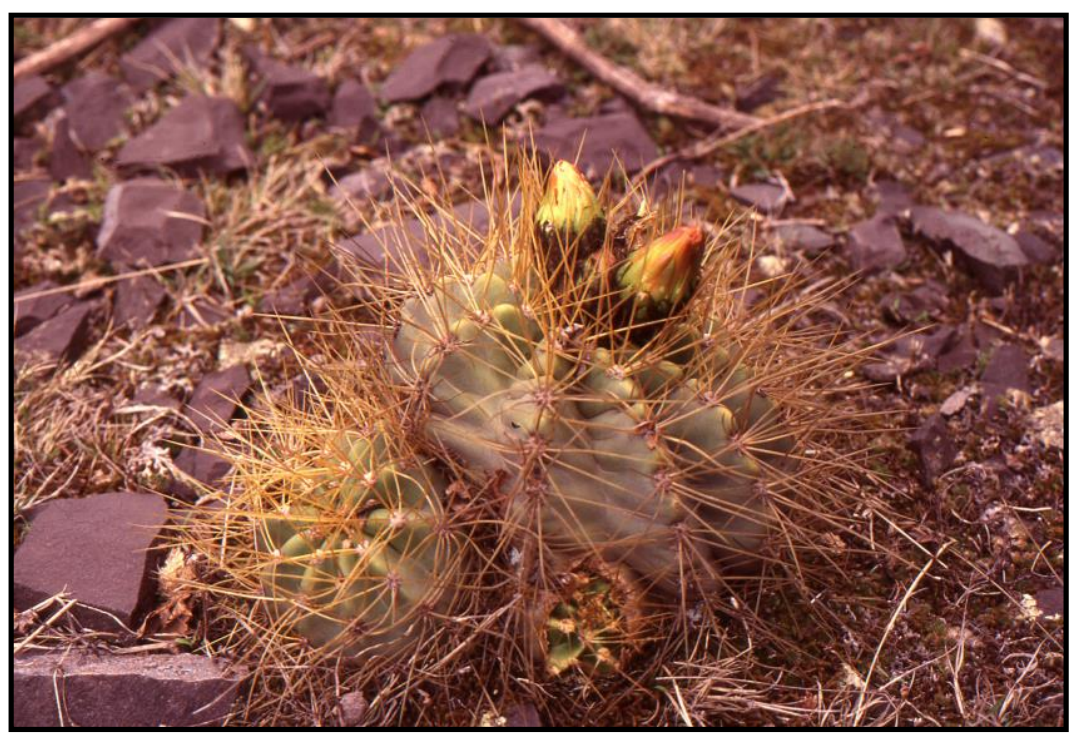

Figura 62. Lobivia walterii. Provincia de Salta, Departamento Rosario de Lerma.

Comentarios taxonómicos y nomenclaturales: Trichocereus walteri de acuerdo con sus características morfológicas y los resultados moleculares (Albesiano \& Terrazas 2012), corresponde al género Lobivia.

Lobivia walterii muy similar en su morfología vegetativa a $T$. smrzianus, pero una vez que se conocen sus flores es posible identificarlas, incluso por caracteres vegetativos, como las espinas. Backeberg ([1935] 1936) describió Echinopsis smrzianus, pero años después (1966), al conocer una flor lo ubicó en Trichocereus; ya que las plantas que en un principio vio sin flores y con las cuales hizo la descripción eran una mezcla de $T$. smrzianus y L. walterii; por lo cual mencionó que "es muy variable" (en sus caracteres vegetativos) en la descripción original.

Schlumpberger y Renner (2012), realizaron el estudio filogenético en el género Echinopsis s.l. basado en datos moleculares del cloroplasto (espaciador intergénico trnS-G, la región trnL y el intron rp/16). Entre sus resultados se encuentra que $L$. walterii es hermana de $T$. smrzianus (muestras tomadas de cultivo), a pesar de que se distinguen por sus caracteres morfológicos y fenológicos, ya que las flores de $L$. walterii son cortas $(9 \mathrm{~cm})$, amarillas y diurnas, mientras que las de $T$. smrzianus son largas (13-19 $\mathrm{cm}$ ), blancas y nocturnas. El criterio de este autor es que los caracteres florales son de rápida variación por la presion de los polinizadores.

Material de Herbario estudiado: Argentina, Prov. Salta, Dpto. Chicoana, 12 Nov. 1995, R. Kiesling, O. Ferrari y R. Moro 8721 (SI); Posta de la Virgen del Valle, 2878 m, 8 Dic. 2009, J. Novara et al. 13250 (MCNS); ibidem, Qda. de Escoipe, Nov. 2000, R. Kiesling s.n. (MERL 56734). 


\section{ANÁLISIS CLADÍSTICO}

\subsection{Introducción:}

Estudios filogenéticos en cactáceas (Nyffeler 2002, Ritz et al. 2007, Hernández et al. 2011), utilizando caracteres moleculares reconocen a la tribu Trichocereeae y al género Echinopsis s.l. como parafiléticos. Nyffeler (2002), incluyó en su estudio las secuencias de los genes de cloroplasto trnK/matK y trnL-trnF de 70 especies pertenecientes a 48 géneros de Cactaceae, de las cuales nueve pertenecían a la tribu Trichocereeae, mientras que Echinopsis s.l. estaba representado por tres especies: Echinopsis (Trichocereus) chiloensis (hermano de Harrisia pomanensis), Echinopsis (Lobivia) pentlandii (hermano del clado H. pomanensis-E. (T.) chiloensis) y Echinopsis glaucina permaneció sin resolver. Ritz et al. (2007) incluyeron en su estudio 20 géneros de los 27 géneros de la tribu Trichocereeae (según la clasificación de Anderson 2005) y nueve especies del género Echinopsis s.l. (que incluyen según Barthlott \& Hunt 1993: Echinopsis s. str., Lobivia, Setiechinopsis y Trichocereus), y utilizaron tres regiones no codificantes del ADN cloroplástico (espaciadores intergénicos atpB-rbcL, trnK-rps16 y trnL-trnF). Sus resultados también confirman la cercana relación entre Echinopsis s.I., Espostoa y Haageocereus, como había sido sugerido por Anderson (2005). Hernández y colaboradores (2011) analizaron 224 especies de 108 géneros, secuenciando el marcador nuclear ( $p p c$ ) y cuatro marcadores de cloroplasto (matK, el intron rpl16 y dos espaciadores intergénicos trnL-trnF y trnK/matK), encontrando que Echinopsis s.l. (siete especies) y la tribu Trichocereeae (representado por 18 géneros y 33 especies) son parafiléticos. Sin embargo, se recuperaron las tres especies estudiadas del subgénero Trichocereus ( $E$. chiloensis-E. pasacana- $E$. pachanoi) como monofilético, y Harrisia relacionado con Trichocereus, como fue sugerido por Nyffeler (2002).

En otra filogenia molecular para Cactaceae, se recuperaron resultados contrastantes para Echinopsis s.I. Korotkova et al. (2010) estudiaron las relaciones de Pfeiffera usando datos de secuencias de ADN cloroplástico de más de 10 géneros. En su árbol de Cactoideae utilizando análisis Bayesiano, la tribu Trichocereeae (representada por seis géneros y siete especies), fue recuperada como monofilética, pero no Echinopsis s.l. Notablemente Harrisia pomanensis fue hermana de Echinopsis pentlandii. Bárcenas y colaboradores (2011) usaron secuencias de nucleótidos de la región del gen del plastidio trnK-matK en 532 especies, encontrando que la tribu Trichocereeae fue monofilética y Echinopsis s.l. no; sin embargo, Echinopsis chiloensis era hermana de E. pentlandii, y el clado E. chiloensis-E. pentlandii fue hermano de H. pomanensis, esta relación coincide a la obtenida por Korotkova et al. (2010), en su árbol de Cactoideae, donde Harrisia pomanensis fue hermana de Echinopsis pentlandii.

Más recientemente, Schlumpberger y Renner (2012) estudiaron las relaciones del género Echinopsis s.l. [Chamaecereus, Echinopsis s. str., Helianthocereus, Lobivia, Setiechinopsis y Trichocereus], en 84 taxones y secuenciando tres regiones no codificantes de ADN cloroplástico (el 
espaciador intergénico trnS-G, la región trnL y el intrón rp/16), encontrando que tanto Echinopsis s.l. como Trichocereus no son monofiléticos.

Posiblemente, la delimitación de este complejo de géneros de Trichocereeae, i.e. Echinopsis s.l.: Acanthocalycium, Chamaecereus, Echinopsis s. str., Helianthocereus, Hymenorebutia, Lobivia, Pseudolobivia, Soehrensia y Trichocereus, así como la adjudicación de cada especie al género que corresponda, sea el mayor desafío actual en el estudio de las cactáceas sudamericanas. Hasta el momento no se han realizado análisis filogenéticos de evidencia total para la mayoría de los géneros de esta tribu. Por consiguiente, el principal interés de este estudio consiste en poner a prueba la monofilia de Trichocereus y establecer las relaciones entre las especies del género Trichocereus sobre la base de las características morfológicas y moleculares.

\subsection{Materiales y Métodos:}

Grupo interno y grupo externo: En los análisis morfológicos y moleculares se incluyeron como grupo interno a 17 de las 38 especies de Trichocereus (el número total de especies corresponde al tratamiento taxonómico del género, el cual concierne al presente trabajo), cuatro especies de Echinopsis s. str., y cuatro de Lobivia. En el caso de Trichocereus, se incluyeron representantes del subgénero Trichocereus y Medioeulychnia, al igual que del género Helianthocerereus (Tabla 1) propuestos por Backeberg (1958). Las 25 especies seleccionadas para este este estudio representan la diversidad morfológica genérica de los tallos, flores, frutos y semillas.

Para probar la monofilia de Trichocereus, seis especies de géneros relacionados (Eulychnia, Harrisia y Wigginsia), fueron seleccionados de acuerdo a la clasificación de Endler \& Buxbaum (1958) y a la topología de Nyffeler (2002). Además, el género monotípico Setiechinopsis (S. mirabilis) fue incluido para determinar si es parte de Echinopsis s. str. o si es el género hermano de éste. Wigginsia vorwerkiana y Wigginsia corynodes fueron usados para enraizar el árbol.

Un total de 32 taxones fueron incluidos tanto en la matriz morfológica como molecular. Se tiene seguridad sobre la identidad taxonómica de las especies, además de incluir la especie tipo de cada género, excepto para Echinopsis.

La lista de las especies con información del país, nombre del colector, número de recolección y herbario donde se encuentra depositado, aparece en el Apéndice 14.2.

Datos morfológicos: Se realizaron varias exploraciones botánicas a las zonas áridas y semiáridas de la Argentina, Bolivia, Chile, Colombia y Uruguay, con el fin de recolectar y tomar 
información de Echinopsis, Eulychnia, Lobivia, Setiechinopsis, Trichocereus y Wigginsia. La gran mayoría de las mediciones fueron realizadas en el campo (Apéndice 14.1) y complementadas con el material estudiado de los siguientes herbarios: BAB, CORD, CTES, LIL, LP, LPB, MERL, MEXU, NY, SGO, SI y U (Holmgren et al. 1990), y la consulta de las descripciones originales. Para dos especies la información morfológica fue tomada de las descripciones originales, por cuanto no se pudo recolectar material de Harrisia earlei, y las características reproductivas de $H$. hahniana fueron corroboradas con material de herbario.

Las mediciones se hicieron con cinta métrica, registrando los siguientes caracteres: a-hábito; bforma de crecimiento; c-altura total; d-altura del tallo principal; e-diámetro de las ramas; f-costillas (número, ancho, altura y forma); g-areolas (alto, ancho, forma y color); h-número, posición, longitud, coloración y forma de las espinas radiales y centrales; i-flor (longitud total, diámetro del receptáculo a la altura del ovario, número de escamas, pilosidad por areola, longitud, forma y color de los tépalos, largo del estilo, color del estigma y diámetro de la corola); j-fruto (forma, diámetro y color); k-semillas (tamaño, coloración y forma).

Las semillas fueron observadas al microscopio electrónico de barrido (JSM-6610LV); previamente fueron limpiadas con acetona, en un equipo de ultrasonido por uno a dos minutos, posteriormente secadas, y unidas a los porta muestras con cinta doble faz, para luego ser metalizadas en el equipo Denton Vacuum Desk IV. Se emplearon aumentos de 80x. La terminología usada es la de Friedrich \& Glaetzle (1983), y de Barthlott \& Hunt (2000).

Selección y estudio de los caracteres: Treinta y nueve caracteres morfológicos fueron reconocidos (Apéndice 14.3), que se proponen como hipótesis de homología primaria; siguiendo los criterios de conjunción y similaridad, posición, forma y función (De Pinna 1991). De los 39 caracteres, 17 se refieren a estructuras vegetativas, 13 a estructuras florales, cuatro a frutos y cinco a semillas (comenzando la numeración de los caracteres en cero). La matriz se elaboró en Winclada (Nixon 1999), incluyendo únicamente caracteres informativos (se excluyeron las autapomorfías), y con igual peso. Los estados de los caracteres desconocidos se anotaron como (-) y los polimórficos como (*; \$). La matriz incluye 13 caracteres binarios y 26 caracteres multiestado (3-6 estados), estos últimos se codificaron como no aditivos, debido a que no hay información previa sobre la transición entre los estados, y con igual peso. Cada carácter representa una hipótesis de homología, donde el estado presente en dos o más taxones; se interpreta como similitud debido a ancestría común (Nixon \& Ochoterena 2000). Los caracteres de las espinas y las areolas (color, diferencia entre radiales y espinas centrales, posición, número y forma), fueron excluidos del análisis cladístico por ser no variables o presentar variación continua, y no aprobar los criterios de similitud y conjunción (De Pinna 1991). 
Tabla 17. Iniciadores usados para la amplificación por PCR y la secuenciación de las regiones trnL-Fy rp/16.

\begin{tabular}{|c|c|l|c|}
\hline $\begin{array}{c}\text { Nombre del } \\
\text { iniciador }\end{array}$ & \multicolumn{1}{c|}{ Secuencia (5' a 3') } & Usado en \\
\hline \multicolumn{3}{|c|}{ trnL-F } \\
\hline C Forward & CGAAATCGGTAGACGCTACG & Taberlet et al. 1991 & Ampl. \\
\hline F Reverse & ATTTGACTGGTGACACGAG & Taberlet et al. 1991 & Ampl. \\
\hline E Forward & GGTTCAAGTCCCTCTATCCC & Taberlet et al. 1991 & Sec. \\
\hline D Reverse & GGGGATAGAGGGACTTGAAC & Taberlet et al. 1991 & Sec. \\
\hline Cii Forward & TAGACGCTACGGACTTGATTG & Cialdella et al. 2007 & Sec. \\
\hline Fdw Reverse & CAGTCCTCTGCTCTACCAGC & Cialdella et al. 2007 & Sec. \\
\hline \multicolumn{1}{|c|}{ rpl16 } \\
\hline 71 Forward & GCTATGCTTAGTGTGTGTCTC & Jordan et al. 1996 & Ampl. \\
\hline 1661 Reverse & CGTACCCATATTTTTCCACCACGAC & $\begin{array}{l}\text { Jordan et al. 1996, } \\
\text { Applequist \& Wallace 2000 }\end{array}$ & Ampl.-Sec. \\
\hline 584 Reverse & TTCCGCCATCCCACCCAATGAA & $\begin{array}{l}\text { Applequist \& Wallace 2000, } \\
\text { Cialdella et al. 2007 }\end{array}$ & Ampl.-Sec. \\
\hline 584 Forward & TTCATTGGGTGGGATGGCGGAA & Cialdella et al. 2007 & Sec. \\
\hline
\end{tabular}

Extracción del ADN, amplificación y secuenciación: El ADN del cloroplasto fue extraído con el método CTAB (Doyle \& Doyle 1987), siguiendo las modificaciones propuestas por Hartmann et al. (2001), para evitar problemas con el mucílago y otros polisacáridos presentes en los tejidos de las cactáceas. Se realizó un corte de $1 \mathrm{~cm} \times 1 \mathrm{~cm}$ sobre la superficie del tallo de cada ejemplar, el segmento de tejido corresponde a las capas más externas, desde la epidermis hasta el clorénquima. Cada segmento fue puesto en un mortero, adicionándole nitrógeno líquido para facilitar su trituración con el mortero. Posteriormente, las muestras fueron colocadas en sus respectivos tubos eppendorf de 1,5 ml, los cuales contenían $500 \mu$ l de buffer CTAB (2,5\% CTAB, 1,5 M NaCl, 50 mM ETDA, $250 \mathrm{mM}$ de Tris $\mathrm{HCl}$ $\mathrm{pH}$ 8). Después de la incubación a $50^{\circ} \mathrm{C}$ por $60 \mathrm{~min}$, fueron adicionados, y mezclados suavemente $500 \mu \mathrm{l}$ de fenol:cloroformo:alcohol isoamílico (25:24:1). La mezcla fue centrifugada a $14000 \mathrm{rpm}$ durante $5 \mathrm{~min}$. La fase acuosa o sobrenadante fue transferida a un nuevo tubo eppendorf, y los tubos con precipitado fueron descartados, luego se adicionaron $250 \mu \mathrm{l}$ de cloroformo:alcohol isoamílico (24:1). Nuevamente se centrifugaron por $5 \mathrm{~min}$ a $14000 \mathrm{rpm}$. La fase acuosa se transfirió a nuevos tubos eppendorf y el ADN fue precipitado con $900 \mu \mathrm{l}$ de etanol al 100\%. Se centrifugó por $10 \mathrm{~min}$ a $13000 \mathrm{rpm}$, para luego descartar el etanol. Los tubos se dejaron secar boca abajo por 20 min. Para resuspender se adicionaron $100 \mu \mathrm{lde}$ TE buffer, agitando suavemente y dejando en una gradilla por espacio de 3 horas. Con el fin de ayudar a resuspender, los tubos fueron puestos en baño maría por 30 minutos a $35-40^{\circ} \mathrm{C}$. Posteriormente se hizo una dilución 1:10 con el fin de medir la concentración y pureza del ADN en el Biofotómetro. La absorbancia de cada taxón se ubicó en el rango de 1,6-2,2 (a 260 y $280 \mathrm{~nm}$ ), lo cual indica que la pureza del ADN extraído es adecuada para continuar con el proceso. El ADN de dos regiones de cPADN fue amplificado usando la reacción en cadena de la polimerasa (PCR); la primera región (trnL-F) consiste del 
intrón trnL y el espaciador intergénico trnL-trnF, y la segunda región (rpl 16) consiste del intrón rpl 16. Los iniciadores usados para cada una de las dos regiones secuenciadas del cpADN son descritos en la Tabla 17. La región trnL-F fue amplificada usando los iniciadores $C$ y $F$, mientras Cii y Fdw fueron utilizados para secuenciar en aquellos taxones donde estos iniciadores fallaron. Los iniciadores $D$ y $E$ fueron usados, según Taberlet et al. (1991) y Cialdella et al. (2007). La amplificación del intrón rp/16 estuvo acompañada por el utilizados de los iniciadores F71 y R1661, y para la secuenciación se emplearon los iniciadores R584 y F584, en aquellos taxones donde estos iniciadores fracasaron se usaron R1661 y R584 siguiendo la propuesta de Applequist \& Wallace (2000).

La reacción de la cadena de la polimerasa de $25 \mu$ contiene: $3 \mu$ de ADN diluido (1:10), 0,25 $\mu \mathrm{l}$ Taq DNA, 0,25 $\mu$ ldNTPs (0,025 mM de cada uno), 2,5 $\mu$ Buffer minus Mg (1X), $2 \mu \mathrm{IgCl}_{2}(5 \mathrm{mM}), 1 \mu \mathrm{l}$ de cada primer $(5 \mu \mathrm{M})$ y $15 \mu \mathrm{l}$ agua ultra pura. Esta reacción se preparó para cada taxón. La PCR fue realizada en Eppendorf Mastercycler gradient thermal cycler personal, usando el siguiente protocolo: Para trnL-F: 1 ciclo de 5 minutos a $94^{\circ} \mathrm{C}, 34$ ciclos de 30 segundos a $94^{\circ} \mathrm{C}, 1$ minuto a $48^{\circ} \mathrm{C}$, y 1 minuto 30 segundos a $72^{\circ} \mathrm{C}$, y un ciclo final de extensión de 7 minutos a $72^{\circ} \mathrm{C}$. Para rp/16: 1 ciclo de 4 minutos a $94{ }^{\circ} \mathrm{C}, 34$ ciclos de 1 minuto a $94^{\circ} \mathrm{C}, 1$ minuto a $55^{\circ} \mathrm{C}$, y 2 minutos 30 segundos a $72^{\circ} \mathrm{Cy}$ un ciclo de extensión final de 7 minutos a $72^{\circ} \mathrm{C}$.

El producto de PCR obtenido a una concentración de 30-60 ng/ $\mu$ l para cada taxón, y purificado con el kit Wizzard de Promega, siguiendo las instrucciones del producto. Las reacciones de secuenciación fueron realizadas en la Unidad Genómica de INTA Castelar (Buenos Aires, Argentina), utilizando como método de rutina la técnica de Sanger, y la electroforesis en secuenciador automático de capilares (Applied Biosystems 3500xL Genetic Analyzer).

Análisis de datos moleculares: La edición y ensamblaje de las secuencias se realizó en el programa BioEdit (versión 7.0.5.1, Hall 1999), usando como estándar nueve secuencias obtenidas del GenBank (Apéndice 14.2). El alineamiento automático se realizó con el programa Muscle (Edgar 2004), y manualmente con Mesquite (versión 2.74, Maddison \& Maddison 2010). Las inserciones y delecciones fueron codificados de acuerdo al método de codificación simple (Simmons \& Ochoterena 2000). La matriz con las secuencias se unió a las dos matrices de gaps (correspondiente al trnL-F y rpl16), para un total de 133 caracteres informativos de un total de 2194 caracteres.

Análisis filogenético: El análisis de parsimonia se realizó en tres conjuntos de datos: (a) morfológicos, (b) moleculares (trnL-F+rp/16+gaps), y (c) combinando la información morfológica con la molecular (32 taxones y 172 caracteres). Las matrices de datos fueron editadas en Winclada, eliminando las autapomorfías y los datos constantes (no son informativos). Los caracteres se trabajaron con igual peso y no aditivos. 
El análisis de parsimonia se realizó con TNT versión 1.1 (Goloboff et al., 2008). Las búsquedas se hicieron bajo los siguientes parámetros: máx. trees: 10.000; random seed: 0; y con las siguientes estrategias: sectorial searches, ratchet, tree drifting y tree fusing, con 1000 random additional sequences, manteniendo 12 búsquedas. Las búsquedas se repitieron cinco veces (total 60), con el fin de verificar que los taxones con datos faltantes, no afectaran la longitud de los cladogramas. Posteriormente, en Winclada se colocaron los árboles recolectados de todas las búsquedas en TNT, eliminando los árboles subóptimos (de igual longitud y los menos parsimoniosos, en comparación a los árboles óptimos). El árbol de consenso estricto fue calculado usando la opción "Consensus (strict)", y guardándolo como metafile. El criterio de optimización de los caracteres seleccionados fue Acctran, y la longitud del árbol junto con los índices de consistencia y retención fueron estimados en Winclada. Como medidas de soporte de las ramas, se calculó en TNT los valores de Bootstrap en las matrices de datos, con las siguientes opciones: max. trees=10.000; random seed=0; number replicas=1000; search trees with ratchet, tree drifting y tree fusing. De igual manera se procedió con los porcentajes de Jackknife. Todos los árboles fueron editados en Corel DrawX3.

El uso de datos moleculares ha reactualizado el problema de la congruencia taxonómica, es decir el grado de correspondencia entre distintas clasificaciones o agrupamientos, producidos a partir de diferentes conjuntos de datos (Lanteri et al. 2005). Varias medidas de congruencia han sido propuestas, una de ellas es el Incongruence Length Difference (ILD) (Mickevich \& Farris 1981), como se ha calculado en este estudio. El ILD para un conjunto de datos es: ILD $=L_{\text {(morfológica)(trnL-F)(rp|16) }}-\left(L_{\text {(morfológica) }}+L_{\text {(trnL-F)(rpl16) })} /\right.$

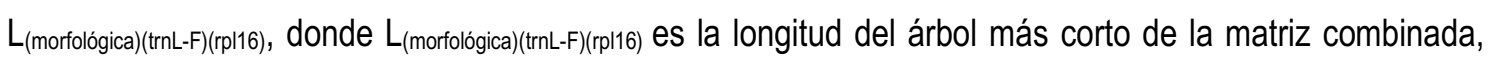
$L_{\text {(morfológica) }}$ es la longitud del árbol más corto a partir de la matriz de datos morfológicos, y $L_{(\text {(trLLF)(rp16) }}$ es la longitud del árbol más corto de la matriz de datos moleculares.

\subsection{Resultados:}

El número de caracteres informativos y los estadísticos para los análisis por separado y combinados se sintetizan en la Tabla 18. Ni el análisis por parsimonia con caracteres morfológicos ni con caracteres moleculares por separado recuperó la tribu Trichocereeae ni el género Trichocereus como monofiléticos (Figura 63 y Figura 64).

Morfología: El consenso estricto de 684 árboles más parsimoniosos ( $L=506 ; \mathrm{Cl}=0,18 ; \mathrm{Rl}=0,27$ ) revela una gran politomía (Fig. 63). Dentro de esta gran politomía cinco clados con bajo soporte $(<80 \%)$ fueron recuperados y soportados por pocas sinapomorfías. Por ejemplo, T. macrogonus var. macrogonus y T. macrogonus var. pachanoi son taxones hermanos, compartiendo el color verde-azulado de los tallos, y el clado T. macrogonus var. macrogonus-T. macrogonus var. pachanoi es hermano de T. bridgesii, sustentado por la presencia de un surco interareolar. Harrisia earlei y $H$. hahniana son hermanas, soportada por la disposición alterna o diagonal de las areolas. Eulychnia breviflora y E. castanea son 
hermanas, soportado por la presencia de pelos en las axilas de las escamas del tubo floral, diámetro del receptáculo de $4-5 \mathrm{~cm}$ a nivel del ovario y frutos semisecos. $T$. deserticola, $T$. pectiniferus y $T$. spinibarbis están cercanamente relacionados con valores de soporte de bootstrap y jackknife bajos, mientras que $T$. andalgalensis, $T$. strigosus y $T$. schickendantzii forman una politomía débilmente soportada.

Tabla 18. Resultados estadísticos del análisis por parsimonia de las matrices individuales y combinadas. Amp (árboles de máxima parsimonia), ac (árbol de consenso), I (longitud=pasos), i.c. (índice de consistencia), i.r. (índice de retención).

\begin{tabular}{|c|c|c|c|c|c|c|c|c|c|c|c|}
\hline Datos & $\begin{array}{c}\text { No. de } \\
\text { taxones }\end{array}$ & $\begin{array}{c}\text { No. de caracteres } \\
+ \text { gaps codificados } \\
\text { (total) }\end{array}$ & $\begin{array}{c}\text { No. de } \\
\text { caracteres } \\
\text { informativos }\end{array}$ & $\begin{array}{c}\text { No. amp } \\
\text { en } 60 \\
\text { repeticiones }\end{array}$ & $\begin{array}{l}\text { No. amp } \\
\text { (óptimos) }\end{array}$ & & & & & & \\
\hline & & & & & & \multicolumn{3}{|c|}{ amp } & \multicolumn{3}{|c|}{ ac } \\
\hline morfológicos & 32 & - & 39 & 684 & 19 & $\begin{array}{c}1 \\
272\end{array}$ & $\begin{array}{l}\text { i.c. } \\
0,34\end{array}$ & $\begin{array}{c}\text { i.r. } \\
0,68\end{array}$ & $\begin{array}{c}1 \\
506\end{array}$ & $\begin{array}{l}\text { i.c. } \\
0,18\end{array}$ & $\begin{array}{l}\text { i.r. } \\
0,27\end{array}$ \\
\hline $\operatorname{trnL}-\mathrm{F}$ & 32 & 1022 + $23(1045)$ & 39 & 958 & 71 & 61 & 0,67 & 0,87 & 67 & 0,61 & 0,83 \\
\hline rpl16 & 27 & 1122 + 27 (1149) & 94 & 300 & 25 & 145 & 0,74 & 0,84 & 152 & 0,71 & 0,81 \\
\hline trnL-F y rpl16 & 32 & 2144 + $50(2194)$ & 133 & 31371 & 1497 & 313 & 0,47 & 0,58 & 247 & 0,60 & 0,58 \\
\hline $\begin{array}{l}\text { morfológicos, } \\
\text { trnL-F y rpl16 }\end{array}$ & 32 & 172 & 172 & 1166 & 1 & 603 & 0,40 & 0,62 & - & - & - \\
\hline
\end{tabular}

Molecular: El consenso estricto de 31371 árboles más parsimoniosos $(\mathrm{L}=313 ; \mathrm{Cl}=0,47 ; \mathrm{Rl}=$ 0,58; Fig. 64) muestran que $T$. bridgesii es la primera especie que se ramifica. La relación cercana entre $H$. hahniana y E. ancistrophora presenta valores altos de soporte (100/100). La relación de hermandad entre Eulychnia breviflora y E. castanea encontrada también en el árbol morfológico- es confirmada, aun cuando presenta valores de soporte bajos 61/51. A nivel molecular, $T$. strigosus se relaciona con $L$. bruchii y L. glandiflora, asimismo, $T$. arboricola forma un clado con $T$. tarijensis como taxones hermanos.

Datos moleculares y morfológicos combinados: El análisis de parsimonia combinado de los datos morfológicos y moleculares resultó en un sólo árbol de 603 pasos con $\mathrm{Cl}=0,40$ y $\mathrm{Rl}=0,62$ (Fig. 65). Los resultados del ILD indican que la separación de los datos morfológicos y moleculares fueron incongruentes (ILD $=0,67)$. Sin embargo, cuando los datos morfológicos y moleculares se combinan, el árbol más parsimonioso es más resuelto. Los miembros de la tribu Trichocereeae se recuperaron por cuatro sinapomorfías (costillas tuberculadas poco sobresalientes, largo total de la flor 4 a 12 veces el diámetro del ovario, escamas del receptáculo triangular-ovadas y entre 20 a 40 pelos en las areolas del receptáculo), y por cuatro homoplasias (flores pequeñas, 6 a $9 \mathrm{~cm}$ de largo, diámetro del ovario y garganta casi semejantes, semillas ovadas y medianas). 


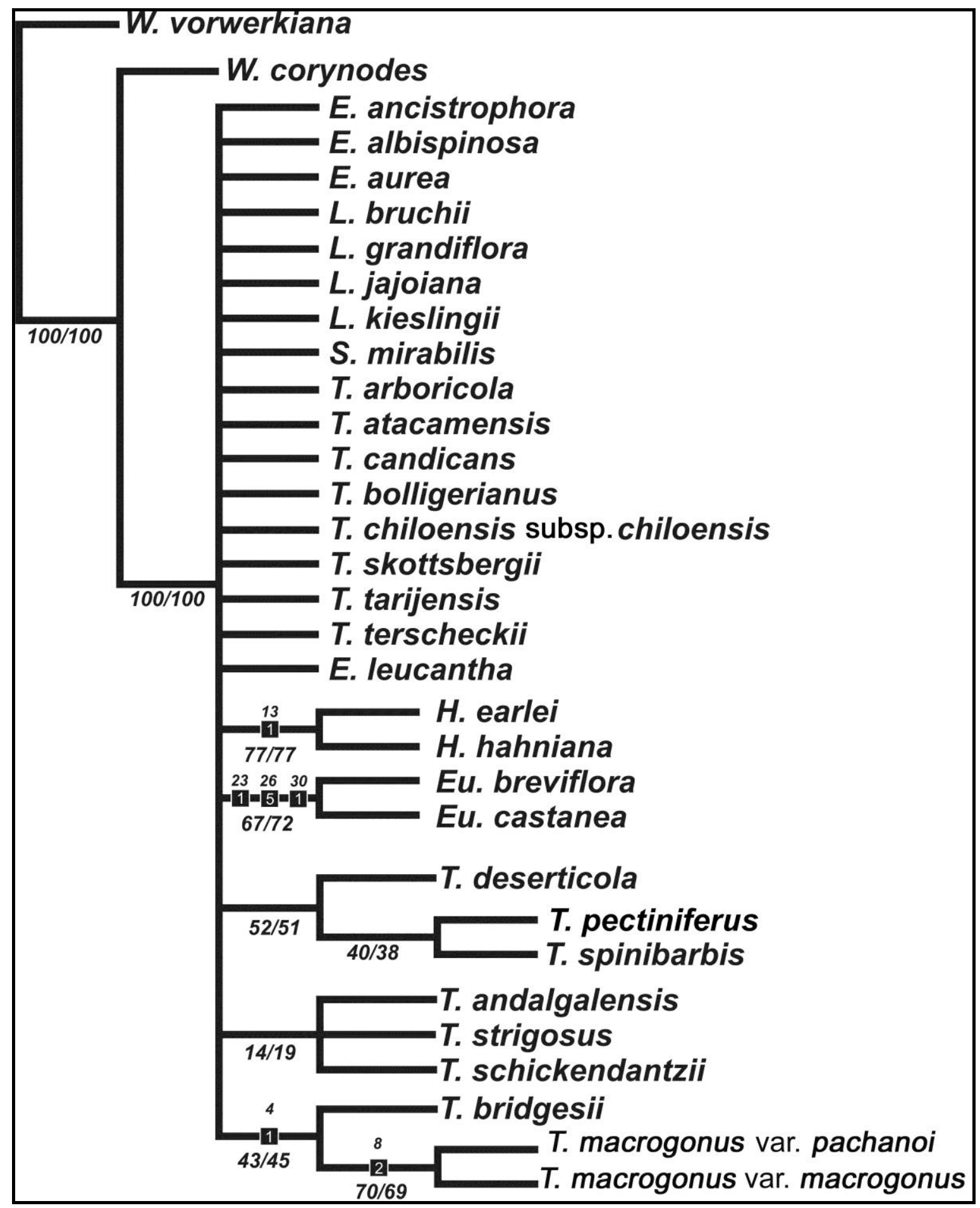

Figura 63. Consenso estricto de 684 árboles más parsimoniosos $(L=506, C l=0,18, R I=0,27$, usando caracteres morfológicos. Los números debajo de las ramas corresponden a valores del soporte de Bootstrap/porcentajes de Jackknife. Números encima de las ramas son los caracteres (Apéndice 14.3), y los estados de los caracteres aparecen dentro de los cuadrados. Los cuadros oscuros corresponden a sinapomorfías. 


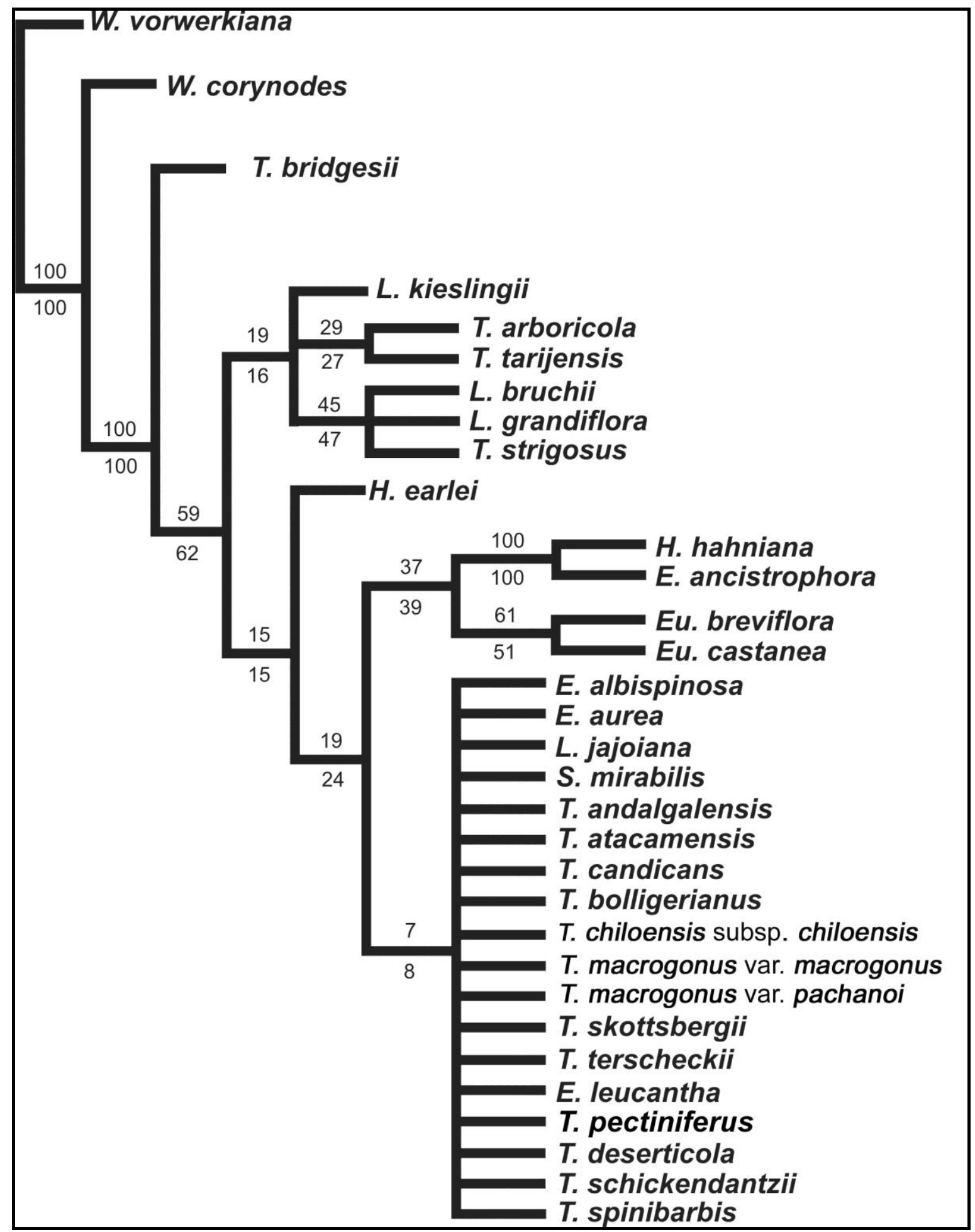

Figura 64. Consenso estricto de 31371 árboles más parsimoniosos $(\mathrm{L}=313, \mathrm{Cl}=0,47, \mathrm{RI}=$ $0,58)$, combinando los conjuntos de datos de trnL-F y rp/16. Números encima y debajo de las ramas indican valores del soporte de Bootstrap y porcentajes de Jackknife, respectivamente. 
Basado en las especies muestreadas (Apéndice 14.2), Trichocereus es monofilético si las dos especies de Harrisia forman parte de él (Fig. 65). Este clado se recupera por tres sinapomorfías, crecimiento basítono con ramas prostradas (1/3 Apéndice 14.3), escamas imbricadas a lo largo del receptáculo floral (24/3), y frutos subglobosos, achatados en los extremos (30/4), y ocho homoplasias: (1) largo máximo de los tallos entre $60-100 \mathrm{~cm}$, (2) ápice vegetativo de los tallos agudos, formando un cono de 45 a $90^{\circ}$, (3) los tallos son cilíndricos, siendo el largo más de dos veces su ancho, (4) ausencia de costillas tuberculadas, (5) apertura floral nocturna, (6) el promedio del diámetro del receptáculo a nivel del ovario es de $2 \mathrm{~cm}$, (7) garganta dos veces más ancha que el ovario, y (8) más de 11 escamas a lo largo del fruto.

El género Trichocereus es hermano de tres especies de Lobivia. La presencia de costillas agudas y las escamas cercanas la una a la otra en el receptáculo floral definen esta relación de hermandad. Además, Lobivia y Echinopsis s. str. son recuperados como parafiléticos en nuestro análisis. Setiechinopsis mirabilis es distintivo, en virtud de la presencia de 13 autapomorfías, dos de ellas exclusivas (forma de tallos fusiforme y margen del ápice de los tépalos internos finalizando en un ángulo inferior a 45 grados).

\subsection{Discusión:}

Los resultados de los análisis por separado y simultáneo para el grupo de cactáceas en estudio, confirman lo registrado en otros grupos de plantas (Simmons et al. 2001, Cialdella et al. 2007, Ruíz et al. 2008, Lehnert et al. 2009), que es el análisis simultáneo el que tiene mayor poder informativo y explicativo de los datos (Nixon \& Carpenter 1996, Gravendeel \& De Vogel 2002, Gravendeel et al. 2004). En el análisis de la evidencia total o simultáneo (morfología + ADN), el género Trichocereus se recuperó como monofilético si Harrisia earlei y $H$. hahniana son parte de él, y están apoyados por una combinación única de caracteres incluyendo algunas sinapomorfías (Fig. 65). Estos resultados difieren de lo encontrado por Nyffeler (2002), Ritz et al. (2007), Schlumpberger \& Renner (2012), quienes utilizaron exclusivamente datos moleculares.

En nuestro análisis de la evidencia total, Lobivia resultó ser parafilético. Es notorio de mencionar que tres especies de Lobivia fueron agrupadas en un clado pobremente soportado, compartiendo una sola combinación de cinco caracteres homoplásicos (flores pequeñas, 6 a $9 \mathrm{~cm}$ de largo, escamas lanceoladas en el receptáculo floral, tépalos rojos, frutos semisecos y semillas brillantes). Esta combinación única de caracteres mejorará con la inclusión de más especies de Lobivia. Friedrich (1974) sugiere una hipótesis filogenética (basada en morfología), donde Lobivia tiene un origen distinto de Echinopsis s. str. y Rebutia (grupos hermanos), por la presencia ocasional de espinas en las areolas del fruto, y por la estructura floral, que es semejante a la flor del ancestro de la tribu Echinopsideae. 
Figura 65. El árbol más parsimonioso ( $\mathrm{L}=603, \mathrm{Cl}=0,40, \mathrm{Rl}=0,62)$, basado en evidencia total, morfología y molecular (trnL-F y rp/16). Los cuadrados sólidos representan estados sinapomórficos y los blancos homoplasias, que están presentes de manera no ambigua; los números sobre los cuadrados corresponden a los caracteres morfológicos, y los números al interior de los cuadrados son los estados de los caracteres. Los valores en itálica corresponden al soporte de Bootstrap/porcentajes de Jackknife.

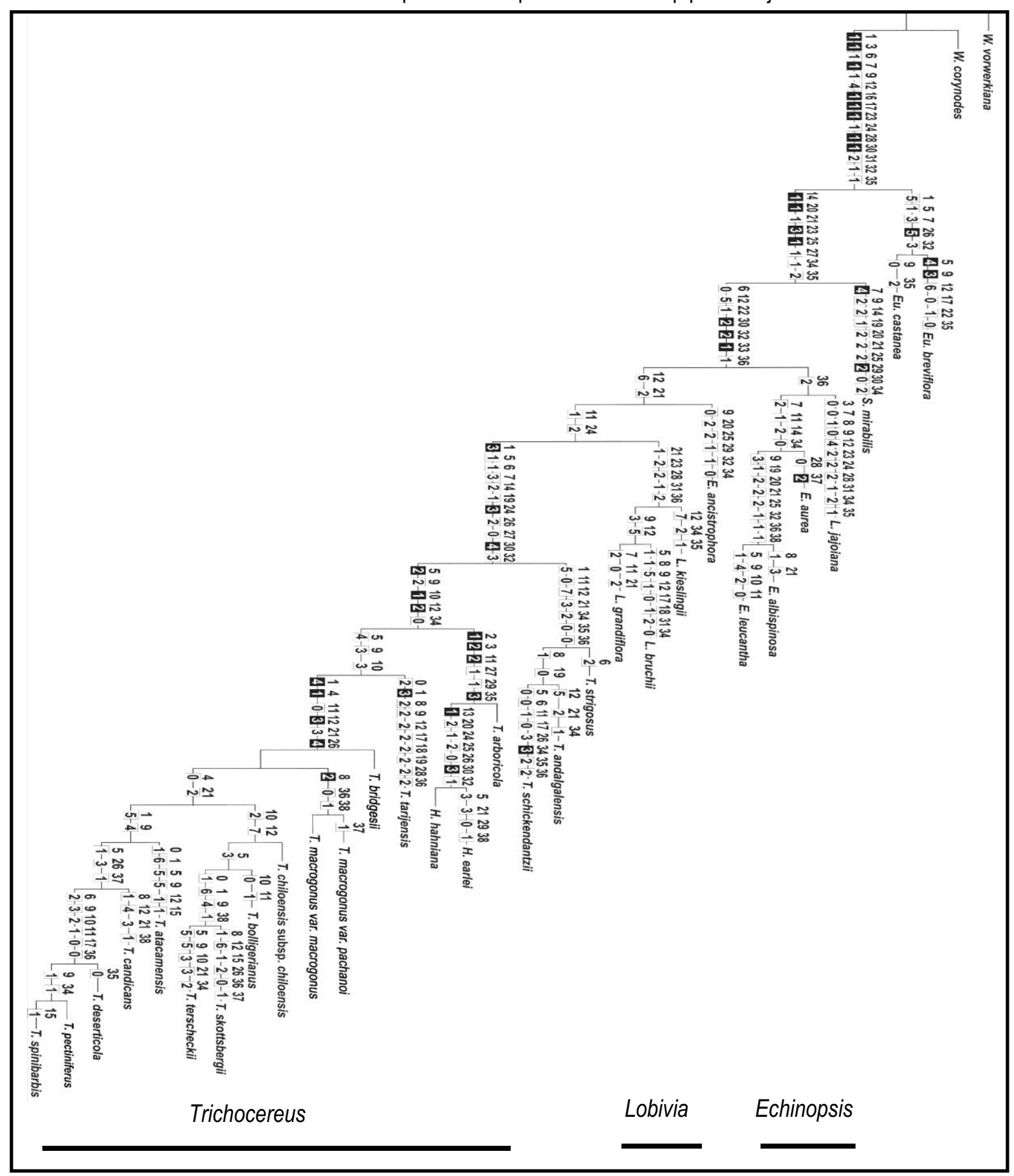


Los resultados obtenidos permiten rechazar esta hipótesis debido a la muestra limitada de Echinopsis s. str. y Rebutia. Las cuatro especies de Echinopsis s. str. incluidas en el análisis representan los extremos de la variación morfológica y no se recuperaron como monofiléticas, por lo que más especies del género necesitan ser estudiados para entender los límites de este género.

Setiechinopsis mirabilis fue el primer taxón en ramificarse en el análisis simultáneo y con un número alto de autapomorfías, por lo que no está estrechamente relacionado con las especies de Echinopsis s. str., Lobivia o Trichocereus. Ritz et al. (2007) encontraron que S. mirabilis es la especie hermana de Echinopsis huotii y Cleistocactus strausii en un clado con Espostoa guentheri como las primeras especies en ramificarsen. Las Peñas et al. (2011) encontraron diferencias citogenéticas (en los estudios cromosómicos) entre S. mirabilis y los taxones de Echinopsis s.l., con lo cual, ellos concluyeron de que Setiechinopsis es un género separado, y los resultados obtenidos añaden más apoyo a esta afirmación.

\section{Trichocereus y la relación de sus especies}

Trichocereus es monofilético si se incluyen Harrisia earlei y $H$. hahniana, lo cual es apoyado por tres sinapomorfías y ocho homoplasias. Riccobono (1909), reconoció a Trichocereus como género, por el porte columnar de sus tallos, además de la pilosidad en las flores. La forma de crecimiento -columnarpropuesta por Riccobono para definir el género, no se recuperó como sinapomorfía, sino la forma de ramificación basítona. El segundo carácter señalado por él referente a la pilosidad en las flores, tampoco se recupera como sinapomorfía, sino las escamas imbricadas en el receptáculo floral.

Algunos clados fueron recuperados dentro del género Trichocereus (Fig. 65). El primero lo integran $T$. strigosus, $T$. andalgalensis y $T$. schickendantzii, definido por siete caracteres homoplásicos, uno de ellos es la forma de ramificación basitona, con ramas arqueadas (1/5) (Apéndice 14.3), costillas obtusas (11/0), número elevado de costillas (12/7), flores largas (21/3), semillas circulares-orbiculares (34/2), semillas muy pequeñas (35/0) y semillas opacas (36/0). Ritz et al. (2007) encontraron que Echinopsis (Trichocereus) schickendantzii es la especie hermana de Samaipaticereus corroanus, y en la filogenia de Schlumpberger \& Renner (2012), Echinopsis (Trichocereus) schickendantzii es hermana de Echinopsis (Trichocereus) thelegonoides y de Echinopsis (Harrisia) hahniana. Los resultados obtenidos no apoyan esta afirmación, e indican que $T$. schickendantzii se agrupa con otras especies del género Trichocereus.

Trichocereus schickendantzii presenta una autapomorfía, semillas estrechamente ovadas (34/3), un carácter omitido en la descripción original por Weber (1896), pero sí mencionado por Kiesling (1978). Además, este taxón presenta siete homoplasias: ramas de $30 \mathrm{~cm}$ de alto (5/0), con ápice hundido (6/0), costillas agudas (11/1) y posición apical de las flores (17/0), diámetro del receptáculo a la altura del ovario de $2,5 \mathrm{~cm}$ de diámetro (26/3), semillas medianas (35/2) y brillantes (36/2). El diámetro del 
receptáculo a la altura del ovario es el único carácter no mencionado ni en la descripción original (Weber 1896), ni en el tratamiento del género (Kiesling 1978). Trichocereus andalgalensis está apoyado por la combinación única de los siguientes caracteres: número máximo de costillas en la parte media de los tallos (15), flores de 10 a $17 \mathrm{~cm}$ de largo y semillas ovadas. De estos tres caracteres, solamente la forma de la semilla se había incluido en la descripción ampliada de la especie (Kiesling 1978).

El segundo clado lo forman $T$. arboricola, $H$. earlei y $H$. hahniana, apoyado por cuatro sinapomorfías: presencia de raíces adventicias (2/1), tallos expuestos totalmente sobre la superficie del suelo (3/2), y con costillas amplias, con un ángulo mayor de $135^{\circ}$ (11/2), y semillas grandes, de 2,0 a 2,9 mm (35/3). Además, se presentan dos homoplasias referidas a la flor (Fig. 65): diámetro de la garganta y ovario casi del mismo ancho (27/1), y margen del ápice de los tépalos internos rematando en un ángulo entre 45 y 90․ Leuenberger (1976) sugirió por primera vez una relación cercana entre Harrisia y Trichocereus, basado en las características del polen. Esta relación cercana es apoyada por este análisis y por otros estudios moleculares (Wallace 1997; Nyffeler 2002; Korotkova et al. 2010; Hernandez et al. 2011, Schlumpberger \& Renner 2012), aunque más especies de Trichocereus y Harrisia necesitan ser incluidos en futuros análisis filogenéticos con datos combinados para apoyar estos resultados. Harrisia earlei y $\mathrm{H}$. hahniana están apoyadas por dos sinapomorfías, viz., la disposición alterna de las areolas en las costillas adyacentes (13/1) y frutos globosos (30/3), mencionado por Britton \& Rose (1920) en la descripción amplia del género. Harrisia earlei presenta cuatro homoplasias: longitud de los tallos entre 2-3 m (5/3), flores de hasta $24 \mathrm{~cm}$ de largo (21/3), margen de los tépalos internos cóncavos (29/0), y presencia de una quilla en la semilla (carácter $38 / 1$ ). Los dos primeros caracteres fueron mencionados en la descripción original por Britton \& Rose (1920).

El tercer clado está conformado por T. macrogonus var. macrogonus y T. macrogonus var. pachanoi, definido por la sinapomorfía, ramas verde-glauco (8/2) y dos homoplasias en la semilla: semillas sin brillo (36/0) y presencia de una quilla sobre la semilla (38/1). Las ramas verde-glauco fueron propuestas en la descripción original (Britton \& Rose 1920) y mencionadas por Madsen (1989), en su descripción ampliada de T. macrogonus var. pachanoi de Ecuador.

El cuarto clado lo componen cuatro especies, para una de las cuales una subespecie particular fue examinada. $T$. chiloensis subsp. chiloensis y $T$. bolligerianus forman un clado con $T$. skottsbergii y $T$. terscheckii, los cuales son definidos como hermanos por cuatro homoplasias: el aspecto arbóreo (0/1), presencia de un tallo principal con ramificación lateral (1/6) (Fig. 65), ramas de hasta $15 \mathrm{~cm}$ de diámetro (9/4), y presencia de una quilla en las semillas (38/1). T. skottsbergii y T. terscheckii comparten con $T$. bolligerianus la longitud de los tallos, 2-3 m (5/3), y las tres especies a su vez comparten con $T$. chiloensis subsp. chiloensis dos homoplasias: costillas 1,1-1,5 cm de alto (10/2), y más de 20 costillas en la parte media de las ramas (12/7).

Trichocereus terscheckii está definido por la combinación única de cinco homoplasias: longitud de los tallos mayor de $8 \mathrm{~m}(5 / 5)$, y hasta $20 \mathrm{~cm}$ de diámetro (9/5), costillas 2,0-2,5 cm de alto (10/3), flores 
largas, 20 a $24 \mathrm{~cm}$ (21/3) y semillas circulares-orbiculares (34/2). Estos estados de caracteres no fueron mencionados por Pfeiffer (1837) en la descripción original de la especie, pero si fueron comentados por Britton \& Rose (1920) y por Kiesling (1978). T. skottsbergii presenta solamente la combinación de seis homoplasias: ramas verde-claro (8/1), numerosas costillas (17) (12/6), diámetro del receptáculo a nivel del ovario de $2 \mathrm{~cm}$ (26/2), semillas opacas (36/0), paredes anticlinales de las células de la testa en forma de $S(37 / 1)$ y espinas flexibles en el centro vegetativo de las ramas (15/1), un carácter mencionado por Backeberg (1950) en la descripción original de la especie.

Los resultados obtenidos no coinciden con los de Backeberg (1950), quien sugiere a $T$. skottsbergii y T. deserticola como sinónimos, o con los de Charles (2005), quien propuso a T. skottsbergii como subespecie de Trichocereus chiloensis.

La especie $T$. bolligerianus está definida por la combinación única de dos homoplasias: costillas bajas (10/0) y costillas agudas (11/1). Estos resultados no apoyan los de Kiesling et al. (2008), quienes consideran a $T$. bolligerianus sinónimo de $T$. chiloensis subsp. litoralis.

El quinto clado incluye a las especies hermanas $T$. pectiniferus y $T$. spinibarbis, definidas por dos homoplasias: ramas adultas de $12 \mathrm{~cm}$ de diámetro (9/1), y semillas ovadas (34/1). Además, ambas especies forman un clado que muestra una relación de hermandad con $T$. deserticola, a través de seis homoplasias: centro vegetativo obtuso (6/2), ramas adultas de $6 \mathrm{~cm}$ de diámetro (9/3), costillas de 1,1-1,5 cm de alto (10/2), costillas agudas (11/1), flores apicales (17/0) y ausencia de brillo en las semillas (36/0). A su vez, T. candicans se relaciona con las tres especies mencionadas, mediante tres homoplasias: ramas de hasta un metro de largo (5/1), receptáculo a nivel del ovario ancho, $2,5 \mathrm{~cm}$ de diámetro (26/3) y paredes anticlinales de las células de la testa en forma de $S$ (37/1).

Finalmente, $T$. atacamensis es recuperado como especie hermana del resto de los taxones de este clado, cuyo ancestro se caracterizaba por las ramas laterales arqueadas en la base, para luego erguirse, además las ramas adultas son anchas, $15 \mathrm{~cm}$ de diámetro. Es interesante mencionar que Trichocereus spinibarbis presenta una homoplasia, espinas flexibles en el centro vegetativo (15/1). Esta especie claramente pertenece al género Trichocereus, ya que estudios previos sugerían que pertenecía al género Cereus (Schumann 1899) o Eulychnia (Britton \& Rose 1920; Ritter 1980b), los cuales no fueron apoyados en este análisis.

\section{Echinopsis, Lobivia y Trichocereus}

Curiosamente, los autores europeos que reúnen Trichocereus y Lobivia con Echinopsis, (ej. Hunt et al. 2006), reconocen Haageocereus y Weberbauerocereus -exclusivamente de Perú- los que presentan menores diferencias morfológicas con Trichocereus, que entre Trichocereus con Echinopsis y Lobivia. Sin embargo, Hunt y colaboradores (2006: 90), quienes son partidarios de reunir los géneros no parecen estar tampoco convencidos de su posición: "Courrent botanical opinion favours uniting several 
popularly recognized but closely interrelated genera under Echinopsis, pending a better understanding of the group as whole."

Por lo tanto, mientras Hunt et al. (2006) parecen ser los que sugieren unir una colección de géneros hasta ahora poco comprendida bajo Echinopsis s.l., basados en la inexplicable cita "opinión botánica actual"-, la naturaleza de dicho beneficio es a la vez no obvio e inexplicable.

Los estudios filogenéticos en Cactaceae (Nyffeler 2002, Hernández et al. 2011, Bárcenas et al. 2011) y en los géneros Rebutia, Pfeiffera y Echinopsis s.l. (Ritz et al. 2007, Korotkova et al. 2010, Schlumpberger \& Renner 2012), basados en secuencias del cloroplasto y del núcleo, sugieren que las relaciones dentro de la tribu Trichocereeae se encuentran sin resolver, además de que Echinopsis en su sentido amplio, no es monofilético, y que se encuentra cercanamente relacionado con el género Harrisia.

De acuerdo con los resultados Schlumpberger y Renner (2012), Echinopsis s.I. es polifilético, y podría ser monofilético si se incluyen 17 géneros (Acanthocalycium, Arthrocereus, Cephalocleistocactus, Cleistocactus (incluyendo Borzicactus), Denmoza, Espostoa (incluyendo Vatricania), Haageocereus, Harrisia, Matucana, Mila, Oreocereus, Oroya, Pygmaeocereus, Rauhocereus, Samaipaticereus, Weberbauerocereus y Yungasocereus). La clasificación filogenética entra en conflicto con las clasificaciones de Anderson $(2001,2005)$ y Hunt et al. 2006, por lo que sugieren incorporar caracteres morfológicos (de la semilla y formas de crecimiento), para la delimitación de los géneros de Trichocereeae.

Posteriormente, Schlumpberger (2012) propone dividir Echinopsis s.I. en los géneros que ya habían sido reconocidos, por ejemplo Trichocereus, que incluiría sólo dos especies $-E$. lagenaeformis $(=T$. bridgesii) y E. pachanoi (三T. macrogonus var. pachanoi) y Reicheocactus, difícil de reconocer morfológicamente, por su similitud en el tallo, espinas, flores y frutos con Lobivia densispina. Schlumpberger (2012) publicó erróneamente las combinaciones, al no citar el basónimo, y consultando los ejemplares de Schlumpberger depositados en el Herbario de Córdoba, se encuentran errores en las identificaciones y sobremuestreo en poblaciones que son hibridas $-T$. candicans subsp. pseudocandicans y T. strigosus var. vatteri-.

Con base en los resultados de la filogenia molecular de Echinopsis s.l. (Schlumpberger \& Renner 2012), Hunt (2013) acepta la solución que hacen Albesiano y Terrazas (2012), de restablecer Lobivia y Trichocereus, lo cual estaría de acuerdo con Buxbaum 1958; Rundel 1974; Leuenberger 1976; Kiesling 1978; Rauh 1979; Ritter 1980a, 1981; Eggli 1984; Gibson \& Nobel 1986; Bregman 1992; Kiesling 1999b; Perea 2005; Trevisson \& Demaio 2006; Kiesling et al. 2008; quienes consideran que Trichocereus y Echinopsis deben permanecer separados, por la forma de los tallos, que en general es cilíndrica en Trichocereus y más o menos globosa en Echinopsis, por las flores del primero que son anchas (tubo floral y el ovario de más de $2 \mathrm{~cm}$ de diámetro), y con abundante pilosidad, y los frutos muy jugosos en Trichocereus y semisecos en Echinopsis. Geográficamente, Trichocereus y Echinopsis se superponen sólo marginalmente, ya que Echinopsis se distribuye desde el Atlántico hasta el piedemonte de los Andes, 
mientras la gran mayoría de las especies de Trichocereus se presentan en altitudes altas en los Andes 0 montañas pre-andinas.

Kiesling (1978) considera que las similitudes son pruebas de un origen común, pero ellos han evolucionado independientemente lo suficiente como para constituir dos géneros separados.

Trichocereus también es cercano a Lobivia, con un grupo intermedio que fue elevado a género: Soehrensia (Kiesling 1978). Las especies de Soehrensia son consideradas por Kiesling (1999b) como parte de Lobivia. Los resultados obtenidos apoyan esta afirmación, sobre la base de la relación de los taxones hermanos de L. grandiflora y L. bruchii (S. bruchii). Sin embargo, como se ha mencionado anteriormente, se debe incluir un mayor número de especies en futuros estudios filogenéticos para apoyar estos resultados.

En general puede afirmarse que los autores con experiencia de campo, tienden a reconocer estos géneros, mientras que los que solo conocieron las plantas en cultivo tienden a agruparlos.

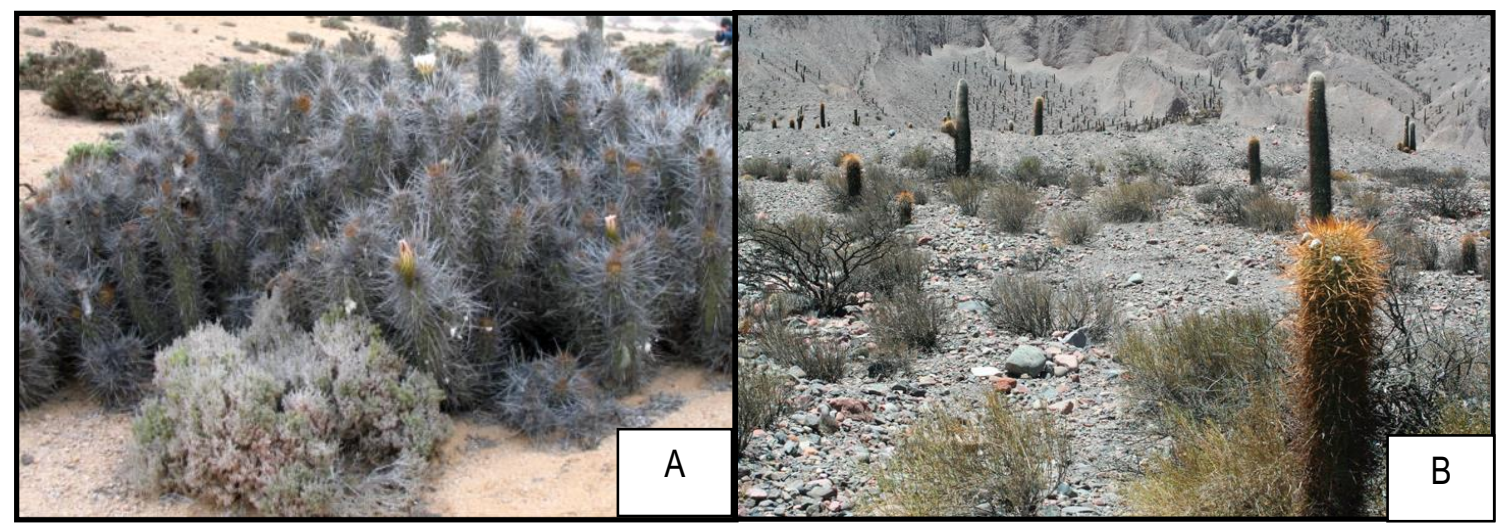

Figura 66. Hábito: A) Ramas de T. deserticola que surgen desde la base. B) Plantas arborescentes de $T$. atacamensis con tallo principal y ramificación lateral.

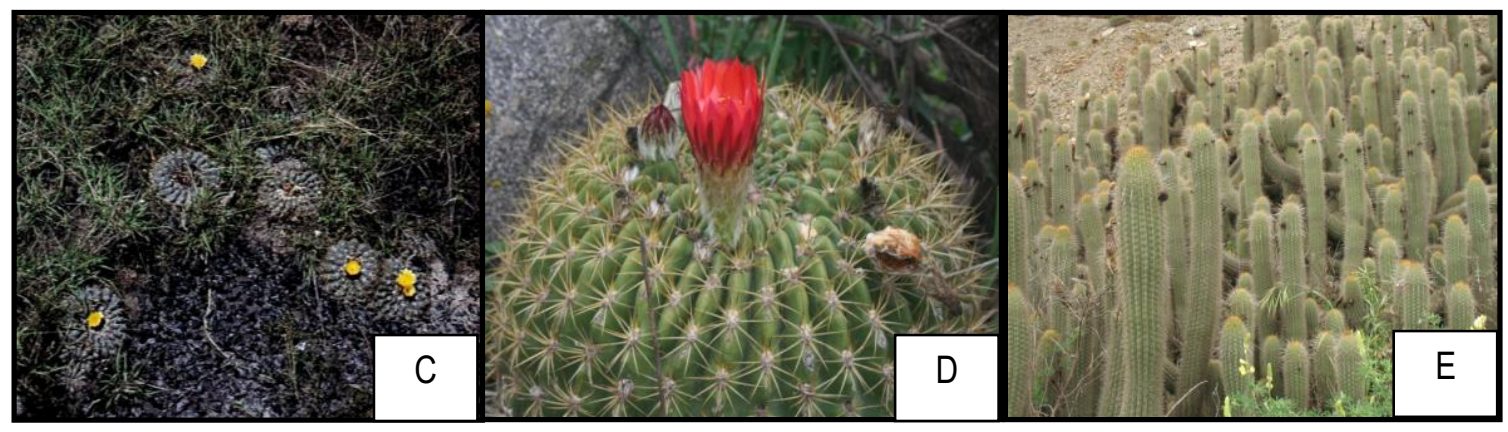

Figura 67. Forma de crecimiento: C) Individuos geófitos de Wigginsia vorwerkiana. D) Tallos globosos y sin ramas de L. bruchii. E) En $T$. bolligerianus las ramas emergen de la base, en una posición recta y paralela la una con la otra. 


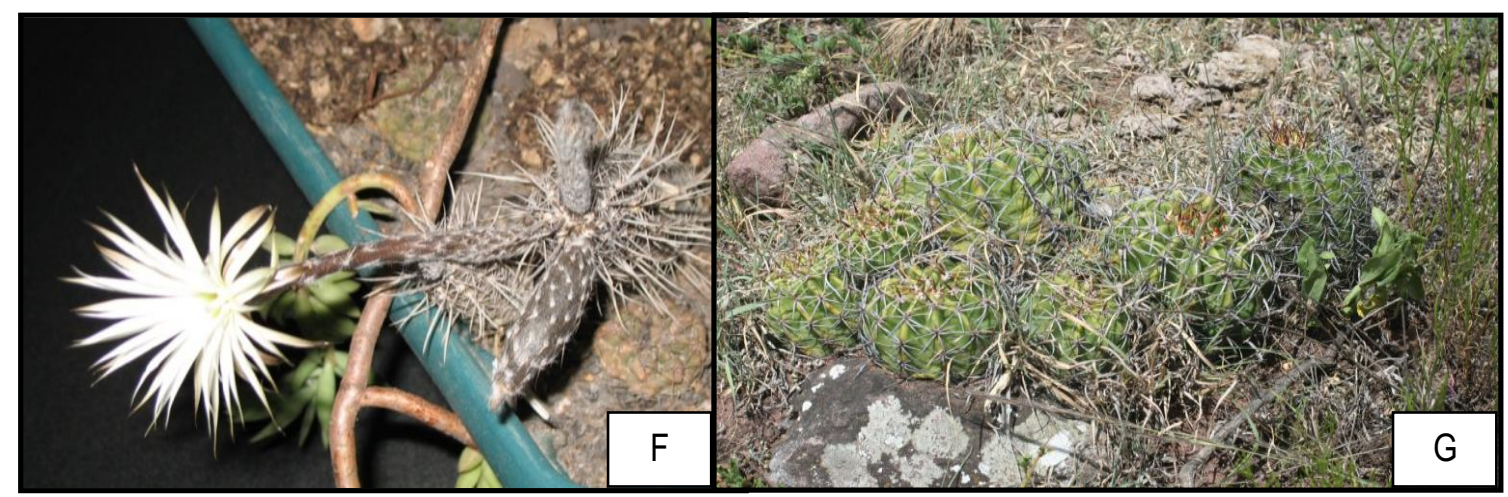

Figura 68. Forma de los tallos: F) Fusiforme atenuándose en ambos extremos en Setiechinopsis mirabilis. G) En Echinopsis albispinosa el largo es menos de dos veces su diámetro.

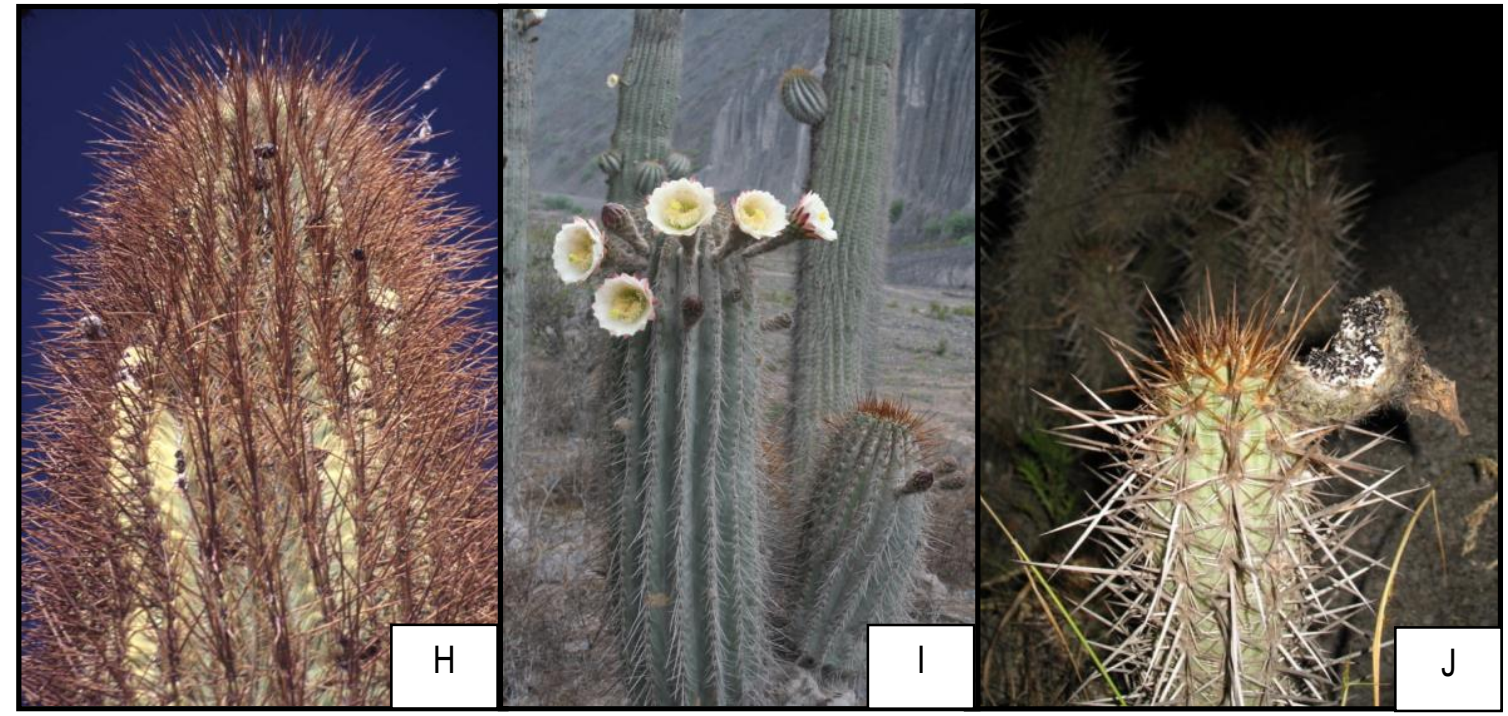

Figura 69. Dureza de las espinas en el ápice de los tallos: H) En T. atacamensis las espinas son flexibles. I) En T. terscheckii son rígidas. J) En T. pectiniferus son rígidas, al doblarlas se quiebran.

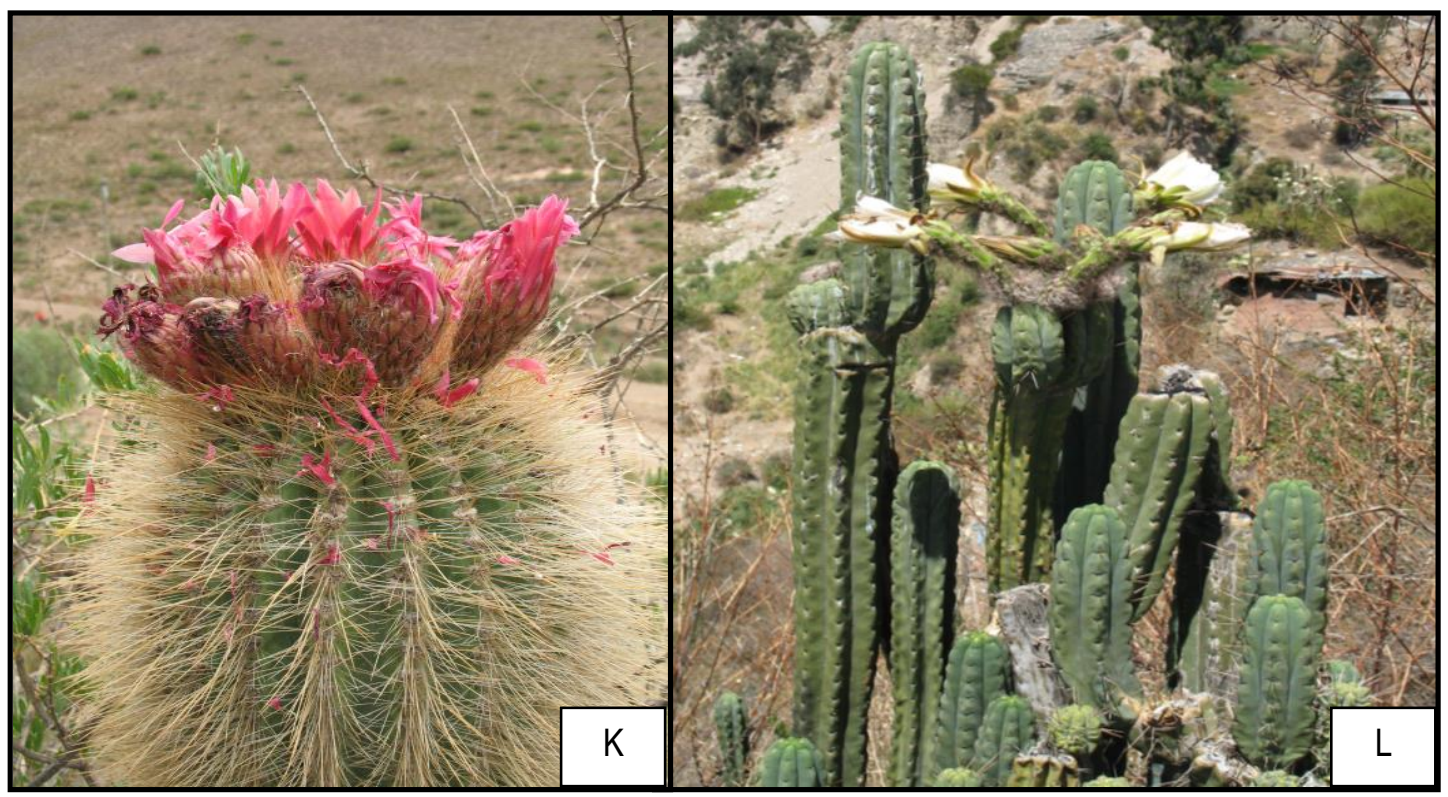

Figura 70. Posición de las flores: K) En T. tarijensis las flores se disponen en el ápice conformando una corona. L) Flores dispuestas a lo largo de los tallos en $T$. bridgesii. 


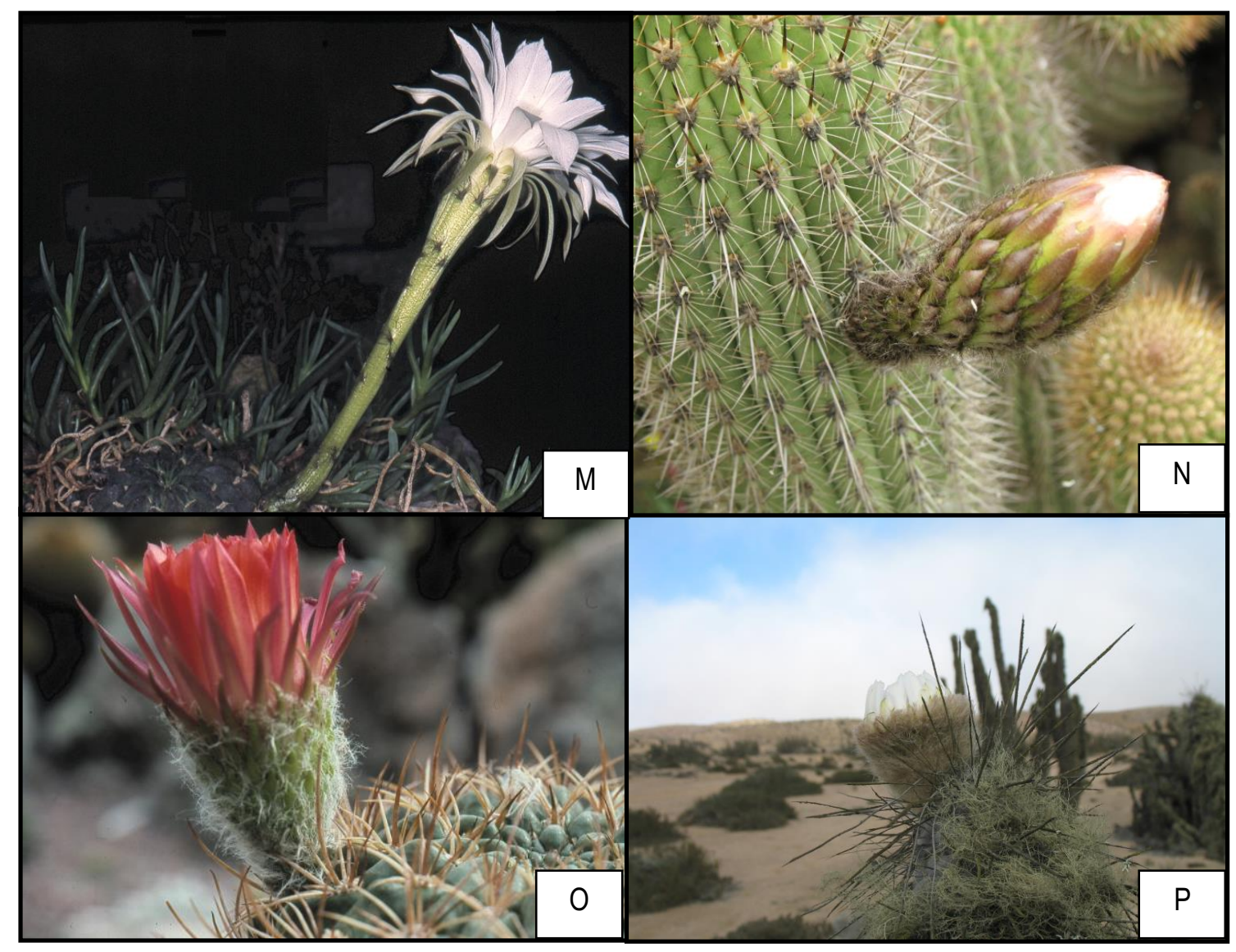

Figura 71. Pilosidad en las areolas del receptáculo: $M$ ) $E$. ancistrophora con menos de 20/areola. N) T. bolligerianus entre 20 y 40 pelos/areola. O) Lobivia kieslingii entre 20-40 pelos/areola. P) Eulychnia breviflora más de 40 pelos en cada areola.

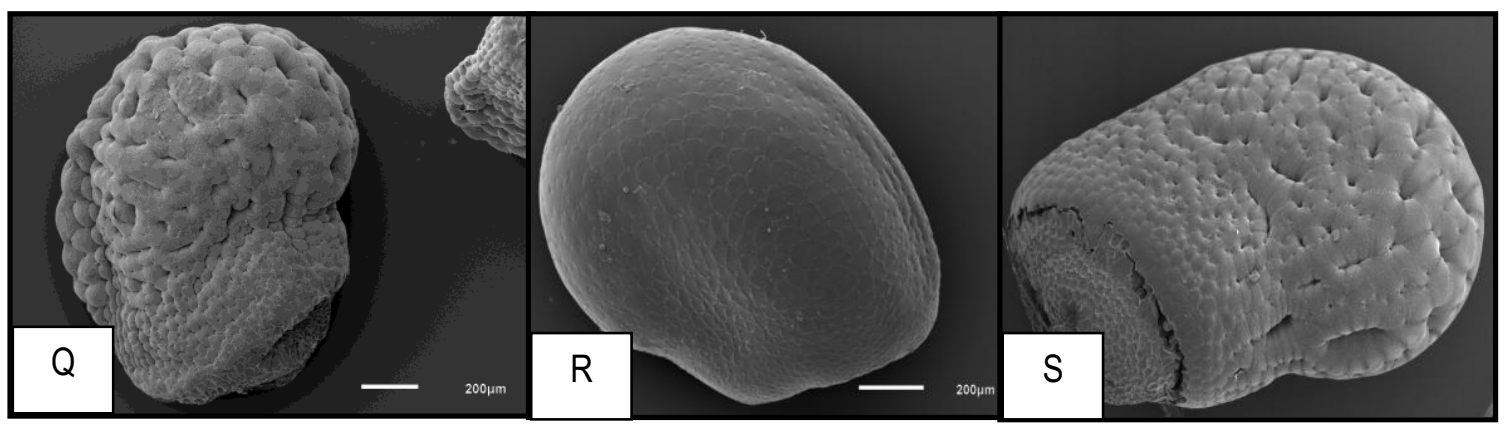

Figura 72. Forma de las paredes anticlinales de las células de la testa y quilla $\mathbf{Q}$ ) En forma de $S$ y con quilla en $T$. macrogonus var. pachanoi, R) $T$. strigosus con células de la testa en forma de U. S) $T$. atacamensis sin quilla.

\section{Helianthocereus-Trichocereus}

Backeberg (1949) propuso Helianthocereus para algunas especies de Trichocereus, y en su publicación de 1959a el menciona 13 especies de Helianthocereus. Sin embargo, Kiesling (1978) opina que el género Helianthocereus debe ser considerado sinónimo de Trichocereus, debido a que quedarían separados $H$. pseudocandicans y $T$. candicans, taxones tan relacionados que en este trabajo son tratadas como subespecies. Un caso similar es el de $T$. strigosus var. vatteri, que por sus flores coloreadas y diurnas debería incluirse en Helianthocereus, mientras que los caracteres morfológicos son muy similares 
a $T$. strigosus, excepto por el tamaño de sus flores. Helianthocereus andalgalensis, $H$. atacamensis y $H$. tarijensis no forman un clado monofilético; ellos pertenecen a tres clados diferentes dentro de Trichocereus en el análisis simultáneo (Fig. 65). Con base en los resultados presentados acá, se acepta la propuesta de Kiesling et al. (2008), de que Helianthocereus debe ser considerado sinónimo de Trichocereus.

\subsection{Evolución de caracteres:}

El presente análisis revela que varios de los caracteres analizados son de alto valor informativo para descubrir relaciones entre géneros y especies de la tribu Trichocereeae. Entre los caracteres sin homoplasia se encuentran las raíces adventicias (2), la posición de las areolas entre las costillas adyacentes (13), el pseudocefalio (16), y los frutos con restos de tubo floral (33). Estados de carácter homoplásicos que aparecieron más de dos o tres veces en forma independiente dentro de la tribu Trichocereeae o del género Trichocereus son para los tallos (hábito arborescente, presencia de un tallo principal con ramificación lateral, no basal; costillas bajas; espinas flexibles en el ápice de las ramas vegetativas), en la flor (garganta y ovario casi semejantes; flores largas, entre 20 a $24 \mathrm{~cm}$ y margen del ápice de los tépalos internos agudo), y en las semillas (forma, tamaño, brillantez y forma en $\mathrm{S}$ de la paredes anticlinales de la testa). Tres estados de carácter aparecen más de tres veces en forma independiente (centro vegetativo hundido, posición apical de las flores y presencia de la quilla en la semilla), sin embargo muchos caracteres establecidos corresponden a autapomorfias, y poco contribuyen a las relaciones entre las especies o del género.

\section{Respecto a la transformación de los caracteres:}

Hábito y forma de crecimiento: Las especies del género Trichocereus muestran diferentes formas de crecimiento, dependiendo de los cambios que se presenten en la dominancia apical (Gibson \& Nobel 1986). Existen plantas arborescentes, con tallo principal y ramificación lateral, como $T$. atacamensis (de Argentina, Bolivia y Chile, Fig. 66B), T. skottsbergii (de Chile) y T. terscheckii (de Argentina, Fig. 69I). Estas especies presentan tallos anchos $(15 \mathrm{~cm})$, debido a la presencia de médulas gruesas, y a un desarrollo anatómico que produce un incremento en el número y amplitud de las costillas (Gibson \& Nobel 1986). Hay plantas con tallos que emergen de la base, en una posición recta y paralela, como T. bridgesii (de Bolivia, Fig. 70L), T. macrogonus var. macrogonus y T. macrogonus var. pachanoi (de Ecuador y Perú), T. chiloensis subsp. chiloensis y T. bolligerianus (de Chile, Figs. 67E; 71N), o bien arbustos erectos bajos, con abundantes tallos delgados, por ejemplo T. candicans (de Argentina), T. pectiniferus (Fig. 69J), T. deserticola (Fig. 66A) y T. spinibarbis (de Chile), los cuales raramente sobrepasan los $2 \mathrm{~m}$ de alto. Estas plantas ascendentes bajas presentan menos dominancia apical en comparación con las cactáceas arborescentes, y se desarrollan cuando las ramas basales se forman inicialmente durante el crecimiento de las plantas, y cuyo desarrollo estuvo acompañado por una reducción del diámetro de la médula, y la 
formación de pocas y estrechas costillas (Gibson \& Nobel 1986). Otra hábito de crecimiento es el columnar o el parecido a la forma de un barril como T. tarijensis (de Argentina y Bolivia, Fig. 70K), en donde las ramas basales no se forman, y toda la energía se concentra en el desarrollo de un solo tallo (Gibson \& Nobel 1986). Finalmente, cuando T. bolligerianus crece cercano a la costa chilena, sus tallos cuelgan de los riscos. Igual característica fue observada por Gibson \& Nobel (1986), en $T$. peruvianus ( $T$. macrogonus var. macrogonus) sobre la costa peruana.

Desde el punto de vista filogenético, dentro de la tribu Trichocereeae la condición plesiomórfica, globoso sin ramas, se presenta en Echinopsis, Lobivia y Setiechinopsis. En Trichocereus donde el carácter plesiomórfico es basitono con ramas postradas (1/3), los siguientes cambios son observados: i) basítono con ramas arqueadas (1/5) en los clados de $T$. strigosus, $T$. andalgalensis, $T$. schickendantzii y T. candicans, $T$. deserticola, $T$. pectiniferus, $T$. spinibarbis, ii) columnar (1/2) en $T$. tarijensis, iii) basítono con ramas erectas (1/4), iv) mesotona arqueada (1/6) en $T$. atacamensis y en el clado de $T$. skottsbergii y T. terscheckii. El hábito arbustivo en la tribu Trichocereeae cambia a arborescente en el género Trichocereus, como autapomorfías en $T$. atacamensis y $T$. tarijensis, y como una sinapomorfía en clado de T. terscheckii y T. skottsbergii. En el caso de T. chiloensis subsp. chiloensis, su forma de crecimiento, basítono con ramas erectas, derivó de basítono con ramas postradas, y no de una forma en barril (plantas con tallos esféricos y mayores de $50 \mathrm{~cm}$ de alto), sugerida por Hernández et al. 2011, cuya conclusión se basa en la observación de este carácter en el árbol filogenético obtenido a partir de secuencias moleculares, más no un análisis simultáneo incluyendo datos morfológicos.

Flores y polinización: La apertura floral, la fragancia, el color de los tépalos, la longitud, grosor, forma y pubescencia del tubo floral, son algunos de los caracteres que están influenciados por el tipo de polinizador (Mandujano et al. 2010). La presencia de pelos y ausencia de espinas en el receptáculo, evita daños por los polinizadores como colibrís y polillas, que se alimentan del néctar de las flores (Gibson \& Nobel 1986).

Apertura floral: En Trichocereus, el carácter plesiomórfico es la floración nocturna (19/1). Las flores diurnas (19/0), aparecen como reversiones en el clado de $T$. andalgalensis-T. schickendantzii, y en T. tarijensis. En Trichocereeae, flores nocturnas aparece independiente en Setiechinopsis mirabilis y en el clado $E$. albispinosa y $E$. leucantha.

Longitud de las flores: El ancestro de la tribu Trichocereeae presentaba flores pequeñas (6-9 $\mathrm{cm}$ ), estado que se mantuvo en forma independiente en L. kieslingii, L. bruchii y E. aurea. En Trichocereus, el carácter plesiomórfico corresponde a flores medianas $(10-17 \mathrm{~cm})$, y las flores largas (20$24 \mathrm{~cm})(21 / 3$ Fig. 65) aparecen de manera independiente dos veces, y por reversión se adquieren independiente en $T$. terscheckii y $T$. candicans. 


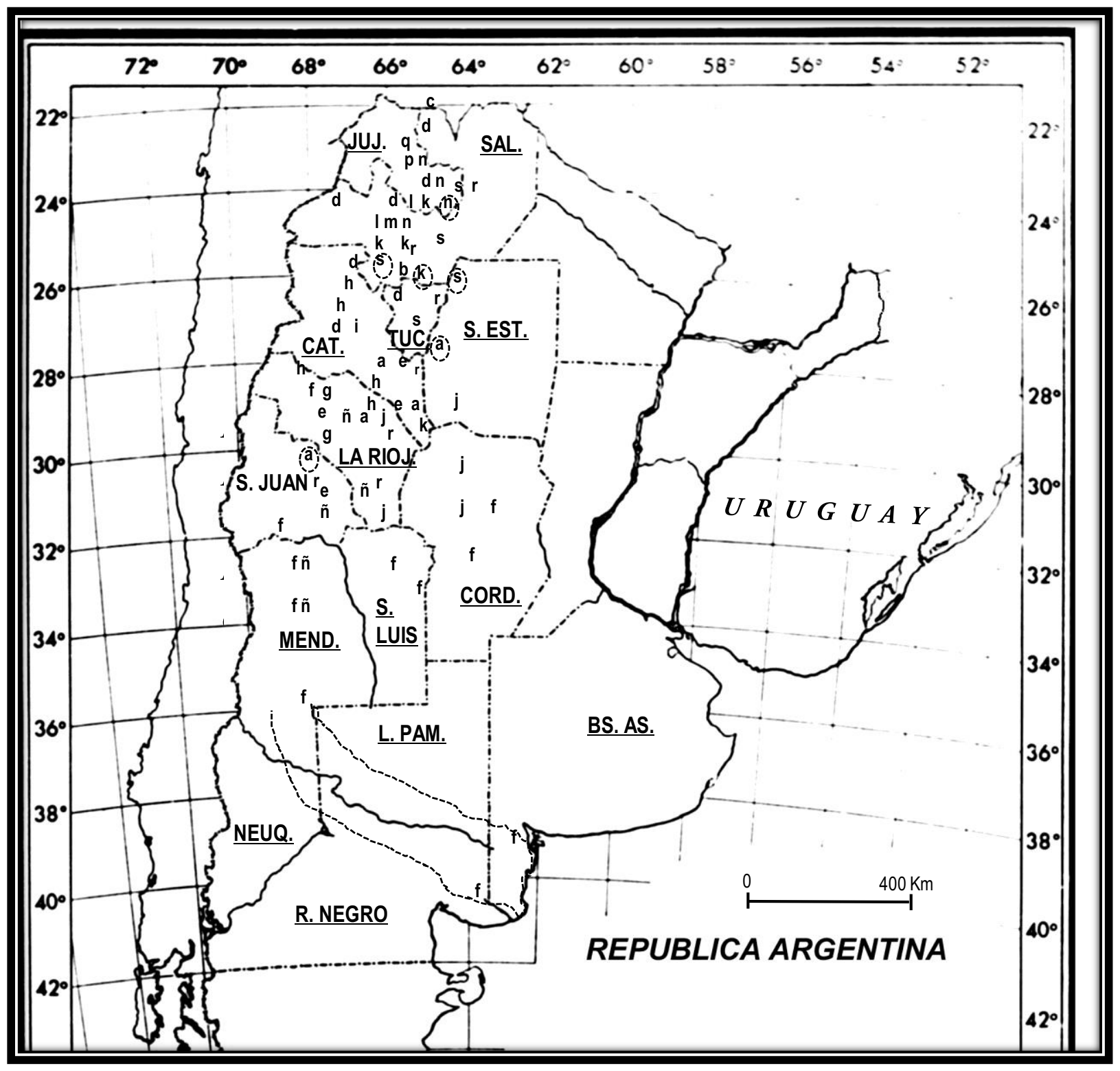

Figura 73. Distribución de las especies de Trichocereus en la Argentina: a) T. andalgalensis, b) $T$. angelesiae, c) $T$. arboricola, d) $T$. atacamensis, e) $T$. cabrerae, f) $T$. candicans subsp. candicans, g) $T$. candicans subsp. pseudocandicans, h)T. huascha var. huascha, i) $T$. huascha var. pecheretianus, j) $T$. lamprochlorus, k) T. schickendantzii subsp. schickendantzii, I) T. schickendantzii subsp. shaferi, m) $T$. schickendantzii subsp. smrzianus, n) T. spachianus, ñ) T. strigosus var. strigosus, o) T. strigosus var. vatteri, p) T. tarijensis var. tarijensis, q) T. tarijensis var. poco f. poco, r) T. terscheckii, s) T. thelegonus. Las localidades bordeadas por línea punteada corresponden a información no documentada por pliegos de herbario, sino por observaciones de fotos o comentarios personales. 


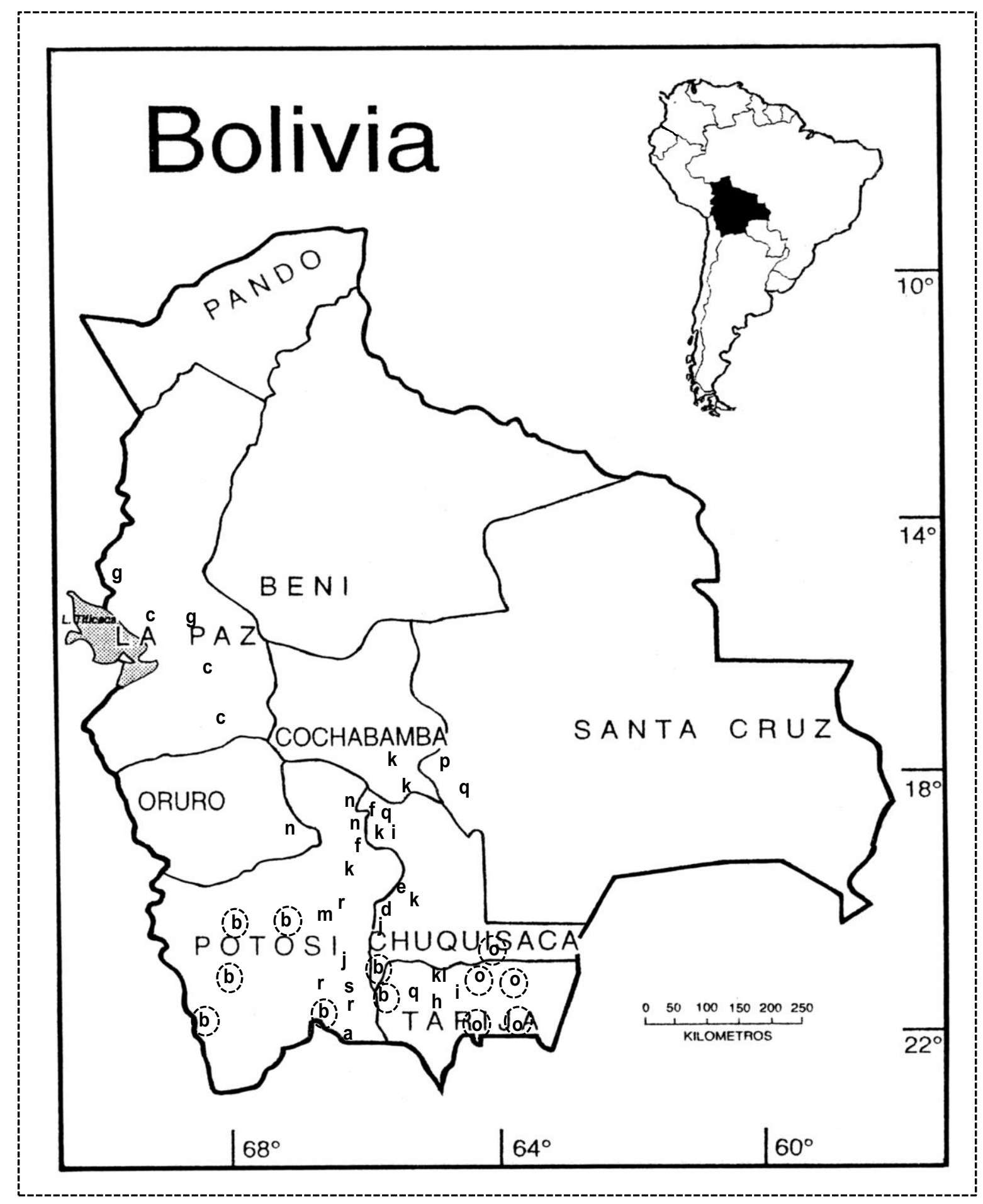

Figura 74. Distribución de las especies de Trichocereus en Bolivia: a) T. arboricola, b) $T$. atacamensis, c) $T$. bridgesii, d) $T$. camarguensis, e) $T$. clavatus, f) $T$. herzogianus, g) $T$. macrogonus var. macrogonus, h) T. narvaecensis, i) T. spachianus, j) T. tacaquirensis, k) T. taquimbalensis, I) $T$. tarijensis var. tarijensis, m)T. tarijensis var. poco f. poco, n) T. tarijensis var. poco f. albiflorus, o) T. terscheckii, p) $T$. vasquezii, q) $T$. vollianus, r) $T$. werdermannianus, s) $T$. wilkeae. La localidad bordeada por línea punteada corresponde a información no documentada por pliegos de herbario, sino por observaciones de fotos o comentarios personales. 


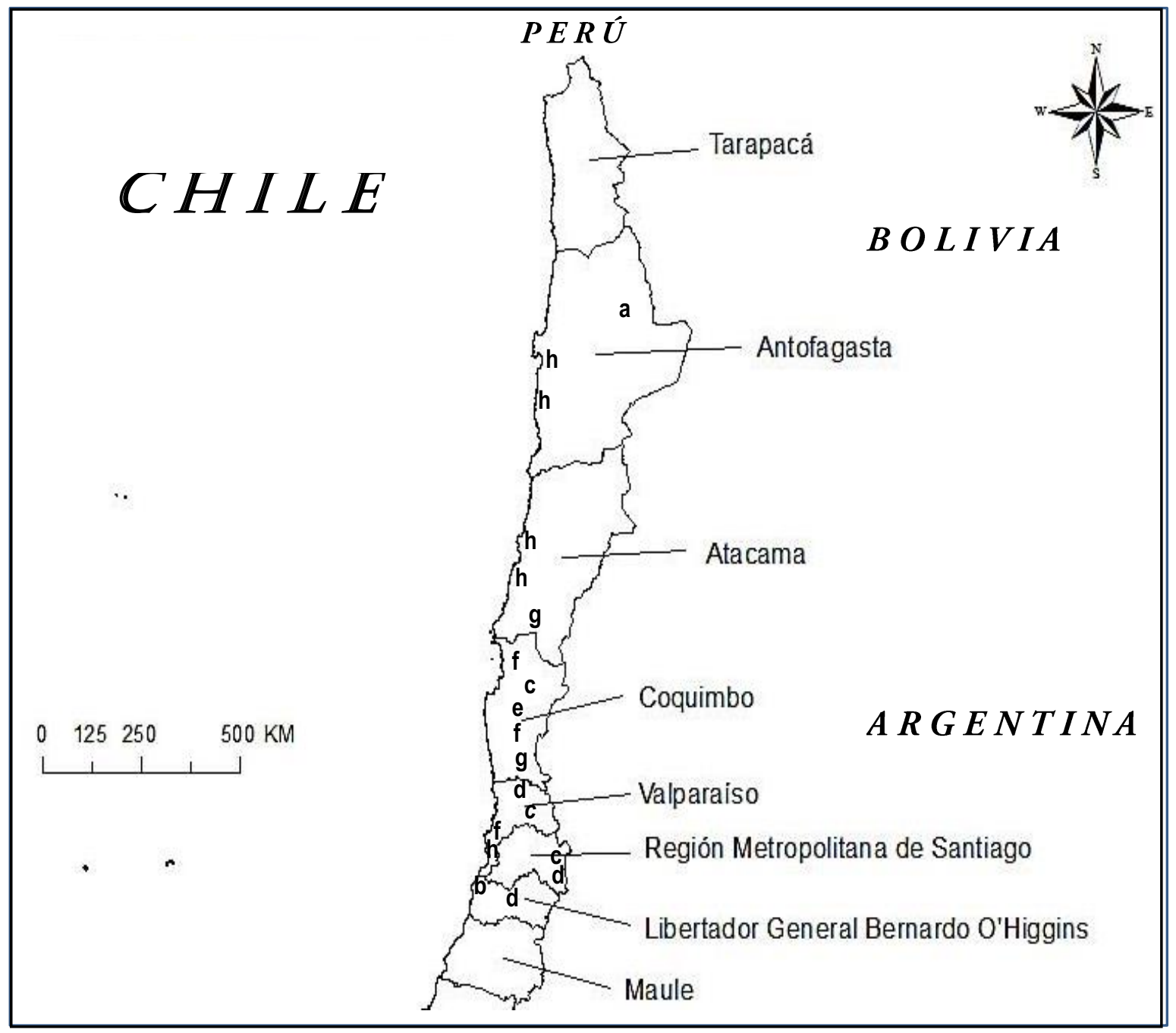

Figura 75A. Localización de los taxones de Trichocereus en Chile: a) Trichocereus atacamensis,

b) Trichocereus bolligerianus, c) Trichocereus chiloensis subsp. chiloensis, d) Trichocereus chiloensis subsp. australis, e) Trichocereus chiloensis subsp. eburneus, f) Trichocereus chiloensis subsp. litoralis, g) Trichocereus chiloensis subsp. panhoplites, h) Trichocereus deserticola. 


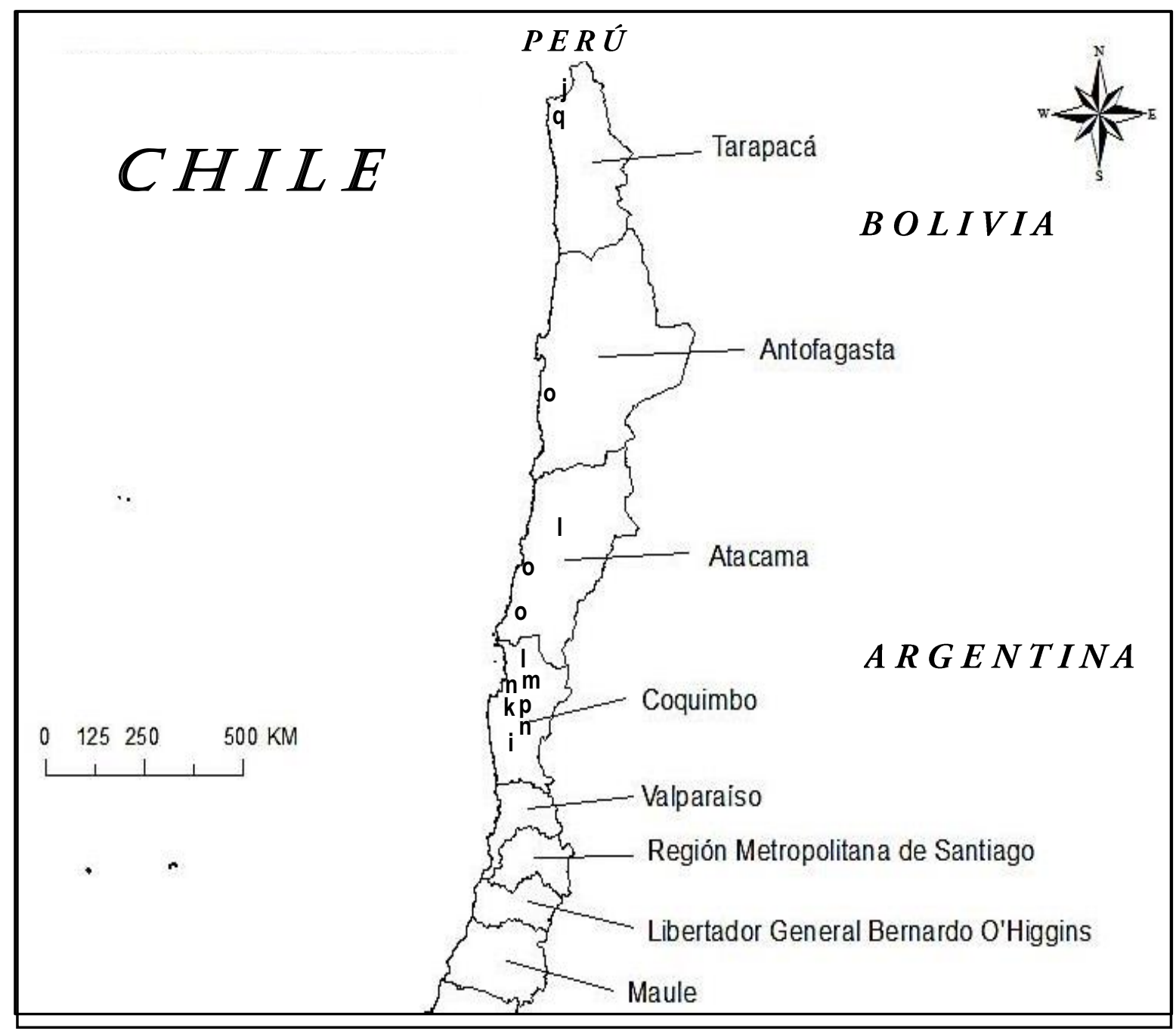

Figura 75B. Localización de los taxones de Trichocereus en Chile: i) Trichocereus faundezii, j) Trichocereus macrogonus var. macrogonus, k) Trichocereus macrogonus var. pachanoi, I) Trichocereus nigripilis, m) Trichocereus pectiniferus, n) Trichocereus skottsbergii, o) Trichocereus spinibarbis, p) Trichocereus undulosus, q) Trichocereus uyupampensis. 


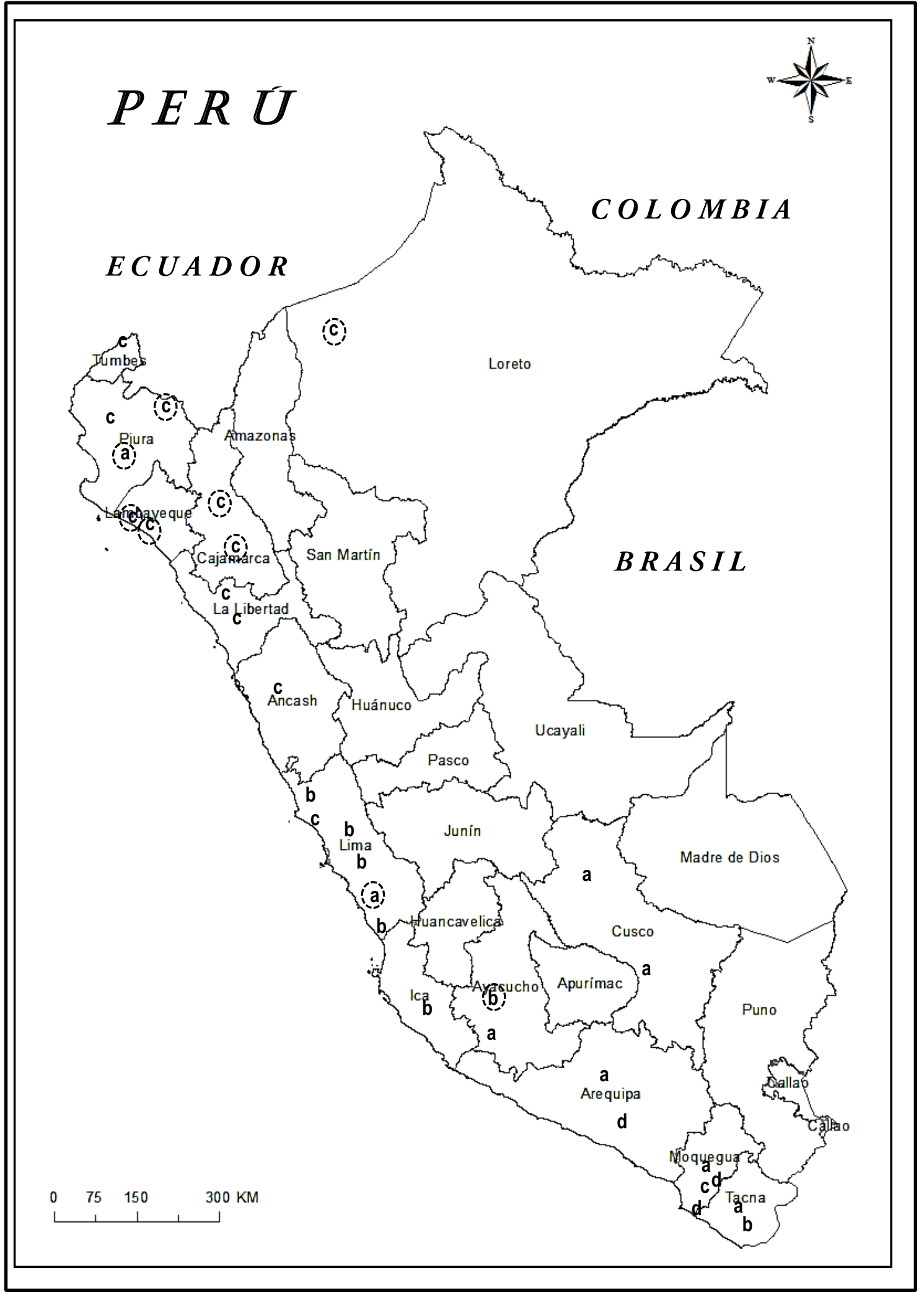

Figura 76. Distribución de los taxones de Trichocereus en Perú: a) $T$. cuzcoensis, b) $T$. macrogonus var. macrogonus, c) T. macrogonus var. pachanoi, d) T. uyupampensis. La localidad bordeada por línea punteada corresponde a información no documentada por pliegos de herbario, sino por bibliografía (Ogunbodede et al. 2010). 


\section{CONCLUSIONES GENERALES}

Trichocereus (Cactaceae: Cactoideae: Trichocereeae) es un género sudamericano representado por 58 taxones (38 especies, 10 subespecies, 8 variedades y 2 formas) que habitan principalmente las zonas áridas y semiáridas de la región andina de Ecuador, Perú, Bolivia, Chile y la Argentina. Sus especies constituyen elementos dominantes del paisaje y definen provincias fitogeográficas.

Como resultado del estudio taxonómico se proporcionan iconografías, descripciones originales, descripciones detalladas, distribuciones y hábitats, comentarios taxonómicos y nomenclaturales, exsiccatas, y doce claves, una clave general, tres por países, tres de subespecies, cuatro de variedades y una de forma.

\section{Conclusiones del Tratamiento taxonómico:}

1. La distribución del $93 \%$ de los taxones se restringe a un país (Argentina, Bolivia, Chile y Perú), y el 7\% se localiza en dos o tres países (Argentina-Bolivia; Argentina-Bolivia-Chile; Bolivia-Ecuador-Perú), por ejemplo $T$. arboricola y $T$. tarijensis se distribuyen en la Argentina y Bolivia; $T$. atacamensis en la Argentina, Bolivia y Chile; y T. macrogonus en Bolivia, Ecuador y Perú.

2. Del estudio taxonómico se presentan doce combinaciones, once nuevos sinónimos, tres nombres nuevos, nueve lectotipificaciones y cincuenta y dos neotipificaciones.

3. Se aclara la identidad de Cereus macrogonus Salm-Dyck, especie tipo del género Trichocereus (Berger) Riccob., también se establecen sus sinónimos, afinidades, y se designa un Neotipo que coincide con el protologo, contribuyendo a la estabilidad nomenclatural del género.

4. Del estudio de la descripción original de Cereus macrogonus se interpreta que la especie, muy posiblemente originaria del Perú, fue también llamada más recientemente Trichocereus peruvianus Britton \& Rose. Esta identidad concuerda con el uso del nombre en la literatura botánica y en horticultura, el cual se ha mantenido hasta el presente.

5. Trichocereus pachanoi Britton \& Rose es considerada una variedad de T. macrogonus (SalmDyck) Riccob., T. macrogonus var. pachanoi (Britton \& Rose) S. Albesiano \& R. Kiesling y se designa un lectotipo.

6. Sobre la base del estudio taxonómico y el análisis filogenético se excluyeron de Trichocereus ocho especies, por considerarlas sinónimos de otros géneros, T. coquimbanus es sinónimo de Eulychnia coquimbana; T. grandiflora, T. lobivioides y T. rowleyi son sinónimos de Lobivia grandiflora; T. formosus, $T$. ingens y $T$. uebelmannianus de Lobivia formosa y $T$. walteri de L. walterii. 


\section{Conclusiones del Análisis Filogenético:}

Las relaciones filogenéticas de Trichocereus fueron examinadas sobre la base de 39 caracteres exomorfológicos y secuencias de ADN del cloroplasto, trnL-F y rp/16 de 17 especies de Trichocereus, incluyendo otros tres géneros de la tribu Trichocereeae (Echinopsis, Lobivia, Setiechinopsis), dos de Notocacteae (Eulychnia, Wigginsia) y uno de Hylocereeae (Harrisia).

Los resultados de los análisis de los datos moleculares y morfológicos por separado y simultáneo (morfología + ADN) para el grupo de cactáceas en estudio, confirman que es el análisis simultáneo el que tiene mayor poder informativo y explicativo de los datos. De acuerdo con el análisis de la evidencia total o simultáneo, se abordó a las siguientes conclusiones:

1. La tribu Trichocereeae se recuperó como monofilética, apoyada por una combinación única de caracteres (con 2/3 de los tallos mostrados en superficie, pseudocefalio ausente, flores dispuestas lateralmente y fruto obcónico).

2. El género Trichocereus es monofilético si las dos especies de Harrisia $(H$. earlei y $H$. hahniana), forman parte de él. Este clado se recupera por tres sinapomorfías, crecimiento basítono con ramas prostradas, escamas imbricadas a lo largo del receptáculo floral, y frutos subglobosos, achatados en los extremos.

3. El género Trichocereus es hermano de tres especies de Lobivia. La presencia de costillas agudas y las escamas cercanas la una a la otra en el receptáculo floral definen esta relación de hermandad.

4. Lobivia y Echinopsis s. str. son recuperados como parafiléticos. Setiechinopsis mirabilis es distintivo, en virtud de la presencia de 13 autapomorfías, dos de ellas exclusivas (forma de tallos fusiforme y margen del ápice de los tépalos internos finalizando en un ángulo inferior a 45 grados).

5. Dentro de la tribu Trichocereeae la condición plesiomórfica globoso sin ramas se presenta en Echinopsis, Lobivia y Setiechinopsis. En Trichocereus donde el carácter plesiomórfico es basitono con ramas postradas, los siguientes cambios son observados: i) basítono con ramas arqueadas en los clados de $T$. strigosus, $T$. andalgalensis, $T$. schickendantzii y $T$. candicans, $T$. deserticola, $T$. pectiniferus, $T$. spinibarbis, ii) columnar en $T$. tarijensis, iii) basitono con ramas erectas, iv) mesotona arqueada en $T$. atacamensis y en el clado de $T$. skottsbergii y $T$. terscheckii. El hábito arbustivo en la tribu Trichocereeae cambia a arborescente en el género Trichocereus, como autapomorfías en $T$. atacamensis y $T$. tarijensis, y como una sinapomorfía en el clado de $T$. terscheckii y $T$. skottsbergii. 


\section{LITERATURA CITADA}

Abbey Garden. 1981. Cactus and succulent Catalogue. California.

Ahumada M., Faúndez L. 2007. Manual de reconocimiento de especies de flora de las veranadas, región de Coquimbo. Servicio Agrícola y Ganadero, Chile.

Albesiano S. 2012. A new taxonomic treatment of the genus Trichocereus (Cactaceae) in Chile. Haseltonia 18: 116-139.

Albesiano S., Kiesling R. 2012. Identity and neotypification of Cereus macrogonus, the type species of the genus Trichocereus (Cactaceae). Haseltonia 17: 24-34.

Albesiano S., Terrazas T. 2012. Cladistic analysis of Trichocereus (Cactaceae: Cactoideae: Trichocereeae) based on morphological data and chloroplast DNA sequences. Haseltonia 17: 3-23.

Albesiano S. 2014. Trichocereus, en P. Jorgensen, M. Nee y S. Beck (eds.), Catálogo de las plantas vasculares de Bolivia, pp. 467-470. Missouri Botanical Garden Press, St. Louis.

Anderson E.F. 2001. The Cactus Family. Timber Press, United States.

Anderson E.F. 2005. Das Grosse Kakteen-Lexikon. E. Ulmer, Stuttgart.

Applequist W.L., Wallace R.S. 2000. Phylogeny of the Madagascan endemic family Didiereaceae. Plant Syst. Evol. 221: 157-166.

Arakaki M., Christin P.A., Nyffeler R., Lendel A., Eggli U., Ogburn M., Spriggs E., Moore M.J., Edwards E.J. 2011. Contemporaneous and recent radiations of the world's major succulent plant lineages. Proceedings of the National Academy of Sciences, USA 108: 8379-8384.

Arias S., Terrazas T. 2006. Análisis cladístico del género Pachycereus (Cactaceae) con caracteres morfológicos. Brittonia 58 (3): 197-216.

Backeberg C. 1935. The cactus regions of Chile, Bolivia and Patagonia. Blätt. Kakteenf.: 7.

Backeberg C., Knuth F.M. ("1935”) 1936. Kaktus-ABC. Gyldendalske B, Denmark:

Backeberg C. 1937. Trichocereus peruvianus Br. \& R. Blätt. Kakteenf. 4: 9.

Backeberg C. 1941. Seltene Cereen des Westandinen Suedamerica. Kakteenkunde: 16-20.

Backeberg C. 1949. The Natio Lobiviae. Cact. Succ. Journ. Gr. Brit. 11(3): 53.

Backeberg C. 1950. Trichocereus skottsbergii, en C. Skottsberg (ed.), Acta Horti Gothob. 18: 146.

Backeberg C. 1953. Un nouveau Trichocereus voisin de T. shaferi et T. schickendantzii. Cactus (Paris) No. 35: 147-148.

Backeberg C. 1955. Helianthocereus pecheretianus. Cactus (Paris) No. 46-47: 277-278.

Backeberg C. 1958. Die Cactaceae 1. Gustav Fischer Verlag, Jena.

Backeberg C. 1959a. Die Cactaceae 2. Gustav Fischer Verlag, Jena.

Backeberg C. 1959b. Die Cactaceae 3. Gustav Fischer Verlag, Jena.

Backeberg C. 1966. Das Kakteenlexicon: enumeratio diagnostica Cactacearum. Gustav Fischer Verlag, Jena. 
Backeberg C. 1976. Cactus Lexicon 3 ed. Blandford Press, England.

Backeberg C. 1979. Das Kakteen Lexicon. Edición 5. Fischer Verlag, Jena.

Badano E.I., Schlumpberger B.O. 2001. Sistema de cruzamiento y estimaciones en la eficiencia de polinización sobre Trichocereus pasacana (Cactaceae) en dos poblaciones del noroeste Argentino. Gayana Bot. 58 (2): 115-122.

Bárcenas R.T., Yesson Ch., Hawkins J.A. 2011. Molecular systematics of the Cactaceae. Cladistics 27 (5): 470-489.

Barthlott W., Hunt D.R. 1993. Cactaceae, en K. Kubitzki, J.G. Rohwer \& V. Bittrich (eds.), The families and genera of vascular plants, pp. 161-197. Springer Verlag, Germany.

Barthlott W., Hunt D.R., editores. 2000. Seed diversity in the Cactaceae. Succulent Plant Research 5: 1 173.

Berger A. 1900. Cereus spachianus Lem. Monatsschr. Kakteenk. 10: 92-95.

Berger A. 1904. Cereus macrogonus S.-D., Monatt. f. Kakteenk. 9: 190.

Berger A. 1905. A systematic revision of the genus Cereus. Rep. (Annual) Missouri Bot. Gard. 16: 57-111.

Berger A. 1929. Kakteen: anleitung zur Kultur und Kenntnis der wichtigsten eingeführten Arten. Verlagsbuchhandlung von E. Ulmer, Stuttgart.

Borg J. 1937. Cacti. Macmillan Co. London.

Borg J. 1951. Cacti. Blandford. London.

Brako L., Zarucchi J.L. 1993. Catalogue of the Flowering Plants and Gymnosperms of Peru. 45. Missouri Botanical Gardarden Press, St. Louis.

Bravo H., Sánchez H. 1991. Las cactáceas de México III. México D.F.: Univ. Nac. Autón., México.

Bregman R. 1992. Seed studies in the subtribe Borzicactinae Buxbaum (Cactaceae); morphology, taxonomy, phylogeny and biogeography. Bot. Jahrb. Syst. 114 (2): 201-250.

Britton N.L., Rose J.N. 1920. The Cactaceae: Descriptions and illustrations of plants of the cactus family II. Carnegie Institution, Washington.

Buxbaum F. 1950. Morphology of cacti. Section I. Roots and stems. Pasadena: Abbey Garden Press.

Buxbaum F. 1953. Morphology of cacti Section II. The flower. Pasadena: Abbey Garden Press.

Buxbaum F. 1955. Morphology of cacti. Section III. Fruits and seeds. Pasadena: Abbey Garden Press.

Buxbaum F. 1958. The phylogenetic division of the subfamily Cereoideae, Cactaceae. Madroño 14: 177206.

Buxbaum F. 1964. Was ist ein Cephalium? Kakteen And. Sukk. 15: 43-48.

Cabrera A.L., Willink A. 1980. Biogeografía de América Latina. Secretaría General de la Organización de los Estados Americanos, Washington.

Cárdenas M. 1953a. Notas cactológicas de Bolivia: Dos Trichocereus nuevos. Revista Agric. (Cochabamba) 8: 15-19.

Cárdenas M. 1953b. The pasacanoid Trichocerei of South America. Fuaux Herb. Bull. 1(5): 6-25. 
Cárdenas M. 1953c. Un viaje botánico por el sur de Bolivia. Revista Agric. (Cochabamba). No. 9: 3-19.

Cárdenas M. 1957. Nouvelles cactées Boliviennes. Cactus (Paris) No.57: 246-264.

Cárdenas M. 1959. Nouvelles Cactées Boliviennes VI. Cactus (Paris) 14 (64): 159-184.

Cárdenas M. 1963. New Bolivian Cacti. Cact. Succ. J. (Los Angeles). 35 (5): 157-159.

Cárdenas M. 1969. Manual de Plantas Económicas de Bolivia. Ichtus, Bolivia.

Castellanos A., Lelong H.V. 1938. Los géneros de las Cactáceas Argentinas. Anales Mus. Argent. Ci. Nat. Bernardino Rivadavia 39: 383-420.

Castellanos A., Lelong H.V. 1943. Opuntiales vel Cactales, en Descole (ed.), Gen. Sp. Pl. Argent., t. 1, pp. 47-142. Apud Guillermo Kraft, Buenos Aires.

Cenizo V., Mazzola M., Corró B., Kin A. 2013. Características morfológicas y anatómicas de las plántulas de Trichocereus candicans (Cactaceae). Bol. Soc. Argent. Bot. 48 (3-4): 443-451.

Charles G. 2005. Echinopsis chiloensis subsp. skottsbergii, en D. Hunt \& N. Taylor (eds.), Notulae Systematicae Lexicon Cactacearum Spectantes V. Cactaceae Syst. Init. 19: 13.

Cialdella A.M., Giussani L.M., Aagesen L., Zuloaga F., Morrone O. 2007. A phylogeny of Piptochaetium (Poaceae: Pooideae: Stipeae) and related genera based on a combined analysis including trnL-F, rp/16, and morphology. Syst. Bot. 32 (3): 545-559.

Davis W.E. 1983. Sacred plants of the San Pedro cult. Bot. Mus. Leafl. 29: 367-386.

De Pinna M.C. 1991. Concepts and test of homology in the cladistics paradigm. Cladistics 7: 367-394.

Diers L. 2008. Over chromosome bij cactussen - ter herinnering aan Albert Buining (3). Succulenta 87: 180-187.

Dodds L. 1937. Lobivia formosa (Pfeiffer) new combination. Cact. Succ. J. (Los Angeles) 8: 146-150.

Doyle J.J., Doyle J.L. 1987. A rapid DNA isolation procedure for small quantities of fresh leaf tissue. Phytochem. Bull. 19: 11-15.

Edgar R.C. 2004. Muscle: multiple sequence alignment with high accuracy and high throughput. Nucl. Acids Research 32 (5): 1792-1797.

Eggli U. 1984. Stomatal types of Cactaceae. Pl. Syst. Evol. 146: 197-214.

Eggli U., Muñoz-S. M., Leuenberger B. 1996. Cactaceae of South America: the Ritter Collections. Englera 16: 182.

Eggli U., Leuenberger B. 2005. The Cárdenas type specimens of Cactaceae names in the herbarium of the Instituto Miguel Lillo, Tucumán, Argentina (LIL). Willdenowia 35: 179-192.

Eggli U., Walter H. 2012. Proposal to reject the name Cactus coquimbanus (Cactaceae). Taxon 61 (3): 686-687.

Endler J., Buxbaum F. 1958. Die pflanzenfamilie der Kakteen. A. Philler Verlag, Minden.

Faúndez L., Kiesling R. 2007. Nuevas combinaciones en Cactaceae. Darwiniana 45 (2): 237.

Fernández J.L., Estupiñan C. 2005. Echinopsis pachanoi y Opuntia quitensis, dos cactáceas nuevas para la Flora de Colombia. Bol. Soc. Latin. Carib. Cact. Suc. 2(3): 3-4. 
Font F., Picca P. 2001. Natural hybridization between Trichocereus atacamensis (Philippi) Marshall and Denmoza rhodacantha (Salm-Dyck) Britton \& Rose (Cactaceae). Bradleya 19: 59-66.

Friedrich H. 1974. Zur taxonomie und phylogenie der Echinopsidinae (Trichocereinae). I.O.S. Bull. 3 (3): 79-93.

Friedrich H., Glaetzle W. 1983. Seed morphology as an aid to classifying the genus Echinopsis Zucc. Bradleya 1: 91-104.

Gajardo R. 1995. La vegetación natural de Chile: Clasificación y distribución geográfica. Universitaria, Santiago.

Gibson A.C., Nobel P.S. 1986. The cactus primer. Harvard University Press., Cambridge (US:MA)/London (GB).

Goloboff P.A., Farris J.S., Nixon K.C. 2008. TNT, a free program for phylogenetic analysis cladistics. Cladistics 24: 774-786.

Gravendeel B., De Vogel E.F. 2002. Revision of Coelogyne section Moniliformes (Orchidaceae) based on morphology, plastid and nrDNA ITS sequences. Blumea 47 (3): 409-462.

Gravendeel B., Eurlings M., Berg C., Cribb P. 2004. Phylogeny of Pleione (Orchidaceae) and parentage analysis of its wild hybrids based on plastid and nuclear ribosomal ITS sequences and morphological data. Syst. Bot. 29 (1): 50-63.

Haage F.A. 1927. Samen und Pflanzenhandlung. Kakteen-Preisverzeichnis [Catalog]. Germany.

Haage F.A. 1938. Samen und Pflanzenhandlung. Kakteen-Preisverzeichnis [Catalog], Germany.

Hall T.A. 1999. BioEdit: a user-friendly biological sequence alignment editor and analysis program for windows 95/98/NT. Nucl. Acids. Symp. Ser. 41: 95-98.

Hartmann S., Nason J.D., Bhattacharya D. 2001. Extensive ribosomal DNA genic variation in the columnar cactus Lophocereus. J. Mol. Evolution 53: 124-134.

Hernández T., Hernández H., De Nova A., Puente R., Eguiarte L., Magallón S. 2011. Phylogenetic relationships and evolution of growth form in Cactaceae (Caryophyllales, Eudicotyledoneae). Amer. J. Bot. 98 (1): 44-61.

Hilgert N., Kiesling R. 2002. The utilization of cacti in the upper rio Bermejo basin, Salta, Argentina. Haseltonia 9: 41-50.

Hoffmann A. 1989. Cact. Fl. Silvestre Chile. Fundación Claudio Gay, Santiago.

Hoffmann A., Walter H.E. 2004. Cact. Fl. Silvestre Chile. 2a. ed. Fundación Claudio Gay, Santiago.

Holly Gate Nurseries Ltd. 1977-1978. Seeds List. W. Sussex, Great Britain.

Holmgren P.K., Holmgren N.H., Barnett L.C. 1990. Index Herbariorum. Part I: the herbaria of the world, 8th edition. New York: New York Botanical Garden.

Houghton A.D. 1931. The Cactus Book. The Macmillan Company, New York.

Hunt D.R. 1967. The genera of the Cactaceae, en Hutchinson J. (ed.), The Genera of Flowering Plants, pp. 427-467. Oxford University Press, England. 
Hunt D.R. 1989. Echinopsis, en S.M. Walters, J.C.M. Alexander, A. Brady, C.D. Brickell, J. Cullen, P.S. Green, V.H. Heywood, V.A. Matthews, N.K.B. Robson, P.F. Yeo y S.G. Knees (eds.), The European Garden Flora, vol. 3, Dicotyledons (Part I), pp. 237-243. University Press, Cambridge.

Hunt D.R. 1992. Cites Cactaceae Checklist. Kent. Whitstable Litho, Whitstable.

Hunt D.R. 1999. Cites Cactaceae Checklist. 2nd ed. Royal Botanic Gardens, Kew/International Organization for Succulent Plant Study, England.

Hunt D.R., Taylor N., editors 1986. The genera of the Cactaceae: towards a new consensus. Bradleya 4: 65-78.

Hunt D.R., Taylor N. 2006. Lectotype and neotype designations. Cactaceae Consensus Init. 21: 4-10.

Hunt D.R., Taylor N., Charles G., International Cactaceae Systematics Group. 2006. The New Cactus Lexicon. DH Books, Milborne Port.

Hunt D.R. 2013. The New Cactus Lexicon Illustrations. DH Books, Milborne Port.

Innes C. 1990. Cacti. London. Collins Publishers.

Ito Y. 1957. Diagr Austroechinocact. Japan Cactus Laboratory, Japan.

Jordan W.C., Courtney M.W., Neigel J.E. 1996. Low levels of intraspecific genetic variation at a rapidly evolving chloroplast DNA locus in North American duckweeds (Lemnaceae). Amer. J. Bot. 83: 430439.

Katagiri J. 1952. Studies on the cromosome number in certain Cactaceae. Japanese Journ. Breeding 1: 233-236.

Katinas L., Gutiérrez D.G., Torres S.S. 2000. Carlos Spegazzini (1858-1926): travels and botanical work on vascular plants. Ann. Missouri Bot. Gard. 87: 183-202.

Katinas L., Gutiérrez D.G., Torres S.S. 2004. Type material of Carlos L. Spegazzini in the Museo de La Plata Herbarium (LP), Argentina. III: Cactaceae. Darwiniana 42 (1-2): 177-200.

Kiesling R. 1976. Novedades en Trichocereus (Cactaceae). Hickenia 1(6): 29-34. 1976.

Kiesling R. 1977. El género Trichocereus en la República Argentina. Trabajo de grado para optar la título de Doctor en Ciencias Naturales. Universidad Nacional de La Plata. La Plata, Argentina.

Kiesling R. 1978. El género Trichocereus (Cactaceae) I: Las especies de la Rep. Argentina. Darwiniana 21(2-4): 263-330.

Kiesling R. 1999a. The Cacti of Bolivia. Succulentes (numere speciele 1999) 22: 3-16.

Kiesling R. 1999b. Cactaceae, en Zuloaga F. y Morrone O. (eds.), Catálogo de las plantas vasculares de la República Argentina 2, pp. 423-489, 1245-1246. Monogr. Syst. Bot. Missouri Bot. Gard., St. Louis.

Kiesling R., Meglioli S. 2003. Cactaceae, en Kiesling R. (ed.), Flora de San Juan, República Argentina, Vol. II, pp. 161-193. Estudio Sigma, Buenos Aires.

Kiesling R., Ferrari O. 2005. 100 Cactus Argentinos. Editorial Albatros, Buenos Aires. 
Kiesling R., Larocca J., Faúndez L., Metzing D., Albesiano S. 2008. Cactaceae, en Zuloaga F. y Morrone O. (eds.), Catálogo de la Flora Vascular del Cono Sur de Sudamérica, pp. 1715-1830. Instituto Darwinion (Arg.)-Missouri Botanical Garden Press, St. Louis.

Kiesling R., Saravia M., Oakley L., Muruaga N., Novara L. 2009. Flora del Valle de Lerma, Cactaceae. Aportes Botánicos de Salta-Ser. Flora 9 (2): 1-45.

Kiesling R., Saravia M., Oakley L., Muruaga N., Metzing D., Novara L. 2011. Cactaceae. Aportes Botánicos de Salta-Ser. Flora 2 (7): 1-142.

Kimnach M. 1990. A new epiphytic cactus: Trichocereus arboricola. Cact. Succ. J. (Los Angeles) 62(1): 35.

Köhres G. 1986. Seedlist [Catalog]. Frankfurt.

Korotkova N., Zabel L., Quandt D., Barthlott W. 2010. A phylogenetic analysis of Pfeiffera and the reinstatement of Lymanbensonia as an independently evolved lineage of epiphytic Cactaceae within a new tribe Lymanbensonieae. Willdenowia 40: 151-172.

Krainz H. (ed.) 1975. Trichocereus macrogonus, en Die Kakteen, 1. I. Unpaged.

Kreuzinger K. 1935. Verzeichnis amerikanischer und anderer Sukkulenten. [Catalog]. Czechoslovakia.

Kupper W. 1929. Das Kakteenbuch. Verlag der Gartenschönheit, Berlin-Westend.

Labouret J. 1853. Monogr. Cact. Librerie Agricole, Paris.

Lambert J.G. 2010. Cacti of Argentina. 2da edition. Concordia-Roeselare.

Lanteri A., Cigliano M., Margaría C. 2005. Análisis filogenético de datos moleculares. Congruencia taxonómica, soporte y confianza estadística de grupos y árboles, en Lanteri A. y Cigliano M. (eds.), Sistemática Biológica: Fundamentos teóricos y ejercitaciones, pp. 155-173. Edulp, La Plata.

Las Peñas M.L., Urdampilleta J.D., Bernardello G. Forni-Martins E.R. 2009. Karyotypes, heterochromatin, and physical mapping of 18S-26S rDNA in Cactaceae. Cytogenet Genome Res. 124: 72-80.

Las Peñas M.L., Kiesling R., Bernardello G. 2011. Karyotype, heterochromatin, and physical mapping of $5 S$ and 18-5.8-26S rDNA genes in Setiechinopsis (Cactaceae), an Argentine endemic genus. Haseltonia 16(1): 83-90.

Lehnert M., Kessler M., Schmidt A., Klimas S., Fehlberg S., Ranker T. 2009. Phylogeny of the fern genus Melpomene (Polypodiaceae) inferred from morphology and chloroplast DNA analysis. Syst. Bot. 34 (1): $17-27$.

Lemaire C. 1838. Cact. Aliq. Nov. Horto Monvilleanum, Paris.

Lemaitre A.B., Pinto C.F., Niemeyer H.M. 2014. Generalized pollination system: are floral traits adapted to different pollinators? Arthropod-Plant Interactions 8: 261-272.

Leuenberger B., Eggli U. 1996. A note on a mixed type collection: Cereus deserticola Werderm. (Cactaceae). Willdenowia 25: 687-691.

Leuenberger B.E. 1976. Die Pollen Morphologie der Cactaceae. Diss. Bot. 31: 1-321.

Looser G. 1929. Catalogus Cactacearum Chilensium. Revista Chilena Hist. Nat. 33: 598-600. 
Lowry M., Mendoza M. 2011. Notas on cacti from the northwest of Bolivia with a new Echinopsis species. Cactus World 29 (2): 91-102.

McNeill J., Barrie F.R., Buck W.R., Demoulin V., Greuter W., Hawksworth D.L., Herendeen P. S., Knapp S., Marhold K., Prado J., Prud'homme Van Reine W.F., Smith G.F., Wiersema J.H. y Turland N.J. (eds.). 2012. International Code of Nomenclature for algae, fungi, and plants (Melbourne Code). Adopted by the Eighteenth International Botanical Congress Melbourne, Australia, July 2011. Koeltz Scientific Books.

Maddison W.P., Maddison D.R. 2010. Mesquite: a modular system for evolutionary analysis. Version 2.73 http://mesquiteproject.org.

Madsen J.E. 1989. Cactaceae 45, en G. Harling \& B. Stahl (eds.), Flora of Ecuador, no. 35, pp. 1-79. Quito: Götenborg, Stockholm, University of Götenborg, Riksmuseum, Pontificia Universidad Católica del Ecuador.

Mandujano M.C., Carrillo I., Martinez C., Golubov J. 2010. Reproductive Biology of Cactaceae, en K. Ramawat (ed.), Desert Plant: Biology and Biotechnology, pp. 197-230. Springer Link, London.

Marshall W.T., Bock T.M. 1941. Cactaceae. Abbey Garden Press, United States.

Mauseth J.D. 1993. Anatomía de Cactus VI. Quepo 7: 4-11.

Mauseth J.D. 2004. Wide-band tracheids are present in almost all species of Cactaceae. J. PI. Res. 117: 69-76.

Mauseth J.D., Plemons B.J. 1998. Evolution of extreme xeromorphic characters in wood: A study of nine evolutionary lines in Cactaceae. Amer. J. Bot. 85 (2): 209-218.

Mauseth J.D., Kiesling R., Ostolaza C. 2002. A Cactus Odyssey: journeys in the wilds of Bolivia, Peru and Argentina. Timber Press, Portland, Oregon.

Méndez E. 2000. Hibridación natural entre Trichocereus candicans y T. strigosus en la provincia de Mendoza (Argentina). Hickenia 3 (21): 73-76.

Mickevich M.L., Farris J.S. 1981. The implications of congruence in Menidia. Syst. Zool. 30 (3): 351-370.

Mordhorst A. 2008. Die Entstehung, Entwicklung und Viefalt chlorotischer und panaschierter Kakteenhybriden. Kakt. And. Sukk. 59 (8): 215-222.

Moreno N. 1984. Glosario Botánico Ilustrado. México: Continental.

Mottram R. 1997. Two new names in Echinopsis. Cactaceae Consensus Init. 2: 8.

Muñoz C. 1960. Las especies de plantas descriptas por R.A. Philippi en el siglo XIX: Estudio crítico en la identificación de sus tipos nomenclaturales. Ediciones de la Universidad de Chile.

Navarro G. 1996. Catálogo ecológico preliminar de las cactáceas de Bolivia. Lazaroa 17: 33-84.

Navarro G., Maldonado M. 2002. Geografía ecológica de Bolivia: vegetación y ambientes acuáticos.

Centro de Ecología Simón I. Patiño-Departamento de difusión. Bolivia.

Nixon K.C. 1999. Winclada (BETA) ver. 0.9.9. New York: Ithaca.

Nixon K.C., Carpenter J.M. 1996. On simultaneous analysis. Cladistics 12: 221-241. 
Nixon K.C., Ochoterena H. 2000. Taxonomía tradicional, cladística y construcción de hipótesis filogenéticas, en Hernández H.M., García A.N., Álvarez F., Ulloa M. (eds.), Enfoques contemporáneos para el estudio de la biodiversidad, pp. 15-37. IBUNAM Fondo de Cultura Económica, México.

Nyffeler R. 2002. Phylogenetic relationships in the cactus family (Cactaceae) based on evidence from trnK/matK and trnL-trnF sequences. Amer. J. Bot. 89 (2): 312-326.

Ogunbodede O., McCombs D., Trout K., Daley P., Terry M. 2010. New mescaline concentrations from 14 taxa/cultivars of Echinopsis spp. (Cactaceae) ("San Pedro") and their relevance in the shamanic practice. J. Ethnopharmacol. 131: 356-362.

Ortega P., Saravia M., Sühring S., Godínez H., Zamar M. 2010. Reproductive biology of Echinopsis terscheckii (Cactaceae): the role of nocturnal and diurnal pollinators. Plant Biology 13 (Suppl. 1): 3340.

Ostolaza C. 1995. Etnobotánica II. Quepo 9: 73-82.

Ostolaza C. 2011. 101 Cactus del Perú. Ministerio del Ambiente, Perú.

Perea M.V. 2005. Relevamiento de Cactáceas en la Provincia de Catamarca. Consejo Federal de Inversiones, Buenos Aires.

Petersen E. 1927. Tasschenbuch für den Kakeenfreund. Schreiber, F. F. Germany.

Pfeiffer L. 1837. Enum. Diagn. Cact. Sumtibus Ludovici Oehmigke, Berlin.

Pinto R. 2002. Lobivia ferox Britton et Rose (Cactaceae), nuevo registro para la flora chilena. Gayana Bot. 59 (2): 65-72.

Rauh W. 1958. Beitrag sur Kenntnis der Peruanischen Kakteenvegetation. Springer Verlag, Heidelberg.

Rauh W. 1979. Kakteen an ihren Standorten. Verlag Paul Parey, Berlin und Hamburg.

Rausch W. 1974. Trichocereus vasquezii Rausch spec. nov. Kakt. And. Sukk. 25(9): 193-194.

Rausch W. 1975. Lobivia. Die tagblütige Echinopsidinae aus arealgeographischer Sicht. Wien (A): Rudolf Herzig. 3 vols., Austria.

Reyna V., Flores J. 2001. El uso del "San Pedro" (Echinopsis pachanoi) en medicina tradicional peruana. Quepo 15: 28-37.

Riccobono V. 1909. Studii Sulle Cattee. Boll. Ort. Bot. Palermo 8 (4): 236-237.

Říha J., Šubík R. 1981. Welt der Kakteen und anderer Sukkulenten in Farbe. Mosaik Verlag, Czechoslovakia.

Ritter F. 1962. Trichocereus glaucus Ritter spec. nov. Kakt. And Sukkulent. 13: 180-181.

Ritter F. 1979. Kakteen Südamerika 1. Brasilien/Uruguay/Paraguay. Germany.

Ritter F. 1980a. Kakteen Südamerika 2. Argentinien/Bolivien. Germany.

Ritter F. 1980b. Kakteen Südamerika 3. Chile. Germany.

Ritter F. 1981. Kakteen Südamerika 4. Peru. Germany. 
Ritz C., Martins L., Mecklenburg R., Goremykin V., Hellwig F. 2007. The molecular phylogeny of Rebutia (Cactaceae) and its allies demonstrates the influence of paleography on the evolution of South American mountain cacti. Amer. J. Bot. 94(8): 1321-1332.

Roig A., Schlumpberger B.O. 2008. The cactus-specialist bees of the genus Brachyglossula Hedicke (Hymenoptera: Colletidae): Notes on host associations and description of a new species. J. Kansas Entomol. Soc. 81(2): 84-91.

Rothers M.D. 1923. Unsere katteen und Sukkulenten. Frowtzich \& Sohn, Frankfurt.

Rowley G.D. 1974. Reunion of the genus Echinopsis. IOS Bulletin 3 (3): 93-99.

Rowley G.D. 2004. Intergeneric hybrids in Cactaceae - an update. Cactaceae Syst. Init. 18: 11-12.

Ruíz E., Sosa V., Mejía M. 2008. Phylogenetics of Otatea inferred from morphology and chloroplast DNA sequence data, and recircumscription of Guaduinae (Poaceae: Bambusoideae). Syst. Bot. 33 (2): 277283.

Rümpler's K.T. 1885. Handb. der Kakteenkunde. Leipzig.

Rundel P.W. 1974. Trichocereus in the Mediterranean zone of central Chile. Cact. Succ. J. (Los Angeles). 46: $86-88$.

Salm-Dyck J. 1850. Cact. Hort. Dyck. Cultae 1849. Apud Henry and Cohen. Typis C. Georgii. ed II.

Schelle E. 1926. Kakteen. Tübingen: A. Fischer Vlg.

Schick R. 2011. Echinopsis sensu stricto and Trichocereus: Differentiating the genera. Cact. Succ. J. (Los Angeles) 83: 248-255.

Schlumpberger B.O., Badano E.I. 2005. Diversity of floral visitors to Echinopsis atacamensis subsp. pasacana (Cactaceae). Haseltonia 11: 18-26.

Schlumpberger B.O., Raguso R.A. 2008. Geographic variation in floral scent of Echinopsis ancistrophora (Cactaceae); evidence for constraints on hawkmoth attraction. Oikos 117 (6): 801-814.

Schlumpberger B. 2012. New combinations in the Echinopsis alliance. Cactaceae Syst. Init. 28: 29-31.

Schlumpberger B., Renner S. 2012. Molecular phylogenetics of Echinopsis (Cactaceae): polyphyly at all levels and convergent evolution of pollination modes and growth forms. Amer. J. Bot. 99 (8): 13351349.

Schultes R.E, Hoffmann A. 1979. Plants of the Gods. Mc Graw-Hill, New York.

Schumann K. 1890. Cactaceae, en Martius C.F.P., Eichler A.G. Urban I. (eds.), Fl. Bras. Enum. Pl., vol. 4 (2): 186-334. F. Fleischer, Monachii and Lipsiae.

Schumann K. 1897-1898. Gesamtbeschr. Kakt. Neudamm, Berlin.

Schumann K. 1899. Gesamtbeschr. Kakt. Neudamm, Berlin.

Simmons M.P., Ochoterena H. 2000. Gaps as characters in sequence-based phylogenetic analyses. Syst. Biol. 49: 369-381. 
Simmons M.P., Savolainen V., Clevinger C., Archer R., Davis J. 2001. Phylogeny of the Celastraceae inferred from $26 \mathrm{~S}$ nuclear ribosomal DNA, phytochrome B, rbcl, atpB and morphology. Molec. Phylogen. Evol. 19 (3): 353-366.

Spegazzini C. 1905. Cactacearum platensium tentamen. Anales Mus. Nac. Buenos Aires 11: 477-521.

Spegazzini C. 1923. Breves notas cactológicas. Anales Soc. Ci. Argent. 96: 61-75.

Spegazzini C. 1925. Nuevas notas cactológicas. Anales Soc. Ci. Argent. 99: 85-146.

Stuessy T.F. 1990. Plant Taxonomy. New York: Columbia University Press.

Taberlet P., Gielly L., Pautou G., Bouvet J. 1991. Universal primers for amplification of three non-coding regions of chloroplast DNA. PI. Molec. Biol. 17: 1105-1109.

Trevisson M., Demaio P. 2006. Cactus de Córdoba y el centro de Argentina. Literature of Latin America, Buenos Aires.

Trevisson M., Perea M. 2009. Cactus del oeste de Argentina. Literature of Latin America, Buenos Aires.

Veg Saatzucht Zierpflanzen Erfurt. 1979. Kakteensamen [Catalog]. Germany.

Wallace R. 1997. The phylogenetic position of Mediocactus hahnianus. Cactaceae Consensus Init. 4: 1112.

Weber A. 1896. Cactées en D. Boissier dictionnaire d'horticulture: Dictionnaire d' horticulture illustré. Paul Klincksieck, Paris.

Weber F.A.C. 1899. Cereus, en D. Bois (ed.), Dict. Hort. P., pp. 280-281. Klincksieck, Paris.

Wenzel. 1937. Kakteen-Hauptkatalog [Catalog]. Czechoslovakia.

Werdermann E. (1936) 1937. Bluh. Kakteen And. Sukk. Pflanzen Vol. 4. J. Neumann-Neudamm, Berlin.

Werdermann E. 1942. Brazil and its Columnar Cacti. Abbey Garden Press, Pasadena. 


\section{XIII ÍNDICE DE NOMBRES CIENTÍFICOS}

A

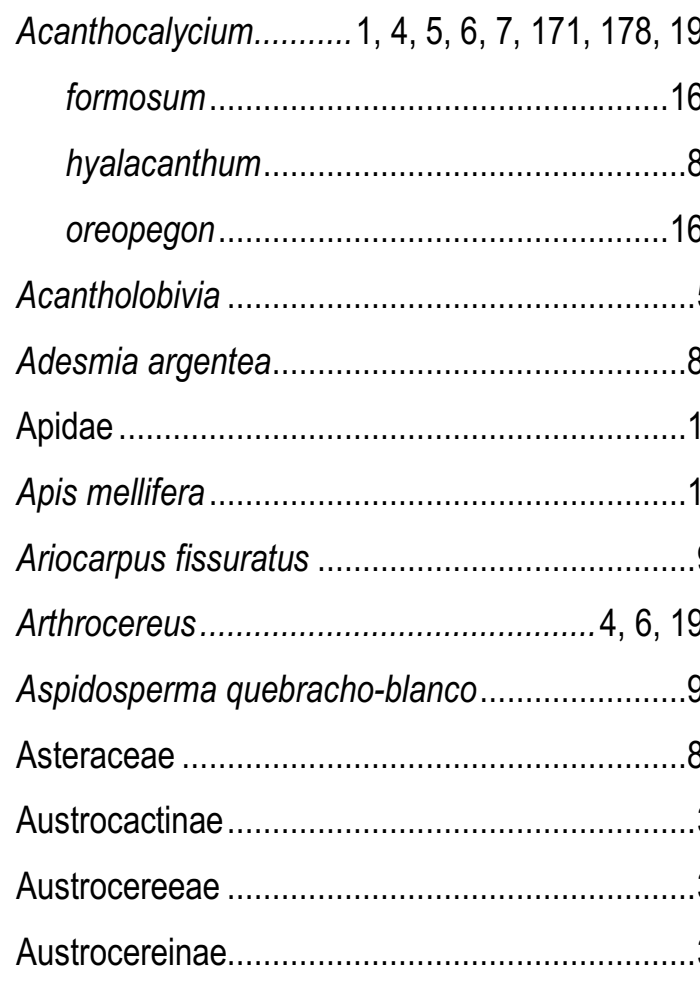

B

Berberis boliviana ...........................................146

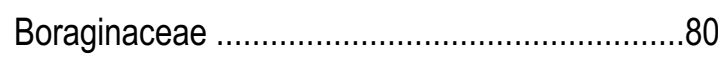

Boreocereeae ..................................................... 4

Boreocereinae .................................................... 4

Brachyglossula .............................................11

ancasti ............................................................

communis.................................................... 11

martinezi ....................................................11

Bromelia serra ..............................................99

Bulnesia retama...............................................130

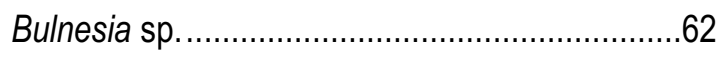

\section{C}

Cactaceae..... 1, 6, 15, 20, 97, 177, 191, 202, 228

Cactoideae........................ 1, 5, 11, 24, 177, 202

Cactus

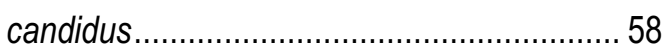

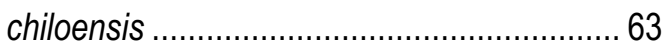

coquimbanus..................... 109, 110, 168, 168

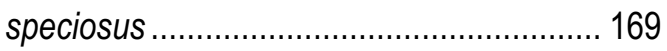

Carica quercifolia ........................................... 137

Cassia aphylla................................................... 127

Cephalocereus

arrabidae ...................................................... 23

pasacanus...................................................... 41

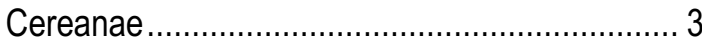

Cereeae ...................................................... 3

Cereinae ............................................................... 3

Cereoideae ................................................ $3,4,6$

Cereus1, 2, 3, 19, 20, 21, 23, 89, 125, 128, 152, 190

andalgalensis ..................................32, 33, 34

atacamensis .......................... 2, 41, 42, 43, 44

bridgesii............................... 3, 22, 23, 47, 49

f. brevispinus.............................................. 47

f. lageniformis......................................... 47

var. brevispina...................................47, 49

var. lageniformis...................................... 47

var. longispinus .................................47, 50

candicans......................................... 3, 56, 57

f. courantii ................................................ 56

f. gladiatus ............................................... 55

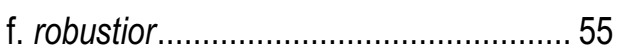

var. courantii ........................................... 56

var. dumesnilianus ................................. 56

var. gladiatus............................................ 55 

var. robustior $.55,57$
var. tenuispinus.
$.55,57$
chilensis

f. eburneus. .69

var. brevispinula......................................64

var. eburnea ...........................................69

var. flavescens.......................................64

var. heteromorpha..................................64

var. panhoplites ....................................... 73

var. polygona ...........................................64

var. poselgeri............................................64

var. pycnacantha .....................................64

var. zizkaana ............................................65

chiloensis $3,63,64,125$

f. eburneus. .69

var. brevispinula.......................................64

var. eburnea .........................................69

var. flavescens......................................64

var. heteromorpha.....................................64

var. panhoplites ................................. 73,74

var. polygona ..........................................64

var. poselgeri..........................................64

var. pycnacantha ...................................64

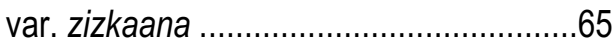

coquimbanus................................ 3, 109, 168

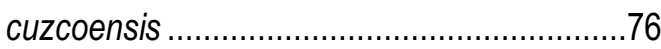

deserticolus...................................... 78, 79, 80

eriocarpus ......................................... 2, 41, 43

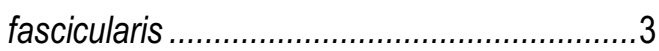

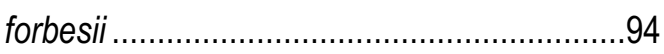

gladiatus .............................................55, 57

huascha .............................................. 86,87

var. flaviflora ................................... 86,88

var. rubriflorus.................................. 32,34

intricatus........................................126, 128

lagenaeformis...........................................47, 49

lamprochlorus......................... 3, 92, 93, 94, 95

var. salinicola .....................................56, 95

litoralis......................................................... 71

macrogonus $3,19,20,21,22,24,25,95,96$, $97,98,101,202,232$

nigripilis ...........................................106, 107

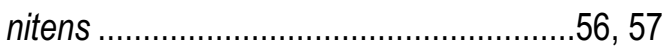

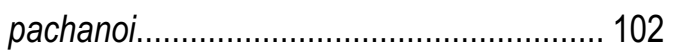

pasacana............................................... 3, 41

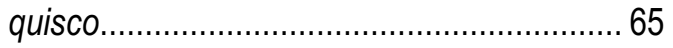

rosei ................................................ 100, 101

santiaguensis ...........................120,122, 123

schickendantzii ...................................3, 111

spachianus ........................... 3, 120, 121, 122

spinibarbis ................................. 124, 125, 126

strigosus.................................... $3,126,127$

var. intricatus........................................ 126

var. longispinus ............................127, 128

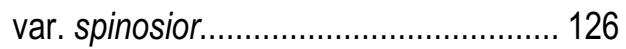

tacaquirensis ......................................133, 134

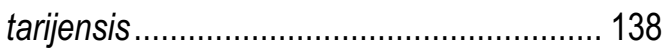

terscheckii ........................................147, 148

thelegonoides....................................120, 122

thelegonus...................................... $3,150,151$

Chamaecereus........................ 1, 5, 6, 7, 177, 178

grandiflorus ................................................ 171

Cinnabarinea ……............................................. 5

Cleistocactus strausii ......................................... 188

Colletidae........................................................ 11

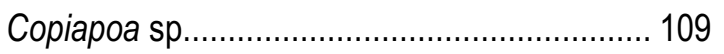

Cylindrolobivia.................................................. 5 
D

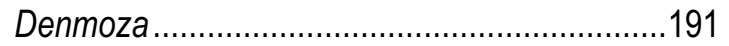

Denmoza rhodacantha..........................................15

Deuterocohnia sp.......................................37, 144

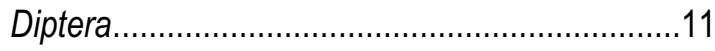

Dodonaea viscosa .............................................137

Dolichophaonia sp. .........................................11

\section{E}

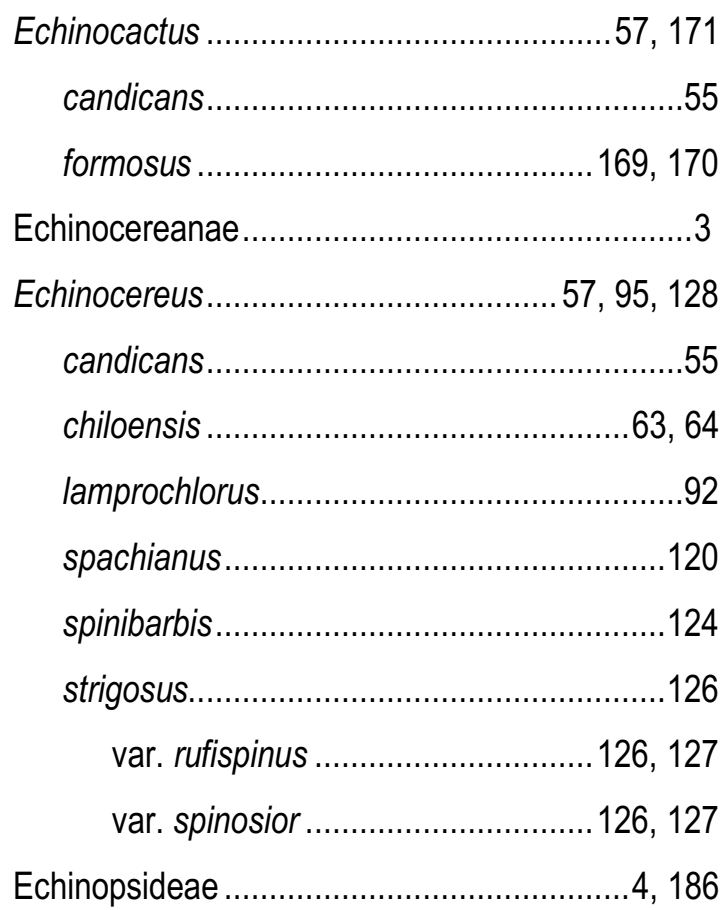

Echinopsis 1, 2, 3, 4, 5, 6, 7, 11, 18, 19, 21, 25, 187, 188, 190, 191, 196, 203, 228, 229

albispinosa 193 (Fig.), 196, 226, 235

ancistrophora $183,194,226,236$

angelesiae. . .36

antezanae ...4

arboricola .38

atacamensis 4,41

subsp. pasacana .41

aurea 196, 228

var. dobeana .32 bertramiana $.4,145$

bolligeriana $44,45,46$

bridgesii. 47

cabrerae 50

camarguensis 4,53

candicans. $2,4,55$

var. gladiata 55

var. tenuispina 55

caulescens .53

cephalomacrostibas...................................... 4

chalaensis ................................................... 4

chiloensis .................................. 4, 46, 63, 177

subsp. chiloensis................................. 189

subsp. litoralis ........................................ 71

subsp. skottsbergii .............................. 117

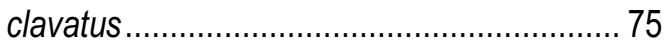

coquimbana...................................4, 109, 168

courantii............................................. 4, 56

cuzcoensis ............................................ 4, 46

deserticola ............................................ 4, 78

escayachensis.............................................. 4

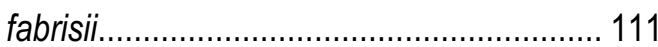

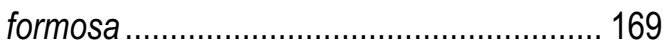

friedrichii................................................. 4,114

fulvilana ......................................................... 4

glauca .................................................. 4,156

f. pendens...................................156, 159

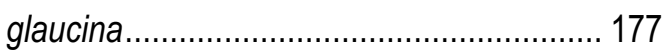

grandiflora ...........................................171, 173

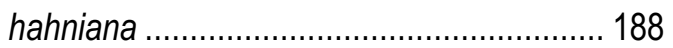

herzogiana ........................................ 4, 83

var. totorensis .......................................... 83

huascha ................................................ 4, 86

subsp. robusta ........................................ 87 


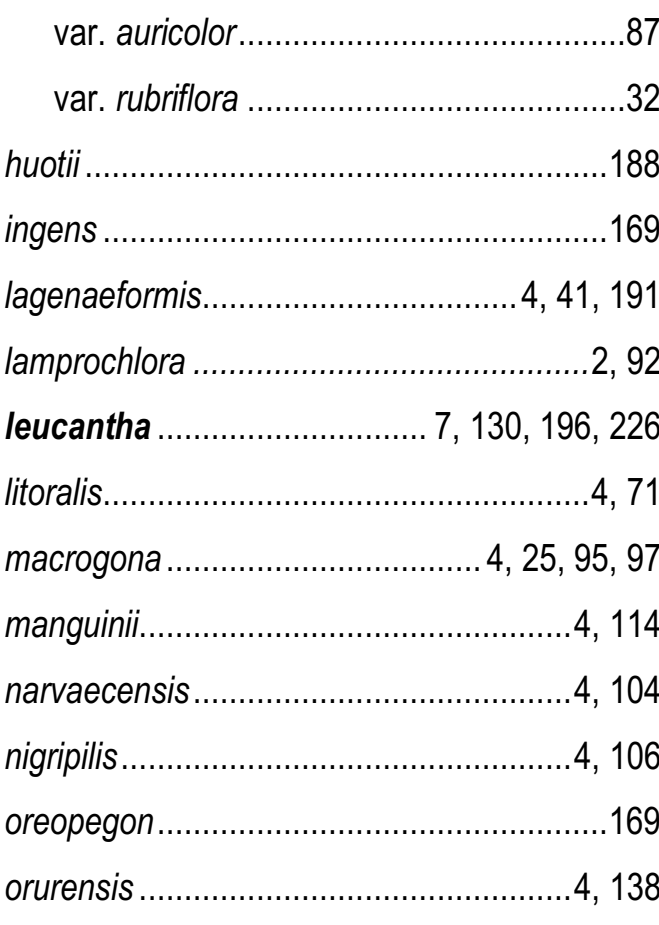

var. albiflora ..........................................145

pachanoi4, 18, 25, 97, 98, 99, 102, 177, 191, .236

pasacana ........................................ 4, 41, 177

pecheretiana .................................................. 91

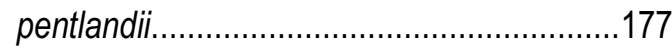

peruviana .................4, 18, 21, 25, 97, 99, 104

subsp. puquiensis ..................................100

poco ................................................... 4,141

var. albiflora ............................................145

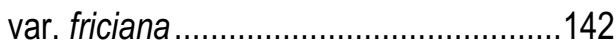

pseudocandicans ..........................................60

puquiensis..............................................4, 100

purpureopilosa ............................................92

purpureopilosus............................................. 4

quadratiumbonatus......................................121

rivierei ........................................................ 4

rowley ........................................................171

rowleyi...............................................171, 173

rubinghiana ............................................. 4,121 santaensis ............................................4, 102

santiaguensis ......................................... 4, 120

schickendantzii ...................................111, 188

serpentina .................................................. 159

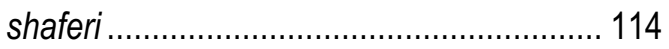

skottsbergii ..........................................4, 117

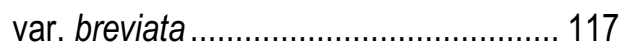

smrziana.......................................115, 116

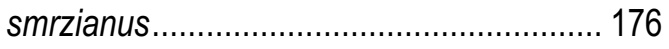

spachiana ................................................ 120

spinibarbis ................................................. 124

strigosa .............................................. 4,126

tacaquirensis ........................................ 4, 133

subsp. taquimbalensis.......................... 135

taquimbalensis ......................................4, 135

var. wilkeae............................................. 166

tarijensis................................................... 438

subsp. bertramiana ................................ 145

subsp. herzogianus .................................. 83

tarmaensis........................................................ 4

terscheckii ..............................................4, 147

var. montana ............................................ 147

thelegona .............................................. 4, 150

thelegonoides...............................4, 120, 188

toratensis............................................................. 4

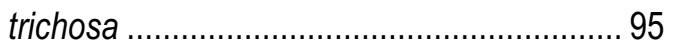

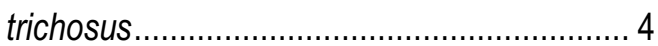

tulhuayacensis................................................. 4

tunariensis.............................................. 4,152

uebelmanniana ............................................. 169

uyupampensis .......................................4, 156

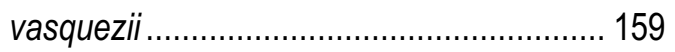

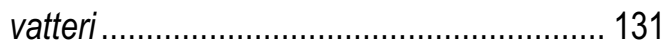

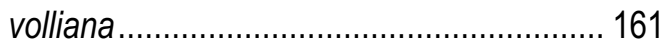




$$
\text { vollianus. }
$$

walteri .174

werdermanniana $4,164,166$

werdermannii.... 166

Encelia canescens .80

Ephedra americana..............................................49

Eriocereus .......................................................

Eriolobiviae ...........................................................

Espostoa guentheri .188

Espostoa $4,6,177,191$

Eucerei ...3

Eulychnia 70, 81, 108, 110, 126, 168, 169, 178, $179,190,203,228$

\section{breviflora.} $126,182,183,194,236$

castanea. 182,183

coquimbana. 168, 202

eburnea. 69

iquiquensis . .81

spinibarbis 126, 168

Eulychnia sp. .109

\section{F}

Fabaceae .80

Fuchsia lycioides ...............................................72

Furiolobivia . .5

\section{G}

Gymnocalycium spegazzinii . .37

\section{H}

Haageocereus $4,6,177,190,191$

fascicularis ...3

Harrisia 3, 4, 5, 177, 178, 186, 188, 189, 191, 203, 228 earlei39, 179, 182, 186, 188, 189, 203, 226, 229

hahniana39, 182, 186, 188, 189, 203, 226, 229

pomanensis

$.94,177$

Harrisiae ... 4

Helianthocereus 3, 4, 5, 6, 7, 19, 177, 178, 194, 195

andalgalensis .32, 195

atacamensis $.41,195$

bertramianus 145

grandiflorus 3,171

herzogianus. 83

var. totorensis 83

huascha 3, 86

var. auricolor 87

var. macranthus .. 87

var. rubriflorus 32

narvaecensis 104

orurensis 138

var. albiflorus 145

pasacana.

3,41

pecheretianus.

3,91

var. viridior 91 poco 141

var. albiflorus........................................ 145

var. fricianus .......................................... 142

var. sanguiniflorus.................................. 138 pseudocandicans...........................60, 62, 194 var. flaviflorus....................................60, 62

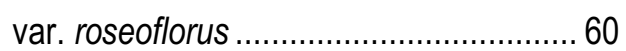
tarijensis....................................... 3, 138, 195 Heliotrichocerei .................................................... 3 Heliotropium stenophyllum ................................. 80 
Hylocereae

.4

Hylocereeae

$5,205,226,230$

Hymenoptera. .11

Hymenorebutia $1,4,5,6,7,184$

K

Kageneckia lanceolata .137

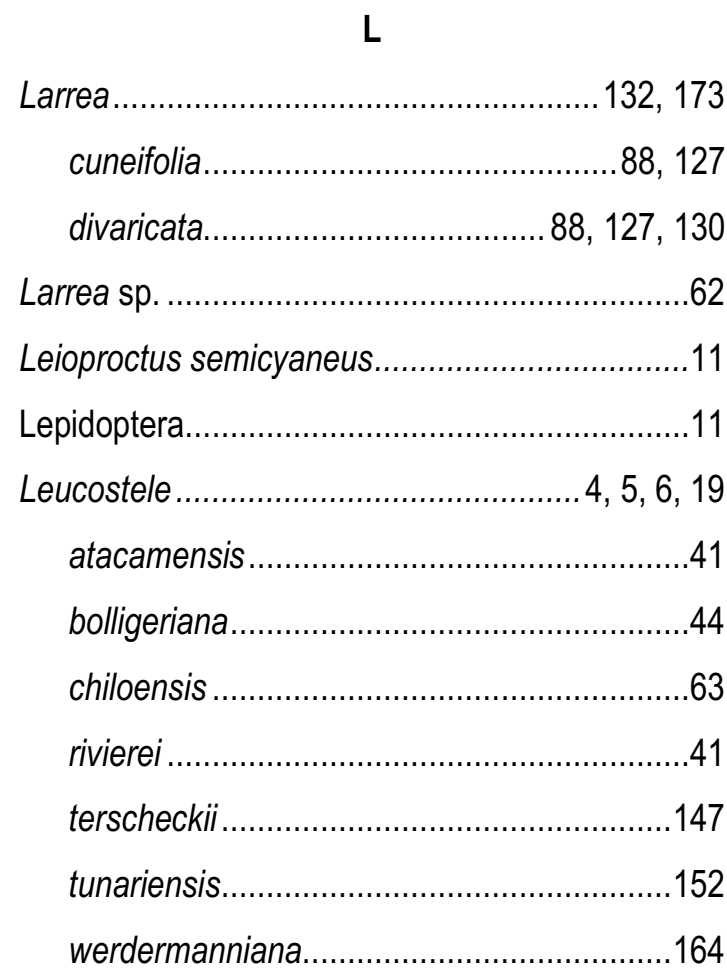

Lobivia 1, 2, 3, 4, 5, 6, 7, 89, 171, 173, 176, 177 , 178, 179, 186, 187, 188, 190, 191, 196, 203, 228,

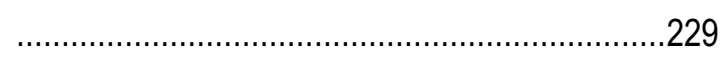

andalgalensis .32

bruchii 173, 183, 190, 192 (Fig.), 196, 226, .235

formosa................ 7, 169, 170 (Fig.), 202, 235 var. bertramiana...................................... 145

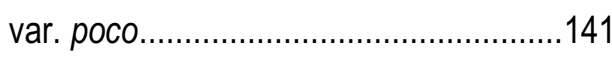
var. tarijensis .......................................138 var. uebelmanniana ...............................169

grandiflora 6, 7, 11, 35, 171, 172, 173 (Fig.), 174, 192, 198, 202, 226, 235, 235, 237

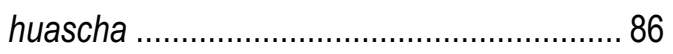

var. andalgalensis ............................... 32

var. calliantha....................................... 131

var. grandiflora...................................... 172

var. robusta............................................ 87

var. rubriflora............................................... 33

var. walteri ............................................ 174

jajoiana.................................................. 226

kieslingii................... 173, 194, 196, 228, 236

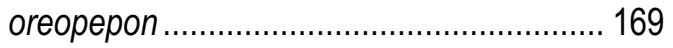

purpureominiata.......................................... 172

walterii............. 174, 175, 176 (Fig.), 202, 235

Lobiviae .............................................................. 3

Lycium 132

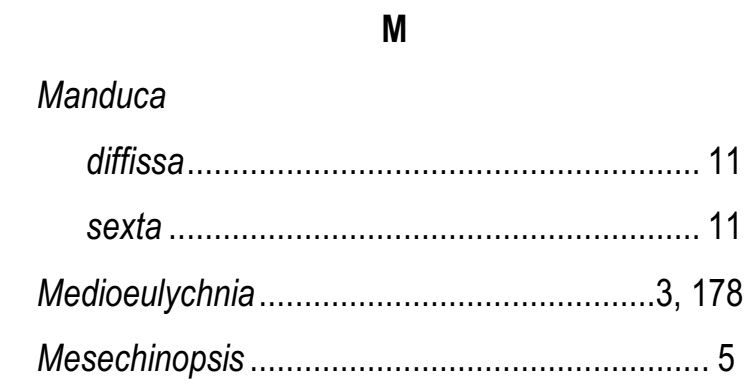

\section{$\mathbf{N}$}

Neobinghamia............................................ 4, 6

Neohelianthocereus ............................................ 3

Neolobivia...................................................... 4, 5

Notocacteae ...................................203, 228, 231

Nyctocerei...................................................... 3,4

Nyctocereinae ..................................................... 4

Nyctotrichocerei .................................................. 3 
Opuntia

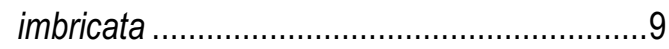

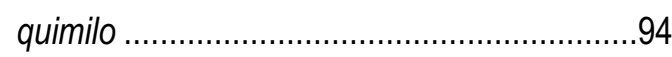

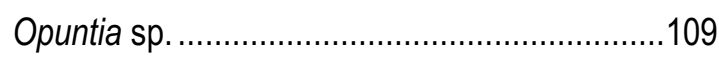

Oreocereus.......................................................191

celsianus......................................................... 15

fossulatus. .49

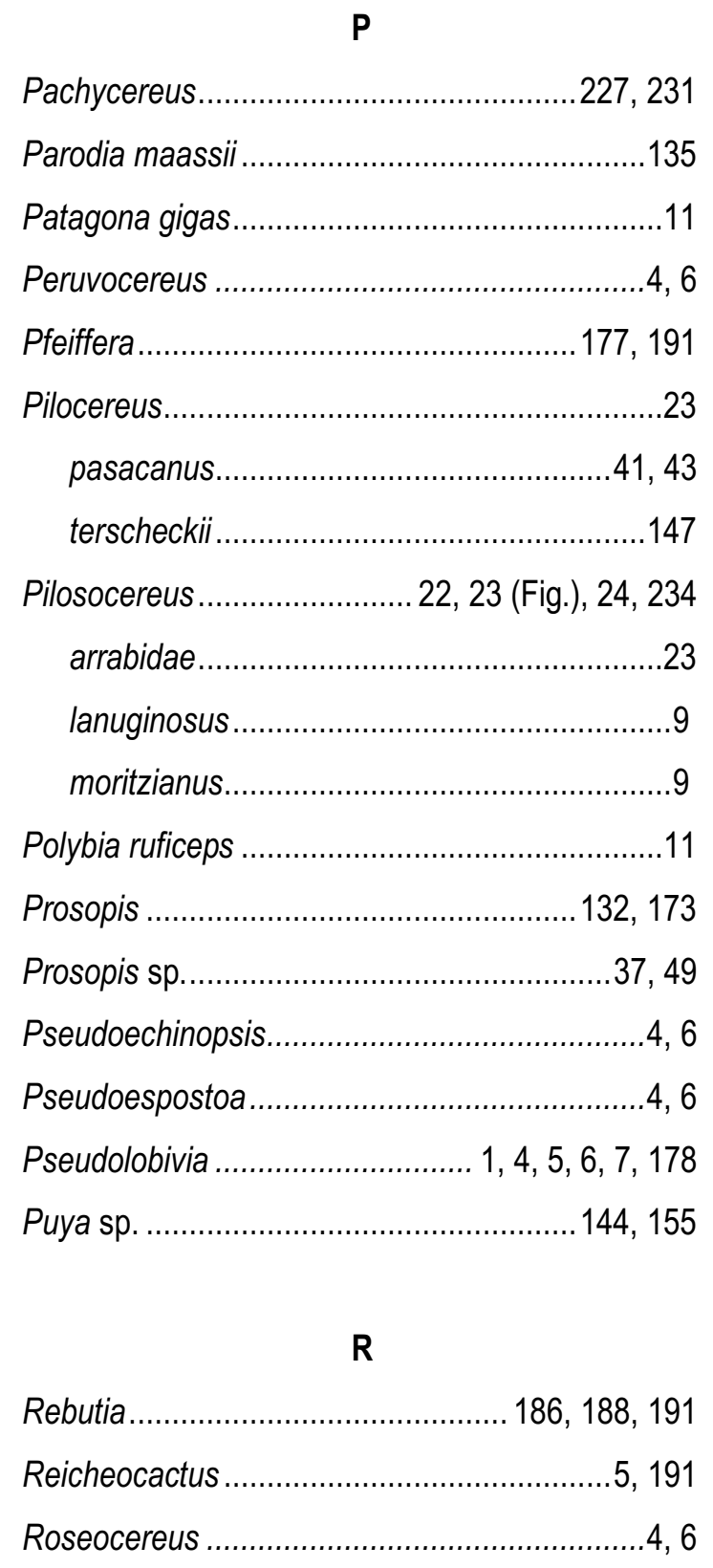

S

Salpingolobivia ................................................... 5

andalgalensis ........................................... 32

huascha .................................................. 86

Samaipaticereus .......................................... 191

Samaipaticereus corroanus ............................. 188

Schinus

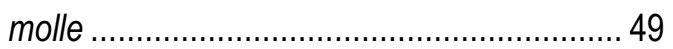

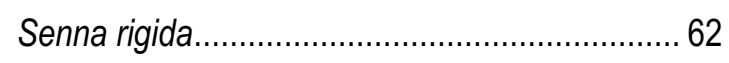

Setiechinopsis $3,4,5,6,7,177,178,179,188$, 196, 203, 205

mirabilis 11, 178, 186, 188, 193 (Fig.), 196, 203, 226, 235

Soehrensia 1, 4, 5, 6, 7, 57, 116, 152, 171, 178, 192

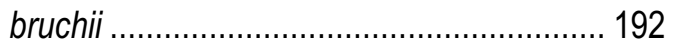

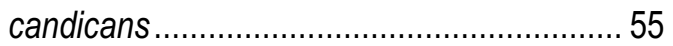

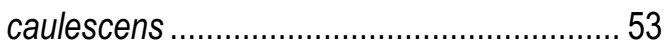

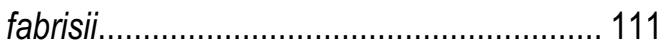

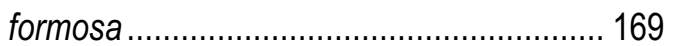

var. maxima ..................................169, 171

var. polycephala ....................................... 169

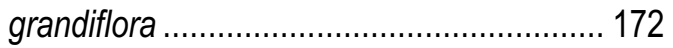

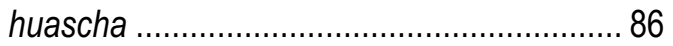

var. rosiflora ....................................... 87,88

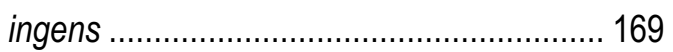

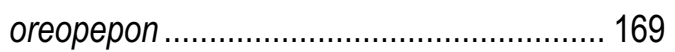

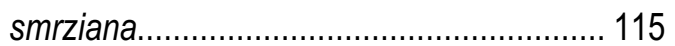

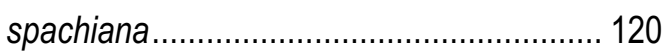

thelegona .................................................. 150

thelegonoides............................................ 120

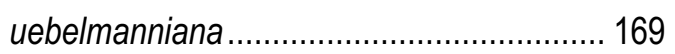

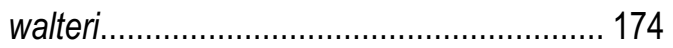

Stenocereus 
griseus . .9

queretaroensis .9

\section{T}

Tephrocactus

articulatus. .130

weberi. .37

Trichocereeae 1, 2, 4, 5, 6, 11, 177, 178, 182, 183, 191, 195, 196, 202, 203, 226, 230, 231

Trichocerei. .3

Trichocereinae $1,4,6,7$

Trichocereus 1, 2, 3, 4, 5, 6, 7, 9, 10 (Fig.), 12, 15, 16, 17 (Fig.), 18, 19, 20, 21, 22, 23, 24, 39, 40, $46,57,64,70,81,89,95,97,99,103,108,110$, $116,123,126,128,149,152,168,169,171,173$, $176,177,178,179,182,186,187,188,189,190$, 191, 192, 194, 195, 196, 202, 203, 228, 229, 232 , 236,237

andalgalensis 4, 5, 9, 12, 16, 26, 29, 32, 33, 34 (Fig.), 35, 89, 128, 174, 183, 188, 189, 196, 197 (Fig.), 203, 226, 232, 236, 237

var. auricolor . .33

angelesiae 5, 16, 28, 29, 36, 37 (Fig.), 38, 197 (Fig.), 234, 236, 237 angelesii. 5,36

antezanae . .5

arboricola.........5, 12, 27, 29, 38, 39, 40 (Fig.), 183, 189, 197 (Fig.), 198, 202, 226, 228, 233, 236,237

atacamensis 3, 8, 9, 10 (Fig), 13 (Fig.), 15, 16, 25, 26, 29, 31, 41, 42, 43 (Fig.), 149, 190, 192 (Fig.), 193 (Fig.), 194 (Fig.), 195, 196, 197 (Fig.), 198 (Fig.), 199 (Fig.), 202, 203, 226, $232,233,235,236,237$ subsp. pasacanus 41

var. pasacana 6,41

auricolor $33,87,88$

bertramianus 145

bolligerianus 9, 13 (Fig.), 16, 29, 32, 44, 45, 46 (Fig.), 189, 190, 192 (Fig.), 194 (Fig.), 195, 196, 199 (Fig.), 226, 232, 233, 235, 236 bridgesii 3, 5, 16, 26, 27, 30, 47, 48, 49 (Fig.), 50, 182, 183, 191, 193 (Fig.), 195, 198 (Fig.), $226,228,233,236$

var. brevispinus...................................... 47

var. lageniformis...................................... 47

var. longispinus. 47

cabrerae 4, 15, 16, 28, 29, 50, 51, 52 (Fig.), 197 (Fig.), 233, 236, 237

cajasensis 53,55

callianthus $5,131,132$

camarguensis 5, 27, 30, 53, 54 (Fig.), 76, 128, 129, 198 (Fig.), 233, 236, 237 subsp. caulescens. .53 candicans 3, 4, 5, 8, 9, 11, 13 (Fig.), 15, 16, $26,30,55,56,57,58,62,94,95,132,190$, 194, 195, 196, 226, 232, 237 subsp. candicans 58, 59 (Fig.), 197 (Fig.) .233, 236 subsp. pseudocandicans 58, 60, 61, 62(Fig.), 191, 197 (Fig.), 233, 236

var. courantii 56 var. gladiatus. 55,56

var. nitens. .56

var. robustior. .55

var. roseoflorus 60,62

var. tenuispinus. 55

caulescens 5,53 
cephalopasacana . 41

chalaensis 21,24

chiloensis 3, 5, 14 (Fig.), 15, 16, 26, 28, 32, $63,64,65,72,75,120,177,190,196,232$ subsp. australis 14 (Fig.), 65, 67, 68 (Fig.), 199 (Fig.), 232, 233, 236 subsp. chiloensis $5,9,11,46,65,66$ ...(Fig.), 189, 195, 196, 199 (Fig.), 227, 233 subsp. eburneus 65, 69, 70 (Fig.), 199 (Fig.), 233, 236 subsp. litoralis 5, 8, 65, 71, 72, 73 (Fig.), 190, 199 (Fig.), 233, 236 subsp. panhoplites 14 (Fig.), 65, 73, 74 (Fig.), 199 (Fig.), 232, 233, 236 var. australis $5,67,68,71$ var. borealis $.5,65$

var. conjungens $.5,45,46$

var. eburneus .69

var. nigripilis. .106

var. panhoplites .73

chilensis var. australis .68

chilensis var. borealis .65

chilensis var. eburneus 69

chilensis var. panhoplites .73

chuquisacanus .5

clavatus 27, 30, 75, 76, 198 (Fig.), 236 coquimbanus....... 3, 5, 109, 110, 168, 169, 202 var. nigripilis. .106 courantii. . .56

cuzcoensis 3, 5, 28, 30, 76, 77 (Fig.), 78, 201

(Fig.), 233, 236

deserticola $3,5,8,15,27,32,57,78,79$ (Fig.), 80 119, 183, 190, 192 (Fig.), 195, 196, 199 (Fig.), 203, 227, 233, 235, 236, 237

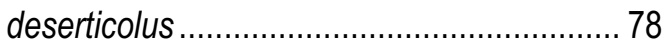

eremophilus.................................... 5, 6, 41,43

fabrisii.................................................... 4,111

fascicularis ...................................................... 3

faundezii 8, 26, 32, 81, 82 (Fig.), 83, 200 (Fig.), 233, 236, 237

formosus 169,202

fulvilanus $5,78,80$

gladiatus 55

glaucus $5,6,110,156,158,159$

f. pendens 156,159

grandiflora 202

grandiflorus 172

herzogianus 9, 28, 31, 83, 84, 85 (Fig.), 86, 154, 198 (Fig.), 233, 236, 237

var. totorensis $83,85,86$ huanucoensis 102,104

huascha 3, 4, 10 (Fig.), 15, 27, 30, 35, 86, 88, $89,94,95,174,237$

subsp. robustus. 87

var. flaviflora 86

var. huascha 89, 90 (Fig.), 197 (Fig.), 233, 236

var. pecheretianus 10 (Fig.), 89, 91, 92 (Fig), 197 (Fig.), 233, 236 var. rubriflorus 32 ingens 169, 202 lamprochlorus 3, 4, 27, 30, 37, 57, 58, 92, 93, .94 (Fig.), 95, 197 (Fig.), 233, 236, 237 litoralis $.71,72$ lobivioides 172,202 macrogonus 2, 3, 19 (Fig.), 20, 21, 22, 24, 25, $27,30,31,50,95,96,97,98,99,101,202$, 232 
var. macrogonus 15, 16, 24, 78, 99, 101, 182, 189, 195, 196, 198 (Fig.), 200 (Fig.), 201 (Fig.), 227, 228, 236

var. pachanoi 9, 12, 16, 18, 24, 98 (Fig.), 99, 102, 103 (Fig.), 104, 182, 189, 191, 194 (Fig.), 195, 200 (Fig.), 201 (Fig.), 202, 227, $228,234,236$

var. peruvianus .99

manguinii. .114

narvaecensis 29, 31, 104, 105 (Fig.), 106, 198 (Fig.), 234, 236, 237

neolamprochlorus. .92

nigripilis 8, 27, 32, 106, 107, 108 (Fig.), 200

(Fig.), 234, 236

orurensis .138

var. albiflorus .145

pachanoi $3,5,18,21,23,24,97,98,99,102$, .202

f. peruvianus .99 pasacana $3,4,16,41,44,177$

pectiniferus 10 (Fig.), 14 (Fig.), 26, 32, 57, 108, 109, 110 (Fig.), 168, 183, 190, 193 (Fig.), 195, 196, 200 (Fig.), 203, 227, 232, 234, 235 , .236

peruvianus $3,5,16,18,21,23,24,97,98,99$, $100,101,196,202,204$ poco $141,142,143$

var. albiflorus 145,146

var. fricianus. .142

pseudocandicans $4,58,60,61,62$ puquiensis. 100,101

purpureopilosus 92,94

quadratiumbonatus $5,121,122$

riomizquensis .5 rowleyi $4,177,204$

rubinghianus. 121

santaensis $21,24,102$

santiaguensis 120,122

schickendantzii 3, 4, 5, 9, 12, 27, 30, 106, $111,112,114,115,128,183,188,196,203$, $204,227,237$ subsp. schickendantzii 112, 113 (Fig.), 197 (Fig.), 234, 236 subsp. shaferi.... 112, 114, 197 (Fig.), 236 subsp. smrzianus112, 115, 117 (Fig.), 197 (Fig.), 234, 236

scopulicola 5 serenanus $5,6,78,80$ serpentinus 159 shaferi $3,114,204$

skottsbergii 3, 8, 15 (Fig.), 25, 31, 117, 118, 119 (Fig.), 120, 189, 190, 195, 196, 200 (Fig.), 203, 204, 227, 232, 234, 236, 237 var. breviatus 117,119 smrzianus $4,115,176$

spachianus $2,3,4,15,20,28,29,31,94,95$, 120, 121, 122, 123 (Fig.), 197 (Fig.), 198, 234, 236 spinibarbis 8,12 (Fig.), 26, 32, 57, 72, 82, 83, 110, 124, 125 (Fig.), 183, 190, 195, 196, 200(Fig.), 203, 227, 232, 234, 236, 237 strigosus $3,4,5,9,15,16,27,30,37,38,52$, 58, 126, 127, 128, 129, 183, 194 (Fig.), 196, 203, 210, 227, 236, 237

var. flaviflorus. 127

var. intricatus. 126

var. longispinus. 127 
var. strigosus 129, 130 (Fig.), 197 (Fig.), 234,236

var. variegatus 127,128

var. vatteri 129, 131, 133 (Fig.), 191, 194, 197 (Fig.), 234, 236

tacaquirensis 5, 28, 31, 133, 134, 135 (Fig.), 137, 198 (Fig.), 234, 236

subsp. taquimbalensis. .168

tacnaensis $5,100,101$

taquimbalensis 28, 31, 135, 136, 137 (Fig.), 198 (Fig.), 234, 236

var. wilkeae 166,167

tarijensis 4, 6, 8, 9, 11, 13 (Fig.), 15, 16, 26, $28,29,31,86,106,138,139,140,143,144$, 145, 183, 193 (Fig.), 196, 202, 203, 227, 232, 236,237

subsp. tarijensis 106,237

var. densispinus 142

var. poco f. albiflorus145, 146 (Fig.), 198

(Fig.), 234, 236

var. poco f. poco 144 (Fig.), 197 (Fig.), 198, (Fig.), 234, 236

var. poco .6, 140, 141, 142, 143 (Fig.), 234 var. tarijensis 140, 141 (Fig., 197 (Fig.), 198 (Fig.), 234, 236

tenuispinus 5

terscheckii 3, 4, 5, 9, 10 (Fig.), 11, 12, 14 (Fig.), 15, 16, 26, 29, 31, 37, 52, 147, 148, 149 (Fig.), 165, 189, 193 (Fig.), 195, 196, 197 (Fig.), 198 (Fig.), 203, 227, 232, 234, 235, 236, .237

var. montanus 147,148

terscheckioides $5,147,149$

thelegonoides $3,4,120,122,123$ thelegonus 3, 4, 8, 10 (Fig.), 12 (Fig.), 26, 29 , .. 150, 151, 152 (Fig.), 197 (Fig.), 232, 234, 236 torataensis $5,102,103,104$

totorensis. 83

trichosus 95,96

tunariensis......5, 28, 152, 153, 154 (Fig.), 235 uebelmannianus 169,202 undulosus8, 25, 32, 154, 155, 156 (Fig.), 200 (Fig.), 235, 236, 237 uyupampensis $26,30,32,156,157,158$ . (Fig.), 200 (Fig.), 201 (Fig.), 235, 236 vasquezii 26, 30, 40, 159, 160 (Fig.), 198 (Fig.), 235, 236, 237 vatteri $4,131,132$ vollianus 5, 27, 31, 161, 162, 163 (Fig.), 198 (Fig.), 235, 236 var. rubrispinus 161,163 walteri. 174, 176, 202 werdermannianus $5,25,31,135,164,165$, 166, 198 (Fig.), 235, 236

wilkeae 28, 31, 166, 167 (Fig.), 168, 198 (Fig.), 235, 236

Trichocereus xmendocinus 15,58

\section{W}

Weberbauerocereus. $4,6,190,191$

Wigginsia $178,179,203,228,230$ corynodes 178,228 vorwerkiana 178, 192 (Fig.), 226, 235

\section{Z}

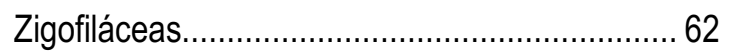

Zuccagnia ....................................................... 132

punctata ...............................................62, 88 


\section{APÉNDICES}

\subsection{Formulario para la toma de datos morfológicos en campo:}

\begin{tabular}{|c|c|c|c|c|c|}
\hline \multicolumn{6}{|c|}{ "Taxonomía y filogenia de Trichocereus (Berg.) Riccob. (Trichocereeae-Cactaceae)" } \\
\hline \multicolumn{4}{|c|}{ Descripción del Área } & Fecha: & DD/MES/AÑO \\
\hline Altura (msnm) & & & \multicolumn{3}{|l|}{ Localidad } \\
\hline Coordenadas & & & \multicolumn{3}{|l|}{ Provincia/Dpto } \\
\hline \multicolumn{6}{|c|}{ Descripción Morfológica General } \\
\hline Biotipo & & Altura Total $(\mathrm{m})$ & & Diámetro del Tronco & \\
\hline Altura del Tronco & & Altura Ramas Basales & & Longitud Ramas Basales & \\
\hline Diámetro Ramas Basales & & Altura Ramas Medias & & Longitud Ramas Medias & \\
\hline Diámetro Ramas Medias & & Color Epidermis & & & \\
\hline \multicolumn{6}{|c|}{ Descripción Morfologica ápice } \\
\hline COSTILLAS: $\mathrm{N}^{\circ}$ Costillas Base & & Ancho de costillas & & Altura de Costillas & \\
\hline Forma de Costillas & Obtusas__Agudas_ & AREOLAS :Forma Areolas & & Ancho Areola & \\
\hline Alto areola & & Color Areolas & & & \\
\hline \multicolumn{2}{|l|}{ ESPINAS CENTRALES: $\mathrm{N}^{\circ}$ de espinas } & Longitud & & Forma & \\
\hline Color & & Disposición & & & \\
\hline ESPINAS RADIALES: $\mathrm{N}^{\circ}$ de espinas & & Longitud & & Forma & \\
\hline Color & & Disposición & & & \\
\hline \multicolumn{6}{|c|}{ Descripción Morfológica Base } \\
\hline COSTILLAS: $\mathrm{N}^{\circ}$ Costillas Base & & Ancho de costillas Base & & Altura de Costillas base & \\
\hline Forma de Costillas & Obtusas___Agudas_ & \multicolumn{2}{|l|}{ AREOLAS :Forma Areolas Base } & Ancho Areola Base & \\
\hline Alto areola Base & & Color Areolas Base & & & \\
\hline \multicolumn{2}{|l|}{ ESPINAS CENTRALES: $\mathrm{N}^{\circ}$ de espinas } & Longitud & & Forma & \\
\hline Color & & Disposición & & & \\
\hline ESPINAS RADIALES: $\mathrm{N}^{\circ}$ de espinas & & Longitud & & Forma & \\
\hline Color & & Disposición & & & \\
\hline \multicolumn{6}{|c|}{ Descripción Flores y Frutos } \\
\hline Longitud Flores & & Diámetro Corola & & Diámetro Ovario & \\
\hline Diámetro Tubo Floral & & Forma & & Color Tépalos Externos & \\
\hline Color Tépalos medios & & Color Tépalos Internos & & \multicolumn{2}{|l|}{ Longitud Tépalos Externos } \\
\hline Longitud Tépalos medios & & Longitud Tépalos Internos & & Posición Estambre & Espiral__ / Anillo_ \\
\hline Longitud Estilo & & Longitud Estigma & & Forma Fruto & \\
\hline Color & & Longitud & & Diámetro & \\
\hline Dehiscencia & & Color interno & & Color Externo & \\
\hline Semillas & & Color & & Rugosidad & \\
\hline Forma & & Tamaño & & & \\
\hline Pelos__Cerdas__ /Escamas_ & del Tubo F & o Otras Observaciones: & & & \\
\hline Registro Fotografico & & & \multicolumn{3}{|c|}{ Obeservaciones: } \\
\hline Numero de recolección: & & Colector: & & & \\
\hline
\end{tabular}

\subsection{Especies estudiadas:}

Taxones, con información del país, nombre del collector, número del espécimen y herbario donde éste fue depositado, número de acceso al GenBank (http://www.ncbi.nlm.nih.gov/entrez/ query.fcgi?CMD=search\&DB=nucleotide). Abreviaturas: Lc: de una colección viva; BAB: Instituto Nacional de Tecnología Agropecuaria, Argentina; COL: Herbario Nacional Colombiano; LIL: Fundación Miguel Lillo; LP: Museo de La Plata; LPB: Herbario Nacional de Bolivia; SI: Instituto de Botánica Darwinion, Argentina; CTES: Instituto de Botánica del Nordeste, Argentina; MERL: Instituto Argentino de Investigaciones de las Zonas 
Áridas; SGO: Museo de Historia Natural, Chile; NY: New York Botanical Garden; U: Herbarium Utrecht, Netherlands.

\section{Tribu Notocacteae}

Wigginsia corynodes (Otto ex Pfeiff.) D.M. Porter. Uruguay. R. Kiesling 10231 (SI), 10232 (SI). W. vorwerkiana

(Werderm.) D.M. Porter. Colombia. S. Albesiano et al. 1735 (COL). Eulychnia breviflora Phil. Chile. U. Eggli et al. 2868 (SI). AY566662, DQ100007. E. castanea Phil. Chile. U. Eggli \& B. Leuenberger 3083 (SI). AY566662, FN673680.

\section{Tribu Hylocereeae}

Harrisia earlei Britton \& Rose. Cuba. DQ099939, DQ100008. H. hahniana (Backeb.) Kimnach \& Hutchison. Paraguay. T. Rojas 8499 (SI). LC O. Ferrari. El espécimen ha nos ha sido enviado por M. Kinmach y es un clonotipo; ej: reproducción vegetativa a partir del espécimen usado como tipo.

\section{Tribu Trichocereeae}

Echinopsis albispinosa K. Schum. Argentina. R. Kiesling I-83. LC O. Ferrari. E. ancistrophora Speg. Argentina.

A. Krapovickas \& A. Schinini 31416 (CTES), A. Schinini 16161 (CTES). A. Burkart 14458 (SI). LC 0. Ferrari. $E$.

aurea Britton \& Rose. Argentina. B. Piccinini \& J. Hilfer 3854 (BAB). Lc O. Ferrari. E. leucantha Walp. Argentina. F. Biurrum et al. 920 (SI), E. Haene 440 (SI), D. Leguiza 28 (SI), R. Sanzin 616 (SI), R. Sanzín s.n. (SI). Lc O. Ferrari. Lobivia bruchii Britton \& Rose. Argentina. Castellanos 1 (SI), A. Cocucci 2001 (SI), R. Kiesling 8709 (SI), M. Saravia 33 (SI), F. Zuluaga 10504 (SI). LC O. Ferrari. L. grandiflora Britton \& Rose. Argentina. LC O. Ferrari. L. jajoiana Backeb. Argentina. R. Kiesling 8915 (SI), W. Rausch 217 (SI). Lc O. Ferrari. L. kieslingii Rausch. Argentina. W. Rausch 573 (SI). LC O. Ferrari. Setiechinopsis mirabilis Backeb. ex de Haas. Argentina. R. Kiesling 9321 (SI). LC R. Kiesling 9321. Trichocereus andalgalensis (F.A.C.Weber

ex K.Schum.) Hosseus. Argentina. H. Sleumer 1671 (LIL), 1951 (LIL), Peirano 9906 (LIL), Schreiter 10389 (LIL), Vervoorst 3404 (LIL). P. Cantino 593 (SI), R. Kiesling 1068 (SI). T. arboricola Kimnach. Argentina. Hilgert 1510 (SI). Lc Hilgert 1510. T. atacamensis (Phil.) W. T. Marshall \& T. M. Bock. Argentina. D. Drogheti s.n. (LIL), Peirano 9797 (LIL), Schreiter 7204 (LIL). Herbario 66736 (LIL). A.L. Cabrera 16340 (LP). A. Burkart 17616 (SI), M.M. Costa 2547 (SI), R. Kiesling 802 (LP). Bolivia. M. Arakaki \& N. Quispe 1723 (LPB). Chile. H.C. Martin 516, 517 (SI). LC O. Ferrari. T. bolligerianus (Mächler \& Helmut Walter) S. Albesiano. Chile. S. Albesiano et al. 2039 (MERL), 2040 (MERL). Walter 213 (SGO). T. bridgesii Britton \& Rose. Bolivia. S. Albesiano \& N. Quispe 2094 (LPB), St. G. Beck 4039, 17906 (LPB), R. Kiesling, et al. 
10031a (LPB), J.C. Solomon 9458 (LPB), 9460 (LPB), 15576 (LPB), 15778 (LPB), 1709 (LPB). T. candicans Britton \& Rose. Argentina. R. Kiesling 9 (LP), 799 (LP), 801 (LP), 808 (LP), Stukert s.n. (LP), C. Spegazzini s.n. (LP). A. Castellanos s.n. (LIL), J. Fortuna s.n. (LIL), H. Sleumer 335 (LIL), 352 (LIL), 355 (LIL). S. Albesiano \& R. Kiesling 2092 (MERL). A. Burkart 15966 (SI), Gerling 19 (SI). T. chiloensis subsp. chiloensis Chile. U. Eggli \& B. E. Leunberger 2570 (SGO), 3042 (SGO), 3052 (SGO). T. deserticola (Werderm.) Looser. Chile. U. Eggli \& B. Leuenberger 2653 (SGO), 2664 (SGO), 2999 (SGO); U. Eggli 2888, 2915 (SGO); S. Albesiano et al. 2055 (MERL), 2058 (MERL), 2060 (MERL), 2061 (MERL), 2089 (MERL). AY566655. T. macrogonus var. pachanoi Britton \& Rose. Perú. J. N. Rose et al. 22806 (NY). F. Ritter 1467 (U). T. macrogonus var. macrogonus Britton \& Rose. Bolivia. L. Cayola et al. 1533 (LPB), 1534 (LPB), R. Kiesling et al. 10041 (LPB). T. pectiniferus Britton \& Rose. Chile. S. Albesiano et al. 2053 (MERL), 2084 (MERL), 2085 (MERL), 2086 (MERL). U. Eggli \& B. E. Leuenberger 2574 (SGO). AY566654. T. schickendantzii Britton \& Rose. Argentina. J. Schreiter 6450 (LIL), 9742 (LIL). T. skottsbergii Backeb. Chile. S. Albesiano et al. 2050 (MERL). Eggli \& B. E. Leuenberger 2579 (SGO). E. Werdermann 885 (SI, U). T. spinibarbis (Otto ex Pfeiff.) F. Ritter. Chile. S. Albesiano et al. 2087 (MERL), 2088 (MERL), 2091 (MERL). AY566654. T. strigosus Britton \& Rose. Argentina. K.J. Hayward 210 (LIL), H. Sleumer 354 (LIL). H.A Fabris \& F.O. Zuluaga 8329 (LP), R. Kiesling 82 (LP), 808 (LP), C. Volponi 250 (LP). F. Biurrum 2825 (SI), 3063 (SI), A. L. Cabrera et al. 27122 (SI), E. Haene 124 (SI), R. Kiesling 1061 (SI), 1206 (SI), Zanzin 544, s/n (SI). T. tarijensis (Vaupel) Werderm. Argentina. H. Sleumer 3577, 4100, 4101 (LIL). H.A. Fabris 6366 (LP), 6388 (LP), R. Kiesling 26 (LP), D. Muhr 35 (LP). Dell'Prete 2330 (SI), A. L. Cabrera \& L. Constance 18993 (SI), M. Cárdenas 1 (SI), K. Fiebrig 2770 (SI), R. Kiesling 4014 (SI), H. Sleumer 3135 (SI). Bolivia. G. Bourdy 2829 (LPB), R. Kiesling \& D. Metzing 8393 (LPB), R. P. López 03 (LPB), J. C.

Solomon 11334 (LPB). S. Albesiano 2065 (MERL), 2071 (MERL), 2074 (MERL). T. terscheckii (J.Parm. ex Pfeiff.) Britton \& Rose. Argentina. F. Biurrum 3157 (LP). R. Kiesling 802 (LP), S. Venturi 2071 (LP). F. A. Roig 47177 (MERL), S. Albesiano et al. 2062 (MERL), 2064 (MERL). F. Biurrum 1203 (SI), 2517 (SI), 3060 (SI), P. Cantino 460 (SI), E. Haene 121 (SI), Joergensen 1528 (SI), R. Kiesling 142 (SI), E. Ulibarri $424(\mathrm{SI})$.

\subsection{Lista de caracteres morfológicos y sus estados:}

Lista de caracteres morfológicos y estados de los caracteres

0. Hábito: (0) arbusto; (1) plantas arborescentes. Arias \& Terrazas (2006) plantearon varias categorías para definir el hábito en el género Pachycereus, con base en la presencia o ausencia de un tallo principal y la posición de las ramas sobre este. Con base en lo anterior, se proponen los siguientes estados: Arbusto con tejido leñoso, ausencia de un tallo principal y las ramas salen de la base. Plantas arborescentes presentan tejido leñoso, con tallo principal y ramificación por encima de la base. 
1. Forma de crecimiento: (0) Geófitas; (1) globoso sin ramas; (2) columnar (con un tallo principal erecto y grueso); (3) basítono con ramas postradas (las ramas se producen hacia la base, sin un tallo principal central); (4) basítono con ramas erectas (las ramas emergen de la base en una posición recta y paralela la una con la otra); (5) basítono con ramas arqueadas (las ramas laterales se arquean en la base, para luego erguirse); (6) mesotona (con un tallo principal, ramas arqueadas por encima de la base).

2. Raíces adventicias (raíz que se origina por fuera del sistema radical, Moreno 1984): (0) Ausente; (1) Presente. En la familia Cactaceae estas raíces se forman a partir de las areolas o de la epidermis del tallo, especialmente cuando entran en contacto con el suelo (Bravo \& Sánchez 1978).

3. Grado de exposición de los tallos: (0) con $1 / 3$ de los tallos sobresalen del suelo, exponiendo únicamente el ápice; del cual emergen las flores y los frutos (Wigginsia); (1) con 2/3 de los tallos mostrados en superficie (Echinopsis, Eulychnia, Lobivia y Trichocereus); (2) tallos que se exponen totalmente (Harrisia, T. arboricola).

\section{CARACTERES VEGETATIVOS}

4. Surco interareolar: (0) ausente; (1) presente. Especies como T. bridgesii, T. macrogonus var. macrogonus y $T$. macrogonus var. pachanoi presentan un surco muy profundo encima de las areolas.

5. Largo máximo de los tallos: (0) 10-30 cm; (1) $60-100 \mathrm{~cm}$; (2) $150 \mathrm{~cm}$; (3) 2-3 m; (4) 4-7 m; (5) > $8 \mathrm{~m}$. Se refiere a la longitud alcanzada por los tallos en estado adulto.

6. Aspecto del ápice o punto de crecimiento: (0) hundidos; (1) agudo (márgenes que terminan en un ángulo entre 45-90\%); (2) obtusos (ángulos mayores de $90^{\circ}$ ).

7. Forma de los tallos: (0) obcónico, la parte superior más o menos plana, la parte inferior principalmente subterránea; (1) más o menos globular; (2) cortamente cilíndrico, largo menos de dos veces su diámetro; (3) cilindrico, largo más de dos veces su diámetro; (4) fusiforme (elipsoide que va atenuándose en ambos extremos).

8. Color de los tallos: (0) verde-oscuro; (1) verde-claro; (2) verde-glauco. La coloración de los tallos puede estar influenciada por la acumulación de ceras o por la abundancia de cloroplastos (Mauseth 1993). En el grupo estudiado se distinguen tres tonos de verde en plantas adultas.

9. Diámetro de las ramas en plantas adultas: (0) $9 \mathrm{~cm}$; (1) $6 \mathrm{~cm}$; (2) $3 \mathrm{~cm}$; (3) $12 \mathrm{~cm}$; (4) $15 \mathrm{~cm}$; (5) 20 $\mathrm{cm}$. Las mediciones representan la moda del diámetro, cuyo valor no se sobrepone significativamente entre las especies.

10. Altura de las costillas en la parte media de los tallos: (0) Bajas, 0,6-1 cm; (1) muy bajas, 0-0,3 cm; (2) medianas, 1,1-1,5 cm; (3) altas, 2,0-2,5cm. 
11. Forma de las Costillas: (0) obtusas (entre $90^{\circ}$ y $\left.135^{\circ}\right)$; (1) agudas (45 a $\left.90^{\circ}\right)$; (2) amplias (cuando el ángulo es mayor de $135^{\circ}$ ). Estas observaciones fueron realizadas de frente.

12. Número máximo de costillas en la parte media de los tallos: (0) 23; (1) 28; (2) 6; (3) 10; (4) 13; (5) 15; (6) 17 ; (7) 20. El número de costillas en las diferentes especies puede variar con la madurez; sin embargo, éstas llegan a tener un número definido. En el caso de las especies estudiadas cada valor usado como un estado de carácter corresponde al valor de la moda en la madurez; los cuales no se sobrelapan significativamente en entre las especies.

13. Posición de las areolas en costillas adyacentes: (0) opuestas; (1) alternas. En Harrisia earlei y $H$. hahniana las areolas están en diferentes niveles (alternas) en las costillas adyacentes, mientras en las especies de Echinopsis s. str., Lobivia y Trichocereus, las areolas se presentan al mismo nivel (opuestas).

14. Costillas tuberculadas: (0) muy sobresaliente; (1) poco sobresaliente; (2) ausente. En la zona que circunda la areola, se presenta una protuberancia en forma cónica.

15. Consistencia de las espinas en el ápice de los tallos: (0) rígidas; (1) flexibles. Espinas rígidas se quiebran al doblarlas, y las flexibles se arquean fácilmente.

\section{CARACTERES REPRODUCTIVOS}

16. Pseudocefalio: (0) presente; (1) ausente. En la parte apical de los tallos, las areolas jóvenes forman una estructura pilosa, blanca, de la cual emergen las flores, y los frutos permanecen ocultos mientras maduran, además, las areolas continúan con su función vegetativa. El hecho de que el tallo continúe con su función fotosintética sumado a la ausencia de peridermis, son dos características que permiten definir la presencia de pseducefalio, de acuerdo con Buxbaum (1964).

17. Posición de las flores: (0) apical; (1) lateral, se presentan desde dos hasta más de 10 flores a lo largo del tallo.

18. Corona de flores: (0) ausente; (1) presente. Cuando varias flores se disponen en círculo alrededor del ápice del tallo.

\section{FLORES}

19. Tiempo de apertura floral: (0) diurna; (1) nocturna.

20. Proporción largo total de la flor con respecto al diámetro del ovario: (0) igual longitud de la flor y diámetro del receptáculo a nivel del ovario; (1) largo de la flor 4 a 12 veces el diámetro del receptáculo a nivel del ovario; (2) largo de la flor 15-20 veces el diámetro del receptáculo a nivel del ovario. Las especies de la tribu Notocacteae se caracterizan porque la longitud de la flor es igual al diámetro del receptáculo a nivel 
del ovario. En las especies de las tribus Hylocereeae y Trichocereeae por lo general son más largas que anchas.

21. Longitud de las flores: (0) muy pequeñas, de $3 \mathrm{~cm}$ a $6 \mathrm{~cm}$; (1) pequeñas, de 6 a $9 \mathrm{~cm}$; (2) tamaño mediano, de 10 a $17 \mathrm{~cm}$; (3) largas, de 20 a $24 \mathrm{~cm}$. Estas mediciones representan los valores de la moda, las cuales no se sobreponen entre las especies.

22. Axilas de las escamas del tubo floral: (0) con pelos y cerdas; (1) con sólo pelos. En las especies estudiadas, los pelos y cerdas siempre se presentan limitados a las areolas del tubo floral.

23. Escamas del receptáculo floral: (0) ausentes o poco notorias; (1) lineares (angostas, cortas y con los márgenes opuestos en paralelo); (2) lanceoladas (o angostamente elípticas, el ancho disminuye en cada extremo); (3) ovadas-triangulares (elípticas con la base amplia). Las escamas en el receptáculo floral pueden ser poco notorias como en Wigginsia, o ser muy evidentes en la mayoría de los taxones estudiados. Sus formas están definidas por la relación largo-ancho (Stuessy 1990: 221).

24. Disposición de las escamas a lo largo del receptáculo floral: (0) ausentes o no evidentes; (1) dispersas (se distribuyen de tal manera que se observa la pared del tubo floral); (2) cercanas entre sí (es el estado intermedio entre las dos anteriores); (3) imbricadas (se disponen de manera sobrepuestas unas a otras).

25. Pilosidad en las areolas del receptáculo: (0) más de 40 pelos en cada areola; (1) entre 20 y 40 pelos/areola; (2) menos de 20/areola.

26. Diámetro del receptáculo a nivel del ovario (cm): (0) 1,0; (1) 1,5; (2) 2,0; (3) 2,5; (4) 3,0; (5) 4-5. El valor es la moda, la cual no se sobrepone significativamente entre los taxones.

27. Relación entre el diámetro de la garganta y el ovario: (0) garganta dos veces más ancha que el ovario; (1) garganta y ovario casi del mismo ancho. En una flor de cactus, la garganta es la parte intermedia entre el tubo y el limbo de los tépalos (Moreno 1984).

28. Color de los tépalos: (0) amarillo; (1) blanco; (2) rojo.

29. Angulo del ápice de los tétalos internos: (0) obtuso, los márgenes son cóncavos y culminan en un ángulo mayor de $90^{\circ}$; (1) agudo, los márgenes rematan en un ángulo entre 45 a 90\%; (2) acuminado, los márgenes pueden ser rectos o convexos, terminan en ángulo menor de $45^{\circ}$.

\section{FRUTO}

30. Forma: (0) oblongo (de forma más o menos rectangular); (1) obcónico (de forma cónica, con la parte más amplia en el ápice); (2) ovoide (en forma de huevo, con la parte más amplia cerca de la base); (3) globular (aproximadamente esférico); (4) subglobular (similar a una esfera, achatado en los extremos).

31. Consistencia de los frutos: (0) secos; (1) semisecos; (2) jugosos. La consistencia de los frutos está dada por la cantidad de suculencia (contenido de agua) que presentan los funículos. 
32. Número de escamas sobre el fruto: (0) ausentes; (1) menos de siete; (2) entre ocho a diez; (3) más de 11. Una vez que el fruto es maduro, se contaron las escamas vistas en una superficie, o éstas están ausentes o varían en número. El valor de la moda no se traslapa significativamente entre las especies.

33. Fruto con restos del tubo floral: (0) ausente; (1) presente. Buxbaum (1955), Arias \& Terrazas (2006) mencionan que en la parte apical de los frutos de las cactáceas y en el género Pachycereus, permanecen restos del tubo floral, perianto, estilo y estambres. En Trichocereeae se presentan remanentes de los tépalos y el estilo, los cuales caen una vez se completa la maduración de los frutos, dejando una cicatriz llamada depresión umbilical.

\section{SEMILLAS}

34. Forma: (0) ampliamente ovales (proporción largo/ancho: 1,1-1,4); (1) ovaladas (1,5-2,0); (2) circularesorbiculares (menores de 1,09) y (3) estrechamente ovaladas (2-3). Se sigue Barthlott \& Hunt (2000), en definir la forma de la semilla en términos de la proporción del largo con respecto al ancho.

35. Tamaño: (0) muy pequeñas $(0,3-0,8 \mathrm{~mm})$; (1) pequeñas $(0,9-1,1 \mathrm{~mm})$; $(2)$ medianas $(1,2-1,9 \mathrm{~mm})$; (3) largas $(2,0-2,9 \mathrm{~mm})$. Con base en la propuesta de Barthlott \& Hunt (2000), el tamaño de la semilla se define por la longitud del eje mayor. En este estudio se reconocen cinco estados de carácter, donde no se traslapan entre las especies.

36. Brillantez: (0) sin brillo; (1) semi brillantes; (2) brillantes. La ornamentación de la testa produce el grado de brillo en las semillas.

37. Forma de las paredes anticlinales de las células de la testa: (0) rectas; (1) en forma de S; (2) en forma de U. Las paredes periclinales de la célula de la testa pueden ser rectas o presentar diferentes grados de plegamiento, aquí reconocidas como onduladas, tipo $\mathrm{S}$ o tipo $\mathrm{U}$.

38. Quilla: (0) ausente; (1) presente. Algunas semillas muestran un borde que sobresale en el dorso de la semilla, el cual corresponde al plegamiento de las capas superiores de la testa (Barthlott \& Hunt 2000, Arias \& Terrazas 2006). 


\section{4. Índice de figuras:}

Figura 1. A) Plantas ascendentes de $80 \mathrm{~cm}$ de alto en Trichocereus spinibarbis. Tallos ramificados a nivel del suelo y cubiertos por líquenes. B) Trichocereus thelegonus con ramas reclinadas sobre el suelo, con los extremos apicales ascendentes, y presencia de mamelones subhexagonales en las costillas

Figura 2. Trichocereus atacamensis con individuos erectos de hasta $15 \mathrm{~m}$ de alto, con tallo de $50 \mathrm{~cm}$ de diámetro. C) Provincia de Salta, Quebrada del Toro. D) Provincia de Jujuy, Quebrada Humahuaca, Maimará

Figura 3. E) Rama de Trichocereus bolligerianus en cuyo ápice se observan las areolas con pilosidad amarilla, una espina central (base verde y ápice marrón) y espinas radiales 12-16 (algunas son verdes en la base y ápice marrón, otras son gris-claro). F) Ápice del tallo de Trichocereus tarijensis con areolas de tomento blanco-crema; espinas centrales 1-8, aciculares, amarillo-crema con punta marrón-rojizo; espinas radiales 4-19, aciculares, algo onduladas, blanco-crema 0 amarillas. G) Trichocereus candicans con pilosidad amarilla y gris en el ápice, cuatro espinas centrales y ocho espinas radiales.

Figura 4. H) Flores subapicales de Trichocereus terscheckii rodeadas por tejido caulinar (hipanto), estambres blancos y dispuestos en dos series, la inferior y la superior (indicadas por las flechas), cámara nectarial debajo de la serie inferior de los estambres, estigma con 16 lóbulos. I) Flor campanulada de Trichocereus chiloensis subsp. australis, de $21 \mathrm{~cm}$ de largo y tubo floral recubierto de escamas, de cuyas axilas surgen pelos marrones, tépalos internos blancos.

Figura 5. J) Primera etapa de formación de los frutos en Trichocereus chiloensis. K) Restos de hipanto y perigonio en el fruto de Trichocereus chiloensis subsp. panhoplites. L) Fruto con dehiscencia longitudinal en Trichocereus pectiniferus....

Figura 6. M) Semillas medianas (1,4 mm de largo) de Trichocereus skottsbergii, con células de la testa en forma de S. N) Presencia de estrías intercelulares (indicadas por la flecha) y poros que permiten la hidratación)

Figura 7. Distribución del género Trichocereus a lo largo de los Andes de Ecuador, Perú, Bolivia, Chile y la Argentina, donde alcanza la costa Atlántica. Distribución demarcada por una línea punteada negra

Figura 8. Trichocereus macrogonus cultivado en una casa rural al norte de Chile (entre Vallenar y Ovalle).

Foto de Daniel Schweich.

Figura 9. Parte de la publicación de Salm-Dyck (1850) con la descripción original de Cereus macrogonus

Figura 10. Ilustración de Cereus macrogonus en Schumann, Flora brasiliensis (1890), sin duda una especie de Pilosocereus, según el concepto actual

Figura 11. Trichocereus andalgalensis. Provincia de San Juan, Valle Fértil.

Figura 12. Trichocereus angelesiae. Provincia de Salta, en el trayecto de Cafayate a la Viña, El Obelisco a Tres Cruces.

Figura 13. Trichocereus arboricola. Planta de cultivo, colección de N. Hilgert, recolección del Parque Nacional Baritú. 
Figura 14. Trichocereus atacamensis. Argentina, Provincia de Salta, Qda. del Toro. Chile, Provincia El Loa, Comuna Calama, Pampa Puno. Foto Luis Faúndez.

Figura 15. Trichocereus bolligerianus. Chile, VI Región del Libertador General Bernardo O'Higgins, Costa de Pichilemú

Figura 16. Trichocereus bridgesii. Bolivia, Municipio La Paz 49

Figura 17. Trichocereus cabrerae. Argentina, Provincia La Rioja, entre Chilecito y Famatina. 52

Figura 18. Trichocereus camarguensis. Bolivia, Dpto. de Tarija, a la entrada del municipio de Camargo.......54

Figura 19. Trichocereus candicans subsp. candicans. Argentina, Provincia de Mendoza, cerca de la ciudad de Mendoza.

Figura 20. Trichocereus candicans subsp. pseudocandicans. Argentina, Provincia de La Rioja, entre Chilecito y Famatina.

Figura 21. Trichocereus chiloensis subsp. chiloensis. Chile, IV Región de Coquimbo, Provincia Elqui 66

Figura 22. Trichocereus chiloensis subsp. australis. Chile, VI Región de O' Higgins, Prov. Cardenal Caro, Comuna de Litueche

Figura 23. Trichocereus chiloensis subsp. eburneus. Chile, IV Región de Coquimbo, Provincia Choapa....... 70

Figura 24. Trichocereus chiloensis subsp. litoralis. Chile, V Región de Valparaíso, Prov. Petorca, La Ligua, Los Molles

Figura 25. Trichocereus chiloensis subsp. panhoplites. Chile, IV Región de Coquimbo, Provincia Limarí, Ovalle, Higueritas Unidas

Figura 26. Trichocereus cuzcoensis. Bottom of Rio Urubamba Valley at Km 56 on road Cuzco-Urubamba, ca. $6 \mathrm{Km} \mathrm{W}$ of Calca (6 Km E of Yucay)..

Figura 27. Trichocereus deserticola. Chile, II Región de Antofagasta, Parque Nacional Pan de Azúcar, Comuna Taltal, Las Lomitas.....

Figura 28. Trichocereus faundezii. Chile, IV Región de Coquimbo, Prov. Choapa 82

Figura 29. Trichocereus herzogianus. Bolivia, Dpto. Potosí, camino de Vitichi a Potosí.................................. 85

Figura 30. Trichocereus huascha var. huascha. Argentina, Provincia de Catamarca, norte de Belen ..... 90

Figura 31. Trichocereus huascha var. pecheretianus. Argentina, sur de Catamarca, Cuesta de Zapata, límite con La Rioja.

Figura 32. Trichocereus lamprochlorus. Argentina, Provincia de La Rioja, El Milagro..... 94

Figura 33. llustración de Madsen (1989) de T. macrogonus var. pachanoi (como Echinopsis pachanoi). A. Tallos con flores. B. Sección longitudinal de la flor. C. Fruto. D. Semillas.

Figura 34. A) Trichocereus macrogonus var. pachanoi. Chile, entre Vallenar y Ovalle, Foto Daniel Schweich. B) Quito, Ecuador, Foto H. Smidlock

Figura 35. Trichocereus narvaecensis. Bolivia, Departamento de Tarija, camino a Narváez. 105 
Figura 36. Trichocereus nigripilis. Chile, IV Región de Coquimbo, al N de la Serena.................................. 108

Figura 37. Trichocereus pectiniferus. Chile, IV Región de Coquimbo, camino a los Choros.......................... 110

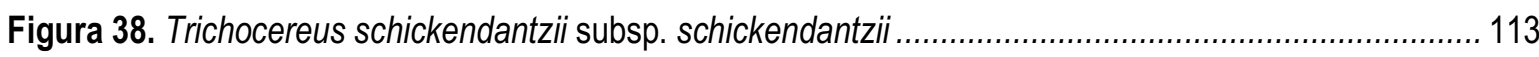

Figura 39. Trichocereus schickendantzii subsp. smrzianus. Argentina, Provincia de Salta, San Martín, en

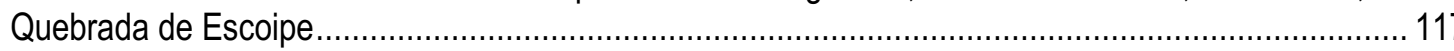

Figura 40. Trichocereus skottsbergii. Chile, IV Región de Coquimbo, Puerto Oscuro, al borde de la playa.. 119

Figura 41. Trichocereus spachianus. Provincia de Jujuy, tomado de cultivo. 123

Figura 42. Trichocereus spinibarbis. Chile, Provincia Huasco, comuna Vallenar, cerca de Vallenar 125

Figura 43. Trichocereus strigosus var. strigosus. Argentina, Provincia de Mendoza, Departamento Capital, cerca del Parque General San Martín 130

Figura 44. Trichocereus strigosus var. vatteri. Argentina, Provincia de La Rioja, Departamento Chilecito, Cuesta de Miranda. 133

Figura 45. Trichocereus tacaquirensis. Bolivia 135

Figura 46. Trichocereus taquimbalensis. Bolivia, Departamento de Tarija, camino a Incahuasi, pasando el puente.

Figura 47. Trichocereus tarijensis var. tarijensis. Argentina, Provincia de Jujuy, al norte de Humahuaca, hacia Tres Cruces, al sur de Esquinas Blancas. A la derecha un ejemplar anormal por tener tallo dicótomo

Figura 48. Trichocereus tarijensis var. poco. Argentina, Provincia de Jujuy, Quebrada de Humahuaca 143

Figura 49. Trichocereus tarijensis var. poco f. poco. Foto: Hunt et al. (2006): 254 144

Figura 50. Trichocereus tarijensis var. poco f. albiflorus. Foto : Hunt et al. (2006): 254. 146

Figura 51. Trichocereus terscheckii. Argentina, Provincia de San Juan, Departamento Valle Fértil, sur de Balde del Rosario

Figura 52. Trichocereus thelegonus. Argentina, Provincia de Salta, Departamento Guachipas, Alemania, entre la ciudad de Salta y Cafayate 152

Figura 53. Trichocereus tunariensis. Foto Hunt et al. (2006): 238. 154

Figura 54. Trichocereus undulosus. Chile, IV Región de Coquimbo, Provincia Limarí, Peña Blanca. 156

Figura 55. Trichocereus uyupampensis localizada al sur de Perú, Dpto. de Arequipa 158

Figura 56. Trichocereus vasquezii. Bolivia, Dpto. Santa Cruz 160

Figura 57. Trichocereus vollianus. Bolivia, Dpto. Chuquisaca, Prov. Oropeza, camino a Yotala 163 
Figura 58. Trichocereus werdermannianus. Bolivia, Departamento Potosí, Provincia Nor Chichas, San Antonio, Quechisla

Figura 59. Trichocereus wilkeae. Bolivia, Departamento Potosí, camino de Villazón a Tupiza......

Figura 60. Lobivia formosa. Provincia de San Juan, Estancia Don Carmelo.

Figura 61. Lobivia grandiflora. Provincia de Catamarca, entre Andalgalá y Concepción .....

Figura 62. Lobivia walterii. Provincia de Salta, Departamento Rosario de Lerma

Figura 63. Consenso estricto de 684 árboles más parsimoniosos $(L=506, C l=0,18, R I=0,27)$, usando caracteres morfológicos. Los números debajo de las ramas corresponden a valores del soporte de Bootstrap/porcentajes de Jackknife. Números encima de las ramas son los caracteres (Apéndice 14.3), y los estados de los caracteres aparecen dentro de los cuadrados. Los cuadros oscuros corresponden a sinapomorfías

Figura 64. Consenso estricto de 31371 árboles más parsimoniosos $(L=313, \mathrm{Cl}=0,47, \mathrm{Rl}=0,58)$, combinando los conjuntos de datos de trnL-F y rp/16. Números encima y debajo de las ramas indican valores del soporte de Bootstrap y porcentajes de Jackknife, respectivamente

Figura 65. El árbol más parsimonioso ( $\mathrm{L}=603, \mathrm{Cl}=0,40, \mathrm{Rl}=0,62$ ), basado en evidencia total, morfología y molecular (trnL-F y rp/16). Los cuadrados sólidos representan estados sinapomórficos y los blancos homoplasias, que están presentes de manera no ambigua; los números sobre los cuadrados corresponden a los caracteres morfológicos, y los números al interior de los cuadrados son los estados de los caracteres. Los valores en itálica corresponden al soporte de Bootstrap/porcentajes de Jackknife

Figura 66. Hábito: A) Ramas de T. deserticola que surgen desde la base. B) Plantas arborescentes de $T$. atacamensis con tallo principal y ramificación lateral

Figura 67. Forma de crecimiento: C) Individuos geófitos de Wigginsia vorwerkiana. D) Tallos globosos y sin ramas de L. bruchii. E) En T. bolligerianus las ramas emergen de la base, en una posición recta y paralela la una con la otra.......

Figura 68. Forma de los tallos: F) Fusiforme atenuándose en ambos extremos en Setiechinopsis mirabilis.

G) En Echinopsis albispinosa el largo es menos de dos veces su diámetro......

Figura 69. Dureza de las espinas en el ápice de los tallos: $\mathrm{H}$ ) En $T$. atacamensis las espinas son flexibles.

I) En T. terscheckii son rígidas. J) En T. pectiniferus son rígidas, al doblarlas se quiebran.

Figura 70. Posición de las flores: K) En T. tarijensis las flores se disponen en el ápice conformando una corona. L) Flores dispuestas a lo largo de los tallos en $T$. bridgesii.....

Figura 71. Pilosidad en las areolas del receptáculo: M) E. ancistrophora con menos de 20/areola. N) $T$. bolligerianus entre 20 y 40 pelos/areola. 0) Lobivia kieslingii entre 20-40 pelos/areola. P) Eulychnia breviflora más de 40 pelos en cada areola.

Figura 72. Forma de las paredes anticlinales de las células de la testa y quilla $\mathbf{Q}$ ) En forma de $\mathbf{S}$ y con quilla en $T$. macrogonus var. pachanoi, R) T. strigosus con células de la testa en forma de U. S) $T$. atacamensis sin quilla

Figura 73. Distribución de las especies de Trichocereus en la Argentina: a) $T$. andalgalensis, b) $T$. angelesiae, c) $T$. arboricola, d) T. atacamensis, e) T. cabrerae, f) T. candicans subsp. candicans, g) 
T. candicans subsp. pseudocandicans, h)T. huascha var. huascha, i) T. huascha var. pecheretianus, j) T. lamprochlorus, k) T. schickendantzii subsp. schickendantzii, I) T. schickendantzii subsp. shaferi, m) T. schickendantzii subsp. smrzianus, n) $T$. spachianus, ñ) $T$. strigosus var. strigosus, o) $T$. strigosus var. vatteri, p) T. tarijensis var. tarijensis, q) T. tarijensis var. poco f. poco, r) T. terscheckii, s) $T$. thelegonus. Las localidades bordeadas por línea punteada corresponden a información no documentada por pliegos de herbario, sino por observaciones de fotos o comentarios personales .....

Figura 74. Distribución de las especies de Trichocereus en Bolivia: a) $T$. arboricola, b) $T$. atacamensis, c) $T$. bridgesii, d) $T$. camarguensis, e) $T$. clavatus, f) $T$. herzogianus, g) $T$. macrogonus var. macrogonus, h) $T$. narvaecensis, i) $T$. tacaquirensis, j) $T$. taquimbalensis, $\mathbf{k}) T$. tarijensis var. tarijensis, I) T. tarijensis var. poco f. poco, m) T. tarijensis var. poco f. albiflorus, $\mathbf{n})$ T. terscheckii, o) $T$. vasquezii, p) $T$. vollianus, q) $T$. werdermannianus, $\mathbf{r}) T$. wilkeae. La localidad bordeada por línea punteada corresponde a información no documentada por pliegos de herbario, sino por observaciones de fotos o comentarios personales

Figura 75A. Localización de los taxones de Trichocereus en Chile: a) Trichocereus atacamensis, b) Trichocereus bolligerianus, c) Trichocereus chiloensis subsp. chiloensis, d) Trichocereus chiloensis subsp. australis, e) Trichocereus chiloensis subsp. eburneus, f) Trichocereus chiloensis subsp. litoralis, g) Trichocereus chiloensis subsp. panhoplites, h) Trichocereus deserticola

Figura 75B. Localización de los taxones de Trichocereus en Chile: i) Trichocereus faundezii, j) Trichocereus macrogonus var. macrogonus, k) Trichocereus macrogonus var. pachanoi, I) Trichocereus nigripilis, m) Trichocereus pectiniferus, n) Trichocereus skottsbergii, o) Trichocereus spinibarbis, p) Trichocereus undulosus, q) Trichocereus uyupampensis.

Figura 76. Distribución de los taxones de Trichocereus en Perú: a) T. cuzcoensis, b) T. macrogonus var. macrogonus, c) T. macrogonus var. pachanoi, d) T. uyupampensis. La localidad bordeada por línea punteada corresponde a información no documentada por pliegos de herbario, sino por bibliografía (Ogunbodede et al. 2010). 


\section{5. Índice de tablas:}

Tabla 1. Clasificación taxonómica de Trichocereus (1920-2013), indicando especies, subespecies, variedades, y géneros relacionados.

Tabla 2. Diferencias entre $T$. andalgalensis y $T$. huascha. 35

Tabla 3. Diferencias entre $T$. angelesiae y $T$. lamprochlorus. 37

Tabla 4. Diferencias entre $T$. angelesiae y $T$. strigosus. 38

Tabla 5. Caracteres que diferencian a $T$. arboricola de $T$. vasquezii 40

Tabla 6. Diferencias entre T. strigosus, T. cabrerae y T. terscheckii 52

Tabla 7. Diferencias entre $T$. candicans y $T$. lamprochlorus. 58

Tabla 8. Diferencias entre $T$. faundezii y $T$. spinibarbis. 83

Tabla 9. Diferencias entre $T$. herzogianus y $T$. tarijensis 86

Tabla 10. Caracteres vegetativos y reproductivos que distinguen a $T$. narvaecensis de $T$. tarijensis subsp. tarijensis

Tabla 11. Diferencias entre T. narvaecensis y T. schickendantzii. 106

Tabla 12. Diferencias entre $T$. deserticola y $T$. skottsbergii de acuerdo a los caracteres morfológicos. 119

Tabla 13. Otros caracteres que distinguen $T$. camarguensis y $T$. strigosus son: 129

Tabla 14. Diferencias entre $T$. terscheckii y $T$. atacamensis 149

Tabla 15. Diferencias entre $T$. undulosus y $T$. skottsbergii. 155

Tabla 16. Caracteres que distinguen $L$. grandiflora de $T$. huascha. 174

Tabla 17. Iniciadores usados para la amplificación por PCR y la secuenciación de las regiones trnL-F y rp/16.

Tabla 18. Resultados estadísticos del análisis por parsimonia de las matrices individuales y combinadas. Amp (árboles de máxima parsimonia), ac (árbol de consenso), I (longitud=pasos), i.c. (índice de consistencia), i.r. (índice de retención). 
Tesista: M. Sc. Sofía Albesiano

Docente Escuela de Ciencias Biológicas

Universidad Pedagógica y Tecnológica de Colombia, UPTC

\section{Director: Dr. Roberto Kiesling}

Investigador de la Unidad de Botánica, del Centro Regional de Investigaciones Científicas y Tecnológicas (CIRCYT)

Instituto Argentino de Investigaciones de las Zonas Áridas-IADIZA.

\section{Co-directora: Dra. Susana E. Freire}

Profesor Titular de Botánica Sistemática II

Facultad de Ciencias Naturales y Museo, UNLP

Investigador Independiente CONICET 